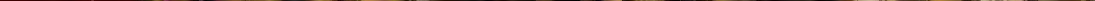


an

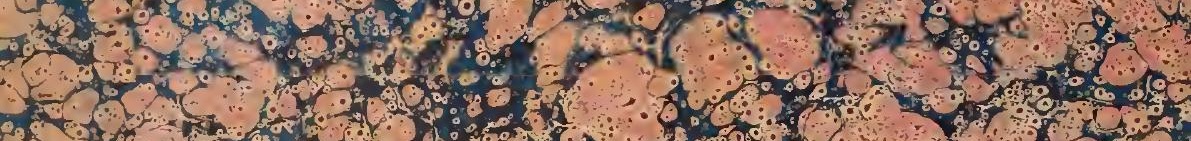

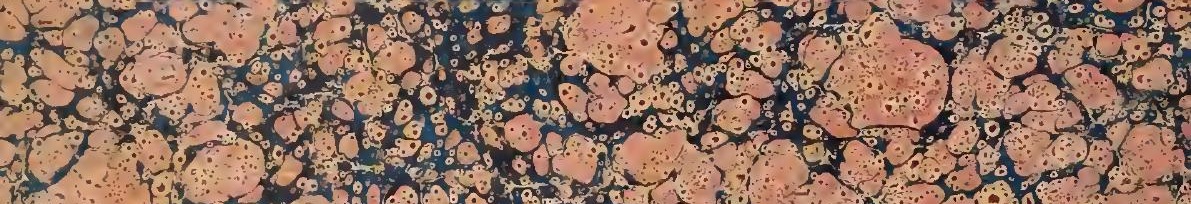

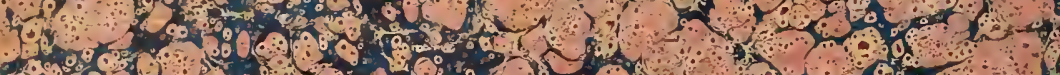

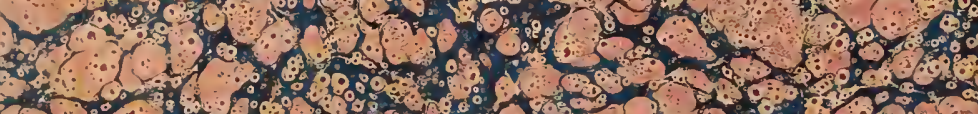

T.

(1)

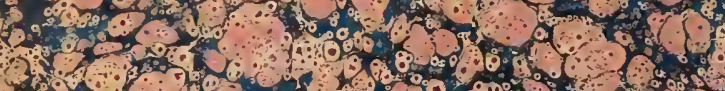

(1)

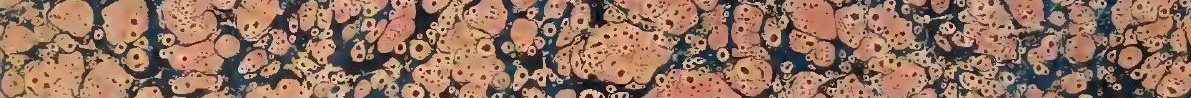

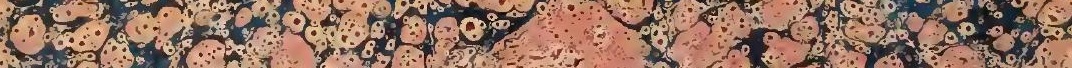

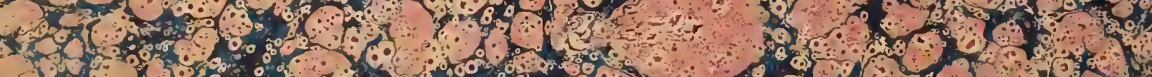

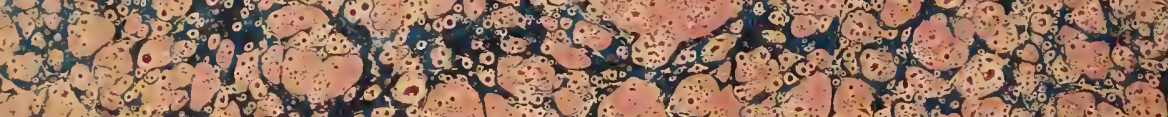

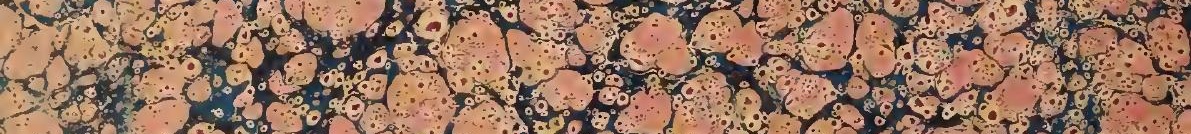

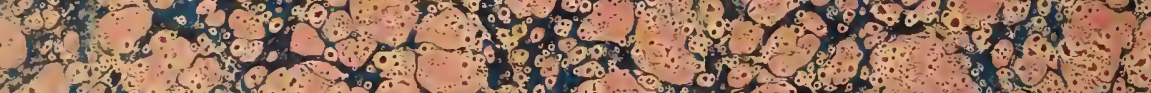

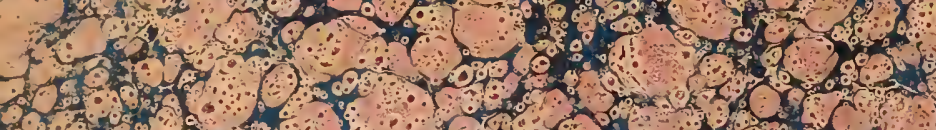

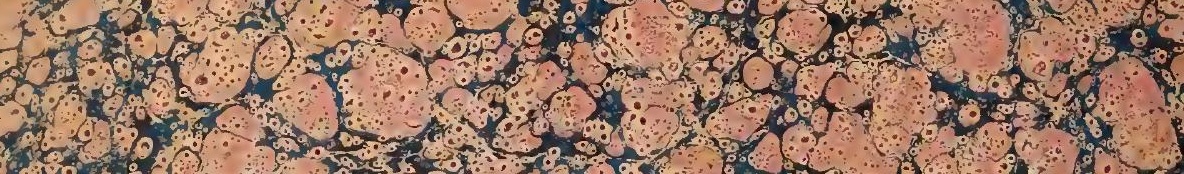

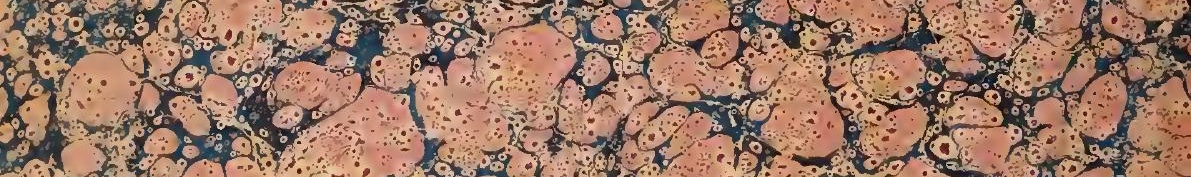

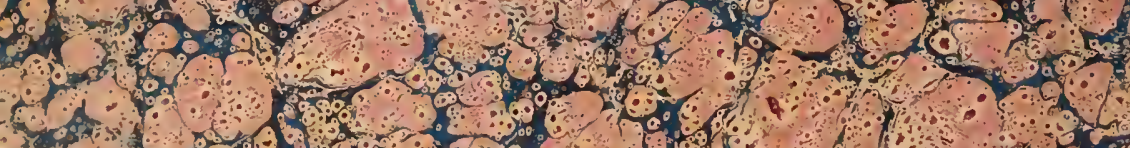

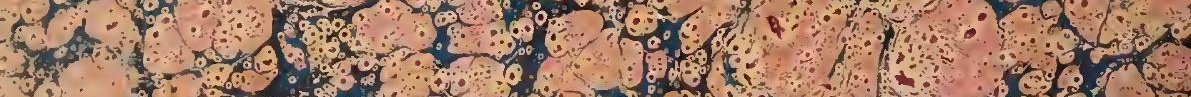
(1)

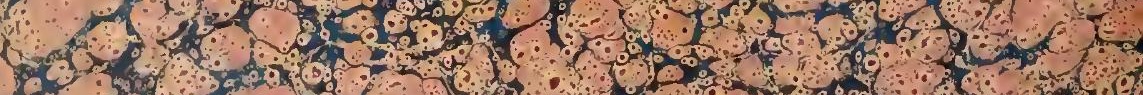

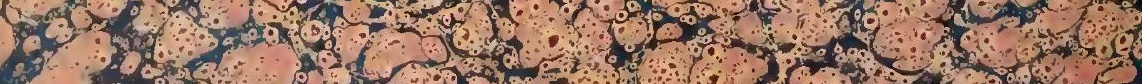

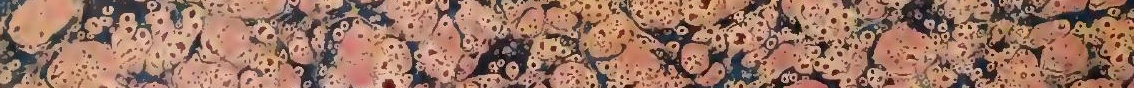
I. 


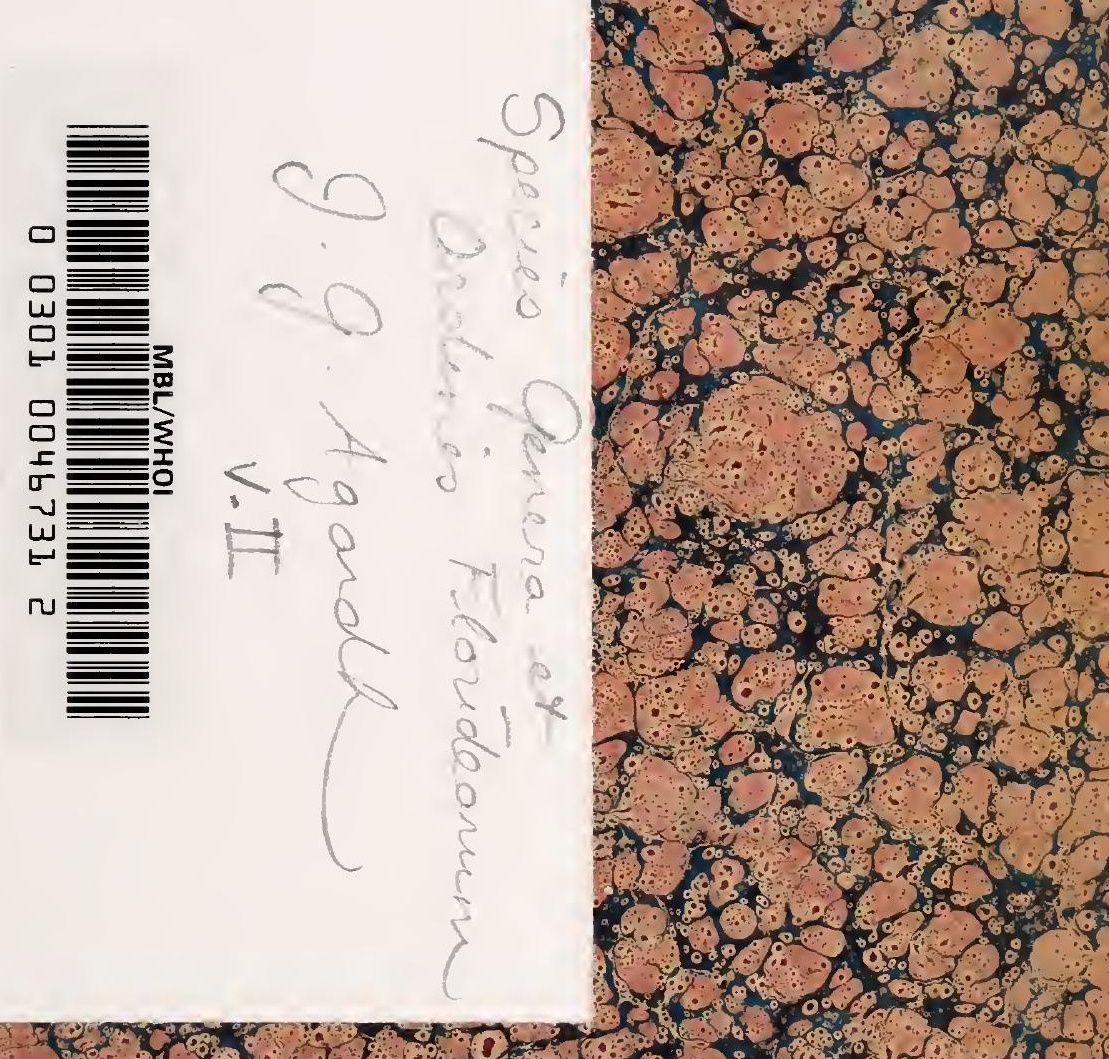

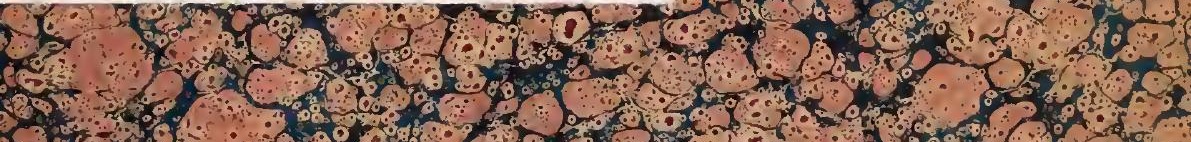

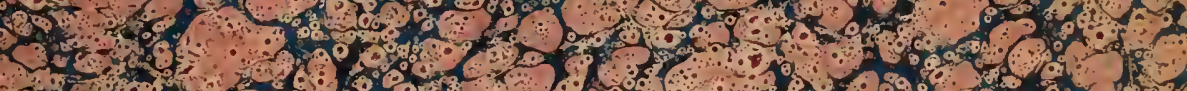

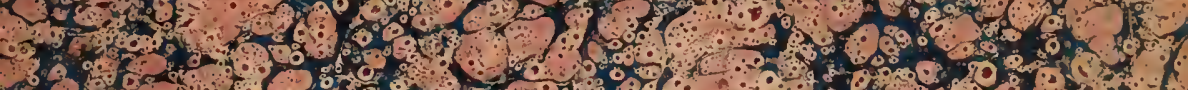

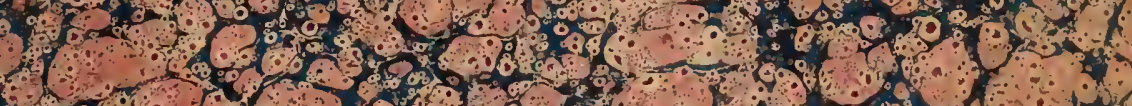

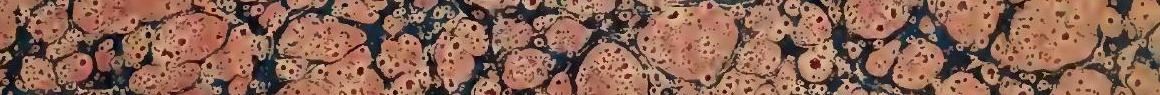

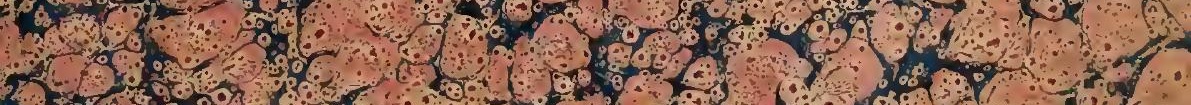

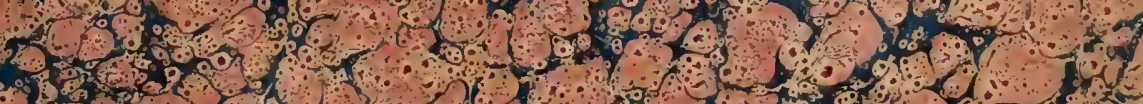

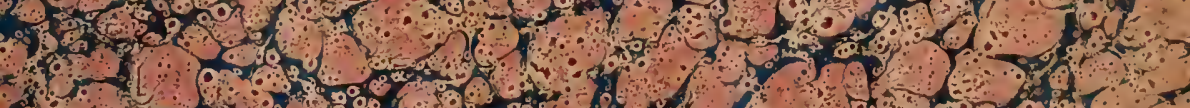

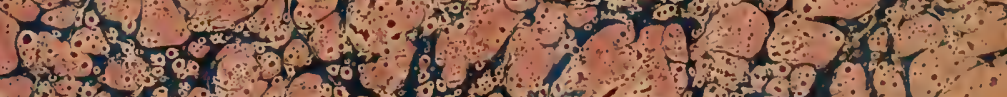

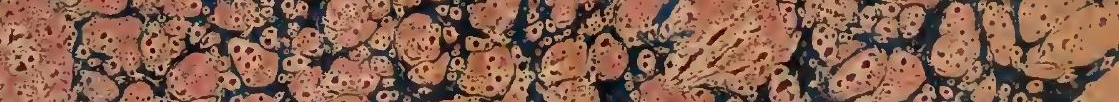

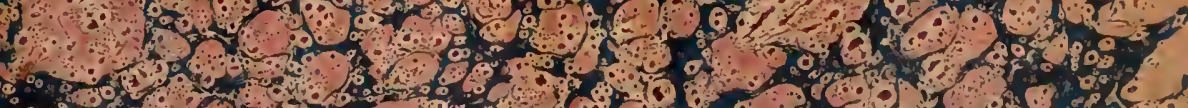

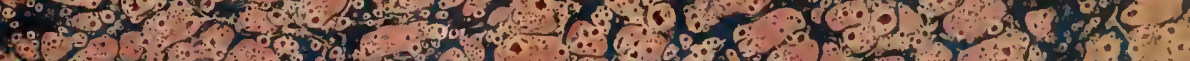

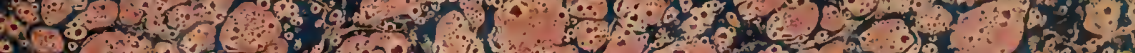






\section{SPECIES GENERA ET ORDINES}

\section{ALGARUM,}

SEU

DESCRIP'TIONES SUCCINCTA SPECIERUM, GENERUM ET ORDINUM,

QUIBUS

ALGARUM REGNUM CONSTITUITUR.

AUCTORE

\section{JACOBO GEORGIO AGARDH,}

E. O. BOTANICES IN ACADEMLA LUNDENSI PROFESSORE.

VOLUMEN SECUNDUM:

ALCAAS FLORIDEAS COMPLECTENS.

LUNDA: APUD C. W. K. GLEERUP.

INIPIA: APUD T. O. WEIGEL. PARISIIS: APUD MASSON.

LONDINI: APUD W. PAMPLIN.

1851. 
$\mathrm{SP}]$

DE:

I, IPS I 


\section{SPECIES GENTRA ET ORDINES}

\section{FLORIDEARUM,}

SEU

DESCRIPTIONES SUCCINCTA SPECIERUNI GENERUM ET ORDINUM,

QUirus

FLORIDEARUM CLASSIS CONSTITUITLR.

AUCTORE

\section{JACOBO GEORGIO AGARDH.}

VOLUMINIS SECUNDI:

PARS PRTOR.

LUND N: APUD C. W. K. GLEERUP.

I.IISIA: APUD T. O. WEIGEL. PARISIIS: APUD MASSON.

LUNDINI: AYUH W. PAMPIN.

18.51. 
dicitur, conveniunt. Ab hac praterea incuria, ni fallor, etiam nove quxedam species ortæe sunt; ut quum Gracilaria spicifera Sulır et sub nomine Speciei primum dato et dein, genere mutato, sub diverso nomine specilico bis occurrit. Gracilaria spicifera enim, quæ erat, adpellatur (pag. 760) IJynea spicifera. Nescio an mendum scripturæ sit illud IIarveyi, quum scripsit "H. spicigera;" eum vero loc nomine intelligere eandem Algam et ex Ner. Austr. Lab. $X L I X$ et ex speciminibus ab ipso distributis satis constat; attamen ab Harveyo missum exemplar, guod hoc nomine inscriptum fuit, Kützingio fit (paģ. 775) Sphærococcus Jlarveyi Kütz. Quum vero launc Sph. Harreyi, quem ipse in IIb. Binderi denominaterat, postea sub nomine dato deprehendit, IJpneam facit, qua tertia vice ita (pag. 760) nomine H. Harveyi enumeratur.

Quamobrem ne propter illas quidem Kützingianas species supervacaneam duco novam Floridearum expositionem. Volumen vero, quod hodie publici juris facio, tertiam partem tantum Floridearum comprehendit; ad religuas partes mox redibo. Generalia quædam de Florideis earumque fructuum structura, quæ non nisi absoluto opere bene forsitan conscribantur, sequente volumine præmittam. Quæ autem sit ipsius Systematis ratio, hoc paucis verbis hodie adumbrare debui.

Ilistoriam Algologiæ qui novit, is non ignorat principio quasi fundamentum in Florideis describendis positam esse Frondis formam et tanquam faciem. Tum qux esset in fructu figura considerari coeptum est. Deinceps dispositio fructuum et frondis ipsa structura examini subjecta. Mihi, atque haud scio an nonnullis præterea, ita visum erat, ex quaque frondis structura certam quandam fructuum formam atque dispositionem pendere; quamobrem utriusque et in fronde quæ esset structura et in fructu quæ forma, quis locus, in descriptione habita est ratio. IJodie vero monstrari potest admodum dispares esse posse fructus floridearum in simillimo et habitu et frondis structura. Possunt etiam in externa, yuamvis magna, similitudine fructum, nuclei vel ipsa gemmidia, semina ut ita dicam, immane quantum discrepare. Itaque hodie trita illa antehac vestigia relinquens sic statno, similem frondis structuram fructusgue similem formam aut dispositionem analogian labbere, non affinitatem. Ilanc vero nullan esse nisi sit in uncleis fructuum, quos capsnlares dixerunt, congruentia. Sic mili videntur familixe Ceramiearum, Gloiocladearum, Gastrocarpearum, spongiocarpearum, Coccocarpearum ita tantum recte esse ab Algo- 
logis institutæ si gradus quosdam perfectionis, sive sit in evolutione frondium sive in forma aut dispositione fructum, non affinitates luerbarum significatas his nominibus volunt. Lt in reliquuis Plantarum familiis sic in Florideis apparet quun summa forme simplicitas, tum a simplicitate illa ascensiones, existuntque alix aliis complicatiores, perfectioresque; idque ita ut a diversis formarum principiis orientes per series et ad exitus abeant diversos. Quamobrem in unaquaque seric si non invenirentur, cogitari certe possent Ceramieæ, Gloiocladeæ, Gastrocarpeæ et quæ sunt reliquæ. 


\section{CONSPECTUS DISPOSITIONIS FLORIDEARUII.}

Series I. Gongylosperme a. Nucleo cystocarpii nudo aut inter fila vel cellulas frondis suspenso, raro intra pericarpium externum recepto, subgroboso, simplici aut nucleolis plurilus constante; gemmidiis intra periderma hyalinum, mucosum aut membranaceum, plurimis, nullo ordine conglobatis.

SUbSEries 1. Goxgrlosperiex. Cystocarpii nueleo simplici, rotundato aut lobato, transformatione cellulæ seu articuli formato. Gemmidia iterata divisione endochromatis orta, nullo ordine conglobata, membrana ambiente cellulæ inclusa, rotundato-angulata.

ORDO I. CERAMIEA. Frons articulata monosiphonia, nuda aut strato cellularum corticata fibrisve decurrentibus cooperta, demum quandoquidem cellulosa. Favellæ ad ramos nudæ aut ramellis involucratæ, intra periderma gelatinosum hy̧alinum gemmidia plurima rotundato-angulata, nullo ordine disposita, forentes. Sphærosporæe transformatione ramuli aut cellulæ corticalis formate, externæ aut cellulis corticalibus inclusæ.

TRIBLS I. CALLITHAINIER.

Callithamnion.

Corsnospora.

Ballia.

Griffithsia.

Ilalurus.

Ptilota.

Dassphilia.

Crouania.

Dudresnaji.

Ifanovia.

Illalopleģma.

ptilocladia. 
ThIIIS II. CERIIMII: L:

Ceramirms.

Centruceras.

Camprlieplıra.

Microcladia.

Carpobleplaris.

ORDO. II. CRYPTONEMEA. Frons cellulis filiformilus rotunditisve brevioribus contexta, strato continuo filorum moniliformium aut cellularum verticalium cincta. Cystocarpia frondi aut verrucis externis Nematlecioideis immersa, rarius intra pericarpium proprimm excepta, nucleo rotundato simplici, intra periderma hjalinum gelatinosum gemmidia plurima rotundato-angulata, nullo ordine conglobata, forente. Splıærosporæ transformatione cellularum corticalium formatæ aut in Nematheciis evolutæ, immersæ.

TRIBLS I. NEMASTOME E.

Gloiosiplıonia.

Nemastoma.

Schizymenia.

Grateloupia.

Prionitis.

Acrotylus.

Furcellaria.

TRIBUS II. GASTROCARPEA.

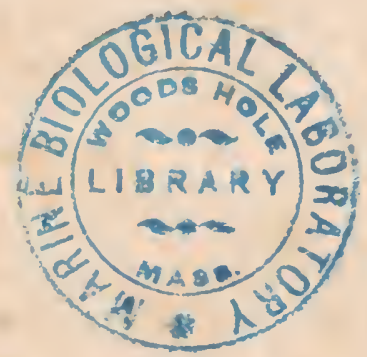

Halymenia.

Sclimmelmannia.

? Clıı̨symenia.

TRIBLS III? FNLCIIEA.

filoiocladia.

Fauclica.

Epjmenia.

TRIBLS IV. RIIIZOPIILLELE.

Rlizophỵllis.

TRIBLS V. CRIPTONEMIII:

Cryptonemia.

Subsertes II. COCCIOSPERMELE Cystocarpii nucleo mucholis plurimis composito; nucleolis transformatione collula seu articuli 
formatis. Gemmidia iterata divisione endochromatis orta, nullo ordine conglobata, membrana ambiente cellule inclusa, rotundatoangulata.

ORdo Ill. GIGARTINEE. Frons cellulis filiformibus rotundatisve brevioribus contexta, strato continuo filorum moniliformium aut cellularum verticalium cincta. Cystocarpia frondi immersa aut intra pericarpium proprium excepta, nucleo ambitu subindefinito, cellulis prægonantibus plurimis plus minus adproximatis constituto, nucleolis intra periderma liyalinum membranaceum gemmidia panciora rotundato-angulata, nullo ordine conglobata, foventibus. Sphærosporæ transformatione cellularum strati corticalis formatæ aut in Nematheciis evolutæ, immersæ.

TRIBUS 1. ENDOCLADIEA:

Gloiopeltis.

Endocladia.

TRIBUS II. PISSOELLEA.

Polyopes.

Rissoella.

TRIBUS III. GIGARTINEA:

Gloioderma.

Cliondrus.

Iridæa.

Gigartina.

TRIBUS IV. KALLYNENILE.

Kallymenia

Constantinea.

Callopliyllis.

Polycoclia.

Cystoclonium.

TRIBLS V. TYLOCARPLAL.

Alınfeltia.

Gymnogongrus.

Pliyllophora.

SUbSERES III. NEMATOSPLRIER ${ }^{1}$ ). Cystocarpii nucleo nucleolis in unum sæpe subcoalescentibus composito; uucleolis transformalione filorum a placenta radiantium formatis. Filis gemmidiiferi 
paniculato-ramosa articulata, intıa articulos supremos gemmidia numerosa oblonga, iterata divisione endoclıromatis orta, demum rullo ordine conglobata, mucu solidescente conjuncta, forentia.

Ondo IV. SPYRIDIEE. Frons articulata sensim corticata. Cystocarpii uucleus intra pericarpium cellulosum clausum exceptus. Sphierosporæ transformatione ramuli aut cellulæ corticalis formate, externie.

Spyridia.
Bindera.

Ordo V. DUMoNTIEA. Frons inarticulata tubulosa, filis percursa et diaphragmatibus quandoquidem intercepta. Cystocarpii nucleus frondi immersus aut intra pericarpium externum exceptus. Spliærosporæ frondi immersæ.

TRIBLS I. DUNONTIE E.

Dumontia.

? Halisaccion.

Catenella.

Rlıabdonia.

TRIBLS II. CHYLOCLADIEA.

? Chrysymenia.

Chylocladia ${ }^{2}$ ).

Cliampia.

ORDO VI. RHODYNIENIE E. Frons membranacea cellulosa. Cystocarpii nucleus intra pericarpium externum exceptus. Sphærosporæ frondi aut Nematheciis immersæ.

Euthora.

Stictoplıyllum.

Rlodymenia.

? Epymenia.

Rlıodoplıyllis.

? Stenogramme.

? Faucliea.

Plocamium.

Delesseria Külz.

Sriries II. Desurospernez. Nucleo Cystocimpii nudo aul inter fila vel cellulas frondis suspenso, vel intra pericarpiun extermum recepto, peridermate nullo communi colibito, filis fasciculatis gemmidiiferis constante; gemunidiis intra articulos filorn seriatis, ant tantum in articulo terminali prolutis. 
SUBSERES I. DESMIOSJER.ME T. Filis gemmidiferis abbrevialis a puncto centrali quoquoversum radiatibus, nucleum subglobosum formantibus, aut a pariete cystocarpii egredientibus in fasciculos plures collectis, intra articulos terminales gemmidia singula rotundato-oblonga foventibus.

ORDo VII. IIELMINTIOCLADEF. Frons cellulis elongatis brevioribusque rotundatis contexta. Cystocarpii nucleus simplex, infra stratum periphericum suspensus, peridermate nullo obtectus, filis fasciculatis a centro radiantibus ramoso-fastigiatis constifutus, intra articulos terminales gemmidia singula rotundata fovens.

\section{TRIBUS I. GLOIOCLADE.E.}

Helminthocladia ${ }^{3}$ ).

Ilelmintlora $\left.{ }^{4}\right)$.

Nemalion.

TRIBUS II. SCINAIE.E.

Scinaia Bivona (Ginamuia Nont.)

TRIBLS III? LIAGOREJ.

Liagora.

ORDo VIII. HYP.VEACEA. Frous filis elongatis cellulisque brevioribus contexta. Cystocarpia intra pericarpium externum nucleolos plurimos, periphericos et ad fila interiora suspensos, continentia; filis gemmidiiferis nucleoli quoquoversum radiantibus, intra articulos teruninales gemmidia rotundata singula fuventibus.

\section{TPIBUS I? CAULACANTIIEA.}

Canlacanthus.

TRIBLS II. IIYPNEL.

IIy pnea.

Acantlococeus.

Ordo IX. CHETANGIEl:. Frons filis temissimis, interioribus anastomosantibus, exterioribus verticalibus contesta. Cystocarpia eryptam rotundatam frondi immersam refernutia, fasciculos plurimos lilorum, secus parietes cryptiu dispositos, contimentia; lilis gemmirliiforis intra arliculos terminales genmidia oblonga singula foventilus.

\section{? Apopiliaca.}

Chretamgium.

(Notlogeniit). 
ORDO I? GELIDIEA: lirons cellulis elongatis angustis brevioribusque rotundatis contexta. Cystocarpia externa 1-2-Locularia, fasciculos plurimos filorum, secus parietem longitudiualem (aut dissepimentum) dispositos, continentia; filis gemmidiiferis intra articulos terminales gemmidia oblonga singula foventibus.

\section{Geliclium. \\ Suluria. \\ Pterocladia ${ }^{5}$ ). \\ ? Ptilophora.}

Subseres II. HORMOSPERMEA. Filis gemmidiiferis submoniliformiter articulatis, superficialibus aut intra pericarpium exceptis et a placenta basali radiantibus, intra articulos superiores gemmidia seriata, rotundato-oblonga, foventibus.

ORdo XI. SQUAMARIEA. Frons globosa aut sæpe horizontaliter expansa, filis cellulisve muco laxiori cohibitis aut solidescente concretis contexta. Gemmidia in filis moniliformibus superficialibus Nemathecioideis formata, in articulis filorum seriata, discoidea aut rotundatis.

TRIBLS I. CRUORIEA:

Actinococcus ${ }^{6}$ ).

Petrocelis ${ }^{\gamma}$ ).

Cruoria ${ }^{8}$ ).

Contarinia.

TRIBUS II. SQUAMARIA:

Hildenhrandtia ${ }^{9}$ ).

Hæmatocelis ${ }^{10}$ ).

Peyssonellia.

TRIBUS III? RIIODODERIEEE.

Rhododermis ${ }^{11}$ ).

ORdO XII. CORALLINEE.

ORDO XIII. SPIIEROCOCCOIDEA. Frons filiformis aut meminanaceo-expansa, filis elongatis cellulisve brevioribus contexta. Fila gemmidiifera pericarpio inclusa, a placenta basali egredientia, moniliformiter articulata, intra articulos gemmidia seriata oblongorotundata, terminalia obovata, foventia.

TRIBUS I. SPIIAROCOCCELE.

Callibleptıris.

? Acropeltis. 
bieurellia.

Corallopsis.

Plocaria.

Melantlualia.

Sarcodia ${ }^{12}$ ).

Dicranema.

Heringia.

Thysanocladia.

Sphærococcus.

TRIBUS II. NTTOPHYLLEE.

Araclinophyllum.

Nitopliyllum.

Hymenena.

Botryocarpa.

Botryoglossum.

Hemineura.

Hypoglossum.

Phijcodrys.

SubSERIES III. CORYNOSPERMEE. Nucleo cystocarpii nudo vel frondi immerso aut sæpissime intra pericarpium externum recepto; filis gemmidiiferis a placenta basali radiantibus, in articulo terminali clavato transformato gemmidia singula pyriformia foventibus.

ORdo XIV. WRANGELIEA. Frons articulata ant corticata et axi articulato percursa. Cystocarpii nucleus nudus aut tantum coma filorum tectus. Fila gemmidifera invicem libera, a placenta radiantia, in articulo terminali clavato transformato gemmidia singuliı, pyriformia, foventia.

TRIBLS I. WRANGELIE.

Wrangelia.

TRIBUS II. NACCARIEA.

Naccaria.

(Atractophora)

ORDO XV. CHONDRIE E. Frons inarticulata filis aut cellulis contexta, axi centrali quandoquidem percursa. Cystocarpii nucleus frondi immersus aut intra pericarpium externum exceptus. Fila gemmidiifera invicem libera, a placenta radiantia, in articulo terminali clavato transformato gemmidia singula, pyriformia, foventia.

TRIBUS I. SPONGIOCARPER.

Polyides. 


\section{TRIBLS H. LOMIENTARIE A.}

Lomentaria.

\section{TRIBLS III? SOLIERIE S. $_{\text {. }}$}

Solieria.

Eucheuma.

TRIBUS IV. BONNEMLISONIEE.

Lictoria.

Delisea.

? Phacelocarpus (Euctenodus liüt\%.)

Bonnemaisonia.

Laurencia.

ORDo XVI. RHODONELEA. Frons articulata aut celluloso-areolata. Cystocarpii nucleus intra pericarpium externum exceptus. Fila gemmidiifera invicem libera, a placenta radiantia, in articulo termillali clavato transformato gemmidia singula, pyriformia, foventia.

1) Cystocarpia in hac subserie sunt quasi favellarum evolutio suprema, gemmidiis a filis transformatis evidenter ortis, at omnibus simul in maturo fructu gelatina ambiente cohibitis. Fructus hoc modo transitum a Favellis ad Coccidia efticiunt. Ordines quoque nunc familias Gongylospermearum, nunc Hormospermearum proxime tangunt. Spyridieæ sunt Ceramieæ quasi in superiore evolutionis gradu positæ. Dumontieæ ex una parte ad Gastrocarpeas, ex altera tum ad Sphærococcoideas, tum ad Lomentarieas valde accedunt. Rhodymenieæ Faucheas et Sphærococcoideas conjungunt; quin immo Faucheas ad Rhodymenieas transferendas esse fere suspicor.

$\left.{ }^{2}\right) \mathrm{Si}$ in hodierna dispositione species Chylocladiæ Grev. in diversa genera abeant et nomen Lyngbyanum Lomentariæ uno generi adoptetur, alteri (typo Ch. clavellosa) nomen Chylocladiæ conservari, fas est.

$\left.{ }^{3}\right)$ Helmintnocladia. J. Ag. (non IIarv.) genus nov., typo Mesogloia purpurea Harv.

$\left.{ }^{4}\right)$ Hecsismora. J. Ag. (non Fries) Genus nov. typo Mesogloia divaricata $\mathrm{A} g$.

$\left.{ }^{3}\right)$ Prerocladia. J. Ag. Nov. genus, typo Fuco lucido Turn; fructu capsulari in una pagina elevato, solitario (nec bınis oppositis, in utraque pagina proeminentibus) a Gelidio distinctissimum.

6) Acrixococcus külz. est plantuli Floridea, sphærosporis cruciatim divisis, in articulis totius fili demum evolutis, distinctissima.

${ }^{7}$ ) Pernocelis $J$. Ag. nov. Gen., typo Cruoria pellita IIarv. (non Fries); sphærosporis cruciatim divisis rotundis, in medio filo singulis, distinctissimum.

8) Cruonia Fries sphærosporis oblongis zonatim divisis a I'etroceli disersum, plures continet species, nomine Cruorize pellitie confusas. 
9) HiLdenbnaxdra plura subgenera (aut genera?) sphærosporis diversa complectitur. Spharosporæ cruciatim divisæ in H. Nardi; zonatim divisæ in H. (Hæmatophlæa) Crouanii $J . A g$.

$\left.{ }^{10}\right)$ Hzvatocels $J$. Ag. nov. gen. Nematheciis supra frondem late effusis, sphærosporas zonatim divisas, paranematibu scinctas, continentibus, a Hildenbrandtia et Peyssonellia diversum, plures continet species novas et insuper Erythroclathrum Schousboei Liehm.

11) Rhododenis Crouan mscr. (non IIarvey) nov. Genus, fronde membranacea, sphærosporis elevatis inter paranemata rigida sparsa nidulantibus cruciatim divisis, distinctissimum, affinitate dubium, forsan Nitophyllo adproximandum.

12) Sarcodia J. Ag. gen. nov. typo Khodymenia Montagneana $H$. el Harv. structura frondis ab affinibus distinctum. 


\section{SERIES I. GONGYIOSPERMEA.}

Nucleo Cystocarpii nudo aut inter fila rel cellulas frondis suspenso. raro intra pericarpium exlernum recepto, sulogloboso, simplici ant nucleolis pluribus constante; gemmidiis intra periderma lıyilinum, mucosum ant membranaceun, plurimis, nullo ortine conglobalis.

\section{Orion I. CERAIIEA.}

C.ramice J. Ag. Symb. I. p. 3̈. Alg. med. p. 69. Encl. Gen. Pl. Suppl. III. p. 3i. IIarvey. Phycol. Brit. p. XI. (mut. linit. ap. omues). Ceramiearum \& Floridearum Gen. C. Ag. $\$$ Aucl.Callithmnice (partim) Ceraniex it cymnophleacex (partim) Kӥ̈љ.

Frons articulat:a monosiphonia, nula aut strato cellularum corticati librisie decurentilus cooperta, demum quindoquidem cellulosa. Faeclla ad ramos nudie, ant ramellis involucrate, iul'a periderma gelatiuosum lyalium gemmidia plutima rotundatoangulatil, Itullo ordine dispositi, forentes. Sphcerospore transformatione ramuli aut cellula corticalis formate, externe ant ralrus collulis corticalibus incluse.

Mge pulchre roseo-coccines, rarius pupurascentes, radice

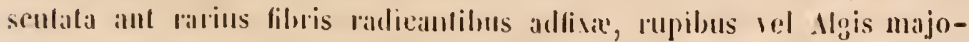
ribus allatie, monosiphonice el andiculata, phurma filiformes vare ramoser, nommllie articulis antostomosantibus et reliculatin conjunrlis frondosir (Ilanorial, Haloplegnua); filiformes sunt ant mudie ol simplici serie anticulormu superimpositurum constantes (Callithamnion, Ballia, Corsnospora, Criffillsias); ant intio nuda, demum fibris a basi ramorum iufar ifsalun membanam frondis incrassalie decurrentibus corlicate, vel filis evtra asem decurrentibus et stratum pro- 
prium formantibus cooperte (Ptiluti, Dulresnaja); aut ab inilio strato proprio corticali interupto vel continuo obtecte (Ceramiere). Ramificatio frondium nunc omnino ragia, nunc dichotoma, nunc finnata, pinnis distichis tetrastichis aut quoquoversum egredientibus, unne proprie rerticillati (IIalurus, Crouania, Dudresnajil), verticillis ant distantibus ant confluentibus, ramisque rerticillorum defintis vel quodammodo indefinitis et cum retate sensim plurimis.

Organa fructificationis triplicis generis observata. 1:0 Favelle externe nudx, ad ramos lateraliter sessiles (Callithamnion, Cornnosporil) vel ramulis immutatis paucis suffultre, aut plus minus transformatis involucrate (Cermuiex, Griffillsia, Llalurus, Ptilotis), aut inter ramulos verticillorum quasi immerse (Crounniı, Dudresnaja), nucleo simplici, rotundato vel lobato, aut pluribus composito constintes, intra periderma lıjalinum, mucosum aut submembranaceum, remmidia nullo ordine conglobata forentes. Gemmidia rotundata aut pressione mutua angulata, muco lasiori, vis solidescente, invicem separata. Placenta propria rarissime adest (Haloplegma): nuclei plerumque ad ramum sessiles, laterales aut terminales. 2:0 Spharospore nunc transformatione ramuli alt articuli integri formater (Callithamniese), nunc cellula corticali transmutata ortic (Ceraniex); illa isd ramos externe, nuda aut ramulo vel involucro proprio suffulte, he extra stratum corlicale prominentes nude aut cellulis corlicalibus vicinis obtecta; in plurimis sphrerice, nucleo triangule juadridiviso, in nonnullis sphreroidere, nucleo transversali divisione bipartito (Crouanie sp.) rel sepius cruciatim quadridiviso (Callithamnii sp.), in patucissimis oblonge, nucleo zonalim in sporas 4 soluto (Dudresuaji), aut pyriformes nucleo indiviso [?] (Corynospora). Spherospora aliquaudo composite obveniunt, l. e. intra perisporium externum non sporie simplices sed sphicrospore, sporas 4 contiuentes, formantur (Callithamuii sp.). 3:0 Antheridia ad ramos immutitos nudi, rel ramulis subtransformatis insolucrata, ramulo minuto thansformato ipsil orta, cellulis miuntissimis lıyalinis, asem circumeirca dispositis, constautia. Spermato\%oa lyyalina, appendice flig, loreve tempus a a ilial, olservavit $\Lambda$. Derbis (Principes de la Classif. des. Algues. p. 2\%).

Antheridia, spherospore at Favelle in diversis individuis normaliter obveniunt, diversis quoque aut fere iisdem locis pjusdem plantie erolutil; rarissime in eodem individuo fivelle et sphero- 
spote observatie fuerunt, non tamen promiseue obsenirntes, sed suo (1na)que typico Joco nata *).

Preter organa haec normalia of omnilus sine dubio communiil Seirospore in nommullis (Cillithamnii speciebus) olsservatie finermnt. Filis fasciculatis, dichotomo-fastigiatis, articulato- moniliformibus constant, intrat articulos corpusculat ova!ia, multo obscurius coloratil quam atficuli filormo sterilimm, forentes. Corpuscula hate spharosporarum more in sporas solvi, llarvey anctor est; milii indivisa semper obvenermut. P'reter seirosporas in istem, ni fallor, plantis et spherosporic et fiurlla normales evolvuntur. Iline seirosporas almormem potins evolntionem suspicor, quam organa in certis plantis normalia, que bel fincllis vel spherosporis aliarmu allaloga hiabenda essent.

Ceramieamm nomine jam apme Aatrdlium (Syst. Alg. Introd. et Sp. Alg. Vol. II.) fimniliam quandam institutam invenimus. Qun rero quum omues propric artienlatils plorideas (Rhodomrleas efe.) complectebaltur, tum alias minus evidenter arficulatias escludedat. In Sỵmbolis meis atçne dein in Alois Mediterrancis familiam a ceramieis et Florideis quibusdim intecedentium luctorum fundarr molitus sum, chalacteres a fructu peculiari, fuem favelle nomine antea designatrerant, petens. Fimniliam ita compositan plurimi Nfologi hodiemi adoptarunt. Decaisne alio omnino sensn Ceraminas definivit; primum enim Polysiphoniam (in Pl. de l'srab. p. 182) iistem adnmmerarit, dein (Classif. p. 62) P'olysiphoniam quidem expulsit, at Dasyam et bigenean inter Coramicas, Ptilotam vero inter Thamnophoreas enumcravit. Lü̈\%ing alio quorque modo snas condidit harum plantarmm finuilias. - Hodie ipse linites antea doctos - no: rero characteres fimilia - aliyuantulım mutandos censeo. Analysis fructum accuratior tantis in nonullis generibus differentias obtulit, ut hae genera expellenda crederem: Wrangelianı puto et Splridiam altue huic prosimam binderam. Wrangelia gerit fructns, a farelli Ceramiealmm vis minus dissimiles, qnam qui longe alimm in Systrmate locum I'olysiphonia, omnimm consensu, vindicarunt. - Qquo itatque a Ceramieis jure separantur Polysiphonia et senera luic affinia, eodem quotue: Itrangelial, yuantumeumpue sit

* In Callithamnii specio hoc observarunt lia Crouan, et specimen utroque fructu instructum mili benevole communicarunt. Idem in Cerami specie villere crelidi, at dubius sum anne specimen hoc plurilus revera conposilum sil. 
alio respectu simillima, a Ceramieis expellenda est. Nec spyridix veras offerunt favellas: gemmidia a placenta cellulosa radiantia mihi adparnerunt, sunt oblongo-obovala, invicem libera (?) atque intra pericarpium cellulosun clausum excepta; quæ omnia fuam maxime a fructu Ceramiearum abhorrent. Ut itaque Polysiphonia in sua serie est Ceramio in alia serie analoga, ita quoque Wrangeliam et Spyridiam grenera Ceramicis polills analoga quam affinia consideranda esse putarem. - Crouaniam et Dudresnajam dneente habitu Gloiocladeis antea adnumerari; love loco, forsan imvita natura, at urgente charactere ex axi monosiphonio petito, Ceramieis conjunxi.

Qualem itaune familiam hodie ciremuseripsi, a cryptonemeis fronde articulati aut sallin axi monosiphonio differt; fructu cum his fere conveniens. I Wrangelia, spyridia, Jolysiphonia, atque generibus horum affinibus, fructu capsulari distat; structura frondis in omnibus his subsimilis et analogia.

Genera nonuula, filis anastomosantibus in reficulum conjunctis et frondem rarie confignratam formantibus insignia, fructu nondum bene cognito, affinitate adhue dubia eensenda sunt. Ilabitu frondis cum Rhodomeleis quibusdam conveniunt, et una cum his (Dictyuro, Thuretia etc.) a Kützingio inter Callithamnieas disponuntur. Mihi, si ex structura frondis judicium de his plantis ferre liceat, nomnulli genera Ceramicis, alia Rhodomeleis aflinia videntur. Genera quoque isla hoc loco ita disposui.

\section{EXPOSITIO GENERUM SYNOITIC.}

\section{TRIBUS I. CALLITIIAIIVIEE. Sphierospore transfurmatione ra-} muli aut artienli integri formatre.

1. Frons filiformis, ramosa, nuda, aul rami demum fibris decurrentibus corliculi.

a). Favelle nudae aul ramo uno allerove sulfulla. Sphærosporæ nula singulæ triangule aut cruciatim divisa . . . .

J. Cinlowthimsios. " " pyriformes indivisa (?) ramello incurvo tecta

II. Conyosponi. HI. B.ILIA.

b). Favella incolucro regulari incluse. 
Frons pinnata inferne plus minus corticata
pinnis homogeneis .
V1. Pticota.
tilis subheterogeneis
obsita VII(?). D.ssyrmit.

2. Frons ramellis cooperla, gelatinoso-lubrica. Fucella inler ramellos frondis suspensu.

Sphærosporæ triangule aut transierse divisa . IIII. Crocisis. $"$ zonatim divise . . . . . . IX. Dedresris..

3. Frons reticulo filorum anastomosantium el concretorum constans.

Frons filiformis dichotoma
" plana lobata
" compressa pinnata

TRIBIS II. CERAMIEA. Sphrerospore morphosi cellule corticalis formatie.

Frons interupte corticata, cellulis corticaliluus ro-

tundatis nullo ordine dispositis . . XIII. Ceraniey.

ubique corticata, cellulis ${ }^{\circ}$ corticalibus rectan-

gularibus regulariler seriatis . . . MTY. Cextroceras.

ubique corticata, cellulis corticalibus rotun-

datis minutis.

Frons teretiuscula . . . . . XT. C.MpILEPHon..

" plana dichotoma. . . . . XYl. Microclidis.

$"$ " pinnata. . . . . XYll. Cirrporbepiunis.

\section{TRIBLS I. CALLTTHIINIEE.}

I. Callithaunion lyngb. Hydr. Dan. p. 122. Ag. sp. Alg. II. p. 136. Harv. Man. p. 403. J. Ag. Alg. med. p. 69. Endl. Gen. pl. Suppl. III. p. 34. (escl. sp. ap. omnes). Callithannion et Plılebothamnion Kï̈t. Pliycol. Gen. p. $370 \mathrm{squ}$., $s p$. Alg. p. 638 squ. Cillithamnion, Mutithannion et Poecilothamnion Nageli neuer. Algensyst. p. 198 squ. Cillithimmion, Spermollamnion et Trentepohlia Aresch. Enum. p. 103 squ.

Frons filiformis ranosa, artienlati, monosiphonia, demum sape lilris articulatis, intra membranam externam decurrentilus, i: ferme corticatis. Favelle, sicpe linx, axillires rel ad ramulos sessiles, nudie, ramulis paucis raro stipatie, intra periderma hyalinum yemmidia plurima angulatid forentes. Spha- 
rospore trausformatione ramuli aut atticuli terminalis formate, in ramulis nude, oblongo-sphericie, triangule ant transversim divisie. (Itarrey Plyge. Brit. lal). IXI; LXXVII; CXX; CXXXVI; CL.XYF etc.)

frondes filiformes, forma ef ramificalione varie; in infimis specicbus, lanuginem in aliis Alogis referentibus ant villo purpureo scopulos oblegrontibus, sub-icaules, filo primario ramisque conformibus, non raro a filo repente surgentes, in superioribus caulesecntes, lilo nempe primirio evidenter firmiori et distincto, sxpe extus corlicalo. Rami nunc vagi, oppositis alternisque promiscue obvenientibus, muc constumter oppositi, nune alterni, unne secundi, ramulis supremis in nonnullis speriebus dichotenis. Ramorum quoque in rante silus diversi; in uomullis frons tota disticha; in aliis rani tetrastichi, ef rum caule dreussati, in aliis denique rami quofuoversm eorediunlur, spiralem ordinem fere serpuentes.

Simplici serie longifulinali cellularum (articulormm) frons contesta est. Irticuli cylindrici, pro masnitudine spreinninis in eadem specie, longiludine variantes; juniores temui membrana cincti, seniles in mullis speciebus pirrietibus rassis constaules, et fasciculo librarum a ramis miljoribus inter stralis parielis decurenti insuper corticati. Corlicale lıoc stratum fubum primarimm sepe ommino inchulit, el frons (inferion) intrlienlata appal'el. filme corticales a ramo deoramm tendentes, articulalle dichotone, juxta ramum, ex yno emillunlur, simplici cellula constantes, sensim lisciculata ovaJunt et supra lulmun talius expanse, cum vicinis ramorum aliorum sensim miste, lubun primarimu investimnt. Iоoc in C. pmpturfero, ante alias, luculentissiuum vili.

Organa fructification is normalia triplicis generis. 1:0 Favella in ramulis externe, plermmute (an semper?) literales, sed ramuli apice in latus sepe defleso, quandoquidem adparenter terminales, mudxe ant ramulis proximis (non mutalis) irregulariter involucralie, singulx aut sxpe gemina, intra membranam lisius includentem semmidia plurima angulata foveutes. 2:0 Splopesporæe ex terminali arliculo ramuli aut ramelli, propric ad id evoluti et siepe unico articulo constantis, formatx, oblongx, mituritite subspherica, nucleo in nonmullis ertuciatim, in plurimis triangule diviso. 3:0 Antheridia in mullis speciebus observata, ramulum minutum, decompositum at contractum, mentieutia, oblonga, loco spherosporarum plerumjue obvenientis. 
Preter organa hee normalia et omnilus sine dubio çommunia, seirospora in nommllis observitie fuerunt. Constint filis fasciculalis, dichutomo-fastigialis, articulito-moniliformilus, intra articulos corpuscula ovalia forentibus, quie spharosporas triangule divisas axistimavit ef ita depinvit llarvey, que mihi rero semper indivisa obvenerunt. Laterali divisione articuli cujusdam infraterminalis inchoantur, utrinque probuberantiam hemisphericam, sensim magis separatam of subdivisam formantes. De natura horum organorum magnopere dubito; nucleos articulorum spherosporarum more subdividi, hum credidissem, nisi hujus observationis Itarveym auctorem habuerimus; certum enim vidntur sphtreposporas normales in speciminibus occurere, que nullia alia nota a speciminibus scirospuras gerentibus diffrant. Nec scirosporits certis quibusdam speciebus fructum cystocarpii efficere pularerim; adsunt enim favelle nomiles in una sillim specir, qua seirosporas generat. An species diverse, at quoad organa vegetalionis simillims, hoc loco commutentur, quarum nonnulle (Callillamnia vera), favellis et splaerosporis triangule divisis instructe (Call. Versicolor, Call. Bj̧ssoides), alic seirosporis el spherosporis cruciatim divisis ornitie ad genus proprium Seirosporae Ilarv. profrgande sint (Seirospora Griflithsiana, Seir. interruptil)? Proter lats species insuper nonnullie nane occurrunt (C. mirabile et C. eflorescens), qux utrum sphierosporas seriatas, an seirosporas indivisas haboant, dubito.

In nonnullis specichus spharospore compositie obvenimn; h. e. spluerospora in plures partes solvitur, quarmm quaque in sporas i lliangule dilabilur. Iloc in C. Borreri et C. purpurifero tantum vidi. Itrum vero lioc constanter in his specichus obveniat, guod crediderim, an tantum in speciminibus lusuriantibus obtineat, quod llarvey et D:na Griffitls eredere videntur, nondum milhi clarmm.

Genus a Lyngybeneo constitulum, immivlis paucis Dasyie et Gritfithsix speciebus; lis expulsis, in speciehus Mgarmm Agardlıi adoptatum, et eodem sensu a plurimis admissmm, eximic naturale. Opinionem alium primus professus est Cel. Duby, yui Ceranio iterum conjungendum esse monuit. Confitendum vero fructus in Ceramitis tunc temporis parum cognitos et male intellectos fuisse; rationes, quas suce opinionis altulit Cel. Duby, in Symbolis nostris (p. 41) refutare conarimus, Divisionem generis, defectu vel presentia strati corticalis fundatim, primi moliti sunt Cel:i Crouan (in Desmaz. Crypt. Fr. Fasc. VII); subnenus Prerostiam speciobus corticatis, numen Callithamnii speciebus ecorticatis conservantes. Hoc fundumento 
quoųue insistit Külzing, Callithamnion specielus feorlicalis, Phalebollamuion corticalis, genera insfituens. Divisionem ila ortam onniato artificialem considero, el syrecies matrime affines separantom. Nieweli allum substiluit divisionis tund:amentum. In Intillamnio (C. crucialo) "axem" "foliis" ornalum assumsit; Callithamnio (C. sominudum, C. tofricum, C. rosemu. (. scopulorum) "frondem" asilus indefinitis allerne pimatis constilulam, trilıil. In Poccilollamnio (C. versicolor C. "raumblum) denique "frondem" anihus definitis, seta caduca forminalis, constintem invenit. Conferanl opus aucto-

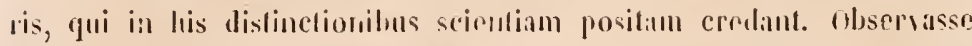

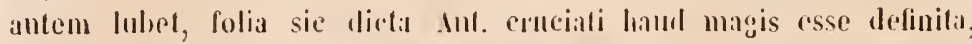
quam axes laterales $\mathrm{C}$. seopulorum; inter ares indefinitos Callillanmnii et dofinitos Porcilothamnii mullam aliam differentiam me imenire, 'fuam que ramilicalione allerne pinnata aul dichotoma oritur; ceteras diversilales, yuas enumeravil, nempe presentiam setarum, spherosporarum in ramo ramuligero (nee in rumulo) erolutionen, spherosporarum in eodem articulo plurimm proventum, ita esse parvi momenti, ut in eatem specir contrintia sapissime observantur. Harvey in Flora llibernica (nee postea) species nanas ad Trentepolılian relewavil. Areschong, Itarveganal vestiơia sequens, sphaerosporas agglomeratas harmm specierum favollas (memlorana ambiente destitulas) consideravil, spherosporasq̣ue in his inveniri dubitavit; utrumque falsum esse, or iconilns postea datis llarveyanis satis elucet; favellis vero nondum in his detectis, larum prasentia potius dubitandia fuisset. - Spherosporarmm deniyuc differentia goneris divisionem instituendan esse, exemplo aliorum generum urgente, forsitan quis putel. lieneria lero loo modo orla species alias simillimas distrahumt. Interea lace loco notandum splaarosporas cruciatim divisas in C. cruciato, C. plumuli, C. Orbigniano me observasse; triangule vero divisas in C. Hoccoso vidit llarvey, et in aliis phribus opposite-pinnatis ipse ineni. Fodem modo in Cill. versicolore et C. Byssoide spherosporas triangulo divisas, in C. interrupto et C. seirospermo nucleum linea transversali in duas saltim partes divisum occurrere observarnnt. Splacerusporas in nonnullis specicbus compositas existere jam supra adnotavi. Precipua itaque mutationes, quas in limitibus generis ducendis admisionus, ah instituto genere Corynospore pendent. Nec lıo revera charactere acutiori a Callithamnio differt, ynam qua alia genera differentiis mox allatis instituerentur. Species vero Corynospore habilu quoque diverser, et majorem produnt cum Griflitlsiis in ipsa textma fiondium aflinitatom. 


\section{STMOPSIS SECTONLII GENERIS,}

1. Frons vage ramosa acaulis, filis nempe primaris ramisque consimilibus; ferlilis ramulosa, ramulis abbrerialis sape opposilis, spharosporas solilarias aul sapius aggregalas ferentibus.

* Parasila, a callo radicali caspilosa, nana.

1. C. Daviesh.

2. C. SECUNDATUM.

3. C. Lexcmins.

4. C. HFrLonescexs.

̈. C. MIRARIL..

* Rupicoler, a cullo rulicali cuespilose.

6. C. MESOC.MIII)

7. C. sinclosin.

8. C. Rotili.

9. C. C.sispitosur.

10. C. Flonidecin.

*** Majores, intricatep, articulis ad genicula contractis.

11. C. istricstem.

12. C. SFIERICUN.

13. C. inREgLlare.

**** Najores repentes, arliculis cylindraceis.

1f. C. Roseolcy.

II. Frons opposile pinnata.

$\doteqdot$ Repentes, subucaules, filo primario decumbente radicante, secundariis erectis plumosis.

13̈. С. в.ив.ıтU..

16. C. Turxeis.

17. C. Plema.

18. C. ELEGais.

†† Repentes, tota decumbentes ralicantes, distiche.

19. C. Aústrale.

†† Caulescentes, erecto, spharosporis triangule divisis.

20. C. Hoccosur.

计计 Caulescentes, erecta, spherosporis cruciatim dirisis.

21. C. cntcistis.

22. C. MUCnoxatim. 
๒3. C. PLuatha.

24. C. Orbignianu.

๑.:. C. FLACCIDLM.

20. C. ptilota.

†ิ计门 Ramis rerticillatis ternis quaternisque.

27. C. Tendifoliun.

28. C. Mrurty.

III. Frons secundatim decomposita, ramis inferioribus quoquoversum egredientibus, superioribus secundatis flabellutis.

29. C. Stnictili

30. C. scopiniti.

IV. Frons alterne pinnatu ant ramulosa.

1. Ramis inferioribus et superioribus quoquoversum egredientibus.

$\dagger$ Ramulis superioribus pinnatim dispositis.

* Fronde fere a busi ecorticata.

31. C. CACDATEM.

32. C. ROSELM.

33. C. Funceldan.e.

** Fronde sursum longe corticata.

34. C. Giracdit.

3̈. C. Gaillonit.

iิ Ramulis superioribus sublichotomis.

36. C. I.Tennuptey.

37. C. Brssones.

38. C. conyubosti.

39. C. TERSICOLOR.

40. C. SEInOSPEnYicy.

2. Fronde tota distiche pimnata.

* Spherosporis ex terminali articulo pinnule formatis.

4. C. Gricillinem.

42. C. THuYoines.

* Spharosporis ex pinnella laterali formatis, in pinmula lateralibus, introrsis.

43. C. Deconpositex.

1.6. C. TRIPIXNTtu. 
Callithamnion.

3. Ramis inferioribus quoquocersum eqredienlibus, superioribus distiche plumosis.

* Fronde fere a basi ecorlicala.

4.̈. C. scopleoncy.

16. C. polsspenuty.

4. C. BonnEM.

* Fronde sursum longe corlicula.

48. C. IMPLIC.ITL.

49. C. Litissincy.

:50. C. НоокеR.

34. C. Acrospinmu.

ॐ2. C. TETHCUN.

4. Ramis inferioribus quoquorersum egredientibus ramulosis, ramulis abbrecialis cum rachide decussalis, fronde sursum longe corlicala.

* Ramulis pinnalis lalus planum rachidi adverlentibus.

:33. C. TETRIGONE.

\%\%. C. gittatum.

5.j. C. FenIXII.

: Rumulis pinnalo-decomposilis lalus planum, ramellis orbalum, rachidi adcertentibus, lateraliter et extrorsum pinnulalis.

56. C. Friticulosci.

57. C. Broniki.

:38. C. MoNTigini.

39. C. Gictchindi.

60. C. PURuUREenci.

61. C. AnBUEGTLI.

*** Ramulis subdichotomo-decomposilis.

62. C. GRATLLATM.

63. C. GRINDE.

I. Frons rage ramosa acaulis, flis nempe primariis ramisque consimitibus; ferlilis rumulosa, ramulis abbreriatis sape opposilis, spharosporas solitarias aul stepius aggregatas ferentibus.

* Parasile cespitose nane.

1. C. D.triestr (Dillv. Br. Conf. Introd, p. 73) nana, lanuginem tenuissimam referens, filis tenuissimis ad medium ramosis, basi apicerque longe producto nudiusculis, ramis patentibus 
sparsis, superne ad genicula contractis, ramulis fructiferis albmresiatis pilo lyalino sape terminatis, oppositis secundatisre, spltærosporis in ramuli articulo infimo solitariis ant geminis.

Conferra Daviesii Dillw. I. c. Tab. Suppl. F!!

Callith. Daviesii Ag. Sp. Alg. II. p. 186!! Harv. man. p. H17!! Külz. sp. p. 638 !

Trentepolılia Daviesii var. $\gamma$ (excl. reliqu.) Aresch. Enum. p. 117 :

Ceramium Daviesii Bonnem. Iiydr. p. 91!

Callitlı. pulses Ag. sp. Alg. p. 187!! Külz. sp. p. 639!

Callith. virgatulum Ilarv. Br. Fl. p. 349 !!

Conferva lanuginosa Dillw. Lab. Ä̈ (fide IIarrey!)

Callith. lanuginosum lyngb. Ilydr, lab. 41! Harv, man. p. 113! huls. sp. p. 639 !

Conferva srata Ag. Syst. p. 104!!

Ceramium roseolum Crouan in Dcsmas. Crypl. Fr.

Exsicc. Wyall Aly. Danm. n. 189!

Hab. in Ceramio, Polỵsiplonia ete. parasiticum ad littora Eurofiea Oceani Mllantici et Sinus Codani.

Fila Algarum aliarum quasi pube tenuissima roseo-carnea obducit. I'lanta ipsa vix lineam longitudine exsuperat. Fila tenuissima, solitaria nudo oculo haud discernenda, a callo radicali plura simul exeuntia, inlerne simplicia, ad medium circiter ramosa, apice longe producto iterum simplicia. Rami patentes stricti, quoquoversum egredientes aut sape secundi, inferiores longiores tilo primario conformes. Ramuli fructiferi unico articulo fere constantes, sed pilo elongato hyalino sape terminati, inferiores non raro oppositi, immo aliquando plures rerticillati, superiores sape secundi. Sphærosporæ in articulo ramuli infimo infra geniculum laterales erectiusculæ, solitarix aut geminæ, rarius ternæ, interiore latere sessiles, ohovatæ. Articuli diametro 3-4plo longiores, exsiccatione saltim ad geuicula contracti, variegati, endochromate ad apicem articuli coacervato, basi hyalino.

Jiter species ut synonymas supra allatas nullam video specificam differentiam. Articulorum longitudine et presentia vel defectu pilorum altquantulun variat. Confervæ lanuginosæ Dillw. specimen nullum vidi, sed in Phycol Brit. p. Xl. hæc species Callithamnio Daviesii subjungitur.

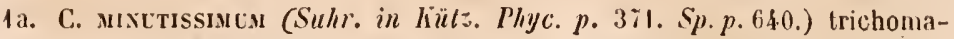
tibus solitáriis tenerrimis minutis, subsimplicibus, ramis apice piliferis; articulis diametro duplo longioribus; tetrachocarpiis axillaribus ad basin ramulorum sessilibus.

Ilab. ad Polysiphoniam nigrescentem in sinn Codano.

Jeser. Kiitz. transscripsi.

1b. C. Machoscontcus (Niggeli mscr. in hüls. sp. p. 640.) trichomatibus ad $1 / 10^{--1 / 6 " ' ~ l o n g i s, ~ r a m o s i s s i m i s, ~ r a m i s ~ f a s t i g i a t i s ~ u n i l a t e r a l i b u s, ~ a p i c e ~}$ 
2. C. SECuxbdtey (Lynyb. Mydr. Dan. p. 129) nana cespitosa villoque densissimo investiens, lilis tenuissimis a medio ramosis subfastigiatis, ramis erecto-patrutibus subsecundatis, rumulis finctiferis abbreviatis dense seriatis secundis, spltxrosporis in ritmuli articulo infimo subsolituriis terminalibus.

Callith. Davievii $\beta$. secundatum Lyngb. l. c. lab. \&.l B. fig. \& -..6 (nitidissime!!)

Callith. Secundialum Ag. Sp. II. p. Isi! Ilarv. man,p. 118! hïlz. sp. p. 639! Houl. H\% . Ilg. p. 13.8.

Callith. Daviesii var $\delta$. (excl. reliqu.) Aresch. Enum. p. 117!

(Cerumium Daviesii Chauv. (non Ag.)

Callith. Lenormandii Suhr. mscr! hïls. sp. p. 640 !

Exsicc. Chaul. Norm N:o 160!

longe cuspridatis (piliferis); articulis diametro parum longiorilus, subientricosis.

Hab. in sinu Neapolitano.

4c. C. Pygм.xu (küls. $s p . p$. 640.) trichomalibus solitariis, parasiticis,

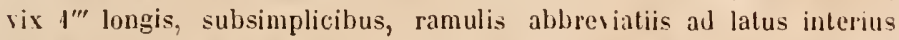
tetrachocarpiis minutissimis; articulis diametro triplo longioribus.

C. affine lïü. Pliyc. p. $3 i 1$.

C. ceramicola hüt. dctien.

Hal). in mari adriatico ad Hormoceras moniliforme.

11. C. P.I.texs (7unard. dell. Callilh. p. 12) filis tenuissimis erectis cxeppitoso-fastigiatis parum ramosis, ramulis secundis elongatis: articulis diametro 3-4plo longiorilus, geniculis leviter contractis; utriculis sporiferis sessilibus ellipsoideis ad latus internum ramulorum inferne sitis. Jlab. Ad oras Dalmatix legit Sanilri.

Cæspes fastigiatus vix $\$-\ddot{z}$ lineas altus. Fila dilutissime rosea uitidissima hyalına sub microscopio fere aclıromatica 1/1en lin. crassa. Rilmuli secundi elongat apice altenuati piliformes sape ramulc unico alterus huc illuc intercalati. Utriculi sporiferi ad anticulos inferiores ramulorum siti et hinc fere axillares.

le. C. Posidoxi.f (Zanaid. Call. p. 13) filis brevissimis fastigiatis simpliciusculis supra medium vestitis utriculis sporiferis ad quodique giniculum egredientibus vel breviter pedunculatis; articulis diametro 3 - iplo lougioribus, geniculis parum contractis.

IIal. Ad oras Dalinatix legit Sandri.

Cáspes minutus lineas duas altus ad folia Posidonia parasitans. Fila simpliciuscula, stricta, erecta, fistigiata apice ohlusa, $1 / 1$ ro lin. crassi. Utriculi sporiferi creberrimi seu ad yuodque geniculum exeuntes oborati haud raro pedunculati pedicello brevissimo aliquando in ramulum monarthrodium producto utriculum all lalus externum anplectentem.

Descr. auct. transscripsi. 
Hab, in Confervis, Porpliyra, Rhod. palmata, Serfulariis efe. in oceano Mtantico ab insulis Foeroearum usque ad littora Gallize.

Cæspites vix lineam alti, hemispherici, sxpe aggregati villoque denso alias Algas investientes. lïla inferne simpliciuscula, a medio circiter ramosa, ramis erecto-patentibus subfastigiatis plerumque secundis. Rami omnes ramulis abbreriatis, articulis paucis constantilus, dense seriatis, interiore latere ramorum secundis, obsiti. Sphærosporæ in his evolsuntur. Ramulus fructifer bresissimus, unico articulo fere constans; sphærospora in hoc pedicello terminalis, subsolitaria. Articuli subcylindrici, diametro sesqui-duplo longiores. Color roseus.

Sphicrosporas ad ramulos externe sessiles describit Montagne, quod vix de hac specie valet.

Crassior et intensius colorata quam C. Daviesii Dills., apicibus obtusis ramorum vix superemineutibus quoque diversa. Mihi videtur species distinctissima.

Callitl. Daviesii rar a. Lyng. specius sui juris mihi videtur, cum C. Daviesii Dillv. articulis rariegatis ad genicula contractis conveniens, tilis duplo crassioribus diversum. C. Secundatum crassitie filoruin aquat, al) hoc rero aliis characteribus differt. Ut species mihi tamen adluc; obscura, quare novum nomen, huic inveniendum, usurpare nolui.

3. C. Luxurats (J. Ag. mscr.) nana, cespitosa villoque densissimo investiens, filis tenuissimis a basi dichotomis decompositis filstigiatis, ramis patentihus sepe secundis, ramulis fructiferis adbreviatis oppositis secundatisve, spharosporis in ramuli arliculo infimo subsolitariis.

C. luxurians J. Ag. Küls. sp. p. 639!

C. Daviesii Desmat. pl. Crypt. Franc.

Ilab. in Sinu Codano folia fluctuantia Zosterse marinse villo densissimo obducens.

3a. Calt. Brassıcecм ( hülz. Phyc. p. 3il. Sp. p. 639) trichomatibus tenerrimis ramosis, basi dlilute roseis, apice hyalinis, acluromaticis, aequalibus; ramis alternis elongatis; articulis diametro subduplo longioribus, xgre conspicuis; tetrachocarpiis minutissinis, plerumque axillaribus.

Hah. in mari adriatico ad 7osteram marinam.

3b. C. Savaxu (Menegh. lill. ad Corin n. 3) "ilis temuissimis. caspitosis, inferne undis, superius ramosis, ramis erectis plerumpue alternis, extrenitatibus conformilus, articulis diametro triplo longioribus, capsulis terminalibus, solitariis, ellipticis."

Hah. parasitica in foliis Zosterae ad Genuam (Meneghini!)

besce. anct, transscriprit. 
Cæspes expansus hemispliericus $1-1 \frac{1}{2}$ lineam altus, filis tenuissimis a basi dichotomo-fastigialis constitutus. Rami dichotomi quoquorersum egredientes, sape secundati palentes, ramulisque hrevioribus virgati. Matmuli fructiferi inferiores aliquando oppositi, superiores sape secundi. Sphærospora in ramulo brevissimo uniarticulato plerumque terminales et solitaria, nunc gemina, ulraque ni fallor pedicellata. Color obscurins e violaceo-carneus.

Crescendi modo et exteriori habitu lere magis quam characteriluus microscopicis cognoscenda. Nudo oculo C. Rothrii lere refirt, colore forsan aliquantulum diversa. Sub microscopio ad C. Daviesii proxime accelit.

4. C. EFfronescers ( $J$. Ag. mscr.) nana caspilosa, filis temuissimis a lasi dichotomis decompositis fastigiatis, ramis patentibus sepe secundis strictis, articulis diametro 6-8plo longioribus, ritmulis frucliferis abbreviatis sparsis, demum corymbosis, splarrosporas in articulis moniliformilous seriatas gerentilus.

C. Daviesii ıar r. Aresch. Enum. p. 117. Tıb. V. D. (excl. syn.)

llab. ad lillora sinus Codani in Fuco purpurascenti parasitica.

Caspites 2-3 lineas alti. Fila stricta, a comnuni basi radiantia, decomposito-dichotoma, fastigiata. Rami patentes subsecundati. Articuli cylindracei diametro 6--8plo longiores. Ramuli fructiferi articulis plurilus elongatis constantes, dichotomi subfastigiati, articulis supremis breviorilons moniliformibus, sphærosporas ita seriatas foventibus.

Habitu et ramiticatione hoc C. luxurians amulatur, articulis longioribus et spharosporis corymbosis diversum. Icon Areschougii ramos strictos, in nostra insignes, non gerit; ob dispositionem capsularum huc referendam credidi. Specimina ad littus rarissime rejecta legi.

5. C? Mtrabile (Suhr Bot. Zeit. 1839. 1. p. 73) nana, crespitosa, filis tenuissimis a basi dichotomis fastigiatis, ramis pistentibus sparsis, articulis diametro $2-3$ plo longioribus, raumlis fructiferis abbreviatis subaxillaribus corymbosis spharosporas in alliculis moniliformibus seriatas gerentilus.

Trentepolılia mirabilis Sulır. l. c. lab. IV. fig. 47 !!

Trentepohlia Daviesii $\beta$. (cxcl. rel.) Aresch. Enum. p. 117 !

Callith. mirabile hïlz. sp. p. 639!

b̈a. C. Sp.nnsu (IIarv. Brill. F\% p. 348) "nana caspitosa, filis vage et sparsim ramosis, ramis erecto-pateutilus iurequalibus, articulis diametro duplo-triplo-longioribus, capsulis obovatis sessililus sapius axillaribus."

C. sparsum Harv. l. c. Man. p. 117! hül. sp. p. 643!

Hal, in Stipite velusto Laminaria Saccharine ad littus Britannia!. 
IIab, in Chondro crispo et furcellaria parasilicum ad litlora Gallix (11h. Sulu!) et Bahusire (Areschomg).

Cxspes minulus (in nostris viridis) lineam altus. Fila a basi raJiantia, subdichotomo-ramosia, ramis patentibus fastigialis. Articuli ad genicula subcontracti. In axillis ramorum ramuli proveniunt minuti, dense corymhosi, intra articulos breves sphærosporas? foventes.

Species sane distincta, sed me judice hujus generis incerta. Sphærosporas bene erolutas non vidi, et color omnino viridis. Sec. Areschoug, qui plantam in Bahusia lectam ad eandem speciem refert, color recentis purpureus.

\section{Rupicole cospilose.}

6. C. mesocarpu (Carm. mscr.) nana cespilosa, filis tenuissimis parce dichotomis, ramis patentilus sape secundis, ramulis fruchiferis ad medium filorum aggregatis 1-2-articulatis, sprerosporas 1-2 gerenlibus.

Call. mesocanpum Carm. mse. sec. Hare. in Br. Fl. p. 3ł8. Man. p. 116. Kï̌ls. sp. p. 642!

Ilab. ad rupes Britantix. (Carmichad).

"Caspites nunerosi, stratum purpureum formantes. Fila $2-3$ lineas longa parce ramosit, ramis longis strictis erectis simplicilus et subsecundis. Cansula ad mediun filorun aggregatæ, secundx aut oppositæ in pedunculis elongatis uni-articulatis aut-furcalis; in ramulu furcato capsulæ aut axillares ant ex uno furca ramo transmutala. Fibre repentes radicales nulla." bescr. Carmich.

Mihi ignota species. Ex littore Gallix plantam coran oculis haheo, quis ad hanc speciem torsan pertineat. Itabitus C. Rothii. Rami multo magis patentes, interiore Jatere ramulis secundatis abbreviatis (demum capsuliferis?), articulis $1-3$ constantibus, olsiti. Ramificalione itague C. Siecundato similis, at sine dubio C. Rothii alfinitate proxima.

Lineam vix alta, caspitulis sparsis minutie et habitu a C. Rothii mclius quam ramificatione dignoscitur. Huc forsau pertinet $\mathrm{C}$. floridulum Lyngh. lta Auctor.

ïh. C.nLl. numue (hü/s. Sp. p. 639) cespite minutissimo, velntino; trichomatibus brevissimis verticalilus, dense aggregatis, apicem versus plerumque parum incrassatis, suloramosis, apluilongis; articulis dixunetro sesqui- ad duplo longiorilus, cylindricis, ultimo obtuso: ryslocarpiis olovato-oblongis.

Hab. parasiticum in renis Jrider labyrinthifolia ad Cap. b. Spei (Pappe).

Color primum coccineus, demum palleseens et sordide riridis.)

Descr. auct. Iransscripsi. 
7. C. SPideosur (Suhr in. Flora 1840 p. 292) nana, carpitosil, tilis tennissimis parce diclotonis, ramis paltentiluss, ramulis fructiferis abbrevialis secus lotam superiorem pallem secumlis alternisyne, splurerosporis in ranulo furcato oppositis secundisque 6-S corymboso-agregratis.

Callith. spinulosum Suhr. l. c!l hüts. sp. p. 646!

Ililb. ad oras Giroenaliaidie (Villl!)

Ilabitus et stalura C. Rothii, colore forsan aliquantulum magis in violaceum tendente. Fila a basali puncto radiantia stricta, ramis lateralihus erecto-patentibus subfasciculatis paucis. Ramuli fructiferi plurimi, secus totam superiorem partem fere ad geniculum quodque exeuntes, articulis 2-3 constantes, plerumque ad geniculum quodque furcati aut trichotomi, intermedio ramulo ad sphærusporam relucto, lateralibus sphærosporas oppositas aut secundatas gerentibus; sphærosporæ itaque in ramulo sub)corymboso plurimæ, 6-8. Articuli diametro 3-4plo longiores.

A. C. Rothii differt dispositione ramulorum fertilium, sphærosporisque in ramulo numerosioribus; articulos quoque hahet sxpins longiores. Descriptio Suhrii in multis peccat. Utrum parasitica an rupicola sit, clulito; contra Suhrium rupicolam credo. Ad hanc speciem forsan quædam formæ C. Rothii revocandæ, quod vero deficientibus fructilsus non facile dijudicatur. 8. C. Rotmi (Turtons Syst. VI. p. 1806) nana, cespitosa, filis tenuissimis parce dichotomis, ramis erecto-adpressis, ranulis frnctiferis abbreviatis infäa apiecs ramorom pancis, sphacrosporis in ramulo simplici furcatove terminalibus $3-6$ corymbosoaggregalis.

Conferva Rothii Turton l. c. sec. Dillv. Br. Conf. tab. 73!! Enyl. Bot. $t a b .1702$.

Ceramium Rothii Berkel. Glean. tab. 20!

Callith. Rothii Lyngb. Ilydr. Dan. p. 129. tab. 41! Ag. sp. Alg. II. p. 483!! IIarv. Man. p. 116, Phycol. Brit, tab. 120, B!! Kütz. sp. p. 640!

Trentepohlia Rothii Harv., Aresch. Enum. p. 115!

Callith. paniculatum Schousb!

Conferva violacea Roth. Cat. Bol. I. p. 190.

Exsicc. Jurg. Alg. Dec. II. 1. 10. Grev. Alg. Brit. I. n. 13! Wyatt. Alg. Danm. N:o 188! Chauv. Norm. n. 110! Aresch. Scand. n. 8.

Ilab. ad rupes (oceani allantici a Grueulandia (Vahl!) usque all Tingin Arice (Schoushoe!); in simn Codano! ad littus Anerice Borealis sec llarrey.

Cæspitosa, cæspitibus aggregatis purpureo-coccineis, lineam-semipollicem altis, rupes investiens. Fila tenuissima parce ramosa, ramis extrorsum sulsecundis at longius distantibus quasi dichotoma. Rami erectoadpressi, inferiores longiores, subfastigiati. Ramuli fructiferi infra apices provenientes, oppositi aut alterni, simplices aut semel furcali articulis pancis constantes. Spharospora in ramuli articulo supremo dex oppositæ, 
iul 3 , vel in ramuli furcati articulis superiorilus plures : -6 corymlosoaggregata, ellipsoidex, satis magna. Articuli diametro 2-3plo vel immo 4plo longiores.

Varictatis all instinr, Byssum purpuream Liglf. Scol. p. 1000, (Dillw. lab. 43, Engl. Bot. lab. 192, IIarv. man. p. 116) Call:o Rothii subjungit Harvey; quod quonam jure factum sit, in medio relinquam. Mihi plures sub hoc nomine missas algas ex Insulis Orcadum, Shetland, lonæ (ad!' muros templi in ruinam lapsi obvenientem) observanti, plexum filorum, quorum superiorem partem detersam credo, constituere videntur. Plures C. Rolhii analogas species similem plexum sistere, et originariam B. purpuream plante boreali pertinere, cujus tantum sterilia specimina vidi, colore dilutius roseo, ramis patentioribus et articulis superioribus longioribus a C. Rothii diversæ, suspicor. Inter Synonyma allata C. Rothii, nonnulla acl hanc formam forsan revocanda sunt. Anne hæc sit C. sparso Harv. identica, dubito.

A. D. Mohr in cavernis rupium ad littus llibernix lectam Algam coram oculis haheo, colore pulcherrime coccineo insignem. Fila habet stricta, superne subfasciculato-ramosa, ramis elongaiis apice obovato-incrassatis, (denique sphærosporam immersam gerentibus?). Diversam speciem suspicor.

9. C. Caspitosum (J. Ag. mscr.) caspritosi, filis tenuissimis parce dichotomo-pinnatis, ramis erecto-adpressis, ramulis fructiferis abbreviatis fere a basi ad apicem pinnatim egredientibus vagis patentibus, spharosporis superiore ramulormm litere pluribus, seriatis ant sub-corymbose aggregiltis.

Hilb. ad rupes maris atlantici prope Brest (Crouan!).

Caspites efficit semipollicares, purpureos, densos. Fila a radicihus fibroso-intricatis erectiuscula, stricta et distanter dichotoma aut potius ramis consimilibus hic illic pinnata. Rami erecti aut subpatentes. Ramuli per tolam filorum longitudinem exeuntes, ahlureviati, patentissimi, simplices aut ramulis brevioribus superiore latere obsiti et splıerosporas aut simplici perlicello affixas aut in diviso aggregatas gerentes. Sphrrosporas oblongas, evidentes sed indivisis vidi. Articuli diametro quadruplo longiores.

Species nuihi videtur C. Rothii proxima, at characterihus allatis diversa.

A. C. floridulo longius recedit.

99 C. Coxstnucun (Ilering in Flora $1846 \mathrm{p}$. 212 "filis capillaribus, articulis superne constrictis, diametro quadruplo longiorilus; ramulis alternis, articulis xqualibus, diametro duplo longioribus; summis alılreviatis, articulis diametro aequalibus.

Ilab. ad Natal-Point in littore Africa australis, Corallinis insidens. Pollicare, purpureum, charta arcte adharens."

bescr. auct. transscripsi. 


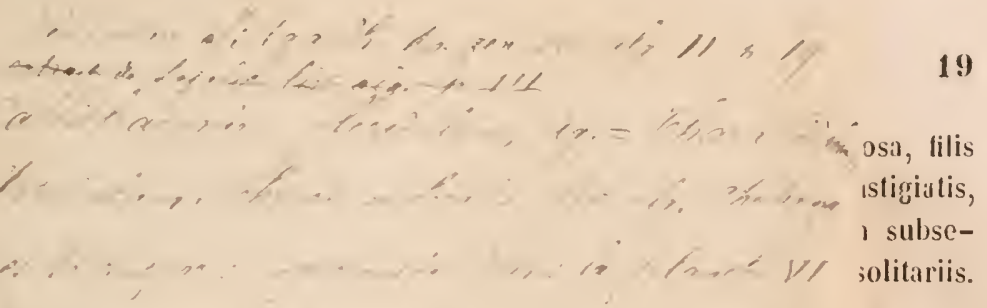

iyc. Brit.

Ralfs!) et

enuissimis sti, stricti, ramis su;onstantes,

Jlariey)

gerentes. Articuli diametro 3-bplo longiores, a exsovenu ad genicula contracti. Color exsiccatæ purpureus, inferne subviride pallens. Chartæ. minus adhæret.

Species sec. Harrey in littore occidentali IIbernia frequentissima, rupes longe lateque cæspitibus pannosis obtegens, demum ægagropila in littus rejecta.

C. floridulum Lyngb. est habitu ita diversum, ut identicum credere non potuerim; nec bene cum alia specie mihi nota conjungendum.

\section{*** Majores intricata, arliculis ad genicula contractis.}

11. C. INtracatun (Ag. Syst. p. 132) filis primariis repentibus [?] secundariis maximopere intricatis rage ramosis, ramis divaricato-patentibus, articulis ad genicula contractis dimetro duplo longioribus, sphærosporis ...

Ceramium intricatum $\mathrm{Ag}$. $\mathrm{l}$. $\mathrm{C}$.

Callith. intricatum Ag. sp. p. 182. Kütz. sp. p. 640.

llab. inter Algas majores intricata, ad Gades (Cabrera!); ad oras Gillia (sec. Kütz.).

Cxspes vix unciam altus. Fila capillo tenuiora maxime intricata (ita ut nec basis nec apices extricari possunt), irregulariter ramosa. Rami ramulique divaricati. Articuli diametro duplo longiores, exsiccatione ad geniculd contracti obscuriores, in medio perlucentes. Color cxspitis obscure purpureus, filorum sul, lente variegatus. Sulstantia rigidiuscula.

Descriptionem, in Spec. Alg. datam, fere transscripsi plante, cujus unicum tantum specimen vidli. Sequentilus quoad characteres proxima, at filis duplo tenuioribus ramisque patentioribus diversa. 
iut 3 , vel in mumuli furcati articulis superioribus plures $;$ - 6 corymlısoaggregatx, ellipsoidex, satis magna. Articuli diametro 2-3plo rel immo 4) lo Jongiores.

Varietatis at instar, Byssum purpuream Liglf. Scol. p. 1000, (Dille. tab. 43, Engl. Bot. Lab. 192, Ilarv. man. p. 116) Call:o Rothii subjungit IIarrey; quod quonam jure factum sit, in medio relinquam. Mibi plures sub hoc nomine missas algas ex Irsulis Orcadum, Shetland, Jonx (ad' muros templi in ruinam lapsi obvenientem) observanti, plexum filorum, quorum superiorem partem detersam credo, constituere videntur. I'lures C. Rothii analogas species similem plexum sistere, et originariam B. purpuream plan

dilutius $\mathrm{rC}$

C. Rothii

hanc form

tica, 'dubi

A. D.

ram oculi

cta, super

satis, (des

suspicor.

9. C. Ci

dich

abb।

pate

seri

Ililb

Cas

fibroso-in

mis cons

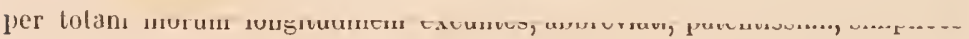
aut ramulis brevioribus superiore latere obsiti et sphærosporas aut simplici pedicello affixas aut in diviso aggregatas gerentes. Spharosporas oblongas, evidentes sed indivisas vidi. Articuli diametro quadruplo longiores.

Species mihi videtur C. Rothii proxima, at characteribus allatis diversa. 1. C. lloridulo longius recedit.

9a C. cosstrictum (Ilering in Flora 1846 p. 212 "filis capillaribus, articulis superne constrictis, diametro quadruplo longioribus; ramulis alternis, articulis aqualibus, diametro duplo longioribus; summis ahbreviatis, articulis diametro aqualibus.

Ilab. ad Natal-Point in littore Africe australis, Corallinis insidens.

I'ollicare, purpureum, chartæ arcte adharens."

Descr. auct. transscripsi. 
10. C. Floridulu (Dillw. Conf. Syn. p. 73) yloboso-crespitosia tilis tenuissimis parce dichotomis, ramis erecto-adpressis fastigiatis, ramulis fructiferis brevissimis secus superiorem partem subsecundis, spharosporis in ramulo indiviso terminalibus solitariis.

Conf. floridula Dillw. l. c. lab. Suppl. F!

Callitl. floridulum Ag. sp. p. 188. Hart. man. p. 116 et I'lyyc. Lrit. lab. 120 A! Kü̈s. sp. p. 640!

Exsicc. Hyall Damm. N:o 219!

Hab. in rupibus arena obductis ad littora Anglix (Ralfs!) et Gallix (sec. Harvey).

Cæspites rotundato-hemisphærici, fere pollicem alti, filis tenuissimis irregularius dichotonis fastigiatis constituti. Rami pauci, elongati, stricti, erecto-adpressi, ad apices numerosiores. Ramuli fructiferi in ramis superioribus secundi, simplicissimi, pedunculo 1-2 articulato constantes, sphærosporam solitariam terminalem (triangule divisam, sec. Harvey) gerentes. Articuli diametro 3-5plo longiores, in exsiccata ad genicula contracti. Color exsiccatæ purpureus, inferne subviride pallens. Chartæ. minus adhæret.

Species sec. Harvey in littore occidentali Hibernia: frequentissima, rupes longe lateque cæspitibus pannosis obtegens, demum ægagropila in littus rejecta.

C. floridulum Lyngb. est habitu ita diversum, ul identicum credere non potuerim; nec bene cum alia specie mihi nota conjungendum.

\section{*** Majores intricate, articulis ad genicula contractis.}

11. C. intracatuy (Ag. Syst. p. 132) filis primariis repentibus [?] secundariis maximopere intricatis vage ramosis, ramis divaricato-patentibus, articulis ad genicula contractis diametro duplo longioribus, splærosporis ...

Ceramium intricatum $\mathrm{Ag}$. $\mathrm{l}$. $\mathrm{c}$.

Callith. intricatum Ag. sp. p. 182. liülz. sp. p. 640.

llab. inter Algas majores intricata, ad Gades (Cabrera!); ad oras Gillia (sec. Külz.).

Cxspes vix unciam altus. Fila capillo tenuiora maxime intricata (ita ut nec basis nec apices extricari possunt), irregulariter ramosa. Rami ramulique divaricati. Articuli diametro duplo longiores, exsiccatione ad geniculd contracti obscuriores, in medio perlucentes. Color cæspitis obscure purpureus, filorum sub lente variegatus. Sulsstantia rigidiuscula.

Descriptionem, in Spec. Alg. datam, fere transscripsi plantre, cujus unicum tantum specimen vili. Sequentilus quoad characteres proxima, at filis duplo tenuioribus ramisque pateutioribus diversa. 
12. С. spixn:Cry (Crouan mser.) globozo-exspitosit, filis a basi radiantibus ramoso-fastigiatis, ramis vigis inlerne sparsis superne densioribus rectiusculis, articulis ad genicula contractis diamrtro duplo longiorilus, sphaerosporis. . . .

\section{Ilal). in Fuco plicito palmsilical ad Brest (Crontan!)}

Globi fere sphærici, densissimi, diametro semipollicares. Fila a basi quoquoversum radiantia, inferne elongata simplicia, superne irregulariter dichotoma, ramis erectiusculis, fastigiata. Rami sursum vix attenuati. Articuli arl genicula contracti, ellipsoidei, diametro duplo longiores. Fila crassitic capillaria. Color fuscescens.

13. C. Hangllake (J. Ag. Symb. p. 43) filis primariis repontibus radicantibus, secundariis erectiusculis vige ramosis, ramis paltentibus, articulis ad genicula contractis diametro 2 -4plo longioribus, ramulis fiuctiferis [?] ilbbreviatis oppositis multifidis, superioribus secundis, sphacrosporis ...

Call. irregulare J. Ag. l. c. Alg. medl. $p$ 70. Kü̈lz. sp. p. 642!

Call. compactum Schousb. mscr.

Ilab inter bulbos Posidonia, a mari rejectos, intricatis, ad littus Galloprovincix (1pse! Solier! Perreymond!); ad littus Tingitanum (Schollsboe!)

Pollicaris, filis primariis ut videtur repentibus, secundariis erectiusculis intricatis vage ramosis. Rami inferiores sæpe oppositi, superiores sæpe secundi, fructiferi demum ramulis abloreviatis oppositis et superne secundis olsiti. Ramuli isti decompositi (in nostris vere nondum fructiferi). Articuli ad genicula eximie contracti, ellipsoideo-oblongi, in primariis 4 plo, in ramis superioribus 2 plo diamelro longiores. Color recentis purpurascens, exsiccatæ sæpius sordide virens.

11a. C. inondnatum (Zanard. dell. Callilh. $p$. 12.) "filis capillo tenuioribus intricatis huc illuc arcuato-recurvatis irregulinter ramosis, ramis ramulisque patentissimis; articulis longitudine varia; utriculis sporiferis breviter pedunculatis ramulis plerumque oppositis.

Hab. Ad oras Dalmatix legit Sandri.

Caspes vix semiuncialis. Fila tenuissima $1 / 9$ lin. crassa, intricata, rigidiuscula, varie flexa et arcuato-recurvata irregulariter ramosa. Rami ramulıque nunc alterni, sæpissime secundi, (quandoque oppositi, crebri, vel longo intervallo distantes plerumque angulo recto egredientes, longiores brevioribus intermixti. Articuli longitudine in ipsis ramulis insigniter varia brevissimi longioribus intercalati.

Ad C. intricatum Ag. accedere videtur, notis vero allatis ab ipso bene distinguitur pracipue oh ramos arcuatos in convexitate ramulis secundis approximalis instructo:s.

Descr. auct. transscripsi. 
Call. variabili Ag. affinitate ut videtur proximum, ramiticatione irregulari, ramulis sxpius oppositis conveniens, at cuplo crassius, et articulorum forma diversum. A. C. barbato articulorum forma quoque dignoscatur.

\section{* * Repentes majores, arliculis cylindraceis.}

14. C. noseolui (Ag. Sp. Alg. II. p. 182) filo primario repente radicante, secandariis erectis vige ramosis decompositis, ramis patentibus hic illie oppositis sæepius alteruis secundisve, articulis 4-8plo diametro Iongioribus cylindraceis, splwerosporis interiore latere pinnularum subpedicellatis paucis, favellis... .

Callith. roseolım Ag. l. c. kült. sp. p. 642?

Callith. repens Lyngb. et Auct. (partim!)

Spermothamnion Turneri Aresch. Enum. p. 113.

Exsicc. Aresch. Scand. N:o 30.

Ilab. in Sinu Codano ad alias algas parasitica; all Ilelgolandian (Binder!)

Cæspes dense investiens, aliquando ultra pollicaris, sæpius pollicaris, e carneo roseus. Fila primaria repentia, secundaria erecta, strictiuscula aut aliquando intricata, vage ramosissima. Rami ramulique conformes patentes elongati longeque acuminati omnino vagi, in inferiore parte hic illic oppositi, in superiore alterni aut sxpe secundati, longe plerumque distantes. In ramulis his, interiore latere, proveniunt sphærosporæ, plerumque in ramello pauciarticulato terminales et solitariæ, nunc in ramello geminæ aut ternæ introrsæ et sessiles. Articuli cylindracei plerumque prælongi, 4-8plo diametro tongiores.

Præter sphærosporas descriptas obveniunt (in aliis speciminibus?) intra ramulos 6-8 involucrantes incurvos, globuli subsphærici numerosissimi, limbo cincti, sphærosporis subsimiles (an demum divisi?). Utrum ramulis involucrantihus revera insidant, an in apice rami, involucrum ferentis, ex communi quasi gelatina emergeant, dijudicare nequeam. Al, Areschougio hi fructus favellis analogi considerantur; mihi, olim vivos examinanti, sphærosporæ adparuerunt, Consimiles omnino in speciminibus C. Turneri a Borrero ex Anglia missis olveniunt, qui ab Agardhio ( $\mathrm{S}_{\mathrm{p}}$. Alg. p. 160) favellæ existimahantur. Teræ autem farellæ sec. IIarvey (Phyc. Brit. tab. 179 fig. 6) in C. Turneri alsunt.

C. repens Lyngl,. et Auct. Scandinavia est pars infima sterilis hujus speciei. Simili modo C. repens Anglorum est pars infima sterilis C. Turneri. Utraque species, in stotu bene evoluto, sine dubio altera alteri proxima et analoga, vix identica. Alo Areschougio utraque conjungitur. Verum C. Turneri ex oris Scandinavix nondum vidi. 


\section{Frons opposile pinnala.}

† Repentes, subacaules, filo primario decumbente radicanle, secunduriis ereclis plumosis.

15. C. Barbutum (Ag. Sp. Alg. p. 181) rufo-purpureum, filis inferioribus intricatis subvage ramosissimis nudis, suprrioribus pinnatis, pinnis oppositis patentibus simplicibus, infimis plume longioribus, articulis diametro 2-3plo longioribus, spluerosporis in parte inferiore pinnarum lateralibus.

C. barbatum Ag. l. c. IIarv. Man. p. 114 el Phycol. lab. 163! Engl. Bol. suppl. Łab. 2889. Кӥ̈z. sp. p. 643.

Callithamnion Mytili Schousb.

Callithamniou Ralfsii Ilarv.

Hab. in mari mediterraneo ad Massiliam (Schousboe!); in rupiJus limo olductis ad oras Anglix.

Caspes $1-2$ pollicaris sordide purpureus aut rufescens, valde intricatus, vage ramosissimus. Fila nunc omnino nuda, nunc apice pinnata, pinnis oppositis patentibus (abbreviatis et plumam linearem formantibus fide fig. Harveyanx vel) inferioribus longioribus, superioribus sensim brevioribus, plumam ambitu triangularem ita formantibus. Plumæ hinc illinc interruptx (detabentil)us pinnis quibusdam, aliis persistentibus in ramos demum excrescentibus?). Sphærosporas ad pinnas lateraliter evolutas, intra perisporium laxius triangule? divisas, sparsas vidi.

Harrey quædam dubia de identitate plantæ mediterraneæ et atlantica movit, diversitate insistens, quæ in deficientibus plumulis plantæ, in speciebus Algarum descriptæ, adesse videretur. Specimina l. c. descripta

45a. C. pectinatum (Nont. Prodr. Phyc.p. 9.) microscopicum, filo primario repente pinnato, pinnis pinnulisque oppositis patentibus, articulis cylindricis diametro duplo longioribus aut æqualilus; tetrachocarpiis axillaribus.

Callithamnion pectinatum Monl. l. c. el Voy. Pol. Sud. p.90. Ilook. et Ilarv. Cr. Antarct. p. 79. Кӥlz. sp. p. 647.

Hab. alias Algas in oris Auklandicis lectas perrepit.

Frons trilinearis, minutissimil, oculo nudo vix discernibilis. Filum primarium repens, $7 / 2 n 0$ millim. crassum, bipinnatum. Pinnæ distichæ, opposite, horizontales, $1 / 4$ millim. longx, patenti-crectx, siccando quandoque patentissimx, iterum pinnulate. Pinnulæ $\ddot{b}$ ad 6 lorevissimæ, simplices aut inferius uno alterove ramulo instructæ. Articuli teretes, geniculis nullo modo constrictis, fili primarii diametro duplo longiores pinnarum pinnularumplue sensim decrescentes et apicem versus eodem breviores. Tetrasporæ vel ad basin pinnarum vel in axillis pinnularum sitæ, sphrericx, triangule divisa, purpurex. Color roseo-purpureus. Chartio adharet. 1:̈b. C. lastocidous (Mont. Prodr. Phyc. p. 9). minutum (2-3 lineare), tilo primario repente bipinnatim ramoso, ramis ramulisque 
revera plumulis carent, at alia, ex eodem fonte provenientia, iiselem instructa sunt. Hac in omnibus cum planta Ifarveyana, quantum ex icone data judicare liceat, conveniunt, excepta tantum forma plumula, quas in nostris triangularis, in llarveyana linearis. Ame plumula in juvenili planta lineares, in adultiori triangulares, in senili deficientes sint? Specimen anglicum nullum ad manus habeo.

16. C. Tunxar (Mert. mscr.) filo primario repente radicants, secundariis erectis opposite pinnatis, pinnulis simplicinscmlis patentibus, arliculis 4-8plo diametro longioribus, sphrerosporis interiore latere pimnularum sessilibus aggregatis subasillaribus, favellis in ramulo terminalibus pluribus involucratis.

var. «. Turneri filis secmudariis strictis, pimnis patentibus, anticnlis pralongis, spltxerporis supra axillam aggregatis, pinmula superiori sterili, favellis involucralis.

Ceramium Turneri Nert. in Roth. Cat. III. p. 127 tab. 5! Ag. Syst. p. 142. Grev. Crypt. Fl. tab. 3äs!

Conferva Turneri Dillw. tab. 100! Engl. Bot. tab. 2339. (nec tal). 1637). Cillithamn. Turneri Ag. sp. Alg. p. 160! IIarv. man.p. 114 el P'hyc. tab. 179! J. Ag. Aly. med. p. 70. liütz. sp. p. 649!

Call. subverticillatum Zanard.

Exs. Wyatt Danm. N:o 183!

oppositis brevibus (abortu raro secundis) triplo tenuioribus; articulis cylindricis diametro 2-4plo longioribus, supremis æqualibus.

Callithamnion leptoclidum. Mont. l. c. et Voy. Pol. Sud. p.91. Lü̈z. sp. p. 642 .

IJab. ad Rhodymeniam Palmettam in freto Magellanico lectam, Heterosiphonia consortem invenit Montagne.

Filum primarium reptans, variæ longitudinis, ut plurimùm bi-trilineare, 1/100 millim. crassum, utrinque emittens ramos oppositos decumbentes. Rami sub apice vel ex ipso apjec articulorum exeuntes, alteri filo primario conformes et eum crissitudine fere æcuantes alteri brevissimi, ex binis ternisve articulis constantes, ad apicem scutulo dentato-fimbriato, cujus ope frondi Florideæ supradictæ inhæret, terminati. Hic ultimus arlversum labet semper ramulum illis, qui ramos ornant, quoad tenuitatem longitudinemque, simillimum. Rami 2 ad 3 millim. Iongi, $6 / 100$ millim. crassi, pinnulis oppositis instructi. Pinnulæ s. ramuli ultimi ordinis, subsimplices, oppositæ, raro iterum pinnulis secundis onustæ, distantes, $1 / 3$ millim. longæ $1 / 50$ millin. crassa, ex apice articuli orta, inferiores patentes vel patentierectx, superiores densiores, incurva, fastigiata. Articuli fili repentis diametro fere quadruplo, ramorum duplo tantum longiores, supremorum eodem arjuales, eximic et ubique cylindrici. Substantia membranacea tenerrima. Chartæ vitroque adhæret.

16a. C. Lamounouxir (Dub. Bot. Gall. II.p. 970). "amoene roseum minutum valde cespitosum rigidiusculum substrictum ramosum, ramis elonga- 
var. $p$. Variabile filis secundariis vage expansis decompositis, pinnisubhorizontalibus sxpe altornis secundisve, articulis brevibus, spluerosporis in pinnula ablireviata pancis, favellis . . .

Callith. variabile $A y . s p . p$. 463. Lï̈z. sp. p. 639!

Callith. Turneri $\beta$. Harv.

Conf. repens Lillw. et Auct. (partim).

Callithamnion axillare Schousb!Suhr. Regensb. Fl. 1840 p. 291. Kü̈l. sp. p. 649 !

Callith. Giraudii Solier. mescr!

Callith. abbreviatum Kü̈љ. $s p . p$. 649 !

Hab. aliis Florideis (Furcellaria etc.) parasitica, in Oceano N1lantico a Ilefgolandia! Isque ad Gades; ad Imericam horealem (see Ilarvey); in mediterraneo ot adriatico.

Carspites pollicares densi, filis primariis decumbentilus et radiculis abbreviatis discoicleis radicantibus. In var. «. sunt fila secundaria erecta, quoquoversum radiantia, stricta, simplicia at pinniata. Pinnse angulo fere $43^{\circ}$ egredientes, inferiores plerumpue pinnulata, superiores simpliciusculæ; pinnulæ inferiores oppositæ, aliquando ahortu alternæ, superiores sxpe secundatæ. Articuli plerumque præxlongi, in filis secundariis diametro sæe splo longiores. Sphærosporæ sulsessiles aut brevi ramulo adfixæ, adproximatæ, interiore (aut superiore, latere pinuæ piunulæve seriatæ, omnes axillæ adproximatæ, superiore parte piunarum sterili. Fasellæ ramulis paucis involucrate, plures plerumque conjuncta. Color roseus.

Var. $\beta$., ut illam intelligo, est planta quam var. $\alpha$. firmior, magis irregulariter ramosa et magis plerumque decomposita. Pinıæ angulo fere recto egredientes. Sphærosporæ in pinnis seriatæ, nunc sessiles, nunc in pimula breviori paucæ. C. variabile Ag. (forma Tergestina) a C. variabile Anglorum vix distat, nisi pinnis inferioribus brerissimis subdiraricate ramosis.

Callith. repens Auct. vix species mili videtur sed polius forma aut planta jurenilis nunc C. Turneri, nunc C. roseoli. C. sulsverticillatum Zan. a C. Turneri non uisi pinnis \& tetrastiche rerticillatis diversum, ad formam primariam sese habet ut var. hurridula ad C. plumulam. Areschoug C. roseolum cum C. Turneri conjunxit (Enum. Phycear. p. 113), quod quonam jure factum sit, milis haud liquet. Conveniunt crescendi modo repente; distant vero ramificatione, fructu et habitu. Lı C. Turneri rami

tis pinnatis, pinnulis inferiorilus simplicibus alternisve elongatis subulatis, pinnulis superioribus abhreviatis in sterilibus simplicibus in fertilibus 2-5tidis, articulis superioribus diametro 2-4plo, iuferioribus multulies longioribus, conceptaculis pinnulis alureviatas terminautulus pedicellatis slolosis ordto-blobosisque."

Ceramium Lamourouxii Imb. l. c. Mem. Cer. 1. Tub. II. fig. B!

llab. ad litlora Calvadosii in Fucis majoribus (Lamouroux). 
ieolo, rami

la minori;

Ic causam

;e speciei

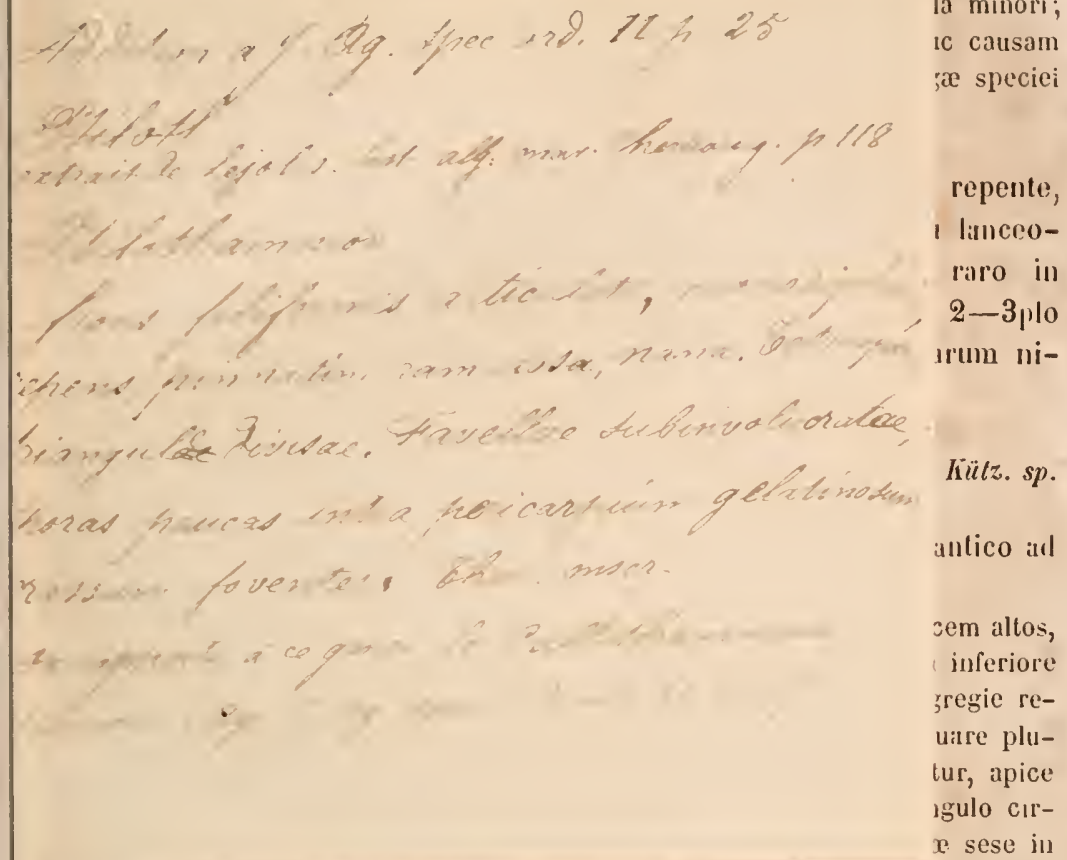

exsuvsta tangant; omnes obtusa. Superiores et inferiores aliquando alterux aut secundac. Articuli diametro 2 plo in majoribus 3 plo et forsan 4plo longiores. Sphærosporæ in articulo terminali pinnarum evolutæ. Color roseus.

C. plumula pusillum (Lyngb. (ab. 39), ab Agardhio ad C. plumam relatum, est species diversa.

18. C. Elifialis (Schousb. mscr.) violacem, filo primario repente, secundarios erectis a basi fere pinnatis ambitu oblongis, pinnis opposilis patentibus simplicilus aut superioribus in pluman consimilem evolutis, articulis in rachide diametro duplo longiorihms, spherosporis in anticulo torminali pinnarum niduburihus. Callitlt. elegans Schousb. in IIerl.; Ag. Sp. Aly. II. p. 162. liutz. sp. p. 6\%?.

C. Nluma Mont. Can. p. 176?

Callith. pulchellum Schousb. in IIb.

llab. in saxis arena obductis matris allantici ad 'Tingin (Schousboe!)

Crespites vix semipollicares, pulchre violacei. Fila primaria repentia videutur, at breviora; secundaria erecta, spatio ad lasiu mula, dein 
var. Pariabile filis secundariis vayo expansis decompositis, pinni; suhhorizontilihus siepe alternis secundisve, articulis hrevihus, sphærusporis in pinumla abloreviatia paucis, favellis . . .

Callith. variabile Ag. sp. p. 163. Külz. sp. p. 639!

Callith. Turneri $\beta$. Harv.

Conf. repens litlw. et luct. (partim).

Callithamnion axillare Schousb! Suhr. Regensb. Fl. 184.0 p. 291 . Külz. sp. p. 649 !

Calli

Call

Hill

I:ntico

Ilirvey)

Cins

ablurevia

quoquov

4:5" egri

læ; pinn

secunda

Splo 10.

proximis

nes axil

lis pauc

Var

regulari

recto ef

pinnula

bile An

cate rà

Cal

planta $\mathrm{j}$

a C. Tu

mam pr

C. roseolum cum C. Turneri conjunxit (Enum. I'hycear, p. 110, yau quonam jure factum sit, milhi haud liquet. Conveniunt crescendi modo repente; distant vero ramificatione, fructu et habitu. Lı C. Turneri rami

tis pinnatis, pimnulis inferiorilous simplicibus alternisve elongatis subulatis, pimulis superioribus abloreviatis in sterilibus simplicibus in fertilibus 2ribus multoties longioribus, conceptaculis pinumlas abhreviutas terminantihus pedicellatis slohosis ovalo-glohosisfjue."

Ceramium Lamourouxii Dub. l. c. Mem. Cer. I. Tab. II. fig. B! 1lab. ad litlora Calvadosii in rucis majoribus (Lamouroux). 
normaliter oppositi, aloortu rarius alterni aut secundi. In C. roseolo, rami raro oppositi; spherospore sparse sunt, raro line in pinnula minori; caspites tenuiores, at sxpe longiores; articuli quoque ol hanc causam longiores. Conf. tenella (Dillw. suppl. tab. F.) hujus aut analoga speciei videtur forma juvenilis.

17. C. PLuM (Dillw. intr. n. 119) rosemm, filo primario repente, secundariis repetis basi nudis a medio pinnatis ambitu lanceolatis, piunis oppositis crectinsculis simplicilus ant raro in pluman consimilem exerescentibus, articulis diametro $2-3$ plo longioribus, sphrerosporis in articulo terminali piunarum nidulantibus.

Conferva pluma Dillw. l. c. lab. F!l

Callithamnion pluma Ag. Sp. II. p. 162. IIarv. man. p. 115! Kï̈lz. sp. p. $697 !$

Ilah. in Stipite Lanninarixe efc. parasitica, in occano atlantico anl oras Britannix! et Gilliie!

Nana in aliis Algis cespites minutos, vix umquam semipollicem altos, efficit. Fila primaria repentia et radicantia, secundaria erecta inferiore parte nuda a medio circiter pinnata, plumam minutissimam egregie referentia. Pimne ut plurimum simplicissimæ, mediæ longiores, quire pluma ambitu lanceolata; aliquando una vel altera pinna prolongatur, apice plumam consimilem gerens; pinnæ infra apicem articulorum aıgulo cırciter $30^{\prime \prime}$ egredientes, plerumque ita dense stipatæ ut proximæ sese in exsiccata tangant; omnes obtusæ. Superiores et inferiores aliquando alternæ aut secundæ. Articuli diametro 2 plo in majorihus 3 plo et forsan 4plo longiores. Sphærosporæ in articulo terminali pinnarum evolutæ. Color roseus.

C. plumula pusillum (Lyngb. $t a b$. 39), ab Agardhio ad C. plumam relatum, est species diversa.

18. C. Eugans (Schousb. mscr.) violaceum, filo primario repente, secundariis erectis a basi fere pinnatis ambitu oblongis, pinnis oppositis patentibus simplicihus aut superioribus in plumim consimilem evolutis, articulis in rachide diametro duplo longiorihus, spherosporis in articulo terminali pinnarum nidulantihus. Callith. elegans Schousb. in IIerb.; Ag. Sp. Alg. II. p. 162. Kü̈t. sp. p. 647 .

C. pluma Mont. Can. p. 176?

Callith. pulchellum Schousb. in IIJ.

Ilab. in saxis arena olductis maris atlantici ad fingin (Schousboe!)

Cespites vix semipollicares, pulchre violacei. Fila primaria repenlia videntur, at breviora; secundaria erecta, spatio ad hasin nula, llein 
per totam longitudinem pinnata, pinnis inferioribus paulo brevioribus, superioribus aliquando prolongatis et plumosis. Pinnæ oppositx angulo $43-60^{\circ}$ egredientes, invicem distantes, licet infra geniculum quodque egredientes. Articuli in rachide diametro vix duplo longiores, in pinuis duplo longiores. Sphærosporas in pinnis superioribus evolutas et, ni fallor, triangule divisas vidi.

C. plumæ proxima at certe diversa species. Rachis et pinnæ in C. pluma ejusdem fere crassitiei; in C. eleganti rachis duplo crassior quam pinnæ; hinc pinnæ distantes in C. eleganti, adproximatæ in C. pluma.

\section{† Repentes, tota decumbentes rudicantes, disticha.}

19. C. austiale (J. Ag. Symb. I. p. 42) repens radicans distiche pinnata, decomposita, pinnis oppositis utrinque pinnulatis, pinnulis, obtusissimis, articuli ejusdem sæpe ternis, duabus collateralibus, tertio opposito, articulis oblongis diametro 2-4plo longioribus, geniculis contractis.

Callitl. australe J. Ag. l. c. Lü̈ъ. sp. p. 649.

Hab. parasitica in aliis Aggis ad oras Nove Hollandix.

Frons semipollicaris crassa, tota ni fallor decumbens et radiculis ais inferiore parte articuli geminis quaternisve oppositis apice discoideis radicans, pinnisque a superiore articuli parte egredientibus distiche pinnata. Pinnæ sublıorizontaliter patentes, ambitu sullineares. Pinnulæ brevissimæ articulis $3--4$ constantes, infra geniculum quodque egredientes, præcipue sursum pinnellatæ. Articulus pinnulæ infinus pinnellas ternas subconstanter gerit, quarum duæ (sursum) collaterales sunt, una supra alteram disposita; pinnula vero sensim in pinnam excrescente, articuli sequentes eodem modo pinnellis 3 nis instruuntur, quare frons uno latere (sxpius saltim) pinnas seminas, altero singulam, geminarum superiori oppositam, gerit. Articuli in filo adultiori diametro 3plo longiores, in pinnis vix duplo longiores, omnes ad senicula contracti et hinc oblongi; terminales vix attenuati obtusi.

Species robusta, habitu fere Polyzoniæ incisæ si nudo oculo conspiciatur, nullæ speciei mihi notæ arcte adfinis.

18a. C. menoptenum (Mont. Canar. p. 177) cespitosum roseum microscopicum, filis primariis repentibus, secundariis surrectis simplicibus, non nisi ad apicem pinnatis, pinnis omnibus furcatis, capsulis ellipticis pinnulas terminantibus.

Callithamıion Pluma var. micropterum Mont. l. c.

C. micropterum hülz. sp. p. 648 .

llab. ad insulas Canarias.

Ltrum varietas an species distincti esset, dubitavit Auctur. 
t十七 Caulescentes, erecte, sphurosporis lriangule dirisis.

20. C. Floccosum (Müll. Fl. Dan. tab. 828) fronde erecta distanter ramosa opposite pinnata, pinnis simplicibus subulatis erectopatentibus, articulis inferioribus diametro splo longioribus, sphærosporis pedicellatis in parte inferiore pinnarum lateralibus, triangule divisis.

Conferva floccosa $\mathrm{Fl}$. Dan. l. $\mathrm{c}$.

Callitlamnion floccosum Ag. sp. (partim) II. p. 158 IIarv. Phyc. Brit. tab. 81 ! hü̈ъ. sp. p. 64.6 !

Callith. plumula Lyngb. Hydr. Dan. p. 127 (excl. syn.)? $5-7$.

Callith. Pollexfeni Harv. in Ann. Nat. IIist. XIV. p. 186 tab. 3 fig.

var. $\beta$. pusilla fronde nana, pinnis ohtusioribus.

C. plumula $\beta$. pusilla Lyngb. l. c.!!

Hab. in Oceano atlantico boreali ad littora Scotice (Dickic!) Orcisdum ot Færuearum (Lynghye!)

Frondes 2-4 pollicares erectæ, distanter ramosæ, a basi articulatæ, nudæ, tlaccidæ, crassitiem capillarem parum superantes, inferne pinnis subdenudatæ, superne pinnis densioribus et ramis pinnatis subalternis obsitæ. Pinnæ supra medium articuli egredientes, oppositæ, simplicissimæ, quartam lineæ partem vix æquantes, ima basi subcontractæ, medio crassiores, apice longe acuminatæ; pinna una vel altera excrescente, rami formantur conformibus pinnis obsiti. Articuli in filis primariis infimi breviores, sequentes usque 8plo diametro longiores, superiores iterum breviores diametro 2-3plo longiores. Sphærosporæ ex pinnarum articulis inferioribus evolutæ, pedicello uni-articulato suffultæ, sphæroideæ, triangule divisæ (ex Harvey). Favellæ ignotæ. Magis quam plurimæ videtur lubrica.

Varietatem allatam huc pertinere, vix dubium milhi videtur. Neutiquam enim ad C. plumam, ad quam ab Auctoribus ducitur, referendam esse, ex descriptione tota velut ex specimine originali satis patet. Erecta est, decomposito-pinnata, caule evidenti instructa, capsulasque gerit laterales, quæ omnia a C. pluma abhorrent. C. floccosum in Speciebus Algarum cum C. plumulæ forma confusum fuit. Nomine C. plumulæ C. floccosum a Lynghyeo exacte describitur, sed synonyma plurima eidem non pertinent. Harvey pro more præsentem eximie illustravit; articulorum vero longitudinem aliam vidi.

t+t十 Caulescentes, erecte, spherosporis cruciatim divisis.

21. C. Cruclutum (Ag. Bot. Zeit. 1827 p. 637) cespitosa, filis erectinsculis parce ramosis, dense pinnatis, pinnis pinnulatis oppositis aut verticillatis tetrastichis apice ramorum conglomeratis, 
pinuulis simpliciusculis obtusis, inferioribus oppositis, superioribus sæpe ilternis secundisve, sphrecosporis loco piumularum inferiorum medie frondis, cruciatim disisis.

var. «. majus pinnis patentibus.

Callithamnion cruciatum Ag. l. c.; Sp. Alg. v. II. p. 160. IIarv. Man. p. 104. el Phycol. Brit. lab. 164! J. . Ig. .1lg. med. p. 70! Külz. Sp. Alg. p. 649! Aresch. Enum. Phyc. p. 111!

Antithamnion cruciatum Negeli.

Callithamnion imbricatum Schousb. mscr.! Suhr. Regensb. Fl. 1840 p. 281. Külz. sp. Alg. p. 630 !

Callithamnion dubium Zanardini! Lett. II. p. 13.

Callithamnion Naccarianum Rudolphi! in Naccari lelt. al Don Gius. Monico. n. 5.

var. $\beta$. pumilum minor, pinnis patentissimis sublıorizontalibus.

Cillith. pumilum Ilarv. in IIook. Br. Fl. II. p. 339.

C. cruciatum $\beta$. pumilum Harv. man. p. 404 ! Kӥ̈ъ. sp. l. c.

C. decipiens J. Ag. Alg med. p. 70 !

var. $\%$ radicans filo primario decumbente pinnas laxiores sursum rmittente.

C. cruciatum $\beta$. radicans J. Ag. in Linnea 1841 p. 14. Aresch. l. $c$.

Ilib. $a$. et $\beta$. ad rupes limo olductas maris Atlantici a Britannia usque ad Tinein, in mediterrane et adriatico; $\gamma$ ad littora Sinus Codani.

Cæspes densus plerumque pollicaris. Fila erectiuscula pinnıs plus minus dense vestita, et pinna una vel altera in ramum excrescente parce ramosa, apice ob pinnas juveniles densissimas comoso-capitata. Pinnæ $1 / 2-1$ lineam longæ, nunc hinæ oppositæ, nunc \& verticillatæ, tetrastichæ, patentes angulo circiter if:", pinnulatie, pluniam referentes cujus latus planum rachidem spectat (h. e. ut spiculæ Tritici, non ut Lolii ad rachidem). Pinnulæ simpliciusculæ, apice vix attenuatæ, obtusæ, inferiores oppositæ, superiores alternæ aut secundæ, et non raro pinnulæ inchoanti brevissimæ oppositæ. Articuli tili primarii supra medium leviter contracti, infra apicem pinnas emittentes, diametro $2-4$ plo longiores. Sphærosporæ in media fronde evolutæ, metamorphosi pinuularum inferiorum ortx, in pinne parte inferiore itaque oppositx, oblongx, intra perisporium duplex! hyalinum cruciatim divis

Var. $\beta$. est statura plerumque multo minor. Fila simplicia aut parcissime dichotoma, pinnis brevissimis ad seniculum quodque angulo subrecto egredientibus, sed mox incurvis rigidiusculis piunulatis obsita. Pinnulæ inferiores oppositæ incurva, extrorsum pinnellis paucis ornata, superiores simplices in rachide flexuosa alternæ. Articuli fili primarii diametro sul)-3plo longiores.

Var. $\gamma$. Fili halet vix uncialia, primarium radicans, radicihus elongatis disco radicali terminatis; pinne erectæ olpositæ, pinnulas plerumyue secundas emittentes. 
22. C necrovitem (\% Ag. mscr.) respitosa, lilis erectiusculis parce ramosis, dense pinnatis, pinnis oppositis ant rerticillatis tetrastichis apice lamormm conglomeratis, simplicibus ant semel furcatis subulatis mucrone hyalino terminatis.

Cill. cruciatum Hook. el Hlarv. Lond. Journ. III. p. 43̈3. IV. p. 412. Ilab. ab oras Tasmannixe (Hh). Hooker!)

Habitus C. cruciati, at major videtur, $2-3$ pollicaris. Fila primaria satis firma, pinmus terminalibus paucioribus conglomeratis capitata. Pinnæ omnes subsimplices, nunc ima basi, nunc medio semel furcata, basi crassiores, sursum sensim attenuatæ et mucrone hyalino acuminatæ; raro infra apicem ciliæ, mucrone similes, 2-3 unilaterales obveniunt. Articuli forma et longitudine præcedentis.

Species sine dubio distinctissima.

23. C. Prunula (Ellis Phil. Trans. 57 p. 426) filis erectiusculis ramosissimis dense pinnatis, pimnis oppositis aut rerticillatis tetrastichis, inferioribus recurvatis sursum pectinato-pinnatis flus minus decompositis, sphærosporis loco pinnularum inferiormm superioris frondis, cruciatim divisis.

var. ce. plumula distiche pinmata, rachide et pinnulis in eodem plano extensis.

Conferva plumula Ellis l. c. tab. 18, Dilhe. Conf. tab.50!

Callithamnion plumula $A g$. Sp. II. p. 159! IIarvey Man. p. 104. Alg. Tasm. n. 10 ! J. Ag. Symb. I. p. 43. Aresch. Enum. p. 110 ! Kӥ̈z. sp. p. 647 ! Mont. Fl. Alyer. p. 14.7!

Ceramium plumula Ag. Syst. p. 142 ! Bonnem. Ifydr. Locul. p. 731

Conferva Turneri Engl. Bol. lab. 1637 (non tab. 2339).

Exsicc. Chauv. Norm. n:o 6! Wyatt. Danm. n. 138 ! Aresch. Exs. ง. 29 !

var. $\rho$. crispum pinnis verticillatis tetrastichis sursum pimulatis, pinnulis divaricatis.

Cẹramium crispum Ducluz. Ess. p. 47 !!

Callith. plımula var. horridulum $J$. Ag. Symb. $p$. 43.

Callith. refractum Kül.s. sp. p. 630 !

Ilab. in Oceano Atlantico ab oris Sinus Codani usque ad Gades; ad liftorit Americe Septentrionalis (Harvey); in mari mediterraneo! et adrialico!; in Oceano australi ad Cilp Horn et Tasmanniam (Harvey); $\beta$. in mari mediterraneo frequentior.

Frons $2-4$ pollicaris ramosissima, ramis patentibus vagis, terminalibus siepe trichotomis, a basi articulata et pinnatia. Pinna 2 opposita aut \& verticillatx, tetrastichx, paulo infra apicem superiorem articulı egredientes, inferiores patentissime horizontales et refractie sursum pimnulatx, superiores patentes et erectiuscule simpliciores, supremæ aliquando extror- 
sum pinulate. Pinnula sursum secundm nunc simpliciores, breviores aut valde elongatæ, nunc secundatim decomposite, pinnellis introrsis; pinnula pinnellaque omnes aut eodem plano dispositx, aut eximie divaricatæ (var. $\beta$. ); ha plerumque basi firmiores, apice acuminatæ, frondi ispectum horridum tribuentes. Articuli diametro 2-4plo longiores, in medio sæpe leviter contracti. Sphærosporæ locum pinnularum occupantes, ideoque interiore latere pinnarum pinnularumque secundæ, ] subsessiles, cruciatim divisæ. Favellæ in ramulis superioribus plerumque binæ-quaternæ, ob rachidem lateraliter defiexam subterminales pinnisque ambientibus subinvolucratæ.

Formas allatas, habitu valde dissimiles, species diversas facile crederes. Sed rami verticillati aliquando in forma ceterum plana occurunt. $\mathrm{E}$ fundo profundiori protractam, pinnulas valde elongatas gerentem vidi. Antheridia loco pinnularum regulariter disposita, massam effluentem hyalinam globulis nullius certe formæ compositam referentia, semel observavi. Sporas, sphærosporarum divisione ortas, gerninantes vidi.

24. C. Orbigniaum (Mont. Pl. cell. cent. I. p. 331 ) filis erectiusculis ramosissimis dense pinnatis, pinnis (oppositis aut)

23a. Call. Sinile (Hook. et Harv. in Lond. Journ. IV. p. 271) fronde subsolitaria rigidiuscula ramosissima, ramis alternis v. subdichotomis articulatis enerviis, ramulis brevissimis oppositis distichis crassis sursum pectinatis e quoque ramorum articulo horizontaliter porrectis, pinnulis robustis simplicibus ramosisve, articulis ramorum diametro sesqui-duplo longioribus, ramulorum diametrum subæquantibus.

Call. Simile Hook. et. Harv. l. c. Crypt. Ant. p. 183! Kiütz. sp. p. 648 !

Hab. in Oceano australi ad insulam Kerguelen (Hooker).

Frons $2-5$ unc. longa, gracilis, rigidiuscula, repetitim distiche ramosa; ramis omnibus articulatis acquilatis. Ramuli $1 / 2$ lin. longi, distiche oppositi, e medio articuli cujusvis per totam frondis longitudinem orti, rohusti, subacuti, horizontaliter patentes, secus, marginem superiorem dispositi, ramulis secundariis obsiti. Color fusco-ruber.

C. plumulæ simillimum, sed rigidiusculum, ramis latioribus, ramulis roloustioribus, articulisque brevioribus.

23b. C. мacropterum (Menegh. in liütz. sp. p. 630) trichomatibus decomposito-ramosis; ramellis quaterno-verticillatis, tetrastichis, divaricato-adscendentibus, elongatis, bipinnatis; pinnis oppositis verticaliter distichis, ultimis pinnulisque ad latus interius secundis, attenuatis, longissimis aculis; articulis primariis diamelro $1 \frac{1}{2}-2 \mathrm{plo}$, secundariis $4-8$ plo longioribus.

Ilal, in Dalmatia.

An a C. Plumula var. listincta?" Descr. a Kiitzingio mutuatus sum. 
verticillatis tefrastichis, inferionibus recurvatis utringue opposite pinumlatis, pinmulis secunde pimellatis, splierosporis in pinmulis subavillaribus, erueialiun divisis.

Callithamnion Orbignianum Monlagn. l. c. Flor. Boliv. p. 7 lab. VII.

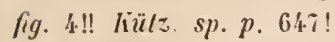

\section{Uial), in Oceano Pacifico ad orals P'ernviæ (d'Orbigny!)}

Fila primaria capillaria semipedalia vage ramosissima et densissime pinnata. Pinne fere omnes recurvato-patentes, (in spec. a me olsserv.) tetrastiche verticillatæ, infra geniculum quodque egredientes, semilineam haud longæ, utrinque pinnulatæ. Pinnulæ aut simplices aut piunellatæ, pinnellis secundis a hasi latiore acuminatis. Spærosporæ sæpissime in axilla pinnularum evolutæ, sessiles aut subpedicellatæ, cruciatim divisæ. Articuli diametro 2plo-3plo-longiores. Color roseus precedentis.

Antecedenti habitu proximum, pinnis utrinque pinnulatis facillime dignoscitur.

25. C. Flaccidul (Hook. fil. et Harv. in Lond. Journ. IV. $p$. 273) filis erectiusculis ramosissimis dense pinnatis, pinnis oppositis (aut abortu alternis) patentibus opposite pinnulatis, pinnulis terminalibus extrorsum subsecundis, sphærosporis in piınuli plurimis secundis, cruciatim divisis.

C. flaccidum Ilook. et IIarv. l. c. Crypt. antarcl. p. 184 tab. 188, fig. I! Külz. sp. $p 648$.

var. $\beta$. allernifolium ramis ramulisque alternis secundisve rarissime paucis oppositis.

Hab in Oceano antarctico ad Hermite Islind et Cap IIorn (IIooker).

Frons 2-4unc. longa, laxe ramosa, membranacea, flaccida, rosea. Caules ramique gracillimi, filiformes. Rami primarii et secundarii oppositi alternive distichi, elongati, patentes; ramulis ultimis brevibus simplicibus patentibus oppositis secundisve, apice incurvis. Articuli ramorum primariorum diametro multoties, secundariorum 6-10plo, ramulorum sesquilongiores. Sphærosporæ introrsum seriatæ, ad quodque geniculum egredientes, demum ut videtur cruciatim divisæ.

Species sec. auctores C. Turneri proxime affinis. Mihi, ex icone plantam describenti, ob ramificationis normam et sphærosporarum divisionem C. plumulæ potius adproximanda videtur.

23c. C. Polracastuci (hütz. sp. p. 618) ramosissimum, ramis ragis, ramulisque ubique obsessis pinnis reflexis minutis rigidis, sublbipinnatis, pinnulis pinnelisque brevibus rigillis, divaricatis rellexisijue, apice acute spinescentibus, subsecundis, interdum oppositis; articulis diametro sesquilongioribus.

Ilab. ad littora Britanniæ.

Descr. auct. transcripsi. 
26 C. Priloti (Hook. el Harv. in Lond. Journ. IV. p. 2శ2) rigidula setacea, filis erectiusculis ramosissimis dense pinnatis, pinnis ix disticlis venoso-striatis opposite pinnulatis, pinnulis simplicibus patentibus subulatis, splırosporis al pinnulas sparsis . . .

C. Ptilota Ilook. et Ilarv, l. c. Crypt. Antarct. p. 183 tab. 189 fig. I! Küts. $s p$. Alg. p. 648 !

Ilab. in Oceano antarctico ad Crozet insulas, in Nacrocysti natante insidens (Hoolier).

Frons 1-2 uncias longa. Caulis crassitudine setæ equinæ, repetitim pinnatim ramosus; ramis suboppositis patentibus demum deflexis, inferioribus subuncialibus; secundariis breviusculis pinnatis, pinnis plurimis densis, oppositis, simplicibus subulatis, e omni articulo rami ortis. Articuli diametro duplo longiores. Color fusco-ruber. Chartæ vix adheret.

Plantam, cujus unicum tantum specimen observarunt, ex icone et descriptione Auctorum descripsi.

\section{t十t+十 Ramis verticillatis ternis quaternisque.}

27. C. tervifolium (Hook. et Harv. in Lond. Journ. IV. p. 272) fronde erectiuscula, rage dichotomi lasius ramulosil, ramulis. abhreviatis ternis simplicibus fnrcatisque, favellis bilobis ramos terminantibus.

Callith. ternifolium Hook. et. Harn. l. c. Crypt. antarcl. pag. 183 tab. 189 fig. 2! Kü/z. sp. Alg. p. 6 อ̈0.

Hiab. in Oceano antarctico ad Calp IIorn, in aliis Mlois parasitica; c fundo protracta (Ilooker).

Species perpusilla, parasitica, caspitosa, sub $1 / 2$ unc. longa, vage ramosa, rosea, flaccida et membranacea. Ramuli e omni ramorum articulo orti, plerumque terni, raro bini quaternive, graciles, breves, simplices, erecto-patentes. Articuli caulis ramorumque diametro 4-5plo, ramulorum sub-duplo Iongiores. Favellæ magnæ rotundatæ. Sphærosporæ lriangule divisa.

28. C. Mrusuri (Suhr Flora 1840 p. 282) fronde erectinscula parce ramosa spongioso-cylindracea, filo ramulis densissimis vestito constituta, ramulis ahbreviatis cylindraceis verticillatim pinnatis, pinnis sublorizontalibus diclotomis rel alterne rimosis divaricatis acmminatis, splıærosporis infra apices piunaroun introrsis.

Callıth. myurum Suhr. l. c! Külz. sp. p. 650!

Call. dasycladum J. dy. Symb. I. p. 42. 
labl. ad oras Perurie in Gelidio seminudo parisitica.: (IIb). Binder!)

Frons erectil, $1 / 2-1$ pollicaris, pennam columbinam fere crassa, cylindraceo-acuminata, ramo uno alterove conformi ornata, frondibusque novellis basi plerumque stipata, filo ramulis densissimis vestito constituta. Ramuli subclavato-cylindracei, filo centrali pinnis verticillatis vestito constantes. I'nna verticillate \&, duabus paulo brevioribus, abbreviate, patentes-subhorizontales, lecompositæ. ['innule sulsconformes, ve] sipius dichotomæ alternere ramosæ, ramis divancatis densissimis crassis mucronato-acuminalis. Articuli in filo primario diametro sesquilongiores; in pinnis aquales. Splærosporæ in pinnulıs sessiles, ni follor introrsæ, triangule divisæ.

l'æeter spharosporas maturas et triangule divisas vidi articulos singulos infra apicem furcatim ramulorum hinc inflatos, quasi resiculosos.

Varietatem hujus, vel forsan speciem distinctam, ex oris Indix orientalis coram oculis habeo, ramulis longioribus et articulis pinnarum diametro sesquilongioribus diversam.

28a. C. Sprescexs (hülz. Phyc. gen. p. 373) "trichomate minori subramoso, ubique vestito ramellis minutis rerticillatis, distantibus, patentissimis, divaricato-ramosis, subdichotomis, spinescentibus, medio articulorum primariorum (diam. subtriplo longiorum) insertis."

C. spinescens Kïlz. l. c. el sp. Aly. p. 634. Sond. Alg. Preiss. p. 19! $\beta$. julaceum ramellis superiombus approximutis adpressis.

IIab. ad Nov. Hollandiam.

:Tripollicare tenuissimum. Rami primarii et secundarii distichi, romellis minutissimis verticillalis acutis simplicibus rel iterum ramellosis. Articuli fili primarii ramorumque diametro $3-4$ plo, ramellorum duplo longiores. Sphærosporæ oblongæ in ramulis ultimis ad genicula sessiles, hyalinæ, nucleo triangulatim quadripartito." Sond. $l$. $c$.

28b. C. Preissit (Sond. Alg. Preiss. p. 19) "minutissimum, repens, parasiticum, ramis erectis, ramulis subpatulis verticillatis pinnatis; articulis ramorum diametro sultriplo longioribus, ramellorum æequalibus.

Callithamnion Preissii Sond. l. c. Kütz. sp. p. 634.

Irab. ad littus occidentale Novæ IIollandix (I'reiss).

Parasiticum, Callitlramnio pectinato Montagn. aftine. Rami vix 2 lineas longi, circumscriptione liueari-lanceolati. Ramulorum pinn patentes, distichæ, acutr. Fructus deest. Color roseus."

28c. C. Pelductica (Ilarv, in liooli. Journ. 3 p. 449) "filis e basi communi late stuposa ortis tenuilus pellucidis monosiphoncis roseis vage subdichotome ramosissimis; ramis ad quodque geniculum ramulis brevissimis subulatis oppositis vel verticillatis oruatis, articulis diametro $1 \frac{1}{2}-{ }^{2}$ plo longioriluus. 
III. Frons secundalim decomposila, ramis inferioribus quoquoeersum egredientibus, superioribus secundatis flabellatis.

2J. C. Strictum (Ag. Sp. Alg. p. 185) fronde erectiuscula secundatim decompositi, a basi articulata, ramis inferioribus quoquoversum egredientibus, superioribus flabollatis decomposito-pinnatis, pinnis introrsum secundis erectiusculis, sphærosporis interiore pinnularum latere seriatis plurimis.

Call. strictum Ag. l. c! Külz. sp. p. 643!

Call. Crouanii hütz. sp. p. 612! (excl. syn. Dillw.)

Call. semipennatum J. Ag. Alg. med. p. 72! külz. sp. p. 643 !

Exsicc. Desmaz. Cr. Fr. n. 1038.

Hiab. in Oceano Mtlantico calidiori ad littus Tingitanum (Schousboe!), ad Brest (Cronin!); in mari mediterraneo ad littus Galloprovincix (Perreymond!)

Cæspitem format semipollicarem, pulchre roseum. Rami secundatim decompositi, inferiores vero nunc unum nunc alterum latus occupantes, superiores introrsum secundi, sensim tenuiores. Articuli cylindracei, adultiores (exsiccatione?) ad genicula contracti, in ramis pinnatis diametro triplo, in secundariis tenuioribus usque 4 plo diametrum superantes. Sphærosporæ fere sphæricæ, in ramulis ita abbreviatis dispositæ, ut conjunclione multarum racemos minutos secundos interiore latere formare videantur.

Species distinctissima, sphærosporis aggregatis ad C. Turneri accedens, ramificatione ab omnibus facillime cognoscenda. In Algis mediterraneis novo nomine hanc Speciem proposui, forma diversa articulorum insistens; comparatis hodie speciminibus utramque formam conjungendam censeo. Mediterranea est contractior et firmior; atlantica magis elongata et gracilior.

Spyridia pellucida Ilarv. l. $c$.

Callith. pellucidum Ilarv. Tasm. p. 45 ! Kütz. Sp. p. 652.

Ilab. ad Tasmaniam (Gunn).

Crassities Ceramii rubri. Longitudo $\ddot{b}-6$ pollicaris."

28d. C. vertigillatim (Suhr. in Ftora 1840 p. 290) 3-4 lin. allum, filo primario simplici ad geniculum quodque ramis $3-4$ verticillatis obsito, ramis alterne et fasciculatim ramulosis."

lfah ad Cap. b. Spei (Ecklon).

29.. Callitif. unilaterale (Zanard. Callilh. p. 12) "tiliz basi ultra capillaribus repentibus, ramis ramulisçue unilateralibus erecto-adpressis, ultimis tenuissimis fastigiatis; articulis diametro k- bplo longioribus; ntriculis sporiferis numerosissimis subracemosis.

Griffithsia repens. Zanurd. Saggio di classif. p. 56.

Hab. Dalmatia ad algas perrepens. 
30. C. scoparium (Hook. et Harv. in Lond. Journ. IV. p. 273) caulesens stuposa, fronde rectid decomposita, caule fibris intertestis corticato, ramis quoquorersm egredientibus cauli subsimilibus, superioribus fasciculatis pinnato-fastiviatis, pinnis secunditim pinnulatis erectiusculis, sphierosporis....

Call. Scoparium Hook. et Ilarv. 1. c. Crypt. Antarct. p. 184. tab. 189. fig. 3 !

Phlebothamuion Scoparium fiüls. sp. $p, 656$ !

Hab in Geeano Australi ad insulas Falkland et Cap Horn.

Frondes 2-3 pollicares cæspitosæ. Caules crassi inarticulati, fibris flexuosis stuposi, parum ramosi. Rami conformes, per totam longitudinem ramulis gracilibus strictis quoquoversum egredientibus densissime obsiti. Ramuli articulati irregulariter divisi, aut pinnati, aut secundatim vel subdichotome divisi, semper stricti erecti, sxpius adpressi. Apices acuti aut obtusi, simplices aut ramellis secundis pectinati. Color obscure purpureus. Substantia rigida. Nudo oculo C. tetricum et C. crinitum [?] æmulatur, sub lente diversissima species. Habitus Sphacelariæ scopariæ." Descriptionem ab Auctore mutuatus sum.

\section{Frons alterne pimnala unt ramulosa.}

1. Ramis inferioribus et superioribus quoquover sum egredientibus.

$\dagger$ Ramulis superioribus pinnalim disposilis.

* Fronde fere a basi ecorlicala.

31. C. Cacditum (J. Ag. Symb. p. 46) fronde erectiuscula alterne decomposito-pinnata a basi nuda articulata, ramis quoquoversum egredientibus elongatis pinnatis, apice sæpe longe producto nudiusculis, pinnis intermediis pinnulatis, inferioribus superioribusque simplicibus patentibus incurvatis, spltærosporis in pinna sursum pinnulata interiore latere subsecundis paucis. Callith. caudatum J. Ag. l. c. Alg. med. p. 72. liül. sp. p. 645.

Cæspes minutus vix 4 - $\ddot{3}$ lineas altus. Fila primaria horizontalia deorsum radicantia capillo crassiora, sursum ramos verticales bi-terque ramulosos emittentia, ramulis omnibus e latere tantum interno ad quodque geniculum exeuntibus stricte adpressis fastigiatis, ultimis gracillimis. Articuli diametro usque sextuplo longiores in filis primariis ad geniculos eximie contracti. Utriculi sporiferi ad ramulos brevissimos sxpe oppositos versus medium frondis siti et ita numerosi ut fere gloiocarpa generis Griffitlısia simulent. Color coccineus; sulstantia rigidiuscula." 
Ilab ad rupes iı limito maris Mediterranei; ad littora Galloproviacia (Ipse! Giraluly! Solier! Perreymond!)

Crespes pollicaris densus, filis tenuissimis constitutus. Fila erectiuscula iuferne ramosa, ranis simpliciusculis. Rami patentes, pinnati. Pinnx nutc ad geniculum quodque egredientes, nunc longiori intervallo deficientes, medı longiores et pinnulatæ, ni fallor cum rachide decussatæ, superiores inferioresque simplices, breves, parum attenuate, incurve, angulo $43^{\circ}$ egredientes; apices ramorum nunc parum elongati minusque supereminentes, sxpius elongati omnino nudi aut pinnis albreviatis hic illic secundis obsiti. Articuli ubique conspicui, 2-4plo diametro longiores. In planta fructiferd pinnæ sursum secunde pinnulatæ evadunt; morphosi harum pinnularum sphærosporæ formari videntur, nunc in pinna solitariæ, nunc plures, at plerumerue paucæ, sphieroideæ triangule divisæ. Color saturatius roseus. Charte arctissime adhæret.

Species distinctissima, hodie a pluribus Galloprovinciæ Algologis, dliversis locis, inventa.

32. C. roseun (Roth. Cal. II. p. 182) fronde erectiuscula alternis decomposito-pinnalia ima basi corticita, ramis quoquoversum ogredientibus pinalis apjee subcorymbosis, pinnis patentibus, inferioribus pinnulatis, superioribus simpliciorihus, spherosporis in pinula simplici interiore latere subsecundis paucis.

31a. C.ILl. Fl.1gelline (Zanard. dell. Call. p. 11) "filis ultra capillaribus distiche ramosis, ramis ramulisque alternis, ultimis subsimplicibus flagelliformibus; articulis primariis diametro multoties longioribus.

llab. ad oras Dalmatiae legit Sandri.

Caspes densissimus, basi intricatus, lubricus, fere uncialis. Fila ramosissima $1 / 45$ lin. crassa, ramis ramulisque alternis adpressis flagelliformibus ultimis usque ad $1 / 3$ tio lin. attenuatis. Articuli primarii basi inflati, melio angustati, diametro usque 8-plo longiores, versus apicem frondis seusim sensimque decrescentes exsiccatione stria sanguinea ex muco collapso orta longitudinaliter percursi fere ut in C. pedicellato; articuli ramulorum diametro 3-4plu longiores. Color obscure purpureus; substantia mollissima mucosa.

Primo intuitu oculo nudo C. crucialum Ag. amulat, qui tamen characteribus microscopicis toto caelo distinguitur."

31b. Call. enonglezu (Zanard. dell. Call. p. 11) "filis capillaribus fasciculato-ramosis, ramis ramulisque alteruato-secundatis simplicibus clongalis, articulis diametro multoties longiorıbus.

Hab. ad oras Dalmatiae legit Sandri.

l'recedenti affine, tamen distinguitur dispositione et longitudine ramulorum nec non eorum crassitie fere duplo majore. Color roseus, substantia rigidiuscula quam mucosa. Articuli colorati nec exsiccatione stria sanguinea percursi." 
Conferva rosea Roth. Cat. II. p. 1S2? (non Cat. III. p. 14.5) Engt. Bot. tab. 966 ?

Callithamnion roseum IIarv! in Hook. Br. Fl. II. p. 34.1. Man. p. 106! (non Ag. Sp.)

Phlebothamnion roseum liüz. sp. p. 633 (partim!)

Callith. octosporum Ag. sp. p. 177! Küts. sp. $p$ 639!

Exsicc. Wyatl Danm. $N: 0$ 44!

flab. in algis rupibusyne limo obductis Oceani atlantici ad littora Auglia et Gallia. (Turner! Borrer! Grifliths! Ilarves! Ipse!)

Frons erectiuscula, 2-3 pollicaris, filis vix capillaribus, primario inferne corticato. Rami pyramidati decompositi, quoquoversum egredientes. Ramuli conformes quoquoversum pinnati. Pinnæ infimæ simpliciusculæ, sequentes pinnulatæ elongatæ, ita ut rami apice corymlosi evadant. Sphærosporæ in pinnulis indivisis interiore latere subsecundæ, plerumque geminæ, rotundatæ, triangule divisæ. Favellæ in ramulis geminæ. Color coccineus. Chartæ satis arcte adhæret. Articuli diametro 2-4plo Iongiores.

"Rothium et reteres plerosque nomine Confervæ roseae plures et arlmodum diversas formas descripsisse et distribuisse, in propatulo nobis videtur. Duas equidem a Cel. Auctore conmunicatas plantas coram oculis habeo, quarum una ad Bayonne lecta (quae igitur est in Catal. II. descripta ${ }^{2}$ et vera) ad Call. roseum Harv. proxime accedere videtur; altera a priori diversissima et plantae in Cat. III. descriptae non male conveniens, Call. polyspermo identica. Haec in tìguram a Dillwyn datam non male quadrans, ut verum Call. roseum in Speciebus Algarum Agardhi descripta fuit. De planta Dillwyniana dubia tamen mili restant. Specimina plura al) ipso missa (ad Yarmouh lecta!) ad C. roseum liarv. pertinere crediderim; iconem vero lubentius ad c. lanosum Harv, trahere voluerim." J. Ag. Symb. p. 44. - Icon in Engl. Bot. data parum characteristica mihi videtur; specimina vero a Daws. Turner missa verum C. roseum Harv. sistunt.

33. C. Funceldaple (J. Ag. mscr.) fronde erechinseulil alleme decomposito-pinnata, a basi articulati rigidinsenla, ramis ranulisque quoquorersum egredientibus pinnatis, pinuis patrntihus, inferioribus lon;ioribus fere fastigiatis subecunde pinnmlatis, splierosporis splixericis all ramulos sparsis.

Callith. Byssoides Aresch. Enum. p. 107 (non Arnott).

Ilab, in Furcellaria parasiticum ad oras Bahusix (Ipse! Aresclioug!)

Cospes circiter pollicaris, pulcherrime roseus. Fila decompositoramosa, ramis alternis, inferne vix corticata. Ramuli laterales breves quoquoversum egredientes et quoquoversum pinuati. Pinnae ramulorum inferiores rachiden longitudine fere xquant, sxpe incurve et extrorsum pin- 
nulis paucis secundis obsitæ; pinnæ superiores simplices sæpe secundæ; omnes a basi latiore apicem versus attenuatæ. Articuli inferiores diametro 6plo, superiores 4plo diametro longiores. Sphærosporæ nunc in pinnis inferioribus extrorsum pinnulatis extrorsæ, nune, in superioribus introrsæ, omnino sessiles, obovato-sphæricæ, triangule divisæ. Favellæ 2 pluresve, profunde lobatæ.

Ramificatione inter C. roseum et C. interuptum intermedia. A. C. roseo Harv. differt pinnis inferioribus longioribus, rachidem longitudine subæquantibus, sphærosporis sparsis et forsan favellis, quæ in C. roseo magis rolundatæ, in nostra conico-lobatæ. A. C. Byssoide dignoscitur rigiditate, ramulis superioribus pinnatis (nec dichotomis), sphærosporis sessilibus, subsphæricis et sparsis (nec pedunculatis, obovato-ellipsoideis introrsis).

\section{** Fronde sursum longe corticata.}

34. C. Giraudi (Kütz. sp. p. 6弓̈6) fronde erectiuscula alterne decomposito-pinnatis, sursum longe corticata, ramos articulatos quoquoversum egredientes flaccidissimos ambitulanceolatos subpinnatos apice corymbosos emittente, pinuulis simpliciusculis erectis strictis, sphacosporis interiore ramulorum 'latere sparsis.

Phlebothamnion Giraudii Kiütż. $l . c$.

Hab. in littore Galloprovincia ad Antibes (Girandy!).

Cæspes sesquipollicaris pulcherrime roseo-coccineus. Fila primaria fere setacea, sursum longe corticata, ramulos articulatos tenuissimos pinnatim et quoquoversum emittentia. Ramuli inferne subalterne pinnati, apice subcorymbosi, ramellis elongatis strictis erectis. Articuli in caule vix conspicui, in pinnis diametro 4-6plo longiores, pinnularum terminales vix breviores. Sphærosporæ interiore latere pirinarum sparsæ obovatæ, aliquando ad idem geniculum geminæ.

Species videtur rarissima, pulchra et distincta. Habilus fere C. versicoloris at elegantior, quasi juvenilis. C. roseo Harv. ex una parte et C. interrupto ex altera proxima, al, utraque caule longe corticato diversa. Rami stricti et articuli longi admodum elegantem formam ei tribuunt.

33. C. Galloyi (Crouan mscr.) fronde erectiusculil alterue decomposito-pinnita sursum longe corticatil, ramis guoguoversum egredientibus pinnatis apice fisciculato-corymbosis, pinnis erectiusculis pinnatim decompositis, spharosporis ad pinuas superiores interiore latere sparsis.

Ceramium Gailloni Crouan in Desmaz. Cr. Fr.

Phlebotlımnion Gailloni ľüŁ. sp. p. 63̈.

llab. ad littora Gallica Atlantici Oceani; Brest (Crouan!) 
Cæspites 1-2 pollicares, densi, ramis caulescentilus plurimis constituti. Caules sursum longe corticati, ramis plurimis ornati, superioribus sensim brevioribus. Rami ramulique pinnatim decompositi, terminales eximie fasciculato-corymbosi; ramuli secundarii erectiusculi, rachidem longitudine subxquantes, ipsi pinnatim divisi. Articuli inferiores diametro 3-4plo longiores, superiores parum breviores, in rachide corymborum breviores et contracti. Spbarospora inter pinnas corymborum sparsx, introrsæ, obovatæ, triangule divisæ. Farellas non vidi.

Tanta est hujus speciei cum C. versicolori in externo habitu similitudo, ut cum hac sape confusam fuisse suspicarer. Accuratius examinata, ramificatione pinnata dignoscitur. A. C. roseo, cum quo ramificdtione convenit, corymbis densioribus et caule corticato differt.

\section{it Ramulis superioribus subdichotomis.}

36. C. imterruptum (Sm. Engl. Bot. tab. 1838) fronde erectiusculis alterne decomposito-ramosa, ima basi subcorticata ficcidissima, ramis ramulisque quoquoversum egredientibus, ambitu sublanceolatis, ramulis superioribus dichotomis incurvis subæequelongis aut altero breviori introrso, sphærosporis interiore latere axillarum sparsis, articulo abbreviato pedunculatis, maturis ellipsoideis cruciatim divisis.

Conf. interrupta Engl. Bot. l. c !!

Callith. interruptum Ag. sp. p. 474. Kiül.s. sp. p. 641!

Hab. in alliis $\Lambda$ g gis parasitica ad littora Britanniæ (Borrer!) et Galliæ (Crouan!).

Ita ad unguem cum C. Byssoide convenit, ut præter sphærosporas nullam vel levissam videam differentiam. Utrum hoc charactere, species distincta judicanda sit, dijudicent qui plantam rarissimam loco natali observare potuerint. Specimina seirosporis ornata inter ea, quæ sphrrosporas gerunt, obveniunt. Utrum C. interrupto adnumeranda sint specimina omnia seirosporis et sphærosporis cruciatim divisis ornata; C. Byssoidi vero specimina favellis et sphærosporis triangule dirisis instructa; an etiam in C. Byssoide et seirosporie et favella inveniantur; an denique eidem speciei spbierosporæ cruciatim et triangule divis $x$, seirospora atque favellæ tribuantur, milhi sane non liquet.

33a. C. SEssile (Menegh. Giorn. Bot. 184/ p. 284) "trichomatibus flabellato-dichotomis corymbosis, apice clavatis; articulis dianetro 6-8plo longiorilus cylindricis; tetrachocarpiis obovatis in dichotomiis sessilibus." Kü̈ъ. sp. p. 64.1.

Hab. ad Dalmatiam. 
37. C Bisso:ars (Arnotl. mscr.) fronde erectiuscula alterne decomposito-ramosa, ima hasi subcorticata, flaccidissima, lamis ramulisque quornoversum egredientibus ambilu sublanceolalis, ramulis superioribu dichotomis incurvis subequilongis aut altero breviori introrso, sphacrosporis interiore latere axillarum patucis, juvenilibus obovato-clavatis, maturis subrotundatis triangule divisis.

Callith. Byssoides Árnolt msc. Harv. in Hook. Br. A. II. p. 342. Han. p. 107!!

Phlebothamnion Byssoides Kü̈ъ. sp. p. 687 !

Callith. alteruatum Schousb. mscr.!

Ceramium polyspermum Crouan. (nec. Ag.) in Desmaz. pl. Crypt. Exs. Hyall Danm. n. 185 !

var. $\beta$. arachnoideun, alticilis tentrissimis pralongis.

C. araclinoideum Ag. sp. p. 481. Kütz. sp. $p .642$ !

Itab in aliis, algis parasitica ad littora Anglix (Irnott! Grifliths!), ad Tingin (Schoushoe!); in mari mediterraneo ad Insulam St. Marguerite (Ipse!); $\beta$ ad littora allantica Amprica septentrionalis.

Cæspes 1-2 pollicaris, filis densis fiaccidissimis constitutus, subgelatinosus. Frons ima basi corticata, attamen tenuis, in ramos plurimos quoquoversum egredientes soluta. Rami ramulique ambitu sublancoidei. Supremi subcorymbosi. Ramuli ramellis quoquoversum egredientibus pin11ati, pinnis principalibus subrequelongis quasi dichotomis, cum rachide decussatis, incurvis, introrsum nudis aut ramellis brevioribus subsecundatis obsitis. Sphærosporæ inferiores juxta axillas interiore latere disposite, superiores in ramellis indivisis introrse, paucis evolutis subsecundx, basi attenuatæ at sessiles, axillares et quasi ramulum tertium trichotomiæ efficientes; jnveniles clavate, sensim obovatie, demum rotundate et triangule divis $x$. Favellæ geminatæ conic $x$. Articuli diametro quadruplo longiores. Color roseus.

Conf. interruptam Erigl. Bol. et Call. Byssoides Arnolt esse plantas maxime affines, comparalis speciminibus authenticis edocti sumus. Icon in Engl. Bot. data plantam bene exprimit et nullo modo ad C. pedicellatum, ad quod illam referunt Algologi Anglix, pertinet. De differentia aut identitate ulriusque speciei, quæ infra antecedentem attuli, comparanda sunt. C. Byssoides Aresch. Enmm. p. 107 ad prasentem haud referendum juto, ramulis rigidioribus patentibus et ipsa ramiticatione diversum; nec $110 n$ sphiarosporis facilins dignoscendum. C. arachnoidenm $\mathrm{Ag}$. C. Byssoidi $\mathrm{A} / \mathrm{n}$. certe proximum et quantum ex speciminibus nou bene prixparatis distinguere liceat identicum, articulis paulo longioribus diversum. Ad C. liyssoides quocpue pertinere milhi videlur specimen, nomine C. Hookeri a Ilookero missum, quod in Spec. Aly. C. Ag. p. 173 memoratur. 
38. C. Conmibosum (Sm. Engl. Bot. tab. 235̈2) froade erectiusculi alterie decomposito-ramosa ima basi corticala, ramis ramulisque quoquorersum equredientibus, terninalibus corynbosis, ramulis dichotono-fastioitis erecto-patentibus, sphierosporis interiore ranulorum latere sparsis, farellis rotmudatis geminis.

Conf. corymbosa Engt. Bot. l. c.!

Callith. corymhosum Lyngb. Ilydr. Dan. p. 123 lab. 38! Ay. Sp. Alg. II. p. 165. Harv. Man. p. 112!

Phlebothamnion corymbosum kïlt. sp. p. 6̈̈7!

Ceramium pedicellatum $F t$. Dan. $t a b .15960 \mathrm{fg} 2$.

Ceramium fruticulosum Bonnem. Ilydr. locul p. 86 !!

Exsicc. Chauv. Aly. Norm. N:o 33! W'yalt Danm. n. 92!

Ilal), in aliis algis parasitica, in Sinu Codano et mari Atlantico!

Ciespes 2-3 pollicaris. Fila nunc a basi fere dichotoma tenuia et fere ecorticata, nunc caulescentia filo primario firmiore ultra setaceo inferne corticato. Ramuli dichotomo-fastigiati, aliquando trichotomi, ad geniculum quodque divisi, terminales eximie corymbosi, ambitu fere oborati. Articuli longitudine admodum variant, plerumque diametro fplo longiores. Sphærosporæ sphæroideæ interiore ramulorum latere sparsæ, aliquando ex eodem geniculo geminæ, triangule divisæ. Favellæ rotundatæ, sixpe geminatx. Color pulcherrime roseus.

Adest forma robustior, caulibus eximie crassis, ramulisque patentioribus instructa, articulis diametro sesqui-duplo longioribus. Icon in Engl. Bot. data in hanc respectu articulorum et ramiticationis quadrat. A liätzingio nomine Phl. corymbiferi l. c. eadem ni fallor descripta. In specie, articulorum longitudine valde variante, varietatem considero, nec speciem distinctam.

39. C. varsicolor (Draparn. mscr.) fronde erectiuscula alterne decomposito-ramosa sursum longe corticata, ramis ramulisque quounoversum egredientibus, ramulis in ramo caulescente subpiurtatim dispositis, terminalibus diclıotomo-fastigiatis erectopatentibus, fasciculato-corymhosis, splıæosporis interiore ramulorun lateve sessilibus triangule divisis, favellis rotundatis spirsis.

Cunf. versicolor Draparn. (fide Agg.)

Callith. versicolor $A g . s p . p .170$ !

Plılebothamnion versicolor Kütz. sp. p. 6.37!

Poecilothamnion versicolor Nageli neur. Aly. Syst. p. 202 tab. VI. fig. 7-29 (partim)!

Cerım. früticulosum Rolh. Cal. Bol. Tom. III!! Lyngb p. 124 lab. 38?

Ceram. Byssoides Ducl. p. 69.

Ceram. Ducluzei Bonnem. Ilyde. toc. p. 8:3! 
Hab. in aliis algis parasitica ad oras maris Mediterranei! et Adriatici! in oceano Atlantico ad littora Gallix?

Cæspites $2-3$ pollicares, densi, ramis caulescentibus numerosis constituti. Caules sursum longe corticati, ramis plurimis ornati; Raıni ambitu pyramidati, vel potius conici, ramis superioribus sensim brevioribus. Rami ramulique in suo quique caule crassiori subpinnatim dispositi, at quoquoversum egredientes; terminales eximie fasciculato-corymbosi. Ramuli secundarii rachidem longitudine subæquantes, erecto-patentes, subregulariter dichotomi. Articuli inferiores diametro quadruplo Iongiores, superiores in ramulis eandem servantes longitudinem, in rachide corymborum multo breviores. Sphærosporæ rotundatæ triangule divisæ, ad axillas et inter ramos superiores sparsæ. Favellæ rotundatæ subaxillares. Antheridia ad latera ramellorum subsecundatim aggregata.

Species pracipue ramificatione laterali et caulibus crassioribus corticatis a C. corymboso distincta. A. C. Seircspermo non nisi fructibus differt. Utrum revera in Atlantico obveniat, ut ex synon. Bonnemaisoni concludere liceat, an species mediterranea sit, dijudicare non audeo. Specimina atlantica cum C. Gailloni accuratius comparanda videntur. Synonymon Nægelii hoc loco attuli, licet favellæ descriptæ ad C. Byssoides pertinere videantur.

40. C. Seirospermuin (Griff. mscr.) fronde erectiuscula alterne decumposito-ramosa sursum longe corticata, ramis ramulisque quoquoversum egredientibus, ramulis in ramo caulescente subpinnatim dispositis, terminalibus dichotomo-fastigialis erectopatentibus fasciculato-corymbosis, sphærosporis sparsis pedunculatis cruciatim divisis, seirosporis in corymbo terminalibus. p. 108.

Callith. seirospermum Griff. mscr.! IIarv. MIan. p. 113. Aresch. Enum.

Phlebothamnion seirospermum Kütz. sp. p. 657!

C. versicolor $\beta$. seirospermum IIarv. in Ilook. Journ. I. p. 302.

Seirospora Griffithsiana IIarv. Phyc. Brit. tab. XXI! Lü̈z. sp. p. 896.

C. Corymbosum? Decsne. Class. lab. 16 fig. 1 !

Exsicc. Wyatt Danm. N:o 19.

39a. C. Rigesceis (Zanard. dell. Callith. p. 11) "filis ramosissimis lanosis rigidiusculis basi setaceis fibris decurrentibus vestitis, apice tenuissimis sæpe piliferis divaricato-fastigiatis subcorymbosis; articulis diametro subquadruplo longioribus.

Hab. Venetiis ad littus rejectum.

C. versicolori affine, tamen diversum, distinguitur frondis rigiditate, ramulis ultimis tenuioribus piliferis divaricato-expansis rarioribus potius luam dense approximato-fasciculatis ut in eo, articulis margine hyalino circumdatis, colore pallide roseo numquam variegato." 
IIab. in aliis algis parasitica ad rupes demersas oceani atIantici; ad littora Britannix (Griffitls!) et sinus Codani (Areschoug!)

Frondes a callo radicali solitarix aut pance, 1-3 pollicares, crassitiem setæ xquantes, dense corticatæ. Rami subspiraliter alterni, quoqnoversum egredientes, plurimi, patentes, inferiores longiores, decompositi, ranulisque subcorymbosis virgati. Ramuli inferne rumellis pinnatim dispositis, superne corymbosis dichotomis constantes. Ramelli, in ramulo corymboso supremi, demum fertiles evadunt, toti transmutati, scirosporas constitnentes, intra articulos plurimos inflato-moniliformes, quibus constant, corpuscula ovalia evolventes. Articuli in ramis diametro 8plo, in ramulis 4 plo circiter longiores; steriles cylindracei, fertiles multo (relative) breviores ellipsoidei. Color pulchre coccineus. Substantia satis gelatinosa.

Harvey intra articulos seirosporarum sphærosporas triangule divisas demum oriri contendit; Areschoug vero sphærosporas pedunculatas solitarias, cruciatim divisas observavit. Ipse intra articulos seirosporarum numquam divisionem quandam vidi. A. C. versicolori, in quo favellas et sph:erosporas triangule divisas, observavi, vix nisi fructibus differt C. seirospermum. Utraque species itaque accuratius examinanda; C. versicolor ad C. seirospermum sese habet ut C. Byssoides ad C. interruptum.

\section{Fronde tola distiche pinnata.}

\section{* Spherosporis ex terminali articulo pinnula formatis.}

41. C. Gracilunum (Ilarv. in Hook. Br. Fl. II. p. 345) fronde erectiuscula alterne decomposito-pinnata, disticha, a basi articulata, plumulis decompositis, pinnula articuli infimi pinnæ cujusvis nulla aut sequentibus subminori, sphærosporis ex terminali articulo pinnulæ formatis, in pinnula subsolitariis.

Callith. gracillimum IIarv. l. c. (non Agardh) el Man. p. 111. Phycol. Brit. lab. VII Külz. sp. p. 644 !

40a. Seir. flaccida (Külz. sp. p. 896) "pallide rosea, trichomate capillari, $1-1 \frac{1}{2}$ pollicari, ramosissimo, ramis flaccidis erecto-patentibus, ramis lateralibus alterne pinnatis, elongatis; articulis diametro 4-6plo longioribus."

Hab. in mari lonico (Rabenhorst).

40b. SEll. numilis (Külz. sp. p. 897) "rosea, 2-3"' alta, trichomatilus primariis $1 / 60-1 / 50$ "' crassis, rigidulis, subramosis, ramulis lateralibus divaricatis abbreviatis, alterne et parce pinnatis, pinnulis inferioribus patentissimis, supremis corymbosis; articulis diametro duplo longioribus, ultimis sæpe piliferis."

Hab. in mari Ionico (Rabenhorst). 
Phlebothamnion gracillimum liütz. sp. p. 635 !

Call. Thuyoides Chauv. Alg. Norm?

Exsicc. Wyalt. Danm. N:o 43.

Hab. in rupibus limo obductis oceani atluntici ad oras Inglia (1):na Griffiths!) et Gallix (Crouan!)

Frons caspitosa $2-3$ pollicaris, a basi articulata, ramosissima. Pinnæ primariæ et secundarix ambitu sullanceolate, distiche et alterne pinnulatæ. Pinnulæ simpliciusculie aut pinnellis paucis obsitæ, ex articulo quoque erumpentes, patentes; infima, seu quæ ex infino articulo oritur, sequentibus aut minor aut omnino abest (raro in parte inferiore cxteris subrequalis). Articuli cylindracei 4-5plo diametro longiores in ramis primariis; in secundariis breviores. Sphærosporæ in pinnula subsingulæ, ex articulo terminali formatæ, pinnella una alterave inferiore stipatæ, aut in pinnula simplicissima terminales, triangule divisæ. Favellæ in ramulis majoribus sessiles rotundatæ aut irregularius lobatæ. Color roseus. Chartæ arcte adhæret.

Species Algologorum Angliæ a homonyma Agardhiana, quæ Call. Thuyoides forma videtur, differt. Kiuitzing hanc speciem tum inter Callithamnia tum inter Phlebothamnia sua (seu corticito filo primario donata) enumerat. Caulis vero a basi articulatus, sæpissime saltim nudus.

42. C. Thuroines (Sm. Engl. Bot. tab. 2205) fronde erectiuscula alterne decomposito-pinnata, disticha, a basi articulata, plumulis decompositis, pimnula articuli infimi pinne cujusvis sequentibus xquali aut majori magisve composita, sphærosporis ex terminali articulo pinnule composite formatis in piunula pluribus.

Conf. Thuyoides Engl. Bol. l. c.

Callithamnion Thuyoides Ag. sp. II. p. 172! IIarv. Man. p. 111. J. Ag. 1ly. med. p. 73. Кй̈љ. sp. p. 645 !

Call. tripinnatum liarv. in Hlook. Fl. p. 346 (non Ag. et Harv. postea). Call. gracillimum Ag. sp. p. 168! (nec Angl.)

Exs. Wyall Danm. N:o 186.

Hab. in rupilums Oceani Atlantici ad littora Angliæ (Griffitls!) ot Gallix (Griteloup! Cronan!); in mari Nediteranco ad littora (lecitania (Ipse!) in Adrialico (C. Agardlı! Biasoletto!)

42a. C. тruxatcy (Menegh. Giom. 484k p. 288) "trichomatibus decomposito-pinnatis, pinnis lineari-lanceolatis apice truncatis pinnulisque alternis, rigidis, erectis, infra articulationem exortis; rachide flexuosa, pinnula inferiore cujusque ordinis semper interna; pinnulis ultimis sape secundis; articulis diametro triplo longioribus." Lülz sp. p. 64k.

Hal, ad Dalmatiam. 
Caspes pollicaris rel parum Iongior. Frons a basi articulata et densissime distiche pinnata, ramis plerumque quadripinnatis. Pinna secundarix ambitu sublineares, lineam circiter lata, pinnis tertiariis brevibus densissimis infra geniculum quodque egredientibus. Harum pinnarum pinnula infima, ex articulo infimo sursum egredienc, cateris xqualis ant major (in superioribus) magisre composita (ipsa bipinnata in inferioribus). Sphærosporæ in pinnulis (pinnatis) evolute, ex articulo terminali transformatx, nune pinnella una alterave suffullx, nunc harum pinnellarum articulo terminali quociuo fertili plures adproximata, triangule divisa; saje in pinnula infima terminales, axillares facile crederes.

Duplex forma adesse viletur, utraque al Algolozis Anglixe conjuncta. Una robustior, densius pinnata, articulis inferioribus diametro vix duplo longiorihus (C. gracillimum Ag.). Altera laxius pinnata, articulis inferioribus diametro 4plo longioribus (C. Thuyoides Ag.). Ab utraque differt C. gr:icillimum Anglorum pinnis gracilioribus, ob simplicilatem pinnularum et alticulos longiores magis invicem distantibus, sed precipue pinnula infima minori aut omnino nulla et sphærosporis in pinnula subsolitariis. Pinuta fertilis in C. Thuyoide magis composita sphærosporas plures plerumque gerit.

\section{** Spherosporis ex pinnella laterali formatis, in pinnula la-} teralibus, introrsis.

43. C. Decospositcin (Gratel mscr.) fronde erectiuscula alterne decomposito-pinuata, disticha, a basi articulatil, plumulis decompositis, pinnula articuli infimi pinna cijusvis sequentilus requali aut majori magisve composita, sphwerosporis interiore latere pinnularum subsolitariis.

Mertensia decomposita Gralel. mscr.

Ilab. in oceano atlantico ad oras Gallixe (Grateloup!)

Cæspes pollicaris aut parum Iongior. Frons a basi articulata et densissime distiche pinnata, ramis plerumque quadripinnatis. Pimne secundarix ambitu oblonga, pinnis tertiariis infra geniculum quodque egredientibus. Harum pinoarum pinnuld infima cxteris xqualis, aut fere magis composita, introrsum plerumque pinnulata. Sphærosporæ interiore latere

43a. C. AFFixe (Ilarv. in Ilook. Br. Fl. II. p. 344) "ramosissimun, rumis secundariis circumscriptione rotundatis longis alterne plumulatis; plumulis peringustis lineari-claratis simpliciter pinnatis; pinnis brevibus erectis, superioribus sensim longioribus, attenuatis, apice densis; articulis ramorum diametro 3plo-4plo, pinnarum sesquilongioribus.

Callithamnion affine Harv. I. c. Man. p. 110. hülz. sp. p. 64.4. 
pinmularum sparsæ, sæpe solitarix et axillæe adproximatæ. Articuli ramorum principalium fere 4plo, pinnularum 2plo diametro longiores. Color roseus. Alga gracillima pulcherrima.

Inter C. Thuyoidem et C. tripinnatum intermedia, ramificationem illius cum fructibus hujus conjungens.

44. C. TRIPINytum (Gratel. mscr.) fronde erectiuscula alterne decomposito-pinnata disticla, inferne demum corticata, plumulis 1-2 pinnatis, pinnulis patentibus subfalcatis, infima pinnæ cıjusvis subaxillari a sequentibus remota, splıærosporis in pinnula (præecipue asillari) interiori latere secundis.

Mertensia tripinnata Gratel. mscr.

Callith. tripinnatum Ag. sp. Alg. II. p. 168. J. Ag. Symb. p. 4.5. Alg. med. p. 72. Harv. Phycol. Brit. tab. 77 ! (eximie! non Harv. ill Britt. Fl.) Phlebothamnion tripinfatum lï̈tz: $s p . p$. 654 !

Hab. in rupibus maris niediterranei ad littora occitanix (Ipse!), et oceani atlantici ad littora Gallix. (Grateloup!) et Britanniæ.

Frons caspitosa 1-2 pollicaris, alterne 3-4:dri-pinnata, tota disticha. Rachis primaria inferne fibris inclusis corticat:. Pinnæ inferiores breviores, mediæ longiores, ambitu obovato-lanceolatæ. Pinnulæ intimæ pinnæ cujusvis simpliciusculæ aut ima basi pinnella simplici ab articulo infimo egrediente erecta instructæ; sequentes mediæ pinnella axillari instructæ, dein ad medium nudæe, a medio utrinque pinnellata; aliquando pinnellæ 2-3 axillari conformes, ab articulis proxime sequentibus egrediuntur; aliquando spatium inter axillarem et superiores alternas secundis quibusdam ornatur. Sphærosporæ in pinnella axillari præcipue obvenientes, in sequentibus rariores, in deorsum spectantibus ut videtur admodum rara; interiore margine plures secundatæ, spharoider, triangule divisa. Articuli in rachide primaria diametro sesquilongiores, in pinnis 3plo longiores.

Species putcherrima, distinctissima, pimnis secundariis ad bisin spinula subsolitaria arcuata instructis, caterum nudis vel supra medium pinnulatis, cognoscenda. Ab Algologis Angliae forma C. Thuyoides sub nomine C. tripinnati olim venditata fuit. Hodie, charactere diagnostico invento, nullis dubiis vexata.

Hab. ad Insulas Scotix (Greville).

Ramosissima, 2-3pollicaris, crespitosa. Fila primaria valde divisa, ramis plurimis secundariis alterne obsita; rami circumscriptione rotundati aut ovati, alterne plumulati; plumulæ breves angustissimæ; pinnulæ infimæ distantes spiniformes; superiores elongatæ et approximatx. Color intense rubens. Articuli caulini diametro quadruplo longiores, venis longitudinalibus angustis dense instructi. Capsulæ in axilla pinnarum vel ad articulum infimum.

Descr. Auct. transscripsi. 


\section{Ramis inferioribus quoquoversum egredientibus, superioribus distiche plumosis.}

* Fronde fere a basi ecorlicata.

4:3. C. scoptlonur (Ag. sp. II. p. 166) frondibus crespitoso-aggregatis, alterne decomposito-pinnatis, a basi articulatis, ramis irıferioribus quoquoversum eoredientibus, plumulis subdistiche pinnatis, pinnis simplicibus aut sursum secunde pectinatis, sphærosporis interiore latere pinnarum secundis.

Call, scopulorum Ag. l. cl J. Ag. Alg. med. p. 73! hülz. sp. p. 644!

Call. roseum tenue Lyngb. Hydr. Dan. p. 126 tab. 39 !

Call. pusillum Schousb. mscr!

Exsicc. Chauv. Norm. N:0 84!

Ilab. ad scopulos Oceani Atlantici ab insulis Foeroearum (Lyngbye!) usque ad Tingin (Schousboe!); in mari mediterraneo ad oras Niceæ (Ipso!) et Galloprovinciæ (Perreymond!).

Cæspites densissimi subsphærici, diametro semipollicares, tactu lubrici, in mari ex purpureo et violaceo iridescentes, in exsiccata purpurascentes. Frons 2-3pinnata, a basi articulati. Pinnæ inferiores breviores, pinnula una vel altera erectiuscula instructæ, superiores distiche pinnulatie, paginam planam nec marginem filo primario advertentes, dorso, seu latere exteriore, pinnula singula sæpe ornatæ, rachide inter pinnulas alternas eximie flexuosa. Pinnulæ ut plurimum simplices, articulis $5-8$ constantes, rarius interiore latere pinnellis brevissimis secundis (quarum inferiores longiores) instructæ, et sphærosporas obovatas interiore latere subsessiles gerentes. Rami omnes angulo $45^{\prime \prime}$ egredientes. Articuli diametro sesqui-triplo longiores.

Plantam vivam mediterraneam descripsi. Hæc duplo tenuior quam atlantica, ramulis apice densioribus, et pinuulis sursum sæpius pectinatis

43̈i. Callith. nintellum (Zanard. Callith. $p .10$ ) "filis capillaribus parce ramosis cæspitosis pinnatis versus apicem corymboso-fastigiatis, pinnis alternis subflexuosis; articulis primariis diametro 3 -4plo longioribus, ultimis diametro 2-plo longioribus; utriculis sporiferis creberrimis ad latus internum pinnularum secundatis.

Hab. ad oras Dalmatiæe legit Sandri.

Cæspes semiuncialis ad Corallinds affixus. Fila basi nudiuscula versus apicem ramosa, ramis fastigiato-corymbosis, pinnata, pinnis alternis inferioribus pinnulatis hirtis, superioribus simplicibus subflexuosis. Utriculi sporiferi in summitate frondis numerosissimi, parvi, secundi, sessiles, sporis margine hyalimo angustissimo cinctis. Color purpureus. Substantia membranacea.

Callithamnio scopulorum Ag. affine." 
diversa. Conveniunt vero crescendi modo eximic characteristico. Planta Tingitana et Gallica a Calvados sunt laxius pinnatx; Foeroensis eximie contracta et robusta. Planta itaque satis ut videtur varians; an plures species hoc loco confuse?

46. C. Polssipriun (Ag. sp. Alg. II. $p$. 169) rronde erecliuscula alterne decomposito-pinnata fere a basi articulata, ramis inferioribus quoquoversmu pgredinatibus, plumulis sublistiche pinnatis ambitu sublinearibus, pinuis basi nudis infra medimm pinmulatis, pinnulis patentibus simplicinsculis in rachide plongala alternis, splaceosporis interiore Iatere pinmularum secundis.

Call. polyspermum Ag. l. c. Ilarv. Man. p. 107!

Phlebothamnion polyspernum liüz. sp. p. 653 !

Conferva rosea Rolh. Calal. III. p. 143!! Dillw. tab. 17?

Callith. roseum Ag. $s p . p .16$ !

Lamourouxia Servanti Bonnem. mscr!

Lamourouxia polysperma Bonnem. mser!

Ceramium roseum Bonnem. IIydr. loc. Ed. II. p. 79? (sphrosporis). Ceramium didymum Bonnem. l. c. p. 80 (favellis)!

Forma juvenilis pinnulis apice subcorymbosis.

Call. Grevillei Marv. in IIook. Br. Kl. II. p. 34.े. Man. p. 140!! Küz. sp p. 6\%4!

Call. roseum Grev. Edin. p. 311 (ex Harv.)

Call. purpurascens Johnst. (ex llarv.)

Conferva Borreri Engl. Bol. Lab. 1741 (partim! fide sp. a D. Turner missi!)

Exsic. Jurg. Lec. Alg. I. N:0 9 ! Wyall Danm. $n$ 140!

Hab. in Oceano Allantico boreali ad lillora britannia! et Galliae!

Caspites globosi, I-3pollicares, densi. Frons ramosissima, a basi articulata aut tenuissime corticata, ramis inferne quoquorersum egredientibus, apice plumosa, plumis distiche et alterne pinnatis. Pinna amlitu

46a. C. Gracile (Ilook. et Ilarv. Crypt. antarct. I. p. 79) "filo primario repente ramoso, caulibus erectis laxe bi-tripinnatis, pinnis ramosis valde elongatis, pinmulis brevibus alternis erecto-patentibus simplicibus vel apice ramulosis, articulis primariis diametro $4-\ddot{p p l o}$, secundariis subtriplo longioribus.

Callithamnion gracile Ilook. et Ilarv. l. c. tab. 78 fg. I! Lond. Jouru. IV. p. 275. Kйlz. sp. p. 64.6!

Hab. in oceano australi ar insulas Campbell.

Fila 1--2 unc. longa, gracillima, e fibrillis ramosis repentibus orta, laxe irregulariter alterne rarius opposite pinnatim divisa. Spbarosporie sessiles minute splıæricæ. Favelle ignotie. Articuli pellucidi. Color roseus. Substantia tenera." 
oblongo-linenres, unferne mudr, superne et infra medium pinnulatie. Pinnulac simplices aut apice pinuellis pancis instructer, patentes aliquando sulurecurvate, obtusx; inferiores superioribus vix longiores et ita breves ut apex inferioris basem proxime sequentis in eoden latere parum superemineat. Articuli (fili primalrii) infimi diametro duplo, superiores 4plo longiores, supremi iterum breviores. Sphwrospora in pinnulis plurima, interiore latere secunde, splierica, triangule divisa. "Favella magna rotundata ovaticre geminata." Color roseo-purpureus.

47. C. Borkeri (Sm. Engl. Bot. tab. 1741) fronde erectiusculat alterne decomposito-pinnati, ramis inferioribus quoquoversum egredientibus, plumulis subdisticlıe piunatis ambitn late triangularibus, pimnis basi nudis supra medium pinnulatis, pinnulis patentibus simplicinsculis subflabellatis, splæærosporis interiore latere pinnularum juxta hasem secundatis, compositis.

Conferva Borreri Sm. l. c! Dillw. Intr. n:o 143!

Callithamnion Borreri Harv! in Ilook. Br. Fl. II. p. 344. Man. p. 110. Pluyc. Brit. tab. 159 ! liutz. sp. p. 643!

Callith. seminudum Ag. Bot. Zeit. 182; p. 637. Sp. Alg. II. p. 167! J. Ag. Alg. med. p. 72 !

Conferva miniata Drap. mscr!

Ceramium miniatum Ag. Syst. p. 141! Bonnem. Ilydr. loc. p. 82!

Cer. pinnulatum Ag. Syst. p. 139.

Callith. roseum Schousb!

Exsicc. Chauv. Norm. u. 136! Hyatt Danm. n:0 187!

Hilb. ad rupes limo obductas ocrani allantici, a littore meridionali Anglix usque ad Tingin; in mari mediterraneo et adrialicu.

47a. C. Fascicclatem (IIarv. in IIook. Br. Fl. II. p. 343) crespitosum ramis erectis flexuosis fastigiatis; plumulis elongatis erectis lineariobovatis truncatis; pinnis longis flexuosis, inferioribus simplicibus adpressis, superioribus erecto-patentibus apice ramulosis, articulis ramorum triplo, pinnarum duplo diametro longiorilus, sulstorulosis. Callithamnion fasciculatum IIarv. l. c. Man. p. 109. liütz. sp.p. $6 \ddot{3} 2$. Hab. ad oras Britannix.

"Bi-tri-pollicaris, basi mudiuscula, sursum dense ramosa, flaccida; apices ramorum nudo oculo quasi truicati apparent; ramuli longi et flexuosi, erecli, superiore dimidia parte dense plumosa, plunulis elongatis et adpressis. Color pulchre purpurco-rubens. Articuli ciulini olsscuri, fibris articulatis percursi. Capsulæ ad basem pinnarum rara, subsolitaria elliptica."

Deser. anct. transscripsi.

species sec. Auctorem dubia, ad C. Borreri forntas arcte accedens. 
Frons plerumpue 2-3pollicaris, caspitosa, ramosissima, rachide a bosi articulata, inferne ramulis intricatis spongiosis obducta. Rami quoquoversum egredientes, apice plumosi. Ilumæ majores ambitu oviato-oblongx, distiche et alterne pinnatæ; pinnæe basi nudx, supra medium pinnulatæ, ambitu triangulares; pinnula simplices, aut inferiores pinnulatæ, patentissimæ subulatæ, inferiores prolongata sæpe ita longæ ut superiorum apicem xquent, ita quodammodo, corymbum formantes distichum. Articuli diametro 2-4plo longiores, ad genicula subcontracti. Spharosporæ interiore latere pinnularum seriatæ, ad articulos inferiores secundæ, sphæricæ, composita, sphærosporas simplices 8 intri perisporium foventes; sphærosporæ simplices triangule divisæ (ex Harvey). Antheridia sphærosporarum loco disposita observavit Harvey. Favellae ad ramulos superiores geminatæ. Color roseo-purpureus, in arjua dulci cito mutatus, exsiccatione iterum plerumque roseus.

Species pulchra, sphærosporis compositis a Callithamniis plurimis abludens, inter qua quoad characteres ad C. polyspermum maxime accedit. Est vero hoc multo tenuius et habet pinnulas pinnation dispositas, nec nabellatas. Nomine C. Borreri plures species a veteribus confusas suspicor; specimina ad Yarmouth lecta et nomine C. Borreri inscripta vidi, quæ ad C. polyspermum cerlo pertinent. Ex descriptione vero ef icone C. seminudo identica videtur.

\section{* Fronle sursum longe corlicata.}

48. C. IMPLicituy (Suhr. mscr.) fronde erectiuseula alterne decomposito-pinnata, sursum longe corticata, ramis inferioribus quoyuoversum egredientibus, plumulis subdistiche pinnatis; pinnis basi mulis a medio pinnulatis, pinnulis patentibus simpliciusculis in rachide elongata alternis, sphrerosporis iuteriore latere pirmularum secundis.

-Callith. implicatum Suhr. mscr. (fide kiitz).

Phleboth. implicaturn fiüls. sp. p. 6:33!

Itab. in Oceano pacilico ad Valparaiso (Hb. Bimder!)

Frons in nostris vix bipollicaris; sed rami ramulique primarii corticati. Pinna ex his provenientes inferne nuda, a medio circiter pinnulatx, pinnulis infimis simplicibus, mediis supra medium pinnellatis, ultimis iterunt simplicibus, omnibus patentibus. Articuli in ramis vix conspicui; in pinnis rudi, diametro 2-3plo lonziores.

Itrum hac sit planta Suluii, an diversa, penitus ignoro. Cum descriptione a lüitzingio data satis convenit; locus natalis utriusque idem. Nostra planta cum C. polyspermo ita convenit, ut diversitatem forsan dubitaveris; differt tantum ramis sursum longius corticatis.

49. C. L.tissinum (Hook. el Harv. in Lond. Journ. 1815 p. 452) fronde erecliuscula alterne decomposito-pinnata, inferne dense 
corticala, ramis inferioribus quopmoversum egredintibus apice subdistiche plumosis, pinnis a lasi alterne pinnalis, pinnulis patentilus clongatis, infrioribus parce pinnellatis, spharosporis ad pinnulas interiore latere seriatis, basi atprosimatis, pedicello brevisimo sulfultis.

Callith. latissimum Ilool. el Hlarv. l. c. Alg. Tasm. p. $16 ! !$

l'hlebothamnion latissimum liül.s. sp. p. 6̈̈6!

Hab. in Oecano allstrali all littora Tismanuie (Gum!)

Frons videtur ta--äpollicartis, lateque expansa. Rami primarii insigniler crassi, corticati, pinnis tenuissimis olsiti. I'inne alterne pinnulate: ui fallor, quorplnoversum egredientes; pinnulie superiores simplices, inferiores pinnulis $1-3$ (sippe cxtrorsis) plerumque obsitæ, omnes elongate almodum tenues, patentes. Splierosporæ pedicello uniarticulato suffulta, et plerumque terininales, nunc sublaterales apiceque pedicelli juxtaposita, in pinnula juxta hasem iutcriore latere plures secunda, minuta, triangule divise. Articuli diametro $2-3$ plo longiores. Color roscus.

Planta exsiccata ad C. llookeri proxime accedere videtur; sed rami ramulique resera nustquan distichi, iicet exsiccata itẹrum iterumpque pinnata adpareat. l'ro magnitudine planta, pinunla tenuissima ramis majoribus crassis. Situs spharosporarum characterem distinctionis optimum probet.

30. C. Ilookek (Dillu. Lab. 106) fronde ercetiuseula alterne decomposito-pinnatid inferme dense corticata, ramis inferioribus fuoquoversun egredientibus, apice subdistiche plumosis, pinnis fere a basi pimnatis, pinnulis patentibus, inferioribus pinnellatis, sphrerosporis ad pimmulas utroque latere sparsis sepe subaxillaribus.

Conf. Hookeri Dillu. l. c. (auctoritate Harreyi).

Callith. Hookeri Ilarv. Man. p. 106 !

Phlebothamnion Hookeri Külz. sp. p. 6ə̋3!

Cillith. spinosum Ilarv. Man. p. 11 I.

Phlebothamnion spinosum Külı. sp. p. 6333!

Callith. lanosum Ilarv. in Ilook. Br. Hi. II. p. 34 .

Cer. Dudresnayi Bonnem. (fide Kïitz.) Ilydr. loc. p. i7.

Exsicc. Wyall. Danm. N:o 139!

Ilab. in Oceano allantico ad littora Britannie (D:na Griffitls!)

Caspites 2 -4pollicares ramosissimi. Fila adultiora ramorum fero omnium corticata et fibris tubun centralem intra membranam circumdanlibus polysiphonia. Rani principales quoruorersum egredientes dense ränulosi, apice ramulisque plumusis. Pluma distiche alterne hi-tri-pinuater, ambitu late lanceolatæ. P'inn:e ima basi nudiusculx. Pinmula patentes nunc robustiores et breviores, nunc clongata molliorem habitun plante vilsuentes. Articuli in filo primarii haul conspicui; superiores diametro 
2-3plo longiores. Sphærosporæ sæpe interiore latere pinnularum 2-3, nunc utroque latere inordinatæ, sphærica, triangule divisæ. Favellæ infril apicem pinnarum geminæ lobato-rotundatæ. Color roseus, in robustioribus exsiccalione purpurascens, in mollioribus dilutior.

An huc pertineat Conf. Hookeri Dillw., mihi satis dubium videtur. specimen a Hookero ipso olim missum luc certo non pertinet. Ceramium divaricatum Grat. ad C. Hookeri Harv. proxime accedere milhi videtur, rachide magis flexuosa et piınis inferioribus patentissimis diversum.

¿̈1. C. Acrospernum (J. Ag. mscr.) fronde erectiuscula alterne decomposito-pinnata, sursum longius corticata, ramis inferioribus qnornoversum egredientibus apice subdisticlıe plumosis, pinnis a basi supra medium nudis, pinnulis erecto-patentibus simpliciusculis, sphærosporis interiore latere pinnularum infra apicem pancis.

C. roseum Chauv. mscr. (non Ag.; nec Harvey.)

Ilaly. in Oceano atlantico ad oras Gallix (Chauvin!)

Cæspes 2-pollicaris, exsiccatione purpureus. Fila primaria sursum longe et dense corlicata decomposito-pinnata, ramis majoribus quoquoversum egredientibus, plumis subdistichis. P'innæ a basi supra medium nudæe aut, pinnula una alterave ohsitæ, supra medium irregularius alterne pinnulatæ, pinnulis inferioribus longioribus subpinnellatis, superioribus siñplicibus erecto-patentibus. Articuli in caule diametro æquales, in pinnis vix duplo longiores. Sphærosporæ infra apices sæpius solitariæ, raro $2-3$ introrsæ, triangule divisæ. Favellæ rotundatæ magnæ, in pinnis subterminales.

Ad C. Borreri forsan nimium accedit, licet pluribus characteribus et hahitu diverso satis distincta videatur. Multo irregularius ramosa, oculo nudo vix conspicue plumosa, articulis brevioribus instructa, longius corticata, fructuumque dispositione dignoscenda.

52. C. tetriculy (Dillw. Conf. lab. 81) fronde erectiuscula alterne decomposito-pinnata ramolis inferne dense vestita hirta, ramis inferioribus quoquoversum egredientibus, plumulis subdistiche pinnatis ambitu lanceolatis, pinnis fere a basi pinnulatis, pinnulis patentibus simpliciusculis utrinque attenuatis, sphærosporis in processubus pinnularum interiore latere secundatis.

Conferva tetrica Ilillw. l. c.! Engl. Bot. Lab. 1943.

Callithamnion tetricum Ag. Sp. Alg. II. p. 179! Ilarv. Man. p. 108. Pliyc. Brit. lab. 188!

Phlebothamnion tetricum kül.sp. p. 632!

Ceramium congestum Bonnem. Ilydr. locul. p. 77.

Exs. Wyalt. Danm. n. 141! 
Hub. in rupibus Oceani allantici ad littora Britannix et Gallie usyue ad Tingin Africa!

Frons 3-6pollicaris et aliquando major ramulis intricatis fibrisrne radicalibus inferne dense restita, chordam fibris male contortis hirtam referens, apice in plumulas rigidiusculas soluta. Rami conformes numerosi, quoquoversum egredientes. Plumulæ plus minus compositx. Pinno ambitu lineari-lanceolatæ, a basi distiche et alterue pinnatx. Pinnula patentes simpliciusculæ, basi apiceque altenuatx, distiche racemosæ. Pinncllæ subconformes at brevissimæ demum in superiore parte pinnularum proveniunt, quarum in latere interiore sphærosporæ evolvuntur $2-3$ seriatæ, sphæricæ, triangule divisæ. Favellæ geminæ, in pinnis con!ractis evolutæ. Articuli in filo primario evidentes, at fibris corticalibus parum evidentibus vestiti, ad genicula aliquantulum contracti, diametrø æquales (in parte inferiore frondis, ramorum, rachidis) aut duplo longiores (in pinnulis etc.). Color sordide vinosus. Chartæ minus arcte adhæret; madefacta aquam avide imbibit, at facile dissolvitur.

Var. $\gamma$. minus Ag. Sp. est forma C. seminudi, colore sordida, sphærosporis compositis cognoscenda. Ceramium guttatum Bonnem. a Kützingio huc trahitur; mihi autem alia planta sub hoc nomine missa. Adest præterea Cer. congestum Bonnem., quod ad Call. tetricum vix duhie pertinet.

4. Ramis inferioribus quoquoversum egredientibus ramulosis, ramulis abbreviatis cum rachide decussatis, fronde sursum longe corticala.

\section{* Ramulis pinnatis latus planum rachidi advertentibus.}

53. C. tetr.agonu (With. Arr. V. p. 405) fronde erectiuscula, alterne decomposito-pinnata, iuferne corticati, ramis inferioribus q1ı0quoversum egredientibus plumas distiche pinnatas subfa-

52a. C. IInTum (Hook. et Harv. Crypt. antarcl. p. 80) "caulibus nigrescentibus intertextis, primariis robustis basi renosis continuis hirtis apice articulatis, secundaris elongatis ramulis pinnatis quadrifariis densissime vestitis, pinnulis simplicibus incurvis obtusis, arliculis diametro sesquilongioribus.

Callithamnion birtum Ilook. et Ilarv. l. c. tab. 78 fig. 2. Lond. Journ. IV. p. 275. Külz. sp. p. $60 ̈ 3$.

Hab. ad insulas Auckland, aliis Algis parasitica.

Caules caspitosi, fibris intertextis basi comilati, 2-3unc. longi, robusti, vage quadrifariam ramosi, per totam longitudinem ramulis quadrifariis densissime veldli. Rami cauli similes, longitudine varii; ramuli in- 
sciculato-fastigiatas, latus sub-planum rachidi advertentes, gerentilus, pinnis subsimplicilus incurvis acuminalis, spltierospolis interiore latere piunitum subsecundis paucis.

Far. e. pinnis subtorulosis, basi contractis apice abluphius acuminatis, alticulis diannetro srsquilongionibus ad genicula contractis.

Conf. tetragona Wilher. l. c. Dillw. Conf. Lab. 6ä!! Engl. Bot. t. 1690.

Callitl. tetragonm .1y. Sp. Aly. II. p. 176! IIare. Man p. 108. Phycol. Brit. tab. 136! J. Ag. Aly. med. p. 74 !

Phlebothamnion tetragonum hïls.sp. p. 6ï4!

Exsicc. Hyat. Danm. N:o 90 ! Chaum. exs. n. 60!

Var. P. pimnis eylindraceis longe subulatia, articulis diametro 2-3plo dongioribus ad genicula vis contractis.

Callitlı. granulatum Hare, in Hook. Lr. Fl. II. p. 33\%. (non Agardh).

Call. IJarveyanum J. Ag. Symli. I. p. 4.j.

Cer. Irachiatum Bonmem. Ilydr. loc. Eil. II. p. si (quoad descr.)!

Call. brachiatum Harv. Plyyc. Bril. tab. 13i!!

Ilab. in aliis Mgis parasitica, in Geeano Allantico ab oris sintus Codani (Ipse!) insulisque Oreadum usune ad littoria Gallia meridionalis!; iı mari mediterranteo ad Cenr (1psen!); (ad insulas Canallias et Cilp. b. spei sec. Bonnem.)

frons $2-3$ pollicaris caspitosa, erecta, filo primario siphonibus numerosis angustis corticato, arliculis perlucentibus usque ad basem conspicuis. Rami ramulique plurimi, fuoquoversum egrelientes, ambitu sulcylindracei, plunulis nempe abbreviatis quorguorersum egredientibus alternis obsiti. Plunula patentes, infimx ad pimmam sape indisisam reducte; medix majores, alterne el sublistiche pinnata, pinnis sulbsimplicibus fastigiatis et in rachide satis lrevi subfasciculatis, rersus rachidem incurvis; snpreme simpliciores. Plumula omnes latus planum rachidi advertentes. P'inne nunc (in rar. a) crassissimx, hasi attenuate, apice abruptius acuminatx, ob genicula contracta subtorulosx; nunc magis subulatæ tenuiores et articulis hinc longioribus instructa. Articuli diametro duplo-triplo longiores. Sphærosporie ad pinnas superiores plumulæ evolutx, paucie 2-3, interiore latere secundatx, triangule divise. Favella solitariæ aut gemina, apice plumula brevissime pedunculatx el pinuis

feriores breves caulibus habitum hirtum funalenre impertiunt, superiures longiores et pinnati eradunt; secundarii (r. plumulic) pinnati, pinnis alternis erecto-patentibus elongatis oltusis incurvis, rachide flexuosa. Color atro- vel fusco-ruber. Sphærospora sphærica, solitarix, latere interiore ramuli affixa, pusillic. Substantia rigidlusculi. Chartic adlseret."

Deser. Auct. transscrijsi.

Habitu ad C. tetricum proxime accedit. 
inferiorilus cincta. Culor roseus. Madefacta arquam avide imbilit, et sat bene reviviscit.

Species inter robustiores et facillime distinctas totius generis. Duas formas offert, quarum una a IIarvey cum Call. granulato olim confusia fuit. In Symbolis meis confusionem indicari, et Ilarveyanam specien, "si revera a C. tetragono distaret" novo nomine inscribendam esse dixi. Iu Manuali suo Ifirvey hanc formam ad C. tetragonum revocavit et denique in sua Phycologia nomine C. hrachiati Bonnem. eximie illustravit. Complectitur autem C. Lrachiatum Bonnem. utramque formam, ut ex synonymia velut ex speciminibus ab codem distrilutis satis patcit.

54. C. Gutratom (Bonnem. Ess. p. 88) fronde erectuscula alterne decomposito-pinnata, inferne corlicata, ramis inferioribus quoquoversum egredientibus, plumas distiche pinnatas elongattas, latus sulplanum rachidi advertentes, gerentibus, pinnis simplicibus incurvis ubtusis, fructibus. . .

Cer. guttatum Bonnem. Ess. p. 88 (fide Crouan;?

\section{Ilab. aliis Ngis parasilica, prope Brest. (Crouan!)}

Caspites densi bi-pollicares purpurei, caulibus plurimis ex eodem puncto egredientibus. Caules primarii sursum corticati, ramellisque paucis hirti, subregulariter alterne ramulosi. P'lumulæ patentes elongatæ, in-

333. C. Microprerci (Hook. el Harv. Cr. Antarct. p. 80) "parrum erectum, caule articulato parce ramoso, ramis distichis alternis circumscriptione obovatis obtusis bi-tripinuatis, pinnis alterne multifidis flexuosis, pinnulis erecto-patentibus obtusis, articulis caulis ramorumque diametro duplo-triplove longiortbus, ramulorum diametro iequalibus, sphærosporis sessilibus solitariis ellipticis.

Call. micropterum Hook. el. Harv. l. c. Lond. Journ. IY. p. 273.

Call. cryptopterum hü̈:. sp.p. 646.

IIul. ad insulas Auchland.

"Radix scutata. Caulis subsolitarius 2-3lin. longus, erectus, parce distiche et alterne divisus. Kami basi pinnis simplicibus ornati, superne bi-tripinnati, nunc pinnulis alterne multilidis ut in C. tetragono. Ramuli alterni, inferiores simplices, superiores iterum divisi. Articuli pellucidi, rosei, venis destituti. Sphærosporæ minute, ramulis sparse, appressx, elliptica, massam quadritidam includentes. Color pulcherrime roseus. Substautia tenera."

Descr. Auct. transcripsi.

Nomine C. micropteri species, ut videtur dirersa, Montagnei jam adest, quare nomen mutavit Kützing. - Ex observatione vero adjecta Auctorum de affmitate speciei forsan concludere liceret, illos suam speciem cum illa Montagnei identicim considerare, licet nullam illius fecerint mentionem. 
ferne pinnulis simplicibus, sursum sensim pinnulis furcatis et pinnellatis, apice densioribus constantes, latus planum rachidi adrertentes. Pinnella incurvæ obtusa. Articuli diametro sesqui-duplo longiores, ad genicula contracti.

Nomine Cer. Guttati hanc speciem inscriptam vidi; suam autem speciem articulis longis donatam describit Bonnemaison, quod nostra speciei valde repugnat. - Species mihi videtur C. tetragonæ proxima, at vix eadem.

35. C. Felixu (Gaill. mscr.) fronde erectinscula alterne decomposito-pinnata inferne corticata, ramis quoquoversum eqoredientibus, ramulos cum rachide decussalos, latıs planum rachidi advertentes, pinnatos, superiores distichos deorsum pinnulitos gerentibus, pinnis subulitis subrecurvato-patentibus, fructibus...

Ceramium Felixii Gaillon mscr. (sec. spec. authent!) Bonnem. Ess. p. 81 .

Ilib. ad oras Gallie prope Dieppe (Girilion!).

Caspes uncialis, filis plurimis, capillaribus et ultra, ab eadem basi provenientilus. Caules inferne fibris articulatis decurrentibus corticati, pinnis decompositis obsiti. Plumx (ni fallor) cum rachide decussatæ, pinnatæ, pinnis simplicibus elongatis subulatis eximie patentibus; superiores subdistiche incurvatx, extrorsum pinnulate, introrsum nudx. Articuli caulium diametro triplo, superiores duplo longiores, evidentes. Fructum non vili.

Species videtur sui juris, sed specimine unico et parum completo a me observato, mihi adhuc olsccura. Cum C. Thuyoide illam comparavit Bonnemaison, sed me judice longe ab illa specie distat. A. C. Hookeri ramificatione et halitu molliori recedit. Ad C. fruticulosum el C. Brodiæi mihi propius accedere videtur, ab utroque tamen diversum.

* Ramulis pinnato-decompositis lalus plamum, ramellis orbatum, rachidi advertentibus, lateraliter et extrorsum pimnulutis.

56. C. fruticurostil (J. Ag. Symb. p. 46) fronde erectiusculil alterme decomposito-pinnatil, sursum longe corticata ramuliscue paucis pullulantibus instructa, ramis quoquoversum egredientilus, ramulos cum rachide decussatos liatus subnudum rachidi advertentes, lateraliter et extrorsmm pinnatos, gerentibus, pinnis subulatis, inferioribus recurvato-patentibus, splaerosporis in pinnis terminalibus sparsis.

Callith. fruticulosum $J$. Ag. l. c.

Call. Hookeri $\beta$. fruticulosum Aresch. Enum. p. 104!

Pllleboth. fruticulosum hiul. sp. p. 6:33! 
Callith. pyramidatum Liclm. in Kröy. Tidsk. II. V. p. 4.79 lab 6 fig. 1. Ilab. in Furcellaria parasiticum ad oras sinus Codini.

Caspes densus 2-3pollicaris, caulibus pluribus e callo radicali egredientibus. Caules ultra setacei undique ramis pyramidati. Rami decompositi ramulisque brevibus obsiti. Ramuli cum caule decussati, lateraliter et extrorsum pinnati. Pintax ramulorum ad geniculum quodque exeuntes, inferiores patentissimæ retrorsum arcuatr, superiores patentes sulicorymbosæ, omnes subulatic. Articuli in caule et ramis extus corticati, diametro duplo longiores, in pinnis diametro 4plo longiores. Spherosporx inter pinnas superiores subcorymbosas sparsæ, nunc axillis adproximata, nunc distantes, triangule divise. Favellæ subaxillares lobata.

Inter C. Brodiæi et C. tetragonum intermedia, differt ab hoc ramulis magis compositis pinnieque in rachide elongata distantibus; ab illo caulibus gracilioribus minusque hirtis, pinnis longioribus minus compositis; ab utroque articulis pinnarum longioribus. A. C. Hookeri, si originaria species Dillwyniana cum recentiori homonyma identica sit, plumulis neutiquam distichis longius recedens.

\section{C. Bnodisi (Harv. in Hool. Br. Fl. II. p. 10ة̈) fronde erec-} tiuscula alterne decomposito-pinnata sursum longe corticata ramulisque pullulantibus hirta, ramis quoquoversum egredientibus, ramulos cum raclide decussatos, latus subnudum rachidi adrertentes, lateraliter el extrorsum pinnatos, gerentibus, pinnis decompositis subdivaricato-patentibus, splterosporis in pinnula divisa juxta axillam interiore latere subsingulis.

Call. Brodixi Ilarv. t. c. Man. p. 10̈̈. Phyc. Bril. Lab. 129 !!

Phlebothamnion Brodiaci liüls. sp. p. 6333 !

Conferva purpurascens Sin. Engl. Bot. lab. 2468?

Callith. purpurascens IIarv. Br. Fl. p. 343. Man. p. 109?

Exs. Wyall. Danm. N:O 184!

\section{Ilab. ad littora Anglia et Scotice (Brodie! Griffills!)}

Frons crespitosa pyramidata, ramis plurimis patentibus obsita. Caulis ramique primarii siphonibus intra membranam decurrentibus plurimis corticati, ramulisque ex siphonibus exterioribus sine ordine pullulantibus hirti, ramisque alternis infra genicula quoquoversum egredientilus decompositi. Ramuli ramos investientes, abbreviati, inferiores majores, decomposilo-pinnati, jureniles subdistichi latus planum rachidi advertentes, seniles lalus subplanum rachidi adversum subincurvum quoque conservant, extrorsum pinnis decompositis subdivaricato-patentibus horriduli. Pinna subulatae plus minus decompositic, infima simpliciuscula. Splhærospora in latere pinnæe interiore et subplano evoluta, juxta axillam pinnularum lateralium subsolitarix, triangule divisie. Favellic rotundatie, in ramulis abbreviatis geıninæ. Articuli pinnarum diametro sesquilongiores. Color purpurascens. Minus arcle cliartæ adhæret, aljuam avide imbilsens. 
Ramificationis normam atque dispositionem spharosporarum apud Ifarey minus rite expositam existimo. Sphicrospore haud in processubus secundatis evolutx mihi adparuerunt, sed juxta axillam pinnularum, quas alternas et cum rachide decussatas credo, interiore latere subsingulir.

38. C. Howtader (J. Hook, in Crypt. Ant. p. 184) fromde erectiuscula alterne decomposito-pinnata sursum longe corticatil, ramis quoquorersum egrredientibus, ramulos cum rachide deenssatos, latus subnudum rachidi advertentes, lateraliter et extrorsum pinnatos gerentibus, pinnis bipinnatis patentibus, spharosporis. . .

Callitl. Montagnei Hook. fil. l. c. lab. 188 fg. 2 !!

Phleboth. Nontagnei Küls. sp. p. 6ä̈!

Call. Gaudichaudii? Ilook. et IItrv. in Lond. Journ. II. p. 2i4.

I'ar. P. caulibus elongatis laxius ramosis basi nudis, ramulis paucioribus gelatinosis.

IIab in Oceano australi ad Cap IIorn., Ins. IIermite et Falliland (J. L. Llooker!)

Radix scutata. Frons 2 -3uncialis (in rar. $\beta$. 4- -3 unc. longa) fruticulosa ramosissima. Caulis crassiusculus $1 / 2$ lin. fere diametro, a basi ramosus v. nudus, superne pracipue in ramos undique patentes divisus. Rami primarii pluries divisi; secundarii ramulis pinnulisve parvis $1-11 \frac{2}{2}$ l:ı. longis undique vestiti. Rami corticati opaci, ramuli ecorticati. Favellie magnæ 2-3lobatie, lobis gemmidiis plurimis farctis. Color siccitate atropurpureus, madore sub lente roseo-purpureus. Sulstantia caulis ramorumque cartilaginea, ramulorum tenera, chartieque adhærens. Articuli diametro subduplo longiores.

Species ex characteribus datis vix ah affinibus cognoscenda, charactere essentiali, qui in situ sphærosporarum forsan positus sit, nondum invento. Sec. Auctores citatos est species inter C. arbusculam et C. Brodiæi internedia, habitum robustum et magnitudinem prioris offerens, pinnulis longioribus et magis compositis diversa; Callithamnio Brodiæi robustior, et caule firmiore predita. Specimen, quod vidi, valde incompletum, quare lescriptionem Auctorum transscripsi.

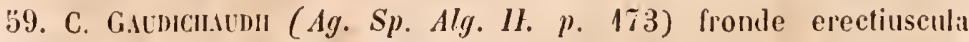
alterne decomposito-pinnatis, sursum lougge corticata ramulisque pancis pullulantibus iuslructil, ramis quoquorersum egredientibus ramulos cum rachide decussalos, litus subnudum riachidi advertentes; literaliter et extrorsum pinnulatos, gerentihus, pimulis decomposilis subdivaricato-patentibus rigidis, splrerosporis in pinnula simpliciuscula interiore latere seriatis $2-3$. 
Callitlı. Gaudichaudii Ag. l. $c$ !

l'lılè. Gandichaudii häls. sp. p. 6:j.̈.

Ceramium interruptum nigrescens Ay. Syst. $p .142$.

Ifal), in Oceano anstrali ad insulas Filliland (Gitudichaud!)

Frons 2-3pollicaris. Lami primarii pyramidati dense corticati subnudi aut ramulis paucissinis inter genicula pulluluntilus instructi. Secundarii rami basi nudiusculi, superne dense decompositi, tertiariique plerumque corticati, ramulis abhreviatis ecorticatis undinge vestiti. Ramuli decompositi pinnis divaricato-patentibus densissimis, superiorilous spharosporas gerentibus simpliciusculis. Articuli diametro sesqui-duplo longiores. Splicrospore in pinnula simpliciuscula plures, plerumque $2-3$ interiore latere secunda, triangule divisa. Favella rotundata, inter ramos corymbosos axillares Color in nostris exsiccutis nigrescens, in vivo sine dulsio plirpureus.

60. C. perperaferin (J. Ag. mscr.) fronde erecliuscula alterne decomposito-pinnata sursum longe corticata, ramis fuoquoversum rggredientihus, ramulos cum rachide decussatos, latus sul-nudum rachidi alvertentes, lateraliter et extrorsum pimnulatus gerentibus, pinnis decompositis subdiraricato-patentibus, splaterosporis (? compositis) in pinnulis terminalibus subrorymbosis plurimis.

Call. purpurilerum J. dy. mscr. in Ilb. Bind. el Pappe (110n Harrey). l'hlebothamnion purpuriferum hïls. sp. p. 636!

Hab, in sinu Tabulari ad alias algas parasiticum. (Pappe!).

39.4. C. D.isytrichicn (Monl. Alln. sc. nal. II. p. it) caspitosum, filimentis capillaribus inferne hirtis tetrastiche rumosis, ramis erectopatentibus sensim altenuatis circumscriplione linearibus ramulisque alternis, supremis fastigiato-corymbosis, articulis diametro duplotriplove longioribus.

Ceramium dasyírichum Monl. l. $c$ !

Callithamnion dasytrichum Monl. Voy. Bonil. p. 51! Küß.sp. p. 614! Hab. in arena littorali ad oras Brasilix.

"Ciespes sescuncialis e filis basi maxime inter se intricalis compositus. Filamenta inferne capilloria ramulis bresissimis simplicibus ramosisque patentibus undique lirta striisque coloratis longitrorsum percursa, tetrastiche ramosa. kami supra articulum medium orti, breviusculi quincunciales, nempe ad C. tetragoni normam in quaternis ordinibus alternanles, patenti-crecti, dichotomi, ramulis fastigiato-corymbosis rel penicillatis. Articuli fili primarii diametro sesqui-quintuplo, ramorum triplo longiores, supremi diametro aquales et acuti. Culor in speciminibus risis roseus, exsiccatione in violaceum sordidum evadens. Sulstantia fenuissima." 
Carspes usque 6 pollicaris. Filum primarium pennam passerinam fere crassum, ramis pyramidatis ramosum. Rami primarii secundarique omnes corticati, ad geniculum quodque ramulosi, inter genicula ramulis nudi, ambitu cylindracei. Ramuli abbreviati, inferiores majores decomposito-pinnati, juveniles subdistichi latus planum rachidi advertentes, adultiores latus internum ramulis nudum conservant, lateraliter pinnati, pinnis extrorsis divaricato-patentihus horriduli. Pinnæ subulatæ plus minus decompositæ, infimæ simpliciuscula. Sphærosporæ compositæ videntur (vix favellæ juveniles?), rotundatæ magnæ intra perisporium latum sporas numerosas foventes, interiore latere pinnarum decompositarum juxta axillas subsingulæ, in pinna plurima, pimnis incurvatis sub-involucrantibus. Favellæ in corymbis densioribus diversæ plantæ evolutæ, transverse oblongx, subsingula. Articuli tili primarii diametro requales, superiores duplo longiores. Charta parum adhæret. Color madefactæ roseus.

Species inter mihi cognitas maxima, externo labitu cum C. purpurifero Harv. satis conveniens, sed accuratius inspecta longe diversa.

61. C. Arbuscula (Dillw. Br. Conf. tab. 83̈) fronde crectiuscula alterne decomposito-pinnata sursum longe corticata ramulispue pullulantibus densissime vestita, ramis quoquorersum egredientibus ramulos cum rachide decussatos, latus subnudum rachidi advertentes, lateraliter et extrorsum pinnulatos, gerentibus, pinnis decompositis, pinuulis inferioribus subrecurvato-patentibus, sphærosporis in pinnula indivisa interiore latere secundis plurimis.

Conferva arbuscula Dillw. l. c. (excl. tig. tab. G.)! Engl. Bol. lab. 1916?

Callith. arbuscula Lyngb. Ilydr. lab. 38 fig. 1-3 (excl. fig. 4-6)!! IIarv. Man. p. $10 \ddot{!} ! !$

Phlebothamnion arbuscula Külz. sp. p. $6 \ddot{6} 6$ !

Dasya spongiosa Ag. sp. p. 121!

Ilab. in Oceano allantico ad littora Focrocarum (Lynghye!) Scotix (Greville! Harvey!) et Islandix.

Cæspites densissimi plerumque 2-3pollicares erecti. Caulis ramique primarii dense corticati ramulisque plurimis pullulantilus tam dense vestiti, ut omnino tomentoso-spongiosi appareant, superne ramosi decompo-

61a. C. struosum (Suhr. in Flora 184.0, I.p. 293) "trichomate crassiusculo ramisque stuposo-corticatis, ramulis virgato-flagelliformilus, fastigiatis el fasciculatis, alterne el patenti-ramellosis fructiferis; articulis diametro sesquilongioribus, interdum subæqualibus." hülz. sp. p. 6.53 .

IIab. ad oras Capenses (Ecklon!)

Bipollicaris, dense caspitosa. 
siti. Ramuli ecorticati et pro magnitudine planta tenues, ni fallor cum rachide decussati, interiore latere pimnis subntad, lateraliter et extrorsum densissime pinnati, pinnis decomposilis, pimnulis inferioribus subhorizontaliter patentibus sape retrorsum arcuatis, superioribus conniventibus. Articuli pinnarum diametro duplo longiores. Spharospora in pinnis sinpliciusculis plurima $8-6$ secundax. Fasella lobato-rotundata, sapius gemina (Harvey). Color purpureo-roseus.

Duas species confuderunt Diliugu et Lynglye, quarum una hujusloci, altera ad Dasyam arbusculam pertinet. Cfr. J. Ag. Symb. p. 34, quo loco hoc ulerius exposui.

\% Ramulis subrlichotomo-decompositis.

62. C. Grisclitum (Ducl. Ess. p. 72) fronde erectinscula alterne decomposito-pinnata sursum longe corticata ramulisque pullulintibus hirta, ramis quoquoversum egredientibus ramulos cum rachide decussatos, latus subnudum raç̧idi advertentes, lateraliter et extrorsum ramulosos gerentibus, ramulis superioribus dichotomis subcorymbosis, segmentis subdivaricatis, sphærosporis in ramulo diviso juxta axillas interiore latere spar'sis.

Ceramium granulatum Ducl. l. c!!

Call. granulatum Ag. sp. p. 177 ! J. Ag. Symb. I. p. 4.3. Alg. med. p. I4! Monl. Fl. d'Alger. p. 147 lab. 4. fig. I. (minus characteristica!)

Phlebothamnion granulatum Kï̈z. sp. p. 638!

Callith. spongiosum Ilarv! in Ilook. Br. Fl. II. p. 346. Ilart. Man. p. 143. Phyc. Brit. lab. 125!

Phlebothamnion spongiosum liülz. sp. p. 658!

Ceramium fruticulosum Schousb. mscr!

Gaillona versicolor Bonnem. Ilydr. loc. p. 68 !!

Gallona arbuscula Bomnem. l. c. (pro parte!)

Gaillona punctata Bonnem. l. c. (pro parte!)

Ceramium Grateloupii Duby. Bot. Gall. II. p. 969 !

Ceramium muscosum Draparn!

Exsicc. Wyall. Danm. n. 93!

Ilab in aliis algis parasitica rupibusque innascens, in mari Allantico a littore Britannice (Ilarvey! et Dna Griffiths!) usque ad Tinģin (Schousboe!); in mari mediterraneo ad littora Gallix (lpse! Pertegmond! etc.) Italis! et Ngyerie (Bory).

Crepites 3-4 pollicares densissimi subspongiosi. Fila inferne et sursum longe corlicata, ramellisque a renis corticis pullulantibus omnino obtecta, spongioso-hirta. Rami quoquorersum egredientes pyramidati, minores seu secundi ordinis ambitu fere cylindracei, ramulis abbreviatis obtecti. Ramuli inferiores ramorum fere pinuati, cum raclide decussati, 
latus subplanum ranellisque orlatum rachidi advertentes, lateraliter et extrorsum pinnulati, pinnulis suhdichotomis, inferioribus simplicioribus. Ramuli superiores subcorymbosi, fere omnino dichotomi, segmentis divergenter patentibus. Articuli diametro sesqui-duplo longiores, inferiores et ramorum principalium dense corticati. Sphrerospora ad ramulos dichotomos superiores evolute, prope axillas interiore latere provenientes, triangule divisa. Firselle magna gemina, ad ramulos superiores. Color purpurens, sape sordidus et fuscescens. Substantia spongiosa. Charta minus adlıarens.

C. Brodiaxi et hujus affinibus propinqua species, ramis dichotomis et habitu facilius cognoscenda. Diu quoque cognita species, at plurimis nominilus inscripta.

63. C. GR.ñe (J. Ag. Alg. med. p. 73) fronde erectiluscula alterne decomposito-ramosa, sursum lunge corticata ramulisque pullulantibus litta, ramis puocnoversum egredientibus, terminalibus corymbosis, ramulis dichotomo-subfastigiatis, segmentis erectis, sphterosporis ad ranulos superiores sparsis. .

Callith. grande $J$. .1g. I. c !

Phlebothamnion grande Küls. sp. p. 638!

Ilab. in rupibus maris mediterranei ad littora Galliat (Solier! Perresmond!)

Species hujus generis forsan maxima, caulibus 1--0̈pollicaribus, penna passerina crassioribus, basi in cespitem junctis, ubique corticatis et residuo ramulorum pullulantium hirtis, simpliciusculis aut pyramidato-ramo? sis, apice in ramulos solutis. Ramuli densissime dichotomi decompositi ad geniculum quodque divisi, axillis: acutissimis, ramellis subæquali longitudine fere corymbosis. Articuli diametro sesquilongiores. Spherosporas $\checkmark$ idi apice ramulorum evolutas, dispositionem vero distinguere non raleo. Color e roseo et pallido variegatus. Substantia videtur satis gelatinosa; exsiccata parum revisiscit.

Rami inferne funem libris contortun referunt; superne fibra quasi soluta apparent et in ramulos expansie. IIubitus linc a C. granulato satis diversus et ad C. versicolorem magis tendens. C. granulato alias sine dubio proximus. Ranificationis veram normam (an rami sint cum rachide decussati?), ob difficulatem qua reviviscit, indicare non potui.

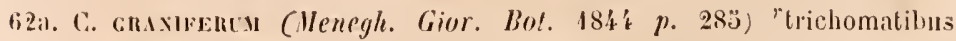
irregulariter ramosis; ramis alteruis subeorymbosis, ramulis ultimis dichotomo-penicillatis, elongatis; arliculis primariis diametro 6-8plo longioribus, geniculis elevatis; tetrachocarpis creherrimis, rhombeoovatis, breviter pedunculatis."

Hab. ad oras Dalmatio. 
Species inquirende.

I. Fronde tola ecorlicala.

* Filis enge rumosis.

64. C. PEDcrecletu (Kütz. Phyc. gen. p. 3il) "trichomatibus sulcapillaribus, rage ramosis; ramis elongatis, palentissinuic. anti-

culis dimetro dmolo log :-..- lis

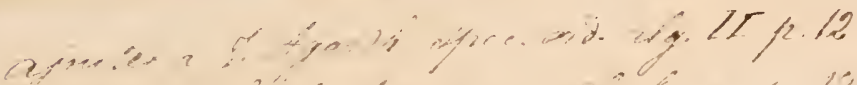

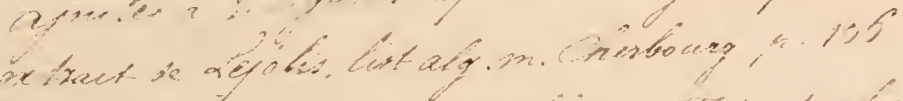

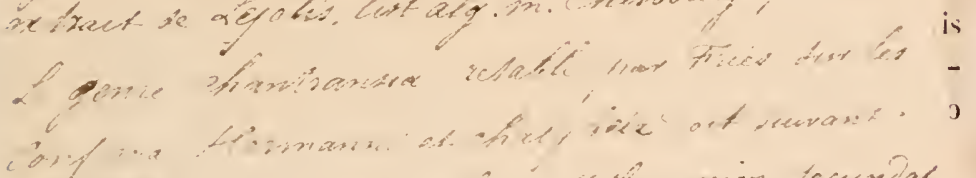

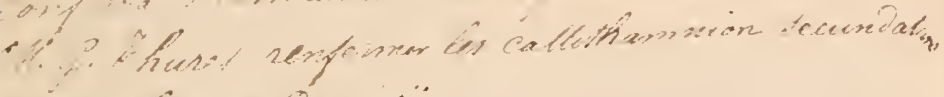

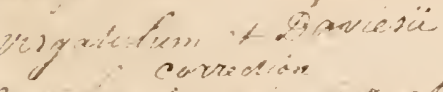
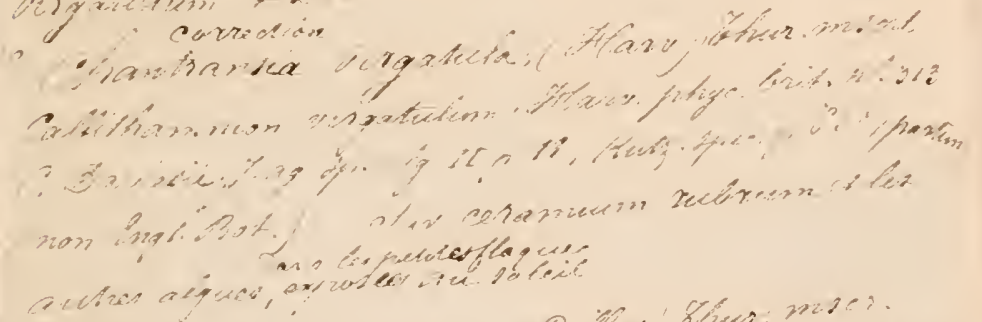

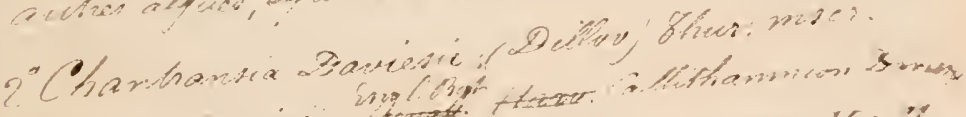

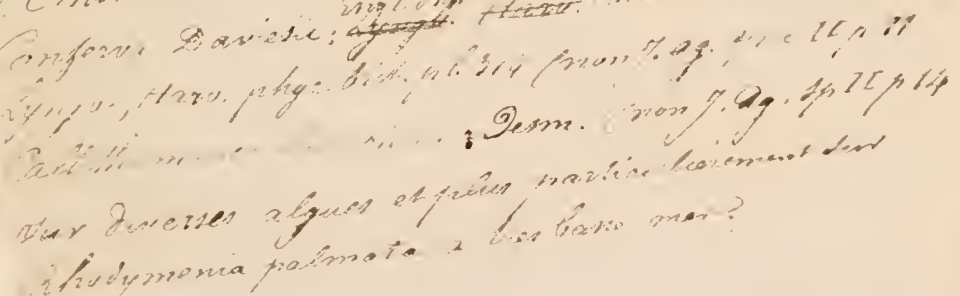

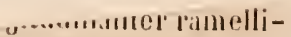
"uce sundelolome corgmbosis flaccidis $(1 / 2+10$ "'), spermatoidia gerentibus, spermatoidiis lateralibus sessilibus; cellulis conglomeratis oblongis hyalinis minutis compositis; anliculis diametro $2-3$ plo, mmellormm 4plo longioribus." llib. in mari Ionico (Rabenlorst). 
batus subplanum ramellisque orbatum rachidi advertentes, lateraliter et extrorsum pinnulati, pinnulis subdichotomis, inferioribus simplicioribus. Ramuli superiores subcorymbosi, fere omnino dichotomi, segmentis divergenter patentihus. Articuli diametro sesfui-duplo longiores, inferiores et ramorum principalium dense corticati. Sphrerospora ad ramulos dichotomos superiores evolutie, prope axillds interiore latere provenientes, triangule disisa. Favelle bagna geminie, ad ramulos superiores, Color purpu-

tomis et imis no-

alterne : pulluinalibus erectis,

\section{(Solier!}

us, penna is et reto-ramotompositi hi longirosporas on raleo. latinosa; ræ quasi lato satis. llias sine I rachide

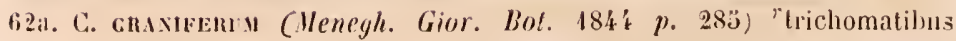
irregulariter ramosis; ramis altemis subcorymbosis, ramulis ultimis dichotomo-penicillatis, elongatis; articulis primariis diametro 6-8plo longioribus, geniculis elevatis; tetrachocarpis creberrimis, rhombeoovatis, breviter pedunculatis."

Ilab, ad oras Dalmatio. 


\section{Syecies innuirender.}

I. Fronde lola ecorlicala. $\because$ Filis enge remosis.

64. C. Pencicciatcy (Külz. Phyc. gen. p. 3il) "trichomatilus subcapillaribus, vage ramosis; ramis elongatis, patenlissinis; arliculis diametro duplo longiorihus; tetrachocarpiis longe petiolatis litteralibus." hüz. sp. p. 6ł1.

Hiab. ad oras Brasiliar.

63. C. Clandestixen (Mont. Fl. Botin. p. l:̈ lab. VII. fig. 2) filis expitosis alrachnoideis irrogulariter ramosissimis, ramis intricatis ramulisgue remotis adscendenti-strictis, articulis diametro quintuplo-subduplo longioriluss.

C. clandestinun Monl. l. c. hül. sp. q. 612.

llab. ad tila Conferve fascicularis in oris Peruvie.

Fila 2 lineas ad sesquipollicem longa.

66. C. mes.mtrocinpun (Menegh. Giorn. Bot. 1848 p. 288) "tricliomatibus tenuissimis paree ramosis, ramis, alternis, patentibus, infra articulationem exortis, apice clavatis, articulis diametro $6-8$ plo longioribus; geniculis contractis; eystocarpiis medio articuli insidentibus, varie Iobatis." liülz. $s p . p .612$.

Iab. ad oras Dalmatice.

67. C. peregrixu (Kütz. sp. p. 896) "dilute roseum, pollicare, trichomatihus primariis setaceis ramusissimis, ramis alternis valde attenuatis ramellosis, ramellis apice dichotome corymbosis, tonuissimis, articulis infimis diametro enqualibus, superioribus 4-6plo longioribus."

Hab. in mari lonico (Rabenliorst).

68. C. [?] strric: (Kü̈z. sp. p. 896) "pallide roseolum semipollicare, trichomatibus primariis capillaribus $\left(1 / 40-1 / 355^{\prime \prime}\right)$ alterne ramosis, ramis primariis subequilongis, longitudinaliter rantellileris, ramellis apice subdichotome corjumbosis flaceidis ( $1 / 2+0 "$ "'), spermatoidia gerentibus, spermatodilis lateralibus sessilibus, e cellulis conglomeratis oblongis hyalinis mimutis compositis; articulis diametro 2-3plo, ramellorum 4plo longioribus."

Hab. in mari Ionico (Rabenhorst). 


\section{Filis allerne pimualis.}

69. C. Phatu (Mont. Fl. Boliv. p. 14 pl. VII fig. 3) "filis (an collapsu?) planis, pluries dichotomo-ramosis, ramis ulliuis pinnatis, pinnis iferum dichotomis, supremis elongatis incursis obtusissimis difformibus, apicem ramuli subabottivi smperantilus; articulis fili primarii diametro decuplo, ramorum duplo longiores, pinnularmm tandem subequalibus."

Call. planum Mont. l. c. Kü̈z sp. p. 6r.t.

Ilab. ad Valparaiso.

Quæ de fructu hujus Algæ memoravit auctor, mihi fabulosa obveniunt.

70. C. Plumosun (Külz. Phyc. p. 372) "parasiticum roseum, minutulım, plumosum; trichomatibus basi senicapillaribus, sursum valde attenuatis, ramis crebris, ultimis distichis, elongalis, gracillimis, rigidulis subligalinis; articulis diametro : 5 -6plo longrioribus." Kü̈z. sp. p. 64 b̈.

IIal). iı mari Septentionali.

7. C. Texussinum (Bonnem. Hydr. l. p. 8f) "cespite biunciali pulpureo; trichomatibus primariis capillaribus, bi-tripinnatis, pinnis pinnulisque erectis valde attenualis, apice tenuissimis, falstigialis, corjmbosis; articulis primariis diametro 8-10plo longioribus, parte inferiori incrassatis, pinnarum 6plo, pinnulirum triplo longioribıs, ultimis obtusis." Kütz. sp. p. 615.

IIab in Oceano allantico ad oras Gallix.

Sec. specimen a Crouan missum, species originaria Bonnemaisoni ar C. Furcellariæ potissimum accedit. Descr. Kiutzingii vero parum in hoc quadrat.

79. C. Avgusritun (Hook. el Ilarv. Alg. Tasm. p. 16) "filis capillaribus dense cespitosis pellucide articulatis tenuibus pluries bipinnatim decomposite ramosissimis roseis, divisuris omnibus alternis, plumnlis (v. ramulis penultimis) virgatis strictis longissimis circunscriptione anguste lanceolatis pimnatis erectis, pimnulis abbreviatis patentibus furcatis v. secunde pinnulatis, tetrasporis glolosis solitariis apicen versus pimularmm sessililms, articulis primariis $6-8$ plo, secumdariis 5plo, ultimis triplo longrioribus."

Ilal). ad oras Tasmania (Gimn).

Céppites 2-4 pollicare.: 
73. C. striatucy (Suhr. Flora 1840 p. 292) fronde 8-lineas alta, ramis alternis decompositis, fructu terminali ramis superioribus cincto, articulis quadratis punctatis.

Iliah. ad Cap. b. Spei.

Ramificatione ad C. pulchellum Ag. adproximatur. Ita fere Auctor.

\section{*:\% Filis opposile pinnalis.}

74. C. Rigidulu (lü̈こ. Phyc. p. 372) "capilliceum, cespilosum, risidulun; trichomatibus basi intense roseis, apice lyyalinis; rat mis ereclis, basi subattenuatis, elongatis, plermmque oppositis, ramulis plerumque alteruis, secundisve, articulis diametro 4-6plo longioribus." liütz. sp. p. 6j6.

Itab. in mari adriatico.

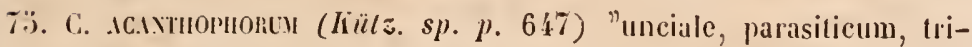
chomate primario capillari aut subsetaceo, parce ramoso ramellis munerosis Iongifudinaliter obsessis, capillaribus, subereetis, apice insigniter et acute spinescentibus, plerumque simplicibus attenuatis, ant bissi ramulo patenti instructis; infra aenicula es articuli parte superiori eyredientibus, plerumque binis suboppositis (raro singulinibus), decussalis; articulis subflaccidis, primariis intimis diamelro aequalibus, seguentibus duplo, mediis quadruplo longioribus, superioribus sensim brevioribus, ramellorum diametro sesugui- ad duplo longioribus, geniculis pirum contractis.?

Ilab. ad Vin-Diemens Land.

76. C. CL.Inonemuty (Zanard. delle C'allith. p. 10) "filis basi setaecis decomposite ramosis, ramulis oppositis pinnulatis, pinnulis inferioribus sursum deorsum inflexis super rachidem reptantibus ranosissimis; articulis diametro fplo longioribus ad basem inllatis anpullaceis in pinmulis reptantibus diametro sesfuiIongुivribus.

Ilab. Dillutitiat, inler Conallos inhabitans.

Froudes bix uuriales lage ramosissima, maxime timen regulariter pinuatr, ramis scilicel instuctis ramulis paulo infra quodque geniculum egredientibus pinmulatis, pimulis inferioribus sen axillaribus sursum deorsum ad rachidem inflexis reptantibus ranosissimis ot corticem fere dendritieum seusim sensimfue confluenteus tandem coustituentibus. Filun primarium tertiam lineie partem crassum superne usijue ad $1 / 360$ lin. atte- 
nuatum. Articuli inferiores diametro fere æquales, medii et ullimi diametro fplo longiores, in pinnulis rero corticalibus sesquilongiores. Color pulchre coccineus. Substantia membranacea flaccidissima.

Habitus fere Wrangelix multitida sed valde tenuior. Species elegantissima et ob pinnulas reptantes corticem dendriticum constituentes insignis. Fructus vero hucusque ignoti."

77. C? Thousasi (Mont. Fl. Boliv. p. 9. Pl. VII. fig. こ̈) filis a basi ramosis, ramis bipinnatis, pinnis pinnulisque oppositis patenti-erectis ultimis subsecundis, articulis fili primarii pinnarumque diametro quadruplo longioribus, pinnularum subequalibus.

Hah. prope Valparaiso.

Dubitavit Auctor utrum Callithamnii an Conferre species potius habenda esset. Küutzing ( $S p, p .648$ ) ad Callithamnion, mullo adposito signo dubii, eandem refert.

78. C. Sertclarioides (Suhr. Fl. 1840 p. 282) fronde 6-lineas alta, opposite pinnata, pinnis validis abbreviatis, pinnulisque lorevissimis 1-2 articulis coustantibus spiniformibus. hülz. sp. p. 650 .

Hab. ad Cap. H. Spei.

79. C. VAriegatum (Suhr. Flora 1840 p. 289) fronde primaria 3-4 lineas alta siepius simplici, pinnis oppositis ant verticillatis patentissimis apice incurvis ant involutis 4-12 articulis constantibus. hü̈z. sp. p. $6 \ddot{00}$.

lliab. ad Cap. b. Spei.

80. C. DEXSUM (Suhr. Flora 1840 p. 28I) fronde primaria 3-4 lineas alta simpliciuscula opposite pinnati, pinnis secunde pectimatis, piunulis apice densissimis. Külz. sp. p. 6:30.

llab. acl oras Peruvice.

\section{*\% Filis rerlicillatim ramosis.}

81. C. R.numosum (Sond. Alg, Preiss. p. 19) "minutissimum repens, ramis erectis, ramulis subpatulis verticillatis pimnatis, arliculis ramorum diametro subtriplo Iongioribus, ramellormm xequalibus.

Ilab. ad littus occidentale Norx Ilollandix (Preiss.). 
Parasiticum, Callithamnio pectinato Montagn. afrine. Rami vix 2 lineas longi, circumscriptione lineari-lanceolati. Ramulorum pinne patentes, disticha, acuta. Fructus deest. Color roseus."

\section{Ir. Filis inferne corlicalis.}

† Ramellis allernatim pinnalis.

82. C. Vibovicun (Menegh. Giorn. Bot. IS 44 p. 28テ) "flichomatiLus bisi fibris decurrentibus corticatis, ramosis; ramis tripinnalis; pinnis pimmlisque alternis diraricatis; rachide flexuosa; pinnis inferioribus superioribusque simplicibus, mediis bipinnatis; pinmulis ultimis raris, inferiori scmper interna, omnibus longe produclis, vix allenuatis, apice obtusis; articulis primaliis diametro duplo, secundariis quadruplo longiorilus; refraclıocarpiis oboralis, pinnis insideutibus; cystocarpiis magnis in ramis primariis opposilis, lobalis." İ̈̈lz. sp. p. 654.

Ilab. ad oras Dalmatice.

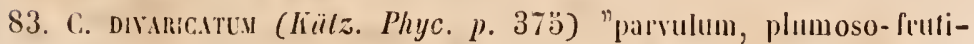
culosum; ramis divaricatis, vel subrecurvis, flexuosis, alterne pinnatis, ramulis subspinescentibus, rectis, righidis; articulis diametro sestuilongioribus; tetrachocarpiis in ramulis lateralibus, solitariis." lï̈tz. sp. p. $6: 3$.

llab. in mari adristico.

84. C. Trafarium (Meneg. Giorn. Bot. p. 286.) "trichomatibus basi corticalis, decomposito-pinnalis, pinnis pinnulisque alternis, trifariis, superioribus distichis, erectis; pinnula inferiore cujusque ordinis semper externa et in pinnis inferioribus in filram decurrentem productia; rachide vix flexuosa; articulis primariis diamctro duplo et ultra, in pinnis piunulisque friplo longiorilus; tetrachocarpiis obovatis, sessilibus, crebris, pinnulis insidentibus; spermatoidiis thyrsoideis ovatis." Külz. sp. p. 6.54. Ilab. ad oras lialmatice.

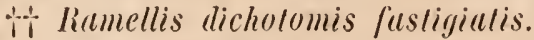

8:. C. Apiculatu (Meneg. Giorn. bot. 1844 p. 302) "pollicare, trichomate capillani superne ramosissimo, ramis bipinnatis ad apicem incrassatis, articulo teminali ampulliformi apiculato; pinnulis pluries dichotomis, erectis, strictis; articulis primariis 
infimis superioribusque brevioribus, mediis diametro quadruplo longioribus, ampullaceis, piunarum usque 10 plo longioribus, superioribus sensim abbreviatis; tetrachocarpiis sessilibus obovatis." Кӥtz. sp. p. 638 .

Hab. ad oras Dalmatie.

86. Phleb. SpINesceis (Külz. $s p . p$. 6̈88) "trichomate primario setaceo; ramis alternis plumosis, longitudinaliter olsessis ramellis fructiferis capillaribus rigidulis dicholome corymbosis, apice acute spinescentihus; articulis diametro $2-3$ plo longioribus. Altit. 2"."

Hab. in Fuco vesiculoso prope Scheveningen.

87. Pir. pachicaulox (lï̈tz. sp. p. 6ว̈8) subsimplex, caulescens; caule crasso, penicillis ramellorum subapproximatis fructiferis vestito; ramellulis subulatis acutis alternis, summis dense aggregatis, minoribus; articulis diametro duplo longioribus, ullimo hreviori, conico, aculo; cystocarpiis subcordatis. Crassities pennie merulx; long. 1-2"."

Ilal), in sinu Biscayensi.

88. PIll. sQcunroscy (Hart. mscr.) "trichomate primario crasso, corticato rigido, obsesso ramis brevibus corticatis patentissimis, dichotome ramellosis, ramellis squarrosis rcorticatis, acutis rigidulis; articulis diam. subrequalibus rel sesruilongioribus." Кӥı. $s p . p .6 \ddot{9} 9$.

Asperocaulon compressum Rudolphi (sec. Kiiit.)

Hib. ad Cap. b. Spei.

89. C. Elupticur (Mont. Canar. p. 17i) nanum parasiticum, filo primario robusto basi striato vage ranoso, ramis virgatis sensim brevioribus pyranidatis, articulis dianetro subbrevioribus aut requalibus, capsulis ellipticis sulppedicellatis, limbo hyjalino lato cinctis.

llab. in Spls. Scoparia parasiticun ad lusulas Canarias.

Bilineare aut parum ultra, arlusculie formam induens miuutulie. Filum primarium pro ratione crassissimum, cum quintam millimetri partem diametro adxquat, hasi venosum, mox articulatum undique ramis conformibus, nempe crassis, vestitum. Rami patentes, apicem versus decrescentes seu sensin breviores erectiuscula, sic ut $\mathrm{llg}$ a late pyramidata virleatur, iterum ramosi, ramulis sulfastigiatis. Capsulir numerosæ el- 
liptica, cum pedicello hreviusculo ad speciem spathulatx. Color rubroluteo-viridique variegatus. Substantia tencrima. Vitro auctissime adliaret - Ita fere auctor.

Obs. Ceranium penicillatum Bory loy. Coqu. n. 99 est forsan Callithamuii species; ex descriptione vero vix patet utrum Florideis au Conferveis melius referutur; nec, si Floridea, utrun Dasye, Irangelia, Griffithsiæe an Callithamnio subjungatur.

\section{Species delende.}

Call. oppositifolium J. Ag. Alg. med. p. Fl est forma Wrangeliae multifidix.

Call. crispellum Ag. Sp. Alg. $p .183$ Dasyic forma videtur.

\section{Corynospora J. Ag. mscr. Callithamnii sp. Aucl.}

Frons filiformis, diclotoma ramilisyue pinnatis obsita, articulatocontracta, monosiphonia. Favellae in ramulo laterali subterminales, involucro ramulorum incurvatorum cinctie, intra periderma liyalinum gemmidia plurima angulata foventes. Sphierospore morphosi articuli terminalis formate, in ramulis nuda, siepe aggregatie, obovato-pyriformes, sporam solitariam (? ant plures ?) continentes (Duby II. Mem. Cer. tab. IV. fig. 4-

Radix in his flantis fibris paucis deorsis constituta. Frondes a basi articulate, articulis subclaveformibus ad genicula contractis constitute, dichotomæ, ramulisque dichotomis fastigiatis quornoversum egredientibus subpinnatim obsitæ, in aquil dulci cito mutatx,

Іа. Lертотнцмхох Külz. $s p . p$. 896.

Trichoma ramosum ccorticatuın. Cystocarpia cornuta axillaria. Tetrachocarpia ignota.

L. Rabexhonstif. Kg. - L. dilute roseum, semipollicare, trichomatibus fastigiatis inferue dichotomis, ramis patentilıs, superioribus alterne ramulosis, ramulis attenuatis apicem versus tenuioribus hyalinis piliformilous; articulis inferioribus diametro $\left(1 / 50-1 / 3 s^{\prime \prime \prime}\right) 5-6 p l o$, ramorum duplo longioribus, summis obsoletis $(1 / 200 "$ "' crassis).

Hah. in mari Ionico (Rabenhor-t)." Descr. Auct. transscrijssi.

Quoad hanc descriptionem Auctoris a Callithamnio vix differt; Cystocarpia cornuta (si lunc terminum rite interpretaverim) in multis Callitbamnii speciebus cognita sunt, quod auctori latuisse videtur, quum Cullithamnio cystocarpia spherica tribuit. 
(endochroma more Griffillısiarum ejicientes?), exsiccate collapse, endochroma intra tubum liyalinum ralde contralientes, pracipue medio articulorum, geniculis in exsiceata sublatioribus.

Fructus adhucdum non rite cogniti. Favelle in C. pedicellata (sec. Harrey) magne, in filis primariis singulie aut geninate; in C. flexuosa et C. ramulosa in ramulo laterali subterminales et involıcro subproprio ramulorum incurvatorm cinctie, fere licmispliserice, intra periderma lyalinum gemmidia plurima foventes. Sphærospore interiore latere ranellorum justi asillas disposite, nunc solitarie, nunc in eadem specic apice ramormm in ramellis transformatis agoregatie (solitariis conformes, at in diversis individuis), articulo proprio pedicellatie, obovato-pyriformes, massam granulosam (sporam indivisam ant plures conjunclia?) intra perisporimm lygalinum foreutes.

Plantix guas loc loco in genus proprimi conjungo, forma articulorum et natura ipsius mombrane frondis Griffitlsiis conventre videntur, habitu cetermm Callithamniorm. Falvellie evidentius quam in Calliflamnio involucrate et subterminales, fere magis Griflitlsie; Sphærospore ut in Callithamnio disposite, nudx. (nec involucratx ut in Griflitlsiis). Ipsa natura rero spherosporarum ceterum mili non perspicua. In dnalns specielnes numquam dirisas vidi, licet magnas ot salis ut villetur miluras, (indivisas quoyue contendit Zannardini in opusculo de Callithamnicis p. i), superlicie suboranulosa intra perisporium; in tertia rero spreic spltærosporie compositæ olvenire videntur; nee lie vero ita in nostris mature, ut normam divisionis perspicere valean.

Cel. Duby primus (2 Mrem. Ceram. p. 22 et 23) contra larum plantarum cum Callitlamniis affunitatem remonstravit, conjunctionem com Griffithsiis urgens. Montagne tertiam speciem Griffiflsia adnumeravit. Ipse confra conjunctionem cum Griffitlsia pluribus locis (Symb. 1. p. 41. Coñt. I. p. 4:56) disputavi, fructum Grifithsie diversum, Callithamnii fere oundem, indigyitans. Ilodie genus normm lis plantis instituens, labitus quandam cum Griffithsiis similitudinem agnosco; fructus vero Callithamnio propinquiores contendo. Fiavellis evidentius involucratis subterminalibus (ramulo terminali nempe involucrante), splarerosporis(fue aliter forsan divisis, genus a Callithamnio diversm potius suspicor quam bene norerim.

Splixerosporæ lıujus generis a Decaisne (Class. lab. 16 fig. 2 el expl. $p$. 83) non sphierospore considerantur, sed organa bulbillis antloya. 


\section{Frons a basi arliculula mula.}

1. C. cLisara (Schousb, mscr.) fronde erectiuscula dichotoma alterne ramulosa, ramulis quoquoversum egredientibus furcatis, superioribus dichotomo-ramulosis, ramellis ad genicula contractis, apicilus clareformibus, spherosporis ellipsoideo-ohovatis interiore ramellorum latere subaxillaribns.

Callith. clavatum Schousb. - Ag. sp. Alg. p. 180! J. Ag. Symb. p. 4.j Alg. med. p. 73 ! hï̈l. sp. p. $6+1$ !

Ceramium Perreymondi Duby II. Mem. Ceram. p. 22 lab. 4 fig. 3 !!

llab. in mari mediterraneo ad littora Galloprovincia (Ipsc! Perreymond!) et in Oceano atlantico vicino ad littus fingitanum (Schousboe!)

Frons 1-2pollicaris, parce dichotoma, a basi articulata, ramulis abbreviatis quoquoversum egredientibus pinnatim obsita. Ramuli erectiusculi; inferiores supra articulum primum furcati, ramellis 2-3articulis constantibus simpliciusculis. Ramuli superiores, in ramos abeuntes, magis compositi. Ramelli terminales omnes clavati obtusissimi, crassi, fere saccati. Genicula articulorum contracta. Articuli diametro \&plo longiores. Spherosporæ interiore ramellorun latere, juxta axillas, dispositæ, ellipsoideæ aut demum obovatx, nunc subsolitariæs aut paucæ, nunc apice ramorum in ramulis subtransformatis minutissimis plurimæ aggregati, (solitariis conformes, sed in diversis individuis). Color carneus. Substantia tenax, in arpua dulci cito mutata, fere more Griffithsiarum.

c. pedicellatæ forsan nimium affinis, huic robustior et magis contracta, ramellis sursum incrassatis obtusissimis dignoscenda.

2. C. Pediceldata (Sm. Engl. Bot. tab. 1817) fronde erectiuscula dichotomo-decomposita et alterne ramulosa, ramulis quoquoversum egredientibus dichotomis, ramollis ad genicula contractis, apicibus cylindraceis subattenuatis, spherosporis ellipsoideo-oboratis interiore ramollorum latere subasillaribus.

Conferva pedicellata Engl. Bot. l. c!! Dillw. Br. Conf. Lab. 108!!

Callith. pedicellatum Ag. sp. p. 174! Harv. Man. p. 114! J. Ag. Aly. Mel. $p$. 73 ! Kütz. sp. p. 6\$1!

Ceran. pedicellatum Dub. II. Nem. Cer. tab. IV. fig. 4!

Ceram. claragerum Bonnem. Ilydr. locul. p. 90 !!

Exsicc. Chauv. Norm. n:o 109! Wyatt. Danm. n:o 94!

Ilah. ad rupes Oceani Atlantici; ad littora Britamnix (Borrer! I:na Ilutchins! Griffills! Ipse!) et Gallix (Bommemaison, Croulan!); in mari mediteraneo ad littora Gallix (Ipse!).

Frons plerumque 2-3pollicaris, aliquando multo major, decompositodiclıotoma, ramulisque quoquoversum egredientibus obsita. Ramuli infe- 
liores simplices ant furcati, superiores decompositi, ipsi nempe ramulis adproximatis obsiti; ramelli terminales cylindracei brevissime plerumque acuminati. Articuli diametro $4-40$ plo longiores, ad genicula contracti. Spharosporie interiore latere ramellorum, juxla axillis; disposita, ellipsoideo-obovatie, nunc subsolitariæ, nunc apice ramorum in ramellis transformatis minulissinis plurime aggregatx, (solitariis conformes, at in diversis Indiviluis) involucro ranulorum exteriorum tecta. Color roseocarneus, exsiccatione sæpe fuscescens. Substantia tenax, in aqua dulci cito mulata, more Griffithsia.

In hac el antecedente specie sphacrosporas indivisas tantum idi, nisi pedicellum, quod rocanl, seu articulum infimum ramuli transformati biarticulati, divisæ sphærosporæ intimam partem consideremus. Aliquando articulus hic intimus desideratur. Favella mihi ignota.

Ceramium clavegerum bonnem. ad C. pedicellatam (nec ad C. clasatam, ut habet lïitzing) certe pertinet.

3. C. Flexuos. (Ag. Syst. p. 141) fronde erectiuscula dichotoma alterne ramulosa, rumulis quoquoversum egredientilus decompositis dichotomo-ramulusis, ramellis cylindraceis incurvis, apicibus aqualibus, spherosporis pyriformibus interiore ramellorum latere suloseriatis.

Ceramium nexuosum Ag. $l$. $c$.

Callıthamnion llexuosum Ag. sp. p. 166! hïts. sp. p. 643?

Ceram. divergens Schousb. mscr!

Callith. flabellatum Schousb. mscr!

Griffilhsia flabellata Mont. in P. Hebb. olia Hisp. p. 9 lab. 6 !

Ceram. pulchellum Gratel. mscr!

Callith. pulchellum Ag. sp. p. 47̈̈! hüls. sp. p. 640̈!

Ceram. Grateloupii Bonnem. Hyılr. loc. p. 82!

Ilab. in Oceano atlantico ad oras Callia meridionalis (Grateloup!) et Arice ad Tingin (Schousboe! Salzman!)

lirons erecta 2-3pollicaris, subindivisa ramulosa, aut ramulo uno alterove prolongato dicholoma, ramis ramulosis. Ramuli quoquorersm egredientes, decompositi ramificalione inter dicholomam et pinnatam intermedia, ramulis majoriluus prolongatis subæquelongis, minoribus pinnatis, rachide inter ramellos eximie fexuosa. Ramelli inferiores patentes subdivaricati, superiores el pracipue frucliferi incurvi, rigidiusculi al fuodammodo corymbosi. Articuli diametro 2-4plo longiores, in slatu recenti ad genicula forsan contracli, exsiccati cylindracei. spharospora pyrifomes, sporas ut videlur $6-8$ foventes, interiore latere ramelli indivisi suls:riala. Favella ramulis paucss involucrata, globose. Color roseus.

I'lanta pulcherrima, antecedentibus specichus ni fallor affinitate prosima, a Montagne olim ad Griffithsiam relata. Cifr. J. Iy. Symb. Cont. I. p. $4.0 ̈ 3$. 
4. C. Pivita (Crouan mscr.) frondre erectiusculia alterne pinnatim decompositi, pimis anounorersm remedicutibus, rachide elongatia pinnulatis, pinnulis c!lindace is paltentibus sursum subintenultis, spharosporis. .

Griflitlsia? pimata Crouan. mscr.

llab. ad littora Gillia prope lirest (Crowan!)

Frons 2-3pollicaris, inferne fere ulta setacea, rdmis sensin atteuuatis, a bass articulata et subuuda; tota pimnatim decomposita, saltim quadri-pinnata. P'innic pinnnlieque ambitu snblanceolate, quoquoversum, ni fallor, egredientes. Pimulie ultimi ordinis simplices in rachide elonwata Hexuos3 alterne, patentes, apicem versus leviter attemati, cylindraceae aut articulis al genicula lesiter contractis. Articuli pinnarum diametro triplo, pinnularum duplo longiores. Endochroma ut in priorilus: exsiccatione plerumque contractum. Fructus non vidi.

C. flexuosa species proxima, sed major, duplo crassior et ramificaltione, ob rachides elongatas eximic pinnata, facilius distinguenda, In C. nexuosa ramificatio revera eadem, sed rachis pinnarum abbreviata, unde rami magis dichotomo-ramulosi adparent.

\section{Frons radiculis ramelliformibus a ramis majoribus externe decurrentibus obtecta.}

5. Cor? Ramelosi (J. Ag. mscr.) fronde alterne ramosa decomposita, radiculis inferne corlicata, rimellisque alternis quoguroversum egredienlibus pinnatis latus planum rachidi advertentibns veslita, pinnis alternis sulmlatis patentibus, articulis cllindraceis diametro expulibus, spherosporis...

\section{Ilab. ad Cap. b. Spei (Pappe! Ill. Cronan!)}

Frons 3-4pollicaris, dense ramosa, ramis conformibus patentibus, inferioribus longioribus. Ramuli ambitu fere cylindracei, ramellis dense restiti, primariicue ra!liculis a ramulis secundariis extra membranam rachidis decurrentibus veliti. Ramelli alubreviati, alterne pinnati, latus planum rachidi advertentes. Pinux subulata patentes simpliciusculir. Articuli in ramulis diametro secquilongiores, in pinnis xquales, ad geniculı vix contracti. Favella in ramellis terminales, pinnis pluribus incurvis multiarticulatis incolucratir, sulgeminatir, intra periderma hyalinum gemmidia plurima foventes. Substantia lubrca villetur; charta arctissine adhieret. Color purpureo-coccincus.

Species spharosporis innotis quoad genus dubia. Substantia fere Griffithsiæ et favellis involucratis a Callithamnio differt. Ramificatione, labitu et ipsa natura ramellorum favellas involucrantiun a Griffittsiat aberrat. Haluro forsan inter omues maxime conveniens; ramuli vero nullomodo verticillati, nec dichotomi, sed alterni et pinnati. Ob consistentiam 
membrance frondis et imolucra subsimilia al Coryuosporam interea retuli, lonec sphacrosporie deteclie affinitatem dijudicabunt.

III. Ballia IIarv, in Hook. Lond. Journ. II. p. 191. Mont. Voy. Pol. Sud. p. 94. Kü̈z. sp. p. 663.

Frons filiformis opposite-pinnata decompositi, articulita, monosiphonia, plesu filorum justa pinnas provenientium supra rachidem incurvatorum demum hirta. Favelle. . Spharospore in plexu filorum incurvatorum evolute, nempe morphosi pinnularum incurvatarum orte, pinnato-aggregate, apice pinnæ incurvato subinvolucrate, splierice, triangrile divise. (IIont. Voy. Pol. Sud. tab. $12 \mathrm{fg} .1$.)

Frondes decomposito-pinnatæ, pinnis pinnulisque quam maxime regulariter opposilis distichis, evolutione pinnarum plus minus ramose, inferne stuposie, nempe fibris radicantilus, extra membranan lili primarii decurrentibus omnino coopertæ, superne nud ap apicilus acuminate aut in pinnis regetis, pinnulas evolventibus, sape obtusx. Pinne initio indivise et prolongitie, filo articulato, anticulis ç̣lindraceis, monosiphonio constantes; proveniunt sensim, a basi sursum progrediente evolutione, pinnulæ, quæ ipsie citissime et fere ipso ortu pinnellis instructe cernuntur. Pinnularmm articulus infimus, cateris initio conformis, citissime mutatur, latitudine espauditur dum altitudine albreviatur, et pinna justa geniculum adponitur, interstitii intercellularis ad instar. Articulo pinne suborali, lıoc modo adponitur supplementum, a geniculo deorsum extensum, prod articulnm externe cylindricum reddit. Pinnelle, quie ox hoc articulo infimo adposito jam antea evolute fuerant, nunc a pinna ipsa oriri adparent, et quisi pinulie simplices utroyne aut tintum inferiore latere pinunle composite observantur. Iste pinnulx simplices, qux ex adposito supplemento infra pinnulam compositam evolvuntur, postea ad evolutionem prone, ramellos emittunt supra rachidem pinne incurvatos demumpue fructiferos. liamelli fructiferi it:une infial et supral pinnulas normales provenimnt, a margine distichi sunt, sed mos supra latus planum rachidis incmrvantur, ipsi ramellis subdivaricatis decompo:anntur, et rachides lirti evadunt. Splicrospore interiore latere ramellorum aggregatae, a pinnellis incurvis transformatic, apice panclli prolongato sterili et incurvo quasi tectie, spherice et triangule divisat. Farellie mihi latent. 
Forme hujus generis ad Splacelariam perperam olim relatie fuerunt. Decaisne, ni fallor, primus Sph. callitrichan Florideis perlinere ostendit et Ilarvey normm huie gents proposuit. Nee hoc immerito, liect omnes nori generis characteres habilu fundare necosse fuerit. Frnetum peculiari evolutione hodie quodue dignoscitur.

Spharospore a becaisne (Pl. de l'Arab. p. 128) primum ut videtur observate, a sequentibus .lyologis neglecte aut ignotie, hoc loco ulterius illustruta et prima viee inter characteres generis introducte.

1..B. calcotracil. (Ag. Syst. p. 166) fronde tri-quadri-pinnata, lamis majoribus inferno stuposis, articulis pinnarum diametro sescyui-duplo Iongioribus.

Sphacelaria callitricha Ag. I. c. Spec. Alg. II. p. 23!! Icon. Alg. Eur. lab. 6! Mont. in D'Orb. Voy. Sert. patag. p. 7 tab. 4. fig. 2!

Ballia callitricha Mont. in D'Orb. Dict. univ. tab. 2. Toy. Pol. Sud.p. 94 ! Kü̈z. sp. p. 663 ! lab. 8 !

Sphacelaria crassa Ig. Syst. p. 167. Sp. II. p. 23! Icon. Alg. Eur.

Ballia crassa fiül. sp. p. 664 !

Ballia Brunonia Ilarv, in Ilook. Journ. Bol. II. p. 191 lab. 9. Crypt. Antarct. $p$. 78 el p. 182! Aly. Nov. Zel. n: 112! Aly. Tasm. n:o 90!

Ballia Hombroniana Mont. Prodr. I'lyyc. antarct. p. 9. Yoy. I'ol. Sud. p. 94 lab. 12 fig. 1! hüts. sp. p. 663 !

Ilab, in Oceano australi ad insulis Nalouinas (Frejcinet!) et littus Patagoniar; ad novam Zelandiam et insulas Aucliturd; ad novam IIollandiam! insulas Van-Diemen (R. Brown! Banme!) et Keryuelen (Ilooker!)

Radix est discus spongiosus. Frons 2-6pollicaris, inferne stuposa pennam columbinam crassa, superne setacea pinnis pinnulisque capilliribus. Rami oppositi aut abortu alterius vagi, apice plumosi decompositi. Pinnx ambitu sublanceolatæ, pinnulis adpressis patentibusve. P'imulis pinnellave indivisa subnlate aculissime. Articuli in pinna pimnellave indivisa cylindracei, in pinna pinnulave divisa ovales, diametro plerumpue duplo longiores, ume longiores nunc paulo breviores, in pinnellis diametro subiequales. Color roseo-purpureus, exsiccatione facile virescens.

Varietates plures, ab auctoribus allatas, unican sistere speciem, auctoritate et ducibus Ilookero et Ilarvey, hoc loco assumsi. P'lurimun mihi abludere videtur specinen a Brownio lectum, pinnulis simpliciusculis pinnarumque apice longe producto pinnulis denudato (Ballia Brunonis); huic proxima (B. callitricha $\mathrm{Ag}$.) gerit pinnas a basi ad apjicem piumulatas patentes et distantiores; B. Hombroniana al) laac non distinguitur nisi pinnulis densioribus minusque patentibus; B. crassa est denique ca- 
teris crassor, magis contracta pinnulis erecto-adpressis. - Extrema rero larrum formarum confluere, et ab atate rel stadio erolutionis - velut sphacelarix scoparix forma æstivales el byemales dirersi - pendere videntur.

\section{Species inquirende.}

2. B. Pretril (hül:. Bot. Zeit. $18: 7$ p. 3i) cespite fustigiato purpureo-chalybeo; trichomatibus erectis basi stuposis, ramosis, ramis elongatis, virgatis, a basi pinnutis, apice in filum elongatum nudum atticulatum tenue productis; pinnis oppositis ahnerialis densissmis contignis erectis; articulis diametro aequalibus vel sesquilongiorihus.

Ilah). ad Cayennam (Le Pricur).

Altitudo pollicaris. -- Ex hül.. sp. p. 66 transscripsi.

Mihi ignota, quoad diagnosem vix a primaria specie distat. Filum nudum articulatum in specimine antecedentis quoque vidi et stadium evolutionis consideravi.

3. B. CULLEssts (Decsn. Class. p. 62) (indescripta).

IV. Griffithsia Ag. Syn. Aly. Scand. Intr. p. XXVIII. Slec. Aly. p. 126. Bonnem. Ilydr. loc. p. 93. J. Ag. Symb. I. p. 39. Alg. med. p. 74. Harv. man. p. 101 et Phycol. Brit. tab. XVI. Endl. Gen. pl. Suppl. III. p. 33̈. (excl. spec. ap. omnes.) Iӥ̈t. Phycol. Gen. p. 373. Sp. Pl. p. 659.

lirons filiformis, dichotome ramosa, articulata, monosiphonia, nudia. Favella seepe plures, involucro regulari, ramellis incurvis phurimis constituto, sessili aut pedunculato, terminali inclusire intra perisporium lyyalinum gemunidia plurima angulatil foventes. Spharospore morphosi ramuli formatie, interiore latere involucri, ramellis incurvis plurimis constituti, serialte', spherice, triangule divisie. (hütz. Plhyc. tab. 4t fig. V; Hare. Phyc. (ab. CLXXXIV).

rondes exespitosie, radiculis filiformibus repentibus conjuncta, mos erecte, plus minus regulariter clichotomie, in paucis ob axillas patentiores adparenter rammlosate, decomposite, siepins eximic filstiggiatie, alliqumdo sulnlatollatie, articulate, articulis cylindracris iut seppus ob genicula exinnie contractil oblongis ant immo ellipsoideis, furcas sustineutibus ditatatis sulpryriformibus. Articuli subduplici 
membrana constitutie, interiore [?] endochroma forente, et exteriore ligalino lasius ambiente. Fibrica monbranam peculiaris, quo fit ut frondes recentes, in aquil dulci depositie, crepitante sonn, succum cellukrem ejiciunt, et membrane contoryuentur atyue collabuntur.

Organa frnctificationis triplicis generis observatal, in diversis plantis intra involucra, pro diversitate speciermm varia, inclusis. Involucra sphærosporarum nune circa genicula verticillation disposita, in ramis majoribus non mulatis ad articulos plures obvenientia, mosc in ramulo laterali pyriformiter inflato solitaria, teminalia et mmbellata, ant articulis singnlis pancisve superata et cirea geniculum verticillata; ramuli involucrantes ex articulis singulis incurvis constant; nunc vero sunt involucra in ramulo laterali breviori terminalia, umbellatim ambientia, ramulis involucrantibus furcatis et articulis plurilus constitulis. Inolucra favellarum ramulis sulsimilibus formata, at diverso modo disposita; in nommullis lateraliter subsessilia, in aliis pedunculata, l. e. in ramulo laterali brevissimo terminalia. Spliærosporæ interiore latere involucri seriate ant ayglomeratæ, transformatione ranelli minutissimi, simplicis aut disisi orte, intra perisporium lasius hỵalinum triangnle divise. Favella plerumıgue plures intra involucrum conjunctie, singule sacculo ligalino cinctie, gemmidia plurima continentes. Intheridia in pluribus speciebus observata, intra involucrum subsimile ut plurimum obenientia, oblongo-tmbinata, glomerulis plurimis circa axem dispositis constantia. Glomeruli collnlis minutissimis agglomeratis confliti.

Genus ita quidem naturale, ut, quo modo primum in infantiat Nigologix findatum fuerit, fere legitime circumscriptum censeatur. Ultimo tantum tempore species dux, Wrangolice et Ilalıri sectiones proprias formantes, excluse fuerunt. In speciebus Alfarum C. Agardhi genus revera pejus fuam in anterioribus operibus limitatum, Crouaniam, lasya et Dictymi species complectebatur. Col. Duby (II. Mem. Cer. p. I8) insequente, ut videtur in primis operibus, Montagneo, jus proprii generis infringere tentavit. Ipse (Symb. p. 39) characteres generis, antea satis vagos, stabilire et opinionem Dubyanam refutare conatus sum, tum species nonnullas, Generi mile aduumeratas, expellens. lusefunentes Nyologi ommes Genus adoptitrunt, limitilus conservatis intactum, donec lintzing speciem, fuan proprian sectionem Generis antecedentes consiseraverant. novi greneris typum proclamaverat. Contra innovationem, ignoto fructu nori gencris, habiluali chanactere nnice fundati, in Aflers. $p$. 17 
invectus sum. Fructu IIaluri dein eximiis D:næ Griffillıs studiis cognito, genus novum recipiendum censeo.

species lıujus generis, tum in maribus Europeis temperatiorilıts, fum in anstrali al Cap. h. Spei, Americam inforiorem et Tismaniam inventie fueruat. Piliasitie vis dicendie sunt, licet nonnulle inter alias $\mathrm{I}_{\text {was }}$ serpant. In mediterrineo nonnullas ineunte astate linctiferas, alias exemute fertiles legi.

1. Involucra spharosporarum ramellis simplicibus abbreviatis incuris constantia, circa genicula frondis non transmutate cerlicillutim disposita.

1. Gr. Scuotsboli (Mont. in P. Webb. Ot. Misp. p. II) fronde cespitosa regulariter dicholoma listigiatit, seguentis erectis, articulis superioribus ellipsoideis diametro duplo longioribus, fertilibus conformibus intra involncrum circa genicula verticillitum, rantellis simplicibus abbreviatis incurvis constans, spherosporas gerentilus.

Griffithsia Schousboci Mont. l. c. Lab. 10! Canar. p. 173! J. Ag. Alg. med. p. 77! Mont. Fl. d'Aly. p. 143! lï̈l. sp. p. 661!

Griffithsia imbricata Schousb. mscr.

Griffithsia opuntia J. Ag. Symb. p. 40!

Griffithsia Giraudii Solier. mscr.

Ilab. inter Mgas et Corallinas repens, in mari mediterraneo (Apse! Solier! Gilaudy!) et adriatico (Biasolefto!); in vicino Ntlantico ad Tiugin (Sclousboe!) et ins. Cimarias.

Cæspites subhemisphærici, unciales, vel paulo majores. Frondes crassin fere pennam passerinam xquantes, dense dichotomæ, articulis $2-3$ segmenta intercedentibus, fastigiatæ et fere flabellatæ, ramis plantæ recenlis sape in planum expansis, inferne subcylindracex, superne eximie moniliformes, articulis segmenta sustinentibus pyruformibus, supremis magis cllipsoideis, mediis crassioribus. Rami fructiferi sterilibus conformes, ad genicula plura frondis mediia involucra verticillata gerentes. Ramuli involucrantes brevissimi incurri, articulo mnico constantes. Frons in mari eximie nitens, fere iridescens, exsiccatione collabens et variegati, geniculis plerumque intensius coloratis, interstitiis lutescentibus; charta arctisime arlharet.

Gr. corallinæ proxima, et characteribus fere iisdem agrius diagnosi circumscribenda, tamen species certe distincta.

2. Gr. Coratumi (Liglf. Scot. p. 988) fronde erecta dichotoma fastigiatia, segucutis crecto-patentibus, articulis superioribus ob- 
Iongis diametro triplo longiorihus, fertilibus conformihns intrat involucrum cirea genicula vellicillatum, ramellis simplicibus ahbreviatis incurvis constins, splarrosporas gerentibus.

Conferva corallina Liglf. I. c. Lingl. Bol. lab. 181:5. I)illw. Con/. I. 98!! Griffithsia corallina Ig. Syn. Introtl. p. XItill. Sysl. p. 14.;. Sp. Aly. II. p. 12ร. Harv. Man. p. 103 ! Kӥ̈ъ. sp. p. 6.39. Aresch. Enum. p. 102.

Callitlamnion corallinum Lyngl. p. 126!

Conf. geniculata Ellis in Phil. trans. 37 tab. 18 fig. f. F.

Conf. corillinoides $L$.

Exsicc. Hyall. Nlg. Danm, n.o 89 !

1libl. in Oceano atlautico a littore Gallixe! el britannix! usque al Islandiam; all oras Simus Codani!

Frondes plures quidem una provenientes, vix tamen caspitosa dicendax, plerumque 3-öpollicares, pennam pasicrinam fere aquantes, sul)distanter dichotoma et magis irregulariter fastigiata, segmentis elongatis patentibus. Articuli in inferiore parte subeylindracei, ad genicula contracti, superiores magis oblongi, diametro 3 -4.plo longiores; non raro sunt medio aliquantulum constricti et superiore apice incrassati. Farellie in ramulis sparser, ad apicem articuli dilatati sessiles, involucro, ramulis ex uniro articulo constantibus minutis bresibus incurvis conslituto, tecli, glomerulis pluribus constantes. Involıcra sphærosporarum circa genirula verticillata, ramulis favellarum similibus constituta. Color carneonitidus. Substantia tenuis; chartx arctissime adlıæret.

Sec. Mont. in Weub. el Berl. Il. Canar. p. 17 ad littora Canariensia lecta fuit, sed sterilis et hinc forsan specie dubia. Sec. Ilook. et Ilarv. Cr. Anl. p. 182 ad Cap Horn et Cap. b. Spei quoque obvenit; sed ex his quoque locis specimina sterilia tantum observata videntur. - Griffithsia flabelliformis (IIarv. Lonl. Journ. 184. p. 450!, maris australis incola, quam postea (Alg. Tasm. $p$. 1:3) ad Gr. corallinam referunt Ilooker et Harvey, accuratius investiganda mihi videtur. Specimen sterile tantum vidi. Fructiferum forsan characteres distinctionis suppeditabit.

3. Gr. Deyoxiexsis (Harv. Phyc. Brit. tab. XVI) fronde erectis dichotoma fastigiata, seginentis erecto-patentibus, articulis su-

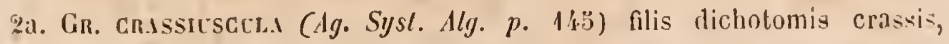
articulis cylindricis medio angustatis, diametro 4 plo longioribus.

Griffithsia crassiuscula Ag. l. c. Sp. Alg. II. p. 129.

Ifal). ad novam Ilollandiam (Mus. I'aris!)

(ir. corallinae proxima, sed duplo crassior, laxe dichotoma, spithamea. Articuli cylindrici, medio angustati, apice rotundati. Genicula contricta.

1ta Auct. 1. e. Sperimen olim in mus. Paris. vidi; species propria videtur, sed ex unico specimine haud rite circumseribend:ı. 
perioribus çlimdraceis ad genicula contractis, diametro 6plo Iongiorilus, fertililus conformilus intra involucrum circa genicula verticillatum, ramollis simplicibus abbreviatis incurvis constans, spherosporas foventibus.

Griffithsia Devoniensis Hart. l. c!! Kült. sp. p. 661!

\section{Ilab. ad oris Inolix meridionales (M:rs Wyatt!)}

Frondes plures collecta erectiuscula, gelatinosæ et flaccida, decomposite dichotome et fastigiate, segmentis inferioribus patentibus, superioribus ereclinsculis. Articuli prielongi, 6 -8plo diametro longiores, sul)cylindracei, geniculis contractis. Spluxrospora in ramis haud transformatis obvenientes, circa genicula dispositil, involucro suffultie. Ramelli involucrantes (sec flariey) articulis pluribus constantes, sphierosporam ad geniculum quodque emiltentes; mihi, plantam exsiccatam observanti, ramelli involucrantes ex unico articulo incurvo utrinque obtuso constare adparuerunt, cujus ad basem internam sphærospora fasciculatim congestie adfixæ sunt. Favella nomlum observatx. Color roseo-carnens.

\section{Incolucre spherosporarum filis tenuissimis piliformilus} constantia, circa genicula frondis verticillatim disposita.

4. Gr. b.1rbata (Engl. Bot. tab. 18I4) fronde ciespitosa erectiuscula dichotoma fastigiata, segmentis crecto-patentibus, articulis superioribus cylindraceis ad genicula contractis diametro 6 plo longioribus, fertilibus conformibus intra involucrum circa genicula verticillatum, pilis elongatis tennissimis constans, splıerosporas solitatias an modimm gerentilus; farellis in ramulo abbreviato terminalibus.

Conferva barbata Emyl. Bot. l. c.

Griffithsia barbat:l Ay. sp. Aly. p. 132. Bonnem. Hydr. loc. p. 97! Harv. Man. p. 102 ! Küls. sp. p. 660!

Ceram. barbitum IMb. II. Mem. Cer. Gab. IV. fig. 2!

laal. in oceano atlantico ad littora dugliae meridionalis (Borrer!) ot Gallia (Bomemaisoil, Croula!)

Cirspes sesquipollicaltis. Frondes seta tenuiores, inferne parce et distanter, a medio dense ef regulariter dichotoma, fistigiata, versus apices valde attenualx. Arliculi omnes fere cylindracei, superiore apice infra geniculum paulatim incrassato, geniculo contracto, diametro 5 -6plo longiores. Jibre tenussima, ipsil planta multiplo tenuiores, lyalina, longissime articulata, rerticillatim ramosa, palentes, a geniculis articulorum superiolum circuncirea egrediuntur, apices tenuissina coma ornantes. In phata spharesporis fructifera, fibra cjusmodi simplices verticillatim cirea genicula superiora egrediuntur; spharespora solitaria ad apicem 
articuli inlim:, paulo crassioris, adfixa cst; supra sphaerosporam ramus involucri fibra tenuissima continuitur. In planta farellis fructifera ramuli abbreviati, laterales, singulis articulis constantes, pyriformiter inflati, involucra apicem circumcirca umbellatim disposita gerunt; iuvolucrorum ramelli abbreviati incurvi, unico articulo constituti, glomerulos favellarum includentes. Chartx aretissime adhæret.

Planta sane singularis et characteribus insigniuribus distincta. Icon in Engl. Bol. data plantam farelliferam; analysis Dubyana in II. Mcm. Cer. ramulum sphacrosporis instructum monstrat. Ipse utrumque fructum observavi et ad proprias olservationes supra descripsi. Characterem specici præcipum, quem in apicibus comosis posuerunt, huic specici non onnino characteristicum puto, utpote eundem in fronde favellifera Gr. corallinæe observavi.

\section{Involucra spherosporarum ramellis simplicibus abbrevialis} incurtis conslanlia, in ramulo pyriformi laterali subsolitaria, terminaliu aut articulo singulo paucisve fertilem continuante.

̈. Gr. phitcanprori (J. Ag. Alg. med. p. $7 \tau$ ) repens, fionde inferne dichotoma superne subsecunde-ramosa, segmentis patentibus, articulis superioribus cylindraceo-oblongis diametro 4-6plo Iongoioribus, fertilibus pỵiformibus articulo simplici ampulleformi paucisve coronatis, intra involucrum ramellis simplicibus abloreviatis incurvis constans splarosporas gerentilus.

Griffithsia phyllamphora $J$. $d g$. l. c. liulz. sp. p. 661!

IIab. inter alias Nogs repens, in limite maris mediterranei ad littora Gallix et Italix (Ipse! P'erreymond!) ad Tingin (Schousloe!)

Ciespites depressi, expansione unciales. Frondes inter alias Algas repentes, tenuissimæ, inferne irregulariter dichotomæ nudiusculæ, superne ramos, apicem rersus sensim breviores, subsecundos vel vagos emittentes. Articuli diametro $4-6$ plo longiores, inferne magis cylindracei, superne geniculis eximie contractis magis ohlongi, superiore apice ramigero inflato; fructigeri eximic pyriformes, infra apicen ramulorum siti, et articulo unico ampulliformi vel sapius ramo, articulis $2-3$ constante, coronati, spherosporas in sinu iuter articulos iuflatos relicto gerentes. Iuvolucrum paulo infra apicem articuli pyriformis egrediens et geniculum verticillo ramellorum cingens, ramellis simplicilus incurvis, supra geniculum ix supereminentibus, constans. Color et substantia caterarum.

Species generis fere tenuissima, vix capillaris, ramificatione irregulari a plurimis abludens, conformatione fructus distiuctissima. Ut in speciebus antecedentibus sunt involucra circa geniculum verticillata, et fertilis articulus plurilus articulis sterilibus continuatur. Sed unicus articulus in 
ramulo singulo fertilis videtur, et hic forma peculiari instructus; articuli hunc continantes pauci, et forsan demum delabentes. Ramuli itaque fructiferi sterilibus dissimiles, transitum indicant ad species, quarum involucra in ramulo proprio laterali terminalia sunt atque umbellatim in apice disposita.

6. Gr. Cespltosa (Harv. mscr.) fronde crespilosa erecliuscula diclıotoma fustiģiata, segmentiș erectiusculis, articulis superioribus obIongis diametro 3-4plo longioribus, fertilibus pyriformibus articulo solitario abbreviato superatis, intra involucrum, ramellis simplicibus abbreviatis incurvis constarıs, spluxrosporas gerentibus.

\section{Hab. in Falsebay ad Cap. b. Spei (Harrey!)}

Cæspites hemisphærici, densissimi, purpurei, sesquipollicem alti. Frondes seta porcina crassiores, decomposito-dichotomæ, fastigiatæ, moniliformiter contractæ. Articuli inferiores cylindracei ad genicula contracti, superiores oblongi, ramum sustinentes subpyriformes, omnes diametro 3-4plo longiores. Rami fertiles paucis articulis constituti; ramuli nempe lateralis abbreviati articulus penultimus plerumque fertilis evadit, ultimo articulo abbreviato coronatus; articulus fertilis, qui sæpe in ramulo est infimus, pysiformiter inflatus, infra geniculum ramellos involucri incurvos abbreviatos emittens, sphærosporas in sinu inter utrumque articulum gerens.

Habitu hæc species fere Gr. Schousboei æmulatur, quare in Algis mediterraneis de utriusque similitudine et forsan identitate observationem protuli; utramque dein conjunxit lüutzing. Hodie, speciminibus fructiferis observatis, bene diversas video. Gr. cæspitosa cum Gr. Opuntioide quoad fructum magis convenit; verticillus nempe involucri in ramulo laterali al)breviato provenit unicus; articulus fertilis sulpyriformis evadit; sed hic, in specie Capensi, articulo unico terminali superatur, dum in mediterranea fertilis articulus fere semper terminalis sit; cæterum articuli inferiores ad genicula magis contrahuntur in Gr. cæspitosa quam in Gr. Opuntioide. Gr. confervoides (Sulir in Regenst. Fl. 1840 p. 281), sec. fraginentum a me visum, a specie Ilarveyana vix differt. Hujus prius descripta nomen forsan adoptandum fuisset, sed nomen parum aptum Harveyano postposui. Longe ante Suhrium Ilarveyanam plantam sub nomine dato cognovi, aliique sine dubio viderunt.

7. Gr. Opuxtroldes (J. Ag. Alg. med. p. 76) fronde caspitosa erectinscula diclootoma fastigiata, segmentis erectiusculis, artienlis superioribus oblongis diametro 4-6plo longioribus, fertilibus pyriformibus in ramulo abbreviato terminalibus, intra involıcrum, ramellis simplicibus abbreviatis incurvis constans, sphxrosporas gerentibus. 
Giriffithsia Opuntioides J. Ag. l. c. Mont. Fl. Alg. p. 143! Kü/s. sp. p. 661 !

llab. inter alias Algas repens ad rupes maris mediterramei; ad littora Italie (Ipse! Nartens!), Galloprovincix (Sulier!); ad Agger (sec. Montigne).

Frons sesquipollicaris, rezulariter dichotomo-fastigiata flabellata, ramis fere in planum expansis, erectiusculis, articulis plerumque singulis aut binis ramos intercedentibus. Rami ultimi paululum attenuati incurvati. Articuli inferiores eylindracei, superiores oblongi, apicilsus rotundatis contractis, apice ramifero pyriformiter inthato, diametro $4-6$ plo longiores, in planta exsiccata ob majorem geniculorum contractionem sepe ellipsoidei. Pedunculi insolucrorum, a ramulo lateraii, singulis aut rarissime binis articulis constante, formati, eximie pyriformes, articulo sterili breviores (tertia vel quarta parte) at duplo crassiores, umbella involucri coronati. Ramelli involucrorum indivisi oblongo-cylindracei incurvi. Color roseo-carneus. Charlie arcte adliæret.

hammlis fructiferis, unico articulo constantibus, lateralibus, fertili articulo terminali, a præcedentibus omnibus dignoscitur; ramellis involucri simplicibus a speciebus serfuentis sectionis, nec non geniculis contractis, nullo negotio distinguenda.

4. Involucra spharosporarum ramellis incurvis furcalis arliculalis conslantia, in ramulo abbreviato umbellatim disposila, terminalia. (Arliculi ad genicula vix contracti).

8? Gr. ftrcellata (J. Ag. Alg. med. p. 75) fronde minuta capillari regulariter dichotoma fastigiata, scomentis erectiusculis, terminalibus furcellatis, articulis cylindraceis ad genicula vix contractis, diametro 5 -6plo longioribus, involucris. . . .

Griffithsia furcellata J. Ag. l. c. Iü̈z. sp. p. 661!

Conferva setacea Spr. in Berl. Mag. 1809 lab. 7 fg. 9 (fide spec.!)

Ilab. ad saxa maris mediteranci; prope Amalfi regni Neapolitani legi; e sinu Panormitano (llb. Sprengel!)

Cxspes vix pollicaris. Frondes tenuissimæ, crassitie capillares, a basi ad apicem dichotomo-decompositie, segmentis vero nunc distantioribus nunc crebriorilus, infra apices plurimis, aliquando subsecundatis, eximie fastigiatx. Articuli cylindracei, ramigeri plerumque superne dilatati, diametro 4-6plo longiores, geniculis pellucidis non contractis. Color recentis miniatus, fere suhsimilis illi, ijuem ceterx species aere expositie primun induuntur; exiccatione in roseum pulcherrimum abiens. Chartx arcte allharet.

Gr. tenui videtur proxima species, attamen abunde diversa, ramificatione dichotomo-fastigiata, apicibus furcellatis, segmentis erectiusculis 
et altitudine minori. Sterilem tantum vidi, quare incertum an hujus loci sit. Ob genicula non contracta huc retuli.

9? Gr. texuis (Ag. sp. Alg. p. 13) fronde capillari sublateraliter ramosa, ramis vagis supra axillam patentissimam adscendentibus, terminalibus longe productis indivisis, articulis cylindraceis ad genicula vis contractis diametro 4-6plo Iongioribus, involucris. . .

Griffithsia tenuis Ag. l. c. Zanard. Syn. p. 69! J. Ag. Alg. med.p. 7 ö. liülz. sp. p.661!

Hab. in mari adriatico; ad Venetiam (Ruchinger! lpje!)

Frons sesqui-bipollicaris, crassitie capillaris, vage ramosa. Rami longiores brevioresque mixti, nullo modo fastigiati, sinu patentissimo, fere anguli recti, egredientes, supra sinum deiu adscendentes, apice longe producto simplici, coma terminali fibrarum verticillatarum capitulati. Articuli ad genicula vix contracti, fere omnino cylindracei, diametro sæpius 5plo longiores. Color roseus. Chartæ arcte adhæret.

Ramificatione peculiari hrec species facilius distinguitur. Apices, in modum Gr. barbata comosi, capitulum tenue referunt.

10. Gr. irregularis (Ag. sp. p. 130) fronde selacea inferne dichotoma, superne subsecunde ramosa, ramis patentibus, articulis cylindraceis ad genicula vix contractis diametro quadruplo longioribus, ramulis fructiferis lateralibus sparsis $2-3$ articulatis, intra involucrum terminale umbellatum, ramellis furcatis incurvis convergentibus constitutum, sphærosporas foveutibus.

Griffithsia irregularis Ag. l. c. J. Ag. Alg. med. p. т̈. Külz. sp.p. 660! llab. ad caules et inter lulbos rejectos Posidonice intricita, ad oras Gillix of Italix.

Frons 1-2pollicaris, crassitie setacea, exsiccatione sordidius purpurea, inferne patenter dichotoma, ramis superioribus sensim brevioribus subsecundatis eximie patentibus. Articuli diametro plerumque 4plo longiores, superiores exsiccatione sæpe leviter ad genicula contrahuntur. Ramuli laterales in media frondis parte fructiferi, articulis plerumque duobus constantes, eximie patentes, apice involucrum umbellatim gerentes. Fila involucralia supra articulum infimum furcata, ramulis in formam unguis incurvi supra spharosporarum congeriem convergentibus. Hibitu fere magis Callithamnion quam Griffithziam xmulatur.

11. Gr. Setacea (Ellis Phil. Tr. 37 tab. 18 fig. e) fronde setacea regulariter dicholoma fastigiatil, segmentis erectiusculis acuninatis, articulis cylindraceis al genicula vix contractis diametro uplo longioribus, ramulis fuctiferis lateralibus sparsis oppo- 
sitisque 2-3 articulatis, intra iurolucrum terminale umbellatum, ramellis fureatis incurvis convergentibus constitutum, sphierosporas foventibus.

Conferra setacea Ellis l. c. Engl. Bot. tab. 1689. Dillw. Conf. tab.82!! Griffithsia setacea Ag. Syn. p. XYVIII. Sp. p. 129! Bonnem. Ilydr. loc. tab. 8 fig. IX! Harv. Man. p. 103. Phyc. Br. Lab. 184! Mont. Canar. $p$. 17̈3! lin̈tz. sp. p. 660! Ilook. et Ilarv. Alg. Tasm. p. 13! Cr. antarct. p. 79 .

Ceramium sctaceum Dnby II mem. Cer. tab. IV. fig. 1.

Ceram. pedicellatum Dec.; Lanour. dict. d'llist. Nat. cum icone.

Lixs. Grev. Alg. Brit. n. 23! Wyatt. Danm. n. 137! Chanv. Norm. n. 8 !

Var. Spharica, cespitibus densiorihus brevioribus hemisphæricis.

Griffithsia sphærica Schousb. mscr. Ag. sp. Alg. p. 130. J. Ag. Alg. med. p. то. Kй̈ъ. sp. p. 660 !

Ccramium penicillatum Ducl. Ess. p. 51! (eximiel)

IJab, in Oceano atlantico ad littora Gallix! et Britannix! ad ins. Canarienses; in mari mediterraneo ad littora Gallix! in Oceano alıstrali ad Tasmaniann (Gunn!)

Crspites densi 2-6pollicares. Frondes crassitie sctaceæ, strictæ, decomposito-dichotomæ, fastigiatæ; segmenta sinubus acutissimis scjuncta, crecta, suprema longe acuminata. Articuli cylindracei, supremi exsiccatione ad genicula aliquando contracti, diametro ut plurimum 4 plo longiores. Ramuli fructiferi laterales, bislineam vix longi, sæpe oppositi, nunc sparsi, articulis 2-3 constantes, apice involucra gerentes. Fila involucralia ulriusque fructificationis similia, ab articulo ramuli fructigeri supremo abbreviato egredientia, exteriora longiora supra articulum infimum furcata, interiora breviora, omnia supra fructus in formam unguis incurvi convergentia. Favellæ glomerulis $3-4$ constantes, singula intra membranam pellucidam gelatinosam gemmidia angulata numerosissima foventes. Sphærosporæ sphæricæ, interiore latere ramulorum involucri aggregatæ, plurimæ. Color coccineo-carneus. Chartæ adlıret.

Inter species, quas hoc loco conjunxi, nullum omnino distinctionis charactere in invenire mihi contigit. Cxspites plantx mediterranex mihi semper breviores et densiores quam in specic Atlantica obvenerunt; ipsa fila utriusque in omnibus convenire mihi adparuerunt. Specimina planta australis sterilia tantum vidi. Præter magnitudinem, qua vulgarem Europæam superant, cum hac congrua.

12? Gr. SECCid (IIarv, mscr.) froinde setacea elongata secmidatim decomposito-ramosa, ramis inferioribus ramulosis, superioribus simplicibus, ramulis patentibus, articulis cylindraceis ad genicula vis contractis dianetio aplo lo!ıgioribus, fructibus.... 
Griffithsia secunda Harv. mscr.

\section{Ilab. ad oras Capenses (Ilarve!!)}

Frons videtur filnris repentibus intricatis ca.pitosa, erectiuscula, crassitie fere setacea, 3pollicaris, indivisa, leviter curva (forsan adscendens), ramos plurimos indivisos aut eodem modo parcius ramulosos, pollicares aut superiores minores emittens, apice breviter nuda. Articuli diametro 4-6plo longiores, ad genicula pellucida aliquantulum contracti, cæterum cylindracei. Fructus a me un visi. Antheridia rero occurrunt infra apicem ramorum, circa articulos plures superiores rerticillatim disposita, interiore latere filorum involucralium rerticillatorum, et si recte viderim unico articulo constantium, infra apicem affixa, turbinato-oblonga, globulis minutissimis hyalinis circa axem glomerulatis constantia.

Habilus, ramificatione excepta, Gr. selacex. Ex dispositione vero Antheridiorum et forma ramellorum involucri forsan concludere liceat, involucra spherosporarum esse circa genicula verticillatim disposita, et speciem primæ aut secundæ sectioni adnumerandam esse. Articuli supremi ad genicula evidentius contracti.

13. Gr. Bixdentaxa (Sond. Bot. Zeit. 1840 p. כ̈2) fronde crassa dichotoma fastigiata, segmentis erectiusculis ohtusis (fructiferis incurvis), articulis cylindraceis ad genicula vix contractis diametro duplo longiorilus, ramulis fructiferis interiore latere segmentorum incurratorum subsolitariis, unico articulo constantibus, intra involucrum terminale umbellatum. . . . .

Griffithsia Binderiana Sond. l. c. Alg. Preiss. p. 21!! Külz. sp. p.660!

Hab. ad oras austro-occidentales Nove Hollandia (Preiss!)

"Fila Kützingiæ canaliculata adnsts, aggrezata, 1 -2pollicaria, inferne simplicia, a medio dicholome ramosa, seta porcina subduplo crassiora, ramis homogeneis apice incurvatis, supremis parum lenuioribus. Articuli omnes sulnequales, dianctro duplo, rarius triplo longiores, medio nou angustati, nec apice rolundati. Favellæ ramellis $4-6$ brevissimis, obtusis involucratæ. Sphærosporas non vidi."

Ita Auctor! mihi, ex fragmentis judicanti, species videtur Gr. secundiflorx valde propinqua. Rami incurvi ex prieparatione in aqua dulci praecipue pendent, ut ex speciminibus Gr. secundiflora ita tractatis satis elucet; differre vero videntur dispositione ramulorum fertilium, qui in Gr. Binderiana intra ramulos incurvos singuli (nec plures secundati) et arliculo involucra sustinente longiori et evidenti, quare involucra Gr. Binderianæ pedunculata, Gr. secundifloræ subsessilia apparent.

14. Gr. seccydfrom (J. Ag. Symb. p. 39) fronde crissa dichotoma subfabellation fastigiata, segmentis erectiusculis obtusis, frucliferis subincurvis, arliculis eylindraceis ad genicula vis contractis diametro 3-4plo longiorilus, ramulis fructiferis in- 
teriore latere segrmentorum secundatis, articulo brevissimo constantibus, intra involucrum terminale umbellatum. ramellis furcatis incurvis convergentibus constilutum, sphærosporas foventibus.

Griffithsia secundiflora J. Ag. l. c! Alg. med. p. 73! Harv. Phyc. Bril. tab. 185! Mont. Fl. Alg. p. 142. liül. sp. p. 660!

Griffithsia crassa Küt. Phyc. gen. p. 37ł!

Griffithsia corallina Ag. $s p$. (partim; quoad spec. mediterranea). Mont. Crypt. Alger. p. 2.

Gr. corallina $\beta$. Bonnem. Hydr. loc. p. 96 ?

Cer. corallinum $\beta$. major Desmaz. Cr. Fr. N:o 103 2.

Cer. Desmazieri Crouan. mscr.

Griffithsia setace:a var. intermedia Chauv.

Griffthsia intermedia Lenorm. mscr.

Ilab. ad saxa rupesque maris mediteranei a Constantinopoli! ad Tinguin! in Oceano atlantico littora Gallia! et Britannia! attingens.

Cæspites usque 6-unciales rigidiusculi densi. Frondes setd plus duplo crassiores, a basi ad apicem obtusum æquali fere ubique crassitic, subflabellatim dichotomæ fastigiatx, articulis in inferiore parle plerumque 4-6 segmenta proxima intercedentibus, in superiore parte, cujus segmenta erecta sæpe flabellata, articulis fere singulis segmenta separantibus. Segmenta erecta supra sinum aculum. Articuli diametro 3plo--4plo longiores, geniculis vix contractis cylindracei. Segmenta fertilia leviter incurva; ramuli fructiferi brevissini, interiore latere segmentorum seriati, secundi, articulo brevissimo, pedunculi loco, involucra terminalia sustinente. Involucra ramellis pauci-articulatis furcatis, supra fructum in formam unguis incurvi convergentibus, constituta; sphærosporæ ad ramellos interiores scriatæ. Antheridia in sinu ramellorum involucri furcatorum obvenientia, turbinato-oblonga, glomerulis minutissimarun cellularum circa axem dispositis constantia. Favellas non vidi. Color pulchre coccineus. Chartie adhret.

14a. Gr. Axtanctica (Ilook. el Ilarv. Cr. Ant. p. 182) filis caspitosis dichotome ramosis flaccidis, axillis inferioribus patentibus, superioribus aculis, ramis elongatis ramulisque nudis ad nodos constrictis, articulis cylindraceis superne paulo incrassatis, ramorum diametro 6 plo, ramulorum subtriplo longiorilus; fructificatio deest.

llab. in rupibus ad Cap Horn, Insulas Ilermite et Falkland.

Fila sub 3-nuc. Jonga, fastigiata, parce ramosa, ranis elongatis, distanter ramulosis, ramulis brevilus. Color rosens; - charte arcte adlaxret. Gr. secundiflore proxim:s at omnilus partilus minor.

Descr. Auct. transscripsi. Milıi tantum ex fragmento sterili et incompleto, a Gaudichaud ad ins. Falkland lecto, cognita. 
Plantam Bonnemaisoni supra citatam, quam huc referunt, vix ad nostram pertinere puto; quum enim in Gr. corallina fructus rite descripsit, et rar. F. fructiferam vidit, differentiam fructificationis nimium adparentem puto, quam ut utramque plantam conjunxerit, nulla facta mentione differentix fructus.

\section{Species inquirender.}

15. Gr. AR.ACixombla (Ag. Sp. Alg. p. 131) filis dichotomis arachnoideis, axillis inferioribus patentissimis; superioribus acutis, articulis diametro plus 6 plo Iongioribus.

llab, ad littora Gallix (Durau!)

Fila cxspitosi, intricata, palmaria et ultra, crassitie fere arachnoidea, implicata, inferne ramosissima, ramis divaricatis et fere horizontalibus, superne dichotoma, axillis acutis, ramisque erectis. Articuli diametro $6-1$ aplo longiores, medio tenuiores, versus utrosque fines incrassati, ideoque genicula tumida. Color cinnabarino-roseus, pulcherrimus. Substantia tenerrima membranacea. Chartæ arcte adharet.

Ita Auct. I. c.; mihi specimina hujus plantæ ita male præparata et distorta videntur, ut nullum judicium de eis ferre maluerim. Articulorum longitudinem singularem a tubo collapso pendere suspicor. - Specimen vero ex oris Angliæ, ad Plymonth lectum, coram oculis habeo, quod ad eandem speciem forsan pertineat, a D:na Griffiths olim ad Gr. setaceam relatum, (an postea ad Gr. devoniensem vindicatum?). Gr. arachnoidea a Montagne (Canar. p. 175) quoque enumeratur et species distincta considerari videtur.

16. Gr. Chilexsis (Monl. in Iï̈lz. sp. p. 660) seticea, vage ramosa, ramis alternis, inferioribus elorgatis, superioribus abbreviatis, articulis diametro $6-8$ plo longioribus cylindricis. - Fructus ignoti.

Ilab. ad oras Chilenses (Ilb. Montagne).

17. Gr. Pogoxoldes (Menegh. Giorn. bot. 184t. p. 290) "trichomatibus pluries dichotomis corymbosis, apice simplicibus, articulis primariis diametro $6-8$ plo longioribus, superioribus semsim brevioribus clavatis, geniculis incrassatis, involucris ad genicula verticillatis, ramellis plerumque simplicibus, tetrachocarpia sotitaria gerentibus." (Külz. sp. p. 66!!)

Ilab), ad oras Dalmatiae.

18. Gr? tonulosi (Zanard. Callith. p. 13) "filis intricalis vage ramosis, ramis ramulisque conformilus divaricatis obtusis; ar- 
ticulis doliiformibus diametro 3-4plo longioribus, genieulis valde contractis.

Hab. ad oras Dilmatiac (Sindri).

Caspes rix uncialis laxe intricalus ramis patentilus ultimis elongatis nudiusculis rage exeuntibus alternis, secundis vel rarius oppositis, longo vel bresi intervallo distantibus parum infra geniculum egredientilous. Fila omnia fere itidem crassa in diametro majore usque terdecimam linea partem attingentia. Articuli valde intlati ad geniculos summopere constricti et ita insigniter torulosi. Color purpureus facile mutabilis.

Structura et habitus omnino Griffithsix, fructu tamen ignoto genus non extra dulitationem determinari potest." Ita Auctor.

19. Gr. Derlel (Mont. Fl. Alg. p. 143) fronde cespitosa tenui roseo-coccinea dichotoma fastigiala, apicibus inxqualiter furecllatis aculis, segmentis patenti-crectis, articulis cylindraceis diametro 2plo-4plo longiorihus, geniculis equalibus, fructu...

Ilab. in Gelidio corneo parasitica ad la-Calle (Durieu).

Cæspites densos in aliis Algis efficit. Frons uncialis et ultra, intricata, capillaris, basi $1 \% / 100$ millim; apicem versus $10 / 100$ millim. crassa, dichotoma, fastigiata, axillis omnilus angulo $45^{\circ}$ patentilus, segmentorum extremorum apices inæqualiter furcati, altero scilicet semper breviore, acutissinzi fere subulati. Articuli diametro 2-4plo ad sumnum longiores. Genicula nec constricta, nec manifeste prostantia. Color roseococcineus.

Gr. arachnoideæ et Gr. furcellatæ colore et ramificatione convenit, sed filis crassioribus, articulis dimidio brevioribus, segmentisque distantibus diversa. A. Gr. tenui, ramificatione regulariter dichotoma et segmentis distantibus differt. Descr. Auct. transscripsi.

\section{Species exclusa.}

Gr. argus Mont. Can. p. 176 videfur species Wrangclia.

Gr. tenuissima Zanard. Sagg. $p .56$ ad Callith. variabile pertinet (efr. Zan. Delle Callith. p. 13).

V. ILalurus hülz. Phycol. p. 374. sp. p. 662. Griffillsix sp. Auct. Verticillaria Gralel.

Frons filiformis ramosa articulata monosiphonia, ramellis abbreviatis incuris verticillatis vestita. Farella siepe plures verticillo ra- 
mellorum frondis suffultæ, in ramulo abbreviato terminales, intra periderma ligalinum gemmidia plurima angulita foventes. Spharospora interiore littere involucri, ramellis incurvis froudis constituti, phrime sphærice triangule divisæ. (Harv. Phyc. Brit. (ab. LXVII).

Frondes spongiose ramosissime, filo primario verticillis ramellormm vestito constintes. Filun primarium articulatum, sul)duplici membrana contextum, interiore endochromil forente et exteriore laxius ambiente. Verticilli ramellormon infra genicula exeuntes, sed extra membranam lutic adpressi donec geniculnm attigerint, exinde patentes, incurvi, semel furcati aut pluries dichotomi, articulati. Sxpe a basi ramellormur, extra membrauam fili primarii, radicule, ramellorum ad instar articulatie, demittuntur, quie filum primarium demum investiunt.

Organa fructificationis triplicis generis observata, in diversis plantis intra ramellos involucrantes froudis sita. Favellie (sec. IIarvey) in ranulis abbreviatis ramellosis terminales, verticillo supremo ramellorum suffulte, ramellis vero patentibus minus evidenter inrolucrate. Spherospore in ramulo axillari abbreviato, ramellis denudato, intra involucrum terminale evoluta; Ramelli iurolucri incurvi, furcati, ramellis frondis sterilis subsimiles. Splıerosporæ splterice plurimx (morphosi ramuli rimellorum formatie?) triangule divise. Autheridia iutra involucra subsimilia evoluta, plurima, glomerulis collularum minutissimarum constintia.

Genus a külzingio formatum, peculiari labitu fundatum, fructu tunc temporis iguoto. In Adversariis $p$. 17 contra novum genus argumenta attuli, qua fructus ignoti quasi sponte sua prebere ridebantur. Sphresporas Griffitlsiie convenieutes eodem loco quoque monstari. Postea Ilarrey pulchra analysi (Phyc. Britan. tab. LXVII) farellits cognitas reddidit, antheridia quoque et spharospolas a D:na Griffiths detectas illustravit. Adpst fivellarum levissima differentia, guxe, habituali diversitate conjuncta, genus proprium forsin justificabit. Ceterum sane Griffitlsix, et quoad naturam menbrane frondis, simillimum.

1. Ha.. Eousetifolus (Ligtf. Sc. p. 984) fronde Vage et ynoquoversum ramosa, ramellis incurvis fureatis dichotomisve dense vestiti; articulis rancllormu diametro $4-6$ plo Iongioribus.

Conferva Equisetifolia Ligtf. l. c. Dillv. Conf. tab. 54 !! Engl. Bot.tab. 1479; Esp. Fuc. Sup. tab. 4. Sur. Berl. mag. 3 lab. 6 fig. 7. 
Verlicillaria Equisetifolia Grat. mscr.

Hilurus Equisetifolius Küuls. Phycol. p. 374. Sp. p. 662.

Griffitlıia Equisetifolia $\mathrm{Ig}$. Sp. II. p. 133. Bonnem. IIydr. loc. p. 9:3!! J. Ag. Alg. med. p. 78 ! Harv. Han. p. 1011 Phyc. Bril, Lab. LXIII! Mont. Fl. Aly. p. 414!

Cladosteplus flavidus Bory.

Conf. inbricata Ilucls.

Conf. cancellata Rolh.

Exs. Wyall. Danm. 11. 181! Chauv. Alg. Norm. n. 31!

Var. simplicifilum ramellis basi furcatis, dein simpliciusculis strictis crissioribus.

Ceramium simplicifilum Dec. Syn. p. 8.

Griffithsia simplicifilum Ag. sp. p. 134! Harv. in Hook. Journ. Bol. I. p. 298 lab. 139! Man. p. 101!

Halurus simplicifilum liül. $s p . p .663$ !

Conf. verticillata Schmiedel. Icon. p. 79 lab. 2.

Hab. in Oceallo atlantico ab oris Britannix usque ad Tingin! in mari mediterraneo! ad insulas Malouinas (sec. Ag. sp.)

Radix callosa fibrisque cooperta. Frondes erectie subsolitariæ, sæpe 6pollicares et pennam corvinam crassæ, cylindraceæ, vage ramosissimæ, ramis patentibus. Filum primarium axile articulatum, articulis diametro duplo longioribus. Verticilli in junioribus partilus subregulares, distantes et discernendi, ramellis plurimis basi patentibus apice incurvis, plerumque pluries furcatis; a basi ramellorum demittuntur radicula, articulatæ et ramellis crassitie aquales, quæ, tilum axile denique investientes, ramellos novos sparsos emittere videntur, quo lit ut frons senilis ramellis cooperta appareat. Articuli ramellorum diametro 4-6plo longiores. InvoIucra sphærosporarum in pedunculo axillari, $2-3$ articulis constante, ramellis nudo, terminalia. Color coccineo-purpureus, exsiccatione sordidus. Substantia frondis spongiosa.

Variat ramellorum crassitie capillari et fere usque seticea, ramellis semel furcatis strictis et dicliotomis iıcurris, verticillis discernendis et confluentibus. Plures species inter has varietates latere, ex hodierna harum plantarum cognitione vix suspicari licet.

2. Hat. R.ADicifonmis (Hook. el Harv. Alg. Tasm. n. 96) fromde distiche ramosa ramellis incurvis sinplicibus fincatisve dense vestita, articulis ramellorum diametro agnilibus vel sestuinlongioribus.

Griffitlısia (Halurus) radiciformis Ilook. el II. l. c.

Halurus radiciformis liuls. $s p . p .663$.

Ilab. ad oras Tasminix (Gunn).

Frons crassa 6--8pollicaris, inarticulata, opaca, pionatim bipinnatimve ramosil, ramis filiformibus distichis sensim altenuatis, ramellis brevissimis 
simplicilus furcatisve incurvis densissime velata. Involucra pedicellata e foliolis dichotomis arcte conniventibus constantia, sphærosporas ad fila multilida affixa foventia. Color intense rubens. In aqua dulci non admodum mutatur. - Descr. Auct. transscripsi. Mihi ignota.

VI. Ptilota Ag. Syn. Alg. Scand. p. XIx. Sp. Alg. I.p. 38́. Syst. p. XXxilI. Grev. Alg. Lrit. Syn. p. LX. Harv. Man. p. 84. Pliyc. Brit. tab. 80. Endl. Gen. Pl. Suppl. III. p. 36. Mont. Voy. Pol. sutl. p. 97. Kï̈t. Phyc. gen. p. 378. (excl. sp. ap. omnes); Ptilota, Rihodocallis et Euptilota Kütz.sp. p. 669 et squ. Plumaria Stackh. in Mlem. Soc. Nat. MIosqu. II. 86.

Frons compresso-anceps pectinato-pinnata decomposita, asi articulato mox corticato, cortice cellularum pluribus stratis constante: intermedio cellulis rotundatis, superficiali collulis minutis, filis elongatis inter cellulas excurrentibus raris aut densissimis. Favella in pinnulia terminales, ramellis conformilus pluribus sepissime involucratie, intra sacculum hyalinum gemmidia plurima angulata foventes. Sphorosporce in pinnis ultimis articulatis monosiphoniis plus minus transformatis ex articulo integiro formatie, solitarice ant aggregate, sphicricie, triangule divisie. (Ilarv. Phyc. Brit. tab. LXXX et CXCI. liütz. Pling. gen. tab. $46 \mathrm{VI}$ ).

Frondes omnium pinnatim decompositie, jugannento filiformi et compresso, seu ancipite aut imno evidentius alato. Pinne in nonnullis speciebus opposite, in aliis alternx; pinne oppositæ vero nunc conformes, magnitudine xunales, aut sxpius una major, altera minor, majoribus minoribusque utrinque alternantibus; piunce opposite nunc difformes, una indivisa phyllodium referens, margine integerrimum aut plus minus profunde serratum, altera composita et eodem modo pionata, phyllodiis et pimnis utrinque alternantibus. P'inne phyllodio oppositie in nonnullis speciebus sxpe parum evolute et cum rtate olsoletic; sed in his plerumque plures pinne phyllodio opposite, ant inter phyllodia alterna utringue, sensim proveniunt. His species injuria alternifolias dixerunt auctores. Nlie drmum species ah origyine alternifolix.

Juvenilis frons in omnilıs articulata et monosiphonia videtur, sed mox corticati, cortice nunc pinnellas ultimas obducente, nunc vero has mudas linumente. Cortex cellulis minutis, endochromate colorato farctis, initio constit. Deorsum et introrsum cellulie hie 
corticales in fila continuantur elongrata et articulatil, in diversis speciebus pauciora et fere uulla aut cum relate plurima; intermedium quoque provenit stratum, cellulis miajoribus rotumbato-angulatis constitutum, cujus inter cellulas, fila elongatal decurrunt. CelJulæ Læ magnæ in nonnullis speciebus (Pt. plumosil) totam internam frondem fere occupant et axem ipsun undipus cingunt; in aliis cellule magne strati intermedii fere nullæ (aut cum atate minoribus inpletie?) et axis filis elungatis densissinnis cingitur; in specichus dense pinnatis, articuli axiles pinuarmu, una cum articulo axili ipsius jugamenti, in sectione trunsversali conspiciuntur, quare in plano axili cellule magna 3 -3 in conspectum veniunt, filis invicem separate.

Favellie in pinnula transformata semper, ni fallor, forminales, nunc, pinuula transformata brevissima, in pinnula superioris ordinis literales apparent (Pt. Cormosissimis); iuvolucro in Pt. elegante fere nullo aut pinnellis paucis parum incurvis formato, in plurimis regulari, pinnellis circiter $5-7$ ambientibus incurris, simplicibus integerrimis aut serratis, aut ipsis pinnatifidis constante. Nuclei 2-pluresve intra involucrum; simguli infra sacculum lyalinum gemmidia rotundato-angulatia plurima forentes. Sphærospore in pinnulis plus minus transformatis, nempe ahhreviatis monosiphoniis et articulatis, simplicibus aut decomposilis, evolutx; in simplicilus subsolitarie ex articulo terminali, in decompositis plurimæe ex articulo pinnarum solitario aut teruinali formati; sphærosporie vero in his nunc pauciores disticlıe, nunc evolutione ramellorum pinnulam undique ambientium of demum fertilium densissime aggregati; singulie intra perisporium sphæricum nucleum triangule quadri-divisum foventes.

Genus eximic naturale jam in Synopsi Algarum Scandinarix al) Igardlio constitutum et a posteris omnibus receptum; quile autem tunc linitatum, speciem unicam heterogeneam includens. Sulir (Beitr. zur Algenkund. Flora 1836, I. p. 29) omnium primus diversitatem fructificationis in diversis speciebus indicarit, et in duas sectiones genus dividendum monstravit, has vero sectiones

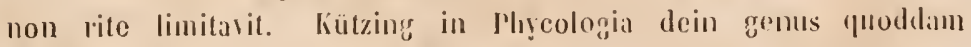
Carpoblepharis instituit, cui formas I't. flaccidae Auct. adnmmeravit, ipsam vero plantan typican Turmeri l'tilote speciem existimavit. IJoc in Speciehus Mgarum emendavit, sed hoc loco ipsmun Ptilotiv genus in genera 3 dissolvit, que structure differentiis diversa predicavit. Structure differentias adesse non negandum est; omnes 
tamen species ad eundem typum constructas accuratius inquirenti facile patebit. Axem ptiluta indicat kützing; pendet vero differentia ex pinnarum longioni ant minori distantia; in speciehus quarum piunæ longius distant, articulus avilis ipsius jugamenti in sectione transversali tantum cernitur; in aliis vero specielus pinne ita adproximate ut cellulie asiles pinnarum una cum articulo axili ipsius jugamenti in sectione transversali frondis collaterales conspiciuntur; aliquando immo ejusmodi articulos 5 observavi. In Plilota (hülz.) fila elongata deficere, eorum vero loco cellulas rolundato-angulatis axem cingere, stituit Kützing. Fila elongatia in Pt. plumosa sparsissima esse, confitendum est; tamen adsunt, sed parum evoluta; eodem modo cellulie rotundato-angulatie et in Rihodocalli et in Euptiloti obveniunt, sed sparsiores. Varietates prælerea ipsie, quas Ptilotæ plumosie adnumerit Kützing unam eandemrgue structuram non offerunt; ha enim (Pt. elegans et Pt. serrata) structurim aliorum generum milii monstrarunt.

1. Pinnis oppositis conformibus, aqualibus aut una majore, allera minore, majoribus allernis.

1. Pt. Eligaxs (Bonnem. Hydr. loc. p. 22) frondis decompositepinnate pinnis in raclide filiformi (non alata) oppositis conformibus, pinnulis usque ad rachidem sub-monosiphoniam pinnatisectis, pinnellis obtusis simplici serie articulorum constantibus, sphresporis apice pinnellarum solitariis, favellis in pinIIula terminalibus subnudis.

Ptilota elegans Bonnem. l. c!! Küls. Phyc. p. 378!

Ptilota plumosa $\gamma$. tenuissima Ag. Sp. I. p. 386!! Aresch. Enum. p. 97 ! 84.

Ptilota plumosa $\beta$. capillaris Grev. Alg. Bril. p. 13̈. Harv. Man. p.

Ptilota sericea Harv. Pliyc. Brit. Lab: 191!

Exs. Wyatl. Danm. n. 77! Chauv. Alg. Norm. n. 166 !

Ilab. in Oceano allantico a Norvegia! usque ad Galliam!; ad bittus orientale Americe borealis (sec. Harrey); in sinn Codano!

Frons 2-ipollicaris, densissime decomposite pinnata, pinnis cujuscumque sit ordinis oppositis (uisi alterius abortu, majoribus alternis), majoribus minoribusque promiscuis, minori (cieterum conformi) majorique opposito. Rachis nusquam alata, filiformis, in senilibus sippe lierta: in pinnulis, qua pinnellis simplicibus instructa sunt, rachis simplici serie articulorum constituitur; articuli isti diametro equales, infra geniculun 
utrinque contracti et ita forma fere urceolati. Pinnellic regulariter opposita, in articulis vicinis basi subcontigua, simplici articulorum diametro xqualium serie constitntx. Sphrospore ex terminali pinnellie articulo transformata (sxpe composita). Farcllie apice pinnulæ geminx, nudx aut pinnellis proximis leviter incurvis sulfultx.

Hanc specien Harvey, ut ei mos est, eximia analysi primus rile stirbilivit, ab aliis tamen longe antea distinctam. IIarvey ipse lanc distinctionem jam a Gmelino factam contendit, nomenrue hujus sur planta conservavit. Nlhi opus Gmelini adeunti hoc maximopere dubium adparuit; quin immo verosimilius Gmelini liguram ad Gelidii cornei formam pertinere, cui ab Algologis antea quorue relata fuit. Synonyma Gunneri milhi quoque suspecta. Nomen itaque Bonnemaisoni, nullis vexatun dubiis, adoptandum credidi.

2. Pr. Hunesi (J. D. Hook. in Lond. Journ. Bot. 1843 p. 271) frondis decomposito-pinnatie pinnis in raclide filiformi (non alata) oppositis conformibus, pinnulis usque ad rachidem mox cellulosam pinnalisectis, pinnellis subulatis simplici serie arliculorum constabtibus, sphærosporis apice pinnellarum solitariis, farellis in pinnula terminalibus involucratis, involucri ramis pinuatis.

Ptilota Harveyi Hook. l. c. Hook. et Harv. Crypl. Ant. p. 181 lab. $187 ! !$

Euptilota Harveyi hülz. Sp. Alg. p. 671!

IJib. in Oceano allstrali ad Hermite-lsland, Cap Horn, et insulas Falkland (J. D. Hooker!)

Frons suncialis, immo pedalis, crassitie slipitis $1 / 2$ linere. Rachis filiformis, compressa sed non alata, juvenilis articulata monosiphonia, mox cellulis obducta; Senilem non hirtam vidi. Ramiticatio regulariter opposita, pinna majori minorique, prater magnitudinem conformibus, oppositis. Pinnellæ articulis plurimis $7-1 \%$, simplici serie dispositis, diametro paulatim longioribus, constitutæ, basi leviter, apice longe attenuata, oltusius acuminatæ. Articuli pinnularum rectangulares. Favelle intra involucrum plures, rotundatix, ramellis incurvis pinnatis plurimis tecta. Spharospora ex terminali articulo pinnellarum formatæ, (sec, fig. citat.) subsolitaria, (sec. diagnosin) aggregata. -

Ab antecedente specie differt magnitudine, pinnellarum forma, articulis longioribus in pinnella pluribus, favellarumpute involucro. Fructus ipse non vidi. hiitzing præsentem et antecedenten ad diversa genera refert. Milii structura in utrarque specie eadem adparuit.

Varietatem peclinalum, pinnulis subdistantibus, Auctores I. c. alfermut.

3. Pr. plunosa (Lin. Mant. p. 131) frondis decomposite-pinnatx pinnis in raclide ancipite-alata oppositis conformibus pinnati- 
partitis, pinnellis a basi latiore lincari-lanceolatis cellulosis anticulorum serie singula costatis, sphærosporis apice pinnellilum pinnatim dispositis adprosimatis, favellis in pinnella terminalibus involucratis, iuvolucri ramis simplicibus.

Fucus plumosus L. l. c. Fl. Dan. lab. 330. Esp. Fuc. tab. 4.3. Turn. Hist. Fuc. lab. 60 (excl. var. $\beta$.) Engl. Bol. Lab. 1308.

Ptilota plumosa Ag. sp. (excl. v. $\gamma^{\circ}$ ) I. p. 38\%). Syst. p. 195. L.yngb. Ilydr. p. 33 lab. 9 fig. 4 et 3 ! Grev. Alg. Brit. p. $13 ̈ 3$ lab. 16 ! Harv. Man. p. 84 et Phyc. Brit. tab. 80! hüts. Phyc. tab. 46. VI. Sp. Alg. p. 660 (excl. var.) Aresch. Enum. p. 97 (excl. var. $\beta$ ).

IIal). in Oceano aflantico septentrionali ad littora Norvegeie! Foeroearum! Orcadum! usque arl Scotiam et liftora sinus Codani! descendens.

Frons decomposito-pinnata, 1-12pollicaris; anceps et alata, rachide lineam dimidiam latitudine superans. Ramificatio reguliriter opposita, pinna majori minorique magnitudine excepta conformibus oppositis. Pinnellæ juveniles simplici serie articulorum costate, cellulis minoribus alatæ, adultiores inferne costa corlicata, superne nudia articulata, instructa; omnes a basi latiore sensim attenuatie, leviter incurvæ, longitudine latitudinem (juxta basem) 3-5plo superante. Pinnellæ, quæ marginem interiorem pinnularum ornant, et pinnulæ minores, quæ majoribus oppositæ sunt, præcipue fertiles; fructus itaque introrsum seriate. Spharosporæ supra medium pinnellarum secus marginem utrumque seriata, pedicello brevissimo monosiphonio suffultix, plurimæ adproximatæ, distichæ. (Pedicelli revera seriem novam pinnarum constituunt, quarum articuli ultimi in sphxrosporum transmutantur, sed liec series tantum in fertili plinta adest). Favellie (introrsum quorque seriatæ) in pinnellis terminales, longius pedicellatæ, ramellis $3-7$ simplicibus cellulosis incurvis involucratæ.

Ifanc speciem sæpissime Laminarix digitatæ parasiticam esse, Pt. elegantem vero plerumque rupicolam obvenire, Iarvey statuit, quod meæ experientix quoque convenit.

2. Pinnis oppositis difformibus, una foliiformi indirisa, allera eodem modo composita; foliis allernis, pinnis inter folia aliquando repetilis seriatis, aliquando obsoletis.

4. Pr. sarbata (Külz. Bot. Zeil. 184i p. 36) frondis decomposilopinnatre pinnis in raclide ancipite alata oppositis inequalibus, una indisisa inciso-serratil, altera pimnatipartita, pinnellis a basi latiore lineari-linceolitis cellulosis, sphrerosporis ad apicen pinnulie transformatie circumcirca densissinis in slomerulum conicum congestis, favellis in pinnella terminalibus involucratis, involucri ramis serratis cellulosis. 
l't. serrata lï̈l. l. $c$ !

Pt. plumosa \&. serrata hül. sp. p. 670 !

Pt. plumosa $\beta$. Asplenioides Ag. Syn. p. 39. Lynyb. Hydr. p. 28 (excl. syn.) tab. 9 fig. 2!

llab. in Oceano aretico ad lillus Torregie! ret mare allum (Ruprechl!); in pacifieo ad insulam Sitclaa!; in allantico ald Groenlandian! Terram novim (De la Pylaic!) et insulas Foeroearum (IJngloge).

I'tilote plunrosa proxima, habitu statura el ramilicatione comeniens. Pinnæe vero opposita non conformes; una pinnatipartita plus minus composita, altera simplex profunde serrati indivisa. Serratura juvenilium preeipue in exteriore margine conspicur, in alultis utrinque profundar. Sphærosporæ transformatione pinnula pinnatipartitie (nec serrata) oriuntur; non tantum ut in antecedentibus disticha, sed pinnella plurime brevissime pectinate circumeirca oriuntur, qua una glomerulum, plerumque conicum, densissimum constitunt, cujus inter fila spharospora nidulantur. Glomerulus sphresporarum pinnule sterili scrrate oppositus eradit. Favella codem modo sitir, pedicellate; phylla involucri subplana,

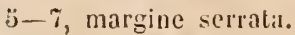

Hac species, rum antecedente plerumgue confusa, ab Agardhio et Lynbyeo jam distincta, sed ab ulroque cum l't. Asplenioide confusa, a Küitzingio dein iterum distincta, sed in opere recentissimo rursus cum Pt. plumosa conjuncta fuit. Characteres autem pracipuos, ill situ et forma fructificationis positos, non invenerat, nes milit clarum anne yrapsentem in duas disiserit (Pt. formosam et Pt. serratam). Harrey utramque speciem ronjunxisse mihi videtur, utpote locorum natalium multa arclica, quæ l't. plumose adscripsit, ad l't. serratam referenda sunt. Pt. serrata ad l't. asplenioidem arcte accedit; differt vero serraturis multo evidentioribus, cum rtate profmndioribus (nec obsoletis), pinnulis magis adproximatis et precipue fructuum pluribus notis.

̋. Pt. Hipyoldes (Ilarv. ap. Beech. Foy. p. 164) frondis compositopinnatre pinnis in rachide ancipite-alata opposilis ineonalibus, una indivisa foliiformi ovato-lanceolata acuminata integerrima, allera pimnatipantita, pinnellis foliiformibus cellulosis, splıerosporis ad apicem pinumle transformate circumcirca densissimis in glomerulum oblongm congeslis, farellis. .

l’t. Hypuoides IIarv. l. c. hüls. sp. p. 670!

P't. Asplenioides Ay. (quoad sp. llixhkeana!) clie!).

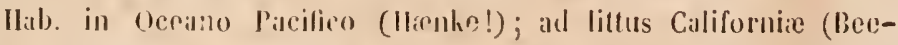

Frons decomposito-pimata saltim ̈̈pollicaris, et lineam fere lata, pulchre coccinea. I'innarum oppositarum una folium referens, altera pinua cst eodem modo pinnulatil. Folia ipsa alterna, lincam circiter longa, semilincam haud lata, ovato-lanceolata, obliqua, acuminata, juniora incurva 
fere falcata, omnia integerrima cellulosa; costa in exsiccato quandoquidem conspicua, nusquam nuda. Sphærosporarum fila ad superiorem marginem pimulæ inchoantia, mox circumcirca evoluta et glomerulum oblongum constituentia, simili modo ac in proximis spharosporas gerentia.

Harveyana descriptio ita bene in nostram speciem quadrat, ut de identitate utriusque planta nulla nobis restent dubia. Sux plantie attamen tribuit fulia lanceolata, quum in nostra potius ovato-lanceolata sunt.

6. PT. ASPLExioldes (Turn. IIist. tab. 62) frondis decompositopinnatæ pinnis in rachide ancipite alitil oppositis inæqualibus, una indivisa subinconspicue serrata, altera pinnatipartiti sxpe obsolefa, repetiti, pinnellis a basi latiore lanceolatis cellulosis, fructilus supra axillas secus marginem utrumque seriatis, sphxrosporis in glomerulum rotundatum congestis, favellis involucratis, involucri ramis pinnatisectis articulatis.

Fucus Asplenioides Turn. l. c. Esp. Fuc. lab. 147.

Ptilota Asplenioides Ag. Sp. Alg. I. p. 387. Syst. p. 193.

Rhodocallis Asplenioides Külz. sp. Alg. p. 671 .

Ilalb. in conchis etc. Oceani arctici ad ostia Lene!; in pacifico ad Kamtschatliam (Clramisso! Horner! Lüllie!)

Frons pedalis, lineam fere lata, decomposito-pinnata, pinnis revera oppositis, una nempe folio indiviso, altera ramo plus minus evoluto constitutis; ramo autem sxpe obsoleto, folia in rachide alterna et $2-3$ lineas distantia adparent. Folia aliquando 3lineas longa et fere lineam lata, in superiore parte lanceolata, basi altenuata, margine parum conspicue serrata, inferiora a hasi latiore lanceolato-attenuata, margine obsolelissime crenulato, senilia patentia, juvenilia incurva. Rami foliis oppositi sæpissime obsoleti; supra axillas vero proveniunt alii, 2--3 seriati, quorum infimus sæpe accrescit, nunc omnes transformantur et fructiferi evadunt. Ramelli fructiferi vero etiam interiore margine foliorum evolvuntur, unde fructus supra axillas utroque sinuum margine seriati conspiciuntur. Glomeruli sphærosporarum fere spherici, tilis in pinnuli circumcirca evolutis, articulatis monosiphoniis incurvis pectinatim pinnatis constituti; sphærosporis ex terminalibus articulis filorum transformalis. Favellie eodem modo sitæe, intra involucrum plures; rami involucri pinnatitidi, rachide cellulosa, pinnis articulatis monosiphoniis. Chartie non bene adhæret. Color in speciminibus nostris sæpe virescens, nunc pulchre carneo-purpureus.

7. Pт. DExs. (Ag. Sp. Alg. I. p. 387) frondis decomposito-pinnate pinnis in rachide compressa-ancipite oppositis inxupualibus, una indivisa lanceolato-falcata extrorsum serratia, altera composita sipe abbreviata repetita, pinnellis incurvis extrorsum divarica- 
te pectinatis, faciniis acutis subserratis, spharosporis in glomerulos oblongos, secus marginem interiorem pinnellarum seriatos, dispositis, fivellis. .

Pt. Jensa Ag. l. c. Syst. p. 193 !

llab. in Oceano pacifico [?] (II). Igardh!)

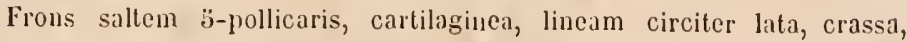
compressa, anceps sed vix alata dicendil, tota fere cellulis magnis circa axem centralem dispositis constituta. Pinnæ revera opposite videntur, sed inæquales; una indivisa foliiformis, lanceolato-falcata, extrorsum profunde serrata fere pinnatipartita; apice laciniisque a basi latiore acuninatis, adultioribus subserratis. Altera pinna est composita, pinnulis folia indivisa xmulantibus, at angustioribus et magis incurris, laciniis profundiorihus plerumque sulserratis, non in idem planum extensis, sed alternis disergentibus. Pinnæ lıæ conıpositæ nunc elongate, sæpius brevissimæ et vix lineam superantes, repetita divisione quasi multifidx, in planta adultiori plurimo seriatx, $2-3$ singulis foliis respondentes: hac pinnarum compositarum multiplicatione frondis margines densissime fimbriatæ evadunt. Sphærosporæ transformatione pinnellarum, qux interiore latere pinnularum incurvatarum seriate sunt, formantur; sunt plurima in glomerulos oblongos congestæ.

Ob crassam et cartilagineam frondem hæc species habitu a cæteris sat diversa videtur, sed ad eundem typum evidenter formata. Quoad structuram magis cum Pt. plumosa quam cum Pt. Asplenioide convenit.

Locus natalis, qui huic speciei in Sp. Alg. Agardhi adscribitur, certe falsus; mare pacificum hahitare suspicor.

7a. Pr. pectisita (Harv. ap. Bcech. Voy. p. 164) "jugamento compresso filiformi sub-bipinnato, pinnis pinnulisque alternis, ramulis extremis (nascentibus pectiniformibus) distichis divaricato-multifidis.

Ilah. ad oras Californix.

Ramulo minuto pectiniformi, deorsum inciso-serrato, qui pinnula oppositus est, hæc species dignoscitur. In frondibus senilibus, multiplicatione hujus ramilicationis, ramuli confuse multitidi. Pinnula, seu rami secundarii, similibus ramulis alternis obsitie: et spatia inter has ramulis fructiferis multifilis, sphicrosporas dense glomeratas gerentibus, occupantur." Descr. Auct transscripsi.

Quoad descriptionem hace evidenter l't. densa proxima, et nullus, quo distinguatur, hodie adest character. Lx fragmento plantæa, qux ad Harveyanam speciem pertinere suspicor, et ex eodem loco natali provenit, laciniis quam in I't. densa obtusiorihus instructa videtur. Utrum vero hic character, distinctam speciem, an tantum rarietatem indicet, in meslio relinquere cogor. 


\section{Pimnis regulariter alternis conformibus.}

8. Pt. Pappeard (J. Ag. mscr.) frondis decomposite pinnate pinnis in rachide filiformi-compressa alternis, pinnulis jurenilibns simplicibus, adultis pinnatis demun cellulosis, pimnellis simplici serie articulorum constantibus, articulis diametro longioribus, spharosporis in pinnula abbreviata subcorymbosa aggregatis, favellis. . .

Pt. Pappeana J. Ag. mscr. in IIb. Binder.

Euptilota Pappeana Kü̈z. sp. p. 6ri!!

Ilab. ad Cap. b. Spei (Pappe! Hh). Areschong! et Crouan!)

Frons 3-4pollicaris, pennam passerinam fere crassa, pinnulis capillaribus; habitu fere Sphacelariam plumosam referens. Pinna juvenilis et terminalis simplex, simplicique serie articulorum constans, patens incurva, plus minus obtusa; ut increscit frons, pinnæ basi cellulosæ evadunt et similibus pinnulis pinnatæ; rachis itaque pinnarum basi cellulosa, apice monosiphonia articulata, pinnulis alternis infra genicula esredientibus. Pinne ulterius increscentes inferne denudatre, pinnulis aliis delapsis, paucis in ramos evolutis. Articuli in pinnula singula sipe $12-4 \%$, diametro paulo longiores. Sphærosporæ in pinnula abbreviata fere corymbosa evolvuntur, in pinnellis secundatis alternisque laterales et axillares, ramellis transformatis ortæ, triangule divisæ.

9. Pт. articulata (J. Ag. Symb. p. 36) frondis decomposito-pinnate pinnis in rachide ancipite alternis, pinnulis compositis inferne cellulosis, pinnellis simplici serie articulorum constantibus, articulis diametrum vix requantibus, fructibus. . .

P't. articulati J. Ag. l. c. Ilarv. Tasm. n. 83. Kütz. sp. p. 670!

Pt asplenioides Auct. (quoad spec. nov. Hollandia)?

IIab. ad oras Nove Ilollandiæe (Labillardiere!) ad Tasmaniam (GuIn).

8a. Pт. setigena (Ilarv. mser.) "jugamento primario angustissimo, secundariis setaceis pimnatis, pimis alternis Callithamnoidibus ecorticatis, simplicibus vel alterne pinnulatis elongatis gracilibus, erectopatentibus, superioribus concretis, omnibus apice obtusis; articulis diametro sesquilongiorilsus."

Rhodocallis setigera Kütz. sp. $p .670$.

Hab. ad Cap. b. Spei (Ilarvey.)

Species mili ignota. A Pt. Pappeana distincta videtur, gnum liitzingius, qui utramque vidit, unam ad Euptilotam, alteran ad Rhodocallen referat. 
Frons ut in cateris decomposita, rachide ancipite, pinnis alternis a margine egredientibus; sed jugamenta quoque pinnarum principalium cellulis magnis centralibus subrectangularibus perlucentibus quasi articulita, licet cortice obducta. Pinnellar breves obtusiuscula monosiphonia, articulis diametro brevioribus rel subxqualibus. Pimulac apice articulatre inferne mox corticate, inter pinnellas approximatas flexuosic. Fructus in nostris hand bene evoluti.

Sub lente cellula magna centralis, literalesqne utrinque duo (ita : 5 !) planum centrale occupant, filis invicem separate; versus superficiem utriusque pagine, cellula pauca sparsic olveniunt, filis maximum partem frondis internæ occupantibus.

\section{Pt. Coralloldea (J. Ag. Symb. I. p. 3̈̈) frondis decomposito-} pinnatie pinnis in rachide ancipite alternis, pinnellis polysiphonis corticatis lineari-attenualis incurvis dentatis, spherosporis ad dentes pinnularum in pimnula abbreviata monosiplonia pimatim subcorymbosa plurimis, favellis. . .

Pt. coralloidea J. Ag. l. c. Sond. Alg. Preiss p. 22!

Euptilota? coralloidea hült. Sp. Alg. p. 672!

Hab. ad oras Novie Hollandix (Hb. Greville!); ad littus occidentale (Preiss!).

Frons 3-4pollicaris, coccineo-rubra vel purpurascens, radice scutulata conchis adhærens. Jugamentum $1 / 2-3 / 4$ linex latum, inferne parum compressum, sed marginibus eridentibus anceps, sectione transiersali cellulas 3 magnas, medium planum occupantes, sparsasque paucas infra paginam utramq̨ue, filis plurimis invicem scjunctas, ipsasque ejusmodi filis demum impletas, offerente. Pinnæ pinnulis majoribus, et minoribns dentibusque alternantibus decompositæ. P'innulæ ultimæ 1-2lineas longx, lineari-attenuate, plus minus incurve, præcipue extrorsum denticulata. In planta fructifera ex dentibus emittuntur fila articulata monosiphonea, densissime pindatim decomposita, pinnis alternis, articulis diametro xqualibus, terminalibus in sphærosporas mutatis.

Frons exsiccata, lucem versus adspecta, habitum enndem articulalum, quem in antecedente jam notavimus, offert. Dum rero cellulie centrales in priori fere tantum conspiciuntur, cellnli 3 in presenti adparent, unde frons potius cellulosa, quam articulata, dicitur. Pinns alterna, sxpe ita adproximate ut subopposite adparent. Substantia cartilaginea.

10a. Ru. lisegaxs (hütz. sp. p. 670) "ramosa, ramis patentiluss; jugamento gracili angustissino sulstoruloso, pimmlis alternis elongatis, ulta setaceis, ubique corticatis, rigidis patentibus approximatis acutis subincurvis, fructibus terminalibus, cystocarpiis involucratis." llab. ad noram Hollandiam (Ilb. Binder). 
11. Pt. Fonuosissim. (Mont. Prodr. Ph. ant. p. 8) frondis decomposito-pinnat pinnis in rachide ancipite alternis, pinnulis pinnatifidis, pinnellis corticatis a basi latiore attenuatis serratis, spherosporis marginalibus singulis, pedicello monosiphonio suffultis, firvellis in pinnula sessilibus, involucri foliis 4 pinnatifidis.

Pt. formosissima Mont. I. c. Voy. au Pole Sud Crypt. p. 97 tab. 9 fig. 3! llook. et Ilarv. in Crypt. antarct. p. 78 tab. 77 !

Euptilota formosissima külz. sp. p. 671!

Hab. in Oceano australi ad insulas Auckland (D'Urville, Hooker elc.)

"Radix callus exiguts. Frondes aggregatie 6-10unc. longx, 4--6latæ, flabelliformes. Caulis hasi teres, nox plano-compressus, linearis vel utrinque subattenuatus, $1 / 2-1 \frac{1}{2}$ lin. latus, distiche ramosissimus. Pinnx $1 / 4$ unc. longæ, alternæ pinnatæ v. bipinnate; pinnulis brevibus, alternis, patentibus, serratis v. pectinatis, apice subacutis. Favellie sessiles, involucro quadrifoliato pectinato cinctio, spharica, sporis minutis angulatis farctæ. Sphærosporæ marginales, pedicellatæ, glohosæ, demum 4-partitæ. Color amoene puniceus. Substantia cartilaginea, firma. Chartæ laxe adhæret."

"Caulis non stricte articulatus dicendus, sed costa evidenti articulata percursus." Hook. el llarv. l. c.

Vla. Thandogarpes Ilarv, in Ilook. Icon. Mant. Yol. III. tab. 662. Hook. et llarv. Alg. Tasm. p. 12. Carpothamuion Kü̈z. sp. p. 668.

"Phycoma tiliforme ramosum, ex axi centrali articulato stratis duobus cincto compositum. Stratum pericentrale longitudinaliter nilbrosum, corticale parenchymaticum, cellulis minorilus rotundato-angulatis formatum. llami obsessi ramellis fruticulosis fructiferis ramosis callithamnoideis, unicellularibus. Tetrachocarpia singularia lateralia."

Genus mihi plane ignotum; quoad fructus Heterocladiæ analogum a Ilarvey primum judicatum, dein ab ipso Ceramieis relatum.

1. Tn. Guxiaxus (Ilarv. in Ilook. Icon. tab. 662) caule $3-4$ " longo, 1/2"' crasso, irregulariter ramusissimo, ramis superiorilus creberrimis sul)fastigiatis erecto-patentilus, terminalibus ramulos fructiferos lise sparsos gerentibus; ramulis penicilliformibus basi solidis, ramellis unicellularibus divaricatim ramulosis; ramellulis acutis, breviter articulatis, articulis diametro xqualibus vel duplo longioribus.

Carpothamnion Gunnianum hülz. sp. p. 668.

Hab, ad Van-Diemens-Land.

2. Tu? LAurexcis (Hook. et Harv. Alg. Tasm. p. 12) purpureo-coccineus; caule cartilagineo-filiformi hasi cylindrico apicem versus suljcompresso ramosissimo; ramis alternis erecto-patentilus distichis, iterum divisis, ranulis lanceolatis. 
VII? Dasypillua Sond. in Mohl. et Schl. Bot. Zeit. 1813 p. 53. Alg. Preiss. p. 22. Kïll. sp. p. 673.

Frons filiformis distiche pinnata decomposita diorgana, axi continuo, et filis articulatis invicem liberis constans. Axis tubo centrali articulato, siphonibus ceutralem circumdantibus phuribus filisque infra genicula tulhi centralis verticillatim egredientibus oblique excurrentilus dense corticato, contestus; filat rerticillatia extra axem libera, nullo ordine dispositi, alterne pinnatis. Spharosporce ex articulis terminalibus filorum formatie, sphærice triangule dirisæ. Facella. . .

Frondis teretiusculæ, disticlie pinnate decomposite, pars infima nuda, superior masima filis densis tomentosis. Adsunt itaque axis continums ef fila articulatil, quæe tomentum externum et forsan demum decidum efficiunt. Axis constituitur: 1:0 tubo centrali articulato, articulis diametro triplo longioribus, ad genicula contractis, enduchromate fuscescente coloratis; 2:0 siplonibus (seu cellulis) longitudine articulus tubi centralis acinantibus, at amplioribu;, lỵalinis, plurimis in orbem circal tubum centralem dispositis. 3:0 filis a tubo centrali infra genicula verticillitim egredientibus, initio lorizontalibus, mox obliquis et sublongitudinalibus, infra periphertian coloratis ramosis et demum in fita libera caterna sensim abentibus. Fila esterna nullo ordine cogredientia, at densissima, in stratum proprium hand coalescentia, sed invicem libera, hori-

Carpothamnion? Laurencia hü̈z. sp. p. 669.

Hab. ad oras Tasmanix (Gunn.)

Genere dubia, fructu adhuc ignoto. Structura caulis ad Thamnocarpum valde accedit. - Ita auctores.

3. Tir. Pricota (Ilook. et Harv. Aly. Tasm. p. 14) fronde plano-compressia lineari costato vage et pirnatim composito, disticho, ramis erectis ancipitibus pinnatis bipinnatisve, pinnulis basi vix angustatis erectis falcato-incurvis sepe secundis; glandulis marginalibus; cystocarjuis pedicellatis minutis involucratis, involucri ramulis simplicibus incurvis.

Carpothamnion? Ptilota hülz.sp.p. 669.

llab. ad Port Arthur Tasmania (leannerett et Lyall).

Habitu Ptilotam et ante alias Pt. corallojdean haec assimilat; structura rero caulis diversa. In fructu differentia fere nullia adest. - Ita Auctores. 
\%ontilia subineura fere distiche pinnala et latus planum asi advertentia. Spharosporæe ex articulis horum transmutatis formantur; articulo pinnarum terminali in spharosporam subspharican triangulo disisam abeante. Favellie a me nondum observate; (sec. Sonder): "Farellidia 10-20 in apice pinmularmn frondis externa et filis densissimis involuta, non frondi immersa, spherica, granula minutissina subangulati includentia, cum spherosporis semper in una eademque pinnuli." Sed si organil, qua vidi, sunt eatem ac quix a Sondero observata sunt, nil nisi sphærosporas, quarum nucleum decompositione quadam in granula collapsun suspicor, existimandas puto.

1. D. Preissil (Sond. l. c.)! Alg. Pıeiss. p. 22! Kü̈z. sp. p. 673! IIab. ad littus occidentile Nove Ilollandie (Preiss!)

Radis scutulata. Frondes 3-äpollicares, fuscescentes, tomento rubente obductx. Rami primarii diametro semilinem, teretes, subhorizontaliter patentes, majores 1-2pollicares compositi, minoresque simpliciusculi sine ordine mixti. Pinnulæ alternæ sesquilineam longæ, teretes ex basi latiore sensim attenuat $x$, acuminate, leviter incurre. Tomentum frondis filis constituitur, quorum articuli diametro duplo longiores sunt.

VIII. Croudania J. Ag. Alg. med. p. 83. Endl. Gen. Plant. Suppl. III. p. 36. Chauv. Rech. p. 50. Harv. Phyc. Brit. Iab. 106. Nesogloie sp. Ag. et Auct. Griffitlsia sp. Ag. Spec. Alg. Callithamnii sp. Kütz.

Frons tereliuscula gelatinosa, quoguoversum ramosa, asi articulato monosiphonio nudo ramisque verticillatis dichotomo-fastigialts invicem liberis, stratum subcontinum periphericum initio formantilus, demum distantilus, constituta. Facella pone apicem ramulorum s!bsolitaria, ad basem filorun verticillatorum afficie iisque obtectie, iul'il perideruı hyalinum gemmidia rolundata plırima foventes. Spharospore all basem filormm verticillatorum affixe, iisque subincluse, spherica triangule aut transversiu divise (llarv. Phyc. Brit. tab. CVI.)

Frondes teretes vige ramosissince, eximie gelatinose, strilto asili et peripherico constitutie. Ixis articulatus monosiphonius, articulis sulnellucidis, infra genicula ramellis 3 pluribusve verticillatis obsitus. Verticilli in ramis junioribus subconfluentes et strittum fere continum peripherieum formantes; in adultis, ut pro- 
Iongantur articuli asis, distantes, frondem nodosim reddentes. Fila verticillormm moniliformitor articulata, ad articulum quemque divisi, justil basem pinnatil, superne dichotoma, fastigiatis. Fructus utriusque generis ad basem verlicillorum siti. Rami favellas gerentes infra apicem attenualum incpassali, firrellas singulas aut geminas adproximatas intra ramcellos verticillatos undiyne ambientes gerentes. Favellie intra mombranam gediltinosim liyalinam gemmidia rotundata lixiora, mullo ordine ut videfur disposila, forentes. Splaxrospore pro magnitudine ipsius plante magne, ad articulos infimos filorum verticillatormm affixx, ramisque ambientibus horum subincluse, intra perisporium laxius triangule qnadridivise, aut transversali divisione bipartitn.

Si ipse tubus axis dissecatur, membrana illius crassa et quasi duplex, interstitio cclluloso, adparet. Mihi antem exsiccatam observanti, hæe structula non ita perspicua adparnit, ut de observatione certus sim.

Genus fuoad plurimos claracteres ad Callitlramnia verticillita valde accedens, ramollis verticillatis densioribus, in planta juvenili fere stratum periplericum continum formantibus, (in senili obsoletis, axem nodosun nudum linguentibus), precipue distinctum. Al, loc vero claractere pendent alii: frons eximic gelatinosa ef fructus inclusi. Ab altera parte Dudresnayam tangit, fure rero splserosporis, aliis claracteribus posllatbitis, facillime distinguitur.

Genus a D:na Griffitls primum indicatum, in Nogis Ned. a me institutum, plurimi lodiemi algologi adoptarunt, excepto tantum Kü̈tzinģio, qui plantam tỵpicam Callitlamnio adnumerat.

1. Cli. atrexuata (Bonnem. mscr.) froncie sursum attenualu, splaterosporis splıxicis triangule divisis, in ramo verticillorum singnlis.

Batrachospermum atlenuatum Bonnem. in Ilerb. Ay!

Cr. attenuata J. Ag. Alg. med. p. 83. Harv. Phyc. Brit. tab. 106! Crousu. in Ann. Sc. Nat. 1848. 10 p. 37ij. Pl. 12 fig. 24-2ij!

Mesogloia attemata Ag. Syst. p. 84 !

Mesogloia? moniliformis Gri/f. in Harv. man. p. 49.

Griffithsia nodulosa $\mathrm{Ag}$. Sp. II. $p .136$ !

Callithamnion nodulosum häts. Pliyc. p. 373. sp. p. 6.31!

Itah. in mari adriatico et mediteraneo, aliis alegis parasitica; in Oceano attantico ad littora Gallie (Bonnemaison! Croutn!) et Anglia inferiora (D:na Wyatt!). 
Frons 1-2pollicaris, setam crassitie plerumque superans, pennam jasserinam vix attingens, ramis patentibus quoquoversum egredientibus decompositis. Pars inferior frondis fere in modum Ceramii diaphani hyalino et sordide rubro variegata et nodosa, verticillis ad nodos rubentes obsoletis distantihus. Apices ramorum verticillis adproximatis subcontinui. Articuli tum in axi, tum in verticillis diametro sesqui-duplo longiores. Color purpurascens, plerumque sordidus.

Triplici nomine hæc planta ut nova descripta fuit, tribusque generibus diversis adnumerata. In Symb. meis (pag. 47) identitalem omnium indicans, nomen primitus datum, licet forsan minus aptum, restituere coactus fui.

2. Cr. Bispori (Crouan. in Ann. Sc. Nat. 1848. 10. pag. 374) fronde subcylindriea, spherosporis ovalihus transversa divisione sporas geminas foventibus, in ramo verticillorum binis.

Cr. bispora Crouan l. c. lab. 12 fig. 21-23!!

Ilab. in Oceano atlantico prope Brest (Crouan!)

Species pracedenti ita proxima ut, sphærosporis exceptis, nullam videam inter utramque differentiam. Sphærosporæ vero forma et divisione diversa, insignes offerunt distinctionis notas. Sporæ geminæ intra splæærosporam tantum evolvuntur.

Forsan hoc loco monendum, ne forma crispa Callith. plumulæe pro hac specie determinetur.

\section{Dudresnaya Bonnem. in Journ. Phys. XCIV. 180. Crouan} in Ann. Sc. Nat. III. 98. J. Ag. Alg. med. p. 84. Decaisn. Class. p. 63. tab. 16 fig. 8. Endl. Gen. Plant. Suppl. III. p. 36. Nesogloire sp. Agardh. Callithamnii sp. Kütz. Phycol. Nemalion sp. Kü̈z. Sp. Alg.

Frons teretiuscula geliatinosi quoquoversum ramosa; axi filisque investientibus stratum subcontinuum periphericum formantibus constituta; axis tubo articulato monosiphonio, demum celluloso lilisune longitndinalibus cincro, contextus; fila peripheriea a tubo axili verticillatim egredientia, demum nullo ordine densissima tri-dichotoma fastigiata invicem libera. Favella ramellis obtecte, minutie, intra membranam hyalinam gemmidia rotundatoangulata plurima foventes. Spharospora in filis periphericis terminales oblonge, zonatim divisie.

Frondes eximic grlatiosie, tretes, quoquoversum vage lamoste, decomposite, ramis tenuioribus sensim attenuatis. Axis frondem percurrens ab origine tubo articulato monosiphonio subpellu- 
cido constit; serius tubus iste fit cellulosus, cellulis ad genicula pracipue evidentibus. I tubo axili frondis jurenilis, infra geniculi, fila egrediuntur \& (aut forsan plura) verticillata, lıorizontaliter piatentissima, articulata, ad articulum quodjue ramosa, ramis inferme oppositis, superne dichotomis, eximie fastigiata, arem verticillis densis at regularibus cingentia. Lis his antem filis periphericis rami nonnulli cursu longiludiuli excurennt, tubum primarium articulatum investiunt, et lune strato densiori cingunt. libla hec longitudinalia sunt ipsis periphericis fiis paulo firmiora, alias conformia, endochromate colorato et tubo tenuiori a cellulis tubi primarii facilins distincta; laec fila longitudinalia demum nova fila peripherica lorizontalia emittunt, quæ frondem strato fere continuo peripherico cingunt. Frons itaque jurenilis rerticillis regularibus at proximis obsita, senilis rerticillis confluentibus quasi continua. Fila peripherica in omni statu libera, nullogue muco colıibita.

Favelle filis periphericis, supra basem, adfisæ, eorumque filsciculis obtecte, ita ut intra peripheriam frondis nidulantes conspiciuntur, nucleo plerumque miuori rutundato, constitute, intra membranam liyalinam gelatinosam gemmidia rotundata nullo ordine dispositil, foventes. Splıæosporæ in filis periphericis ex articulo terminali incrassato et transmutato formate, oblongo-splıroideæ, nucleo intra perisporimm zonatim quadripartito.

Genus a Bomnemaisonio quondam instifutum, postea neglectum fuit, donec Cel:i Croman genus restituendum urserunt, analỵsi dałta structura diferentias a crteris Mesogloiæ speciebus indicante. In Algis mediterr. dein characteres generis rite exposui, splıerosporarun tamen divisione tunc nondım milıi perspicua. Hac quidem a Decaisneo illustrata, generis characteres legitimos exposuit Endlicher. Kützing, qui in Plıycologia specism typicam generis Callithamnio adnumeraverat, in Speciebus Algarmm lıanc ad Nemalion repulsit, neglecta structuræ summa differentia, ex analysibus in Engl. Bot. a Crouan et Decaisne datis jam satis perspicua. Licet unicuique rem accuratius examinanti cellule interiores fere inanes, filis circumdantibus multiplo crassiores, satis conspicure sint, et tubus primatrus articulatus in ramis ultimis facillime quiden observetur, hxe oinnia tamen denegat Kützing, milhique vitio rettit (Bot. Zeit. 181.7 p. 16:3) quod structuram rite exposmerim el genus reformatum adoptaverim. Sin vero structure differentiam nullam invenerat kützing, adluc mirandum quod nee cystocarpiorum in diversis Nemalionis sui speciebus differentias, nec spherosporarum divisionem 
a Decaisneo jam expositam meminerit. Mirum sane quantum de planta tamdiu cognita halncinatus est celebris Germanie Phycologus!

1. D. perpurifera (J. Ag. Alg. med. p. 85) fronde pyramidata densissime ramosa, filis periphericis ima basi trichotomis, superno dichotomis moniliformibus, articulis ellipsoideis diametro duplo longiorilus.

Dudresnaya purpurifera $J$. Ag. l. $c$.

Nemalion purpuriferum Külz. sp. $p$. т13.

Hab, ad lapides sinum olscuriorum, in mari mediterraneo ad littora Italixe et Gallix (Ipse!)

Frons circiter 3-pollicaris, pennam corvinam fere crassitie æquans, decomposito-ramosissima, ramis abbreviatis ita densis ut difficillime separentur et praparatione fere confluant. Rami quoquoversum egredientes, tenuiores at cæterum conformes, inferiores longiores, unde frons ambitu pyramidata. Articuli tubi axilis sunt cylindracei diametro sesqui vix duplo longiores. Fila peripherica eximie fastigiata, inferne trichotoma, a medio et superne dichotoma, ad genicula contracta, articulis ellipsoideis diametro vix duplo longioribus, periphericis subrotundis. Favellæ generis. Sphærosporas non vidi. Color recentis obscure purpureus; in arqua dulci præparata chartam, cui arctissime adhæret, margine coccineo late tingit.

A sequente specie differt articulis filorum verticillatorum ellipsoideis, diametro vix duplo longioribus. Hunc characterem in opere supra citato rite exposui; Kützing speciei nostræ dirersitatem in dubium rocans, characteris præcipui nullam omnino fecit mentionem. Specimina utriusque plantæe iterum comparavi et characterem constantem inveni.

2. D. coccises (Ag. syst. p. 51) fronde pyramidata deuse ramosi, filis periphericis inferne opposite ramosis, superne dichotomis, articnlis ẹlindraceis diametro 3-4plo longioribus. 962 !

Mesogtoia coccinea Ag. l. c! IIUrv. Man. p. 48! Dub. Bol. Gall. p.

UTua coccinea Poir [?] sec. Ag. l. c .

Dudr. coccinea Bonnem. Journ. Phys. 9. p. 180 (sec. Eindl.)

Nemalion coccineum liülz. sp. p. 713!

Rirularia verticillata Engt. Bot. lab. 2466 !!

Cullithamnion verticillatun Kü̈z. Phyc. p. 373.

1)udresuaji formosa bonnem! (tide spec.!)

Batrachosperma rivularioides Bory (sec. Dub)

lixs. Hyalt Danm. n. 148. 
Hlab. in Oceano aflantico isl oras meridionales Anglix! et Gallix!

Frons $4-8$ pollicaris, crassitie pennam corvinam xquans, deuse ramosa, ramis plerumque satis distantilus conformilus, sxpe ambitu pyramidata. Articuli lubi axilis cylindracei, diametro 3-4plo longiores. Fila peripherica inferne ramis patentioribus oppositis, superne erectiusculis dicholomis dirisa, ad genicula rix contracta; articuli cylindracei tenues, diametro 3-4plo longiores. Favellas et spharosporas generis visli. Color coccineus; chartæarctissime alharet.

Duas species in Syst. Alg. Agardhi nostra complectitur: junior verticillata Mes. coccineam; adulta rqualis N. fruticulosam sistit.

\section{Species inquirenda:}

3. D. Boniva (Hont. Fl. Alg. p. 43) purpurascens, fronde ramosissima laxe flexuosa; ramis obsolete dichotomis ramulis spillsis densissime obtectis; ramulis divisis articulatis, articulis alternatim diaphunis et coloralis.

Cladostephus dubius Bory Morée n. 1495 lab. 37 bis. fig. 6 !

Ililb. in mari mediterraneo ad oras Grecix.

Descriptio, a Bory data, plantam hujus generis forsan indicat; vix tamen ex hac descriptione elucet, quibus notis a prioribus distinguatur.

\section{X? Illanowia Sond. in Mohl. et Schl. Bot. Zeil. 195's p. 52.} Alg. Preiss. p. 23. Kütz. Sp. p. 672.

Frons cylindrica dichotoma, filis articulatis monosiphonis reticulatim line inde connatis, extrorsum fila conformia libera patentia emittentibus, contexta. Fructus. .

Frons tota composita est a filis 4-S centralibus elongatis, intor se line inde connatis, articulatis. Quæ fila longitudinaliter estrorsum emittunt ramos numerosos abbreviatos anastomosantes, apice summo libero horizontaliter patentes. Fila centralia asen referentia suberassiora, articulis diametro 3 plo-4plove longioribus, lateralia articulis dianctro duplo longiorilus, articulis ultimis brevissimis obtusis.

Quoad adspectum filorum Genus videtur Griffithsie aut Wrangelix proximum, Italydictyo inter lihodomeleas analogum, si non affume. Fructu ignoto, affinitas dubia manet. 
IIab. in caulibus Caulinie Intaretice ad littus occidentale Noræ Ilollandiæ (Preiss!)

Frondes plures agyregatx, digitales, cylindricm, lineam crassæ, basi simplices, apice vel medio subramosie, ramis paucis dichotomis fastıgiatis, frondi primarix conformibus et vix tenuioribus. Subspongiosia, colore roseo-rubro.

XI? Hatoplegia Mont. in Ann. Sc. Nat. 1842. Cent. III, p. 28. Endl. Gen. Pl. Suppl. III. p. 36. Sond. Alg. Preiss. p. 24. Külz. sp. p. 672. Rilodoplesia Ilarv. in Ilook. Icon. XIII. lab. 613 .

Frons foliacea spongiosa, filis articulatis monosiploniis contexta. Fila centrilia inferne approximata parallela, superne subflabellatim divergentia anastomosibus juncta, ramos, tomentum utriusque pagina formantes, dense emittentia. Favella in pustulis supra paginam hemispluerice prominentibus plures, nude at filis ambientilus tectx, placentie adfixx, intra membranam lyalinam gemmidia a placentula radiantia rotundato-angulata plurima forentes. Spharospora in tilis periphericis terminales, splıæricæ triangule divisæ (sec. Sonder).

Frondes planæ foliacex, flabellato-spathulate demumque pinnato-lobatie, spongioso reticulo conflate. Fila reticulum constifuentia, nonuulla lonģitudinalia quasi costam costulasque formantia, ex quibus progredimntur periplserica; illa inferne parallela et adproximata, superue flabellatim divergentii, frondi ejusfue lobis formam tribuentia; læc ad utramque paginam marghinesque subltorizontaliter egredientia, abbreviata; costis proxima anistomosilus juncta, peripherica libera incurva. Fila utriusque generis articulata monosiphoniil.

Favella in verrucis supra paginam planam hemisphaxice prominentibus evolutie; vertucx structurim frondis offerentes, filis periplericis incurvis quasi involucrum formantibus, interiorilus plitcentam in ramos plures divisam constituentibus; rami placenta singuli cellulis dichotomo-fastigiatis compositi, nucleum integrum subreniforme gerentes. Nuclei intra gelatinam ant membranam evidentem gemmidia plurima angulitu-rotumdatia, a cellulis placentie radiantia forent; unclei nonnulli fertiles maximi, gemmidia coccineo-colorata gerunt, alii (abortientes aut juveniles) minuti vix co- 
Iorati placentulis conformilus affixi, intra membranam minutissima granula conlinent. Splicrosporas, a Sondero descriptas, ipse non vidi.

Fructus capsularis structura a Ceramieis aliquantulum ahbudit, nec Gigartineis convenit. Iloc respectu ad Fanclseam et Ejymeniam prosime accedere mili videtur.

1. II. Duperreti (Hont. Cell. ex. Cent. HI. n:o 69) fronde flahellato-spathulata a margine fimbriato lobulos conformes emittente, lilis periphericis abbreviatis, articulis diametro rqualibns.

H. Duperreyi Mont. l. c. lab. 7 fig. 1!!! Kü̈ъ. sp. p. 672!

Ilab. caulibus Amansiæ multifide adnuta, ad littora Martinice (Duperey!); ad oras Africe australes et austro-occidentales (sec. Sonder).

"Frondes deorsum stipites Florideæ, cui parasitat, incruslantes, dein plano-expansx, primo flabellate, landem plus minus elongato-spathulatr, apice sentiorbiculares, undulata, fibris eas constituentibus solutis (hlueris) tenuissime fimbriolatæ, in utrarque pagina tomento denso spongiosoque vestitæ, ad speciem, præsertim sub lente granulosæ, ex ambitu undulato frondiculas concolores sibique conformes quibus ramosiuscula aut tantum divisæ fiunt, promentes. Frondes adultæ sesqui-biunciales, tres lineas latæ. Color rubro-sanguineus ad rubricosum vergens. Chartæ non adhæret." Ita Monl. l. c.

2. II. Preissil (Harv. in Hook. Icon. XIII. lab. 613) froude pinuato-lobata composita, pinnarum lobis sulsecmndatis oblongis, filis periphericis elongatis, articulis diametro sesfunilongioribus.

Rhodoplexia Preissii IIarv. l. $c$.

HIaloplegma Preissii Sond. Alg. Preiss. p. 24!! Kül. sp. p. 672!

Hab, ad caulem Canlinix? antarclice in litore occidentali Nova Ilollandiæ. (Preiss!).

1a. II. Mrricaxicy (lï̈l. ap. Mohl. Bol. Zeit. 1847 p. 22) phycomate rigidiori flabellatim subreniformi crassiori; trichomatibus rigidioribus.

II. africanum hïlz. l. c. Sp. p. 692 !

Zonaria rosea Suhr.

Hab. ad oras Africe australis. (IIb. Binder).

Rigiditate et substantia crassiori reticuli frondis, quod a substantia et crassitie ipsarum cellularum pendet, distinguitur; articuli fuoque quam in II. Duperreyi breviores. Ita hülz. $l$. $c$. 
Radix scutulata. Frons 3- ̈ppollicaris, basi angustior, in medio 3-4lin. Iata, bi-tri-pinnatifida. Pinne semi-pinnatifida, uno nempe margine subintegra et incurva, altero in lobos conformes plures diriso. Lobi oblongi, obtusi, sinnati. Fila peripherica sunt incurva, articulis circiter 10 constantia, attenuala aut obtusa, articulis diametro sesquilongioribus. Fructus Generi adscriptos in lıac observari.

XII? Pthlocladia Sond. in Mohl. et Schl. Bot. Zeit. 184:3 p. 32. Alg. Preiss. p. 23. Külz. sp. p. 67 \%.

Frons compressa pinnalim decomposita spongiosa, coatesta filis articulatis di-poljchotomis anastomosantibus, a tubo centrali atticulato infra genicula egredientibus, teminalibus fastigiatis stratum externum frondis constinentibus. Fructus. . .

Frons ex tercti compressa videtur et distiche pinnata, pinnis majoribus compositis minoribusque simplicibus, a basi latiore attenuatis, mistis, roseo-sanguinea spongiosa, exsiccatione friogillima. Filım crassmm arliculatum, articulis diametro 3 plo longioribus, caulem ramosque percurrens, axem frondis constituit; hoc ad quodque geniculum obsessum lilis multo tenuioribus horizontalibus articulatis, quie stratum periphericum frondis efliciunt. Fila interiora strati peripherici longe articulata intricata polychotoma et anastomosibus juncta; exteriora breve articulata submoniliformia dichotoma et fistigiati.

Genus, fructu ignoto, quoad affinitatem dubimm, Ceramicis a Sundero adscriptum, cui quoque loco forsan jure retineatur, nisi ad Liagoram propius accedere, fructificatio cognita tandem doceret.

Xlla? Spoxgotnichex hilz. Bol. Zeil. 1847 p. 36. Sp. Alg. p. 674.

"Phycoma roseum spongiosum compressum pectinato-pinnatum e axi centrali crasso articulato ranisque ex geniculis axis ortis constitutum; fila peripherica horizontalia densa abbreviata dichotoma apice subflabellata, intermedia longiora inter se anastomosantia hyalina. Fructus ignoti.

1. Sр. риснотомим (hïls. l. c.) plycomate tereti rigido crebre dichotomo tomentoso-villoso; ramis divaricatis flexuosis, superioribus apicem versus attenuatis obtusis. Crassities penna anserinic, ramorum superiorum penna columbina.

llab. ad Vera Cruz. (IIl). Binder).

Milıi ex descriptione allata tantun cognita. An cum Dictyuro occidentali $J$. Ag. identica sit, dubito. 
1. P'т. P'ticuns Sond. in Mohl. et Schl. Bot. Zeit. 18403 p. 52. Alg. Preiss. p. 23. Küls. sp. p. 674 .

Hish. ad rupes et conchas in littore occideatali Nuve Hollanlandix (Preiss!)

Radix scutata. Frons ambitu triangularis, 3-4pollicaris, ima basi parum angustata, lineam circiter lata, ramis seu pinnis inferiorihus subhorizontaliter patentibus bi-vel tri-pollicaribus, intermediis sesfuipollicariluus erectiusculis, superiorihus sensim? brevioribus. Pinnulæe ultimie subulatie subincurve lineam longax.

\section{TRIBLS II. CERMMIIEE.}

Sphærospore transformatione cellulie corticalis formatie.

XIII. Ceraniuuir Lyngb. Ilydr. Dan. p. 11\%. Ag. Sp. Alg. II. p. 138 (excl. sp. ap. ult.); Ilaro. Man. p. 98. J. Ag. Aly. med. p. 80. Endl. Gen. pl. Suppl. III. p. 36. J. Ag. adoers. p. 19. Ilarv. Phycol. Brit. tab. 90, 139 etc.; Ceramii sp. Roth. et Auct,; Boryna Grateloup. in op. manuscr. Bonnem. Ilydr. Locul. p. 32. Bory.; Dictrdermi Bonnem. in Journ. Phys. XCIV. 185.; Hormoceras, Gongroceras, Trichoceras, Echinoceras Celeceras, Acantlioceras, Ceramium et l'teroceras hützing in Linnea 181.1. Pliyc. Gen. p. 378 et Sp. p. 67't.

Frons filiformis, diclotomia ant pinnalim lamosia, articulatis, monosiphonia, ad genicula stralo cellularum definito aut. decurrente et interstitia obducente corticatia, cellulis geniculorum nullo ordine dispositis. Facelle ad ramulos sessiles, ramellis conformilns pluribus subregulariter involucratix, intria saccullum lıjalinun gemmidlia plurima angulatit foventes. Spharosporce morphosi cellularum corticiliun formita, plus minus extrit stratum corticale prominentes, sphrericie trimngnte divisie. (Kü̈z. Phyc. tab. 46 fig. I-IV, tab. 47. Hart. Phyc. tab. XC. etc.)

frondes tenuissime cilpillares iut selicea et ultria, ut plurimum reçnlariter dichotomie et fistigialix, dicholomia detnum, ramulortum latcraliun erolutione, in muttis obscura; nunc caulem

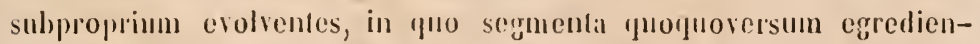
tia rallunlormun lateralinm ad inslar disponumtnr; ant denique frons compressa revera distiche pinnata obrenit. Segmenta terminalia juvenilia fere semper subregulariter furcata, forcipem ramellis incurvis clatusum formantia, admltiona aut forcipem clatusum vel aper- 
fun conservantia, aut utrumqque ramellum erigentia, aut unum iterum decompositum porrisentia, altero minori. Simplici serie Iongitulinali cellularum (articulorum) frons contesta est. Articuli cylindrici, aut, ad genicula contracti, oblongi et lere rotundati, pro magnitudine speciminis longiores aut crassiores et breviores, memhrana liyalina crassiore constantes; ad genicula insuper strato corlicali obducti. Stratum corticale, collulis nullo ordine dispositis, angulatis coutextum, nunc ad genicula zonam definitam coloritam constituens, interstiliis membrana articuli nuda et pellucida formatis, nunc zona cum xtate, præcipue deorsum, expanditur et interstitia antea pellucida plus minus obducit, numc zonæegeniculorum, jurenili retate confluentes, postea quorque contigua manent, frondem totam corticatam reddentes, strato corticali in his cum retate sensim densiori. Cellulæ corticales ad erolutionem ulteriorem pronie, sxpe in radiculas, pilos flexiles aut spinulas rigridas, exteriore forcipum latere pracipue insignes, excrescunt. Radicula, tubis elongatis obtusis constitutie, pilique articulati flexiles, in eadem specie prasentes aut deficicutes, a loco, quo vivunt individua, sine dubio pendent. Spinulie rigidiusculic acutissime, muc articulatx, 2-4 raro pluribus articulis constantes, nunc inarticulati, quoad locum yuo evolsuntur et articulationis normam in diversis speciebus, diverso modo constanter obvenientes, in eadem specie vero rariores aut densiores, in ramulis junioribus precipue insignes, in adultis obsoletiores, in senilibus deficientes, aliguando novil prole precipue in fructiferis pullulantes.

Fructus nunc in segmentis superioribus, nunc in prolificationibus, in planta favellifera sapissime evolutis, obvenientes. Favella in segmento aut abbreviato, aut parum mutato sessiles, ramellis abbreviatis 3-6 involucratx, solitarixe aut gemine intra involucrum, cordato-rofundatie, gemmidia angulata plurima intra sacculum lıyalinum forentes. Splærospora, transformatione cellula corticalis orta, ut magnitudiue angentur magis magisque prominent; in diversis vero speciebus aut totum geniculum fertile fit nodoso-inflatum, aut cellule geniculi fertiles singule tument et extra reliçuas cellulas amergunt, nunc perisporio lỵalino tantum vestita, unne strato cellularum sterilium ambiente teclæ. In singulis geniculis aut 1) singula cellula in sphrerosporam mutatur, qua tunc semper externum latus forcipum occupat; geniculis multis fertilihus sphxrosporie in lineam longitudinalem externo latere segmentorum seriate conspiciuntur; aut 2) plures cellulæ ejusdem geniculi in splue- 
rosporas mutantur, que tunc vel simplici serie vel duplici circa genicula verticillatim disposite, rel ordine proprio relicto hic illic unilaterales, rol immo interstitial corticata occupant. Spherosporie emerontes in nommllis conflumt (aut forsan aliquando ab initio composite, ut in Callithamnii speciebus idem obtinet?), Iucleum majorem extermum formates, farellam mudinn mentientes.

Genus quoddam nomine Ceramion, jam ab Mansonio constilutum, sed ut ox descriptione viletur species diversas, forsan PoIysiphonias, comprehemdens. A liothio dein adoptatum, sed ila extensun ut Neras diversissimas comprehenderet. Al) lgardhio in primis operibus itil restrictum ut Ceramicas plurimas hodicrnas complecteretur. Iynghyeus hodiernis fere servatis limilibus, Polysiphoniis tamen quibusdim male introductis, primus genus Ceramii ita purgavit et charactere definivit, ut hodicrna adoptetur scientia. Agatdhius in speciebus Ngrarum genus L.jughanum, quod ipse ut sectionem propriam rite indicarerat, dein agnovit, sed limitibns Spỵidias quoque inchudentibus circunscriptum. Ilarvey has expulsit. Kützing denique genus itis conditum in genera 9 nova dissolvit, que vero neutipuan adoptandia censeo, nec ab alis adoptalia video. Hlumc refutare ipse operan dedi (Advers. l. c.), characteres, quibus genera sula condidit, peculiari examini subjiciens. Fodem fere tempore Meneghini (Parl. Giorn. I. p. 178) et Zanardini (Delle Callithamniea p. 3) conlıa liützingianam generis dismptionem disseruerunt. Cicramium clavulatum Ig., quo genus Centroceratis condidit Kütyiug, una cum altera specie, quam inter ceramia a külzingio retentam suspicor, hoc loco ut proprium genus separavi.

Species plures hujus gencris, urgatissimas et immmeris ludentes formis, veteres Mrgologi jam distinxerant. Agardhius plurimas formas ad paucas quasdan species revociverat. Kützing raro levitatis exemplo, mantuamque fere formam, quan minime abludentem, speciem propriam charucteribus nullius omnino valoris ut plurimum circumscriptam, salutavit. Hoc modo specierum numeris usque ad 90 in ultimo ejusden opere increvit. Ejusmodi species, nec ah alio, funi specimina origunalia non viderit, enucleandas, nec ab) Arologis adoptandas, omnino pretcremudas censeo; "ne scientix nimis jam synonỵmis obrute, noro sint oneri, prodenti Agologorum cordatiorum silentio etiam in posterum prencendas" (Endlicheri de his Ceramiorum generibus notula in Suppl. III. p. 36). Meneglini, more uon prorsus alicuo, specierum numermu ultáa 
modum auxit, species suas tamen claracteribus completioribus, sed me judice inconstantibus, definivit. Ltriusque species ad calcem adjeci, ne iis deficerem qui in his scientian positam credunt.

Specierum justam discriminationem primus molitus videtur Gratoloup, qui in opere quodam (manuscripto?), quod Confervooraphiam appellasse videtur, species multas hodiermas jamdudum distinxerat et speciminibus distributis Algologorum judicio subjecerat. Quse vero species, in Speciebus Algarum Agardhi baud receptie, Agologis hodiernis ignotæ videntur. Aitas itaque nostra admodum paucas Ceramiorum species agnoverat; Chauvin novam speciem, paulo postea a D:1la Griffiths quoque dislinctam adjecit, Carmichael aliam; ipse quoque nonmullas, duce precipue D:na Griffills, justis circumscribere limitibus conatus fucram. Algologis Angliæ dein debemus, quæ de specierum cognitione et justa discrininatione comperimus. Hoc loco me aliquid huic cognitioni adjecisse spero; longe tamen abest quin in lıoc genere acta alluc clausa considerarem. Species in loco natali accuratius observate multa dabunt emendanda.

Adsunt in hoc genere exempla, sphærosporas et favellas in eodem cespite et forsan [?] in eodem individuo obvenire.

\section{SYYOPSIS SECTIONUII GENERIS.}

1. Frons inermis, arl genicula stralo corticali zonala, interslitiis mudis.

a. Sphererosporis per frondem sparsis, ad genicula singulis aut uggregatis uno latere erumpentibus, supe confluentibus, favellas mentientibus.

1. Cer. araginometa.

2. Cier. GlichlLhium.

3. Cer. fastigiatum.

b. Spherosporis in fronde lineam longitudinalem externo segmentorum latere formuntibus, al genicula sub-sinyulis, plus mimus extrorsum prominentibus.

4. Cer. subtile.

8. Cer. tenuissincm.

6. Cier. minuloscu.

c. Sphurosporis circa genicula rerlicillatis sparsisque emergentibus, sape aggregatis confluentibus. 
1. Spherosporis circu genicula cerlicillutis, immersis sulprominenlibus.
8. Cer. strictum.
9. CERr. ELEGiSTS.
10. Cirr. disphation.

2. Frons inermis, ad geniculu strato corliculi decurrente, et interstilia plus minus obducente, instructa.

11. Cer. chrciximum.

12. Cisr. rebrum.

13. Cer. obsoleter.

14. CER. Nitexs.

15. Cist. Denbesit.

3. Frons spimulosa, spinulis externo lalere segmentorum terminalium procipue conspicuis.

a. Spherosporis externo segmentorum latere lineum longitudinalem formantibus, ad genicula singulis.

16. Cer. echojotiz.

17. CER. NONILE.

b. Spharosporis circa genicula verlicillalis plurimis.

18. Cer. acisthosotis.

19. Cer. Gilister.

20. CER. FL.IBELLIGENCM.

4. Frons compressu, disliche decomposilı.

21. CFr. minatur.

22. Cer. PExitur.

?3. CEn. GiNGELLATUM.

1. Frons inermis, al genicula struto corlicali zonata, intersliliis mudis.

a. Spharosporis per frondem spursis, ad genicula singulis aut aggregatis uno latere ermmentibus, sape confluentibus el facellas mentientibus.

1. Cer. aricunomecy (Ag. Syst. p. 134) fromde capillari sursum attenuata regulariter dichotomo-fastigiata, sementis erecto-pateutibus, terminalibus forcipatis, articulis inferioribus diametro 3-iplo longioribus, intrestitiis hyalinis, spharosporis per frondem sparsis, ad genicula singulis aut aggregatis, uno batere erumpentibus, pluribus sxpe conflurntibus. 
Ceramium diaphanum var. arachnoidea Ag. l. c. Sp. Alg. II. p. 132.

Cer. tenuissimum Aresch. Enum. p. 100 lab. IV. D.

Gongroceras? tenuicorne liüls. in Linnaa 1841 p. 736. Sp. Alg. p. (68)!

Ilah. in sinu Codano! et mari Baltico!

Frons inferne capillaris, sursum sensim attenuata, dichotomiis crebris decomposita ef fostigiatil; axill inferiores patentiores, superiores segmentis magis erectis acutiores. Articuli inferiores sæpissime 3 -4plo, aliquando in eodem specimine 6plo diametro longiores, hyalini, geniculis subelevatis. Sphxrosporre sine ordine per fronlem sparse, genienlis fertilibus nunc 2-3 adproximatis, nunc longe distantilus, ad singula genicula aut solitarix extra geniculum omnino erumpentes, perisporio laxo hyalino inclusa, aut plures semiverticillata et ad unum latus erumpentes aggregatie et subconthentes, farellas omnino rmulantes. Color violaceus inferne sordidus. Chartæ sat bene adlıaret.

Hec forma, ad nostras oras frequens, splimrosporarum situ a cateris facilius distincta, ad Cer. tennissimum forsan proxime accedit. Sphærosporæ jam in Speciel). Alg. (sul. Cer. diaphano) memoratie, dein a lïitzingio descripta, loco utroque pro favellis habita. Occurrunt vero sphærosporæ agglomeratre, eodem modo ac in Cer. Deslongchampii, una cum spharosporis solitariis in eodem specimine; aggregata splaxrospora favellarum nucleum mire referunt.

2. C. Gricilumurn (lïtz. in Linn. IV p. 733) fronde pertenui flaccidissima dichotoma ramulisque subdissimilibus lateralibus obsiti, ramulis dichotomo-fastigiatis forcipatis, articulis ramorum diametro 5-6plo longioribus, ramulorum aqualibus ad genicula nodosis, splacrosporis per frondem sparsis ad genicula singulis emergentibus nudis, favellis in ramulo subterminalihus, ramellis involucrantibus elongatis forcipatis plurimis patenter umbellatis.

Hormoceras gracillimum lï̈lz. l. c. (fide) IJarv. Sp. Alg. p. 67ä!

Ceramium gracillimum Griff. et Harv. in Harv. Phyc. Brit. tab. 206!! Ceran. llaccidum Harv. mscr.

IIib. ad Corallinas etc. palasitica in Oceano atlantico ad littora Britannixe (Ilarrey!) et Galliae (Crouan!); in mari mediterraneo ad littora Galloprovincia (Perregmond!); in adriatico (sec. Kützing); in marri Indice occidentilis ad St. Thomas (Oersted!)

Frons dense cespitosa, 2-3pollicaris, capillo multo tenuior, flaccidissima, distanter dichotoma ramulisque lateralibus abbreviatis dense diclotomo-fastigiatis, ambitı obovatis, distantis brevioribus obsita. Apices forcipati in ramellis juvenilibus; ramelli adultiores sat patentes. Articuli in- 
feriores value elongati, diametro multo longiores, superiores sensim breviores; ramulorum brevissimi diametro aquales. Genicula elevata, cellulis relative magnis corticata, intense purpurea. Sphærospora in ramulis lateralibus evolutæ, sparsæ, extra genicula omnino emergentes, singulæ. Farellæ in ramulis ramisve minoribus terminales gemina, ramulis umbellatis 5-6 involucrata; ramuli involucrantes patentes, omnes forcipati, ipsam favellam longitudine triplo superintes. Chartie aretissimo adhæret.

Species ut ridetur sit distincta, eximia icone a Ilarrey illustrata, tenuitate et habitu jam cognoscenda. Rami nempe primarii longis articulis constituti, fere toti lyyalini, nudo oculo rgrius observandi; ramuli vero ob genicula approximata ef intensius colorata conspicui, quasi membra disjuncta plantæ dissolutæ adparent. Sub lente ramuli ob geuicula conspicua cellulisque magnis corticata monile fere referentes, peculiarem adspectum quoque præbent. - Hormoceras gracillimum Kütz. I. c. fide Harv. huc retuli. Diagnosis vero ab ipso data aliam speciem indicare mihi videtur.

3. C. Fastiglatum (Ilarv, in Hook. Journ. Bot. p. 303) fronde capillari regulariter dichotomo-decomposita fastigiata, segmentis erecto-patentibus, terminalibus forcipatis, articulis inferioribus diametro 3-4plo longioribus, superiorum interstitiis subcoloratis, spherosporis lineam longitudinalem secus filun formantibus, ad genicula pluribus unilateralibus prominentibus, farellis ad segmentia sessilibus lateralibus, ramellis involucrantibus farellam vix superantibus simplicibus paucis.

Ceramium fastigiatum Harv. l. c. Man. p. 99!!

Gongroceras fastigiatum kül.s. sp. p. 678!

Hab. in Oceano atlantico! mari baltico! mediterraneo! et adriatico (sec. Kützing).

Caspites densi plerumque 2-3pollicares. Frons capillaris a basi ad apicem vix attenuata, regulariter dichotomo-fastigiata, segmentis inferne distantioribus superne densioribus. Articuli inferiores hyalini geniculis coloratis subelevatis distincti; superiores endochromate roseo colorati, quod in exsiccata planta etiom conspicuum, sxpius in strias varie contrabitur. Sphærosporæe sæpe secus totum filum superius formatx, supremis segmentis sterilibus, ad geniculum quodque plures (4-6) subemergeutes. Planta favellifera gerit ramulos laterales spirsos. Favellie in segmentis laterales, plerumque $2-3$ adproximiatir, singulix involucro fultr, minutæ, rotundatæ, diametrum fili, in quo insident, vix superintes. Ramuli involucrantes unilaterales, ipso segmento frondis fiuctifero alterum latus sustinente, 2-h, brevissimi, farellam ipsam longitudiue vix superantes, simplices, fere subulati. Substantia flaccida el charta minus arete ad- 
hærens. Color cæspitis purpureus, filorum (præcipue) terminalium coccineus aut roseus.

In lrac specie, ut in multis aliis, radiculæ ex geniculis inferioribus, func plerumque tumidis, demittuntur. - Specimen cum spharosporis, fuod descripsi, gerit apices segmentorum subdivaricatos. An hoc semper obveniat nescio.

b. Spharosporis in fronde lineam longitudinalem externo segmentorum latere formantibus, ad genicula subsingulis, plus minus extrorsum prominentibus.

3̈. C. Subthe (J. Ag. mscr.) fronde capillari dichotoma superne subalterne ramosa, ramis in rachide clongrita patenter ramulosis, terminalibus foreipatis, articulis inferioribus diunetro $2-3$ plo longioribus, superioribus requalibus brevioribusque, geniculis lix elevatis, spherosporis linean longitudinalem externo segmonortum latere formantibus ad genicula subsingulis subprominentibus, favellis. .

\section{IIab. in sinu mexicano ad Vera Cruz (Lirbman!)}

Frons tenuissima, attamen C. gracillimo duplo crassior, ramificatione inter dichotomam et lateraliter ramulosam intermedia. Rami majores dichotomi, superiores in rachide elongata laterales alterni, nullomodo fastigiati, ramulis eximie patentibus. Ramulorum apices jureniles forcipati, adultiores porrecti. Articuli inferiores vix diametrum ter superant, superiores sensim lreviores, nulla fere inter articnlos ramorum ramulorumque vicinorum differentia; articuli supremi diametro semibreviores. Spharosporæ in ramis penultimis lineam subregularem externo latere segmentorum efficientes, ad geniculum quodque subsingulx aut gemine collaterales, in ramulis majoribus quandoquidesn plures subverticillate, sat prominentes. Favellas non vidi. Color coccineo-purpureus. Chartæe adharet.

Habitu Cer. gracillimo proxima mihi videtur, crassitie major; ramificatione, ramulis non fastigiatis, articulis inferioribus brevioribus, geniculis minus elevatis et spharosporis aliter dispositis dignoscenda. Favella detecta alias forsan notas suppeditabunt.

5. C. Texussinum (Lyngb. Ilydr. Dan. p. 120) fronde capillatri regulariter dichotomo-decomposita fastigiata, segmentis erectopatentibus, terninalibus forcipatis, articulis inferioribus 4-6plo diametro longioribus, interstitiis pellucidis, spherosporis lineam longitudinalem externo segmentormm latere formantibus ad genicula subsingulis erumpentibus, farellis infra apices 
lateralibus, apiec ramellisque involuerantibus favellam vix sulperantibus simplicilus paucis.

Ceram. diaphanum var. tenuissimum Lyugb. t. c. lab. 37. B. fig. 4! Gongroceras? tennissimum Kul. in Limn. 4842 p. 736. Sp. p. 680! Ceramium nodosum Ilarv. Plhycot. Bril. Lab. XC!! Alg. Tasm. n. 87! Ceramium diaphanum rigidum Grifl. el Harv. mscr. Gongroceras nodiferum hüls. Sp. Alg. p. 678!

? Hormoceras nodosum hïls. in Limn. l c. p. 732 et Sp. Alg. p. 674 !

Hals, in maribus linropais a Sinu Bottnico per Codimum et Atlanticum usque ad Ilispanianı; in milri mediteraneo; ad New York et Tasmaniam (sec. Hiarrey).

Cespites magni rotundati plerumque 3-4pollicares. Fila circiter crassitie capilli, a bosi ad apicem vix attenuata, regulariter dichotomo-decomposita ramulisque sparsis lateralibus hic illic ohsita. Axillæ plus uninus patentes. Articuli sursum sensim breviores, geniculis purpureis sxpe eleratis, interstitiis hyalinis. Splhærospore tum in ramulis lateralibus, tum in segmentis ultimis penultimisque evolute, in tumore celluloso exteruo latere geniculi sulssingule. Favella infra apices ultimos ita dispositx ut apex et ramuli involucrantes $2-3$ farellam vix superent. Color ex lateritio purpureus. Sulsstantia rigidiuscula. Charta laxius adhif'ret.

Plantam Lyngbyanam supra citatam liuc pertinere, tum characteres tum locus natalis satis superque probant. Homonymam plantam kützingii eandum esse, specimina ex codem fonte oriundo suadent. Hormoceros nodosum Kü̈t, quod, fide speciminis al, ipso Küitzingio determinati, huc eitat Harrey, in ultimo sun opere tamen seposuit Kützing et speciem Harveyanam novo nomine salutavit. Ex diagnosi Külzingiana haud elucet an sphærosporas suæ speciei villerit.

6. Cer. rinulosum (Hook. et Harv. Alg. Tasm. n. 88) fronde cilpillari dichotoni et ad geniculum fere quodque ramulis patentissimis obsita, segmentis terminalibus strictis acutis, articulis inferioribus diametro 3 -plo longioribus, interstitiis subcoluratis nudis, splaxrosporis lineam Iongifudinalem exteruo segmentorum latere formantihus ad genicula subsingulis erumpentilus, "favellis sulbterminalibus involucro polỵplugllo subtensis."

Ceramium ramulosum Hook. el Harv. l. c.!!

Gongroceras ramulosum liül. sp. p. 678!

llab. ad oras Tasmannia (Giunn!)

Cxspes (intricatıs) purpurcus. Fila crassitic capillaria, sursum sensim attenuata, dichotoma et ramulis ad geniculum quodque angulo rere recto egredientilus, simplicibus furcatisque, obsita. Segmenta terminalia 
vix forcipata. Articuli inferiores diametro vix 4plo longiores, geniculis purpureis interstitiisque leviter coloratis variegati, superiores breviores et distinctius colorati. Sphærosporæ externo segmentorum ranulorumque latere seriatx secundx, ex geniculo singulæ erumpentes. Farellas non vidi; Ilarvey easdem morlo allato descripsit.

Cer. tenuissimo quoad dispositionem sphærosporarum proxima, ramificatione satis diversa.

Obs. Nomine C. pellucidi formam inscriptam vidi, quam hujus sectionis speciem propriam suspicor. Filis capillo crassioribus regulariter dichotomis, apicibus parum forcipatis, sphærosporis externo segmentorum latere lineam longitudinalem formantibus in quoque geniculo pluribus, inferioribus semiverticillatis, ab aliis speciebus diversa videtur. Specimina vero paucissima et fragmentum tantum fertile vidi, quare hoc loco speciem propriam proponere nolui. Nomine cæeterum C. pellucidi plures species diversas intellectas fuisse, vereor.

c. Spherosporis circa genicula verticillatis sparsisque emergentibus, sape aggregatis confluentibus.

7. Cer. Desloygchaypil (Chauv. Alg. Norm. n. 83) fronde subsetacea decomposito-dichotoma ramulisque lateralibus subulatis obsita, segmentis erectiusculis, terminalibus indivisis et subrectis subulatis, articulis inferioribus diametro 3-4plo longioribus, interstitiis nudis, splıerosporis verticillatis sparsisque erumpentibus, sæpe uno latere aggregatis confluentibus.

Ceramium Deslongchampii Chauv. l. c!! Dub. II. mem. Ceram. tab. 3 fig. 7! Ilarv. Tasm. n. 86.

Gongroceras Deslongchampsi Kü̈t. in Linn. l. c. p. 733 ! Pliyc. gen. tab. 46, I! Sp. p. 677 !

Ceramium Agardhianum Grifl. mscr. Ilarv. Man. p. 99.

Exs. Chauv. l. c. Hyalt. Danm. n. 218!

Hab. in Oceano Atlantico ad Helgolandiam (Binder!), Angliam (Griffillss et Ipse!) Galliamque (Chauvin!); ad Tasmaniam (sec. Ilarvey).

Cospites sordide purpurei 3-pollicares. Fila capillo plus duplo crassiora, minus regulariter dichotoma, ramulisque lateralibus obsita. Segmenta erectinscula; ranuli patentiores. Apices segnentorum subulati ramulique laterales acuti recti aut levissime tantum forcipati. Articuli purpureo et sordide luteo variegati, inferiores diametro 3-4plo longiores, superiores breviores. Sphærospora nunc regulariter dispositer, singula aut duplici serie verticillatæ, nunc sparsiores, denum erumpentes, intra perisporium hyalinum singula, supe unilateraliter aggregate, favellas mentientes, sporis vix discernendis. Charta minus arcte adheret. 
Apices recti subulati et sphærosporæ mox erumpentes hanc speciem facilius distinctam reddunt.

d. Spharosporis circa genicula rerticillatis, immersis subprominentilus.

8. Cer. Strictun (Grev. el Harv. mscr.) fronde capillari regulariter dichotomo-decomposita fastigiala, segmentis erecto-patentibus, terminalibus forcipatis, articulis inferioribus $4-6$ plo diametro longrioribus, interstitiis pellucidis, sphaerosporis simplici serie circa genicula verticillatis, fivellis in segmento lateralibus, involucri ramellis elongatis plurimis farellam demum longe superantibus.

Var. ce. Stricta zonis geniculorum angustissimis, ultimis penultimisque sterilibus, inferioribus fertilibus.

Ceramium strictum Grev. et Ilarv. in IIarv. Phycol. Brit. Syst. List. p. XI!!

Gongroceras strictum Külz. sp. p. 678 (quoad synon.)!

Var. $\beta$. delicata zonis geniculorum latioribus, penultimis fertilibus adproximatis moniliformihus.

Conferra delicala Clem. ens. p. 322 (quoad spec.)!

Hab. in Oceano atlantico! mari mediterraneo! et nigro! ad insulas Malouinas!

Caspites plerumqque 3-pollicares. Fila circiter capillaria, regulariter dichotomo-fastigiata, et quandoquidem prolificationibus lateralibus dichotomis fastigiatisque olssita, a basi sensim attenuata. Segmenta angulo acutiori discreta, terminalia forcipato-incurvati. Articuli inferiores sapissime diametro 4 plo longiores, interstitiis elongatis pellucidis inter geniculorum zonas, quæ diametro semper breviores. Sphærosporæ unica serie transiersali circa genicula fertilia verticillatæ. Favellæ in segmentis penultimis antepenultimisque laterales, subcordato-reniformes, diametro filum in quo insident superantes, ramellis $4-6$ patentibus, fasellie longitudinem 2-3plo superantibus, involucratæ. Chartic arctius adhæret.

8a. Cer. mivaricatur (Crouan. mscr.) fronde capillari dichotoma, segmentis divaricatis subretrofractis, terminalibus simpliciusculis, articulis purpureo et livido variegatis, inferioribus diametro fplo longiorilus, fructibus. .

Hab. in Oceano atlantico ad Brest (Crouan!)

Species distincta videtur, sed sterilis tantum a me obscrata. Caxspites rotundati. Fila fragilia. Charta vix adharet. 
Varictates supra allate characteribus fere omnibus conveniunt; zonx genicnlorum in var. $\beta$. diametrum fili supcrioris fere æquant, in var. $\propto$. dimidium diametrum vix exsuperant. In var. $\beta$. genicula penultima fertilia evadunt atque inflata, brevissimoque spatio sejuncta; apices quoque nudo oculo conspicue colorati adparent. In var. «. genicula inferiora, interstitio majori sejuncta, fertilia sunt; apices hinc minus conspicue colorati.

9. CER. ElEgitis (Ducl. Ess. p. 33) fronde subsetacea regulariter dicholomo-decomposita rastigiata, segmentis erecto-patentilus, terminalibus forcipato-erectis, articulis inferioribus 2-4plo diametro longioribus, interstitiis pellucidis zonas longitudine superantibus, splterosporis subduplici serie cirea genicula verticillatis, farellis in ramulo subterminalibus, involucti ramellis subdivisis favellam longe superantibus,

Ceram. elegans Ducl. l. c. (excl. syn. et variet.)!

Boryna diaphana Gratel.!

? Hormoceras moniliforme hüls. in Linn. l. c. p. 733. Phyc. gen. lab. 46 fig. 2 ! Sp. pl. p. 673.

llab. in mari mediterraneo! adriatico! ot atlantico (Gades!).

Plerumque tripollicaris, crassitie setacea, regulariter dichotoma prolificationibusque sparsis obsita, sensim attenuata. Apices incurvato-forcipati. Articuli plerumqque 3 plo aut duplo diametro longiores; zonæ geniculorum longitudine sua diametrum fili aquantes; pulchre purpurex; interstitia pellucida zonis sesqui-duplo longiora. Sphærospora subduplici serie circa genicula verticillatæ in segmentis majoribus, in superioribus simplici seric dispositæ. Favellæ involucro umbellato cinctie, in ramulis brevibus terminales; ramelli involucri ex apice ramuli, in quo insident favellæ, ramellisque propriis $4-3$ formati, favellam longe supereminent et non raro dirisi occurrunt. Chartæ arcte adhæret. Color seniculorum plerumquo eximie atropurpureus.

Grateloup hanc speciem a Cer. diaphano, quam vero Cer. elegantem adpellaverat, jam bene distinxit. Descriptio a Ducluzeau data in nostram exi-

9a. Cer. alstrale (Sond. Alg. Prciss. p. 20) "minutum, filis dichotomis, ramis erectis, superioribus abbreviatis obtusiusculis, geniculis olscuris subcontractis, articulis medio diaphanis diametro subbrevioribus.

Hab. ad Nova Hollandix litus occidentale. Herb. Preiss. N:o 23340.

Parasiticum, 3--6 lineas longum, roseum, siccatum nigrescens. Fila aggregata, tenuia, crelre dichotoma, ramulis ultimis brevibus, erectis. Articuli suborbiculati, geniculis valde obscuris. Sphicrospora oblonga, ramis adnatx, hyalinx, nucleo triangulatim quadripartito. 
mie quadrat; rarietates autem et Synonyma expellenda videntur. Conferva clegans (Roth. Cal. I. p. 199) nec male in nostram cadit, sed specimina Rothii male præparata videntur.

Variat apicibus suberectis fere lanceolatis. Varietas hac nulla alia nota diversa mihi videtur; specimina vidi nounullis apicibus erectis aliis eximie forcipatis, et alia in quibus apices constanter aut forcipati aut erecti fuerunt. Species nonnullas Kützingianos hos status significare suspicor; II. transfugum l.l. c.c. quoad descriptionem huc pertinere videtur, sed diagnoses, in quibus nulla fructuun tit mentio, in hoc genere nullius same sunt valoris.

10. Cer. Dhrphunu (Lightf. Scol. p. 996) fronde subsetacea dichotoma et sublateraliter ramulosa, segmentis erecto-patentibus, terminalibus forcipato-erectis, articulis inferioribus 3 -4plo dianetro longioribus, interstitiis pellucidis longitudine zonas superantibus, sphærosporis simplici serie circa genienla verlicillatis, favellis in ramulo lateralibus, involucri ramellis pancis simplicibus favellam vis superantibus.

Conferva diaphana Lightf. l. c! Fl. Dan. tab. 931? Dillw. Conf: t.38! Engl. Bot. tab. 1742.

Ceramium diaphanum Roth., Ag. et Auct. (partim!) Lyngb. Ilydtr. Dan. p. 119 tab. 37. B. fig. 3! Harv. Phycol. Brit. tab. 193!!

Ceramium elegans Gratel. (non Ducl.)! quoad specimen!

Boryna elegans Bonnem. Ilydr. loc. p. 36 !

Ceram. diaphanum var. Chauv.!

Hormoceras? pulchellum fiülz. sp. $p .676$ !

Itab. in Oceano atlantico ad littora Europar; ad Cap. b. Spei (Lalande! Ilarvey! Pappe!)

Frondes plerumque 3-4pollicares, inferne setacex, sursum attenuatæ, ramoso-dichotomæ h. e. evolutione ramorum lateralium, qui principales sensim subxquant et dichotomias horum xmulantur, decompositix. Ramuli in rachide longiori laterales initio dicholomi; terminales attenuati, obtusiusculi aut acuti, forcipati, sed mox erectiusculi. Articuli diametro vix quadruplo longiores; zonte geniculorum diametro fili breviores; interstitia pellucida nuda zonis longiora. Sphærosporæ cirea genicula verticillatir, plerumque pauca, unica ad geniculum quodque serie dispositar. Favella in ramulis minoribus, lateralıbus terminalibusque, sublaterales, sape geminx, ramellis $3-4$ simplicibus favellam vix supereminentibus involucrata. Chartæ firmius adhæret. Color geniculorum purpureus.

Nomine Cer. diaphani plurimas hodiernas species fuisse conjunctas, satis constat. Synonyma itaque auctorum plurima, plurimas comprehendentia species, nec ad unam nec ad alteram citanda videutur. Grateloup, sec. specimina in Ilb. Agardhi servat:l, Cer. diaphanum a Cer. eleganti primus, ni fallor, rite distinxerat, inseriuente Bombemaisonio. Uterrjue vero 
nomina primaria utriusque plantæe permutavit. Est enim planta Lightfootii, quoad descriptionem, ad Cer. diaphanum Harv. Phyc. Lab. 193 sine dubio referenda. Icon Fl. Dania: parum characteristica; Lyngbyei non optima, ob favellas vero certe huc referenda. Dillwynii cateris melior, utpote quæ nihil speciei contrarium exhibeat. Harseyi optima.

Hormoceras? pulchellum hulz. nulla essentiali nota diversum mihi videtur. Ramiticatio eadem, nisi rami forsan paulo patentiores; sphærosporæ exdem, inferiores simplici serie verticillatx, superiores exteriore ramulorum latere paucæ, sæpe ad genicula singula solitariæ, (ut hoc in alliis quuque speciebus hujus sectionis obtinet); favellæ in nostris fere effoetæe et hinc ramellis paulo longioribus (increscentibus nimirum post lapsum favellarum) involucrata.

\section{Frons inermis, al genicula stralo corlicali decurrente et interstilia plus minus obducente instrucla.}

11. Cer. circismaten (Külz. in Linn. l. c. p. 733) fronde setacea subregulariter diclotoma fastigiatir, segmentis erecto-patentilus, terminalibus forcipatis apice incurvis, articulis inferiorihus diametro $1 \frac{1}{2}-2$ plo longiorilus, interstitiis pellucidis decurenticorticatis zonas longitudine requantilus, sphærosporis simplici serie circa genicula verticillatis, favellis. .

Hormoceras circimnatum Külz. l. c. Sp. Alg. p. 673.

Ilab. in Oceano atlantico ad littora Anglix! Gallie! et Hispania? in mari mediterranco ad littora Corsicic (IIl). Nartens!)

Species inter majores, 4 -6pollicaris, crassitie setam quandoquiden superans, purpureo et hyalino pulchre variegata, regulariter dichotoma et prolincationibus ex geniculis emergentibus sparsis ramosa. Apices jureniles eximie forcipati, adultiores elongati rectiusculi, apice incurvato. Articuli una colorata et altera pellucida parte constantes, linea angustissima nuda recti al) articulis vicinis sejuncti; pars coloratil strato corticali densiori constat; cellular corticales ex hac, decurrunt lineis rectis et partem pellucidam articuli tenuissimo strato obducunt. Nec tamen cum strato corticali articuli inferioris conjunguntur, sed linea angustissima nuda semper al) hoc separantur. Articulus jpse ellipsoideus in exsiccata et madefacta, circuli is instar pellucidi per stratum corticale translucet; interstitia intercellularia ampla articulos exteriores reddit fere cylindricos. Spharospora ad genicula inferiora evoluta, serie transversali singula circa partem geniculi superiorem coloratam disposita, yuam in aliis speciebus numerosiores, 10-12. Favellas non vidi.

Cum habitu Cer. diaphani Auctorum structuram jungit C. rubri. A formis vero hujus differt linea angusta, qua articuli semper sejuncti manent. 
12. Cer. nebruy (Huds. Angl. p. 600) fronde setacea dicliotoma fastigiati ramulisque lateralibus ramulosa, segmentis erectopatentibus, terminalibus incurvis forcipatisve, articulis inferioribus diametro 2-3plo longioribus plus mimus dense corticatis ad genicula subcontractis, splaxrosporis circa genicula irregularius spriatis, ramellis involucri $4-\ddot{3}$, farellas laterales sipe geminalas plus minus superantilus.

Conf. rubra Huds. l. c. Engl. Bol. Lab. 1166. Dillw. Lab. 34. Fl. Dan. 1. 1482 .

Ceram. rubrum Ag. Syn. p. 60. Lyngb. Ilydr. p. 118 lab. 62. B. 1! Ag. sp. II. p. 146! Harv. man. p. 98. Phycol. Brit. n:o 181! Dub. Bol. Gall. p. 967! ійє. sp. Alg. p. 683̈!

Boryna rariabilis Bonnem. Fss. p. 33.

Conf. nodulosa Lighle.

Conf. tubulosa Ihuds.

Conf. flosculosa Ell. Ph. Tr. 37 lab. 18.

Cer. Morisianum Berlol. in Moris. Stirp. Sard. Elench. p. 23 (fide Külzing.)

Exs. Wyall. Danm. n. 42! Chanv. Alg. Norm. n. 114! Aresch. Scand. n.

llab. in Oceano aretico! allantico! pacificu! el australi!

Var. «. decurrens interstitiis jurenilibus nudis, cum xtate sensim corticatis confluentibus, adultis corticatis subpellucidis, geniculis obscuris, ramis lateralibus conformibus diclotomis.

Cer. diaphani forma Aucl.

? Hormoceras decurrens hül. in Linn. 1842 p. 733. Sp. p. 673.

Ilib. in sinu Codano! oceano Atlantico! mari nigro!

Var. $\beta$. proliferum interstitiis jurenilibus tenue corticatis, articulis inferioribus geniculo obseuriori distiuctis diametro duplo longioribus; ramis lateralibus fructiferis, spluerosporarum simpliciusculis brevibus subulatis, favellarum dirisis.

* secundalum ramulis introrsum subsecundatis, ad genicula singulis, ramellis involucri favellam xquantibus.

Ceramium secundatum Lyngb. Itydr. Dan. p. 119 lab. 37. A!

C.eramium rubrum $\beta$. secundatum $A g$. $s p$. II. 1 . 149.

Ilal). in Oceano atlantico ad Focroas! et Terre Neuve!

** proliferum rauulis ad genicula plurihus aggregatis subverticillalisve, ramellis involucri farellam longius superautibus.

Ceramium rubrum proliferum Lyngb. Ilydr. p. 1191 Ag. Sp. II.p. 149. lucus Lagascre Clem. Ens. p. 31 ö.

Ceram. botryocarpum Grev. el Ilarv. 
Cer. rubium pedicellatum Mont. Alg. p. Ain.

Cer. lanciferum hütz. Bot. Zeit. 1847 p. 33. Sp. Alg. p. 686!

Ilab. in oceano atlautico! sinu codano! mari mediterraneo! et nigro! In oceano pacilico! et australi!

Var. $\gamma$. tenue interstitiis jurenilibus et adultis densius corticatis, fronde dichotoma subfastigiata, ramulis secundis favellas gerentibus, ramellis involucri favellas superantibus.

Cer. rubrum tenue $A g$. $s p$.

Cer. barbatum külz. sp. p. 68\%?

Boryna gracilis Bonnem. Ess. p. 5.?

Hab. in mari mediterraneo! et atlantico calidiori!

Var. $\delta$ virgalum interstitiis jurenilibus tenue corticatis, articulis inferioribus geniculo olsenriori distinctis diametro $2-3$ plo longioribus, ramis lateralibus fertilibus elongatis utrinque attenuatis simplicibus fureatisque, ramellis involucri favella duplo longioribus.

Cer. rubrum $\delta$, virgatum Ag. $s p$. II. $p .149$.

Cer. rubrum membranaceum $A g . s p$. II. $p$. 450.

Hormoceras siliquosum Kütz. Bot. Zeit. 1837 p. 33. Sp. Alg. p. 676!

Ceramium flagelliferum küts. sp. p. 686 !!

IJab. in Oceano ylaciali a Japponia liossica! ad Groenlandiam!; in atlantico usque ad Gades! et Brasiliam!; in mari australi!

Var. E. fasciculalum interstitiis juvenilibus atque adultis densius corticatis, ramis lateralibus fasciculato-corymbosis.

Boryna variabilis var. fusciculata Bonnem. Ess. p. 53.

llab. ad oras atlantici oceani!

Var. ร. corymbiferum interstitiis juvenilibus atque adultis densius corticatis, fronde sublateraliter ramosa, ramis corymbosis diclotomo-fastiyiatis, favcllis in segmento laterulibus, ramellis involucri farellam parlum superantibus.

Boryna variabilis var. corymbifera Bonnem. Rss. p. 83 !

Cer. involutum külz. sp. p. 686 ?

llab. in Oceano atlantico ad lillogi Europara! et Terre Nove (De la Pylaye.); in australi ad insulas Maloninas!

Var. э. pedicellatum interstitiis jurenilibus atque adullis densius corticatis, fronde sparsin prolifera, prolificationibus vagis, fructiferis segnento conformilus.

Cer. rubrum pedicellatum Dub. Bot. Gall. p. 967!

Cer. pedicellatum Dec. (fide sp. a Grateloup. missi!)

Ceram. rubrum Harv. Pliyc. tab. 181! 
Ilab. in Uceano atlantico ad littoria Europara! et Anerica!; in sinu Codano! Oceano pacifico!

Radix scutata. Frondes carpitosa, aliquando usque pedales, plerumque multo minores, setam crassitie exquantes ant superantes, sursum attenuatx, plus minus regulariter dichotome et fastigiatæ, ramificatione nunc ob ramos proliferos subirregulari. Axilla patentes. Segmenta terminalia nunc eximie forcipata incurva, nunc forcipata erectiuscula et patentia, uunc altero ramo lougiori parum distincte forcipata, apice supremo plus minus incurvo. Articuli decurrente strato corticali plus milus dense obducti, per hoc stratum translucentes spherici aut ovales conspiciuntur, diametro $2-3$ plo longiores, immo aliquando longiores. Farellæ. aut ipsis segmentis adnatæ, aut sapisime in ramulis prolificantibus evolutæ, singula aut geminie, ramellis incuris $3-\ddot{3}$, nucleum æquantibus aut superantibus, involucratæ. Sphrerosporæe strato corticali circa genicula immersæ, serie transwersali simplici aut duplici (præcipue in var. $\delta$.) dispositæ, nunc ordine vix conspicuo (in ramis majoribus var. $\delta$.) in vicinia geniculorum aggregatæ. Chartæ plus minus adhæret. Color coccineus, purpureus, fulvus vel luteo-virescens.

Varietates principales supra enumerare molitus sum, characteres, quibus præcipue distinguantur, unicuique tribuens. Plures species an hoc loco confundantur, dijudicare nolui; mihi vero inter eastem characteres certos et constantes invenire haud contigit. Habitu maxime abludit var. $\delta$. Var. «., quam non quippe typicam, sed quia seriem rarietatum quodammodo inchoantem, primam enumeravi, quasi transitum ad Cer. diaphanum efficit. Verum autem Cer. diaphanum strato corticali non decurrenti dignoscitur.

13. Cer. obsoletuy (Ag. sp. II. p. 145) fronde sefacra dichotoma sulfastigiata ramulisque introrsum secundatis dense seriatis prolifera, segmentis patentibus, prolificationibus utrinque attenuatis secundatim compositis, artieulis inferioribus dianetro aqualibus dense corticatis, spharosporis circa articulos prolificationum verticillatis, ramellis involuci $50-6$ farellas demum superantibus.

Cer. obsoletum Ag. l. c. Mont. Bonile p. ๖ว̆. Кй t. sp. p. 687!

Cer. rubrum var. firmum $A g . s p . p .149$ (quoad sp. capensia!)

Gaillona Lehmanni Rud.

Ceram. pediculus Suhr.

Ilab. in mari Capensi aliis Agris innata (De la Lande! Pappe! etc.); in oceano Indico ad insulas Philippinas (? Hb. Binder!)

Frons semipedalis, crassitie fere pennæ passerinx, sursum sensim attenuata, patenter decomposito-dichotoma, segmentis terminalibus subsecundatis fastigiata et plerumque secus totam longitudinem interiore segmentorum latere prolifera, prolificationihus basi altenuatis simplicibus aut 
secundatim compositis, apicibus attenuatis. Articuli ubique corticati, inferiores diametro æquales, prolificationum fertilium diametro duplo breviores. Sphærosporæ haud circa gersicula, sed circa interstitia regulariter verticillatæ, parum prominulæ, in pagina oculo adversa $3-4$ conspicuæ. Favellæ in prolificationibus quoque evolutæ, sublaterales, ramellis incurvis, 5 et pluribus, cinctæ. Color intense purpureus. Chartæ minus adhæret.

Ceramio rubro secundato proxima, sed tirmior et articulis brevioribus facilius distinguenda.

Sph. micrococcus Mart. Fl. Brasil p. 39 huc forsan referendus; a me vero non visus.

14. CER. viters (Ay. Syst. p. 136) fronde subsetacea diclotomoramosa diffusi ramis patentissinis, superioribus vage secundatis, terminalibus indivisis rectiusculis subulatis, articulis inferioribus diametro $2-3$ plo longioribus dense corticatis, fructibus.

Ceramium rubrum var. nitens Ag. l. c. Sp. Alg. II. p. 449 !

Hab. in mari Indiæe occidentalis, Corillis adnata (Hb. Aspegren!); ad Jamaicam (Swartz!), ad insulam St. Crucis (Rilvn! Benzon! Oersted!)

Frons intricato-cæspitosa diffusa, setam crassitie haud æquans, sublateraliter ramosa, ramisque excrescentibus dichotoma, superne subincurva, ramis externo curvaturæ latere sæpe secundis, fere horizontaliter egredientibus, secundatim parce divisis, apicibus porrectis indivisis subulatoattenuatis. Articuli ubique corticati, cellulis rotundatis minutis fere puncta æmulantibus; inferiores usque 3 plo diametro longiores, interstitiis minus intense coloratis, superiores diametro aquales et breviores. Color miniatorubens, sæpe nitens. Substantia videtur gelatinosa, unde exsiccatione subcartilaginea; apices (et sæpe planta inferior) compressi apparent, an exsiccatione collapsi?

Species sine dubio distincta, at fructu ignoto non rite characteribus circumscribenda. Ramiticatio fere Confervæ fractæ.

13. Cer. Derbesil (Solier mscr.) fronide setacea dichotoma et lateraliter ramosa minutissime muriculato-asperil suhcartiliginea, segmentis erecto-patentibus, terminalibus forcipatis, articulis inferioribus diametro aqualibus dense corticatis, sphærosporis in segmentis penultimis verticillatis paucis, ramellis involucri umbellatis favellas superantibus.

Ceramium Derbesii Solier mscr. Kü̈z. sp. Alg. p. 687!

Ilab. in mari mediterraneo ad littora Galloprovincin (Perreymond! Solier!) ot Corsicæ (Leveillé!) 
Planta caspitosa $11 / 2^{-2}$ pollicaris, pro magniludine firma et sat cartilaginea, ramis primariis crassis, secundariis tenuilus. Segmenta patentia, suprema sat erecta, nunc eximie forcipata, nunc inæqualia plus minus incurva. Microscopio subjecta, asperitatibus prominentibus minutissime muriculata. Articuli diametro rix sesquilongiores, ubique corticati. Ramuli favelligeri subcomposite umbellati, ramellis involucrantibus favellas superantibus, aliis simplicibus, aliis elongatis iterum divisis et fructiferis. Sphærosporæ in segmentis penultimis medio incrassatis subsparsæ, aut in rerticillo $2-3$, minutæ. Color pallide rubens.

Species ad Cer. rubrum proxime accedens, sed ut videtur distincla. Articuli inferiores diametro aquales, nec $2-3$ plo breviores, ut a Kützingio dicitur. Setas tenerrimas, quas huic speciei adscribit, non vidi. Apices vero aliquando molliter pilosi.

3 Frons spinulosa, spinulis exlerno latere segmentorum terminalium pracipue conspicuis.

a. Spharosporis externo segmentorum lalere lineam longitudinalem formantibus, ad genicula singulis.

16. Cer. echiosotun (J. Ag. Adiers. p. 27) fronde subsetacea regulariter dichotomo-decomposita fastigiati, segmentis erectopatentibus, terminalibus forcipatis incurvis, articulis inferioribus diametro 3-4plo longioribus, interstitiis pellucidis nudis, geniculorum spinulis sparsis inarliculatis liyalinis, splıærosporis externo forcipum latere ad genicula singulis, filvellis in segmento lateralibus subgeminis, involucro polyphyllo cinctis.

Cer. Echionotum J. Ag. l. c. Harv. Pliyc. tab. 191!

Echinoceras oxyacanthum Külz. Phyc. germ. $p$. 292.

Chætoceras echionotum Külz. Bot. Zeit. $1847 \mathrm{p} .331$

Acanthoceras echionotum Kütz. Sp. Alg. p. 684!

Hab. in oceano atlantico a Britannia! usque ad Gades! et insulas Azoras!; in mediterraneo!

Frondes dense cæspitos $x$, setacex aut tenuiores, sursum parum attenuatæ, 3-4pollicares, eximie dichotomo-fastigialæ, apiceque forcipatæ, prolificationibus sparsis nunc obsitæ. Articuli in juniori planta subcolorati, in adulta hyalini, interstitiis nuxis, geniculis corticatis, zona diametrum longitudine subæquante. Spinulæ circa genicula sparsae, in inferiori planta circumcirca dispositæ, sæpe divergentes, in supcriore exteriore furcarum latere frequentiores, sæpe omnes extrorsæe et ad genicula subsingulæ, hyalinæ et inarticulatæ subulatæ acutissimx. Singula fere sphærospora in geniculo quoque tantum evolvitur, qua externum latus semper occupat, ita ut sphærosporæ geniculorum omnium fertilium seriem longitudinalem ad externum latus segmentorum penultimorum efficiunt. Seg- 
menta lateralia prolıficantia pra cæteris fertilia. Farellæ (a me nondum observatx, sec. Harvey) pone apices frondium ut plurimum juxta axillas dispositæ, ramellis pluribus incurvis involucratæ. Color purpureus.

Variat spinulis densioribus et sparsioribus, circumcirca dispositis aut externe subsecundatis, ex geniculo singulis aut pluribus, longioribus et brevioribus.

17. Cer. Moxile (Hook. el Harv. Alg. Tasm. p. 13) fronde sebacea alterne-ramosa, ramis lateralibus brevioribus, ramulis dichotomis, terminalibus inæqualiter forcipatis precipue externo latere serie aculeorum articulatorum obsitis, articulis diametro $1 \frac{1}{2}-3$ plo longioribus ad genicula nodosis, interstitis superioribus nudis, splaxosporis in tumoribus aculeatis externo segrmentorum later' singulis, "favellis involucro polyphyllo subtensis."

Ceramium (Echinoceras) moniłe Hook. et Harv. l. c!! Celeceras monile liulz. sp. Alg. p. 684 !

\section{f. crassior}

Ceramium puberulum Sond. in Mohl. et Schl. Bol. Zeit. 1845 p. 52 "? Alg. Preiss. p. 20!

Hab. ad oras Tasmaniæ (Gunn!). $\beta$. ad novam Hollandiam (Ilb. Greville! Preiss!)

Frons 3-- 4pollicaris, inferne crassitie setacca, ramis superioribus capillaribus. Rami in tilo prinario elongato alterni et breviores, eodem modo decompositi, ramuli magis dichotomi, apices patenter forcipati, ramellis obtusis, altero breviori. Articuli in parte inferiore subcorticati, oblongi, diametro sesquilongiores; superiores interstitiis plus minus evidenter nudis, ad genicula nodosi et cellulis proeminentibus obtuse muriculati; supremi, nempe segmentorum terminalium, ad genicula intlati et externo latere aculeis biarticulatis brevissimis hyalinis, ad geniculum quodque plerumque singulis, nunc utroque latere paucis, instructi. Sphærosporæ in tumoribus procminentibus cellalosis et minute aculeatis, externo latere geniculorum singulis, interrupte seriatis, immersæ subsingulæ. Favellas non vidi. Color et habitus fere Cer. rubri.

Quoad sphærosporas hrec species ad Cer. tenuissimum proxime accedit; aculeis aliisque notis facilius distincta. Aculei quoad dispositionem et structuram cum iis Cer. acanthonoti proxime conveniunt.

Varietas supra allata nullo respectu a specie primaria diversa mihi videtur, nisi sit fronde firmiori. Fructus vero non vidi, quare diversas posui. Si revera identicæ sint, nomen Sonderi, utpote prius datum, adoptandum.

b. Spherosporis circa genicula vericillatis, plurimis. 18. Cer. aCaуthoNotum (Carm. mscr.) fronde capillari regulariter dichotomo-decomposita fastigiata, segmentis patentibus, tor- 
minalibus forcipatis incurvis, articulis inferioribus diametro 3-4plo longioribus, interstitiis pellucidis nudis, geniculis spinuli singula articulata colorata exteriore latere munitis, spherosporis simplici serie circa genicula verticillatis, favellis in segmento lateralibus subaggregatis, singulis ramello suffultis.

Ceram. acanthonotum Carm. mscr. J. Ag. Advers. p. 26. Ilarv. Phycol. Bril. lab. 140 ! Aresch. Scand. p. 101.

Ceram. ciliatum $\beta$. acanthonotum Harv. in Hook. Bril. Fl. II. $p .336$. Man. p. 100.

Acanthoceras Shuttleworthianum külz. Phyc. gen. lab. 4.6:IV! Sp. Alg. p. 684 !

Hab. in oceano atlantico ad littora Britannia (Dillwṛn! D: ha Griffilhs!) Gallia (Crouan!) et Foeroearum (Lyngḅe!)

Frondes eximie cæspitosæ demumque pannosæ, tenues, circiter capillares, a basi ad apicem vix attenuatæ, dichotomæ et fastigiatæ, apicibus eximie incurvis forcipatis; demum proliferæ, prolificationibus conformibus. Axillæ patentes. Articuli diametro inferne usque 4plo longiores, superiores sensim breviores, interstitiis nudis hyalinis, geniculis corticatis et externo furcarum latere spinula singula obsitis; spinula valida, $3-4$ articulis constante, delteo-conica, endochromate colorato. Sphærosporæ singula serie circa genicula verticillatæ, erumpentes perisporio pellucido. Favellæ in segmentis penultimis laterales, infra axillam rami majoris sæpe aggregatæ, singulæ ramello incurvo suffultæ, involucro aggregatione favellarum sæpe polyphyllo. Color intensius coccineo-purpureus.

19. Cer. ciliatun (Ellis Phil. Tr. 57 p. 425) fronde subsetacea regulariter dichotomo-decomposita fastigiata, segmentis patentibus, terminalibus forcipatis incurvis, articulis inferioribus diametro 2-4plo longioribus, interstitiis pellucidis nudis, geniculorum spinulis verticillatis arliculatis liyalinis, sphærosporis simplici serie circa genicula verticillatis, favellis in segmento lateralibus singulis, ramellis involucrantibus 3 -4 cinctis.

Conf. ciliata Ellis l. c. lab. 18 fiy. h. II. Dillw. Conf. lab. ̈33. Engl. Bot. lab. 2428.

Ceramium ciliatum Ducl. Ess. p. 64 ! Lyngb. Ilydr. Dan. p. 121 lab. 37 ! Aq. Sp. II p. 153 (partim)! J. Ag. Advers. p. 26. Ilarv. Pliyc. Brit. lab. 139! Mont. Fl. Alg. p. 446!

Conferva pilosa Roth. Cat. Bol. II. lab. 5 fig. 2 !

Echinoceras sp. (omnes?) Kü̈tz. Sp. Alg. p. 680!

Hab. in Oceano atlantico a littore Foerocarum usque ad Gades! et Brasiliam (Martius); in mari mediterraneo! adriatico! el nigro!; in Ocrano pacifico (sec. Ilarvey). 
Var. a. cilialum strictum subsetaceum, apicibus summis forcipatis incurvis, spinulis omnibus verlicillatis, sphærosporis inter cilia singulis, in eodem geniculu $5-7$.

llab. in Oceano atlantico et mari mediteraneo frequens.

Var. P. proliferum ( $A g . s p . p$. 154) subflexuosum setaceum, superne reputite incurvatum, spinulis segmenturum terminalium extrorsum secundis, splıærosporis in geniculo subinermi plurimis $8-10$.

Boryna ciliaris Grat. (sec. specimen!)

Hab. in mari mediterraneo et Adriatico.

Cæspites densi 3-4pollicares. Fila in var. «. crassitiem capillarem parum superantia, in var. $\beta$. selacea, dichotoma fastigiata, axillis plus minus patentibus. Ramuli proliferi abbreviati subsecundi (in var. $\beta$. a me tantum observati), segmentis conformes. Segmenta terminalia in var. $\alpha$. brevissime incurva; in var. $\beta$. plerumque eximie incurvata forcipata. Articuli ramorum principalium diametro 2 -4plo longiores; genicula cor-

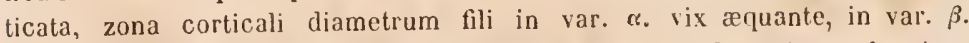
aquante aut superante; interstitia pellucida medio nuda, saltim ad apices aliquando strato corticali excurrente tenuissime obducta. Spinulæ pellucidæ, 3-4 articulis constantes, acutissimæ, articulis infimis majoribus, circa genicula simplici serie verticillatæ, nunc subduplici serie, spinulis inferioribus minoribus; in var. $\beta$. et aliquando in $\alpha_{0}$ spinulæ segmentorum terminalium et prolificationum interiore latere furcarum desiderantur. Sphærosporæ simplici serie verticillatæ, plus minus prominentes,

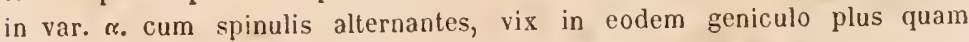
Ł-6; in var. $\beta$. genicula fertilia, plerumque inarmata, sphærosporas continent duplo numerosiores. Favellæ (in var. $\beta$. a me tantum observatæ) laterales, sæpius in prolificationibus sitæ, ramellis $3-4$, duplo longioribus involucratæ.

Sub nomine hujus speciei affines quoque comprehensas fuisse species, satis constat. Quas separandas credidi, jam antea in Adversariis separavi; Harvey easdem dein icouibus eximie illustravit. Hoc loco varietates duas sejunxi, quas examen accuratius vix specie distinctas confirmabit. Differentias ex spinulis petitas a loco natali pendere credo. Vehementissimo fluxu expositos cæspites ciliis longis ornatos vidi. Species itaque omnes generis Echinoceratis a Kützingio enumeratas unius ejusdemque speciei formas, vix varietatis nomine distinguendas, censeo.

20. Cer. flabelugerum ( $J$. Ag. Adeers. p. 27) fronde subselacea dichotoma et lateraliter ramosa ramis fabellato-corymbosis, segmentis erecto-patentibus, terminalibus patenter forcipatis, articulis inferioribus diametro sesquilongioribus superioribusIue dense corticalis, spinnla exteriore latere singula articulata 
colorata munitis, sphærosporis verticillatis subemergentibus, favellis in ramulo lateralibus subagogregatis, singulis ramello suffultis.

Ceramium flabelligerum $J$. Ag. l. c. Harv. Phycol. Bril.lab. 144! Kiülz. sp. Alg. p. 688 !

Hab. in Oceano allantico a littore Britannix! et Gallix superioris (Cavin!) usque ad Gades (Cabrera!) et Tingin (Sclousboe!)

Frons cxspitosa 2-3pollicaris, exsiccatione purpureo-nigrescens, madefacta dilute purpurea, in ramos nonnullos principales dichotome divisa, superne ramis lateralibus alternis fere distichis ambitu subfiabellatis obsita, apicibus in juvenili incurvis forcipatis, in adulta porrectis patentibus. Spinulæ externo latere forcipum, ad geniculum quodque singulæ, articulis tribus plerumque constantes, endochromate colorato. Stratum continuum corticale et genicula et interstitia obducit. Articuli ramorum principalium diametro sesquilongiores, superiores vix dimidium æquantes. Segmenta penultima sphærosporis onusta omnino torulosa; sphærosporit simplici serie circa genicula verticillatæ, denum emergentes. Favellæ infra axillas superiores laterales, plerumque plures aggregatæ, singulie ramello incurvo subsolitario suffultæ.

Hæc species, ut plurimæ alix, gerit segmenta terminalia juventute incurvata, serius erecta patentia; occurrit apicibus pilosis atque nudis, ut hoc in aliis quoque obtineat.

Cer. spiniferum Külz. Sp. Alg. p. 688 nullo dato charactere a Cer. nabelligero distinctum mihi videtur.

\section{"4. Fronde compressa distiche decomposita.}

21. Cer. minatum (Suhr. mscr.) fronde minuta compressa disticlie subpinnata pinnis dichotomo-fastigiatis, segmentis terminalibus hrevissimis dentiformibus a basi lata subito acuminatis divaricatis, articulis inferioribus diametro brevioribus, interstitiis nudiusculis, sphærosporis secus marghines segmentorum utrinque Iongitudinaliter seriatis, fivellis. . .

Hab. in Oceano Pacifico ad littus Peruvia, aliis algis parasitica (Hb. Sulı!!)

Frons minuta semipollicaris, crassitie capillum superans, evidenter compressa et distiche decomposita, segmentis sensim in latus dejectis et pinnas abbreviatas subflabellatim expansas dichotomo-fastigiatas referentibus. Segmenta inferiora axillis acutis patentia, suprema dentiformia quasi apicem bifidum segmenti penultimi constituentia, a basi lata acuminata, $\Delta$-formia divaricatissima. Articuli diametro fere semibreviores, inferiores interstitio brevi nudo sejuncti. Spharospora utrorge latere geniculi sin- 
gula, proeminentes, ita lineam longitudinalem in segmentis penultimis antepenultimisque ad utrumque marginem formantes.

Species distinctissima, a Subrio vero cum speciminibus diversæ plantæ confusa.

22. Cer. peximatu (Crouan mscr.) fronde compressi distiche pinnata, pinnis in rachicle elongata alternis lase pinnulatis, pinnulis sparsis patentilms, segmentis terminalibus forcipatis linearibus acuminatis, articulis diametro subregualibus ubique corlicatis, fructilus.

Cer. rubrum var. penuatum Crouan. mscr.

Hab. in Oceano Atlantico ald Brest. (Crottan!)

Cæspites 3-4pollicares purpurei, filis setaceis. Frons compressa et fere plana, alterne pinnata, pinnis sursum sensim brevioribus. Pinnarum rachis nunc flexuosa, nunc stricta. Pinnæ majores ambitu lanceolatæ, minores fere lineares. Pinnulie lineam rirciter distantes, patentes, simpliciusculæ aut furcatre, inferiores eodem modo pinnellatæ; terminales sipe forcipatæ ohtusius acuminatæ. Articuli diametro breviores aut vix aquales, dense corticati sed ubique conspicui.

Species insignis mihi videtur, habitu cum Microcladia ita conveniens, ut pro forma angustiore hujus facile habeatur. Articuli vero ubique conspicui diversitatem mox produnt. A Cer. rubro, cujus formam existimarunt Cel:i Crouan, fronde distichu-plana longe recedit.

23. Cer. Cancellaturi (Ag. sp. $p$. 145) fronde elata compressis disticlıe pinnata, pinnis dichotomo-pinnulatis. subcorymbosis, segmentis terminalibus olrusiuseulis patentibus, articulis iuferioribus diametlo arpulibus ubique corticatis, spherosporis secus marogines segmentorum ufringue longitudiualiter irregularius seriatis, farellis in pin:ula subterminalibus, involucri ramis plurimis demum elongalis divisis favellam superantibus.

Cer. cancellatum Alg. l. c. Ilook. el Ilarv. Alg. Nov. Zel. in Lond. Journ. IV.p. 350 ! Crypt. antarct. p. 79 !

Pteroceras cancellatum Kǚz. sp. p. 690 !

Hal). ad Cilp. b. Spei (Galldichalld! Ilarvey! Palppe! retc.); in Inari aıstrali!

Frons aliquando semipedalis, inferne pennam passerinam crassa, sursum attenuata selaces, evidenter compressa et distiche decomposita, mulloties pinnata, pinnis ambitu ovatis, majoribus lanceolatis obtusis, ultimis subdichotomis. Segmenta superiora ob furcas approximatas submultitida, terminalia erectiuscula aut patentia, attenuato-obtusa. Articuli vix conspicui, ubique corticati, inferiores diametrum circiter æquantes. Sphærosporæ in segmentis penultimis evolutæ, irregularius dispositæ, plurimæ: 
marginales longitudinaliter subseriatæ, nonnullæ in segmentorum disco sparsæ, quandoquidem plures aggregatie aut subverticillatæ. Favellæ il pinnellis subterminales, solitarix aut rarius geminx intra involucrum polyphyllum undique ambiens; ramelli involucrales favellarum superiorum simplices et nucleum parum superantes, inferiorum non raro divisi et nucleo duplo longiores. Color pulchre coccineus. Chartæ satis adhæret. Variat prolificationibus subseceundis.

Pteroceras flexuosum (Külz. sp. p. 690) jugamento insigniter flexuoso, pinnis gracilibus elongatis, tertiariis distantibus ambitu lanceolatis, a Pt. cancellato Kü̈t. distinctum, speciem propriam vix suspicarem. Specimina, in quibus rachis plus minus flexuosa et pinnæ ambitu angustiores obveniunt, vidi, a Cer. cancellato nullo modo distinguenda.

\section{Species inquirenda.}

24. Cer. virgatum (Hook. el Harv. Alg. Nov. Zeel. Suppl. in Hook. Journ. VII.) "filis strictissimis virgatis indivisis ramosisve, ramis similibus, ramulis dichotone multifidis appressis, axillis angustissimis, apicibus incurvis, articulis concoloribus glibris ramorum diametro equalibus, ramulorum brevissimis, favellis subterminalibus involucro polyphyllo suffultis."

Hab. parasitica in Carpopl. maschalocarpo, ad oras Novie Zelandia (lloolier).

25. Borma COMPACta (Bory Voy. Coqu. n. 97) filamentis abbreviatis crassiusculis dichotomo-crebrioribus; furculis extremitalibus brevissimis corniculatis.

Hab. Ascension (D'Urville).

Congeneribus crassior et minus transparens, bipollicaris, exsiccatione nigricans. Furculi rigide divergentes. Ita Auctor.

26. Cer. Coccineum (Zanard. Sagg. p. 5ö) indescripta.

27. Cer. ixconspicuuy (Zanard. Syn. Alg. p. 75 tab. VIII. fig. 1) filis simplicibus tenuissimis apice rectis, articulis nuảis roseis, geniculis cellnlosis suturate purpureis.

Hab. inter l'olysiphonias maris adrialici.

1. Species Meneghiniana el Külzingiana seclionis prima (sp. 1-10 subjungenda? ?)

1. Cer. patens (Menegh. Giom. Bot. 1844 p. 182) subspithamæum, setaceum, ramulis patentibus ubique ornatum, apicibus plerumque simplicibus et circinatis; articulis inferioribus ampullaceis, diametro du- 
plo longioribus, superioribus sensim brevioribus et in ramulis brevissimis; zonis inferioribus tenuissimis incurrentibus, interstitiis pellucidis; superioribus confluentibus; tetrachocarpiis magnis copiosis, in ramulis propriis aggregatis, fere erumpentibus. Küüz. sp. p. 677. Hab. Dalmatia, Venetia.

2. Cer. Capillageun (Menegh. l. c.) digitale capillaceum; ramis supremis virgatis circinato-forcipatis; articulis inferioribus diametro 8plo longioribus, ovato-fusiformibus; zonis vix prominentibus, diametro æqualihus, margine calloso circumscriptis; interstitiis hyalinis; articulis superiorilous sensim brevioribus, in ramulis brevissimis, zonis ad marginem inferiorem magis adpressis subdecurrentibus, in ramulis confluentibus; tetrachocarpiis copiosis in zonis inferioribus immersis, transverse seriatis, serie simplici vel duplici, in ramulis erumpentibus, subexsertis, magnis, quadrijugis [?] Kïllz. sp. l. c.

Hab. Venetia.

3. Cer. attenuatum (Menegh. l. c.) biunciale, basi setaceum, apice capillaceum, ramis supremis inæqualiter forcipatis vel simplicibus, vix hamatis; articulis inferioribus diametro 4-6plo longioribus, hyalinis, zonis diametro æqualibus, definitis, valde tumentibus; articulis superioribus sensim brevioribus, zonis omnibus distinctis; tetrachocarpiis copiosis immersis; cystocarpiis lateralibus, ramulis, plerumque quinque, involucratis, liülz. sp. l. c.

Hab. Dalmatia.

4. Cer. erumpexs (Menegh. l.c.) unciale, capillaceum; ramis supremis forcipatis, elongatis vix incurvis; articulis inferioribus diametro 6-8plo longioribus, zonis diametro æqualibus definitis valde tumentibus; articulis superioribus vix brevioribus, ultimis tantum quatuor vel quinque exceptis, zonis approximatis semper distinctis; tetrachocarpiis magnis copiosis solitariis erumpentibus subexsertis. Kiütz. $s p . l$. c. Hab. Dalmatia.

5. Cer. granogonium (Menegh. l. c. p. 183) minutulum capillaceum, apicibus forcipatis rectis, articulis inferioribus diametro 4plo longioribus, cylindricis, zonis duas tertias diametri partes latis, geniculorum constrictionem vix adæquantibus; articulis superioribus sensim brevioribus, zonis semper distinctis, tumentilus; tetrachocarpiis solitariis magnis omnino externis; cystocarpiis lateralibus nudis. Gongroceras gymnogonium Külz. sp. p. 679 .

IIab. Dalmatia.

6. Cer. Orsinianem (Menfgh. l. c.) unciale capillaceum, rigidulum, apicibus simplicibus vel furcatis rectis, ramulis alternis decrescentibus ornatis; articulis inferioribus diametro quadruplo longioribus conicis, zonis definitis vix tumentibus obconicis; articulis superioribus sensim breviorihus, zonis semper distinctis et magis prominentibus; tetrachocarpiis solitariis exsertis, in apicibus secundis. 
Gongroceras Orsinianum $\check{i} u ̈ l . s p . l$. c c.

Hab. Ancona.

7. Cer. Kellyen1 (Menegh. l c.) unciale, capillaceum, apicibus forcipatis rectis fine tantum incurvis vel circinatis; articulis inferioribus diametro 4-6plo longioribus, superioribus sensim brevioribus, zonis infimis nodiformibus, mediis magis alpressis, summis subtorulosis confluentibus, sed margine diaphano inclusis, diamelro dimidio angustioribus, in ramis primariis tetrachocarpia subsolitaria, secunda, exserta, magna, margine profunde et irregulariter dentato cyathiformi ex parte tegentibus.

Gongroceras Kellueri Kü̋. sp. l. c.

Hab. 5 Dalmatia.

8. Crr. gibioscy (Menegh. l. c.) minutulum, capillaceum; apicibus simplicibus acutis, rectis vel leviter hamatis; articulis inferioribus diametro vix longioribus, superioribus sensim brevioribus, zonis triplo angustioribus definitis, superioribus latioribus, numquam confluentibus, fructiferis tantum prominentibus; tetrachocarpiis ad latus exterius secundis erumpentibus, stratum corticale deformantibus.

Gongroceras gibbosum fiulz. l. $c$.

Hab. Dalmatia.

9. Honmoceras polyceras (Külz. Linn. $1842 p$. 732) minutulum obscure rubrum, squarroso-dichotomum, apicibus non forcipatis rectis; articulis inferioribus aqualibus; interstitiis nudis distinctis, abbreviatis; cystocarpiis ramulis elongatis (plerumque ő) involucratis; tetrachocarpiis numerosissimis. Sp. Alg. p. 674 .

Hab. in mari adriatico.

10. H. Catexcla (Iӥ̈z. Bol. Zeil. 1847 p. 35) capillare, flaccidum, intricatum, dilute roseum; ramis divaricatis, apicibus rectis obtusiusculis, non forcipatis; articulis hyalinis pellucidis, diametro sesquilongioribus, raro æqualibus (ramorum inferioribus duplo longioribus); zonis minutis anguslis, non elevatis, omnibus distantibus. hülz. Sp. Alg. $p$. 675.

Hab. in mari adriatico et mediterraneo.

11. H. Catexifonme (hülz. sp. p. 673) ramosissimum, ramis elongatis virgatis setaceis, a basi ad apicem usque laxe obsilis ramulis fructiferis elongatis gracilibus rectiusculis parce ramosis toruloso-moniliformibus, articulis primariis diametro $2-3$ plo longioribus; zonis distinctis elevatis distantibus inferiori margine lobato-crenatis, lobulis rotundato-obtusis.

Hab. ad oras Augliæ.

12. H. Duritsculci (liüz. Linn. $1842 p$. 734) rigidulum setaceum digitale; apicibus minutissime forcipatis; articulis inferioribus diametro -. 5plo longioribus; interstitiis nudis opacis, elongatis; zonis infe- 
rioribus abbreviatis, maxime distantibus, superioribus approximatis vel confluentibus. Külz. sp. $p .675$.

Hab. in mari adriatico.

13. H. Coxfluess (Külz. Linn. 1844 p. 734) minutulum (vix semi-unciale), rigidulum; apicibus forcipatis, incurvatis, torulosis; articulis inferioribus diametro æqualibus; zonis confluentibus. Külz. sp. p. $67 \%$.

Hab. in mari adriatico.

14. H. perverscy (Külz. Linn. 1842 p. 734) digitale, setaceum, virgatum; apicibus hamato-forcipatıs; articulis diametro equalibus, zonis superioribus distinctis distantibus, inferioribus confluentibus; articulis velltricosis subglobosis; geniculis contractis. Kül. sp. p. 676.

Hab. in mari septentrionali.

13. H. FRUticclosun (Kül. Limn. 1842 p. 734) setaceum, articulis inferioribus diametro duplo longioribus, zonis inferioribus incurrentibus, fere confluentibus, interstitiis nudis, opaciusculis, brevissimis; tetrachocarpiis in ramulis propriis terminalibus. Kü̈ъ. sp. p. 676 . Hab. . . .

16. H. traxsfugum (Külz. Linn. 1842 p. 734) setaceum, apicibus non forcipatis, leviter curvulis aut rectis; articulis inferioribus globosoellipticis, zonis plus minusve approximatis decurrentibus. Kü/. sp. p. 676 .

Hab. in mari adriaticn.

17. H. Biasoletriaium (Kï̈l. Linn. 1842 p. 73̈) digitale, capillaceum, apicibus circinato-forcipatis, articulis superioribus diametro æqualibus, inferioribus 2-3plo longioribus; zonis confluentibus, interstitiis opacis. Külz. sp. p. 676.

Hab. in mari adriatico.

18. H. sуtrophum (Kül. Phyc. p. 291) semipollicare vel ultra, setaceum; zonis tumidis, depressis, inferioribus interstitiis brevissimis distinctissime separatis, superioribus approximatis contiguis. Kül. sp. p.676. Hab. in mari adriatico.

19. H. pygмeuм (hülz. Bol. Zeil. 1847 p. 33) capillare, crebre ramosum, minululum, ramis rigidis rectis patentibus torulosis; articulis diametro plerumque ærqualibus, zonis inferioribus distantibus, superioribus approximatis contiguis, omnibus nodiformibus. Külz. sp. p. 676. Hab. prope Civita-Vecchia.

20. H. vaniegatoм (Külz. $s p$ p. 676) unciale et ultra, setaceum, rigidulum, apicibus eximie duplicato-forcipatis, circinato-hamatis; articulis ventricosss, inferioribus duplo longioribus, superioribus rqualibus, zonis distinctis, omnibus elevatis nodiformibus distinctis, inferioribus distantibus, superioribus approximatis contiguis, omnibus fructiferis. Tetrachocarpia perfecte immersa.

Hab. ad oras Imericæ australis. 
21. Goxgnoceras pellucidu (Külz. Linn. 1842 p. 733̈) capillaceum, tenellum, flaccidum, apicibus torulosis, circinato-forcipatis; articulis dianetro 4--6plo longioribus, zonis distinctis distantibus, interstitiis hyalinis pellucidis; tetrachocarpiis unilateralibus. Kü̈. sp. p. 678 .

Hab. in mari adriatico.

22. G. PExicillatuy (hüt. sp. p. 678) setaceum ramosum subdichotomum, ramulis terminalibus fructiferis, lateralibus tenuibus subpenicillatis; apicibus leviter curvatis; articulis primariis diametro 2-3plo longioribus; zonis crassis, ad geniculi elevatis, Iatissimis, ubique decurrentibus, infimis confluentibus, superioribus valde approximatis. Tetrachocarpiis in ramulis terminalibus verticillatis.

Hab. ad oras Suecix.

23. G. Uxgulatuy (Külz. $s p$. p. 678) setaceum, ramis terminalibus fructiferis, apicibus recurvis irregulariter torulosis; articulis inferioribus diametro 2-3plo longioribus cylindricis; zonis distinctis, superioribus approximatis subconfluentibus, inferioribus distantibus.

Ceramium ungulatum Suhr. (sec. liuitz.)

Hab. ad Cap. Horn.

2\%. G. PLic.ıтum (Külz. sp. p. 679) minutulum, setaceum; apicibusi breviter furcatis, cornubus monocladiis rectis contiguis in clavam clausis; articulis inferioribus diametro brevioribus, sursum sensim usque duplo longioribus, in extremitatibus iterum brevioribus, diametrum tamen semper excedentibus plicatis, zonis angustis tenuissimis, geniculorum constrictionem non adæquantibus; tetrachocarpiis magnis numerosis gregariis ubique exsertis.

Hab. Dalmatia,

20̈. Trichoceras villosum (Kütz. Bot. Zeit. 1847 p. 33) capillare minutum, apicibus forcipatis, zonis distinctis, omnibus elevatis, inferioribus distantibus nudiusculis, superioribus longe villosis; articulis inferioribus diametro 2-3plo longioribus. Kï̈lz. $s p . p$. 680 .

Hab. in mari Adriatico.

26. Tr. Pallidum (Külz. sp. $p .680$ ) dichotomo-ramosissimum, digitale, ultra setaceum pallide rubescens, subflavescens; articulis inferioribus diametro 2--3plo longioribus, medio et utroque fine constrictis, superioribus diametro æqualibus; zonis superioribus contiguis, inferioribus transcurrentibus. Tetrachocarpia immersa. Zonæ superiores ex geniculis piliferæ, villosæ; pili elongati flaccidi unilaterales, externi, achromatici artıculati [?].

Ceramium pallidum Nageli.

Hab. Anglia.

27. Tr. tasmanicum (Külz. sp. p. 680) majus, apicibus forcipatis, forcipibus leviter incurvatis, denum apertis rectis; zonis superioribus longe 
villosis, omnibus definitis et elevatis; articulis inferioribus diametro triplo longioribus, superioribus æqualibus vel sesquilongioribus; interstitiis pellucidis; ramulis involucralibus pluribus elongatis. Hab. ad Van-Uiemens-Land.

2. Species Kützingiance sectionis secundce (sp. 11-15̈ subjungenda?)

28. Cen. leptophleun (Külz. Limu. 1842 p. 740) capillaceo-setaceum, vix unciale; articulis diametro æqualibus; apicibus acuminatis, hamato-forcipatis; cellulis corticalibus minutissimis, inordinatis; bracteis cystocarpio majoribus, rectis vel falcatis. liülz. $s p$. Alg. $p .686$. $\mathrm{Hab}$.

29. C. Capexse (Külz. Linn. 1842 p. 740) parvulum, setaceum; articulis omnibus diametro duplo brevioribus; apicibus obtusissimis, forcipatis, convergentibus; cellulis corticalibus majoribus. Kütz. sp. p. 686.

Hab. ad Cap. b. Spei.

30. C. Lessoxi (Külz. sp. p. 686) trichomatibus setaceis, superne capillaceis, dichotomis gracilibus; ramis erectis, superioribus forcipatis circinato-hamatis, articulis diametro æqualibus, superioribus sterilibus, inferioribus fructiferis (tetrachocarpia foventibus) nodiformibus, hic illic radicantibus. Color pallidus.

Boryna Lessonii Delise (sec Kütz.)

Hab. ad insulas Malouinas.

31. C. AuckLandicim (Küls. sp. p. GS6) pollicare capillare vage et crebre dichotomum, ramulis superioribus gracilibus forcipatis, forcipibus apertis; articulis diametro æqualibus. Tetrachocarpia in ramis mediis numeros a nodiformia, semierumpentia.

Hab. ad insulas Auckland (Hooker).

32. C. irregulre (Külz. sp. p. 687) setaceum, vage ramosum, ramis corymboso-dichotonis erectis, apicibus leviter furcatis acutis, furculis patentibus; tetrachocarpıis in ramulis superioribus rel in ramulis propriis lateralibus laxiusculis, incurvis, irregulariter conglomeratis, subunilateralibus; articulis diametro æqualibus vel duplo longioribus. Hab. in mari australi.

33. C. Furcellatum (hülz. sp. p. 687) humile setaceum, dichotomum, ramulis superioribus fastigiatim furcellatis, furculis vel erectis vel patentibus, acutis (non convergentibus) fructiferis; articulis obsoletis. IIab. ad Cap. b. Spei.

34. C. villosum (Kü̈z. sp. p. 687) setaceum dichotomum, articulis omnibus diametro xqualibus, geniculis non contractis, pilis longissimis hyalinis fasciculatis tenuissimis flaccidis vestitis.

Hab. in sinu Codano. 
3. Species Meneghiniance el Külzingiana sectionis tertice. (Sp. 16 -20 subjungenda?)

33 C. uxifonue (Menegh. Giorn. Bot. p. 18i) unciale, ultra setacenm, apicibus inæqualiter circinato-forcipatis; articulis perfecte sphæricis; zonis lineola transversali pellucida angustissima excepta articulorum longitudinem omnino tegentibus et geniculorum constrictionem ex integro adæquantibus, in extremitatibus confluentibus; aculeis crassis, obtusiusculis divergentibus, verticillatis, מarticulatis, articulis, extremo excepto, xqualibus.

Echinoceras uniforme Kütz. sp. p. 682. Hab. Dalmatia.

36. C. тumiduur (Menegh. l. c. p. 184) digitale setaceum, ramulos simplices vel forcipatos rectos undique emittens; extremitatibus circinatoforcipatis, forcipibus clausis; articulis inferioribus diametro triplo longioribus in ramis rapide brevioribus; zonis non prominentibus, diametro vix angustioribus, egregie decurrentibus, superius confluentibus, in ramulis torulosis; aculeis verticillatis, magnis, divergentibus, late conicis, triarticulatis, articulo inferiore et medio subiequalibus, extremo valde minori apice solido.

Echinoceras tumidulum Kï̈tz. sp. $p .683$.

Hab. Dalmatia.

37. C. Cristatum (Menegh. l. c. p. 183) 3-4unciale, setaceum; apicibus simplicibus vel inæqualiter forcipatis, circinatis; articulis inferioribus diametro quadruplo longioribus, subcylindricis hyalinis; zonis diametrum æquantibus, ad marginem superiorem leviter prominulis, decurrentibus, in extremitatilus subconfuentibus; tetrachocarpiis magnis, subsphæricis, aggregatis, fere erumpentibus; aculeis verticillatis, ad latus interius obsoletis, crassis, patentibus, incurvis $\ddot{b}$-6articulatis, articulo medio cæteris longiore, extremo minimo.

Echinoceras cristalum Külz. sp. p. 683.

Hab. Dalmatia.

38. C. Ramulosum (Menegh. l. c. p. 183̈) digitale setaceum, ramulos circinatos undique emittens; apicibus circinato-forcipatis: articulis inferioribus diametro sesquilongioribus, ellipsoideis, in ramis sensim breviorihus, in ramulis brevissimis (infimis exceptis); zonis inferioribus diametro tertia parte angustioribus, irregulariter decurrentibus, adpressis, geniculorum constrictionem non ex integro adæquantibus; superioribus sensim angustioribus, magis tumidis, exactius circumscriptis, in apicibus vix torulosis, contiguis, non confluentibus; сystocarpiis lateralibus ramulis plerumque 5 involucratis; aculeis lato conicis, verticillatis, ad latus interius obsoletis, triarticulatis, articulo inferiori longissimo.

Fchinoceras ramulosum Külz. sp. p. 683.

Hab. in mari adriatico. 
39. C. GIGANTEL (Menegh. l. c. p. 183̈) spithamæum, setaceum, apicibus circinato-forcipatis, forcipibus clausis; articulis inferioribus diametro quadruplo longioribus, leviter conicis, hyalinis, superioribus rapide decrescentibus, ellipsoideis; zonis diametro angustioribus, exacte definitis, sterilibus non tumentibus, geniculorum constrictionem adrequantibus, tetrachocarpia ferentibus irregulariter gibbosis, superioribus contiguis nou confluentibus; aculeis magnis verticillatis, 5articulatis, infimo intlato et ceteris valde majore.

Echinoceras giganteum liülz. sp. p. 683.

Hab. Dalmatia.

40. C. Azoricux (Nienegh. l. c. p. 18:3) unciale subsetaceum, rigidum, apicibus circinato-forcipatis, articulis inferioribus diametro æqualibus, superioribus sensim brevioribus; zonis diametro duplo angustioribus, non prominentibus, circumscriplis, in ramulis confluentibus; aculeis longissimis, acutissimis, monocladiis, divergentibus, verticillatis. hülz. $s p . p$. 68 .

Hab. ad Azoras.

41. C. Echinophorum (Menegh. l. c. p. 186, minutum subsetaceum; apicibus circinato-forcipatis, articulis inferioribus diametro sesquilongioribus, superius sensim brevioribus; zonis contractis, angustis, semper distinctis; aculeis longis acutis, monocladiis a tota fasciarum superficie irradiantibus, patentibus, superius divaricatis. Külz. $s p . p$. 68 .ั.

Hab. Dalmatia.

42. C. Dalmaticum (Menegh. l. c. p. 186) unciale, capillaceum; apicibus circinato-forcipatis; articulis inferioribus diametro sesquilongioribus, sursum sensim brevioribus, geniculis æqualibus sape radicantibus; zonis diametro angustioribus, parum decurrentibus, sursum confluentibus; aculeis longis, exilibus, numerosis, erectis monocladiis, acutis verticillatis. Kü̈lz. sp. p. 685 .

Hab. Dalmatia.

43. ACasthocenas tnaxscunnexs (Külz. sp. p. 68k) unciale et ultra, setaceum, ramosissimum, ramis fastigiatis dichotomis, latere ramelliferis; ramellis fructiferis; articulis inferioribus diametro parum brevioribus vel subrqualibus, superioribus duplo brevioribus; zonis superioribus arcte approximatis, subcontiguis, inferioribus parum distantibus, transcurrentibus; spinulis in apicibus lateris exterioris secundatis, acutissimis, rigidis, hyalinis; tetrachocarpiis ad latera exteriora seriatis, tuberculiformibus, in apicibus ramulorum. Color nigro-purpureus. Hab. ad littora Calvadosii.

44. A. oxyacintuon (liülz. sp. p. 68/) unciale, capillari-subsetaceun dicbotome fastigiatum, ubique spinulosum, spinulis rigidis inferioribus minutulis abbreviatis, sparsis, temussimis, superioribus elongatis gra- 
cilibus numerosis, densioribus, secundatis; articulis inferioribus diametro rqqalibus, superioribus duplo lorevioribus, subobsoletis; zonis superioribus confluentibus contiguis, inferioribus transcurrentibus. Tetrachocarpia in apicibus ranorum et ramellorum ad latera exteriora tuberculiformia. Color pallide roseus, siccitate miniatus.

IIab. ad oras Gallix.

43. E. unsutum (Kül. Linn. 1842 $p .736$ ) apicibus simplicibus (non forcipatis), haud clare circinatis; aculeis elongatis, crectis 2-3articulatis (articulo infimo longissimo!, rerticillatis, numerosissimis; articulis trichomatis diametro subxqualibus, zonis distinctissimis, distantilous, interstitiis nudis pellucidis. Külz. sp. p. 681 .

Hab. in mari mediterraneo.

46. E. ARMitum (Küz. Bol. Zeil. 1847 p. 34) pulchre roseo-chalybeum, gracile, elongatum, subsetaccum; apicibus inæqualibus forcipato-circinatis; aculeis numerosis elongatis hyalinis, triarticulatis (articulo infimo longissimo) omnibus patentibus, superioribus subsecundis, zonis decurrentibus, superioribus approximatis et confluentibus, inferioribus distantibus; articulis inferioribus diametro triplo longioribus. Long $3^{\prime \prime}$. kiül. sp. p. 681 .

Hab. Torbay.

47. E. Julaceus (Külz. Limn. l. c.) apicibus circinatis, simplicibus rel inæqualiter forcipatis; aculeis verticillatis longissimis, triarticulatis (articulo infimo longissimo', numerosissimis, superioribus erecto-adpressis, inferioribus patentibus; articulis (trichomatis) diametro iequalibus; zonis superioribus confluentibus, inferioribus decurrentibus, interstitiis nudis obscuris. $-\beta$. articulis diametro $2-3$ plo longioribus. Kiül. sp. p. 681 .

Hab. in mari adriatico.

48. E. imbricıtum (Küls. Linn. l. c.) apicibus circinato-forcipatis, aculeis numerosissimis, verticillatis, triarticulatis (articulo infimo ceteris duplo majori) superioribus adpresso-imlricatis, inferioribus erectis; articulis (trichomatis) diametro æqualibus; zonis superioribus contluentibus, inferioribus subdefinitis; interstitiis opacis. Kü̋z. sp. p. 631 . Hab. in mari mediterraneo et adriatico.

49. E. Dispiaxur (Külz. l. c.) apicibus simplicibus circinatis vel clavatis; aculeis numerosissimis verticillatis aqualibus, omıibus patentibus, superioribus 2-3-, inferioribus $3-4$ articulatis (articulis apicem versus scusim minoribus); articulis trichomatis diametro subæqualibus; zonis distinctissimis distantilsus, iuterstitiis pellucidis. Kü̋.s $s p . p$. 681 .

Hab. in mari adriatico.

Bo. E. sprxuosum (Kül. Linn. l. c.) apicibus circinato-forcipatis; aculeis verticillatis 3-4articulatis (articulo infimo ceteris paullo majori) nu- 
merosis brevioribus, superioribus erecto-patentibus, inferioribus subadpressis; articulis trichomatis $2-3$ plo lonyioribus, zonis angustiorilus distinctissimis remotis, interstitiis nudis pellucidis. Lül\%. $s p . p$. 682.

Hab. in mari adriatico.

54. E. SEcunditur (hülz. Bol. Zeil. l. c.) subsetaceum, flaccidum, gracile, apicibus forcipato-circinatis clausis; aculeis numerosis majoribus flaccidis, superioribus quadriarticulatis (articulis sensim minoribus) secundis, inferioribus - - Barticulatis patentibus; zonis distinctis, superioribus confluentibus, deorsum distantibus, non decurrentibus, interstitiis hyalinis; articulis inferiorilus diametro 2-3plo longioribus.

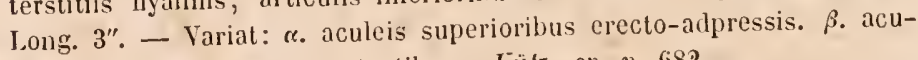
leis superioribus erecto-patentibus. hül. sp. $p .682$.

Hab. in mari adriatico.

52. E. н.мulatum (Fülz. Bol. Zeil. l. c.) setaceum, rigidulum, apicibus arcuato-hamulatis, aculeis ramulorum rigidis patentibus sursum et in latere interno decrescentibus, 3-4articulatis, ramorum majoribus subflaccidis, incurratis, plerumque Garticulatis (articulis apicen versus sensim minoribus); zonis omnibus distinctis, deorsum distantibus, interstitiis pellucidis; articulis inferioribus diametro duplo longioribus. Jong. 2". liülz. sp. p. 68z.

IIab. Tergesti.

s3. L. pelducidum (lïlz. Linn. l. c.) apicibus uncinato-forcipatis; aculeis numerosissimis, elongatis, gracilibus, quadriarticulatis, verticillatis, supremis erecto-adpressis, inferioribus patentibus; articulis superioribus diametro duplo, inferioribus 5̈plo longioribus; zonis definitis angustissimis, interstitiis nudis longissimis, maxime pellucidis et lyalinis. Кӥ̈z. sp. p. 682 .

Hab. in mari mediterraneo et adriatico.

54. E. pubenulun (liülz. Linn. l. c.) apicibus circinato-forcipatis, forcipibus clausis; aculeis brevibus, 2-3articulatis (articulo infimo ceteris parum majori), subsecundatis, inaqualibus; articulis diametro aqualibus, inferioribus duplo longioribus; zonis superioribus confluentibus, inferioribus decurrentibus; interstitiis opacis. liülz. sp. $p$. 682.

Cer. puberulum Sond. Preiss. p. 20? (sec. Kïitz.)

Hab. in mari mediterraneo et adriatico.

63. E. xunusculus (Külz. Linn. l. c.) apicibus vel simplicibus vel inaqualiter circinuato-forcipatis, trichomate inferiori et ramis primariis nudis, ramulis aculeatis, aculeis subsecundis, minutis, 2-3articulatis; articulis trichomatis diametro subxqualibus; zonis incurrentibus, interstitiis nudis pellucidis. liüls. sp. p. 682 .

Hab. in mari adriatico. 
4. Species Iützingiana sect. quarta (sp. 21-23 subjungenda?)

56. C. Pцахсм (hülz. sp. p. 687) pollicare; trichomate primario basi ultra setaceo, carlilagineo, firmo, ramis distiche vel plano-dichotomis flabellatim expansis, ramulis superioriluus erectis adpressis furcellatocorymbosis, subtilibus, apicibus multifidis fastigiatis, nec incurvis.

llab. ad Cap. b. Snei.

\section{Centroceras fiüzing in Linnaca 1841 p. 741. Phyc.}

gen. p. 381. Sp. Alg. p. 685. Mont. Fl. Alg. p. 140. Ceramii sp. Ag. el Auct. Spyridix sp. J. Ag.

Frons filiformis, dichotoma aut prolificationibns ramosa, articulata monosiphonia, strato collularum corticata, cellılis longitudinaliter et transversaliter seriatis lıexaedris. Favella ad ramulos sessiles, ramellis conformibus pluribus subregulariter involucrate, intra sacculum lişalinum gemmidia plurima angulata foventes. Spharosporce morphosi cellularum corticalium formate, plus minus extra stratum corticale prominentes, sphærica, triangule divisa. (Külz. Phyc. tab. 46 V.)

Frondes filiformes teretes, circiter capillares crassitie, regulariter dichotome et fastigyatie, apicibus forcipatis. Fila simplici seric cellularum (articulorum) superimpositorum constituuntur; sed membrana articulos includens cellulis constat, quæ ubique articulum tegunt. Cellul istæe et longitudinaliter et transversaliter seriatæ sunt, hexaedre, quadraticx aut rectangulares, in seriebus Iongitudinalibus alix aliis superpositx, in sericbus vicinis non e regione positæ, sed alternæ; filo transversaliter secto, circa tubum vacuum periphericæ vilentur, peripheria ultra 20 cellulas, simplici serie dispositas, continente. Circa genicula cellulix minus regulariter seriate, ob evolutionem continuam hoc loco peractam. Geniculorum cellulie plerumque intensius coloratx. Spinulix nunc nullie, nunc circa genicula verticillatim evolute, externo latere forcipum et in partibus jurenilibus pricipue conspicux, duobus articulis plerumque constantes, inferiore subcolorato, superiore aculissimo; in senilibus sæpe desunt.

Spharosporie (in ma specio tantum observatie) in prolificationibus axillaribus subumbellatis provenientes, in segmentis terminalibus circa geniculi verticillate, morphosi cellularum corticalium formati, demum extra genicula emergentes, intra perisporium liyalinum triangule divisa. Favelle in segmento frondis abbreviato 
sessiles, sape geminæ intra involucrum, ramellis conformibus $4-\not$ constitutum; nucleus rotundatus.

Genus Ceramio ita prosimmm, ut an jure distinctum sit dubitarem. Nullo omnino charactere differt, nisi cellulis corticalibus regulariter seriatis. Quo fretus charactere speciem typicam generis ad Spyridiam (in Alg. mediterran.) retuli, sphaerosporis tunc temporis milhi ignotis. Ilis vero a Montagneo detectis, et a küzingio dein pulchra analysi ulterius illustratis, aliam de affinitate harum plantarum ideam amplecti necesse est. Genus itarne Centroceratis, a Kützingio interea formatuin, cum Montagneo hodie assumendum putavi, adjecta specie, quam inter Cerania a Kï̈zinģio enumeratam suspicor, structura convenientem, at defectu spinularum abludentem.

Species numerosas, quas enumerarit liützing, unius ejısdemqque speciei formas, ne varietatis quidem nomine distinguendas, censeo. Cfr. J. Ag. Advers. p. 22 et squ.

1. C. cismabarinum (Grat. mscr.) fronde capillari inermi regulariter dichotomo-fastigiata, prolificationibusque sparsis obsiti, segmentis terminalibus forcipatis erectiusculis, articulis inferioribus diametro 2-3plo longioribus, fructibus. . .

Boryna cinnabarina Gratel. mscr.!

Boryna elegans $\beta$. cimnabarina Bonnem. Itydr. loc. $p .86$ !

? Ceramium ordinatum liülz. Ihlyc. gen. p. 381. Sp. Alg. p. 686!

Ilab. in mari adriatico el mediterraneo.

Cæspes bipollicaris, purpurascens. Fila capillari crassitie, a basi ad apicem parum attenuata, regulariter dichotoma et prolificationibus sparsis demum conformibus subramosa. A pices parum incurvi, velut tota planta aculeis omnibus destituti. Articuli ramorum minorum diametro xquales aut sesquilongiores, maiorum 3 plo longiores. Cellulæ corticales æque Iatæ ac longx, sericbus longitudinalibus dispositæ, transversaliter alternx, h. e. in seriebus vicinis non e regione positæ. Genicula parum clevata. Fructus non vidi. Chartæ adharet.

Hanc speciem esse Grateloupii veram specimine authentico certior factus sum. Cum Cer. ordinato hüt. quoad descriptionem convenit, nisi quod articulos diametro axquales describit. Suam speciem inter Ceramia disposuit Küutzing; Grateloupianam Cer. clavulato proximam puto.

2. C. clavelatur (Ag. mscr.) fronde capillari spinulosa regulariter dichotomo-fastiggiata, demun ex axillis prolifera, segmentis terminalibus incurvato-forcipatis, articulis inferioribus diametro 1-6plo Iongioribus, geniculorum spinulis verticillatis, sphx- 
rosporis circa genicula prolificationum verticillatis emergontibus, favellis geminatis, involucri ramis 4-3 filvellam superantilus.

Ceramium clavulatum Ag. apul fiunth. Syn. pl, aquin. $1 p$. 2. Sp. Alg. II. p. 4:32! Mart. Bras. p. 44. Mont. Cuba p. 26 tab. 2 fig. 1 et Canar. (i). $p .473$ !

Spyridia clarulata J. Ag. Alg. med. p. 80 ! Mont. Bon. p. 53! Pol. sud. p. 93 !

Centroceras clavulatum Mont. Fl. Alg. p. 140!

Centroceras sp. omnes hüls. in Linnaca 184t. Phyc. gen. tab. 46 fig. V! Sp. Alg. p. 688! Sond. Alg. Preiss. p. 20 !

Boryna torulosa Bonnem. Ihydr. loc. p. 58 !

Ceramium Gasparinii Menegh. in Giorn. Bot. 1844 p. 186.

Boryna ciliata Bory ap. Belang. Voy. Ind. Orient. $p .177$ (fide Mont.) Boryna Borbonica Grat. mscr.!

Ilab. in oceanis calidioribus ubique; in atlantico a Canariis ad Cap. b. Spei!, a Vera-Cruz! usque ad Rio-Janciro!; in mediterraneo!; in pacifico a Callao! et Taiti (Jacquinot) ad insulas Sandwich!; in indico a littore Ilindostania! usque ad Bourbon! et littus occidentale Nove Holkandix (Preiss).

Cæspites 2-3pollicares purpurei. Frondes teretes capillares, a basi ad apicem xqualem crassitiem servantes, subregulariter dichotomæ, fructifere proliticationibus ex axilla emergentibus singulis aut geminis quasi polychotomæ. Apices supra axillam patulam incurvi, eximic forcipati. Articuli inferiores plerumque diametro 3plo-6plo longiores, aliquando 8 plo diametrum superantes, superiores brevissimi. Spinule a basi lata acutissimi, plerumque biarticulatæ, circa genicula simplici serie verticillatim dispositir, in segmentis terminalibus pracipue conspicua et externo forcipum latere sæpius majores, inferne et interno latere obsoletæ aut minores. Cellulæ corticales hexaedre rectangulares. Sphærosporæ in segmentis terminalibus præcipue prolificationum axillarium evoluta, circa genicula torulosa verticillation dispositæ, subexternæ. Farellæ sæpe geminatre, ramis $4-30$ umbellatim dispositis, nucleo favellie duplo longioribus, involucratie.

Speciei vulgatissima formas in numerosas species divisit liützing, de quibus cfr. J. Ag. Advers. $p .22$ et squ.

\section{Campylapiona J. ag. mscr.}

Frons filiformis dichotomo-ramosa immerse articulata, corticita, cortice cellularmm stratis duobus constante, interiore cellulis lavioribus elongatis, superficiali cellulis minoribus rotundatis . contexto. Spharospora in apicibus incrassatis incurvis immersæ, cir- 
cumcirca nidulantes, cellulis corticalibus formatæ, filis elongatis strati medii stipatæ, rotundatæ triangule [?] dirise.

Frons teretiuscula, aut leviter compressa, fuscescens, irregulariter dichotoma, ramisque elongatis utrinque subattenuatis virgata, imnerse articulata, articulis brevibus, diametro subxqualibus, non nisi dissectione ant in exsiccatil et collabente planta conspicuis, strato corticali denso continuo obducta. Stratum corticale duobus stratis fere distinctis constat; cellule interiores sunt majores et lasius disposita, in sterili tamen adproximata, exteriores minores et rotundatx. Fertilis planta gerit apices in modum Hypnæx incrassatos et incurvatos. Pars incrussata oritur cellulis strati medii eximie evolutis, in fila elongata, tubo articulato percursa, hic illic incrassata et in nodos cellulæformes intumescentia abeuntibus; cellulis strati exterioris rotundatis. Sphærosporæ infra cellulas rotundatas exteriores nidulantes, nullo ordine disposite, intra perisporium rotundatum amplum sporas, triangule, ni fallor, secedentes, foventes.

Genus, favellis nondum observatis, affinitate forsan dubium; quoad structuram Ceramio proximun. Tubus centralis spatium fili dimidium occupat, membrana ampla et crassa. Erolutione strati medii, in planta fertili perinsigni, a Ceramio differt. Spherosporas magnas et perisporio amplo circunudatas vidi.. De disisionis modo tamen non omnino certus sum. Ne cum Ilypnea compáretur, et structura frondis et fructus, quantum innotuerunt, retant.

\section{C. HYPXeoides (J.Ag. mscr.)}

Ceramium rubrum var. firmum Ag. $s p$. (quoad spec. Japonica!)

Ilab. ad oras Japonixe (Tilesitus!)

Magnitudo et habitus fere Cer. rubri virgati, sed densius corticata et articuli breviores. Jertiles apices II. musciformem mire referunt. Iconem Sprengelii, quam huc trahit C. Agardh, longe aliam plantam spectare, suspicor.

XVI. Microcladia Grev. Alg. Brit. p. 99. Ilarv. man. $p$. 63 et Phyc. Brit. tab. 29. Endl. Gen. Pl. Suppl. III. p. 36. ґйtz. Plıус. p. 382. Delesserix sp. Ag. et Auct.

Frons compressa decomposito-dichotoma flabellata, immerse articulatil corticata, cortice cellularmu stratis duobus constante: interiore cellulis magnis rofundato-angulatis; superficiali cellu- 
lis minutis contexto. Facella ad segmenta sessiles, ramellis conformilus paucis involucrate, intra periderma hyalinum gemmidia plurima angulata foventes. Spherospore in seguentis pemultimis incurvis immersa, secus marginem exteriorem nullo ordine disposite, a cellulis subcorticalibus formatie, splacricie triangule divisa.

Frondis compresse linearis diclıotomo-decomposite segmenta flabellatim distiche expansa, tubo articulato opercursa, articulis rotundato-oblongis, dense corticata, corticis interiore strato cellulis magnis rotundito-angulatis, exteriore cellulis minoribus coloratis constante.

Favelle intra involucrum singnlæe, rotundate, intra membranam lygalinam gemmidia plurima fovent. Involucrales rami pauci, plerumgle tres, favellam vix supereminentes, segmentis conformes. Sphærosporæ secus nıarginem exteriorem segmentorum lateralium perultimorum evolutie, lineam longitudinalem unicam formantes aut, cellulis pluribus ejusdem seriei transversalis pragnantibus, irregularius disposite et secus marginem exteriorem subaggregatx, celIulis infra-superficialibus formatie, intra perisporium hyalinum nucleum triangule guadridivisum forentes:

Genus naturale a Grevilleo institutum, ab omnibus receptum. Ramificatione, fructu, labitu et fere structura cum Ceramii speciebus non parum convenit, fronde densius corticata et externe inarticnlata diversum. Cum Carpobleplari, genere Kützingiano, characteres genericos offert simillimos; distant præcipue ramificatione et situ spherosporarum; qui characteres utrum genericæ distinctioni sufficiant, an ejusdem generis sectionibus diversis adtribuantur, nove species detecte forsan docebunt.

1. II. Glandurosa (Soland. mscr.) Grev. Alg. Brit. p. 99 tab. 13. Harv. Man. p. 65. Phyc. Brit. tab. XXIX. Kütz. sp. p. 689. Mont. Fl. Alg. p. 139!

Fucus glandulosus Sol. mscr. in Turn. Ilist. Fuc. lab. 38. Engl. Bot. lab. $213 \ddot{\text { ü. }}$

Delesseria glandulosa Ag. Sp. I. p. 182. Sysl. p. $2: 31$.

Fucus implexus Dec.

Sphærococcus cristatus $\beta$. angustatus Ag. sp.p. 301 (quoad sp. Hispaniæl)

Exsicc. Wyalt Danm. n. 68! Chauv. Aly. Norm. n. 172!

Hab, in oceano atlantico a littore meridionali Anģliæ (D:na Griffitlıs!) us(jue ad Tinguin (Schousboc!); in mari mediterraneo ad Massiliam (Ipse!). 
Crspites 2-3pollicares. Frons $1 / 4-1 / 2$ lineam lata, linearis, infra diclotomias cuneatim expansa, apicibus atlenuatis forcipato-incurvis; segmenta supra axillas patentes erectiuscula, alterna breviora sublateralia; hæc præcipue sphærosporis onusta. Color roseus. Chartæ laxius adhæret.

Primus, ni fallor, hanc plantam in mediterraneo legi et specimina ad Massiliam lecta distribui; inadvertentia mea dein in Algis Medit. nulla jllius mentio facta fuit. Specimina Kamtschatica, in Spec. Algar. C. Agardhi memorata, ad aliam plantam pertinent.

Segmenta aliquando extrorsum spinulis articulatis coloratis seriatis instructa vidi. Specimina nonnulla, quæ ex Biaritz et Tingi milhi proveniunt, sunt humiliora et latiora, articulis internis magis perlucentibus quasi tenuiora, atgue præcipue apicibus obtusis nec vere forcipatis a planta vulgari diversa. An plures species hic lateant?

X VII. Carpoblephiaris kütz. Phyc. gen. p. 449. Sp. Alg. p. 690. Ptilote sp. Ag. et Auct.

Frons compressa pinnatim decomposita, axi articulato corticato, cortice cellularum stratis duobns constante: interiore cellulis magnis rolundatu-angulatis, superficiali cellulis minutis contexto. Favelle interiore latere pinnularum sessiles, ramellis conformibus pluribus involucratæ, intra periderma hyalium gemmidia plurima angulata foventes. Spharospor $x$ in pinnulis lanceolatis immersx, subregulariter transwersim seriatx, a cellulis subcorticalibıs formate, splıxice triangule divisæ.

Frondes compressæ pinnatim decompositæ, pinnis conformilus alternis aut nullo ordine densissime a margine egredientibus, majoribus composilis minoribusque simplicibns intermistis; minorum nonnullis sensin increscentibus et compositis, plurimis fertilibus stichidia lanceolata referentibus, demum deciduis [?].

Frons ab initio corticata videtur. Aris tubo mico centrali articulato, sectione transversili cellulam amulante, constituitur; stratum intermediun crassum, cellulis magnis rotundato-angulatis contextum; superficialis strati cellulx conformes, sed multo minores, endochomate colorato farctre.

Favelle intra involncrum nucleis pluribus, majoribns et minoribus, constant. Nuclei singuli intra membranam aut gelatinam hyalinam gemunidia plurima fovent. Involucrorum ramelli incurri plures ( $\ddot{3}-7$ ), pinnulas angustiores xmulantes. Involucra interiore latere pinnula levissime incurve sessilia. Sphærosporæ in pinmulis 
simplicibus, stichidia lanceolata referentibus immerse, a collulis infra-superficialibus formatæ; cellule lıæ fere ommes pregnantes, apiec stichidii utroque excepto; quia cellule iste sericbus subregularibus disponuntur, splıærospore quorue seriatæ adparent; in seriebus vicinis Iongitudinalitor alternx.

Genus hoc a Sulıio primum indicatum (Beitr. p. 29 in Flora 1836 B:d 1) claractere bene exposito, at non rite limitatum. A lüutzing in Phyc. gen. noro nomine separatum, sed charactere male exposito et limitilus ita ductis ut speciem țpican Ptilotie adnumerilret, formas vero ejusdem ut nori generis species exponeret, quæ omnia in Speciebus Mgarum emendavit. Sphierosporis immersis, celIularum: corticalium transformatione ortis, et structure levi differentia hoc genus a Ptilota bene distinguitur. Ad Jicrocladiam aretius accedit, et cum las forsan non male conjungatur, si species nore intermediæ detegerentur; ut hodie limitantur, distant ramificatione et sphærosporarum dispositione.

1. C. FLICCid (Turn. Hist. tab. 61) frondis decomposito-pinnate piunis nullo ordine egredientibus, majoribus compositis minoribusque simplicilus mistis, omnibus utrinque attenuatis.

Fucus flaccidus Turn. $l$. c.!!

Ptilota flaccida Ag. sp. p. 38s! hüls. Phyc. p. 378!

Carpoblepharis capensis et C. densa Kül. Phyc. p. 449 !

Carpolslepharis flaccida $k u ̈ l z . s p . p .690$ !

Hab. in Eclilonia buccinali ad Cap. b. Spei!

Frondes a disco radicali cæspitosæ plurimæ, usque pedales, lineam circiter latæ, sæpius indivisæ at pinnis plurimis brevioribus obsitæ, nunc his majoribus speciem frondis divisa offerentibus. Pinnæ subhorizontaliter exeuntes, a margine distichæ, sparsiores aut densissima, majores minoresque mixtæ; majores eodem modo pinnulatie, pollicares et ultra, lineares, utrinq̧ue attenuatx; minores lineam longæ, indivisæ, lanceolatie acutic aut obtusx. Favellie ad superiorem marginem pinnularum sessiles, iuvolucro polyphyllo inclusæ. Sphrrosporæ in pinnulis simplicilus lanceolatis plurimie. Color pulchre coccincus. Charte non adharet, nisi jurenilis aut dissoluta.

Varietates distinxerunt: Sulır conferlam, gracilem, nanam, Rudolphi frmam, Kü̈zing Capensem et densam, quæ vero omnes sunt ejusdem speciei formæ, maynitudine, etate etc. leviter aberrantes.

2. C. Pisitifoli (Suhr. Eckl. n:o 43) frondis decomposito-pinnate pinnis regulariter alternis, sursum sensim minoribus, majoribus a basi latiore sensim attenuatis. 
Ptilota? pinnatifolia Suhr. l. c. tab. II. fig. 18!

Carpoblepharis pinnatifolia Kü̈t. Bot. Zeit. 1847 p. 1. Sp. Aly. p. 691 !

Hab. ad Cap. b. Spei. (Ecklon).

Frons 2-3pollicaris, 1-2lineas lata, sensim attenuato, bipinnata, pinnis alternis, inferioribus majoribus, sinubus rotundatis. Stichidia lanceolata incurva. Inferne cornea, sursum tenuior. - Species olim a me visa; quum vero hodie nullum specimen possideo, auctoritate liutzingii hoc loco enumeratam fuisse, dicere fas est. 


\section{ORdO II. CRYPTONEMEE.}

Cryptonemex J. Ag. Alg. med. p. 66. Endl. Gen. plant. Suppl. III. p. 36. Sond. Alg. Preiss. p. 24. Ilook. et Harv. in Hook. Lond. Journ. IV. p. 546 etc. Montagn. Phycologie in Dict. univ. p. 42 (mut. limit. ap. omnes); Floridearum genera $C$. Ag. et Auct.; Gymnopllleacex, Halymeniex, Gigartinex, Gelidiex, et Spliærococcсæ (quoad partes) Külzing. Spec. Algar; Cryptonemex, Furcellariex, Chondricx, Splierococcoidex et Gasterocarpex (quoad partes) Decsne Classific.

Frons cellulis filiformibus rutundatisve breviorihus contesti, strato continuo filorum moniliformium aut cellulurnm verticalium cincta. Cyslocarpia frondi aut verrucis externis Nematlecioideis immersa, rarius intra pericarpium proprium excepta, nucleo simplici (Favella) rotundato, intra periderma liyalinum gelatinosum gemmidia plurima rotundato-angulata, nullo ordiue conglobata, fovente. Spharospore transformatione cellularum corticalium formatie aut in Nematheciis evolute, immersx.

Algx plerumque coccinex aut purpurascentes, nunc atrovirenti suffusæ, frondosæ, forma varix: aliquando cavæ, nempe strato periplerico firmiori (cellulis arcte coalitis, rotundato-angulatis, simplici aut paucis sericbus dispositis, contexto) constantes, intra quod fila aut nulla aut sparsiora vel plurima, tamen lasa inter parictes extenduntur (Ilalgmenicx); sinpirs solidescentes, nune planæ late expansie, membranam integram rageve fissam referentes (Schizymenia), aut laciniatæ et divise (Nemastumx sp., Epymenia, Crsptonemia) rel proprie pinnate (Grateloupia sp.); nune angustiores phanæ aut compresse, dichotome aut pinnatic (Gratcloupiæ sp., Prionitis, Acrotỵlus sp. Fauclıa), nunc teretiusculæ (Gloiosiphonia, Furcellaria, Gloiocladia) ant prismatico-angulatie (Acrotylus sp.). Costa rarissime adest, ant spurie frondem pereurrens (Rlizophyllis), aut sensim in laminam evanescens (Cryptonemix 
sp.). Stipes plerumque brevissimus; nunc magis evolutus laminas, canlis ad instar, sustinens (Clnysymenix sp., Cryptonemixe sp.). Substantia nune gelatinose (Gloiosiphonia, Nemastoma, IIalymenieæ, Gloiocladia), sæpissime carnosæ, rarius clartaceo-membranacex (Cryptonemix sp.).

Cellularum stratis duobus conteste sunt. Interius nunc filis constat elongatis arficulatis ramosis vel anastomosantibus sparsioribus (IIalymeniex), aut densioribus (Nemistomer, Cryptonemix), nunc cellulis abbreviatis rotundato-angulatis (Fauchex, Rhizophyllex). Stratum exterius verticale aut filis moniliformibus dichotomofastigiatis (Nemastomex, Faucher etc.), aut cellulis rotundato-angulatis sulsimplici serie dispositis (Gasterocarpex, Rhizophỵllex, Cryptonemix) constitutum est. In nounullis cellulie interiores filorum verficalium, exterioribus majores, stratum fere propriun efficiunt (Nemastoma, Prionitis). Fila verticalia muco laxiori (Gloiosiphonia, Nemastoma, Gloiocladia) aut sxpissime solidescente colibentur.

Organa fructificationis duplicis generis observata fueruut. 1:0 Cystocarpia situ varia; plutimorum in immutata fronde immersa aut plus minus hemisphicrice prominentia, rarius intra pericarpium proprium excepta (Chrysymenia, lanchea), vel inter fila verrucie externæ Nemathecioidex nidulantia (Acrotylus, Rhizophyllis), aut in parte frondis transmutata siliquxformi plurima conjuncta (Furcellaria). Carpostomium, ni fallor, semper adest; aut rero secedentibus filis strati superficialis efficitur, aut ostiolum rotundatum in superficie demum rumpitur, per quod nucleus elabitur; in nonnullis preterea adparafus filorum anastomosantium, inter nucleum ot ostiolum superficiale extensus, canalem eruptionis proprium circumdat (Chrysymenia, Fauchea, Epṣmenia). Nucleus simplex (Favella), cellula transmutata frondis oritur, intra periderma gelatinosum magisque extensum, gemmidia plurima fovens. Gemmidia rotundata aut pressione mutua angulata, muco rarius conspicuo iuvicem separati, adparenter nullo ordine conglobata. Nuclei seppissine inter fila frondis suspensi, raro supra placentam cellulosam (Clrỵsgmenia, Epymenia) expansi aut ad filanentosam (Fauchea) adfixi, ejusdemquo filis eincti. Favellarum nuclei juveniles iutra periderma laxum partes coloratas pauciores continere videntur; partes coloratie plures pluresque (disisione endochromatis iterata?) intra periderma sensim maris extensum et gelatinosum oriuntur; partes coloratie inferiores majores adparent et quasi placentam periphericis constituentes. In matura favella dissecta gemuniclia (iutra gelatinam aretius ambientem) 
a centrali cellula rodiantia quandoquidem vidi (Halymenia, Clıŗ̣symenia, Faucliea, Lpymenia); alipuando, peridermate acido superfuso soluto, gemmidia colierentia, quasi articulos filorum dichotomofistigiatorum efficerent, observavi.

2:0 Spharospore transformatione cellularum ant filorum corlicalium ubicumque oriuntur; sepissime iuter collulas aut fila haud mutata sparse, rarius in phyllis propris vel in sorum ambitu fere definitum collecte et inter cellulas partum mutatias steriles disposita (Fpynenia, Cryptonemia); nunc in Nematheciis externis evolute. Nemathecia orinutur evolutione peculiari filorum corticalium, filisque constint moniliformiter articulatis diclotomo-fastiogiatis, a puncto aut linea centrali quoquoversum radiantibus, muco laxiori tantun cohihitis. Splıxrospora ex ramulis filorum Nemathecii nonnullis transmutate, filis sterilibus insident et his cinguntur (Acrotylus, Fauchea). Nucleus sphærosporæ spliæricus, spliæroideus vel immo oblongus, maturitate in partes 4, cruciatim aut zonatim dividitur. Splierosporæe zonitim divisæ in Furcellaria, et Acrotylo, observatæ; in Gloiosiphonia, Nemastoma, Schimmelmannia, Gloioclidia nondum cognite; in cxeris cruciation divise.

Ordo, qualean hoc loco limitarimus, ex una parte Ceramicas, ex altera parte Gigartineas potissimum tangit; nonnulla genera, favellis intra pericarpium proprium receptis et placenta propria suffultis instructa, Sphxrococcoideis aut Chondrieis quodammodo adproximantur. Cum Ceramieis structura ipsios muclei ita conveniunt, ut favellas utriusque ordinis simillimas et nulla nota distinguendis putarem. Ceramiex vero articulata sunt et Cystocarpia nuda, ant tantum involucro inclusa, gerunt. Seric tamen subcontinua Genera Ceramiearum in Cryptonemeas transeunt, Dudresuilja et Gloiosiphonia transitum mediantibus. Gigartinex structura frondis cum Cryptonemeis conreniunt; nucleum cystocarpii vero in lis indole nimium diversum existimo, quam ut ufamque fimilian hodie conjungere auderem. Nucleus enim favellidii compositus, transformatione collularum aut filorum plurimorum coalescentium oritur; in plexu filorum aut celIularum stipatissimo gemmidia intra cellulas ramosve filorum, quoquorersum evolutos et plures pluresque sensim transmutatos, parica formantur. Nucleus compositus nulla ambiente membrana cingitur; nec carpostonrium proprim favellidiis adesse mili videtur.

Cryptonemeis ordinem proprimm in Aluis mediterraneis condidi, quem expulsis generibus quibusdian hodie conservo. Fructum capsularem in diversis generibus differentias offerre, jam tunc tem- 
poris observaveram (Alg. med. p. 6I), altamen cystocirpia omnitum nomine favellidii designavi. Postea (Alg. Liebm. p. 11 et 12) differentias las ulterius exposui, et ordines proprias quibusdam generibus fundavi. Llterius in structuram Nuclei inquirens, tum limites ordinis magis adluc mutandos video, tum de indole fructuum idæam aliquantulum diversam profiteor. Ut enim, posthabita structura frondis et externo fructuum labitu, systema Floridearum penitiori cystocarpiorum structura et quasi ipsa indole nuclei fuudare conamur, sequitur ut genera permulta (Polyides, Rhabdonia Catenelli, Dumontial etc.), qux, structura frondis et extermo habitu ducente, Cryptonemeis adnumeranda fuissent, expellenda sint.

Aliam quoque viam in Tribubus ordinis formandis, cuas provisorias antea assumseram (Alg med. p. 82-83), liodie iugressus sımu.

Generi nonnulla, quorum fructus capsulares nondum cogniti, aflinitate adlute dubia a me considerari, per se patet.

\section{EAPOSITIO GENERLM ET TRIBUUN SYNOPTICA.}

TRIBUS I. NEMASTOMEE. Frons filis elongatis contexta, interioribus longitudinalibus articulatis, exterioribus verticalibus moniliformibus diclıtomo-fastigiatis. Favellæ nucleus simplex frondi aut strato nemathecioideo immersus, secedentibus filis corticalibus demum liberatus. Spluerospore inter fila corticalia sparse aut in Nemathecis externis evolutx, cruciatim aut zonatim divisæ.

a. Favellis per frondem immutatam sparsis. Frons tubulosa filiformis gelatinosa.

XVhI. Gloiosiphoxis.

Frons farcla filis interioribus dense interlextis, ramosis. Fronde dichotoma aut subpinnata . . . XIS. Nemastoma.

$"$ integra aut vage tissa . . . . XX. Schuzrmexia.

Frons farcla filis interiorilus anastomosantibus in reliculum conjunctis.

Stratis duobus contextæ . . . . . XxI. Gritelocpla.

" tribus constantes. . . . . . Xxil. Priontrts.

b. Favellis in stralo Nemathecioso immersis

dilli. Aghotrues.

c. Fuvellis in siliquis terminalibus evolutis.

xiry. Furcellaris. 


\section{TRIBUS II. GASTROCARPEE. Frons tululosa, filis interioribus} elongatis articulatis, cellulisque periphericis in stratum membranaceum coalescentibus conteslat. Favella nucleus simplex infra stritum exterius, in pericarpium quandogue elevitum, demum carpostomio ruptun, exceptus. Splacrospore a cellulis corlicalibus formate, cruciatim divise.

Cystocarpiis frondi immersis, carpostomio rolundato demum rupto liberatis.

Fronde dicholoma aut pinnata. . . . . XXV. Halmexia.

\section{Cystocarpiis intra pericarpium exceptis.}

Frondeplumoso-pinnata, carpostomio lacero. . XxVI. Schimalanania.

" ventricosa, aut caulescente et vesiculigera, carpostomio rotundo . . . xivil. Cinrysrueni.t.

\section{TRIBUS III. FACCIEE. Frons carnoso-membranacea, cellulis in-} teriorihus rotundato-angullatis, exteriorilus radiatis verticalibus. Favellix nucleus simplex aut lobis pluribus in unum confluentibus subcompositus, intra pericarpium proprium receptus, placentæ impositus, carpostomio regulari liberatus. Sphærospore inter collulus corticales sparsæ aut in Nematheciis externis evolute, cruciatim divisæ.

Frons filiformis gelatinosa . . . . . XXvill? Glolocladu.

" plana

cyslocarpiis marginalibus, sphærosporis

inter fila nemathecii evolutis. . XXIX. Fatcuea.

cystocarpiis et sphærosporis in phyllis

proliticantibus provenientibus . . XXX. EPYMENa.

\section{TRIBUS IV. RIIZOPHYLLEE. Frons membranacea, cellulis ro-} tundato-angulatis tota contexta. Favelle nuclei simplices in verrucis Nematlecioideis evoluti, secedentibus filis demum liberati. Splæerosporix. . .

XXXI. RHIZOPIYLLIS.

\section{TRIBUS V. CRYPT0NEVIIE. Frons membranacea subcaulescens,} filis interioribus elongalis, cellulisque exterioribus rotunditis subradiatis contexta. Favelle nucleus simplex infra stratum exterius subinflatum, carpostomio regulari pertusum, exceptus. Splixrosporie in soris subdefinitis erolutix. 


\section{TRIBUS I. NEILSTOMEE.}

Frons filis clongatis contexta; interioribus longitudinalibns articulatis, exterioribus verticalibas moniliformibus dichotomo-fistigialis. Favellæ nucleus simplex, frondi aut strato Nemathecioideo immersus, secedentibusfilis corticalibus denum liberatus. Sphierospore inter fila corticalia spirse vel in Nematheciis externis evolute, cruciatim aut zonatim divisæ.

XVIII. Glomosiphonia Carm. mscr. Berk. Glean. Br. Alg. p. 43 tab. 17 fig. 3. Harb. Man. p. 49. J. Ag. Symb. Cont. I. p. 453. Harv. Phyc. tab. LVII. Küutz. sp. p. 814. Landsborough in Ann. and. Mlag. of Nat. Hist. n. 91 p. 233. Nesogloie sp. Ag. et Auct. Dumoutia sp. Gaill. et Auct. Gigartinæ sp. Lamour.

Frons teretinscula gelatinosa quoquoversum ramosi, axi filamentoso tnbuloso filisque investientibns, stratum periphericum continuum formantibus, constans; axis filis dense intertextis longitudinalibus articulitis ramosisque, in medio laxioribus tubum subvacuum formantibus, constitutus; fila peripherica subrerticillata, demum densissima, moniliformia, dichotoma, fastigiata, invicem libera. Favella immersæ, strato peripherico obtecte, intra membranam gelatinosam hyalinam gemmidia plurima rotundata forentes. Spharosporce. . . (IIarv. Phycol. Brit. Lab. LVII.)

Frondes gelatinoso-cartilaginex, teretes, tubulosie, plerumqne indivise at ramis lateralibus plurimis eodem modo decompositis obsite. Axis jurenilium partium constat filis paucis articulitis, filit peripherica subverticillatin emittentibus; fila axis ramosa sensim plura evadunt, et in medio laxiora, spatium tubulosum vacuum, ant tautum sparsissimis filis percursum, linquentia; extrorsum sensim densius fit stratum axile, (filis decurrentibus?) et in inferiore planta filis densissimis constituitur; fila hec exteriora tenuiora et longioribus distantiis articulata. Fila peripherica moniliformiter articulati dichotoma fastigiata, extrorsum stratum continum formantia; articuli interiores longiores oblongi, exteriores breviores ellipsoidei et subsphærici. Favellie ad articulos inferiores filormm peripheria adfixie videntur, conniventibus rumis superioribus obtectie, et ita strato peripherico immersa; uncleus constat gemmidiis rotundatis pluri- 
mis a puncto centrali (inconspicuo) rere radiatim dispositis; nucleus cingitur membrana aut potius strato gelatinoso lyalino, angnsto at evidenti. Sphærospore (a Lynghyeo et Carmichicelio olsservatx [?], postea a nemine vise) inter fila verticillita ramulorum sitie, ut videtur sphæricæ. . .

Geuus Dudresuage fere proximum, deficiente avi articulato et splırosporis (ni fallor) diversum, favellis congruens; a Ilehninthocladia et Nemalione differt favellis et insuper structura alia. A Ilalymenia differt filis periphericis invicem subliberis, vel muco laxiori tantum colibitis.

Generis primus auctor Carmichael dicitur, cujus ex manuscriptis et iconibus primam dedit descriptionem Berkeley. Deinde ab omnibus receptum fuit, excepto tantum kützingio, qui in Plıycologia cum speciebus Nemalionis conjunxit; postea hic quoque genus aguovit.

1. Gl. Capillaris (Huds. Angl. p. 591) fronde angusta tubulosa lateraliter ramosissima decomposita, ramis ramulisque subdivaricatis utrinque altenuatis acutis.

Fucus capillaris Iluls. l. c. Turn. Ilist. tab. 31! Engl. Bot. tab. 2191. Gloiosiphonia capillaris Carm. mscr. in Berkel. Gl. p. 43 tab. 17 fig. 3! Harv. Man. p. 49 et Phycol. tab. LVII! Aresch. En. p. 93 tab. IV. C! Kütz. sp. p. 714 !

Mesogloia capillaris Ag. Syst. p. 51 !

Gigartina lubrica Lyngl. Ilydr. p. \$̈̈ tab. 12 A!

Exs. Aresch. Scand. n:o 65! Desmas. Alg. Franc. n:o 15. M:c Calla Alg. Ilib. . .

IIab. in oceano atlantico a littore Norregix"usque ad Hispaniam (sec. Ilarvey); in sinu Codano!

Frondes a callo radicali plures, plerumque 3-5pollicares, diametro penna circiter columbina, medio crassiores, utrinque attenuata, inferne nudiusculæ sed jam infra medium ramis lateralibus decomposito-ramosissimæ. Ramuli subdivaricati, flexuosi, medio crassiores, utrinque ad tenuitatem fere capillarem attenuati, nullo ordine quoquoversum egredientes. Filia axis longitudinalia articulos labent diametro pluries longiores; in periphericis sunt articuli interiores diametro 3-4plo longiores, oblongi aut subpyriformes; exteriores diametro sularquales et rotundati. Substantia recentis gelatinosa, exsiccatæ cartilaginea (nisi diutius fuerit in aqua dulci demersa, quum gelatinoso-membranacea appareal). Color recentis purpureus facile mutatur, et specimina sæpe flavescentia occurrunt; in aqua dulci præparata ad coccineum tendit. : 
Species videtur sporadice proveniens, apud nos in scrobiculis rupium exteriorum evoluta. Specimina secundun diversum præparationis modum satis habitu diversa; in collectionibus rara.

XIX. Nemastona $J$. ag. Alg. med. p. 89 (excl. sect.) Act. Ilolm. 1847 p. 90. Gymnophlæa Kï̈tz. Phycol. p. 390 et $\mathbf{S p}$. Alg. p. 711 (excl. spec.) Ialynienix et Iridæx sp. Auct.

Frons compresso-plana, gelatinoso-carnosa, diclıotona aut subpinnata, duplici strato constituta; strato centrali filis elongatis simpliciusculis longitudinalibus dense intertextis; peripherico filis verticalibus fasciculatis dichotomo-fastigiatis articulatis, articulis interioribus majoribus, extrorsum in fila moniliformia, muco laxiori aut solidescente colibita abeuntibus, contexto. Favella simplices infra stratum externum nidulantes, secedentibus filis demuin liberatie, intra periderma gelatinosum liyalinum gemmidis rotundata forentes. Sphcerospora ... (Kül. Phycol. lab. 74 fig. IV.)

Frondes ex tereti compressæ aut carnoso-planæ, nunc angustiores fere lineares repetite diclotomæ, multifidæ aut fere pinnatæ, nunc laminam lite expansan lanceolatam, dichotomiis paucis divisam offerunt, uune prolificationibus a disco et margine emergentibus quoque composite. Recentes ex carneo coccincæ, eximie gelatinosæ aut magis carnosæ, exsiccatie clartæ sæpe arcte adhærentes, nunc exsiccatione fere cartilaginex, madefactix aquam avide imbibentes.

Fila frondem constituentia triplici fere strato disponuntur. Intima, stratum compactius longitudinale formantia, sunt elongata et parce ranosa, densissime intertexta, canali interiori colorato intra membranam hyalinam conspicuo, plurima longitudinalia, paucis transversalibus, guare in sectione transversali frondis circuli conspiciuntur plurimi, interjectis filis paucis longioribus. Extrorsum hee fila oblique excurrunt et stratum intermediun lasius efficiunt, articulis brevioribus oblongis constantia; ut ipsam peripherian frondis adpropinquent, densius dichotoma evadunt, cellulis minoribus rofundatis contexta, et fila extiua moniliformia constituential. Fila lıæc extima nunc invicem libera aut muco lasiori colibita, nunc muco evidentiori et solidescente obducta. Favelle infra stratum exterinum nidulantes, secedentibus filis periphericis demum liberatæ. Nucleum divisione iterata cellulie unius formari facile crederes; 
in speciminibus enim favellas gerentibus collule majores (extime forsan strati medii), nucleum coloratum indivisum intra membrinam foventes, siepe obscrvantur, quas favellas inclıoantes sistere fere suspicor. (Ejusmodi prima initia fructificationis in Schizymenia Mertensiana Post. el Rupr. atque congenericis pluribus frequentia observavi). Ciemmidia itaque in jurenili fiuctu pauca, in adıltiore sensim plura, binatim aut quatermatim colserentia, omnia muco liyalino seu peridermate mucoso cohibita. - Sphacosporas nullas vidi; gemmidia antem Favellarum sphrerosporas aliquando refermut; an spharosporie aggregutie, ut in Gigartina, ita in præsenti quoque genere obveniant?

Nemastoma genus in Algis mediterraneis a me quidem inslitutum, sed latius quam fas fuit pittens, Irideas Grevillei ut sectionem propriam quoque complectebatur. Kützing genus Gymnophlaxe eidem plante typica in Plıycologia sua condidit, charactere a deficiente cuticula petito, limitibus quoque legitimis ductis. In revisione Iridiearum capensim, quam in $\Lambda$ ct. Holm. 1847 dedi, characterem a liützingio indicatum, quem antea omiseram, inter clairacteres generis assumsi, atque genus nova el insigni specie ausi. Ilodie vero hunc chiracterem minoris momenti considero, inventis speciebus tota structura convenientibus, at muco solidescente cinclis. Culicula, ni fallor, a muco, fila peripherica includente, oritur; in nonnullis speciobus gelatina ambiens mucosa manet, ef fila, inricem sublibera, singula ambit; in aliis speciohus eadem firmior et solidescens, in cuticulam, omnia fila simul includentem, mufatur. Speciebus loc modo diversis subgenera interea creavi.

Genus mili videtur ad Schizymeniam proxime accedens, structura et fructibus, quantum innotuerint, in utroque genere fere convenientibus; differunt lıabitu et ramificationis indole. A Ilalymenia, cujus species nonnulla labitu mire referunt, utriusque stratli struclura facilius distinguitur. A Dumontia, qua structura strati peripherici fore convenit, differt et fructu et strato interiore multo densiore.

1. Grmoprtas. Fila strati exterioris inticem sublibera aut muco laxiori lantum cohibila.

1. N. vermeutaris (J. Ag. mscr.) fronde gelatinoso-lubrica cylindraceo-compressa subpinnatim ramosa decomposita, ramulis superioribus elongatis longissime attenuatis aculis. 
Jlalymenia Floresia var. angusta Ag. sp. Alg. q. 209!!

\section{IIab. in mari Gaditano (Cabrera! Sclıousboe!)}

Frondes a callo radicali plures, 3-4pollicares, basi attenuatx, mox in crassitiem pennæ corvinæ dilatatæ, superne iterum angustatæ, inferne simpliciores, superne ramosissimæ, ramis principalibus subdiclıotomis, minoribus lateraliter ramosis, ramulis erectis elongatis pollicaribus, a basi latiore longissime attenuatis acuminatis. Frons recens forsan cylindrica, at maximopere gelatinoso-lubrica, exsiccata omnino collapsa, ramisque supra chartam subconfluentibus; madefacta subelastice reviviscit, at compressa rugisque longitudinalibus hic illic obsita manet. Color pulchre roseococcineus. Farellæ minuta a basi ad apicem sparsæ. Habitus fere Dudresnayæ; cui ne adnumeretur, frondis vetat structura. Fila interiora laxiora elongata (centrali nullo); intermediorum articuli diametro sesquilongiores; moniliformium rotundato-ellipsoidei; fila hæc verticalia sunt abbreriata et strato mucoso hyalino, quod quasi pellucido limbo frondem ambit, cohibentur.

A Mertensio primum hæc species F. protei Del. nomine inscripta fuit; ab Agardhio dein varietatis loco ad eandem speciem dubie relata. Habitu tamen jam facillime dignoscentur, et nulla revera inter utramque affinitas.

2. N. Dunoxtioldes (J. Ag. mscr.) fronde succosa gelatinoso-membranacea, ex tereti compressa, dichotomo-decomposita fastigiata, segmentis erectiusculis, terminalibus obtusis emarginatobifidis.

ILab. in mari mediterraneo; specimen unicum ad Massiliam rejectum legi!

Frons 2-4pollicaris, inferne attenuata, mox in crassitiem pennæ fere scriptoria dilatata, sursum iterum paulisper attenuata, segmentis ultimis lineam circiter latis; tota (6-8:ies) dichotomo-decomposita corymbosofistigiata. Segmenta supra axillas rolundatas erecta, terminalia rotundatoobtusa aut enarginatia vel bitida. Substantia gelatinoso-membranacea, exsiccata collapsa, rugis longitudinalibus ad utrumque marginem subsingulis percursa; sacculum refert membranaceum, succo repletum. Structura generis. Fila interiora satis densa; peripherica abbreviata, nuco subnullo cohibita. Charte arctissime adhret. Color purpureo-coccineus.

Præcipuam distinctionis notam ipso nomine indicavi. Quoad habitum Dumontiam aut ILalymeniam tubulosam crederes; sed structura Nemastomæ. Specimen unicum, 1837 lectum, domi conservaveram, quum sul) itinere $1842 \mathrm{Algas}$ mediterraneas describerem, quare in loc opere nulla illius facta fuit mentio.

3. N. Dicnotona (J. Ag. Alg. med. p. 91) fronde gelatinoso-carnosa, ex tereti compressa, dichotomo-decomposita subfastigiata, seg- 
mentis patentilus anguste linearibus cuncatisve, terminalibus (plermmque elongatis) oltusis.

Nemastoma dichotoma $J$. Ag. l. c. Zanard. Sagg. p. 49.

Gymnophlea dichotoma inutz. Pliyc. tab. If fig. IV! Sp. p. 71I!

G. incrassata lï̈ls. Phyc. p. 390. Sp. p. 711.

G. Biasolettiana lï̈lz. l.l. c.c.

G. furcellata Küls. l.l. c.c.

Halymenia Monardiana Mcnegh. (non Montagne).

Ilab. in mari mediterranco ad oras Galloprovincise et Italix (Ipse!); in adriatico (C. Agardh! Biasoletto! aliique.)

Frons 3-4pollicaris plus minus regulariter dichotoma, fastigiata, segmentis supra axillas rotundatas eximie patentibus, nunc sub-divaricatis. Segnenta linearia aut infra axillas subcuneata, 1-3lineas lata, inferiora plerumque angustiora, media latiora, suprema iterum angustiora, terminalia sæpius 3-4lineas longa, lineari-attenuata at obtusiuscula; nunc breviora, cuneato-obtusissima, aliquando subdamæcornia. Substantia gelatinosa carnosa, exsiccatione firma crassa parum cartilaginea; chartæ sat adhæret. Color recentis purpureus fere vini. Structura et Fructus generis. Fila interiora densissima; peripherica muco subnullo cohibita.

Quoad formam et latitudinem segmentorum valde variat: maxime forsan abludens gerit segmenta terminalia subspathulato-lanceolata (G. incrassata liütz?); alia forma est tota linearis angustissima (G. dichotoma Küitz.?); alia inferne angusta apicibus dilatatis (G. Biasolettiana kïitz.?). Formæ ista, a líitzingio ut species propriæ separatæ, mihi ad unam speciem pertinere videntur. Rarius occurrit segmentis conformibus a disco et margine proliferis.

4. N. Margivifera ( $J$. Ag. mscr.) fronde gelatinoso-carnosa a stipite cuneatim expansa in laminam planam lanceulatam integram aut parcissime divisam, a margine phyllis consimilibus proliferam.

IIab. ad littus Gallix prope Brest (Crouan!).

Frons quadripollicaris, a äisco radicali surgens, stipite perbrevi mox in laminam cuneatim expanso, ambitu lanceolata, in medio, ubi latissima, pollicem circiter rquaıs, versus apicem iterum attenuata, omnino integra, aut in segmenta pauca divisa, subdichotoma. A margine foliola nova prolificant, fronde primaria minora, bipollicaria et lineas paucas lata, utrinque atlenuata. Structura generis. Fila peripherica moniliformı ıuco subnullo cohibentur. Substantia gelatinoso-carnosa; chartæ arctissime adhæret. Color coccineus.

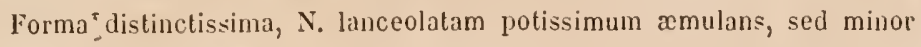
atque ramiticatione diversa.

5. N. L.Ixceolati (Harv. mscr.) fronde gelatinoso-carnosa a stipite cuneation expansa in laminam maximam planam parce dichotomam, segुmentis lanceolatis, margine aculiusculis. 
Iridxa? lanceolata IIarv. mscr.

Nemastoma lanceolata J. Ag. Act. IIolm. 1847 p. 91 tab. VI!

Iridaea Pappeana Sonder mscr.

llab. ad Cap. b. Spei (Harrey! Pappe!)

Frons a stipite pennam corvinam crasso, basi teretiusculo, mox plano cuneatim expansa, 1-2 pedalis, bis aut ter dichotoma, distantiis 4-6 pollicaribus inter segmenta proxima, tota ambitu obovata. Segmenta 2-3pollices lata, intima basi subcuneata, superiora a basi sensim atlenuata. Color ex coccineo aut vinoso-purpurascens. Sulstantia gelatinoso-carnosa, ita ut frons, licet maxima, chartæ arctissime adbæreat.

Species cum nulla alia facile confundenda. Structura generis; fructus non vidi. Ilanc speciem apud lï̈zingium non invenio, nisi forsan nomine Euh. Schizophyllas p. 742 , cui synonymon adtribuitur lr. lanceolata, descripta fuerit. Kallymenia Schizophylla vero et $\mathrm{N}$. lanceolata sunt revera species diversissimæ.

\section{Platoma. Fila strati exterioris muco solidescente cohibita.}

6. N. mutrifind (Schousb. mscr.) fronde gelatinoso-carnosa subplana sessili reniformi dichotomo-multifida decomposita, segmentis cuncato-dibatatis supra axillas rolundatas connirentibus incisodentatis, dentibus obtusissimis brevibus.

Platoma multifidum Schousb. mscr.

Ilalymenia multifida J. Ag. Symb. 1 p. 19. Alg. med. p. 97!

Ilalymenia cyclocolpa Mont. Fl. Canar. p. $163 \mathrm{el} \mathrm{Pl.} \mathrm{cell.} \mathrm{exot.} \mathrm{Cent.}$ III p. 28! Fl. Atger. p. 116 (partim) iab. 11 fig. b. (excl. fig. a.) hülz. sp. p. 716 !

Nemastoma cyclocolpa Zanard. Sagg. p. 30.

Ilab. in oceano atlantico ad oras Tingitanas (Schousboe!) ad Teneriffum (sec. Nontagne).

Frons 2-3pollicaris, amlitu subreniformis, dichotomo-multifida, segmentis supra axillas rotundatas convergentibus et sese tegentibus, eorlem modo compositis; supremis sursum dilatatis, introrsum sape supra axillam arcuatis nudiusculis aut crenulis multifidis minutis paucis instructis, extrorsum inciso-dentatis, formam cornu Alcis fere referentibus, dentibus abbreviatis obtusis. Color coccineo-purpureus. Substantia gelatinosomemlranacea aut subcarnosa; chartie arctissime adharet. Structura generis; fila peripherica muco fere solidescente cohibentur. Fructus non vidi.

Ilanc speciem jam a Schousboeo cognitam et sub citato nonine quandoquidem denominatam, jam ante me Montagneus descripsisse videtur. Nomen Schousboei, quod ut plurimis speciebus congrumm rejecerat Montagne, tamen conservo, quiple quod in hoc genere eximic characteristicum. Speciem praterea suam ad specimen parum characteristicum, ut 
ex icone supra citata judicare liceat, definivit Montagne; dein eandem, ni fallor, cum specie diversa confullit. Specimina Schonsboei, quorum plurima vidi, invicem eximic conveniunt et a sequente sine dubio diversa sunt. Errore hanc speciem a mari mediterraneo oriundam olim credidi.

7. N. cenviconxis (J.Ag. Alg. med. p.97) fronde gelatinoso-carnosa subpluna sessili dichotomo-multifida et a margine dense pinnata, segmentis pinnisque linearibus, terminalibus diraricatomultifidis, lacinulis linearibus obtusis.

Halymenia Cervicornis J. Ag. l. c. Kï̈lz. sp. p. $716 !$ (curvicornis).

Halymenia cyclocolpa Mont. Ft. Alg. p. 116 lab. 11 fig. a. (nec fig. b.)?

Ilab. in mari mediterraneo ad littus Galloprovincixe (Solier!)

Frons circumscriptione sxpe reniformis, 2-3pollices alta, 3-4poll. lata, compresso-plaula crassa, sessilis, disco minuto affixa, area basali nunc latiori indivisa, nunc per hanc quoque in segmenta numerosa $(6-8)$ subpalmatim fissa; segmenta linearia plus minus elongata, conformibus minorilus a margine egredientibus plurimis pinnata. Pinnæ majores 1-:pollicares minoresque 4-6lineas longæ mixtæ; majores eodem modo compositæ, minores basi simplices, rersus medium dilatatæ, apice multifidæ, laciniis a basi latiore paulo attenuatis obtusis divergentibus. Substantia gelatinoso-carnosa crassa; exsiccatione omnino collabens et chartæ arctissime adhærens. Color rinoso-purpureus, nunc in coccineum tendens. Structura generis; sed fila exteriora brevissima dichotomo-fastigiata, muco evidenti colibita.

Species mihi videtur distinctissima; ab antecedente præcipue differt ramificatione pinnata, pinnulis linearibus angustioribus. Duas species a Nontagneo nomine H. cyclocolpæ confusas suspicor. Primum enim specimine Platomæ multifidæ Schousb. a Weblio nuncupato, speciem suam ad hoc specimen, parum characteristicum, ut ex icone in Flora Algeriæ data patet, descripsit. Dein adportatis ex Algieria speciminibus melioribus, hæc cum sua specic congruentia finxit. Mihi vero, si ex iconibus datis aliquod de hac re judicium fere liceat, Algeriensia specinina aut ad $\mathrm{N}$. cervicornem aut ad $\mathrm{N}$. discigenam pertinere videntur; vera enim Plat. multifuda Schousb. ab lis distinctissima est.

8. N. DIScigexi (J.Ag. mscr.) fronde carnosa subcartilaginea plana diclıotoma, a margine et disco dense fimbriata, fimbriis anguste linearibus dichotomis, supra axillas rotundatas incurris, extrolsum obluse dentitis. p. $231 ! !$

Sphærococcus laciniatus $\beta$. discigena Ag. Sp. Alg. 1 p. 298. Syst.

Ilab. in oceano allantico ad Gades (Cabrera!) 
Frondis lamina carnosa inferne latior, unguem fere lata, in segmenla abiens dichotoma, 2-3lineas lata, linearia aut infra divisiones subcuncata, supra axillas rotundatas incurva, sæpe extrorsum in lacinias $2-3$, a basi latiore sublineares obtusas abenntia. A margine et disco proveniunt timbriæ plurimæ, conformes al multo minores, scmiunguem longæ, nonnullis longioribus in segmenta excrescentibus, lineam latæ ant angustiores, densius dichotomæ, ramificatione cæeterum segmentis conformi: laciniæ, utpote multo minores, formam habent dentium obtusorum et sunt magis cartilaginex quam aliæ partes. Structura et favellæ generis; fila peripherica muco solidescente cobibita sunt. Color roseo-pnrpureus. Substantia carnosa; in exsiccata partes latiores magis membranaceæ, angustiores magis cartilagineæ. Chartæ minus adhæret.

Partem inferiorem frondis non vidi. Ex characteribus a præcedente non multum differre forsan videatur, sed revera diversissima. N. cervicornis habet substantiam succoso-membranaceam Halymenix, N. discigena carnoso-cartilagineam Sphærococci ad mentem C. Agardhii.

9. N? CUNEATA (MIenegh. mscr.) fronde gelalihoso-carnosa subplana dicholoma et a margine pinnata, pinnis simplicibus lanceolatis demum furcatis cuneiformibus, apicibus subdivergentibus.

Grateloupia cuneata Meneghini mscr.

Hab. ad oras Siciliæ (Hb. Meneghini!)

Plantæ superiorem partem tripollicarem habeo. Segmenta hujus inferiora 5 -6lineas lata, sublinearia, infra dichotomias, pollicem circiter distantes, vix conspicue dilatata, supra axillas acutissculas patentia; terminalia a basi latiore attenuata, obtusa, subdivergentia. A margine utroque sparsim proveniunt pinnæ, hic illic densiores, nunc per intervallum nullæ, juniores 1-2lineas longæ ligulatæ, sensim in formam lanceolatolinearem abeuntes, demum pollicares a basi angustiore cuneatim dilatatip, apice furcatix, segmentis divergentibus, margine iterum ligulis ornatæ. Cystocarpia per mediam paginam frondis densissima, (in hoc genere) sat magna et nudo oculo conspicua. Color dilutius purpureus. Substantia gelatinosa; chartæ arctissıme adhæret. Fila interiora stipatissima; exteriora rerticalia brevia et paucis articulis constantia.

De affinitate hujus speciei quadam dubia mihi manent; sed nescio quo loco melius disponetur. A Grateloupia longius distare videtur gelatirosa substantia, colore, et structura. Sit forsan conjecturæ locus, Grateloupiam Consentini Küilz, eodem loco lectam et quoad diagnosem uon parum convenientem, ad priesentem speciem pertinere posse.

\section{Species inquirenda:}

10. Grmophlet cavamigses (Külz. sp. p. 712) fronde elongata filiformi tereti-compressa articulato-subconstricta, exsiccatione 
longitudinaliter rugulosa, diclıotoma, segmentis sensim breviorilus, supremis fastigiatis.

IIalymenia capensis Mont. Canar p. 164 ! (excl. syn.)

llab. in littoribus insulie Canarix.

Quoad magnitudinem et circumscriptionem magnopere varians; nonnulla usque 9-pollicaria irregulariter dichotoma; alia 2-pollicaria stricturis fere F. constrictum Turn. referentia; frons exsiccatione plana, in aqua formam subcylindricam recuperat.

Hæc pracipua, quæ de sua planta memoriæ prodidit Montagne; descriptionem dedil fructus, quæ in fructus Nemastomæ satis quadrat. Plantam a me non visam auctoritate Kützingii huc refero.

XX. Scimzymenia J. Ag. mscr. Platymenia J. Ag. Act. Holm. 1847 p. 87; Iridæa Grev. (excl. sp.) [non Bory;] Iridæx et IJulymenia sp. Auct.

Frons carnoso-plana integra aut lacerata, duplici strato cellularum constituta; interiure filis arliculatis parce ramosis densissime intertextis constante; exteriore filis moniliformilus verticalibus muco colibitis contexto. Favella infra stratum exterius utrinque nidulantes, simplices, intra periderma gelatinosum ligalinum gemmidia rotundita, demum per canalem strati exterioris liberata, forentes. Spharosporce strato exteriori demerse, sparsie, cruciatim divise. (Grev. Alg. Brit. Lab. XVII "Iridaea"; Harv. Phycol. Brit. lab. XCVII el CXXIII).

Frondes coccinex ant purpurascentes, colore in sanguineum, lilacinum, amethystinum aut hepaticum, vel senili æatate inmo in fuscescentem tendentes, plerumque magnæ, lite expanse, carnoso-planse, margine incrassato afficie aut stipite evidentiori filiformi-plano insidentes, siepius gregarix. Lamina juvenilis plerumque integra, senilis in plurimis fissa, laciniis externa vi aut incremento ipsius plantæ oriundis, ambitu indefinitis.

Duplici strato frons contedtil est. Interius constit filis elongattis, longitudinalibus transversalibusqque, dense iutertestis, parcius ramosis, evidenter ut plurimum articulatis. Externum filis moniliformibus articulatis diclsotomo-fastigiatis, ab interiore strato rerticaliter exeuntibus, muco solidescente colibitis, constituitur.

Favellie 'nucleo simplici constantes et sxpius minute, extra stratum interius utrinque, ad basem filorum verticalium, nidulantes, secedentibus filis moniliformibus per canalem pervium, guemmidia 
rotundato-angulata numerosa emittentes. Farelle nucleus dissectus gemmidia a placentula interiore subradiantia monstrat. In Sclt. eduli hæc dispositio egre discernenda; in aliis evidentior. Spliarospora strato exteriori frondis immersi, per frondem sparsw, cruciatim divise; in Sclı. eduli rotundatre, minusque regulariter divisæ, in cellulis infra-corticalibus evolutx, dense aggregate; in aliis speciebus (Scl. marģinata, Sclı. undulata) oblorıge, magis sparsæ, inter cellılas fere corticales sitæ.

Species nonnulle lujus generis a Boryo ad Iridaam cum dubio relatie fuerunt; a Grevilleo luic generi typica existimatx, a cæteris auctoribus, nulla facta distinctione, ut tridæse descriptx. Ipse differentia structure frondis fructusque situ alio insistens, genus proprium, nomine Platgmenix, in actis Ilolmiensibus anni 1817 proposui, quod hodie conservo, mutato tantum ob consollum genus Bentlımii nomine.

Ab Iridæa, quale loc genus limitavi, facillime distinguitur favellis non in media fronde sitis, simplicibus et carpostomio apertis, atque structura valde diversa. Structura Kallymeniam magis tangit, sed favellidia hujus in medio strato interiore sila, nucleolis pluribus composita, atque carpostomio nullo aperti. $\Lambda \mathrm{d}$ Grateloupiam forsan proxime accedit, fructu fere conveniens, sed structura alia. Cum Nemastoma denique vinculis affinitatis arctius conjungitur, structure et fructus differentia exigua, lıbitu diverso et ramificationis norma alia. In Nemastoma enim sunt segmenta ambitu definiti, et sensim excrescentia; in Schizymenia dilaceratione laciniæ frondis, si adsint, formantur. Quam quidem liorum generum congruentiam perspiciens, utrumque genus in Mlgis Mediterraneis conjumxi, sectionibus diversis conservatis. Errorem autem in eo commisi, quod in omnibus Iridæis structuram eandem suspicarem, atque, libro Grevillei deceptus, genus primarium Boryanum cum Grevilleano omnino identicum et eadem planta typica constructum fingerem.

Species omnes eximie conveniunt et structura froudis et fructu. Maxime ablndit Emropxa et optime cognita, Sch. edulis, in qua favellæ majores, ambitu irregulares, nucleum conpositum sepe mentiuntur. Sphærospore quoque, in cellulis infra-corticalibus formatx, ita densæ ut stratum proprium fere efficiant, rotundatæ, a cateris specicbus paulisper abludunt. 
I. Facellis parlem superiorem frondis occupantibus, inferiore parte sterili.

1. SCil. Margivata (Roussel mscr.) fronde estipitata membranaceocarnosa oblonga aut suborbiculiri, linc inde elevato-marginita, inargine incrassato affixa.

Hal. marginata Rouss. mscr. in Monlagne Cryplog. Alger.n. 46. hüts. sp. p. 717 !

Iridsea marginata Endl.; Mont. Fl. Alg. p. 124 lab. 10 fg. 3 !

Hub. ad Milleporas crescens, in littore Algeriæ (Roussel); ad littus Galloprovinciæ (Giraud!!)

Frons scuto parvulo marginali adfixa, orbicularis oblongave plana, toto margine subtiliter incrussato undulata, 4-11 poll. longa, 4-7 poll. lata, junior membranaceo-coriacea, demum coriacec-carnosa. Sulstantia Sch. ellulis. Color recentis puniceus, exsiccatæ purpureo-sangruineus. Sphærosporæe inter cellulas strati corticalis sparsæ, oblongæ, cruciatim divisæ.

Fragmentum, quod coram oculis habeo, ad littus Galliæ inventum, margine satis conspicuo, laceratam frondem circumdante, subduplicato et in glandulis minutis immo hic inde producto, instructum est. Speciei itaciue hoc proprium puto, ut illud jam judicavit primus insentor. sed marginem in fronde lasa tantum provenire suspicor, tendentia quadam et conatu naturæe vim externam medicandi. - Cystocarpia nulla vidi; sed plantam luc pertinere, analysis fructus a Montagneo data suadere mihi videtur. Quoad structurum quoque et sphærosporas generis genuina species!

2. Scai. Dubi (Chauv. mscr.) stipite brevissimo compresso in frondem obovatam margine undulatam gelatinoso-carnosam vinosopurpuream, denique irregulariter fissam, cuneatim expanso, cystocarpiis punctiformibus maculas informes per partem superiorem occupantibus.

Halymenia Dubyi Chauv. mscr. in Duby Bot. Gall. p. 944.

Nemastoma Dubyi J. Ag. Atg. med. p. 96 in not.

Kallymenia Dulyyi Ilarv. Phycol. Brit. tab. CXXIIr. (exclus. sjn.)

Euhymenia Dubỵi liütz. sp. p. 743 (excl, syn.)

IIab. in oceano atlantico ad oras Britannixe et Gallix (Clauvin! Crouan!)

Frondes a radice scutata cuneatim expansx, stipite vix lineam superante, 3-9pollicares, 2-4pollices late, fere regulariter obovatx, sxpe obliqux, integrx aut quandoquidem (forsan tantum externa vi?) irregulariter fissæ, margine unlulatæ, juniores gelatinoso-membranacex, adulte magis carnosx. Cystocarpia minutissima, oculo mndo punctiformia, per totam superiorem partem frondis dispositil; infra superficiem utramque 
immersa, rotundata, peridermate hyalino cincta. Chartæ ut plurimum arcte adhæret. Color purpureus fere vini.

Injuria ad hanc speciem referunt Delesseriam Ferrarii Bonnem., quæ est species vera Kallymenix, K. reniformi proxima. Sch. Dubyi favellis simplicibus eorumque infra superficiem dispositione ad Schizymeniam, nec ad Kallymeniam, evidenter pertinet.

\section{Sсн. мixor (J. Ag. Alg. med. p. 90) stipite brevi compresso in} frondem late cuneatam inargine subcresulatam, carnosam, purpuream denique irregulariter fissam expanso, cystocarpiis partem superiorem frondis occupantibus.

Nemastoma minor J. Ag. l. c.

Hal. edulis var. media $A g . s p . A l g . p .203$ (excl. syn. Turn.)

Jridæa minor Endl.; Kütz. sp. p. 72̈3!

Iridæa Montagnei Bory in Monl. Fl. d'Alg. p. 124 lab. 12!

Ilib. in mari mediterraneo ad Malagam (IIænseler!) et Algioriam (Bory, IJb. Solier!) atque in vicino atlantico ad Gades (Cabrera!)

Frondes a callo radicali plures. Stipes evidens planus cuneatus, sensim in frondem abiens. Frons in nostris 2-3pollicaris, (sec. Montagne) aliquando multo major, ambitu obovata, latitudine nunc longitudınem æquante,nunc longior quam lata, juventute ut videtur integriuscula, demum irregulariter tissa, segmentis cuneatis. Margines (in nostris) vix conspicue undulati, sed sæpius eroso-crenati. Cystocarpia totam superiorem partem occupantia, inferiore parte angustiori et cuneata sterili. Color purpureuf levi tinctura violacei. Substantia junioris fere chartacea, fructifera carnosa. Chartæ haud adhæret.

Egre quidem characteribus a pracedente distinguitur. Sch. Dullyi videtur magis gelatinosa, ideoque chartæ adhærens; color magis in vinosum tendens, margines undulati potius quam crenati. Specininibus vero paucis observatis, agre bodie dijudicatur, utrum diversæ species, an tantum varietates ejusdem consideranda sint.

Plantam Boryanam cum nostra identicam esse, ex figuris a Montagneo datis certum milii videtur. Nostra specimina plurima fig. c (inferiorem sinistram) et fig. d tabuli Montagnei xmulantur. Fig. a mihi magis dubia ob magnitudinem, margines undatas, et fructus in macnlas aggregatos, supra totam frondem sparsos. In descriptione vero dispositionem fructuum omnino præteriit Auctor.

4. Scir. Ldelis (Stackh. Ner. Brit. p. 57) stipite elongato sensim compresso et in frondem membranaceo-carnosam obovatam integram aut (externa vi?) superne denique laceratam, margine xqualem abeunte, cystocarpiis maculas informes per partem superiorem occupantibus. 
Fucus edulis Slackh. I. c. Tab. 12. Turn. Hisl. Fuc. Tab. 114! Enyl. Bol. tab. 1307 . form.)

Halymenia edulis Ag. Sp. Alg. I p. 202! Syst.p. 242 (excl. var. et

Jridica edulis Bory Dict. Cl. IX. p. 45. Grev. Alg. Brit. p. 458 lab. 17! Harv. Man. p. 83 et Phycol. Brit. Lab. XCVII! Aresch. Emum. p. 89. hütz. sp. p. 724 !

Fucus dulcis Gm. (partim) tab. 26.

Fucus Lactuca Esp. tab. 64!

F. carnosus Schm; Esp. lab. 76 !

F. palmatus $\beta$. Ligtf.

Icon: Fl. Dan. Lab. 2258!

Exsicc. Wyatt. Danm. n. 78. Chauv. Norm. n. 68! Grev. Alg. Brit. n. 17 !

Ilab. ad rupes demersas oceani allantici a sinu Codano et insulis Orcadum usque ad littora Gallix.

Frondes a callo basali gregarix, plerumque 6-8pollicares, raro ultra pedales, et latitudine 3-6pollicares in suprema latiori parte, stipite semipollicari compresso lineari apice cuneatim expanso surgentes, dein late obovatr, apice obtusissimæ rotundatæ, margine æquales integerrimæ, sed demum in speciminibus magnopere latis longitudinaliter fissæ (an tantum externa vi?) et laciniatæ atque animalibus obesa et erosæ. Cystocarpia maculas informes in parte frondis superiore occupantia, satis conspicua et per frondem sæpe hoc tempore apice decoloratam, quasi verrucæ purpureæ, translucentis. Sphærosporæ infra peripheriam a cellulis corticalibus interioribus formatæ, ita densæ ut quasi stratum proprium formaro videantur, rotundatæ, cruciatim divisæ. Color sanguineo-purpureus. Substantia recentis carnosa, exsiccatæ magis membranacea.

Magnitudine, substantia et forma frondis species distunctissima; olim cum pluribus speciebus male confusa, hodie vix cunfundenda. Specimina mediterranea nulla vidi; quæ ab Agardhio ad Mallagam lecta memorantur, ad Sch. cordatam pertinent; Capensia ad Sch. carnosam, quantum ex fragmento viso concludere liceat, referenda videntur.

b. Sch. Carvos. (J. Ag. mscr.) stipite elongato plano in frondem crassissinam coriaceo-carnosam cuneatim dilatatam, denique in segrmenta numerosil conformia subdigitatim fissam, expanso, cystocarpiis superiorem partem incrassatam occupantibus.

Iridea carnosa J. Ag. mscr. Kütz. sp. Alg. p. 729 !

Platymenia carnosa J. Ag. Act. Ilolm. 1847 p. 89 lab. Vl

IIab. in mari Cilpensi, Van-Kampsbay, (Pappe!)

Frondes ab expansione rudicali gregarix, stipite evidenti sed omnino plano, 1-2 lineas lato, surgentes, sensim cuneatim dilatata, in lacinias plus minusve numerosas et profundas, ipsum stipitem aliquando dividen- 
tes, longitudinaliter fissæ, sæpe subdigitatr. Laciniæ nunc simpliciusculæ angustiores ef fere lineares, nunc cuneatx, 2-4pollices lat $x$, 1-2pedales Iongitudine, atque ita crassæ ut exsiccatæ semilineam æquent et immo superent. Cystocarpia maculas informes partis superioris frondium (hinc multo crassioris) occupant, cxteris in hoc genere similia, simplicia, infra stratum externum crassissimım nidulautia, densissima. Color nunc carneo-coccineus, nunc intensior obscure purpureus et, nisi luci objectus, fere nigrescens. Substantia madefacta eximie carnosa et aquam avide imbibens; exsiccatæ corilicea subcartilaginea.

Species inter omnes distinctissima crassitie, fragmentum corii fere referens, Sarcopbycum inter Laminarieas æmulans, structura non admodum abhorrente.

\section{Favellis per totam fere frondem aque sparsis.}

6. Sch. Mertexsiaxa (Post. el Rupr. Illustr. Alg. p. 18) fronde sanguinea membranace-carnosa sessili umbilicata quoquoversum expansa latissima undulato-plicata sinuosa, cystocarpiis pel totam frondem [?] ieque sparsis.

Ir. Mertensiana Post. el Rupr. l. c. tab. XXXIII!! hï̈t. Sp. Alg. p. 727 !

Ilab. in oceano pacifico boreali ad littora Kamtschatlix (Lütlie!)

Frondes permagnæ, sæpe bipedales et ultra, centro umbilicato affix et ita omnino sessiles, (juniores forsan reniformes) quoquoversum extensa, ambitu rotundato plicatæ et sinuosæ, immo lobata, lobis magnis obtusis. Substantia carnosa, exsiccatæ membranacea pergamena. Color fere sanguineus aut sordide carneus, plantæ senilis immo fuscescens. Cystocarpia magnitudine fere illorum Sch. edulis, per fragmenta fertilia, a me visa, dense sparsa. Specimen integrum plantæ junioris et fragmenta pedalia plantæ adultæ et senilis describenda coram oculis habui.

7. SciI. Bayderi (J. Ag. mscr.) fronde purpureo-hepatica membrinaceo-carnosa sessili, a disco radicali sensim cuncatim expansir, superne latissima obovata, vage longitudinaliter fissa, marghine undulato-crispa, cystocarpiis minutis per totam frondem densissime sparsis.

Iridæea Binderi J. Ag. mscr. in IJb. Binder.; Külz. sp. Alg. p. 727!

Hialb. in oceano pacifico prope Valparaiso (IIb. Binder!)

Frons 1-2pedalis et superne pedem lata, purpureo-hepatica, membranaceo-carnosa, plicata et rugosa, marginergue undulata; madefacta fidgilis et facillime in fragmenta dilacerata (an hoc tantum exsiccatione vitiosa?); a radice scutata mox cuneatim expanditur, ambitu totius cuneato- 
oborato. Specimina a me visa sunt longitudinaliter in segmenta nonnulli latissima divisa. Cystocarpia minuta, infra superficiem utrinque nidulantii, per totam frondem densissime sparsa videntur. Structura et fructus Schizymenix, nec Iridæx. - Species milhi videtur bene distincta, licet $\mathfrak{x}$ gre characteribus circumscribatur.

\section{SCII. APODA (J. Ag. Act. Holm. 1847 p. 88) fronde coccineo-} purpurea membranaceo-carnosa sessili, basi latissime expansa subcordata, sursum dilatata, in lacinias numerosas irregulariter subpalmatisecta.

Platymenia apoda J. Ag. l. c.!

IIal). ad Cap. b. Spei in sinu tabulari (Pappe! IIb. Areschoug!)

Frons circiter pedalis, margine in scutellum incrassato affixa, stipite subnullo, basi latissime expansa cordata aut subreniformis, dein sensim dilitata, cuneato-erectiuscula, ambitu ita fere semicirculum describens. Lacinix ab apice (seu a peripheria semicirculi) versus basem porrectir, 1-2pollices latæ, oblongæ, erectiusculæ, subdigitatæ paucæ. Color et substantia Sch. obovatx.

Tria specimina coram oculis habeo, satis completa et forma convenientia, Sch. obosatæ sine dubio proxima, ot forma generali frondis, defectu stipitis et laciniis disersa. An forma tantum ætate provecta illius speciei? Hoc vix nisi in loco natali dijudicetur.

9. Sсп. овогаті (J. Ag. mscr.) fronde coccineo-purpurea membranaceo-carnosa, a stipite plano cuneatim dilatata oboratoelongata, integra aut parce fissa, marogine undulatu, cystocarpiis minutis per totam superficiem sparsis.

Platymenia undulata var. obovata J. Ag. l. c. Act. Ilolm. $4847 \mathrm{p} .88$ tab. $I I I !$

Ilab. ad Cap. b. Spei in sinu tabulari (Pappe!).

Stipes eridens at brevis, $1-3$ lineas longus, mox planus, a callo radicali cuneatim expansus. Frons $1-1 \frac{1}{2}$ pedalis, sursum sensim latior, omnino oborata, infra apicem rolundatum obtusissimum fere 4 pollices lata, integerrima aut in lacinias nomnullas apice fissa. Margines frondis undulato-plicati, plicis introrsis numerosis. Color pulchre coccineopurpureus. Substantia recentis carnosi, exsiccatie menbranacea.

Cum sequente specie hanc primum conjunxi, sed perpensa tum ipsius frondis forma satis constanti, tum coloris quadam diversitate, diversas ponere hodie anteposui.

10. Scr. uxducata (J. Ag. mscr.) fronde amethystino-coccinea membranaceo-carnosa a stipite plano cuncatim dilatata lanceolato- 
lineari, integra aut parce fissa, marowine undulata subcrispata, cystocarpiis minutis per totam superficiem sparsis.

Platymenix undulata ж. linearis J. Ag. Act. Holm. 1847 p. 88!

IJab. ad Cap. b. Spei in sinu tabulari (Pappe!).

Frondes a stipite ima basi filiformi, dein plano longe cuneato, surgentes, usque lipedales, lineares, 1-2 pollices latæ, utrinque attenuatæ. Margines undulati et fere crispi, aliquando subcrenulati et processubus marginalibus minutis instructi. Color in amethystinum tendens. Cystocarpia ut puncta minuta, oculo nudo conspicua, per totam superficiem, ima hasi tantum excepta, densissime disposita sunt. Sphærosporas oblongas, inter cellulas strati superticialis dense sparsas, cruciatim divisas, elastice extra sectiones tenues, microscopio subjectas, prorumpentes vidi.

Præcedenti certe proxima et a me ipso antea cum illa conjuncta. Forma frondis vero in antecedenti ab initio obovata, apice sensin latior fit et ab apice deorsum denique in lacinias finditur; in præsenti lanceolato-linearis, apice angustior et medio latior, demum media parte latiori quoque fissa, apice indiviso. Color quoque diversus.

11. Sch. erosa (J. Ag. Act. Holm. 1847 p. 89) fronde roseo-lilacina tenue membranacea a stipite plano cuneatim dilatata in laminam cordato-ovatam, inciso-lobatam, margine inferne erosocrenulatam, cystocarpiis. ..

Platymenia erosa J. Ag. l. c. tab. IV!

Iridæa curvata kütz. sp. p. 729?

Ilab. ad Cap. b. Spei in sinu Simonis (Pappe!)

Frondes a disco radicali plures exeuntes, pedales, 6-pollices latæ, stipite plano latius cuneato et sensim in frondem abeunte; juniores obovato-cuneatæ margine inæquali sinuoso, adultiores inferne cuneatæ, margine crenulato, dein sesquipollicari supra basem distantia latitudine ita expansie ut ambitus fere cordato-ovatus evadat. Incisuris pluribus lateralibus terminalibusque frons in lobos plures, forma irregulares, superne dilatatos divisa. Substantia inferne carnoso-cartilaginea, superne tenuis membranacea. Color roseo-lilacinus.

Specimina 2 tantum vidi, invicem congruentia et a cxteris habitu sat diversa, Jridæam Augustinæ quodammodo revocantia. Structura cum cæleris speciebus convenit; tila interioris strati laxiora.

12. Scil. Condita (J. Ag. Act. Holm. Öfvers. $1849 p$. 8:3) fronde roseo-purpurea membranacea a stipite brevi cuneatim dilatata in laminam cordato-ovilam subpalmato-lobatam, margine amplo undulatam, cystocarpiis minutis per tolam superficiem sparsis.

Platymenia cordata $J$. Ag. l. c. 
Ilab. in mari mediterraneo, ad Malagam (Heth. Ag.!).

Frons a slipile brevi semipollicari, ina basi tereti, dein plano late cuneato, surgens, supra stipitem eximie, utrinque æqualiter, late cordata, dein ambitu ovata, 6-8pollicaris, latitudinem inferne attingens fere- 3 -pollicarem, superne sensim angustior, a medio in lobos 3-4 subpalmatim divisa, lobis oblongis aut orato-attenuatis. Margo amplus undulato-plicatus. Color purpureus.

Species certe ab Ir. Eduli, ad quam in Ilerb. Ag. relata fut, longe diversissima. Substantia multo tenuior et forma totius frondis omnino alia. Hoc respectu ab aliis speciebus Europæis quoque distat. Cum Sch. minore convenit colore et substantia; forma vero ef magnitudine frondis, norma divisionis atque cystocarpiis non aque per totam fere frondem sparsis diversa videtur. Neque cum alia specie extranea comparanda. Fructus et structura Schizymenix speciem esse docent, et a Kalymeniis, cum quibus quoque illam camparare liceret, certe distinguunt.

Cum Iridæa Montagnei Bory fig. $a$. in opere Montagnei nostram identicam initio credidi, nec omnino convictus sum illam revera esse diversam. Basis autem in nostra, supra stipitem, egregie cordata, nec oblique cuneata; fructus in nostra nullo ordine supra totam frondem sparsi; in tabula Montagnei rero maculas informes formare videntur.

\section{Grateloupia $A g . s p$. Alg. 1 p. 221. Grev. Alg. Brit.} p. 151. J. Ag. Alg. med. p. 102. Endl. Suppl. III p. 41. MIont. Fl. Alg. p. 100. Kü̈lz. Pliyc. p. 397 et Sp. Alg.p. 730. Harv. Phyc. lab. C. (excl. spec. ap. oinn.)

Frons compresso-plana carnoso-membranacea dichotoma aut pinnita duplici strato constans; interiore filis articulatis in reticulum anastomosantibus contexto; exteriore filis moniliformibus verticalibus muco cohibitis constituto. Facella immerse, infra stratum exterius utriusque paginæ nidulantes, simplices, intra periderma gelatinosum hyalinum gemmidia rotunditi, demum per canalem strati esterioris liberati, foventes. Sphctrospore stratu exteriori demerse, sparse, cruciatim divise. (Kütz. Phycol. tab. 7t fig. III. Harv. Phycol. tab. C.)

Frondes int valde compressx, aut omnino planx, exsiccate plerumyue menbranacex, nunc magis gelatinosie, nunc charticex et fere cartiliginex, recentes duriusculie cilluosie, iterum madefacte aquam avide libentes; ramificatione ralrins diclotome, plerumque pinnate, fronde primaria siepe simpliciuscula, pinnis a margine et prolificationibus a disco simpliciusculis aut iterum iterumpque 
pinnatis. A disco radicali plerunque gregarix proveniunt. Colore violaceo-purpurascente, exsiccatione in atroviridem sæpe tendente, plerumque ornantur.

Stratum interius frondis filis articulatis, anastomosantibus et intertextis, varia directione excurrentibus, plurimis longitudiualibus, contextum est. Fila peripherica verticalia moniliformia, dichotomofastigiata, articulis inferioribus anastomosantibus.

Fructus dıplex. Favellæ aliquando plures adproximatæ, nunc sparsæ, frondi immersæ, in strato exteriore excavato nidulantes, nuclco simplici oblongo constantes. Meubrana lyyalina nucleum ambit, in plurimis tamen parum conspicua. Gemmidia numerosa rotundata, nullo fere ordine conģ lobata; demum per canalem strati exterioris emissa. Nuclens acido superfuso distentus, gemmidia a placentula inclusa radiantia et mouiliformiter colserentia monstrat. Splæerospore inter fila moniliformia strati exterioris nidulantes, sparsæ, cruciatim divisæ.

Genus, quale ab Agardhio conditum, Chretangia nonnulla quoque complectebatur. Greville Fucum verruculosum adjecit, structura frondis lıad parum convenientem, sphærosporis vero zonatim divisis, pericarpio externo, nucleique structura intima sat diversum. Ipse, sphærosporis lujus speciei nondnm cognitis et nuclei diversitate nondum suspecta, speciem genuinam generis existimavi. Kützing, qui eandem quasi typicam depinxit, Clıtangia bene eliminavit, et Iridœam Cutleriæ, quam postea exclusit, in primo suo opere introduxit. Ipse lrane speciem aliamque proximam Capensem, generis proprii typos existimavi, quod in Act. Ilolm. 1847 nomine Pliyllymenix descripsi. Habitu nou parum abludunt; revera autem ramificatio in lis eadem, et structure differentia fere nulla.

Qno modo constitutum est genus, Schizymeniam potissimum tangit, fructu fere in utroque genere identico. Structura atutem frondis Grateloupia fere magis ad Irideam adproximatur. Cellule interiores in reticulum eodem modo anastomosibus conjunguntur, attamen reticulum Grateloupiæ minus laxum, firmiusque colıerens. Polyopes, structura frondis conveniente, nucleum cystocarpii alio morlo ortum, periderıate lyalino destitutum, gerit.

\section{Cuondropnutuu. Fronde dichotoma lineari, cystocarpiis in}

medio segmentorum penullimorum aggregatis.

1. Gr. diciotow (J. Ag. Alg. med. p. 103) fronde compressoplana lineari dichotomo-fastigiata, segmentisque pluribus ad- 
provimatis subdigitita, a disco et margine siepe prolifera, segmentis patentibus linearibus, terminalibus longe attenuatis, cystocarpiis in medio segmentorum penultimorum aggregatis.

Grateloupia dichotoma J. Ag. l. c. Kül̈.sp. Alg. p. 732!

Fucus abscissus Schoush. mscr. (non Turn.)

Chondrus crispus Mont. Canar. p. 157 (fide auctoris).

Ilib. ad rupes et saxa refluxu maris subemersa, in mari mediterraneo ad littora Galloprovincix (Ipse!); in allantico ad Tinyin [?] (Schousboe!); prope Brest (Crouan!).

Frondes a radice scutata gregariæ, $1 \frac{1}{2}-3$ pollicares, inferne simpliciusculæ, infra medium jam divisæe et dein crebris dichotomis fastigiatæ, sæpe segmentis hic illic congestis et eadem altitudine exeuntibus subpalmatx. Segmenta omnino linearia, lineam fere lata, supra axillas acutiusculas patentia; terminalia nunc abbreviata furcato-divergentia, nunc elongata ensiformia incurvata, nunc nonnullis supra alias elongatis, apice iterum dichotomo-fastigiatis, inæqualia, apice attenuato obtusiuscula. Prolificationes rarius adsunt, segmentis frondis conformes. Cystocarpia 4-6 plerumque adproximata, in sezmentis mediis et superioribus immersa. Color ex violaceo-purpurascens.

Habitus et ramificatio Chondri cujusdam minoris; et hoc quidem eo usque ut figuras Chondri (ex. gr. Lamour. Diss. tab. VI. fig. 13) ad nostram speciem calcatas, facile fingeres. Peculiari hac ramificatione a Grateloupiis plurimis nullo negotio specie distinguitur; structura, substantia et colore conveniens.

2. Gr. SPatullata (J. Ag. mscr.) fronde plana lineari dichotomofastigiata segmentisque pluribus adproximatis subdigitata, segmentis patentibus linearibus, superioribus sensim angustioribus, terminalibus elongatis spathulatis.

\section{[lab. in oceano Pacifico ad littus Peruviæ (Ilb. Risso!)}

Frons videtur usque pedalis, fere flabellatim expansa, dichotomodecomposita. Segmenta inferiora (infima in nostr. sp. desunt) \& lineas lata, superiora pro quaque dichotomia angustiora, superiora sesquilineam lata, omnia linearia, aut infra dichotomias parum dilatata; terminalia omnino spathulata sesquipollicem longa, inferne lineam lata linearia, infra apicem, expansa 2 lineas latil, integra et obtusissima, aut emarginata, ad divisionem ulteriorem prona. Segmenta nonnulla fere truncata, et ex apice 4- prolificationes digitatim emittentia. Axillæ patentes, parum rolundatæ. Color amethystino-purpureus. Substantia carnosa. Chartæ laxius adhæret. Sterilem tantum vidi.

Pro Gigartina Burmanni forsan habealur, at accuratius inspecta sane diversissima. Quantum ex structura judicetur, species vera Grateloupia. In boc genere cum nulla specie facilc confunditur. 
II. Gratelocpia. Fronde decomposito-pinnala lineari, cystocarpiis in pinnarum parle hic illic aggregalis.

3. Gr. Filicisa (Wulf. in Jacq. coll. III. p. 157) fronde compresso-plana pinnatim decomposita et a disco prolifera, pinnis a basi angustiori linearibus acuminatis, inferioribus longioribus pinnulatis, superioribus simpliciusculis, cystocarpiis pinnarum disco immersis.

Fucus filicinus Wulf. l. c. lab. 13̈ fig. 2. Turn. IItst. Fuc. tab. 1500! Esp. Icon. Fuc. lab. 67 !

Gratel. filicina Ag. sp. I p. 223. Syst. p. 241!! Grev. Alg. Br. p. 131 tab. 16! Harv. Man. p. 83 et Phycol. tab. C! Mont. Fl. Alg. p. 101! Kütz. sp. Alg. p. 730 !

Gr. porracea Suhr. mscr. et Kütz. Phycol. p. 397. Sp. Alg. p. 730!

Gr. concatenata el Gr. horrida Kü̈. l. c. (sec. spec, ab iisdem auct. proven.)

Gel. neglectum Bory Moree n. 1474 (fide Harvey et descr.) Külz. sp. p. 731 !

Exs. Wyall. Danm. n. 123.

Hab. in oceano atlantico a Britannia meridionali! ad Tingin!, insulas Canarias, Cap. b. Spei! insulasçue Indiæ occidentalis!; in mari mediterraneo! et Adriatico!. In oceano Indico ad Ilindostaniam! et Javam (sec. Kützing).

Frondes a radice scutata plures erectiusculæ, 2-6pollicares, lineares basi apiceque attenuatæ, indivisæ sed per totam longitudinem pinnis narginalibus et sæpe prolificationibus a disco emergentibus obsitæ, apice sæpius nudæ. Pinnæ inferiores sæpius longiores et iterum pinnatæ, superiores sensim breviores et simpliciusculæ, omnes lineares, apicibus attenuatis, lineam vix latitudine superantes. Cystocarpia in pinnis immersa, numerosa adproximata. Sphærosporæ pinnulis immersæ, (sæpe) plurimæ adproximatx. Substantia membranacca at tenax. Color ex purpureo aut violaceo sæpe in virescentem vergens.

Quoad densitatem pinnarum et prolificationum magnopere varians, nunc simpliciter pinnata, nunc 2-3pinnata. Apicibus jugamenti sæpe abruptis, prolificationes densissime proveniunt, pinnæque superiores elongantur ita ut frons haud extricanda caudam vulpinam, ut dicunt, fere referat. Gr. filicina var. ramentacea Mont. pl. Nouv. de Fr. p. 2., Gr. concatenata et Gr. horrida hülz. sunt formæ vix varielatis nomine distinguenda. Nullos saltim characteres allatos invenio, quibus specificam differentiam concludere vellem. Sporoclnus pennatula Poepp. ap. Sprengl. Syst. Veg. IV. p. 329, Grateloupia pennatula hütz. in Bol. Zeit. 1847 \% 24 et Sp. Alg. p. 731, magis forsan differt ciliis minutis fructiferis (sec. hït. . c.). Grateloupia porracea pinnis subfiliformibus pracipue dignoscitur; hæc plerumque ralde clongata, sxpe ultra pedalis. Si inter 
has omnes species plures laterent, nori sane claracteres his quxrendi sunt. Forsan differunt dispositione sphasrosporarum. In forma mediterranea splicrosporas paulo supra hasem pinne incrassatx aggregatas vidi; in planta Anglica totam mediam pinnulam, vix conspicue incrassatam, occupant; in forma, quam porraceam dicunt, sphærosporas in superiore parte pinnulie pertenuis laxius dispositas observavi. Utrum rero hæe sphærosporarum diversa dispositio fortuita sit, an species dirersas indicet, dijudicare non audeo.

4. Gr. proloxgita (J. Ag. Alg. Liebm. in Act. Holm. 1817 p. 10) fronde compresso-plana undulita interrupte pinnata et a disco prolifera, apice prolongato nudiuscula; pimnis a basi angustiori lineari-subulatis, majoribus minoribusque intermixtis.

Grateloupia prolongata J. Ag. l. c. Kü̈љ. sp. p. 730 !

UJab. ad Poclietti in littore Mexicano occani Pacifici (Lisbman!).

Planta Gr. filicinæ certe proxima, ægre characteribus circumscribenda et illius forsan tanfum varictas a loco natali pendens. Est major, simplicior et magis irregulariter pinnata. Frondes a radice scutata gregariæ, 4-8pollicares, 2-3lineas latæ, lineares, inferne pinnis nonnullis longioribus, intermixtis brevioribus, obsitæ, dein fere simplices subundulatie, marginibus et disco nunc nudis, nunc sparsim pinnis brevibus subuIatis obsitis. Color violaceo-atrovirescens et substantia antecedentis.

5. Gr. cuxerfolia (J. Ag. mscr. in Hb. Binder.) fronde plana cuneato-lineari pinnata, hic illic dilatata et palmata, margine et disco ciliis minoribus obsita, segmentis linearibus elongatis obtusiusculis.

Gratcloupia cuneifolia J. Ag. mscr. Act. Holm. Öfvers. $18: 19$ p. 85 ! Кйlz. $s p . p .732$ !

Uab. in mari Indix occidentalis ad La Guayra (IIl). Binder!).

Species bujus sectionis facile maxima. Frondes a radice scutata surgentes gregariæ, nunc lineares simpliciusculæ, nunc magis cuneatæ apiceque truncato palmalæ, nunc subregulariter pinnatæ, latiores fere usciue pollicem latæ, Iongiores subpedales. Pinnæ et segmenta simpliciuscula linearia, margine nuda aut pinnulis minutis ciliata, 2-3lineas lata, basi apiceque angustiora. Prolificationes minutæ in spec. nostr. nunc adsunt, nunc nuliæ. Color atrovirescens. Substantia membranaceo-subcartilaginea.

Species sine dubio distincta, licet hæc quoque charactere ægre definiatur. Segmenta pinnæve, quam in cæteris multo latiora, habitum plantæ tribuunt omnino peculiarem; unde semel visa facillime dignoscatur.

6. Gr. versicolor (J. Ag. Alg. Lieb. p. 10) fronde plina crassillscula pinnatim decompositi, pimnis lineariius utrinque alte- 
nuatis margine dentato-pectinatis, dentibus jurenilibus acuminatis in pinnulas borizontales cuneato-lineares acuminatas excrescentibus.

Grateloupia Sternbergii var.? versicolor J. Ag. l. $c$.

IIab. ad St. Augustin in littore Mexicano oceani pacifici (I.ieb$\operatorname{man} !)$.

Frons circiter bipollicaris, 1-2lineas lata, dense pinnata, pinnis mediis majoribus pinnulatis, superioribus inferioribusque simplicibus. Pinnæ majores pollicares basi longe attenuatæ, dein lineares pinnulis pectinatæ, apice longe acuminatæ subacutæ dentibus minutis munitæ. Pinnæ minores pinnulæque lineam longæ et longiores, basi attenuatæ, supra medium latiores, apice abruptius attenuato subacutæ. Substantia cartilaginea. Color purpureo et atroviridi variegatus.

Tanta est hujus speciei in ramificatione et habitu cum Prionit. Sternbergii similitudo, ut sane incerlus sim, an jure distinguantur. Pinnæ pinnulieque in Gr. versicolore acutiores, numquam divisæ, sed dentium evolutione decompositæ. Color quoque et substantia in nostris diversa. Structuræ levi modificatione differunt. In Gr. versicolore cellulæ strati peripherici infimx cxteris vix majores sunt, et anastomosibus laxe conjunctæ; in Pr. Sternbergii cellulix istre sunt rotundatæ et majores, atque in stratun fere proprium arctius conjuncta. $\mathrm{Ab}$ ictate diversa differentix istæ vix pendent; partes enim et adultas et juveniles utriusque plantio observavi.

III. Pinylduevia. (J. Ag. Act. Holm. 1847 p. 86). Fronde plana simpliciuscula lanceolata, a callo radicali ant a margine folii reducti proveniente, cystocarpiis per frondem sparsis.

7. Gr. layceola (J. Ag. Symb. 1 p. 19) frondibus carnoso-planis lineari-lanceolatis acuminatis margine plano subintegerrimis, simplicibus vel ex margine frondis senilis provenientibus, eyslocarpiis sparsis.

Halymenia lanceola $J$. Ag. $l$. $c$.

Halarachnion lanceola Kï̈lz. sp. Alg. p. 722.

Hab. in oceano atlantico calidiori ad oras Ilispanix meridionalis et prope Cap. Spartel (Schousboe!); ad oras Senegambix (Hb. Crouan!)

Frons juvenilis simplex lineari-lanceolata, margine processubus minutis quandoquidem obsita, aut his magis evolutis, in lobos conformes abeuntibus, parce divisa; frons adulta constat (sxpe) parte quadam frondis senilis, cujus ex margine aut apice truncato frondes novellæ pimnatim aut digitatim exeunt. Prolificationes frondi juvenili conformes, basi api- 
ceque attenuatx, 3-5lineas latæ, longitudine 2-4pollicari. Cystocarnia in inferiore parte prolificationum, et in superiore parte frondis primaria sparsa. Structuri generis. Color violaceo-purpureus, iterum madefactic pallescens. Substantia gelatinoso-carnosa; clarta arctius adlıret.

Sectione tenui microscopio subjecta, llalymenix speciem fere putires. Filit interiora ut in Ilalym. floresia senili dense stipata adparent; ut vero acido superfusa sit, structuram Grateloupix monstrat. Ramificatione quoque cum sequentibus convenit; statura multo minori ab his dignoscitur.

8. Gr. merogctpnica (J. Ag. Act. Holm. 1847 p. 86) frondibus carnoso-pranis lineari-lanceolatis acuminatis margine sulundulato integerrimis, simplicibus rel $c x$ maroine frondis senilis provenientibus, cystocarpiis in soros maculieformes, lineis flesuosis angustis sejunctos, collectis.

Plyyllymenia hicroglyphica $J$. Ag. l. c. tab. II!

lridaea labyrinthifolia Küı. sp. p. 729 (partim?)!

Ilab. in sinu tabulari ad Cap. b. Spei (Pappe!).

Frondes inferne in stipitem attenuate, inde cuneatim expansæ, nunc simplices elongatæ, nunc a fronde primaria minori 1-3pollicari proliferæ, prolificationibus usqque sesquipedalibus. Irolificationes omnes marginales et pinnas mentientes, a basi cximic attenuata cuneatr, usquedum pollicari-3pollicari supra basem distantia latitudinem $1-1 \frac{1}{2}$ pollicarem attigerint, dein plerumque longissime attenuatæ in apicem acuminatum, rarius lineares semcl aut bis dichotomæ. Aliquando tota frons palmatifida adparet. Nargines integerrimi distanter undati. Lamina frondis luci objecta quasi lineis irregularibus inscripta, que soros fructuum ambiunt. Cystocarpia, lineis his exceptis, per totam frondem in maculas minutas oblongas aut valde irregulares collecta. Sphærospora consimili dispositione in diversis individuis obveniunt. Color pulcherrime amethystinopurpureus. Substantia carnoso-chartacea. Chartie non adhæret.

Species distinctissima, pulcherrima, sequenti potissimum adfinis; utraque ob magnitudinem pinnarum Iridæas, seu potius Schizymenias, æmulatur, fructuum situ atque structura ab illis, frondis structura atque ramificatione ab his dignoscenda. Speciem Kützingianam supra citatam cum nostra identican esse vix dubito. Quum rero suæ specici latitudinem 6-pollicarem tribuerit, aut ambitum plantæ divisæ cum hoc indicasse, aut formas liversa specia cum vera confudisse, suspicor.

9. Gr. CUTLER (Binder mscr.) frondibus carnoso-planis lanceolato-linearibus, margme undulato inerualibus subcrenulatis, a disco et margine frondis senilis prolificantibus, cỵstocarpiis nullo ordine per frondern sparsis. 
Irid. Cutleriæ Bind. mscr. Mont. Yoy. Bonit. p. 63. Kü̈љ, sp. $p$ ว26. Grateloupia Cutleria Külz. Phyc. gen. p. 398 tab. 77. III.

\section{llalb. ad oras Chilenses prope Valparaiso (Ilb. Binder!)}

Frondes adultis vidi bipedales, bis pollicem latas, oblongo-lineares, a disco et margine proliferas; prolificationes a margine et disco numerosæ, juveniles lanceolatæ demum fere oblongæ, (in nostris) sæpe truncatio ct ab apice subproliferæ. Margines minute undulatæ subcrenulatie et sæpe prolificationibus novellis ornatæ. Cystocarpia nullo ordine sparsa, in exsiccatia subprominentia, multo majora quam in antecedente. Color eximie violaceus, in lividum demum transiens. Sulistantia membranaceocarnosit. Chartæ laxius adhæret

Sec. Montagne 1. c. hec species quoque ad Martinique lecta fuit. Specinina minora hujus Iridxam violaceam hülz. sistere, mihi dictum fuit.

\section{Species inquirenda.}

10. Gr. Filifonus (Kütz. sp. p. 731 ) "pliycontate filiformi basi subtereti, deinde sulscompresso, inferne lase ranoso, superne ramosissimo subdichotomo, ramis congestis diraricatis pleruntque curvatis, omnibus apice subulato-spinescentibus, hinc inde ramellos unilaterales gerentibus. Crassities pennæ passerinæ rel jarum ultra, ramellorum subsetacea. Alt. 3-4." ". Ilab. ad littora Peruana.

11. Gr. Proteus (Külz. sp. p. 731) "plıscomate gelatinoso-cartiligineo, sursum valde dilatato, irregulariter ramoso, rel diviso ramis bi-trifurcatis, ramellulis numerosis marginalibus lanceolatis. Altit. 4-6"; lat. 2-6"."

Halymenia Proteus IJerb. Kiunth.

llab. in mari mediteranco (Sellow).

12. Cosextivi (Кӥlz. sp. p. 732) "plıусcomate diclotomo plano, diviso, basi cuncato, segmentis apicem versus latioribus, summis angustis repetite bifurcatis. Color fusco-purpureus. Long. 3 -4"; lat. partis medix 3-6"', apice $1^{\prime \prime \prime} . "$

$\beta$. marginifera segmentis ultimis magis elongatis, margine ramellulis elongatis lıgulatis, lanceolato-linearibus ciliformibus ornatis.

Halymenia marginifera Ilering. Herb.

llab. ad oras sicilix.

13. Gr. funbura (Hont. Fl. d'Alg. p. 102) cespitosa, fronde gelatinoso-cartilaginea plana dilatato-cuneata apice irregulariter multifida, segmentis plerumgue acutis. 
Gir. fimbriata Mont. l. c. tab. 13 fig. 3. Külz. sp. p. 732.

llibl. ad littora prope Nlgere.

Frondes cæspitosx, membranacer, cartilaginex, e basi compressa mox planx, dilatate, cuneatr, $4--5$ centim. alta, apice laciniatie, lacinis iterum fimbriato-multifidis, deorsum quandoque et altero margine pinnulatie, fimbriis pinnulisque acutis. Color intense purpureus, violascens, in sicco nigrescens. Fructificatio non adest." Descr. auct. transscripsi.

Gr. dichotoma ab Auctore proxima considerari videtur.

14. Gr? Accklandea (Mont. Prodr. Ant. p. 7) fronde cartilaginea filiformi tereti rage ramosissima, ramis ramentisque confertis fisciculatisque subcompressis basi attenuatis sepius ex insigni frondis tuberculo singulis pluribusve enatis; fructu. . .

Grateloupia? Aucklandica Mont. l. c. Voy. Pol. Sud. Bot. Crypt. p. 113 tab. 10 fig. 1! Hook. et Harv. Crypt. Ant. p. 75. hütz. sp. p. 732.

Hab. ad insulas Aucliand (D'Crville).

"Frons cartilaginea, teres, filiformis, penna passerina vix crassior, 4--3uncias longa, irregulariter vageçue ramosissima. Ilami elongati, sensim attenuati, iterum atque iterum ramosi. Ramuli (s. ramenta) sparsi simplices, conferti, immo fasciculati, varix longitudinis, basi tt apice attenuati, obtusi, membranacci, interlum tubulosi, sæpe ob excrescentiam frondis peculiarem specie bulbosi."

Structuram cum illa Chætangii ornati comparat Auctor. Mihi icon et descriptio data structuræ speciem Prionitidis indicare videtur.

\section{Prionitis J. Ag. mscr. Sphærococci, Gelidii cet. spec. Auct.}

Frons compressa linearis, dichotoma aut pinnata, a disco vel margitue prolifera aut glindulosa, stratis fere tribus contexta; centrali amplo, cellulis filiformilus densissime intertextis; internedio cellulis rotundatis superficiem versus sensim minoribus, superficialibus rotundatis verticaliter radiatis. Favelle frondi itus ciliis inflatis immers $x$, simplices, intra periderma gelitinosum hyalinum gemmidia rotundata, demum per canalem strati exterioris liberati, forentes. Spharosporce plyyllis glandulisve marginalibus immerse, inter cellulas strati superficialis valde evoluti sparsx, ublongæ, cruciatin divisx.

Frondes firme carnoso-cornex, compresso-planæ, marginibus rotundatis, ecostatæ, lineares, ramificatione dichotoma aut pimata plus minus decomposite, margine glandulis minutis, ciliis phyllisve demum evolutis ornate, aliguando a diseo profiferix. 
Stratis fero tribus diversis contextæ sunt frondes. Stratum centrale magnopere evolutum maximam partem frondis constituit, filis longitudinalibus densissime intertextis, granuloso endocluromate sepe farctis, articulatis, articulis claveformibus. Cellulæ rotundatoangulate, serie multiplici disposite, peripheriam versus minores, unedium stratum cingunt; superficiale stratum cellulis rotundatis aut subsimplici serie dispositis (in partibus senilibus), aut plus minus in fila verticalia moniliformia prolongatis. In segmento glandulie aut folioli fertilis axis filis Iongitudinalibus, periplıcriam versns magis anastomosantibus et in reticulum conjunctis, occupalur; periphericum stratum filis moniliformibus verticalibus constat.

Frnctus adlucdum non rite cogniti. In nulla enim specic et sphærosporæ et favellæ simul observatx. Species, qux favellis instructæ olscrvatæ fuerunt, ob ignotas splırosporas genere dubiæ sunt. Favelle in $\mathrm{Pr}$. microphylla frondi immerse, nucleo constant simplici, intra periderma hyalinum gemmidia plurima fovente. - $\mathrm{Cy}-$ stocarpia in Fuco crinito diverse fere indolis videntur; sed in nostris ita juvenilia ut certum judicium de iis ferre non liceat. Cilixe ipsæ in fuco crinito inflantur et in pericarpia ovata submucronata transmutantur. Pericarpium duobus exterioribus stratis frondis contextum est; cellulis nempe exterioribus radiatis, in fila moniliformia evolutis, inferioribusque concentricis lasioribus angulato-inastomosantibus; stratum pericarpii, unico Joco angustius, demum forsan carpostomio rumpitur. Fila strati centralis, loco inflato multo laxiora, longitudinaliter pericarpium percurrunt, cum cellulis anastomosantibus medii strati conjuncta. In plesu lorum filorum oritur nucleus tenacius colırens, cellulis quoquoversum radiantibus constitutus, inter fila suspensus. - Sphærosporæ (in Pr. australi, Pr. pectinata et Pr. ligulata ohservatæ) in phyllis glandulisve marginalibus evolutx, oblongæ, cruciation divisæ, inter fila moniliformia strati exterioris eximie evoluta nidulantes.

Species maris pacifici et australis incolæ, in collectionibus adluc raræ, lıbitu et structura satis convenientes, genus constitumint nondun omnibus numeris stahilitun. Utroque enim fructu nondım in una eademque specie cognito, idæam de genere justam labere nec liceat. Si Pr. microcarpa legitima generis species sit, genus ad Grateloupiam proxime sane accedit, levi structuræe differentia diversum. Structura frondis affinitatem cum Cryptonemia et Thysaluocladia indicat, spharosporxe vero illius et cystocarpia hujus a fructibus l'rionilidis, yuales cognilos habemus, longe recedunt. 
I. Euproxitis. Fronde dichotoma; sporifera glandulis phyllisve marginalitus obsita.

* Spherosporis glandulas minutas marginales occupantibus.

1. Pr. microcarea (Ag. sp. p. 253) fronde inferne teretinscula, superne compressil anguste lineari decomposito-dichotoma flabellato-fastigiata, segmentis (margine nudis), terminalibus aequalibus obtusis.

Sphærococcus microcarpus Ag. sp. Alg. 1 p. 253 et Syst. p. 218!

Chondrus microcarpus hïllz. sp. p. 737!

Phyllotylus microcarpus J. Ag. Alg. Liebm. p. 9.

Ilab. ad littus occidentale Novæ Ilollandix (Mus. Paris!)

Frons circiter 3-pollicaris, inferne teretiuscula, superne leviter compressa, juxta radiceın longius breviusve indivisa, superne ( $5-7$ ties) repetite dichotoma, aut aliquando trichotoma, axillis acutiusculis, segmentis ubique sulæqualibus, lineam fere latis, terminalibus oblusis. Segmenta superiora quasi punctata, favellis immersis, $2-3$ adproximatis, quasi puncta proeminentibus. Color purpureus. Substantia vix cartilaginea, sed tenax et quodammodo flexilis.

Fronde angustiori et minus compressa a sequentibus differt.

Sphærosporis nondum cognitis genus forsan adhuc dubium manet. Dubius hæsi utrum ad Prionitidem an ad Polyopem potius hanc speciem referrem. A Polyope fructus diversi milhi adparuerunt, favellis nempe, nec farellidiis, constituti. A Prionitide specimina nostra (favellifera) defectu glandularum marginalium recedunt.

2. Pr. Cirosdophila (J. Ag. mscr.) Sronde compressa lineari decomposito-dichotoma flabellato-fastigiata, segmentis (margine nudis), terminalibus angustioribus obtusiusculis.

Sphærococcus chondrophyllus Bory Voy. Coqu. n. 63! (nec Turn. et $A g$.)

Ilab, in oceano pacifico australi ad oras Novæ Guinex (IIb. Bory!).

Fragmentum lantum vidi plantæ, quæ huic generi pertinere videtur. A sequentibus differt magnitudine multo minore. Planta videtur 2-3pollicaris, dense dichotoma, segmentis linearibus vix lineam latis, et dichotomiis 2 lineas distantibus, sub spatio sesquipollicari octies repetilis. Color sordide purpureus; substantia firma cornea.

Hanc speciem cum luco chondrophyllo Turneri identicam judicavit Bory; si vero planta Turneri cum homonyma Areschougii identica sit, quod ab Algologis hodiernis vix in dubium vocatur, Boryana planta longissime sane ab illa recedit. 
3. Pr. australis (J. Ag. Alg. Liebm. p. 9 in not.) fronde compressa lineari decomposito-dichotoma flibellato-fastigiata, seg్mentis margine minute glandulosis, terminalibus sublanceolatis, sphærosporis glandulas minutas occupantibus.

Phyllotylus australis J. Ag. l. c.

Ilab. in mari Australi (Hb. Agardh!)

Frons fere 4-pollicaris, eximie fastigiata, segmentis supra axillas acutiusculas patentibus linearibus, sesquilineam circiter latis, terminalibus infra apicem acutiusculum dilatatis et ita forma fere lanceolatis. Inter dichotomias proximas spatium pollicis et ultra adest. Substantia firma fere cornea. Color sordide purpurascens. Glandulæ marginales compressie obtusx, quartam lineæ partem (in nostris) vix longæ, sphærosporas forent.

Glandulas marginales ut capsulas inchoantes 1. c. descripsi; forma enim capsulas Sph. repentis omnino æmulantur, et stratum interius reticulum capsulie interioris haud male refert.

3a. Pr. ofecipiexs (Mont. Voy. Bonile p. 76) fronde compressa lineari irregulariter decomposito-dichotoma, segmentis alternis fasciculatisque margine minute pectinatis, terminalibus sensim attenuatis acutiusculis.

Gelidium decipiens Mont l. c. pl. 145 fig. 2! Külъ. sp. Atg. p. 763! Hab. ad oras Peruviæ.

"Frondes plures ex eodem puncto scutiformi exsurgunt, initio filiformes, mox compressa, tandem planæ, lineares, spithameæ, repetito-dichotomæ. Segmenta (interdum fasciculata) sesquilineam lata, rugis transversis remolis præsertim apices versus obviis exarata, nonnumfuam aculeis distichis lanceolatis bilinearibus minoribusque patentissimis spatio lineari bilinearique sejunctis pectinata, verrucisque crassis sparsis (an statu morboso productis?) onusta. Stratum interius seu medullare constitutum e tilamentis tenuissimis maxime implicatis hyalinis a strato corticali crasso purpureo, e filis tenuissime punctatis seu serie cellularum minutissimarum horizontalium multiplici constante, cellulis alteris diaphanis mediocris magnitudinis sejunctum. Color recens purpureo-violaceus, exsiccatione nigrescens. Substantia cartilaginea lenta."

Licet nullum hujus specimen viderim, tamen ad hoc genus pertinere, mihi apparet vix dubitandum. Habitu quidem ita convenit cum speciebus juxta quos illam collocavi ut dubitaverim utrum ab una an ab altera illam jure distinxerim. Ramificatione minus regulariter dichotoma et vix fastigiata ab Pr. australi; glandulis marginalibus minutis et ramificatione diclotoma a sequentibus diversa videtur. 


\section{** Spharosporis phylla marginalia majora occupantibus.}

4. Pr. rectixita (J. Ag. mscr.) fronde compressa lineari decomposito-dichotoma subfastigiata phyllisque marginalibus anguste linearibus utrinque attenuatis pinnata, spherosporis plyylla malginalia occupantibus.

llab. ad Insulas Chincha prope littus Peruvix (Oersted!).

Ilanta fere pedalis, distantiis bipollicaribus parce dichotoma, irregularius fasligiata, segmentis exacte linearibus $1-2$ lineas latis, infra furcationes paulatim dilatatis, terminalibus sensim attenuatis. Verrucæ irregulares hic illic obviæ. Phylla semipollicaria vel usque pollicaria, anguste linearia, segmentis triplo angustiora, utrinque attenuata, plurima simplicia, alia furcata, jurenilia glandulæ-formia, a margine pectinatim exeunt, nunc opposita, nunc secundata, in superiore parte præcipue densa. Sphærosporæ in his inter fila peripherica nidulantes elongato-oblongæ cruciatim divisx. Substantia cornea. Color (in nostris) atrovirescens.

Species pulcbra, a sequentibus sine dubio diversa. Egrius dijudicatur, an a prioribus species distincta sit. Pr. australis sphærosporarum in glandulis situ, ramificatione evidentius fastigiata et segmentis terminalibus dilatatis dignoscitur; glandulas illius in pbylla excrescere suspicari forsan liceret; sed phylla juvenilia glandulæformia in Pr. pectinata sunt (in nostris) sterilia, et aliam habent structuram. Stratum interius in glandulis Pr. australis reticulo laxissimo constat; in Pr. pectinata sunt fila multo magis stipata. Gelidium decipiens Mont. utrum cum una vel altera specie conveniat, an ab utraque distinctum sit, mihi non licet dijudicare, quum nec plantam viderim, nec de sphærosporarum situ aliquid memorarerint auctores.

5. Pr. ligulata (Grev. mscr.) fronde compressa lineari subdichotoma et a margine pinnata, pinnis clongatis linearibus ulrin-

5a. Gelidum? laxceolatum (IIarv. ap. Beechey p. 16k) fronde plana cartilaginea bipinnata, pinnis elongatis basi attenuatis, pinnulis lanceolatis simplicilus suboppositis.

Hab. ad Californiam.

Frons 6-8pollicaris pinnata, pinnis longis simplicibus, basl apiceque valde attenuatis, medio $\mathbf{1 - 2}$ lineas latis; pinnulis foliaceis lanceolatis sæpius oppositis 2 -6lineas longis. Pinnæ pinnulæque simplices, formam lanceolatam ubique conservantes. Ita Auctor. Kï̈lz. sp. p. $i 66$.

Cum Pr. ligulata quoad descriptionem ita convenit, ut de identitate utriusque planta vix dubitarem; attamen observandum quod pinuas constanter lanceolatas descripsit Harey; in Pr. ligulata sunt pinna lineares, pinnulæ vero lanceolatæ. Caterum, quum de structura et fructu nihil memoriæ prodidit, utramque plantam seorsim proponere debui. 
que attenuatis margine minute glandulosis phyllisque lingulatolanceolatis disticlis secundatisque obsitis, spliærosporis pliylla lingulata occupantibus.

Grateloupia ligulata Grev. mscr.

Ilab. ad oras Californiæ (IIb. Greville!).

Frons ultra pedalis, sesquilineam lata, indivisa aut parcissime dichotoma, sed a margine dense pinnata. Pinnæ irregulariter alternæ aut hic illic fasciculatæ, 3-4pollicares, basi pierumque nudiusculæ glandulisve minutis instructæ, superne pinnulis conformibus obsitæ, apice sæpe rupto truncatæ, segmentis conformibus a trunco pullulantibus. Pinnulæ 2-4 lineas longe foliola propria lingulata referunt, majores semipollicares foliola fere lanceolata, demum in pinnulas lincares forsan abeuntes. Glandulæ marginales minutissimæ, quasi puncta vix elevata conspiciuntur. Verrucx crassæ, pluribus confluentibus verruculosæ, et in margine et in pagina sparsæ. Substantia carnoso-cornea. Color intensius purpureus. Sphærosporæ in phyllis marginalibus sitæ.

Species sui juris, cum nulla alia facile confundenda, ad antecedentes, ramificatione et forma phyllorum tamen diversas, proxime accedens.

\section{Pristerium fronde pinnatim decomposila.}

6. Pr. Sternbergit (Ag. Sp. Alg. p. 275) fronde plana pinnation decomposita, pinnis linearibus utrinque attenuatis margine dentato-pectinatis, dentibus obtusis, majoribus spatlulatis, apice rolundato sensim emarginatis furcatisque.

Sphærococcus Sternbergii Aq. l. c. el Syst. p. 224! hü̈t. sp. p. 766.

Ilab. in oceano australi (IIrenlie!)

Frous 2-4pollicaris pinnatim decomposita, pinnis inferioribus majoribus. Pinnæ bipollicares, lincam-sesquilineam litæ, utrinque attenuatx, basi nudiusculæ, dein pinnatæ pinnulis consimilibus, supra medium pectinatæ; infra apicem nudiusculum dentatx. Pinnulæ nempe maxime juveniles sunt dentiformes obtusæ et brevissimæ, adultiores in ligulas simplices spathulatas excrescunt, infime divisx; omnes angulo fere recto egredientes. Apices pinnularum obtusi et rotundati, sensim emarginati demumque bi-trifidi. Verrucæ minutæe medium pinnarum majorum occupant, nunc in lineam longitudinalem subregulariter dispositx. Color in nostris castaneus. Substantia fere magis coriacea, quam cartilaginea.

De congruentia hujus speciei cum Grateloupia versicolore conferantur quæ infra hanc speciem dixi.

7. Pr. Jubats ( $J . A g ., m s c r$.$) fronde plana pinnation decomposita,$ pinnis linearibus utrinque attenuatis, margine sparsim denticulatis, superne pinnulatis, pinnulis lanceolato-linearibus. 


\section{Prionilis.}

Gelidium crassifolium Post. et Rupr. mscr. (non Grev.)

llab. in mari septentrionali inter Asiam et Americam Rossicam (Expedit. Lütlieana!)

Frons 3-4pollicaris et forsan major, substipitata, foliolo nempe primario angustiori et incrassato. Ex parte liujus superiore fere palmatim exeunt pinna primarix $4-b$, sesquipollicares, basi longe attenuate, supra medium 2-3 lineas latæ, versus apicem truncatum iterum angustate. I'inn secundariæ præcipue opicem versus primariarum densæ, multo augustiores, vix lineam latæ, basi longe attenuatæ, nudæ aut sparsissime denticulatx, supra medium pinnulatæ, pinnulis hic illic aggregatis, alternis aut subsecundis, lanceolato-linearibus subacutis. Denticuli sæpe supra basem incrassatam mamillati. Color fuscescens. Substantia coriacea.

Ramilicatione cum quibusdam formis Callibleph. jubatæ ita convenit ut iconem Turneri (Tub. 70 fg. f.) ad nostra prosentis speciei specimina calcatam facile fingeres. Tota autem planta plana, et structura Prionitidis.

Specimina, qux ex IIerbario Academiæ I'ctropolitanæ accepi, nomine supra allato inscripta fuerunt; plantam vero in opere præclaro Algologorum Rossiæ frustra quæsivi.

8. Pr? crisita (Gm. Fuc. p. 160) fronde compressa lineari vage diclıotomo-subpinnata, segmentis sursum sensim angustioribus, margine et disco phyllis teretiusculis elongatis demum pinnatim ramosis dense obsito.

Fucus crinitus Gin. l. c. lab. XVIII. fig. 2! T'urn. Ilisl. lab. 123! Ag. Dec. Alg. I n. 8 !!

Sphærococcus crinitus Ag. sp. p. 273 et Syst. p. 224. Post. el liupr. Illusl. p. 17!

Gelidium crinitum Külz. sp. p. 766 !

\section{Hab. in mari Kamtschatico (Tilesius!)}

Radix scutata. Frondes semipedales, basi teretiusculæ, mox compressæ et fere planie, decompositæ, ramificatione inter dichotomam et pinnatam intermedia. Segmenta linearia, inferiora 2-3 lineas lata, superiora sensim angustiora, juventute nuda et evidentius dichotoma, habitu fere Chondri, adultiora ciliis dense obsita, apice inmo sæpe in cilia pinnata soluta. Cilia initio teretiuscula et simplicia, sensim magis compressa et segmentis conformia, demum pinnatim divisa, a margine et aliquando a disco prolificantia. Color obscure purpureus, exsiccatione nigrescens. Substantia coriacea. Cystocarpia in ciliis simplicibus inllatis, ovato-mucronatis immersa.

A prioribus habitu satis diversa. Structura fere eadem; in caule cellulæ rotundatæ inter fila strati interioris, et horum reticulo cinctie obveniunt. Yera hujus speciei affinitas, fructibus ignotis, vix dijudicatur. Habitu cum Thysanocladia parum convenit. 


\section{Acrotylus J. Ag. Act. Holm. 1849 öfors. p. 86.}

Frons compresso-plana aut prismatico-angulata, simplex vel dichotoma, duplici strato constituta; interiore filis elongatis ramosis ef anastomosantibus in reticulum conjunctis constante; exteriore cellulis rotunditis versus superficiem minoribus subradiatis contexto. Favella in verrucis nemathecioideis circa apices intumescentibus evolute, plurimæ adproximatx, intra periderma hyalinum genmidia angulata plurima foventes. Spherospore in Nematheciis definite cilcumscriptis maculaformibus, infra apices segmentorum in latere plano evolutis, nidulantes, elongatæ, lilis tenuibus stipatæ, zonatim divisæ.

Frons in una specie simplicissima prismatico-angulati, in altera compressso-plana linearis, dichotomo-decomposita et preterea a margine vel strictura prolifera. Substantia subcoriacea. Color fuscescens, aut sordide purpureus.

Stratum exterinum frondis constit cellulis rotundatis minutis, pluribus seriebus dispositis, externis sonsim minoribus, fila verticalia moniliformia dense approximata constituentihus. Iloc externum stratım quasi periphericum tubi interioris, qui reticulo satis denso occupatur. Constituitur hoc reticulum filis elongatis undique anastomosantibus, in aqua eximic tumentibus.

Fructus in diversis speciehus detecti. In una, quam typicæ congenericam suspicor, fuvella in apice intumescente claveformi, filorum corticalium evolutione spongioso, plurimæ nidulantur. Nuclei simplices videntur, intra periderma hyalinum gemmidia plurima, forma irregularii, rotmolato-angulatis aut conico-cylindracea et truncati, foventes. Fila, quæ stratum spongiosum efficiunt, sunt valde prolongata, dichotomo-fastigiata moniliformiter articulata; supra filorun basem fivelle nidulantur rotundite, filis circa nucleos secedentibus, supra illos iterun approximatis ef per canalem elongatum gemmidia dispargentibus. Pars fructifera, a superficie visa, minutissime tuberculista adparnt.

In altera specie, quam typicam generi descripsi, splırosporas observari. Infra apices segmentorum et prolificationum subspathulatos nemathecia obveniunt, seu maculic slevatie oblonga, margine augusto sterili cinctre, in utraque pagina simul prominentes; constant cellulis periphericis valde prolongatis et in fila moniliformia tenuissima evolutis, inter gnas spherosporæ valde elongatx, diametro fere quadruplo longiores, zonatim divise nidulantur. 
Genns, fructur utroque nondum in eadem sperie simul invento, non omnibus dubiis forsan carens. Si ambo species revera congenerica sint, ab omnibus florideis sane, clatracteribus insignibus utriusque fructus, facile dignoscitur. Sin vero fructus alter, qui hodie ignoturs manet, diversititem genericam specierum proderet, utraque species novum genus sibi sane urgeret. Splierosporals quandam curm Acropeltide iffinitatem indicare, forsan "quis crederet. Sed et iudole macula fertilis et strnetura frondis lioc genus longe differt. Polỵopes, qrod genus cum Acrotylo quoque comparandum appareat, forma Nemathecii, divisione splıcrosporarum et structura quoque frondis (licet lıec differentia rogre verbis exponitur) non miutus distinctum. Cum aliis generibus, gne Nematlecia gerunt, vis comparandum. Cystocarpia in verrucis Nemathecioideis evolıti paucis generibus prira sunt. Rhizopliyllis structura frondis, Peyssoruclia atque Polyides et ipsa Nuclei structura et fronde, nogotio nullo dignoscuntur.

\section{PRisuitoma fronde simplici, prismalico-angulala.}

1. ACr. prisuaticus (J. Ag. Symb. 1 p. 19) fronde simplicissima, hic illic strangulato-prolifera, prismatico 3-4quetra.

Dumontia prismatica $J$. Ag. $l$. $c$.

Gymnophlæa prismaticı liülz. sp. p. 711 !

Ilab. in mari Indico ad oras Ilindostanix (IIl). $\mathrm{Ag}$ !)

Frondes a basi scutata plures gregarix surgunt, 4-5pollicares, pennam corvinam crassæ, simplicissimæ, nunc distinter strangulatx, a striclura per frondem similem continuatæ, acutius 3-4quetræ, apice obtuso. Color purpurascens. Stratum interius sat densum, acido vero superfusum expansum et structuram generis monstrans; stratum exterius filis monilıformibus dense adproximatis, inferne dichotomis, constat. Favellas supra descriptas Generis in hac specie observavi. Apex frondis fertilis clavatus, teretiusculus.

Species sane distinctissima. Ilalymeniæ saccatæ affinem olim credidi, et ita Dumontiæ primum, dein Clıætangio adnumeravi. Structura auten hodie melius perspecta et fructu detecto, aliam omnino de affinitate idæam protiteri cogor. Cum Gymnophlæa a liützingio conjuncta, sed a loc genere longe differt. Habitus quandam similitudinem cum Ginn. Sillicolnioides Kütz. video, sed structura longe alia.

\section{Acrotsus fronde dicholoma, compresso-plana}

2. Ack. atstridis (J. Ag. Act. Holm. Öfiers. 1849 p. 87) froude dichotoma et prolificationibus ramosa, compresso-plana, segmentis linearibus. 
Ilab. ad Sidney in littore Noræ Hollandix; (communic. Baro de Gyllenstierna!)

Frons 4-5pollicaris, compresso-plana, dichotomo-decomposita, fastigiata et insuper a margine prolifera; prolificationibus hic illic densioribus aggregatis simplicinsculis lingulato-linearibus, basi strangulatis. Segmenta linearia et lineam lata, hic illic quasi leviter constricta, terminalia rotundato-obtusa subspathulata et fertilia. Axillæ acutiusculæ. Substantia subcoriacea. Color fuscescens. Sphærosporas Generis supra descriptas in hac observavi.

Habitu hæc species quandam similitudinem cum Rhabdonia firma offert, at nulla revera inter utramciue affinitas adest, ut e fructu et structura frondis facile pateat.

XXIV. Furceldaria Lamour. Ess. p. 23\%. Ag. sp. Alg. 1 p. 101. Grev. Alg. Brit. p. 66. Endl. Gen. pl. Suppl. III. p. 38. J. Ag. advers. p. 36. Areschoug Enum. Phyc. p. 87. Furcellarix sp. Aresch. et Külz.

Frons teretiuscula diclotomo-fastigiata, subtriplici strato contexta. Stratum medullare filis elongatis dense intertextis longitudinalibus, intermedium cellulis brevioribus amplis, externum cellulis minoribus in fila moniliformia verticalia conjunctis, contstitutum. Fructus utriusque generis in apicibus siliquosis demersi. Favella inmerse, a cellulis transformatis strati intermedii ortx, adproximatx, nucleo simplici gemmidia magnal angulata per canalem strati exterioris emittente. Spherospora inter cellulas strati exterioris, in fila evolutas, demersa, pyriformes magna, zonatim divisæ. (Grev. Alg. Bril. lab. XI. Aresch. Enım. ıab. IV. Kü̈z. Phycol. tab. 71).

Frondes cxspitosæ, a radice repente erectiusculæ aut sublicmisplıcrice radiantes, teretes, crebris dichotomiis decomposite, eximie fastigiate, apice in siliquas elongatas utrinque acuminatas, simplices aut ipsas furcatas, demum intumescentes. Siliqux fructifer demum fructibus emissis delabentes, cicatricem truncatam linquentes, a qua frondes novella gemina aut plures pullulint.

Triplici strato frons contexta est. Medulare cellulis elongatis cylindraceis granulosis dense intertextis longitudinaliter excurrentibus constat. Ab lis superficiem versus radii arcuatim exeunt, cellulis brevioribus roturudato-cllipsoide is densius approximatis granulosis constituti. II:ts undique circumdat stratum peripliericun, cellulis 
minorilus in fila subrerticalia moniliformia conjunctis, endochromate minutius granuloso farctis, contextum.

Fructus utriusque generis in apicibus siliquosis diversorum individuorm demersi. Favella in cryptis strati intermedii excavatis nidulantes, satis amplix, mucleo subsimplici laxius colixente constantes; secedentibus filis strati exterioris, gemmidia migna angulatia, a cellulis transformatis strati medii orta, solidescente muco invicem sejuncta, per canalem pervium emittentes; (membranam ambientem favella non vidi).

Splixrosporx in strato externo demersx, filis verticalibus peculiariter evolutis stipatx, plurimx adproximate, magne, oblonga aut prriformes, irregularius zonatim divise.

Genus jam diu fundatum, vix tamen ante ultimum lioc tempus quoad fructus cognitum, immo in splendida Plyycologia Itapveyana sterile aut fructibus nimium immaturis depictum. Fructus attamen a pluribus observatos fuisse, hodic perspicere licet. In siliquis fructus demersos esse omnes fere augurarunt; indolem autem ipsam vis sili cognitam labmerunt. Splıærosporas zonatim divisas jam viderunt Turnerus, Lynglbyeus et Delapylaie, sed ejusmodi fructibus in nulla alia planta cognitis, observatio a posterioribus pratermissa fuit; Agardhius et Greville spherosporas tantum inmafuras et nondum divisas viderunt. Ipse ni fallor primus (Ado. $p$. 36) splıerosporarum indolem, qualem quoque vidit Arescloug, exposui.

Cystocarpia Agardhius primus observasse videtur. Decaisne dein (Classif. p. 70) eadem descripsit, sed antecedentium auctorum observationes, de spluerosporis institutas, ad stas conformare studens, ipsius descriptio minus clara evasit quam res obscura postulaverit. Arescloug (Enum. p. 87) dein cystocarpia, qualia ipse quoque vidi, bene illustravit.

Tubercila, qualia in multis Florideis obveniunt, a ramis verrucose crumpentia, ohservarunt plurimi. Fructificationis quadam functione fungi, diu crediderunt; nullum vero fructum his inesse milii videtur perspicuum.

Indole fructus parum perspecta, genus quoad affinitatem diu dubium mansit. Lamouroux et Agardlı, ob fructus in silinuis nidulantes, Genus Fucaceis adnumerarunt, quo loco contemporanei fere omnes illud retinuerunt. Greville familiam propriam, inter Fucoideas spongiocarpeas et Florideas intermediam, Furcellaria fundavit. Decaisne in eandem familiam Floridearum Furcellariam 
et Polyidem conjunvit; Areschoug (Linn. 1843) et Kützing utramyue plantam demum ad idem genus retulerunt. Fruehu hodie melius perspecto, utrumque genus sine dubio retinebunt phurimi; quodque suo loco inter Florideas disponendum.

1. Ferc. Fistigiat. (Iluds. Angl. p. 588.) Ag. Sp. 1 p. 103! Sysl. p. 274 ! Delapyl. Fl. de Terre Neuve p. 125. Grev. Alg. Br. p. 6 I lab. 11! Harv. Man. p. 5 ' el Phycol. lab. XCIV! Kü̈z. Phyc. p. 402 tab. 71 ! el Sp. Alg. p. 749! Aresch. Enum. p. 88 !

Fucus fastigiatus Illuds. l. c. Gm. Ilist. p. 106 lab. 6 fg. 1! Fl. Dan. tab. 393 .

Fucus lumbricalis Gm. Ilist. p. 108 tab. 6 fig. 2! Turn. Ilist. lab. 6! Engl. Bol. lab. 824.

Furcellaria lumbricalis Lymgb. Ilydr. p. 48 lab. 40.

Exs. Hyalt. Danm. n:o 106 ! Chauv. Norm. n. 14l! Chalm. Scol.n. $42 !$

Ilab. al rupes submarinas Oceani atlantici ab oris Norvegia usque ad littora Gallix et Terræ Nove Americi; in mediterraneo ad littus Sardinie (De Notaris!)

Radix fibrosa, fibris repentibus dense intertextis. Frondes 4-6pollicares, diametro lineam usque æquantes, in cæspites subhemisphæricos evolutx, cylindricx, decomposito-dichotomæ, sinubus acutis, eximie fastigiatæ, demum apice intumescentes fructiferæ. Siliquæ pollicares et ultra, diametro frondis duplo crassiores, utrinque attenuatx, plerumque ipsæ simplices, aliquando furcate; maturæ deciduæ apices truncitos linquentes. Apices aliquando siliquis brevioribus, consistentia tenuioribus et fero gelatinosis terminantur, quas fructiticationis quandam formam fovere din crediderunt, et in diversis semper individuis obvenire observarunt. Cujus naturæ sint, hodie parum liquet; vix tantum siliquarum initia! an antheridia? Color purpureo-nigrescens, exsiccatione niger. Substantia carnosa, exsiccatione subcoriacea.

"Algologi veteres in ảuas species diviserunt pro statu sterili vel fructifero, illum Fuc. fastigiatum, hunc F. furcellatum adpellantes, ut ex Linnæi scriptis patet."

Polyides rotunda Moris el Denotaris Fl. Capr. p. 193, quam jam in Alg. med. $p .92$ a specie ejusdem nominis marium borealium differre dixi, est Furcellariæ species, sphærosporis zonatim divisis instructa, et forsan a 1 . fastigiata non distincta. Peculiari autem statu specimina collecta videntur et forsan nimium compressa, unde superne complanata app:lrent. Cellulæ endochromate granuloso fere destitute. Annuli, quos memorant auctores, sunt revera apices truncati, post siliquarum delapsum conspicui, ex quibus ramuli sxpe plures 2-6 fasciculatim proveniunt; 
ut hoc quorue in vulgari planta sxpius observavi (numquan vero in Polyite a me observatum). Apices, qui complanati in exsiccata planta apparent, ob membranam exteriorem fructiferam et solutam hunc adspectum receperunt.

\section{TRIBLS II. GISTROCARPEI.}

Frons fubulosa, filis interioribus elongatis articulatis, cellulisque periphericis in stratum membranacem coalescentibus, contexta. Farclle nucleus simplex infra stratum exterius, iu pericarpium quandoque elevalum, demum carpostomio ruptum, exceptus. Spherosporie a cellulis corticalilus formate, cruciatim divisie.

XXV. Ilalyuenia $J . A g$. Alg. med. p. 93. Endl. Gen. $p l$. Suppl. III p. 40. Hallymenie sp. Ag. el Auct. Halymenix et Iialarachnii sp. Külz.

Frons cỵlindracea aut ventricoso-plina, gelitinoso-membranacea aut carnosi, diclotoma aut pinnati, memlirana tenui, filis interioribus extensa, constans; filis interioribus lisioribus articulatis et ramosis, versus peripheriam in cellulas rotundato-multangu-

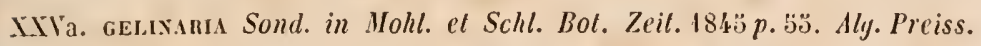
p. 23.

Frons compresso-plana viridis, stipitata, lanceolata, pinnatim ramosa carnosa, lubrica, intus gelatinosa filisque elongatis articulatis percursa. Fructiticatio. . .

Alga marina australasica, siccata coriaces.

1. G. Lrrolde.l Sond. l. c !

Halymenia Ulroidea hïlz. sp. p. 718 !

Hab. ad Novæ Hollandia oram occidentalem (Preiss.)

Frons pedalis, ramis explicatis circiter 6-pollices lata, e radice scululata stipitem emittit tripollicarem. Stipes subcoriaceus, inferne subcompressus, 2 lineas latus, apice latiore planus et sensim in laminam 8-10 lin. latam dilatalus. Lamina, seu jugamentum, ramos emiltit erectopatulos, distichos, oppositos vel alternos, quorum inferiores $3-4$ pollicares, superiores sensim breviores. Rami 3-4. lin. lati, pinnis erectiusculis sul,incurvis linearibus, 1 - 2 lineas latis, rarissime iterum divisis, priediti sunt. Substantia cartilaginea valde lubrica. Struclura interna ferc Chondri." Descr. Auctoris transscripsi.

Planta a me non visa, sec lïitzing species IIalymenix; quare hoc loco illsm disposui. Sonderus Chondro proximam judicasse videtur. 
lis et anastomosantes, demum concretas, abeuntibus, cellulis superficialibus rotundatis minutis. Favelle frondi immersa, infra stratum periphericum suspensie, carpostomio demum liberatie, gemmidia in uncleum simplicem conjuncta intra periderma liyalinum foventes. Spharospora strato periplierico immersie rotundatie, cruciatim divisæ. (Külz. Phycol. tab. 74, III).

Frondes nunc omnino cylindracen, nunc compresse, nunc collipso-planx crassiusculie, recentes semper gelatinoso-carnosie, exsiccatione membranacex aut plus minus cartilaginex; plerumque regulariter dichotomo-fastigiate, ant dichotomiis magis approximatis sulpalmate, numc pinnate, segmentis semper ambitu defuilis et frondis divisione originaria ortis, nee dilaceratione separatis; siepe probiferæ, prolificationibus segrmenta frondis demum iemulantibus. Partes novelle fere tubulose, filis interioribus sparsissimis; in adultioribus fila interiora multiplicantur et densiora evadunt. Fila iuteriora et longitudinaliter et transvorsaliter excurrunt; in media fronde sunt cylindracea articulata et ramosa; ut periphlieriac adprosimantur in cellulas rotundito-multangulas stellatim anastomosantes abeunt. Que quidem cellule, initio laxiores, sensim magis in stratum continum concretx, pluribus (2-3) sericlus dispositx, una cum collulis rotundatis minutis coloratis peripheriam frondis constitumt. Favellæ infra periplţeriam filis ambientibus suspense, (in planta exsiccata mediam frondem occupantes), extrorsum parum prominula, carpostomio rotundato demum evidenti liberate; nuclens gemmidiis arete conglobatis, peridermate liyalino cohibitis, constat. Placenta centralis inclusil adesse videtur, sed lıe gentmidiis stipatis occultata. Gemmidia al) lace irradiantia. Placenta in II. lionlitti membrance exteriori adfixa videtur; in II. Floresia filis interioribus forsan adnata. Spluerospora in paucis speciebus tantum observate; in lis sunt rotundate et cruciation divise, transformatione cellularum corticaliun formatie.

Agardlianum genus Ilalymenie recentiores in plura genera dissolrerunt. Bory Jridicam, Montagne Ginamnian, Jpse Kallymeniam ct Clıysymeniam, Kützing denique IJalarachnion sevaravit. Ilalarachuion, ut in Plıycologia lıo genus (typo It. liyulatil) definivit Kützing, filis interioribus sparsissimis favellisque infra superficien adnatis a Ilalymenia (lypo II. floresia), cujus fila interiora multo densiora et favelle in media fronde nidulantes depinguntur, differret. liem ita se labere, ex speciminibus uadefactis facile judi- 
catur; falsum vero his fingi judicium pulo. Frons enim ll. floresie, maxime gelatinosa, magis collabitur, et membranx collapse tilis conglutinatis parum distenduntur; hine in sectione transversali fila interiora densiora et favella membranis exterioribus aque adproximatre cermuntur. Si vero acido superfuso, quod gelatinam solvit, structura observatur, II. ligulata et II. Iloresia vix mintimam differentiam offerunt. - Ut limites liorum generum in ultimo suo opere duxit kï̈ziñog, genera multo minus adoptanda censeo. Ilalarachnion enim preter typicam speciem species Ifalymenix Küı., Chrysỵmenia, aliasque complectitur.

Ut genus Halymenix hodie intelligo, favellis immersis et dofectu placente proprix a Clirysymenia differt. $\Lambda$ Dumontia fructu, structura stati peripherici et filis interioribus cum etate densioribus dignoscitur. A Kallymenia nucleo Cystocarpii minuto et simplici, infra superficiem suspenso, recedit. Scinaia (Ginannia Mont.) cystocarpia non parum diversa liabet.

\section{Fronde gelatinoso-membranacea terete vel compressa dicho- tomo-fastigiata.}

1. II. mstiguta (J. Ag. Act. Hol. 1849 p. 86) fronde teretiusculi grelatinosa dichotomo-decomposita fastigiata sursum attenuati, segुmentis supria sinus rotundatos erectiusculis, terminalibus longe acuminatis.

Ilib. in mari mediterraneo ad littora Algierix (Hlb. De Notaris!)

Frons tripollicaris, inferne calamum scriptorium crassitie xquans, per dichotomias. (4:ter aut quinquies) repetitas decomposila, segmentis infra dichotomias paululum dilatatis, céterum vero sensin angustioribus, terminalibus a basi latiore sensim acuminatis. Color et substantia fere Chr.

4a. IIar Grstophora (Mont. pl. Cell. III. Cent. p. 26) fronde pallide rosea gelatinosa cylindracea multotics dichotoma segmentis membranaceis subinflato-ventricosis, ultimis acutis vix fastigiatis, siccilate collapsis.

Dum. cystophora Nont. $t$. $c$.

Hlalynenia cystophora Mont. Fl. Alg. p. 114.

llalurachnion cystupliorum Kï̈l. sp. $p$. 721!

Jlab. in littore Monspeliensi (Delile); apud Alger (Bory et Monard).

Ramificatione Ginn. furcellatx, habilum Dum. rentricosie induit. Fruclus Ilalymenix: conceptacula sphxerica, per frondem sparsa, sul, strato corticali nidulantia, congeriem sporarum angulatirum minulissimarum rosearum foventia. - Descr. Aucl. (ransscripsi. 
ventricosæ. Spharosporæ cruciatim divisæ inter cellulas verticales elongato-oblongas strati superticialis sparsæ. Cellulæ intermedix rotundatx, laxiores et anastomosantes, pluribus stratis disposita; centralia fila generis, laxa et anastomosantia. Charte arclissime adhæret.

Quum specimen Dum. cystophoræ Montagnei nullum viderim, cum hilc nostram conjungere non ausus sum. Descriptio data Montagnei ad unguem cum mea convenit, excepta tantum crassitic; suam enim semilineam crassam describit Montagne; quod plantam aliam indicare videtur.

2. H. DECipiexs (J. Ag. mscr.) fronde teretiuscula gelatinosa dichotomo-decomposita fasticiata, sursum vix attenuata, segmentis supra sinus rotundatos erectiusculis, terminalibus obtusis xqualibus.

\section{Ilab. in oceano atlantico ad Gades (Cabrera!)}

Frons 4-pollicaris, pennam corvinam inferne crassa, sursum parum attenuata, omnino ut videtur cylindrici, repetite dichotoma. Segmenta supra sinus angustos at rotundatos erecta et adproximata, terminalia vix tenuiora cylindracea et obtusa. Fila interiora elongata sat densa; cellulic intermedia transversales oblonga; peripherice verticales oblongæ. Color flavo-rubens pellucidus. Chartæ arctissime adlææret; substantia tenue membranacea et gelatinosa.

Forma segmentorum cylindrica a priori primo intuitu distat, habitu cum Scinaia furcellata ita conveniens, ut exsiccata ab illa haud dignoscatur. Structura vero longe differunt. Tenuitate et forma cylindrica frondis a sequentibus recedıt. Nomine II. trigona in Spec. Alg. Agarkhii descripta fuit. Synonymon vero Esperi ad atinm plantam, ni fallor, pertinet.

3. II. eloygata (Ag. sp. p. 209) purpurasecens, ultra pedalis, fronde cylindraceo-compressa gelatinoso-membranacea di- aut trichotomo-fastigiata, segneritis sublinearibus, inferiorihus latioribus.

Halym. elongata Ag. l. c. el Syst. Alg. p. 243! Kü̈ъ. sp. p. 721!

Ilab. in inari allantico ad Gades (Calbrera!)

Frons pedalis et ultra, digitum majorem inferne crassa, superne calamum scriptorium crassitie aquans. Recens sine dubio ex cylindraceo compressa et tubulosa, exsiccata omnino collapsa, apicibus abruptis margine involuti, frondem tubulosam prodens. Ramificatio regulariter dichotom:, aut hic illic trichotoma, distantiis 2-3pollicaribus divisiones vicinas intercedentibus. Segmenta a basi ad apicem fere eandem crassitiem servantia, inferiora superiorihus latiora. Sulstantia membranacea succosa videtur, attimen charte arcte adbaret. Color ex purpureo viridescens. spherosporas inter cellulas superficiales segmentorum superiorum sp:rsas, rotundatas, cruciatim divisas vidi. 
Species distinctissima, ut quoque rarissima videtur, cum II. ligulata nullo modo comparandit. Diagnosi al) antecedentilus xgre circunscribitur, magnitudine facillime distincta. Quoad structuram cum If. floresia convenire mili videtur. Cellulie superficiales verticales; infra lias cellula rotundata majores et subinanes paucis seriebus disposita; fila interiora arctius conglutinata, acido superfuso distenta.

4. II. trigona (Clem. Ens. p. 3/8) coccinea semipeditis, fronde ejlindraceo-compressal gelalinoso-membranacea subcartilaginea, di-lrichotoma fastigiati, segmentis subcuncalo-linearlibıs, apiciluts obtusis.

Fucus trigonus Clem. l. $c$. (fide sp. a Cabrera miss.)

Halymenia trigona var. cartilaginea $A g . s p$. Alg. p. 211!

Hillarachinon trigonum kiülz. $s p$. $p$. i2??

Ilab. in mari atlanlico ad Gades (Cabrera!); ad liflus Gallicia!

Stipes cartilagineus, pennam columbinam xequans, mox extenditur in frondem digitum minorem crassam, tenuissime membranaceam, exsiccatione omnino collapsam, subcartilagineam, 4-6pollicarem. Ramificatio dichotoma, nunc trichotoma, fastigiat:. Axillæ rotundatx. Segmenta termiralia lingulata, sape abrupta et ad cicatrices incrassata, prolifera (quod proximis speciebus commune videtur). Color fere coccineus. Favella in segmentis superioribus sparsæ (in nostris per-paucæ), iisdem H. ligulatie fere duplo majores. Sphærosporæ generis. Fila interiora laxa et magis elastica atque strictiora quam in proximis videntur; ut superficiei adproximantur in cellulas rotundatas, quoquoversum anastomosibus cum proximis junctas, abeunt. His proximæ sunt cellulæ ejusdem fere formie, at cum ricinis densius concretæ; superticiales denique minutæ coloratie subverticales. In planta sphærosporis ornata, superficiales cellulæ fere seriatæ sunt.

Nomine hujus speciei, formæ Scinaiæ furcellatæ in Herbariis sæpe deprehenduntur, licet species sint diversissimæ. In speciebus Algarum Agardhii sub nomine H. trigonæ plures species quorjue conjunctæ. Ex his nomen Clementis ad præsentem speciem pertinet, tide speciminum Cabrerie. - Hal. trigona ad H. elongatam proxime accedere mihi videtur, sed lorevior et latior, atque colore et substantia magis succosa diversil. Speciminibus pluribus visis forsan melius definiendx. Ex adnotatione Cabreræ patet has plantas et ab ipso et a Clementi distinctas haberi. Stipes elongatus cartilagineus in presenti adest; inferiorem partem 1 . elongatæ non vidi.

II. Fronde gelalinoso-memliranacea, compressa aut demum plana, dicholoma, prolificuliomilus sulprimala.

5. H. LIfulata (Woodw. Limn. Tr. III. p. 5̧) fronde gelillinusomembranacea compresso-phana, lineari et diehotoma aut cll- 
neatim expansa et subpulmata, a marogine et disco sape prolifera.

Ulva ligulata Woodw. l. c. Engl. Bol. lab. 420.

Halymenix ligulata Ag. sp. Alg. p. 210 el Syst. p. 244!! Grev. Alg. Brit. p. 162 tab. 17. Harv. man. p. 52 ct Phycol. tab. CXII! (excl. syn).

IIalarachnion ligulatum Kü̈t. Phycol. lab. T4. fig. 1 et Sp. Alg. p. 721.

Ulva rubra Iluds; Engl. Bot. Lab. 1627 !

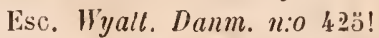

IIab) in oceano atlantico a littore Ilelgolandic et Orcadum usque ad Tingin!

Frons a radice scutata surgens, stipite plus minus evidenti, sensim in laminam aheunte, pollicem longa aut usque bipedalis, nunc linearis vix lineam lata ex cylindraceo compressa, nunc 3-4pollices lata et omnino plana. Ramificatio semper dichotoma, sed in formis latioribus subpalmata, segmentis pluribus eadem altitudine inchoantibus. Segmenta linearia ant subcuneata, semper integerrima, plus minus decomposita, axillis rotundatis. Frons numc nuda, nunc a margine plus minus dense prolifera, prolificationibus ciliiformibus aut segmenta lata frondis amulantibus, simplicibus aut dichotomis, linearibus oblongisve, acutis aut obtusiusculis, basi semper attenuatis. Favellæ per totam superticiem sparsæ. Color coccineus. Substantia gelatinoso-membranacea. Cellulæ strati peripherici minutæ angulato-rotundatæ, unica serie dispositæ, superficiei fere parallelæ, divisione continua ut videtur nultiplicatæ et hinc a superficie visæ geminatim ternatimve approximatæ aut æque distantes. Fila interiora sunt laxissima, plurima inter utriusque paginæ membranam extensa, nonnulla longitudinaliter excurrentia, utraque anastomosibus juncta, mediante cellula menbranam subjacente, huic apicibus adnata; constant tubo hyalino et endochromate subcolorato cylindrico, ad genicula paululum dilatato. Favellæ infra superficiem utramque circumcirca dispositx et omnino inclusæ, pro magnitudine plante minutie, filis ambientibus paucis suspensæ, intra membranam gelatinosam evidentem lyyalinam gemmidia in nucleum dense slipata plurima fovent. Placenta centralis inclusa adesse videtur, sed hæc gemmidiis stipatis occultata; gemmidia ab hac quodammodo irradiantia, basi placentæ membranam externam, apice et gemmidiis internum spatium spect:ntibus. Sphærosporæ ignotæ.

Quoad forman valde varians, structura semper dignoscenda. Dumontia Calvadosii Lamour. quoad iconem datam huc trahere vix dulitarem, sed specimina plura ab Auctore distributa, ad Hesogloiam purpuream pertinent. Ad li. ligulatam refero Platoma undulatum (Schousb. Mscr.), cujus tantum fragmenta vidi informia, ultra pedalia, 4pollices et ultra lata.

Aune nomine II. ligulatæe var. latifoliæ dux plantæ confundantur? Una rarietas latifolia II. ligulatæ; altẹra species propria, fronde omnino plana, parcius divisa et procipue colore pulchre coccineo diversa. In vera II. ligulata color magis in purpureum tendit. 


\section{Fronde carnosa aut gelatinoso-membranacea pluna, dicholoma.}

6. 11. p.trexs (J. Ag. mscr.) fronde gelatinoso-membranacea plina orbiculari dichotoma, seymentis subcuneato-linearibus smpra simus obtusos conniventibus, terminalibus dilatatis obtusis emalgुnatisve diverogentilus.

Ilib. in mari mediterranco ad oras Galloprovincix (Solier! lpse!).

Frons subsessilis bipollicaris in orbem fere expansa, ter aut quater dichotoma. Segmenta $2-3$ lineas lata, linearia, infra dichotomias aliquuantulum dilalata, ob latitudinem brevia; terminalia initio obtusissima, dein emarginata, demum bilida, laciniis divergentibus, tandem supra sinum iterum convergentibus. Axillæ obtusæ, demum rotundatæ. Color coccineopurpureus. Substantid membranaced. Chartæ arcte adhæret. Structuril generis mihi videtur. Cellulix superficiales rotundato-angulatæ, simplici serie dispositæ, cum superficie parallelæ potius quam verticales. IIis sul)jacent aliæ panlo majores subbyalinæ; internum spatium filis elongatis subgranulosis occupatur. - Habitus fere Rhodymenix bifilæ, sed substantia alia.

7. Hlac. Movardiaxi (Mont. Crypt. Aly. p. 8) fronde carnosa plana sessili, dichotomo-subpalmata, segmentis sursum cuneatis, ultimis ceranoideis attemuatis spatlubatisve.

Ifal. Monardiana Mont. l..c. el Fl. Alger. p. 113 lal. 11 fig. 2 ! Küls. sp. p. 717.

II. mesenteriformis Mlonard. mscr.

Ilab. in mari mediterraneo ad oras Mgeria (Nonard el Roussel!)

Frons a radice scutata semicirculariter expansa, 3-4pollicaris, inferne mox divisa et dein per plures dichotomias irregulares subpalmatim decomposita, segmentis cuneatim dilatatis, usqque pollicem latis, superioribus in lacinits irregulares attenuatas vel quaudoquidem spathulatas iutegras obtusas aut sæpe multidentatils abeuntibus. Color coccineo-purpureus. Sulstantia exsiccatio fere pergamena; chartæ nou allixetet. Cellularum series plures memhranam exteriorem constituunt; fila interiora densius quam in speciebus typicis intertexta.

Species certe distinctissima, sed forsan adhuc dubia II:Ilymeniæ species. Fronde gaudet crassa tirmiori, in IIalymenia fere almormi. specimine hujus speciei nondum a me viso, alian speciem pro lac perperam sumsi (Syml. p. 19). 


\section{Fronde carnosa aul gelatinoso-membranacea pinnalim decomposila.}

8. 11. Spithicita (J. Ag. Alg. med. p. 96) fronde gelilinoso-memblanacea plana stipitata cuneata ant oblonga, a marouine pinnatim prolifera decomposita, prolificationibus initio spalhulatis demum lanceolilis.

Halymenia spathulata $J$. Ag. $l$. c.

Halarachnion spathulatum Kütz. sp. $p$. 722?

llab. in mari mediterraneo ad oras Mascilix (Solier!)

Frons $1 / 2-1 \frac{1}{2}$ pedalis et $2-6$ pollices lata, a stipite breri cuneatim expansa, superne nunc latior et apice fere palmatim divisa, nunc iterum angustata atque ambitu lanceolato-oblonga, a margine prolificationes circumcirca emittens. Prolificationes juveniles al) angustiori basi sensim dilatatæ, spathulatæ, apice obtusissimo rotundatx, infra apicem sesquilineam circiter lata; alultiores pinnas magis æmulantes, sesqui-bipollicares et unguem medio latx, lanceolatæ subacuminatx, nova serie sensim ornatix. Hæ pollicem longa et breviores, spathulatx. Rarius a disco prolificationes similes proveniunt. Color pulcherrime coccineus. Sulstantia gelatinoso-membranacea; charta arctissime adhæret. Fructus nullos vidi. Fila interiora laxa, flexa et anastomosantia; his proximæ cellulæ rotundatæ laxius concretæ; superficiales rotundatæ-angulatæ, simplici serie dispositæ, cum superticie fere parallelæ.

Species pulcherrima et distinctissima, ob defectum fructus quoad genus forsan adhuc dulia. An Kallymenia? et in vicinia k. reniformis disponenda. Diagnosis a Kützingio sub citato nomine data bene in nostram quadrat; nullam vero de mea planta fecit mentionem.

8i. Halmo. Latissima (Hook. et Harv. Crypt. ant. p. 77) fronde plana tenui gelatinoso-membranacea latissime ovato-lanceolata simplici bifida vel margine laciniato pinnatifida, laciniis orato-lanceolatis acutis. II. latissima II. et IIarv. l. c. tab. 73 et Lond. Journ. IV p. 263. Küt. sp. p. 718.

Var. $\beta$. bifida fronde lanceolata basi attenuata bifida vel bifurcata laciniis lanceolatis erectis.

Hab. in rupibus Insularum Aucklaṇd et Campbell (Hooker).

Frondes 2-14unc. longio, 4-6latr, tenues hasi cuneatie, late lanceolatie vel ovato-oblongæ, acuta, simplices vel furcatie, margine plano simplici integerrimo vel lacinis plurimis subpinnatifido. Substantia gelatinosa. Favellidia numerosissima per totam frondem sparsil, cellulis medullaribus immersa. Color amoene roseus.

Varietatibus Hal. ligulate accedit. In exsiccata favellida supra frondem tenuissimam prominent; in madefacta fere immersa manent. - Descr. Auct. transscripsi. 
9. II. Flomesi (Clem. Ens. p. 312) fronde gelatimoso-membranacea inflato-plana stipitata elongatia pinnatim decomposila, pinnis pinnulisque linearibus longe acuminatis patentibus integerrimis aut serrato-ciliatis.

Fucus Floresius Clemente l. c. Turn. Ilist. Lab. 256.

Fucus Proteus Delile Egypt. lab. is fig. 1-4.

Halymenia Floresia $A g . S p$. Alg. p. 209 et Syst. p. 243 (excl. rar.)! J. Al. Alg. Med. p. 96! Mont. Canar. p. 163 et Fl. Alg. p. 114 ! Lü̈. sp. p. 716 !

IIab. in mari mediterraneo et vicino allantico; ad littora Africa! Canarix, Hispaniæ (Clemente!) Italia (Ipse!) et Egypti; in adriatico ad Venetian! et Trieste!; in mari rubro (fide Turner).

Alga usque pedalis, evidenter stipitata, stipite a disco radicali surgente, sensim in frondem abeunte. Frons decomposito-pinnata (quadripinnatam vidi) pinnis pinnulisque lineam aut usque pollicem latis, a basi angustiore aul xquali, quandoquidem latiore, linearibus aut sublanceolatis, apice longe attenuato acuminatis, integerrimis aut nova serie pinnularum inchoantium serratis ciliatisve, omnibus eximie patentibus. Favellæ infra superficiem suspensæ, minutx , punctiformes, per lotam fere frondem sparsæ, densæ. Sphærosporæ rotundato-oblongæ cruciatim divisæ, inter cellulas periphericas et his transformatis evolutie, in pinnis densæ. Substantia eximie gelatinoso-membranacea, tenuis; charta arcte adbæret. Color roseus.

Ramificatione eximie pinnata, pinnisque linearibus facile dignoscitur. Var. angusta, quam in Sp. Algar. huc retulit C. Agardh, est species aliena, ne hujus quidem generis.

10. II. Dunillas (Bory Voy. Coqu. n. 69) fronde membranaceoplana stipitata elongata dichotomo-subpinnata decomposita, pinnis pinnulisque linearibus longe acuminatis erecto-patentibus, margine denticulatis.

Ilalymenia Durvillæi Bory l. c. tab. 13 !! hütz. sp. p. 717!

llab. in mari australi ad oras nove Imandiae (I'Civille!)

8b. Hlatra. Consaldi (Wenegh. in Parl. giorn. bot. 1844 p. 296) pliyeomate stipitato ramoso; segmentis membranaceo-planis, cuneato-spathulatis superne bi-tripinatis; pinnis itidem cuneato-spathulatis; pinnulis lanceolatis acutis. Stipes filiformis. Color purpureus. Alt. 11/2". Hularachnion Corinaldi hütz. sp. Alg. p. 722.

Hab. ad Livorno.

A Halar. spathulato Kü̈љ. (Halym. spathulata $J$. Ag.?) differt: "Statura longe minori, phychomate non palmato, pinnis spathulatis et pinnulis lanceolilis." hüts. $l$. $c$. 
Frons a slipite bresi cunentim expanso surgens, pluripedalis, area lasali latiore sulpalmatim divisa, superne dichotoma, segmentis in jugamento intermedio alternis, et ita quodammodo pinnata. Pinnæe erectiusculie, lineares, majores fere pollicem latæ, ninores bislineam aut lineam æquantes, apice longissime attenuate, margine omnium in denticulos minutos producto. Substantia membranacea; chartæ arcle adheret. Color in speciminibus visis virescens. Favellæ infra superficiem pinnarum densis; ni fallor, quoad structuram cum iis II. Floresix convenientes.

Specimina et a Bory et a D'Urvilleo data sunt virescentia, sed sine dubio per exsiccationem mutata.

\section{Species inquirenda:}

11. Hiz. ezongata (Külz. sp. p. 718) phyllomate maģno lanceolato clongato, sxpe pertuso, margine subundulito, interdum margine prolifero.

Ilib. ad Lima (IIb. Binder).

12. II. Choxdricola (Sond. Bol. Zeit. $1845 \mathrm{p}$. 37 ) "fronde gelatinoso-membranacea oblonga cuneata pinnata apice dichotoma, pinnis oblongris lanceolatisve ciliatis.

Ilab. ad littus occidentale Nove Ilollandix. (Preiss).

Frons tripollicaris, semipollicem lata, in stipitem brevissimum sensim attenuata. Ramenta (pinnæ) disticha, 1-2pollices longa, 2-4lin. lata, lanceolata, rarius oblong:a, substipitata, margine dentibus subulatis flin. longis apice interdum bispinulosis ciliata. Color roseo-purpureus. Sphærosporæ sphæricæ triangulatim quadridivisæ, in cellulis magnis sub strato peripherico sitis vel in interioribus nidulantes. Favellidia desunt. An vera Ilalymenia?" Sond. Alg. Preiss. p. 23̈. Kü̈ls. sp. p. 717. An Chondrothamnion?

13. II. Pusilda (Sond. Bot. Zeit. 1845 p. 57) "fronde membranacea plana dichotoma, axillis acutiusculis, segrmentis linearibus suibaculis basi angustatis, maroine integerrimis dentatisve.

Itisl). ad lilfus occidentale Noræ Ilollandixe (Preiss).

Pusilla, pollicaris, semilineam lata. Frons dichotoma vel sparse ramosa, ramis erecto-patulis. Color amoene roseus. Fructus deest. An revera hujus generis?" Sond. Aly. Preiss. p. 23. Kälz. sp. p. 717.

14. ILA. DuBis (Bory ap. Bel. Voy: p. 169) fronde cuneato-flabellata fissa, laciniis extremitate proliferis. Kï̈tz. sp. p. 717. IIal). atd Cap. Comorin.

Habitus Rh. palmatx, sed minor et respeclu magnitudinis latior, substantia aliquantuium magis membranacea, colore in rulorum potius quam in violaceum tendens. Segmenta flabelliformia potius quam palmata, 2-3pollices longa, in lacinulas $2-3$ latiusculas subfurcatas fissa, ligulis ab apice prolificantibus. - Ita fere Auctor, qui plantam de novo examinandam commendat. 
15. Ihat. Chaferonms (Suhr. in Fl. 183 I p. 675) fronde e basi scutata angustil sensim cuncito-dilatatis, apice rotundata integra vel pluries fissa, margyiubus rectis undulatis, sporidiorm olomerulis punctiformibus sparsis obscure Jrunneis. Mont. Canar. p. 164. Kütz. $s p . p$. 7IS.

llab. ad insulas Canarias.

16. Ilatrw? Dontrioris (Monl. Fl. Boliv. p. 2.l) "fronde coriaccomembranacea palmato-fissa intererrima, segmentis aculissime lanceolatis undulato-crispis spiraliter tortis.

Ilab. in oceano pacifico ad oras Peruvix (du Petit-Thouars).

Frons a basi plana lineari angustissima substipitata mox in segmenta plurima triuncialia lanceolata acutissima undulata spiraliterque torta palmato-fissa. Fructus ignotus. Color violaceo-purpureus. Substantia coriaceo-membranacea. Chartæ adhæret."

17. ILL. Negeli (Külz. sp. p. 897) plıycomate palmatim ramoso, ranis subsecunde pinnatis, pinnis patentibus obtuse et parce dentatis, apicibus obtusiusculis. NIt. 4"; lat. 4-6"'; pinne 2-6"' longe, 1-11/2"' Iate.

Ilib. in sinu Neapolitino (Nogeli).

18. Hal. mayosissima (Suhr. Flora 1840 p. 275) pallide rosea, 4-6pollicaris, frondibus tubulosis compressis ramosissimis, ramis superne fere capillaribus, primariis oppositis patentissimis, secundariis irregulariter alternis strictis erectiusculis, infra apicem ramulis spinæformibus $1 / 2$ - I linean longis obsitis, fructibus in ramis secundariis sparsis punctiformilus. Külz. sp. p. 817. Ilab. ad insulam St. Crucis (Ravn.)

Cum. Rhabdonia tenera comparanda mihi videtur.

19. Ila. Lobata (Menegh. All. Congr. Firenz. $1841 \mathrm{p} .11$ ) fronde carnosa plana orbiculari, inultifida Iobis dilatato-orbicularibus, proliferis. Külz. sp. p. 716.

Ililb. in mari Adriatico.

20. Hat. NoYe-ZeELavia (Mont. Voy. Pol. Sud. p. 10i) fronde plana gelatinoso-carnosia spiraliter convoluta dicholomo-pinnala, pinnis basi attenuata subtereti patentibus lanceolatis iterum pinuulatis, acutis integerrimis.

Halym. Novæ-Zelandiæ Mont. l. c. Küts. sp. p. $71 \%$.

Halymenia Urvilliana Mont. Prodr. Pliyc. ant. p. $8 \mathrm{ct}$ loy. Pol. Sud.

Pl. 12 fig. 2 !

Jab. in oris insule Maroa (b'lrille). 
"Frons carnoso-membranacea, plana, siccata rigida, cornea, in arua dulci aliquantisper servata in gelatinam facile abiens, a basi plana, 2 lineas lata, $1 / 2$ lin. crassa, bis dichotoma, axillis rotundatis. Segmenta erecla, convoluta, mox unguem lata, fere semipedalia, utrorue margine emiltentia pinnas simplices, patentes, lanceolatas, basi subteretes aut iterum pinnulatas, pinnulis minoribus de cætero conformibus, integerrinis. Structura: strata terna frondem constituunt; interius e filamentis articulatis ramosissimis laxe intricatis constat, quae ad peripheriam in cellulas triquetromoniliformes seriatas abeunt et in codem plano conjuncta strata duo exteriora efficiunt. Fructus . . Substantia in planta exsiccata cartilaginea rigida, humectita vero carnoso-gelatinosa. Color roseo-purpureus. Chartæ arctissime adhæret." Descr. Auct. transscripsi.

Forsan potius species Kallymeniæ; analysis l. c. data mihi obscura, aut aliter quam ab Auctore factum fuit interpretanta.

XXVI. Schimielinannia Schousb. mscr. Fïts. Bot. Zeit. 1847 p. 24. Sp. Alg. p. 722.

Frons ancipiti-plana tenuissime meinbranacea gelatinosa decomposito-pinnatia et plumosa, stratis duobus contexta; filis interiorilus laxioribus articulatis et ramosis, demun densioribus; strato periplucrico serie subsimplici cellularum rotundatarum constante. Favelle in pinnulis sulsingulæ intra pericarpium hemisphærice prominulum, demun carpostomio ruptum margineque licerum, exceptx, gemmidia conglobata intra periderma hyalintim rotundatum forentes. Sphcerosporce. . .

Frondes pulcherrime roseo-coccinex, tentissime membranacex, eximie gelatinosæ, compresso-planæ inferne ancipites, a margine iterum iterumique densissime pinnati, plumam referentes. Pinna juvenilis lineari-lanceolata, serie lonogitudinali cellularum rotundatoingulatarum, alterne in pinnulas inchoantes, subsimili serie constitutas, excurrentium constat. Gelatina hyalina cellulas pinnæ ambit, sed ita lixe coharens, ut pinnula quasi extra illim liberæe evadunt. It pinna grandescit, pinnulæ quoque emergunt, suo ordine plumosx. Cellula terminalis unica; hujus divisione transrersali cellule inferiores pinnæ formantur; et harum divisione pinuule oriuntur. Cystocarpia in pinnella anguste lineari plerunque solitaria, nunc pauca, pinnellia sæe supra fructum refracts.

Stratum interius frondis filis initio laxissimis, demum densioribus, articulatis et ramosis, endochromate colorato intra tulum latum Iı̣alinum percursis, lougitudinalibus et ad cellulas periphericas subarenatim excurrentilus, constat. Cellulæ peripheriam constituentes simplici fere serie dispositx, rotundate, minutx. Pericarpium a 
strato esteriore frondis formatum, initio hemisphericum, demum apice ruptum, truncato-conicum, margine lacerum, laciniis fre piumulas novellas xmulantibus. Favelle rotundalie, iutra periderma Irjalinum gemmidia rotundata conglobata plurima forentes. Splixrosporas non vidi.

Genus a primo inventore pulclerrime speciei jam fundatum, dıce Kützingio lıdie recipiendım credidi, quum inter species aliorum Fenerum nusfuam bene disponitur. A IIalymenia, ad quam, ut monuit kützing, forsan affinitate prosime accedit, cystocarpiis prominentibus et carpostomio lacero - si quidem lıoc a planta exsiccatil et madefacta dijudicatur — differt. A Naccaria, ad quam Schimmelmanniam olim retuli, cystocarpii structura longe revera recedit; adest tantum in structura ramellorum utriusque generis quædam analogria et similitudo. Externo fructuum habitu, qui in ramellis singuli aut pauci infra apicem refractun nidulantur, Splıærococei quasdam species, ut nempe lıo genus olim limitarunt, imitatur.

\section{ScII. Schousboni J. Ag. Symb. p. 16.}

Sphrococcus Schousboei J. Ag. l. c.

Naccaria Schousboei J. Ag. Alg. med. p. 86.

Schimmelmannia ornata Schousb. mscr. Kü̈l. sp. p. 722!

llab. in oceano Atlantico ad Tingin (Schousboe!)

Stipites a disco ralicali plures, compresso-ancipites, mox in frondem linearem abeunt. Frons primaria plerumque abbreviata, 1-2pollicaris, pinnis elongatis 3 -4pollicaribus densissime pinnata. Pinnæ ambitu lanceolatæ, pinnulis nempe superioribus et inferioribus brevioribus, mediis vix semipollicaribus; rachide ipsa lineari $1 \frac{1}{2}-2$ lineas lata, utrinque longe attenuata. Pinnulæ conformes. Pinnellæ ultimæ fere subulatæ. Chartæ arclissime adhæret.

\section{VII. Chrysyania J. Ag. Alg. med. p. 103 (cxel. sp.).} Endl. Suppl. III. p. 42. Mont. Fl. Alg. p. 97. Cliondrix et Dumontix sp. Auct.

Frons teretiuscula tubulosa, inferne aliquando caulescens, ramosa; filis sparsissimis tubum percurentibus; periphorico strato subduplici: cellulis interioribus rotundato-angulatis, superficialibus minoribus. Facelle intra pericarpium subproprium hemisphxricum, carpostomio regulari apertum, ad placentam bassalem affisæ, filis anastomosantibus circumdatx, gemmidia minuta consomerata forentes. Sphcerospora morpliosi cellularum superficialium formatx, sparsx, cruciatim divisx. 
Frondes teretiuscule aut aliquando teviter compresse, dichotomx, ramulosa aut subpinnatim divisx, sæpissime rentricosotubulose, tubo continuo, rarius collapso-sulplanx, aut inferne caulescentes, ramis vesiculosis; membranacex aut subgelatinosæ et quasi cuticula anlista lyalina cincle, pyropo aut auro nitentes.

Duohus diversis stratis frons contexta est. Exterins, membranam tubi constituens, unica aut pluribus seriebus cellularum constat; cellule interiores majores oblongx, exteriores minores rotumdatx; quo provectior xtate planta, eo plures cellularum series tubum implent; in nonnullis solidescentibus aut caule solido instructis spatium vacuum internum vix adest. Cellulie intimæ in tubulosis disruptionis quædam vestigia aliquando monstrant, que a tubo sensim inflato derivanda videntur. Tubus insuper intus filis sparsissimis articulatis dichotomis - interno strato aliorum generum comparandis - percurritur.

Favella intra pericarpium proprium, hemisphærice inflatum sitx. Pericarpium a parte frondis pustuliformiter inflita et quasi cellularum stratis esterioribus, in duas membranas separatis, ita formafum, ut membrana externa inflata ipsum pericarpium, interior plana aut concava hasem capsulæ efficiat. Inter has membranas fila articulata anastomosantia extenduntur, qux, in diversis speciebus plus minus densa, nucleum Favella undique circumdant. Gemmidia rotundato-angulata, minuta, numerosissima, nullo fere ordine disposita, in nucleum membrana pellucida cinctum, ad placentam basalem affixum et filis circumdantibus colibitum, congesta, demum poro pericarpii emissa. Si dissecatur nucleus favella, gemmidia a placentula radiantia cernuntur.

Splixrosporæ transformatione cellularum superficialium ortie, et inter lats plus minus dense sparsie, minutie, rotundatie, cruciatim divise. (In nostris non bene evolute, sxpins forma irregulares, divisionis normam minus bene monstrant; in Clır. uvarial spherosporas triangule divisas descripsit Montagne, quod si ita sit dijıdicare nequeo).

Species, qux lıc genus constitumnt, partim ad Ilalymenias vel Dumontias, partim ad Clondrias seu Chylocladias ab aucloribus relatx fuerunt. Ilabitu Halymenias non male referunt; differunt vero et structura fructumom peculiari, placenta nempe basali, pericarpio externe elevato, carpostomio evidenti, et frondis structura aliqguantulum diversa. Cellulie nempe stratum externum efficientes sunt potius rofundate contigua quam auastomosantes; fila interiora 
sunt in prorecta saltim xtate fere nulla. Cystocarpia Chrysymenia? in exsiccata plauta supra frondem emineut, et nucleo obscuriori atque pericarpio ampliore constituta apparent, qua nota specimina quoque exsiccata a Ilalymenia dignoscuntur. A Chỵlocladia Cirev differunt fronde tululosa, nec articulato-constricta, gemmidiis rotundatis minutissimis agolomeratis (nec claveformilus et simplici serie a placenta radiantibus) et forma ac dispositione filorum, quæ sporarum nucleum circumdant. Ilis ductus characteribus genus in Mgis mediteraneis condere conatus sum, quod a nonnullis acceptum, ab aliis rejectum fuit. Duas generis sectiones jam tunc iudicari, quas splıærosporis specierum typicarum et structura Cystocarpii melius lıodic cognitis, separandas censeo.

Quoad structuram aliquantulum discrepant species, vix tamen ita ut hodie in direr'sa genera abeant. Frons in Clır. depressa subsolida est, cellulis interioribus permagnis rotundatis; in Chr. rentricosa pars inferior frondis quoque solidescens, cellulis Chr. depressi subsimilibus. In Clur. uvaria stipes solidus cellulis miroribus contextus est.

Species Clırysymenix nostrie a Kützingio longe separantur: Chr. uraria ad Gastroclonium (Cliylocladiam), Clır. ventricosa et Clır. pinnulatis ad Ilalarachnion (IIalymeniam) referuntur. Si autem cujusdam omnino sit vis in generibus definiendis Cystocarpiorum structura, maxime sane differunt plantx a Kützingio consociatie. Clur. uvaria cum Clır. ventricosa hoc respectu eximie convenit et a Clyylocladia gemmidiis minutis, uno super alterum conglobatis, muco gelatinoso in nucleum cohibilis, longe recedit. Placenta cellulis rofundatis contexta et pericarpium externe elevatum genus a llalymenia diversum satis superque probant.

\section{IIAticurisis fronde sublubulosa solidescente, dichotoma aut irregularius ramosa.}

1. Cirr. dichotona (J. Ag. mser.) fronde subinflato-tubulosa membranaceo-carnosa dichotomo-decomposita fastiçiata, segumentis cylindraceo-compressis infra diclotomias subcuneatim dilatatis, apicibus breviter acuminatis.

Itab. in oceano Atlantico ad Teneriffam (II). Agardh!); in mediterraneo prope Massiliam (Ipse!); in mari adriatico (Biasoletto!). 
Frons circiter tripollicaris, inferne angustior caulescens et subsolida, superne inflata tubulosa r,rassitiem calami scriptorii vix xquans. Ramificatio eximie dichotoma et fastigiata, distantiis 20 linearum divisiones proximas separantibus. Segmenta in vira planta fere cylindracea, in exsiccata collabentia, linearia aut infra dichotomias lerissime cuneatim dilatata; axillæ rotundatæ. Cystocarpia per frondem sparsa. Substantia gelatinoso-carnosa. Charte arcte adheret. Color ex carneo virescens. Membrana exterior pluribus scriebus cellularum constat; cellulæ extimæ minutæ coloratæ, interiores hyaline et inanes adparent. Stratum medullare filis densioribus quam in aliis speciebus, longitudinalibus et anastomosantibus contextum videtur.

Tanta est similitudo hujus speciei cum Nemastoma dichotoma, ut nisi structura et farellis longissime ab illa differet, ad unam eandemque speciem facile referantur.

2. Cir. DEPressa (Schousb. mscr.) fronde subinflato-compressa vage expansa irregulariterque laciniata, laciniis oblongis, sursum dilatatis latissimis irregulariter palmatifidis, lacinulis ambitı sinuosis.

Halichrysis depressa Schousl. mscr.

Halymenia depressa Nont. in Webb. Pl. rar. Ilisp. Pent. II fude Crypt. Alg. p. 9.

\section{Ilab. in oceano Atlantico ad oras Tingitanas (Schousboe!)}

Frons crassa subinflatn, gelatinoso-membranacea, ex tereti compressa, estipitata callo radicali affixa, subhorizontaliter expansa, vage laciniata. Lacinize in inferiore parte unguem fere latx sublineares, superne subito dilatate et latissimx, ultra pollicares latitudine, vicinisque margine concrescentibus cohærentes, a peripheria introrsum laciniatæ subpalmatifidæ, lacinulis ambitu sinuosis. Cystocarpia per totam superficiem utrinque sparsa, satis conspicua, magnitudine seminis Sinapis, intra pericarpium hemisphæricum apice pertusum favellas subdepressas, placenta basali affixas, gemmidiis conglomeratis constitutas, foventia. Color fere carneus, favellis purpureis.

In sectionibus microscopio subjectis frons fere solida apparet, filis strati interioris valde adproximatis et fere conglutinatis; acilo superfusa distenduntur, fila interiora anastomosantia el laxa conspiciuntur, strnto peripherico cellulis magnis-rotundatis, extimis minutis, contexto. Structure apparentia deceptus lanc speciem cum Rhod. discigera (Symb. I. p. 13) olim confudi.

2. Canisimasia fronde inflato-lubulosa pinnatim decomposila.

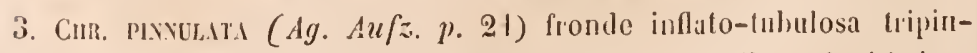
nata, pinnis approximatis suboppositis, terminalibus a basi latiore attenuatis obtusis suboratis. 
Halymenia pinnulata Ig. l. c. in Flora 4827 p. 61.3. J. Ay. Symb. I. p. 19. Zanarl. Syn. p. 88.

Chr. pinnulata J. Ag. Alg. med. p. 106. Mont. Fl. Allg. p. 97!

Halarachnion pinnulatum. Küls. sp. Aly. p. 721 !

Hal. Algeriensis Mont. Ciypt. Alyer. p. 7 tab. 9 fig. 21

llab. in mari adriatico ad Trieste (C. Agardh!); in mediterraneo ad oras Gilltie et Mgerix (IIl). Montagne).

Frons 2-3pollicaris ab ima basi pinnatim decomposita. Pinnx invicem proxima, vix pollicares, iterum iterunque divise, sensim angustiores, terminales abbreviatix fere orata. Color exsiccate purpureus.

Forsan est junior planta sequentis, a qua vix nisi statura minori, pinnis brevioribus et magis adproximatis distinguitur.

4. Corr. vextricosi (Lamour. Ess. p. 45̈) fronde inflitu-tubnlosa irregulariter tripinata, pinnis distantibus suboppositis, terminalibus subcylindricis apice attenuato.

Dumontia ventricosa Lam. I. c. Lab. 10 fig. 6! Zanard. Syn. p. 90!

Halymenia rentricosa . lg. sp. p. 21?.

Chr. rentricosa J. Ag. .1lg. med. $p .106$.

llalarachnion ventricosun lü̈t. sp. p. 721 !

Ilab. in mari mediteranco (Ipse! Giraudy!) licinoque Tingitano (Schousboc!)

Frnns 2-pollicaris aut usque pedalis, crassitic digitum immo æruans, inilato-tubulosa, in stipitem cuneatim attenuata, subiripinnata. Pinnæ nunc subregulariter oppositx, nunc magis irregulariter exeuntes et fere dichotoma, in frondibus minoribus adproximite, in majoribus usque unciam distintes; superiores sensim minores; terminales subconformes. Substantia tenuis membranacea. Color in jurenili aureo-purpureus, in senili virescens, rubro sulfusus. Cystocarpia per frondem superioren sparsa, hemisphærica. Sphærosporæ per frondem sparsæ, cruciatim, ni fallor, divisæ.

Specimina irregularius ramosa ab antecedente facilius distinguuutur; jurenilia, regularius pinnata, difficilius separantur.

3. Cur. resictiosi (J. Ag. mscr.) fronde inllato-tubulosa tripinnata, pinnis approsimatis oppositis, terminalibus a basi aneunstiore expansis subrutundis.

Ilab, in verano Itlantico ad Tingin (Schousboe!).

Frons sesquipollicarie, tote tubulosa, sulsegulariter 3-pinnata, pinnis crassitie fere calami scriptorii, oppositis et apyroximatis, apice hinc expanso precipue densis. P'innulie basi constricta, dein fere rotundita, obtusissime. Color, consistentia et liabitus Chr. pimulata, sed forma rolunda pinnularum diversa. 


\section{Botrociadn frondis caule solido, ramulis inflalo-lubulosis olsito.}

6. Cirr. craria (Wulf. Crypt. aqu. n:o 3) caule filiformi solido dichotomo, ramulis obovatis simplicissimis tubulosis pinnatim obsito. Fucus uvarius Wulf. l. c. fide Ic. pict. in mus. Vindob! Esp. Fiuc. lab. 78! Chondria uvaria Ag. sp. Alg. p. 347. Syst. p. 204!

Chrys. uvaria J. Ag. Alg. med. p. 106. Mont. Fl. Alg. p. 97!

Gastroclonium uvaria Kïüz. sp. $p .865$ !

Fucus Botryoides Wulf. in Jacqu. Coll. III p. 106 lab. 13 fig. 1.

Ulva Uvoides Bory Iles Forl. n. 18.

F. ovalis $\beta$. Botryoides Turn. IIisl. Fuc. II p. 23 (partim).

IIab. in oceano Atlantico calidiore IIt ad oras Brasilix et Marlinicæ! in mediterraneo et adriatico inter spongias et Zoophyta.

Frondes a callo radicali plurimæ, cespitem plus minus densum efficientes. Caules filiformes 1--3pollicares, crassitie pennæ passerinæ, dichotomo-ramosi, inferne subnudi, superne obsiti ramulis vesicxformilus simplicissimis obovatis, basi in petiolum constrictis, $1 \frac{1}{2}-3$ lineas longis, diametro lineam superantibus. Substantia firmior membranacea. Color recentis purpureo-nitens, exsiccatæ sæje virescens. Cystocarpia ramulis resicæformibus immersa, vix hemisphærice prominentia, nucleo gemmidiis minutis conglomeratis constituto, ad placentam basalem affixo. Sphærospora (sec. Mont.) strato corticali inmersæ, sparsæ, tandem triangule divisie.

Hæc species a Wulfenio egregie pro more descripta. Turnerus eandem cum forma $\mathrm{F}$. ovalis confudit, et plantam mediterraneam in specimine ad Yarmouth invento cognoscere credidit. Lamouroux ulramque bene distinxit, insequentibus omnibus recentioribus. Cum Chondria ovali nullam habet, me judice, affinitatem.

\section{Species inquirendia.}

7. Cur. Chlujedya (Menegh. in Parl. Giorn. Bol. I p. 296) "vix pollicare, caule brevissimo simplici, carpocloniis vesicaformibus magnis ellipsoideis vel sxpius ovato-lanceolatis umbellatis. Pliysidrum ovale Delle Chiaje?" Kü̈z. sp.p. 866.

llalb. ad oras Dalmatix.

An potius ad viciniam Chylocladix ovalis transferenda, ut habet liützing?

8. H.thy. Botryomes (Ach. Rich. Voy. l'Astr. p. 14j) caule ramoso sesquipalmari, compressiusculo, resiculis obovoideis hasi attenuatis membranaceis, approximatis, crassitio ure; colore generali viridi. 
IIab, ad novam IIollandiam (I.esson).

Ad IIalymeniam saccatam ab Auctore proxine accedentem dicitur, resiculis vero brevioribus et caule elongto ramoso disersam. Mhit, tantum es lac descriptione plantan cognoscenti, aut cun Rlıablonia? globifera aut cum Chr. uraria comparandis videtur.

\section{Genus affinitule mihi dubium:}

XX VIII? Dasyphloea Mont. Prodr. Phyc. Ant.p. 8 el Voy. Pol. Sud. p. 100. Endl. Gen. Plant. Suppl. III p. 39. Hlook. et Harv. Alg. Tasm. n. 63. Kü̈z. sp. Alg. p. 757.

lirons cylindrica, membranacea, gelatinosa, rosea, undique ramosissima, pilis continuis lı̣alinis densis tota vestita. Fructus: verrucx superficiales hemispltericx, e filis radiantibus ad normam nematheciorum paralleliter junctis composite, quibus nidulantur tetraspore oblonga, in quatuor sporas tandem zonatim divisæ. Structura Ilalymenix.

1. D. WSIGXIS (Mont. Prodr. p. 8) fronde gelatinoso-membranacea tenerrima roseo-purpurea subtubulosa undique vage decomposita, pilis continuis densis tola obsiti.

Dus. insignis Mont. l. c. Toy. Pol. Sud. p. 102 lab. 8 fig. 3. Küuls. Sp. Alg. p. Tï7.

\section{Ilab. ad littora insule Niaroa (D'Urville).}

"Radix callus s. discus minutus. Frons gelatinoso-membranacea, subtubulosa, teres, roseo-purpurea, palmaris, longior, penua corvina tenuior, undique vage ramosissima, circumscriptione late ovata. Rami patenter, basi apiceque attenuati, rarissime lingulati, iterum ramulosi. Structura: fila longitudinalia, ramosa, articulata, apice globoso-inffata rel, pluribus utriculis seriatis, moniliformia, ad peripheriam frondis versa et coalescentia. I'ili ex articulo tilorum extremo oriundi, continui, pellucidi, $1 / 10 \mathrm{millim}$. fere longi, $1 / 100$ millim. ad ortum crassi, acutissimi, villositate densa non tilutum sub microscopio composito, sed et vitris mediocriter augentibus conspicua totam frondem operientes. Fructus: nemathecia seu verrucx maculeformes, minimæ, in ramis obtusiusculis sitæe, e filis constantes radiantibus, parallelis, articulatis, materia colorata refertis; Tetrasporie olylong:r, in verrucis nidulintes, $1 / 2$ s millim. longr, $2 / 100$ millim. crassa, transversin in segmentis gfuatuor, ut in Hypnea solemue est, divisce, viside purpureæ. lila radiantia supra memorata, quæe speciem Nenatlecii constituunt, ex utriculis periphericis oriundx mihi visare sunt, si, in rebus tam exiguis et difficililsus, fidem oculis prabere liceat. Substantia tenerrima, in aqua dulci cito in gelatinam abiens. Color rosèo-purpureus. Chartæ vitroqque arcte adlıxet." 
2. D. T.smanca (Hook. el Hlarv. Alg. Tasm. n. 6̈̈) caule crassu subindiviso, ramis lateralibus creberimis patentibus basi et apice subattenuatis obtusis, ramulis densis yuadrifiriis iterum ramulosis anguste-linearibus vix attenuatis, ramulis fructiferis perbrevibus fusiformibus.

Ilab. ad Tasmaniam (Nrs. Smith).

\section{TRIBUS III. FAUCUEE.}

Frons carnoso-membranacea, cellulis interioribus rotundalo-angulatis, exterioribus radiatis verticalibus contexta. Favelle uncleus simplex aut lobis pluribus in unum confluentibus subcompositus, intra pericarpium proprium exceptus, placentie impositus, carpostomio regulari liberatus. Spharosporæe inter cellulas corticales sparsa, aut in Nematheciís esternis evolute, cruciatim divisæ.

XXIX? Gloiocladia. J. Ag. Alg. med. p. 8\%. Endl. Gen. Plant. Suppl. III p. 37. Kütz. sp. p. 741. Cliondriæ sp. C. Ag. Frons gelatinosa, cylindraceo-compressa, dichotoma, stratis duobus contexta; interiore cellulis rotundatis magnis subinanibus; esteriore filis moniliformibus abbreviatis verticalibus, muco hỵalino inclusis, constante. Fruclus....

Stratum interius constat cellulis rotundato-oblongis, in medio majoribus, extrorsum minoribus, fere inanibus. Invicem muco parum solidescente separatæ videntur. Stratum periphericum filis brevibus, 8-10 articulis constantilus, endochroma coloratum intra articulos globosos foventibus, diclıotomo-fastigiatis, ranis patentibus muco liyalino inclusis, stipatissimis contextum est. Fila laec peripherica et verticalia a filis horizontalibus, supra cellulas medias lase repentilus, oriunda videntur.

Genus quoad structuram forsan Faucliex prosimum, fructu iegnoto affinitate omnino dubium.

1. Gг. ғенсата (C. Ag. Aufz. n. 49.) J. Ag. Alg. med. p. 87. Kü̈z. sp. p. 741 !

Chondria furcata Ag. $l$. $c$.

Ilab. in Splacrococco bificlo parasitica, ad Trieste (C. Mgardlı!) 
Frons roseo-coccinea, gelatinoso-lubrica, teretiuscula, longitudine pollicaris, crassitic pennæ passerinæ, paucis dichotomiis divaricatissimis diisa, segmentis terminalibus a hasi latiore attenualis. - Clarta aretissine adharet, exsiccatione omnino collapsa, iterum madefacta facillime resiviscit.

Fructus a C. Agaruh memoratos frustra in speciminibus quæsivi. Plaıla videtur rarissima, semel tantum et paucis speciminibus lecta.

XXX. FAUcileA bory et Hont. Fl. d'Alg. p. 64. Külz. sp. Alg. p. “87. Cypellon et Dichophycus Zanard. mscr. Phyllotylus (exclus. spec.) J. Ag. Alg. Liebm. p. 9.

Frons carnoso-plana, dichotoma, stratis duobus contesta; interiore cellulis rotundatis, cxteriore filis moniliformibus abbreviatis verticalibus constante. Favella pericarpio proprio marginali obovato inclusx, ad placentam centralem affixæ, nucleo denso clongato filis in reticulum conjunctis cohibito constitute, gemmidia minuta conglomerata per canalem et carpostomium pericarpii emittentes. Spharospore in Nematheciis supcrficialibus pulvinatim expansis crolute, inter fila nematliccii sparse, oblongre, cruciatim divise (Mont. Fl. Alg. tab. 16 fig. 1).

Frondes super corallia lapidesque profundius demersos cxpansæ, depresse, carnoso-membranaccæ, exsiccatione subcartilaginex, rosco-carnex, decomposito-dichotome, segumentis lincaribus integerrimis patentibus. Cystocarpia ad margincs numerosil, fere pediccllata, cum pedicello obovato-o!longa. Ncmathecia in disco segmentorum pulvinatim expansa, oblongo-linearia.

Stratum interius frondis constat cellulis magnis, superficiem versus sensim minoribus, rotundato-oblongis, endochromate granuloso facile cflluente repletis. Supcrficiale stratum cellulis ninutissimis, in fili moniliformia rerticalia conjuntis, constitutum.

Pericarpium cellulosum crassum, extcriore et parte inferioris strati frondis contextum; cellulis extcrioris radiantibus, interioris rotundatis conecntricis. Spatiun péricarpii internum reticulo laso, filis dense et subquadratim anastomosantibus contesto, tolum ocenpatur. In medio hujus reticuli suspensus est nucleus gemmidiorum oblongus, ad placentam pleau filorum anastomosantium densiori contestam, centralem affisus, per canalem angustum cum carpostomio communicantem demum ennissus. Gemmidia rotmndata densissima, placentulam specialem (at placenta eguredientem) circuncirea investicntia. 
Temathecia filis moniliformibus densissime stipatis, tenuioribus, subsimplicibus, in madefacta quoquoversum radiantibus et subliberis, constant. Inter liec fila spliærosporæ adfixæ, pedicello brevissimo suffulı, oblonģ cruciatim quadrilivisæ.

Genus, si quod aliud, distinctissimum, et sphrosporis et fructu capsulari insigne; structura fructus capsularis forsan ad Chrysymeuiam proxine accedens; ipso nucleo, reticulo circumdante, canali inter fila reticuli pervio et cum carpostomio communicante conveniens; sed strato exteriore frondis et splicerosporis longe diversum.

Norum genus primus, ni fallor, proposuit Zanardini, sed quantum comperi nec diagnosin, nec circumseriptionem sui generis attulit; nec constat utrum genus proprium, an tantum novam speciem veteris Tozzettiani generis nomine duto (Saygio p. 42) indicare voluerit. Ipse, detectis sphæerosporis et mira capsularum indole cognita, characteres generis rite exposui (Alg. Liebm. l. c.), sed speciem typicam cum aliis heterogeneis male consociavi. Montagneus in Flora Mgierix Genus rite limitavit et admirabili analysi illustravit. De ortu vero gemmidiorum in quibusdam cum Montagneo dissentio, qui gemmidia in filis a placenta radiantibus oriri dixit, I. e. nuclenun non favellam sed coccidium considerat. Licet iteralis dissectionibus nuclem observavi, fila qualia depinxit Nontagne, num fuam observari, sed gemmidia semper arctissime conglobata vidi, et, ni fallor, membrana ambiente lisalina, modo favellarum, cohibita. Attamen placenta evidentissima adest, et ex hac placentulx forsan plures proveniunt. In maturo fructu nuclei placentularum, si plures revera adsint, in unum conglobatie.

1. F. Repens (Ag. sp. Alg. $p$. 244) fronde sessili depresso-expansa repetite dichotoma, segmentis linearibus patentibus, terminalibus obtusis.

Sphærococcus repens Ag. sp. Alg. 4 p. 4.t et Syst. p. 21:3!

Fauchea repens Mont. Fl. d'Atger. p. 64 tab. 16 fig. 1! Kütz. sp. Aly. p. 787 .

Gracilaria repens $J$. Ag. Aly. med. p. 152.

Cypellon patens Zanard. Sagg. p. 4.2.

Fucus ceranoides var. Esp. lab. 98 fig. 4?

Ilah. in oceano Allantico calidiori ad Timgiu (Schoushoen!) et Gaules (Calprera!); in mediterraneo ad Nizzam (Ipse! Risso!); in adriatico (\%anardini!).

Radice vix distincta sxpius corallibus inharet, a fundo plerumcque protracta. Frons 2--4pollicaris, vage super ulia corpora expansa et de- 
pressa, dichotoma, plerumque ita intricata ut difficilius extricetur. Segmenta patentia axillis rotundatis discreta, linearia aut infra dichotomias cuneata, 1-3lincas lata, terminalia parum attenuala. Margines integerrimi, nisi in planta capsulifera, processulus minutis semilineam circiter longis obtusis plus minus dense ciliata. Nemathecia plerumque in medio disco pulvinulos oblongo-lineares longitudinales efticiunt. Color carneus, aut ex roseo obscure coccineus. Substantia carnosa; exsiccatx cartilaginea.

XXX I. Epryenia Fйlz. sp. Alg. p. 787. Phyllophoræe sp. Grev. Rihodomenia sp. Suhr.

Frons inferne costata et caulescens, sursum in laminas planas subdichotomas expansi, stratis duobus contexta; cellulis iuterioribus oblongis, superficialibus minutis verticiliter radiatis. Fructus in sporophyllis propriis a frondis superficie prolificantibus evoluti. Favelle intra pericarpium liemispherice elevitum crassum, carpostomio apertum, nidulantes, plicenta cellulosa suffulte; gemmidiis minutis plurimis in nucleum subsinplicem intrà gyelatinam colibentem densissime congestis. Spharosporce inter cellulas superficiales prorenientes, oblonga, cruciatim divisx.

Frondes a stipite brevi cuneatim expansæ, dichotomæ, segmentis flabellatis, repetite dichotomis aut sulpalmatis, infinis costatis, costa mox eranescente, a disco et margine aliguando proliferis, terminilibus obtusis rotundatis. Fructus utriusque generis in phyllis minutis, 2-lineas - semipollicem longyis, a disco frondis dense prolificantibus, evolvuutur; Cystocarpia in plyllo plura; Splrerospore per utramque paginam sparsic.

Cellulie frondem constituentes stratis duobus dispositic. Interiores oblongुæ longitudinales, lugaline et quasi inanes, cum ricinis contigux; in costa frondis inferioris exdem at numerosiores. Cellule superficiales minutie rotundate, endochromate colorato farctie, verticaliter seriatx.

Pericarpium crassum, cellulis oblongis superficiem versus in minores radiatas abeuntibus contextum, supra basem phanan hemispherice elevatum et in alterutera pagina phylli prominens, carpostomio regulari (secedentibus nempe cellulis radiatis) apertum. Nuclens densissimus et tenaciter colierens, gelatina aut membrana colibente inclusus, (aliquando intra idem pericurpiunn nucleos 2 ridi), gurasi lobis pluribus formatus, placentie impositus, demun undiyne subliber; intra membranam nuclei plicente speciales, ad singulos lobos tendentes 
adsunt, ex quibus gemmidia minuta angulata radiare videntur. Sphrerosporie oblonga, cruciatim divisa, inter cellulas radiatas strati superficialis evolutæ.

Genus a memetipso (in Alg. Liebm. $p$. 11 in not.) indicatum, a Küutzingio primum sub noro nomine propositum, quoad structuram Cystocarpii ad Clirysymeniam et Faucheam forsan proxime accedens. Cum Delesserieis convenit proventu fructum in phyllis propriis; distat vero structura et sphærosporarum et cystocarpiorum. Gemmidia enim in filis a placenta radiantihus, invicem liberis, haud formari mihi adparerunt; nucieus compactus et tenaciter colserens in Delesserieis quoque abnormi:. Spltxesporx cruciate in nulli alia Delesseriea cognitæ. A Plyglloplora et Cryptonemia differt structura frondis et fructu utroque.

Kützing Cystocarpia Rhodomenix similia describit, quod me judice falsum. Typicx specici aliam adjecit, yuæ quonam jure lıuc adnumeretur mili haud licjuet.

1. E. obrusa (Grev. in Elinb. Journ. of nat. and Geogr. Sc. Ser. III. Fol. III. Pl. IV.) fronde stipitata flabellatim expansa repetite dichotoma, segmentis principalibus inferme cuneatis semicostatis, superioribus cuneato-linearibus, supremis subpalmatis obtusissimis, cystocarpiis in pliyllo pluribus.

Phyllophora obtusa Grev. t. c.!! Hook. et Ilarv. Cr. antarct. p. $73 \mathrm{ct}$ p. 180! Sond. Alg. Preis. p. 2/?

Botryocarpa obtusa Kiül. Bol. Zeil. 1847 p. 1.

Epymenia obtusa Külz. sp. Alg. p. 787.

Rhodomenia Dregeana Suhr. in Flora 1840 I. p. 263!!

IIab. ill sinu tahulari ad Cap. b. Sprei (III). Tumer! Ilb. Greville! Lalande! IIarvey! Pappe! Drege!); ad Cap Iloru et insulas Auckland (s. D. Iloolier).

Planta fere pedalis, ambitu immo latius expansa, segmentis fere in orbem extersis. Segmenta infima costa plus minus perspicua sursum evanescente instructa, inferne sæpe longius indivisa linearia, dein 4-3̈:ie: dichotoma magis cuneata, superiora ita adproximata ut fere palmata adparent, terminalia obtusissima, nunc emarginata, oblonga aut obovata, pollicem circiter lata. A costa et disco frondis ecostatx, atrue a margino dilaceratx, foliola prolificant nunc frondi conformia, nunc multo ininora fertilia, 2-linearia aut semipollicaria, cystocarpiis pluribus instructa. Spharospore in foliolis conformibus at sape latioribus et magis rotundatis. Substantia pergamena. Color rubro-purpurascens. Chartæ non adlixiet. 
lluc pertinent tum Fucus palmatus e Cap. b. Spei Algologorum quorundam, tım Fucus botryocarpus nomnullorum. Externa quxdam cum his specielus similitudo adest, tamen ipso halitu haud difficile distinguuntur.

\section{Species generis milii incerla:}

2. Ep. Vanolosi (Hool. et Ilarv. Lond. Journ. Bot. IV. p. 259) "fronde carnoso-membranacea sangुuinea in lacinias plures late lineares v. cuncatas clongatas furcatas dichotomasque ad basin fere divisi, laciniis hasi angुustatis erectis, apice obtusis emarginatisve, coccidiis [?] superficialibus densissime conspersis sessilibus pedicellatisve deciduis.

Rhodymenia rariolosa Ilook. et Ilarv. l. c. et Crypl. Antarct. p. 170 lab. 180 !

Epymenia variolosa Külz. sp. p. 788.

Ilab. in oceano australi ad Kerguelen Land. (IIooker).

Frons $2-3$, r. $i-8$ unc. longa, ad basin fere in lacinias fissa. Lacinix $1 / 2^{--1}$ unc. latæ, c basi angustata sensim latiores, furcata, bis terve dichotome dirisæ, simubus latis obtusis, margine integerrimo vel parce prolifero, super subterque corporibus granuliferis (coccidia?) sparsa. Coccidia? (iı genere abnormalia) superficialia, subglobosa, basi angusta frondi affixa, cito decidua."

Jta auctores, qui plantam cum Caloph. variegata et Gracil. polycarpa comparant, licet fructificationem diversam indicent. A Kiilzingio ad Ejyymeniam ducitur. Species mihi ex descriptione et icone data tantum coguita, auctoritate Kü̈zingii lıuc relata.

\section{TRIBUS IV. RIIZOPIILLEE.}

Frons membranacea cellulis rotundato-angulatis tota contexta. Fitvelle nuelei sinplices, in verrucis Nemathecioideis evoluti, secedentibus filis denun liberati. Sphrerosporix. . .

XXXII. Rhyopintuls hï̈z. Pliycol. Germ. p. 33!. Sp. Alg. p. 8\%̃. Mont. Fl. Alger, p. 62. Delesserixe et Rihodomenive sp. Auct.

Frons ex ancipite plana linearis dentuta ef sulpiennatim ramosa, stratis cellularum duebus constituta; interioribus cellulis angูılato-oblongis, superficiem versus sensim minoribus, corticalibus 
angulatis. Favella spongiolis Nemathecioideis hemisphrericis immersæ, plures, intra periderma lıyalinum gemmidia plurima rolundata foventes. Spharospore per frondem sparse, cruciatim divisæ [?] (Mont. Fl. Alger. tab. I3 fig. 2).

Frondes decumbentes et supra alias Algas expansæ, vel inter illas implicatie, pulchre coccinex, membranacex, sublincares dentate vel crennlitie atque dentium cvolutione subpinnation ramosic, in specie primaria ex ancipite planx et innerse subcostatie, in altera planæ ecostute lic illic lanceolato-dilatatie. Cellulie frondis omnes fere couformes, rotundato-angulate, peripherice tantum minores. Spongiolæ nematlıcioidex in sub-costa scriatr, semimillimetrum crassa, ob farellas inclusas obscurius coloratie; fila articulata diclıotoma, endochromatibus purpureis insignia, a puncto centrali basilariyue enata, quoruoversum irradiantia, apice fastigiata moniliformia. Inter hæc fila favellæ suspensæ; sunt spliæricæ vel oblongæ, membrana pellucida cinctæ, gemmidiorum congeriem foventes. Gemmidia oblongo-rotundata. (Ita in sp. primaria). - Sphærosporæ (in altera specie a Lynglyco observate) inter cellulas superficiales sparse, rotundale, cruciatim divise.

Genus a Külzingio fundatum, lıbitu peculiari potissimum distinctum; a Nontagneo, quem in fructu (mihi ignoto) describendo pressis pedibus secutus sum, primum fructu detecto cliaractere proprio insignitum. Speciem alteram - forsan alienam, nusquam vero melius disponendam - lıoc loco adposui.

1. Ril. Dextuta (Mont. Crypt. Alg. n. 76) fronde ancipiti plana sul)costata orbiculariter expansa subpinnato-dichotoma, segumentis linearibus dentatis obtusis.

Delesseria alata var. dentata Monl. l. $c$.

Rhizoplyyllis dentata Mont. Fl. Alg. p. 63 tab. 13̈ fig. 2 !

Rhodomenia perreptans J. Ag. Symb. p. 13.

Wormskioldia Squamarice Menegh. Lill. ad Corinaldi n:o 8! Zanard. Lett. II p. 20 ! el Syn. Alg. Adr. p. 92.

Rhodymenia Squamarie De Nol. Alg. Lig. p. 22.

Rhizophyllis Squamarix hütz. Plyyc. germ. p. 334 et Sp. Alg. p. 877!

Hab, in mari mediterraneo, ad frondes Peyssonelia Sifuamarie parasitica, nunc a fulcro soluta.

Frons plerumque pollicaris, in orbem a puncto centrali radians, supra paginam Peyssonelice expansa, ef sxpius radiculis demissis arcte adglutinata, decomposito-ramosa, ramificatione inter dichotomam et pinnatam intermedia. Segmenta linearia distanter et mullo ordine dentibus obtu- 
siusculis inæqualia, apice obtusa dentata, lineam vix lata, costa in exsiccata parum notabili percursa, in recenti et madefacta magis ancipite laud conspicua. Color roseo-coccincus. Substantia membranacea.

Planta videtur a Montagneo primmm descripta, sed a fulcro separati, et varietatis ad instar ad Delesseriam alatam relati, a Meneghinio et memetipso fere eoden tempore species propria considerata.

\section{Riuz.? Basgn (Ilornem. Fi. Dan. tab. 1475) fronde ancipite-} plina ecostata, vage pinnatim decomposita, segmentis sublinearibus irregulariter angustatis dilatatisque, marginiluus crenito-lacinulatis.

Fucus Bangii Ilornem. $l$. c . 728 !

Sphærococcus Bangii Ag. sp. Alg. I p. 233. Syst. $p$ 2ł2. Küls. sp. p.

Chondrus Bangii Lyngb. Ilydr. p. 17 lab. 3!

Rhodomenia Bangii Grev.

llab. inter rhizomata Zostere implicata in Sinu Codano; ad littus Fionie (Hoffman Fang!) et Bahusice (Ipse!)

"Radix exiguus concolor. Frons solitaria duos tresve pollices longa, scmilineam ad unam lata, ecostata, plana, vage ramosa, sinuato-flexuos., implicata, stipite nullo vel perbrevi instructa. Folia vel potius rami lineares, lic illic dilatati, patuli, curvati, sine ordine dispositi, nunc dissiti nunc approximati, aliisque ejusdem latitudinis et divisionis obsessi. Margo ubique lacinulatus, ubi vero frons in folium membranaceum paulo dilatatur, ibi margo sape crenulatus. Lacinula brevissimæ, vix semilineam longæ, raro simplices, acutæ, sæpissime apice obtusæ, et bi-vel trifurcatæ, furcis utrinque falcis instar reflexis, ut plurimum alternatim secundx, e margine frondis convexo progredicntes, el lunc alter frondis margo concavis, integer permanet. Fructus Tubercula subglobosa, 4-granulata in substantia frondis remote et inordinate sparsa, paululum elevalis, fuscorubra. Color intense roscus, ad basin et in medio interdum virescens. Substantia frondis angustatæ cartilaginea, dilatate membranacea, rigidi, tenax. Siccitate non mutatur. Perennis. Hyeme imprimis reperitur."

Lyngbyeum sphærosporas observasse, ex icone data satis clucet. Crescendi modo, habitu et structura non male cum Rhizophylli dentata conienit, quare eidem generi adnumerandam esse suspicor.

\section{TRIBCS V. CRVPTONEMIE.}

Frons membranacea subcautescens, filis interioribus clongatis cellulisque exterioribus rotundatis subratiatis contexta. Favelle nucleus simplex, infra stratum extcrius subinflatum, carpostomio regulari pertusum, exceptus. Sphierospore in soris subdefinitis evolute, strato nemathecioso inmerse, cruciatim divisie. 
XXXII. Cryptonnuia J. Ag. Alg. med.p. 100. Alg. Liebm. p. 11. Mont. Fl. Alg. p. 109. Euhyneniæ sp. Kü̈tz. Plıyllophore sp. Gree. et Auct. Sphierococcus sp. Ag.

Frons plana chartacea suhcaulescens prolifera et ramosa, stratis fere tribus contexta; interiore filis elongatis ramosis dense intertextis; exteriore cellulis rotundatis versus superficiem minoribus constinte. Facelle immersæ, in alterutera pagina sulprominentes simplices, gemmidia rotundati plurima, intra menhranam lyalinam cohibita, demum per ostiolum emittentes. Sphicerosporce in sporopliyllis propriis aut infra apices in soros rolundatos collecte, strato nemathecioso immersie, oblongre, cruciatim divisæ.

Frondes planæ et charticco-membranacex, stipitate stipite in caulem plus minus ramosum sensim mutato, omnino fere enerves, ant caule in costam unicam pluresre transeunte costatie, costa evanescente ant fere ad apicem prolongata, sinuoso-dichotome aut prolificationilus a costil vol margine licso pullulantibus ramose, margine integerrimæ aut denticulatio.

Stralis duobus aut fere tribus frons contexta est. Interius consfat filis elongatis articulatis et ramosis, dense intertextis, granulosa materia sape repletis; in partilus fertilibus fila laxiora evadunt, longiora, magis ramosa et anastomosantia. Iloc cingitur cellulis magnis rotundatis granulosis, que, pluribus seriebus dispositie, superficiem versus sensim minores fiunt et ita quasi duo strata efliciunt.

Favelle intra stratum externum, in alterutera paguina pustuliformiter inflatum et sublemisphericum, demumrue ostiolo regulari aprertum, nidulantes, in plexu filorum anastomosantium suspense, gemmidiis minntis numerosis in nucleum simplicem, peridermate gelitinoso halino cinctum, arcte conglobatis constitutie. Splixesporie ant in foliolis propriis marginalibus, aut infra apices frondium evolutre, strato nemalliecioso, sorum rotundatum formante, immerse. Sorns supra superficiem sterilem paulisper elevatus, filis brevissinis verticalibus constat; inter liæc fila splıxrosporæ minute, oblonge, cruciatim divise, uidulantur.

Forme, quie lutic generi adnumerantur, recentiori æevo primun cognitie videnfur. Nullam apurd Turnerum memoratam invenimus; a Gmelino una suidem jam depicta creditur, gnod tamen nullo modo certum. In Speciebus Agardlii plurime descripte, inter 
species Splıerococei yeneris enumerabantur. Greville species primarias dubie ad Pligllophore genus retulit. In Aggis mediterraneis genus proprium his finxi, guod a kützingio cum Kallymenia conjunctum et, ita compositum, nomine Eulıymenix propositum fuit.

Genus sine dubio distinctissimum; structura frondis et fructu utroque a Plyyllophora, atque ab aliis plurimis insuper tendentia costam formandi diversum. A liallymenia longe recedit, eystocarpii nucleo simplici, spherosporis oblongis in sorum collectis, stratoque nemallicciose evoluto immersis.

I. Acrodiscus. Fronde ima basi caulescente, ecostala, lineari, dichotoma; segmentis infra apicem fertilibus, soro rolundalo spharosporarum instructis.

1. Cr. dicuotoni (J. Ag. Alg. med. p. 100) sulacaulis, fronde cuneata-lineari diclıotoma, segmentis linearibus integerrimis obtusissimis sxpe strangulatis, a strictura et disco prolificantibus, sphærosporis in sorum infra apices segmentorum rotundatum collectis.

Chondrus Vidovichii Menegh. Sunt. in Alt. dell. 3. Congr. Firenze 4841 p. 11. Zanard. Sagg. p. 42. Kï̈l. sp. p. 737.

Euhymenia dichotoma Kütz. sp. p. 742 !

Ilab. inter corallia spongiasque maris mediterranei, ad Nizzam (Ipse!), Massiliam (Solier!), Antibes (Giraudy!)

Frondes sesqui-bipollicares, a basi scutata plures, stipite brevissimo mox expanso in laminam ecostatam cuneato-linearem marginilus aliquantulum inflexis vix canaliculatam, 2--21/2 lineas latam, superne dichotomam; segmenta nunc regulari divisione dicholoma frondis orta, nunc hasi quasi strangulata et prolificationes æmulantia, ulteriore divisione flabellatim expansa, apicibus rotundato-truncatis.

Structura ab aliis speciebus in eo abludit, quod cellule intermediæ exterioribus vix majores sint, sed stratum externum filis inoniliformibus subverticalibus constare alparet. Cellulæ strati interioris sunt filiformes dense stipate. Sphærospora infra apices segmentorum evolutx. Stratum corticale his locis nematheciose evolutum, filis constat verticalibus articulatis fastigiatis, supra stratum sterile paulisper eminentibus; inter hac fila sphærosporæ elongato-oblongæ, minutæ, cruciatim divisæ nidulantur.

Nisi sulstantia crassior et colot dilutior diversitatem quandam proderent, pro mera et vulgari forma Sphar. palmette facilline sumeres; accuratius vero inspecta diversissima.

2. (ir. Crevelata (J. Ag. Symb. 1 p. 18) subcaulescens, caule al)breviato mox in frondem ecostatam dichotomam et fere pal- 
matifidam abeunte, segurentis foliolisque a margine prolificantibus cuneato-linearibus margine denliculatis, splicerosporis in sorum infra apices segmentorum rutundatum collectis.

Phyllophora crenulata J. Ag. l. c. Aresch. Icon lab. II!! Külı. sp. p. $791 !$

Cryptonemia crenulata J. Ag. Alg. Liebm. p. 11 in nol.

Rhodomenia dentata Suhr. mscr. (fide spec. missi!)

Ilab. in oceano atlantico ad oras Americie australis; prope Baliam (IIb. Duby!), ad Pernambucco (Ilb. Areschoug!), ad Curacao (III). Sulı!!).

$\mathrm{Ab}$ expansione radicali frondes plures semipedales gregarie surgunt, stipite brevi infima basi teretiusculo, mox plano cuneato et in frondem abeunte. Frondes cuneatæ aut sublineares, unguem latæ aut aliquando latiores, distanter dichotomæ aut subpalmatifidæ, a margine et quandoquidem a disco proliferæ, truncato-obtusæ, margine denticulatæ, denticulis bifidis trifidisque, demum denticulis obsoletis crenatæ aut immo integriuscula. Color ex roseo purpurascens, in virescentem sæpe tendens. Substantia membranaced. Sori infra apicem segmentorum rolundati, discum occupantes, in exsiccata planta maculam pellucidiorem referentes.

Species a memetipso et Suhrio fere eodem tempore distincta. Nomen Suhrii nusquam publici juris factum video.

II. Criptoxema. Fronde subcostala, costa caulem evidentiorem continuante, prolificationibus a costa et margine emergentibus ramosa; sporophyllis subpropriis soro spherosporarum instructis.

3. Cr. Seviservis (Ag. Icon. ined. II pag. 2) subcaulescens, caule abbreviato, in laminam oblongam evanescenti-uni-bi-costatam inciso-lobatam abeunte, foliolis conformibus novellis a costa producta pullulantibus.

Sphærococcus seminervis Ag. l. c. tab. 17. Sp. Aly. p. 232 et Syst. p. 212.

Cryptonemia seminervis J. Ag. Alg. Liebm. in nol. p. 11!

Euhymenia seminervis liüt. $s p . p$. 742 !

IIab. in mari atlantico ad Giddes et Tingin (Cabrera! Sclıousboe!).

Planta juvenilis stipite lineas nomullas $(3-4)$ longo et pennam passerinam crasso suffulta, circiter 3-pollicaris et pollicem lata, ambitu oblonga, in lobos paucos oblongos, nunc ab apice deorsum productos, nunc magis pinnatim dispositos, divisa; nerro per laminan mediam a costa 
producto, simplici aut sxpe bifido, ramo minori ad lobum basilarem cateris majorem tendente.

Planta senilis folium Delesserix sanguinea non male referens, caule brevi sed crassiori suffulta est, nervo principali per laminam elongatam continuato, secundariisque diversa altitudine ad lobos principales tendentilus instructa, lamina ipsa plus minus læsa foliolis novis a costa pullulantibus. Foliola nova prima jurentute integra, obovato-elongata; mox in formam supra descriptam planta juvenilis transeuntia. Sulstantia chartaceo-menloranacea; chartæ vix adhærens. Madefacta facillime reviviscit; jurenilis tenuissime membranacea et in aqua fluctuans, colore pulcherrime coccineo-roseo.

4. Cr. Lactuca (Ag. sp. p. 231) subcaulescens, caule abhreviato superne alato in laminam reniformem evanescenti-multicostatam palmati-lobatam undulato-crispam abeunte, foliolis novellis a costa pullulantibus basi cuneatis, superne conformilbas.

Sph. Lacluca $A g$. l. c. partim (quoad descriptionem!).

Spl. Lactuca $\beta$. concretus Ag. $l$. $c$.

Ilab. in mari atlantico ad Gades (Cabrera!).

Frons 2-3pollicaris, stipite surgens brevi, parum ramoso aut indiviso, apice expanso in laminam circumscriptione reniformem palmatim multicostatam, costis suprd medium evanescentibus, versus lobos principales tendentibus. Ambitus totus in lobos $3-7$ principales, frondis medium usque attingentes, margine eximie undulatos et in lobos plures secundarios divisos finditur. Lobi omnes rotundati, principales pollicem fere lati. Substantia quam in sequente magis membranacea mihi videtur. liructificatio nondum observata. Foliola nova in hac quoque pullulantia vidi, ambitu initio cuneata, mox reniformia, apice undulato-lobata.

Hainc cum sequente conjunxit Agardh; distinguendam vero credidi quum inter plurima specimina plantæ mediterraneæ numquam presentem viderim. Si planta eadem esset, neutiquam ut forma laminis concretis orta, ut apud Agardhium l. c. dicitur, habeatur, sed contra juvenilis, lobis nondum in foliola diversa separatis. Hoc demum ruoque fit, ut ex specimine vetusto mihi liquet, sed etiam hoc statu a sequente cognoscenda. Quum ceterum foliola pullulantia formam fronlis fere statim recuperent, de diversitate specifica vix dubitandum mihi videtur. Magis sane ad Cryptonemiam seminervem accedit.

5. Ck. Lomutiox (Berlol. Opusc. Bot. II p. 289) caulescens, caule ramoso superne alato et in laminas costatas oblongas abeunte, foliolis novellis a costa pullulantibus obovato-rolundatis leviter sinuosis stipitatis subenervibus.

l'ucus lomation Berlol. l. c. lab. 10 fig. 3 el Am. p. 289 lab. 4. f. 3. sill. lactuca Ag. sp. p. 231 (partim! 
Crypt. Lactuca J. Ag. Alg. med.p. 100. Mont. Fl. d'Alg.p. 109 (partim?). Euhymenia Lactuca hüt.s sp. p. 741 (partim?).

llab. in mari mediterraneo et adriatico inter spongias cavernarum.

Frons 2-4pollicaris, caule surgens alato residuisve foliorum inæquali, demum his obsoletis teretiusculo, pennam columbinam crassitie aquante, foliolis ramisve novis pullulantibus, suo ordine lamina detersis, ramoso. Foliola a caule seu a costa folii pullulantia, nunc a margine læso folii fere usque ad costam derasi provenientia, obovato-rotundata, latitudine longitudinem fere acquante, aliquando superante, margine leviter sinuosa aut plerumque integerrima. In his foliolis cystocarpia sparsa nidulantur, in alterutera superficie paulo magis prominula, ita minuta ut oculum nudum facillime fugiant. Substantia quam in antecedentibus paulo forsan crassior. Color roseus.

Frons ut folium simplex, infima basi costatum et in lobos plures subrotundatos divisum, inchoatur; et ita quodammodo cum antecedente congruit. Lobi vero $\mathrm{mox}$ in foliola separari videntur et planta vulgaris forme ita oritur. Apnd Agardhium utraque conjuncta. Descriptio vero data in præcedentem melius quadrat, quare nomen Bertolonii, tempore prius, præsenti usurpandum credidi.

6. Cr. tuxurans (Mert mscr.) caulescens, caule ramoso superne alato et in laminas costatas sublineares undulatas abeunte, foliolis novellis a costi et margine pullulantibus obovato-oblongis stipitatis subenervibus, sphærosporis in foliolis minutis marginalibus evolutis.

Fucus luxurians Mert. mscr.

Sphærococcus luxurians Narl. Fl. Bras. p. 32.

Phyllophora? luxurians Mont. Voy. Pol. Sud. p. 100 !

Euhymenia luxurians külz. sp. $p .742$ !

Spher. Lactuca var. luxurians Ag. Sp. I p. 232. Syst. p. 212 !

Ilab. in oceano atlantico ad oras Brasilix (Martius!), Martinice (Duperrey!), Senegalix (ex Montagne); in freto Magellanico (d'Trrille); ad uras Ceylone (? Ilb. Agardlı).

Forma generali frondis, colore et substantia pracedentem omnino æmulatur. Lamine frondis vero minus quam in illa obliterantur, ita ut folia multa costata lineari-oblonga plerumque adsunt. Margines horum magnopere undulati, lobis demum separatis. Foliola nova sunt magis elongata. Sphwrosporas in phyllis minntis a margine proliticantibus evolutas, soros in utraque superficie formantes, inter fila abloreviata immersas, oblongas, cruciation divisas vidi. 


\section{Ordo III. GIGARTINEA.}

Gigartineie J. Ag. mscr.; Floridearum gen. C. Ag.; Cryptonchearun genera J. Ag. Alg. Medit.; Gigartinex, Caulacanthex, Cystoclonice Tylocarpex (quoad partes) hü̈z. sp. Alg.; Sphierococcoidece, Gasterocarpex etc. (yuoad partes) Decsn. Classif.

Fro:ss cellulis filiformibus rotundatisve brevioribus contexta, strato coutinuo filorum moniliformium aut cellularum verticalium cincta. Cystocarpia frondi immersa vel intra pericarpium proprium excepta, nucleo ambitı subindefinito, cellulis prognantibus plurimis plus minus adproximatis constituto, mucleolis intra periderma hyalinum membranaceum gemunidia pauciora rotundato-angulatia nullo ordine conglobata forentibus. Spherospora transformatione cellularum strati corticalis formatie aut in Nematheciis evolute, immerse.

Algæ plerumque coccinex aut purpurascentes, nunc amellystino aut atro-virenti suffusx, frondosæ, forma varix; nunc planie late expansa, membranam indivisam vageve fissam referentes (Kallymeniæ sp., Iridæa), aut laciniatæ ot divisie (Caloplıyllis, Polycoelia, Rissoella), vel propric ramosæ (Gigartinæ sp.); nunc angustiores, planx aut compressæ, diclıotomæ aut piınatx (Gymnogongrus, Chondri et Gigartinæ sp.), nunc teretiusculæ (Cystoclonium, Alınfeltia, Gigartine sp.). Stipes plerumque brevissimus, nunc magis evolutus et launinas caulis ad instar sustinens (Constaulinea, Pylloplıora), vel in costam sensim evanescentem abiens. Consistentia sxpissime carHosæ, membranacex aut magyis coriacer, rarius gelatinosie (Gloiopeltis, Gloioderma).

Cellularum stratis duobus contexte sunt. Interius nune tubo constat axili articulato, rimis ejustem stratum periphericum formantibus (Endocladiex); nunc contextum est filis plurimis elongatis ilticulatis ramosis rel anastomosantibus (liissoellea, Gigartinea, 
Kallymeniex), nunc cellulis abbreviatis rolundato-angulatis (Tylocarpex), interspersis quandoquidem filis tenuioribus (Caloplıllis, Polycoclia, Crstoclonium). Stratum exterius verticale rarius cellulis verlicalibus (Kallymeniæ plurimæ), plerumque filis moniliformibus constat. Fila moniliformia aliquando sublibera sunt aut muco laxiori tantum colibentur (Gloiocladia, Gloiodermi); sæpissime mucus solidescit, et fila aretius coltarent.

Organa fructificationis duplicis generis olservata fuerunt. 1:0 Cystocarpia situ varia; in plurimis frondi immersa aut plus minus hemispliærice prominentia, rarius intra pericarpium omnino emersum nidulantia (Plyllophora, Gigartinis). Carpostomium proprium rarissime adest (Polyopes); plerumque sunt cystocarpia initio clausil, demum disruptione partis ambientis aut obtegुentis aperta; in generibus nempe, quorum cystocarpia frondi immersa sunt, particula frondis cystocarpium ambiens a fronde separatur, foramen pervium aut cryptam linquens in superficie frondis; in generibus vero, quorum cystocarpia pericarpio emerso inclısa nidulantur, foramen juxta apicem pericarpii umbilicati plus minus latum rumpitur. Nucleus ipse oritur cellulis prægnantibus plurimis, nucleolos totidem formantibus. Nucleoli vero aut ita coalescentes, ut nucleum simplicem (membrana vero nulla communi cinctum) efficere videantur (Polyopes), aut adproximati et membrana cellularum invicem tantum separati (Tylocarpea), aut sepissime filis sterilibus invicem sejuncti, nucleum compositum evidentius monstrantes. Nucleoli nunc transformatione filorum frondis orti et ramorum ad instar filis sterilibus, vices placentæ gerentibus, adnati (favellidia); nunc vero orimntur a cellulis parum transformatis frondis (kalidia), sive contigni, sive filis sterilibus sejuncti. Favellidiorum nucleoli aut in filis sterilibus circumcirca dispositi, lı. e. a placenta centrali quodammodo radiantes (Gloiopeltis, Rissoella); aut inter flexus placente reticulatim ambientis quasi loculos minutos interspersos efficiunt (Gigartineæ). Gemmidia rotındata aut pressione mutua angulata, muco vix conspicuo invicem sepatata, intra membranam nucleoli nullo ordine conglobata, plurima (attamen quam in favellis multo pauciola)*).

*) Favellidia el Kalidia licet in nonnullis generibus adspeclum offerant admodum diversum, tamen in alis intermedis confluere mibi videntur. In generibus, quorum cellule steriles rotundata sunt, ipsa he cellula, vix mutatir, prægnantes evadunt; nucleoli membranis cellularum 
2:0 Sphcrosporce transformatione cellularum aut filorum corticalium ubicunque formautur, diverso rero in diversis generibus modo; in nonnullis inter cellulas aut fila sterilia strati corticalis sparse obveniunt (Gloiopeltis, liissoella, Kallymenia, Caloplıyllis, Cystoclonium), in aliis a cellulis infra-corticalibus plurintis transformate, certis locis soros plus minus extensos efficiunt, favellidium mire referentes (Gigartinex); in aliis denique Nemutlecia evolvuntur, evolutione peculiari filorum corticalium. Nemathecia sunt rerruce externx spongiose, filis corticalibus prolongatis moniliformiter articulatis dichotomo-fastigiatis radiantibus, muco laxiori tantum cohibitis, contextic. Splırosporæ aut ex ipsis articulis et omnibus filis Nematlıecii transformatis oriuntnr (Tylocarpex), aut ex ramulis filorum nonnullis transmutate, filis sterilibus insident et his cinguntur (Constantinea, Polyopes). Nucleus sphærosporæ intra perisporium splaxricum aut sphæroideum vel immo oblongum in partes 4 maturitate secedit. Sphærosporæ zonatim divisæ in Constantinea, Cystoclonio, et Rissoella observate fuerunt; in Endocladia, Polycoelia et Alnfeltia nondum bene cogrita; in creteris cruciatim diriduntur. In unico Genere - affinitate cæterum dubio - splserosporas triangule divisas videre credidi.

Gigartinearum ordo, ut lıo loco limitatus, Cryptonemeas potissimum tangit. Structura frondis et spharosporx in serie Generum utriusque familiæ subsimiles et analogas ofterunt modificationes; nuclens vero cystocarpii in utraque familia diversus. Favella Cryptonemearum subglobosa intra periderma hyalinum nucleum simplicem, aut forsan nonnullos sed in unum omnino coalescentes, continet. In Gigartineis vero nucleoli singuli favelle nucleo analogi sunt; plurimique nucleoli nuclenm favellidii et Kislidii constitumnt. Nucleus itaque lıorum nulla ambiente membrana anlista inclusus, sed nucleoli singuli intra periderma peculiare gemmidia fovent. Gemmidia quoque in favella numerosiora, quan in nucleolo Gigartinearum. Forma gemmidiorum in utraque familia subsimilis.

Genera Gigartinearum sat bene invicem conveniunt; differentias, quæ in nuclei structura adsunt, in tribubus formandis indicari. Nonnulla genera, quarum cystocarpia nondum vidi (Polycoelia, En-

tantum separantur, et fere contigui sunt. In generibus vero, quorum stratum interius filis reliculatim anastomosantibus contextum est, sunt ramelli laterales clavati filorum reliculi, qui seusim tument: nucleoli itaque non tantum filis sterilibus separati, sed his revera insident. 
docladia, Gloioderma) affinitate dubia manent; unum (Polyopes), crijus quidem cystocarpia iterum iterumque observavi, affinitate famen mili nondum clarum. Nucleus hujus favellam mire amulatur, at periderma ambiens desideratur. Nucleus quougue filis plurimis a centrali quodam puncto radiantibus oriri videtur, ut looc fere in Desmiospermeis obtinet, sed filorum et gemmidiorum forma alia quam in lis. Genus itaque Rissoella proximum finsi, nucleo subsimili modo orto, sed dirersum in eo quod nulla fila sterilia inter fertiles nucleumque formantes, excurrunt.

Splierosporarum soros in nonnullis generibus favellidium mire referre, et ab Auctoribus quoyue recentissimis pro cystocarpiis descriptos fuisse, probe observandum.

Gigartinearum quendam ordinem jam antea condidit kützing, cui quidem characteres fere legitimos adscripsit, a quo vero tum membra familie legitima expulsit, tum eideın genera diversissima adnumeravit. Nlii Auctores genera diverso omnino modo distribuerunt.

\section{EYPOSITIO GENERUM et TRIBLUM SINOPTICA.}

TRIBUS 1. ENDOCLADIEE. Frons sultubulosa, ani monosiphonio articulato percursa, ramis ab axi e⿻上飞edientibus stratum periphericum contigum sustentantibus. Favellidii nucleoli circa placentam centralem dispositi.

Frondis axis (intra lubum frondis) excurrens in ramos alternos . . . . . . XXXIV. Gioloreltis.
verticillatos. . . . . . XXXV. ExdocLAdi.

TRIIBUS II. RISSOELLEE. Frons filis tenuibus piurimis reticulatim anastomosantibus contexta. Favellidii nucleoli a placentula centrali egredientes. Sphrerosporæ inter fila froudis peripherica sparsae, aut in nematheciis externis evolutx.

Favellida frondi immersa. Sphicrosporæ in nematheciis

Xixvi. Polyopes.

" intra pericarpium recepta; spliarosporæ zonatim divisæ . . XXXVII. RissoelLa.

TRIBLS III. GIGARTINEE. Frons filis tenuibus plurimis reticulatim anastomosantibus contexta. ravellidii nucleoli ad 
placentam reticulatim ambientem adnati, distincti. Spherosporic a cellulis infra-corlicalibus transformatie, in soros frondi inmersos plurime collectre, cruciatim divisu.

1. Fila strati peripherici muco mullo aut laxiori cohibita.

XXXYIII, GLo!odenis.s.

2. Strato peripherico muco solidescente cohibito.

Fucellidiorum nucleo ambilu indefinito.

Fronde dichotomo-decomposita, cystocarpiis subprominentibus . . XxxIX. Cuoxpers.

Favellidiorum nucleo plexu intricato filorum cincto.

Fronde plana integriuscula aut vage fissa; cystocarpiis immersis . . . . . . XL. InID.E..

Fronde teretiuscula aut plana ramosa, cystocarpiis intra pericarpium exceptis . . ILI. Gigantix.

TRIBUS IV. KALLMIENIEE. Frons filis interioribus elongatis articulatis, cellulisve rotundatis reticulo filorum cinctis, in celJulas corticales rotundatas, quandoquidem subseriatas abeuntibus, contexta. Kalidii nucleoli plures, filis sterilibus invicem separati. Splıxrospore inter cellulas corticales sparse, aut in $\mathrm{Ne-}$ matlıciis externis inter fila sterilia evolutie, cruciatim vel zonatim divise.

1. Frondes plance ecostate. Strato interiore filis elongatis conlexto.

Sphærosporæ cruciatim divisæ, sparsæ. • . zonatim divisæ, in nematheciis externis evolutæ . . . XLlli. Cossraxtisea.

Stralo interiore cellulis rotundatis, reticulo filorum anastomoexternis evolutæ. $\cdot$.
cellulis rolundatis, reliculo
santium cinctis, constante.

Cellulis interioribus minoribus multiseriatis . Xlil. KaLLimexia. " " lacunæformibus simplici serie dispositis . . XLV. P'OLYcolira.

2. Frondes tereliuscule immerse sub-costule. Sphærosporæ zonatim divisæ, sparsæ . . XLVI. Crstocloxicx.

TRIBUS V. TYLOCARPEE. Frons collulis interiorilius rotundato-angulatis et esterioribus rerticalibus radiatis contesta. 
Kalidii nucleoli plures subconfluentes. Splsxrosporæ in nematlıceiis externis evolutx, ex articulis filorum transformatx, cruciatim divisa.

Lulidia fronde immersa.

Frons teretinscula corneo . . . . . . XLVII. AnNFEltis.

$"$ teretiuscula aut compresso-plana membranace-coriacea . . . . XLVIII. Grmxogoxgrus.

Kälidia inlra pericarpium externum recepla.

Frons subcaulescens

xlix. Phylophori.

\section{TRIBUS I. ENDOCLADIEE.}

Frons subtubulosil asi monosiphonio articulato percursa, ramis ab axi egredientibus stratum periphericum contigum sustentantibus. Favellidii nucleoli circa placentam centralem dispositi.

\section{Groiopeltis $J$. Ag. Alg. med. p. 68. Endl. Gen.} Pl. suppl. III. p. 37. L̆̈̈ts. sp. p. 734. Splır'ococci et Dumontix sp. Auct.

Frons cylindracea tubulosa lubrico-cartilaginea diclotoma et ramosil, stratis duobus contexta; axi tubum vacuum percurrente monosiphonio articulato flesuoso, alterne excurrente in ramos 3-2-chotomos corymboso-fastigiatos demum moniliformes et stratum peripltericum, laxiori unco cohibitum, formantes. $\mathrm{Fa}$ vellidia intra pericarpium hemisphærice elevatum, carpostomio demum apertum, nidulantia, gemmidiis inter fila a placenta ad pericarpium excurrentia evolutis, ovato-angulatis, in nucleum laxius coalescentibus, constantia. Spherospore inter fila moniliformia sparse, oblonga, cruciatim divisæ. (Post. et hupr. Ill. tab. XL. fig. 79).

Frondes teretiuscula diclrotome vel lateriliter ramosæ, gelalinosx, exsiccatione cartilaginex, madefacte in gelatinam solutx, lubulosie. Tubus, caterum vacuus, asi centrali flexuoso tenuiori percurritur, strato peripherico tubum includente; axis constat tubo interiori articulato coloralo, intra membranam liyalinam subgelatinosam laxius ambientem incluso; axis subalterue ramosus, ramis ad peripheriam excurrentibus et stratum tubi periphericum efficienlilus. Fila tubo primario subsimilia a ramis decurrunt ef in iufe- 
riore parte tubum primarium cingunt. Rami ab asi oblique excurrentes, ad ortum siepe trichotomi, dein dichotomi, articulis cylindraceis dum tubum percurrunt, subrotundis minutis dum stratum periphericum efficiunt, constituti. Stratmon periphericum filis moniliformibus densissime stipatis, muco laxiori involutis, contextum est.

Favellidia in ramis frondis superioribus evolnta, intra pericarpium lıemispherice elevalum, lilis moniliformibus strati peripherici formatum, carpostomio regulari pertusun, nidulantia. Placenta centralis adest elevata, a ramis adproximatis axis constans. Rami flexmosi ab hac excurrunt; nonnulli steriles fornicatum tectum pericarpii sustentant, alii fertiles sterilibus interspersi, in gemmidia abeunt. Gemmidia ex articulis horum filorum formata, el singula sacculo inclusa, at compressione (et forsan repetita unius divisione) ordine vix perceptibili demum conglobata, irregulari forma angulatoovatis. Nucleus itaque quasi pluribus confluentibus compositus, nulla communi meıbrana, nullisque fere filis ambientibus cohibitus (pericarpio tantum inclusus). Sphxrosporæ oblongx, inter fila moniliformia densius sparsa, cruciatim divisic. Has in utraque specic depreliendi.

Genus structura frondis Endocladix proximum, et hodie, fructibus lujus nondum rite cognitis, differentia structurx frondis dignoscendum; stratum periphericum in Endochadia magis solidescit, et fila peripherica sunt verticillatim ramosa. T'ubus in Gloiopeltide fere vacuus, in Endocladia ramorum reticulo fere impletus. A Catenella et Gigartina, quibus quodammodo adproximari videtur, axi monosiphonio facilius distinguitur.

1. Gu. Furcatı (Post. el Rupr. Ill. Alg. p. 19) nama pulvinata, frondibus a crustit minuta erectiusculis filiformibus ntringue attenuatis, simplicibus aut parce furcatis.

Dumontia furcata Post. el. Rupr. l. c.!l Kü̈t. sp. Aly. p. 719.

Ilab. in oceano pacifico septentrịonali (Mertens!)

Crusta minuta tuberculosa, saxis adlıarens. Fx hac frondes emergunt, plus minus adproximatæ, teretiusculæ, utrinque atlenuatx, simplices aut bis terve furcatx, ramis patentibus, longitudine semipollicares. Color purpurascens. Substantia cartilaginea. - Structura et sphacrosporc Generis!

Sec. auctores landatos specimina pollicaria raro occurrunt. Icon structuram internam explicans, quam dederunt, licet non omnibus numeris absolutu, tamen ita fida ut, comparata descriptione, genus agnoscere 
potueris. Preter magnitudinem et simplicitatem sequenti conveniens et ita sane proxima, ut de distinctione lezitima forsan jure dubitaveris.

2. GL. TEXIX (Turn. in Ann. of Bot. II. p. 367) cespitosa, frondibus erectiusculis filiformibus utrinque attenuatis decompositodichotomis, segmentis patentibus, terminalihus angustis divaricato-reflexis.

Fucus tenax Turn. l. c. tab. 13. Turn. Ilisl. Fuc. II lab. 123!!

Splixrococcus tenax Ag. sp. Aly. I p. 323! Syst. p. 238!

Gloiopeltis tenax J. Ag. Alg. med. p. 68. Kïlz. sp. p. $73 \%$.

Ilah in mari Sinensi (Ilb. Turner! lürgens! Hoffman liang!)

Radix callus exiguus discoideus. Frondes ex eadem basi plurima, cxspitosx; $1-1 \frac{1}{2}$ pollicares, crassitie penne columbinæ, plerumque omnino teretes, rarius infra dichotomias compressæ, utrinque altenuata, a basi ad apicem dense dichotomx, nunc segmentis plurihus adproximatis vel ex codem loco pullulantibus irregularius divise. Segmenta patentia, terminalia cateris pierumque tenuiora et divaricato-recurva, longius acuminata. Substantia gelatinosa cartilaginea. Color aquose purpurascens, cito in album evanidus. Structuram, favellidia, et sphærosporas generis supra descriptas vidi.

Magnas bujus speciei copias, in foris Sinensium venales, ad eosdem usus adhiberi, ad quos Gummi vel Gluten nobiscum, sed priecipue ad roborandas et vernice linendas chartas, e quilus laternas suas conficiunt, aut ad incrassandas lærigandasque vestes sericas, tenuissimasque lineas, Turnerus memoravit.

XXXV. Fndoctadia J. Ag. in Linneca 1841 p. 449. Acanthobolus Külz. Phycol. p. 393 el Sp. p. 754. Gigartinie sp. Auce.

Frons teretiuscula aculeato-ramosissima, cartilaginea, stratis duobus contexta; axi monosiphonio articulato, verticillatim dense ramoso, ramis polychotomis-dichotonisque corymboso-fastigiatis, cxtrorsum moniliformibus et stratum periphericum frondis constituentibus, muco solidescente colibitis. Favellidia ... Spharrospore (sec. lüttiug) exsertix seriatx, in nemathecia mucosa tenacissima amorpha, ex ramis superioribus tumidis erumpentia, consocjate.

liondes in exspites pulvinatos collecte, minulx, teretiusculæ, subvage ramosissime et spinulis minutis in ramos novos excrescentibus obsitie, purpurascentes aut amethystinx, subcarnosie, ex- 
siccatione fragiles aut cornex, filis intra substantiam frondis evolutis totie constitnte.

Tubus centralis, frondem percurrens, articulatus, membrana pellucida subgelatinosa constitutus, endochromate lutescenti in articulos longitudine diversos, spatio pellucido discretos, plerumque collapso, faretus. Fila ad geniculum quodque tubi centralis egredientia, multo tenuiora, erecto-patentia, juxta axem sublongitudinilia, directione sensim magis lıorizontalia, subregulariter articulati, articulis inferioribus cylindraceis, superioribus subpyriformibus, supremis ellipsoideis, ad geniculum yuodque polyclıotomis, ramis partim consimilibus, partim singulis articulis constantibus; peripleriam versus frondis fila diclıotoma et horizontalia ita fastigiata et approsimata evadunt, ut apices, seu articuli supremi, in superficie frondis quasi cellule rotundate, quaternatim adproximate, alpareant.

Genus structura insigni frondis facillime distinctum. Fructus milıi ignoti, a lützingio modo supra dicto descripti. Species typica, antea ignota, a me ipso et liüzingio fere codem tempore descripta, ab utroque genus proprium considerata. Alteram speciem, a Postels et liuprecht inter Gigartinas descriptam, dein generi nostro vindicavi.

1. Exd. vuricata (Post. el Rupr. Illustr. p. 16) fronde pulvinatocespitosa minuta vage ramosissima, ramis superne adprosimatis diraricatis subulatis minutissime spinulosis, spinulis acutis.

Gigartina muricata Post. el Rupr. l. c.!! lï̈љ. sp. p. 751.

End. muricata J. Ag. Alg. Liebm. p. 10.

Hab. in oceano pacifico ad insulam Sitcha (Kastalsky!).

Caespites minuti vix pollicares. Frondes teretes, crassitie miltimetrum dimidium vix superantes, vage dichotomo-ramosissima, ramis nunc lineas nonnullas distantibus, nunc subfasciculatim exeuntibus, apice plerumque numerosis divaricatis, subulatis, et spinulis minutis acuminatis obsitis. Rami inferiores parum stricti et vage flexi, superiores stricti. Color madefacta purpureus, exsiccata nigrescens. Substintia subcarnosa.

Est serquenti multo minor, exsiccata nigrescens et frugilis, spinulisque subulatis simplicibus diversa. Generice autem conveniens, structura eadem. Nomine Gig. muricate planta Californica a Ilarvey descripta (Bot. of Beechey. Foy. p. 409) exstat, qua utrum diversa an, nomine eodem eidem plantie fortuito dato, identica sit, ex descriptione haud patet.

2. Exd. verxicata (J. Ag. Symb. Cont. p. 449) fronde pulvinatocrespitosa minuta vage ramosissima, ramis patentilus acmminatis 
per totam longitudinem minutissime spinulosis, supremis fere cristatis, spinulis apice sepius bilidis.

lind. vernicata $J$. Ag. l. c. in Linneea 1841.

Acanthobolus Brasiliensis Kü̈z. Phyc. p. 395! Sp. Alg. p. 73̈4!

Hab. in oceano atlantico ad oras Brasilix (Sellow!).

Cæspites 1-2-unciales, fragmentis concharum lopillisre adnati. Frondes teretes, superne subcompressæ, millimetrum fere diametro æquantes, vage dichotomo-ramosissimæ, ramis inferne sparsioribus, superne densioribus, supremis acuminatis sed plerunıque infra apicem bifidis, patentibus et immo patentissimis, omnibus spinulosis; spinulis minutis vix nisi lente conspiciendis, superne subdistichis, sub lente valde augente conspectis apice ustulatis et bi-multifidis. Color madefactæ ex amethystino lividus aut subrubescens; exsiccata lucida et quasi vernice obducta. Substantia exsiccatæ fere cornea.

\section{TRIBUS II. RISSOELLEE.}

Frons filis tenuibus plurimis reticulatim anastomosanlibus contexta. Favellidii mucleoli a placentula centrali egredientes. Splıerosporæ inter fila frondis peripherica sparsie, aut in Nematleciis externis evolutio.

\section{Polyopes J. Ag. Act. Holm. Öfrers. 1849 p. 83.} Chondri et Gelidii sp. Auct.

Frons carnoso-cornea, terntiuscula aut compressa, dichotomo-fastigiata, stratis duolus cellułarum constituta; interiore (filis) cellulis eylindraceis elongatis ramosis et anastomosantilus densissime intertextis; exteriore filis moniliformibus verticalibus muco solidescente cohibitis, constante. Favellidia frondi inmer'sa, carpostomio regulari demum liberata, uucleo simplici constituti, gemmidiis minutis rotundatis ad placentulam sub-pyramidatim collectis. Spharospore in nematheciis maculæformilus, in alterutera pagina frondis proeminentibus crolute, inter fila strati externi prolongata nidulantes, oblonga, cruciatim divisæ.

Frondes teretiusculie aut ex tereti compressie, dichotomofastigiatie, segmentis linearibus, hic illic constrictis, e strictura prolificantibus; recentes subcarnosie tenaces, exsiccatie subcornea, purpurascentes.

Stratis duobus frons constituitur. luterius filis longiludinalibus, seu cellulis eylindraceis elongatis, dense intertestis, ramosis et 
anastomosantilus, extrorsum in fila peripherica arcuatim excurentibns. Fila peripherica densissima verticalia, cellulis rotundatis mouiliformiter seriatis constantia, muco solidescente conjuncli.

Favellidia frondi omnino immersa, certis locis plus minus intumescentibus aggregata. Crypte ferliles infra stratum periphericun excavatie, per canalem elongatum, secedentibus filis periphericis furmatum, cum ostiolo superficiali communicantes. Nucleus simplex, scmi-ambientibus filis strati interioris suspensus, pyramidatus, gemnidia in plexu filorum a puncto seu placentula fasciculatim egredientium eroluta, admodum minuta, forens. Nematlıecia a filis verticalibus strati exterioris aliquantulum prolongatis formata, in alterutera paggina subcanaliculata maculas lineares elongatis, margine sterili cinctas, formantia. Splıærospore elongato-oblongæ, cruciatim divisæ, inter fila dense stipata Nematlıecii nidulantes.

Species unica, quam luuic generi refero, quoad fructus antea vix cognita fuit. A Turnero primum descripta, inter Splaxococcos ab Agardlio enumerata, a Grevilleo ad Chondrum relata, quo loco quoque a kützingio in Plıcologia relicta fuit. Postea in Specielns Alogarun lanc speciem ad Gelidium transtulit. Alteram speciem luic generi antea adnumeravi; hec vero nuclei structura diversa lıodie milii videtur.

Genus sane eximie distinctum, fructu utroque eximias distinctionis notas offerente. A Cryptonemcis omnibus, inter quas Grateloupiam ot Prionitidem structura polissimum amulatur, Favellidiis differt. Nuclei nempe a filis plurimis fasciculatim a placentula egredientibus formantur, nec peridermate lygalino cinguntur, ut hoc in generibus favellas generantibus obtinet. A Grateloupia ef Prionitide insuper nematlıeciis differt. Acrotylus structura frondis, splıerosporisque zonatim divisis laud dubie diversus. $\Lambda$ Gigartineis onınibus nucleo Favellidii simplici et carpostomio evidentissimo facile dignoscitır.

1. Pol. cosstrictus (Turn. Hist. Fuc. III. p. 40). J. Ag. Act. Holm. öfers. 1849 p. 86.

Fucus constrictus Turn. l. c. lab. 1322!!

Sphærococcus constrictus Ag. sp. Aly. I p. 2:32 el Sysl p. 2171

Gelidium constrictum hülz. $s p . p$. 767 !

llab. in mari australi ad insulas Kent prope N. Ilollandiaun (Brown!), ad Cap. b. Spei (Laland! Ilarvey! Pappe! IIl), Areschong!) ad Cillifurniam (Beechey). 
Frons $4-6$ pollicaris, inferne teretiuscula, pennam columbinam rix crassa, superne compressa, marginibus rotundatis, lineam circiter lata, linearis, hic illic cunstricta; per dichotonias numerosas subregulariter fastigiata, apicibus demum abrupto-truncatis, a truncatura prolificantibus, proliticationibus geminis aut raro ternis, initio rotundatis capsulas æmulantibus, sensim prolongatis et formam frondis recuperantibus. Naculæ fertiles, in quibus favellidia adproximata evolvuntur, in latere plano frondis subelevate, rotundatæ; cystocarpia ægre, nisi lente adspecta, observanda, supra superficiem parum elevata. Nemathecia sphærosporarum maculas lineares, margine sterili utringue cinctas, apicibus rotundatas, efficiunt. Color purpureus; substantia firma subcarnosa.

Specimina Novæ Hollandiæ a Capensibus distinguere nequeo. Nostra paulo minora sunt et colore dilutiore prædita. Turneriana vero magnitudine Capensia æquant.

Specimina nonnulla plantæ, huic proxinæx, ex oris Terræ Noræ a Delapylaie, nomine Sph. norvegici accepi. Sunt tantum pollicaria magisque complanata quam P'. constrictus. Species forsan sui juris, sed ex speciminibus nostris, evidenter juvenilibus, characteres eruere vix licet.

Sonder (Alg. Preiss. $p$. 44) lucum constrictum Turneri ut varictatem sux Rhod. australis nuncmpavit. Quilquid sit Rh. australis, a descriptione tamen abunde patet esse specie et genere a Fuco constricto Turneri diversissimam.

\section{Rissoella J. Ag. Act. Holm. Öfvers. 1849 p.}

85. Grateloupia sp. Greville et Auct. Splıerococcus sp. Ag.

Frons gelatinoso-cartilaginea plana stratis duobus contexta; interiore cellulis cylindraceis in reticulum faxum undique anastomosantibus, exteriore filis verticalibus muniliformibus muco solidescente cohibitis, constituto. Favellidia intra pericarpium exteruum subsphiericum, carpostomio demmm pertusmm, nidulantia, nucleolis pluribus confluentibus, placenta centrali suffultis, composita, gemunidis rotundato-angulatis. Spharosporæ strato superliciali demersie, sparsa, zonatim divisx.

Frondes gregarix planx cuneate, varie divisa margुineque denticulatie, recentes gelatinoso-carnose, exsiccate subcartiliginea', violaceo-fuscescentes. Denticuli milrọinales initio minutissinni spinuliformes, dein bifidi et sensim majores, demmm in lacinias fromlis excrescere videntur.

Stratum internum frondis cellulis minutis subcylindraceis, per ramos anastomosantes cum proximis conjunctis, reticulum laxum ita formantibus, constat. Externum stratım filis verticaliter ab interiore exemutibus dichotomo-fastigiatis moniliformibns, muco soli- 
descente colibitis, constat; cellulis minutis rotundatis, in inferiore fili parte anastomoses emittentibus.

Favellidia intra pericarpia externa, per totam frondem dense disposita, excepta. Pericarpium omnino emersum, sphærico-ovatum, apice deunum pertusum, structura fragmentum frondis emulans. Placenta centrulis adest, filis dense intertestis constituta. Inter filit sterilia, a placenta ad pericarpium extensa, fertilia fila abbreviata evolvuntur, nucleolos radiatim dispositos inclıoantia. Nucleoli obconici, gemmidia rotundato-angulata pauca forentes. Sphrorospore oblongo-sphicroidex, inter fila moniliformia strati exterioris sparsie, zonatim divise.

Species, quam lıujus generis typum constituimus, jam a Turnero coggnita fuit. Afinitate Fuco Radula aut F. erinaceo, vel potissimum F. Bangii proximam judicavit. Nostro æevo lix species in genera diversa abeunt, cum quibus Rissoclla nullomodo in unum conjungatur. Agardlius inter Splierococcos mamillosos enumeravit, adjecta observatione, speciem tribui minus convenire. Greville cum signo dubii Grateloupiæ conjunxit, quo loco ipse illam antea (Ali. medit.) retinui.

Genus quoad structuran cum Grateloupia et Gigartina fere conveniens, favellidiis compositis pericarpio emerso inclusis ab illa, sphærosporis sparsis ab lıac, atque divisione splrærosporarum ab utraque distinctum.

1. R. verriculos. (Bert. op. sc. Bol. II. p. 290) fronde planil cuncato-oblonga, vage laciniata dichotoma aut sulpinnatim parec divisa, margine ubique spinulis minutis multifidis densissime denticulati.

Fucus verruculosus l. c. tab. 11 fig. \& a. b. et Amoen. Ital.p. 29.1 tab. s fig. \& a. b. (eximie!)

Spharococcus verruculosus Ag. sp. p. 260 et Syst. p. 222!

Grateloupia verruculosa Grev.; J. Ag. Alg. med.p. 103. Mlont. Fl.d'Alg. p. 102 !

Grat. veriucosa Kütz. Phycol. tab. 73. I. Sp. Alg. p. 731.

Fucus Rissoanus Turn. IIist. tab. 203!

IIab. in rupibus refluxu maris emersis soleque expositis maris mediterranei, ad littora Italix! Sardinix! Corcicx! et Galloprovincix!

Frondes cæspitosæ et gregariæ 2-4pollicares, unguem et fere pollicem aliquando lata, sxpe multo angustiores, ima basi subfiliformes, stipite mox dilatato cuneata, dein lineares aut ollongie, sed pierumque inargailes 
et forma rarix, aliquando undulatæe torta, nunc bis aut ter dichotomx. et magis lineares, nunc subpalmati-lobate et forma magis cuneatæ, nune fere pinnatifidæ ant vage laciniatæ, ambitu plerumque oblongæ. Nargines ubique denticulatie, denticulis brevissimis fere semper apice multifidis. Laminæ frondis nudæ aut aliquando prolificationibus, denticulos marginales rmulantibus, asperæ. Pericarpia in utraque pagina dense disposita, fere sphærica, demum apice aperta, magnitudine seminum Papaveris. Splaærosporæ Irondi omnino demersæ, nudo oculo hand detegendæ. Color recentis in jurentute amethystino-violaceus, plerumque mox in fuscescentem tendens. Substantia exsiccatæ subcartilaginea.

Hæc species forsan primum a Buxbaum descripta, cujus Icon tab 8 ct fig. 4 Cent. secundx ad hanc citatur. Figura rudis, ut judicium ex eir non facile fingatur; planta e Propontide. Specimen ab Allriatico nullum vidi; nec ab Atlantico. Est quidem in Hb. Ag. a Schousboe lectum specimen, nullo autem loco natali adposito; sed ad Massiliam hoc lectum fuisse suspicor.

2 R.? dexticliata (Nont. Bonite. p. 63) fronde plana cuneatolineari dichotomo-subpalmata, margine (et disco) ubique spinulis minutis simplicibus densissime denticulata.

Grateloupia denticulata Mont. l. c. tab. 14:" fg. 1. Kü̈ъ. sp. p. 732.

Hab. ad oras Peruvia prope Payta.

Frons circumscriptione palmata, raro simplex, nisi junior, a basi scutatim affixa brevique spatio integra, mox in segmenta bina iterum semel bisve furcata, divisa. Segmenta lanceclata, 4-:; uncias longa, 6 lineas lata, e margine tenuiter denticulato apiceque prolificationes conformes promentia, disco utrinque aculeis minutis compressis conico-acuminatis veluti in series longitudinales dispositis onusta. Color violaceus. Substantia cartilaginea, lenta, maceratione in gelatinam abieus.

Descript. auct. transscripsi. Specics a me non visa; ex habitu præcedenti proxima videtur.

3. R. CRispa (J. Ag. mscr.) fronde plana cuneatim expansa dichotomo-decomposita, segmentis inferioribus approximatis fere palmatifida, superioribus lineari-cunealis a marsine et disco manillosis proliferis, terminalibus dilatatis multidentatis.

Grateloupia ornata var. $\beta$. crispa $A g . s p . A l g .1 p .223$ !

Ilab. . . . (Collectio Henlieana!).

Frons pusilla sesquipollicaris, formam quandam Gig. mamillosæ fere referens, a stipite brevissimo subnullo cuneatim expansa, $2-3$ lin. lata, dein repetite dichotoma, segmentis vero ita opproximatis ut frons fere palmatifida appareat. Segmenta superiora $1 \frac{1}{2}-2$ lineas lata, linearia, supra axillas eximic rotundatas convergentia, lerminalia dilatata multiden- 
tata. Prolificationes minute cunealo-ligulata, in disco el margine numerosic. Substantia et color R. verruculosa.

Species mihi videlur distinclissima, quoad genus forsan adhuc dubia, fructu ignoto. Struclura frondis a Chetangies differt; el cum nullogenere forsan melius quam cum kissoella convenil. In hoc genere fronde decomposilo-dicholoma non argre dignoscilur.

\section{TRIBUSS III. GIGARTINEL.}

Frons filis tenuibus plurimis reticulatim anastomosantibus contexta. Favellidii nucleoli ad placentam reticulatim ambientem adnati, distincti. Sphrerosporia a cellulis infra-corticalibus transformate, in soros frondi immersos plurimse collecte, crinciatim divisie.

\section{Gloioderia J. Ag. mscr.}

Frons rosea, gelatinosa, compresso-plana, stratis fere tribus constituta; centrali cellulis rotundato-oblongis lase adproximatis, intermedio filis in reticulum laxissimum anastomosantibus, exteriore filis verticalibus moniliformibus muco lasiore colibitis constante. Favellidia ... Spharosporce inter fila strati intermedii, a ranis (filorum) obovatis lateralibus transformatix, demum aggregatie, rotundatx, triangule [?] divisæ.

Frondes eximie gelatinose, roseo-subcarnéx, initio et inferne ut videtur cylindracex, superne dilitatæ compressæ et plures lineas late, prolificationibus a disco et margine provenientibus pluribus ramosie. Prolificationes inferne cylindracex angustiores, superne foliaceo-dilatatæ vage dentatæ aut multifidx, segmentis ambitu subdefinitis.

Frons jurenilis interior filis lasissimis cylindraceis, articulatis et anastomosantibus, ad anastomoses multangulis et hic illic in interiore parte intumescentibus, contexta adparet. lix intumescentilus articulis cellule rotundate et oblongee, diametrum filorun multiplo superantes, formantur; in interiore et media frondis parte cellulie iste sensim numero et magnitudine augentur, atyue in ramis adultioribus stratum contrale efficiunt. lnterior itagne frondis adulte cellulosa, cellulis mediis majoribus elongatis, exterioribus minoribus et magis rotundatis. Stratum intermedium filis elongatis ç̣lindraceis anastomosantibus et in reticulum laxissimum conjunctis 
contestum est; mediante cellula aliyuantulum mijori, in fila peripherica verticalia et dense stipata elongata, dichotomo-fastiogiatis moniliformia, muco laxissimo colibita, abeunt. - Spherospore infra stratum superficiale a ramulis transformatis struti intermedii formantur; ad fila lıjus affixe, laterules, juniores obovate, adultiores globose, intra lasum perisporium nucleum triangule dirisum (si recte viderim; sunt in nostris sat juveniles) foventes. ob ramulos fertiles adproximatos, splıxrosporie demun aggregatx adparent.

Gemus videtır sui juris, sed cystocarpiis ignotis affinitate adluc dubium. Quoad characteres cognitos cum Gigartina satis congruere videtur; color vero et substantia tantum differunt, ut potius Ilalymeniam coram oculis habere putares. A Dudresnaja, cun quo genere colore et substantia et quodammodo structura convenit, revera longius distat, defectu axis centralis et sphresporis longe al:is.

\section{Ge. australis J. Ag. mscr.}

Ilal). ad occidentales Nove Hollandiæ oras (Mlıs. Paris!)

Planta 4-6pollicaris, 2-3lineas lata, inferne cylindracea, prolificationibus densis obsiti, superne cuneatim dilatata, et in segmentacuneatnlinearia vage divisa; prolificationes frondi conformes. Inferne sordide carnea, superne rosea. Substantia gelatinosa. Chartæe arctissime adlıxret; madefacta sat bene reviviscit.

XXXIX. Chondrus hïtz. Phycol. p. 308 (exclus. specieb.) Chondri sp. Lamour. et Auct. Splarococci sp. Ag. et Auct. Frons subcarnosa plana diclotomo-fastiģiata, stratis duobus contesta; interiore cellulis cylindraceis in reticulum anastomosantibus demum crassioribus inæqualibus; exteriore filis moniliformibus verticalibus muco solido colibitis constante. Favellidia uncleolis pluribus in unum confluentibus, placenta reticulatim ambiente suffultis, composita, immersa, in alterutera pagina sulprominentia, demum circuncireal solutil et liberata. Spharosporce in soros subprominentes, infra stratum superficiale nidulantes, phnimæ collectæe, rotundatæe cruciatim divisæ. (Kü̈ъ. Phycol. tab. 73 II. et III).

lrondes plance lincares, numc angustiores quasi ex tereti compresse, nunc latiores et sursum cuneate, in nonnullis subcaniliculate, dichotomo-fastigiate, margine integerrime; recentes subcarnosx, exsiccate subcartilagince, madefacte in gelatinam sensim solutic. 
Stratis duobus contextie sunt. Cellula interioris strati elongate, anastomosibus quoquoversum radiantibus cum prosinis juncte, in juvenilibus partibus cylindracere et anguste, in adultiorihus crassiores et breviores, demum alicjuando ita incrassate, ut parietibus plures adprosimanfur. Stralum externun constat filis verticalibus moniliformibus dichotomis, brevioribus in sterili, in parte farcllidium includente magis evolutis et in una pagina pracipue longioribus.

Favellidia nucleolis pluribus constantia, nunc subimmersa, nunc in una pagina sulprominentia, excavatione conformi in altera, nune omnino fere emersa et in una pagina sessilia, altera plana; semper clausa, filis verticalibus moniliformibus pericarpinm constituentibus, demum circumcirculari solutione a fronde soluti, ant excavationem alterius paginx aut foramen pervium relinquentia. Sphærosporx infra superficiem evolute, plurimx in sorum conjuncte, cruciatim divise.

Clıondri guoddam genus primus Stachlousius in Edit. primu Ner. Br. instituit. Ipse dein in Editione secunda ejusdem operis nomen in Polymorplam mutavit. Sed Lamourous genns aliter limitatum condens, nomen primitus datum restituit. Chondri apud Agardhium species Splærococci effecerunt. Greville gुenus Lamourouxianum restituens, lıoc ad omues species Splıerococei, fronde plana dichotomi insignes, extendit. Vestigia Grevillei recentiores plurimi pressis pedibus secuti sunt. Ipse in Algis Mediterrancis genus aretius circumscribere molitus sum; suadente fructu et structura varias species exclusi, alias, quas ob frondem teretiusculam expulerant, generi vindicavi. Sed fructu in plurimis tunc nondum investigato, nec structuram in plantis consimillimis diversam suspicanti, genus justis definire limitibus milıi laud contigit; quin immo ipsos characteres generis ad speciem lıad legitimam exaravi. Kütring differentiam spliærosporarum primus exposuit et in plura nova generat retus Chondri genus dissolvit. Nomine Clıondri genus adoptavit, fuod aliter paululum limitatum lıodie conservo. Kützingius nimirum suo generi tum Clı. celticum, quem Gymnogongri speciem puto, tum F. constrictum Turneri, quem novi generis typum constitui, introdusit. In ultimo suo opere sub nomine Clıondri veterem diversissimarum specierum farraginem offeudimus.

Genus, quale lıoc loco limititum propono, ad Gigartiman et Iridaam proxime accedit, structura fere eade!ı, spltærosporis in sorum conjunctis, et farellidii slructura simillimis. Al) utroupe vero genere diversum videtur consistentia limiore, ita ut froms made- 
facta lentius multo in gelatinam abeat. Favellidia reliculo illo concentrico, quod in Gigartina et Iridica nucleum compositum ambit, carere videntur. A Gigartina insuper differt favellidiis circulari solutione partis fertilis liberatis; ab Iridrea, favellidiorum sifu et iı alterutera pagina prominentia.

Splierosporæ lüus generis admodum rarx videntur et a paucis tantum observatx. Nisi accuratius inspecti, sori sphærosporarun pro favellidiis facillime habentur. Ilurvey immo ipse, in sua Phycologia, soros sphærosporarum et favellidia quodammodo confudit.

1. Ci. Plimses (Ag. Sp. Alg. p. 206) fronde irregulariter dichotomo-fastigiata, subcanaliculato-plana, segmentis superioribus dilatatis subirregulariter divisis, cystocarpiis immersis utrinque parum prominentibus.

IIalym. platyna Ag. l. c. et Sysl. Alg. p. 243.

Iridæa platyna Post. el Rupr. Illustr. p. 18! Küls. in Bot. Zicit. 1847 p. 24 el Sp. Alg. p. 727 !

Hab. in oceano pacifico ad littora Kamtschatke et Sachalien (Tilesius!).

Alga biuncialis. Stipes cuneatus brevis in frondem sensim dilatafus. Frons dichotoma, nunc regulariter fastigiata, nunc dichotomo-subpinnata, segmentis inferioribus magis linearibus, superioribus siepe eximie cuneato-dilatatis, magis irregulariter fissis. Farellidia frondi immersa, utrinclue parum prominentia, maculas diametro lineæ referentes.

Species milii adhuc multis dubiis vexata. Chondro crispo sine dubio proxima, licet nunc ad Halymeniam, nunc ad Jridaam illam retulerint auctores. Speciem esse a Ch. crispo diversam, mihi immo non perspicuum; favellidiis immersis præcipue differre videtur. Ab altera vero parte Ilaud certus sum specimina omnia a Tilesio lecta ad eandem speciem pertinere. Nonnulla tenuiora typica; alia crassiora carnosa, fructibus ad Clı. crispum magis adproximantur. Ab his vix distant specimina maris atlantici nonnulla, ad Terram novam a De la Pylaie lecta. Marginem frondis sæpo elevatum vidi, ita ut recentem cannliculatam suspicarem.

2. CII. Crisp's (Lin. mant. p. 13.t) fronde diclotomo-fastigiatia plana, segmentis cuneato-linearibus, cystocarpiis in una pagina subprominentibus, altera impressa, ovalibus.

F. crispus L. l. c. Stackh. Ner. t. 12! Turn. Hist. Lab, 216, 217! Eugl. Bot. lab. $228 \%$.

Chondrus crispus Lyngl. Ilydr. p. 15 lab. 5. A. B.! Girev. Alg. lir. p. 129 lab. 13 !! Ilarv. Man. p. 75 el P'hycol. Lab. L.TIII! Aresch. Enum. p. 86. liuls. sp. Alg. p. 73̈3! (exclus. syn.). 


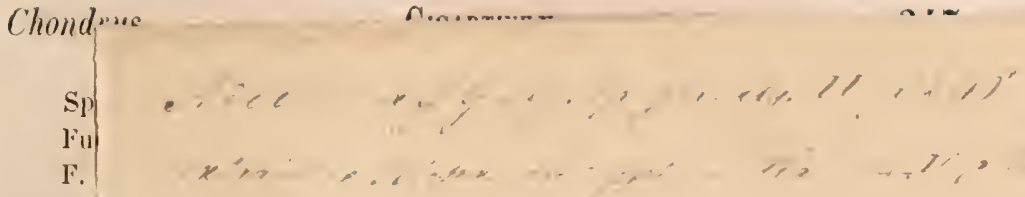

Icon. Ic

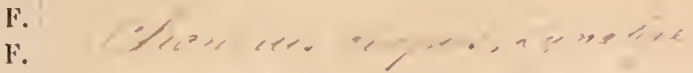

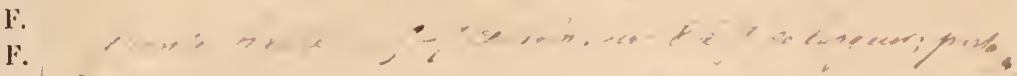

F.

Exis

His

ad llis

Fro.

filiformi

supra b

plerumq

ria aut :

nunc ob

tionibus.

oralia,

satis de

rospora

efficiunt,

gemmidi

Plan

facilius

licet. $\mathrm{U}$

ambitu

joribus,

longitudis

aut mar:

latiores

curvatam

imposuit,

sp. Alg. $p$

p. $2: 3$ ad

De

3. CII. A

fast

stoc

Chron

Ilab.

"Obs

affinis! se

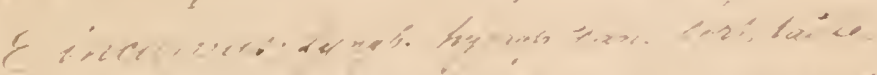

yous

$\therefore 4 \beta \cdots, \cdots$,

$20 e^{\prime}$ 
Jia reticulo illo con-

a compositum ambit, fuvellidiis circulari -llidiorum situ et in

videntir et a pallsori splierosporarum J ipse, in sua P!ılammodo confudit.

rregulariter dichoheutis superioribus immersis ulringue

. in Bot. Zeit. 1847

latkæ et Sachalien

lem sensim dilatane diclolomo-subribus siepe eximie ondi immersa, utrentes.

crispo sine dubio m illam retulerint inmo non perspib altera vero parte speciem perlinere. s ad Ch. crispum ris atlantici nonem frondis siepe

olomo-fistigiatia in una pagina 246, 217! Engl. rev. Aly. Br.p. resch. linum. p. 
Sphar. crispus Ag. sp. p. 2:36 et Syst. p. 21!!! (exclus. variet.).

Fucus polymorphus Lamx. Diss. fig. 1-11; 13-20;23-33!

F. ceranoides Gm. IIist. Juc. p. 113 lab. 7 fig. 1 (excl. syn.) Esp. Icon. lab. 98 f. 1-2?

F. membranifolius Wilh.

F. stellatus Stackh. Ner. tab. 12 !

l. lacerus Stack. Ner. lab. 11.

F. crispatus Fl. Dan. $\ell$. $\$ 26$.

l. filiformis IJuls.

Exsicc. Chauv. Norm. n. 144! Wyalt. Danm. n. 118 et 119.

llab. in oceano atlantico a littore superioris Norvegiat usque ad Ilispaniam; ad littora America borealis; in sinu Codano.

Frondes a disco radicali gregarix, plerumque $3-6$ pollicares, stipite filiformi mox plano et cuneatim dilatato surgentes, pollicari-bi-pollicari supra basin distantia divisæ et dein dichotomo-fastigiatæ, furcationibus plerumque densissimis. Segmenta nunc valde angusta, nuıc latiora linearia aut magis cuneata, suprema aliquando latissima. Apices nunc aculi, nunc obtusi, angusti aut late rotundati. Margines aut nudi, aut prolificationibus lingulatis, demum frondi conformibus, crispi. Cystocarpia fere ovaliá, lineam longa, disco aut prolificationibus immersa, nunc ambitu satis definita, nunc ambitu minus distincta et plerumque minora. Sphærosporæ maculas, favellidia fere æmulantes, in segmentis terminalibus efficiunt, sorum infra stratum externum componentes, cruciatim divisic, gemmidiorum fere magnitudine.

Planta formarum varietate mirifice ludens; vix non semper tamen facilius cognoscenda. Duplicem precipue formarum seriem agnoscere licet. Lna formas angustas lineares apice acutiores, favellidiis minorilus ambitu vix definitis comprehendens; altera latiores planas, farellidiis majoribus, ambitu semper definitis, instructas. Ltraque aut xque per totam longitudinem fastigiata, aut inferne nudiuscula, apice corymbosa; utraque aut margine nuda, aut prolifera. Angustiores formæ purpureo-lividæ; Iatiores sappius violacex. Inter formas angustas, varietas illa, quam incurvalam rocarunt, præcipue eminet; inter latas forma, quæ speciei nomen imposuit, prolifera, prolificationibus fructiferis insignis. Var. $\zeta$. et $\%$ (Ag. sp. Alg. p. 259) ad alias species pertinent. Sphær. crispus Mont. Fl. Botiv. $p$. 23 ad aliam speciem pertinere suspicor.

De usu cfr. König om Geleers använd. $i$ medicinen.

3. Cir. Aminis (Harv. ap. Beechey Voy. p. 408) fronde diclotoma fastigiata canaliculato-plana, segmentis cmeato-linearibus, cystocarpie in utrargue pagina prominentibus subsphericis.

Chondrus atfinis Ilarv. l. c. liü̋s sp. p. 737.

Hab. ad oras Californix (Exp. Beccleyalla; Ill. Diesing!)

"Obscure purpurea, dense caspitosa, 1-2polliciris. Chondro crispo affinis! sed capsulis splsaricis per frondem abundanter sparsis, in utraque 
pagina prominentibus et marginibus inflexis distincta. Quo quidem charactere ad Chondrum canaliculatum accedit."

Ita fere Auctor l. c. Mihi tantum observandum cystocarpia haud semper in Ch. canaliculato esse marginalia, ut habet Harvey. Attamen Ch. affinis et ab hac et a Ch. crispo bene distinguitur, cystocarpiis duplo minoribus, sphericis, in utraque pagina fere æqqualiter promineutibus.

4. Cor. Caxaliculatus (Ag. sp. p. 260) fronde dichotoma fastigiati canaliculato-plana, segmentis linearibus, cystocarpiis iı una pagina proeminentibus emersis.

Sph. canaliculatus Ag. l. c. et Syst. p. 220. Mont. Fl. Boliv. p. 26. Chondrus Canaliculatus Grev; Kï̈l. sp. Alg. p. 736 !

Sph. punctatus Ag. sp. $p .332$.

Hab. in oceano pacifico ad littora Clsilensia (Honke! Mertens! IIb. Binder!).

Formas Ch. crispi fere percurrit, fronde canalicnlata et favellidiis intra pericarpium sulproprium, extra frondem elevatum, inclusis distillguendus. Sph. punctatus nil nisi forma undis jactata et decolorata mihi videtur.

\section{Species inquirende:}

5. Chl. tuberculosus (Hook, fil. et Harv. Crypt. anlarct. p. 76) fronde cartilaginea basi cuncata late lineari furcata v. ter quaterve dichotoma plana v. canaliculata, laciniis patentibus obtusis, axillis rotundatis, verrucis splieroideis parina frondis superiore exstantibus medio depressis demum pertusis massam sporarum rosearum includentibus.

Chondrus tuberculosus Ilook. el Harv. l. c. Kïtz. sp. p. 736 !

Nothogenia tuberculosa Külz. sp. Alg. p. 793 !

IIab. ad insulas Auckland.

Frons 2-uncialis, basi simplex, superne plus minusve furcata, margine simplici pinnulisve ornata. Laciniæ planæ v. pagina superiore canaliculata, patentes v. divaricate, sursum latiores, obtusx. Coccielia v. verruca numerosissima, magnitudine seminis Brassica; globosa, latere concavo frondis sita; exstantia, rarius pagina frondis immersa, basi constricta, apice depressa vel umbilicati, siccitate apothecium Lichenis referentia, demum pertusa. Spora minute. Substantia crassa, carnosocartiliginea, siccitate valde contracta. Color lividus. Chartx laxe adtaret.

Nothogenix variolosie minor sed latior, parcius dichotuma, et fructu valde diverso. Coccidia? in una pagina prominentia, basi constricta, sporis ut in Ch. crispo. Forma fructus fere Iridxa radula; compressus 
Apothecium Collematis rmulat. - Descr. auct. transscripsi. Si revera lıujus generis sit, ad Ch. canaliculatum proxime accedere videtur. liiiziug uno loco inter Cliondros enumerat, alio loco eandem Nothogeniae sul,juugit; loc quoque loco se specimen vidisse dixit. Mili descriplio data fructus potius Chondrum aut Gigartinam spectare videtur.

6. Ca. Divaricatus (Grev, in Aug. St. Hil. Voy. II. p. 448) fronde crassa plana ramosissima dichotoma, margine horizontaliter prolifera, segmentis divaricatis linearibus obtusis. Irülz. $s p$. p. 737 .

llab. ad littus Brasilix (Aıg. St. llilaire).

7. Cır. violaceus (Sond. mscr. in liütz. sp. p. 735) "complanalıs basi stipitatus teretiusculus, inferue remote superne crebre dichotomus, flabelliformis, segmentis inferioribus divaricatis, superioribus patentibus linearibus, axillis proliferis, prolificationibus hine ligulatis, illine flabellato-diclotomis. long. 4-6"; lat. baseos 1/2"', segmentorum ad $1 \frac{1}{2} "$.' Color sordide violaceus, virescens. Substantia cartilaginea duriuscula."

Ilab. ad oras Peruanas oçani pacifici (Hl). Binder).

8. Cil. scutellatus (Külz. sp. p. r36) "phycomate complanato lineari diclıotome ramoso, flabellato, ramis patentibus, apicibas scutellato-spatluulatis. Alt. 2"; ramorum lat. 1/2-1"'. Color obscure purpureus, nigrescens. Sulsstantia coriaceo-cartilaginea firma. Structura distinctissime perenclyymatica. Cystocarpia exserta."

Ilab. ad Cap. b. Spei (Pappe).

Ad hanc speciem Chondrum scutellatum Hering duxit Külzing; mihi a descriptionibus datis judicanti species utriusque diversa videntur. Plantam Heringii ad Gigartinam fastigiatam dubie retuli.

9. Cil. Corlacets (Í̈̈̈lz. sp. Alg. p. 736) "stipite brevi basi tereti subramoso, sursum in plịcoma complanatum carnosim crassum basi cuncatum, regnlariter et pluries diclotomum flabellatum dilatato, segunentis latiuseulis linearibus, superioribus abbreviatis congestis, summis bilidis imbricatis suberispis, simulus plerumque acutis, raro obtusis rotundatis. Substantia firma coriacea calrosa; structural strati corticalis parenchymatica, medullaris epenclıymatico-parenchymatica, cellulis gelineis 
crassis. Color roseus. Cystocarpia immersa, spermatiis minutis (diam. 1/300-1/200"'). (llabitus Pacl!̣carpi dilatati, sed fructu et cellulis medullaribus $2-3$ plo minoribus diversus)."

Hisb. ad Cap. b. Spei (Pappes).

XI. Iridea Bory Voy. Coqu. n. V. (excl. spec.) J. Ag. Act. Holm. 1847 p. 84. Jridex sp. Auct. IIslymenix sp. Ag. el Auct.

Frons gelatinoso-carnosa plana subsimples, stratis duobus contextia; interiore cellulis cylindraceis in reticulum lasissimum mndiqne andastomosantibus; exteriore filis moniliformibus verticalibns, muco solidesceute cohibitis, constante. Favellidia nucleolis pluribus in unum confluentibus, placenta reticulatim ambiente suffultis, composita, medio frondis immersa, solutione partis fertilis liberata. Spherospore in soros frondi immersos rolundatos plurimæ conjuncti, rotundatæ, cruciatim divise. (Külz. Phycol. (ab. 77, 1H).

Frondes in plurimis saltim gregarix ab expansione radicali surgunt, nunc immediatim expanse, nunc stipite breviori aut longiori plus minus canaliculato suffultie, a stipite sensim aut abrmptius in laminam cuneatim abeuntes. Lamina carıoso-crassa, exsiccatione subcartilagginea, madefacta in gelatinam facillime soluta, integra aut irregulariter fissa, numquam vere ramosa aut prolifera, marrgine et disco lavis aut processubus minutis ciliato-aspera.

Stratis duobus conterta sunt. Interius cellulis constat cylindraceis et multangulatis, angulis porrectis cylindraceis cun vicinis anastomosantibus, ommibus reticulum laxissimum in medio land densius formantibus. Stratum externmm filis moniliformibus artieulatis dichotomo-fastigiatis, al, interiore strato rerticaliter exeuntibus, muco solidescente cohibitis, constituitur.

Fructus utriusque generis per lotam frondem in dirersis individuis sp:arsi. Favellidia snnt composita, nempe nucleolis plurilns in nnum conniventibus formata, in media fronde nidulantia ef onnimo immersi, reticulo gemmidias numerosas colibente circumditi, - demum ni fallor circulari solutione strati exterioris denudatia el sporas emittentia. Spharospora in soros farellidia mentientes agspegalie, infra stratum periphericum ufrusque paginie formatx, transformatione articulorum reticnli orle, rotundata, cruciatim divise. 
Bory primus hoc genus distinsit, charactere posito in reticulo laxo frondis interiorem partem constituente. Species autem plants Cigartine, structura conrenientes at fructu paulatim diversas, com genuinis speciebus conjunsit, pluresegue alias Mgis, forma subsimiles, ut dubias Iridieic species emumerarit. Iloc facto Gresille idieam generis ita mutavit ut Fucum cdulem Stachlousei, yuem speciem generis dubiam bory existimaverat, typicam specien proclamaret. Sequentes auctores differentiam Generis Boryani et Grevillei hamb suspicantes, utriusque species in unum conjunserunt. Jpse denique diversitate structurie et fructus diversarum specierum cognita, genus Boryanum restitui, expulsis tantum speciebus Gigartinx, quas lune male retulerat Gallus celebris.

Postels et Ruprecht genus esse membris heterogeneis compositum primi forsan indicarunt. Sed partim summ Iridiex fenus speciebus parum affinibus (Chondri, Gigartine elc.) nimium oneriverant, partim indole fructus utrinsque tunc temproris nondum per'specto, ut rel sphierosporis, juvenilibus aut maturis et disisis, vel farellidiis specimina onusta vidissent, diversas sectiones falsis principiis condiderunt.

Genus Iridex, ut hic constitutum, eximic naturale. Structura et indole fiuctus cum Gigartina prosime conjunctum, fructus situ allquantulum diversm. Cystocarpiis compositis et in medio strilo interiore nidulantibus, Kallymeniam tangit, at ç̣stocarpia utriusque direrso modo formata, spherosporie utriusque generis dirersx, structura frondis alia. - Comparata structura Iridex et Schizymenix, diversit:ns utriusque primo intuitu patet. Sectio transversalis Iridita ob reticulum laxissinum interius, aquam avidissime iubibens, fere statim dissolvitur et utrumque superficiale fragmentum, minus facile solutum, varie contorquitur. In Schimmenia, transversim secta, stratum interius fere medio densius apparet, satis firmum et cohierens, cellulisune constat longioribus minusque ramosis. Crstocarpia utriusutue generis valde diversa. In lridea masna et pluribus nucleolis confluentibus constantia, in medio strato interiore nidulantia, nullo poro aperta, sed ni fillor disrupta parte exteriore demun clabentia. In Selizgmenia farella simplices, infra stratum oxternum utriuspue pagine site et canali per statum esterius pervio aperta, gemmidia intra periderma Iralimm phurima forentes. Spherosporie denique Schizgmenia inter fili superficialia spirsir oblongar, Iridicie rero in soros collecte et rotumbatie. 
1. Irid. olibitosa (Suhr. Beitr. 1840 p. 276) liepatico-purpurascens, fronde latissime obovata aut subreniformi obtusissima levi sessili.

Iridæa orbitosa Suhr. l. c.!! in Flora 1840. I. Külz. sp. p. 726।

Ilab. ad Cap. b. Spei (Ilb. Suhr! Areschoug! Turner!).

Frons a radicali disco immediatim surgens, stipite nullo. Lamina adulta pedalis longitudine, sesquipedem lata, apice præsertim undulatia, luasi latissime cuneita; juvenilis !atissime obovata aut fere orbitosa. Color a purpurascente in hepaticum tendens. Sulstantia crassior quam in $\mathrm{l}$. capensi.

2. Inid. Capexsis (J. Ag. Act. Holm. 1847 p. 85) amethystino-purpurea, fronde cordato-orata obtusiuscula levi evidenter stipitata, slipite brevi subcanaliculato.

Var. «. fronde lata ovata, basi cordata.

Irid. cordata Auclorum (partim! nec Turner).

Var. $\rho$. fronde elongata linceolata in stipitem attenuata.

Ir. cordata elongata Suhr.

Ir. Belangeri Bory ap. Belang. Yoy. p. $160 \mathrm{pl}$. $15 \mathrm{fg}$. 1? Külz. sp. Alg. p. 725.

Ilab. in sinu tabulari et Simonis ad Cap. b. Spei (IIb. Greville! Sulır! Pappe!)

Frondes gregarix, jureniles canaliculato-contortæ elongatæ subspathulata, adultiores a stipite brevi, pollicari aut breviori, cuneatim expansio sublanceolati, pedales et $1 \frac{1}{2}-2$ pollices latio; sensim inferne latitudine crescentes, stipes brevior fit et laminæ ipsius basis in lobos ita producitur ut frons eximie cordato-ovata evadat. Discus laminæ lævis aut prominentibus fructilus subverrucosus; margo integerrimus laxe undulatus. Color a violaceo aut amethystino purpureus, in lividum aliquando tendens, variegatus. Substantia crassa.

In collectionilus plurimis hane speciem pro Ir. cordata Turn. determinatam vidi. Sulır utramque formam bene in unam speciem conjunxit. Bory formam elongato-lanceolatam, ni fallor, ut propriam speciem descripsit; alteram formam, nunc nomine Ir. cordate, nunc Ir. radula determinarit.

3. IR. Miмor (J. Ag. Act. Holm. Öfoers. 1849 p. 86) froude ovalooblouga simpliciuscula lacvi in stipitem evidentem planiusculun abruptius attenuata.

Ilab. in oceano pacifico septentrionali ad Californiam (Douglas!).

frondes inter midlreporas crescentes gregaria, 2-3pollicares, pollicem latitudine xquantes aul parum superantes, stipite clongato fere pol- 
licari planiusculo surgentes, dein al)ruptius cuneatim expansæ in laminam fere ovatam aut oblongam, in nostris integerrimam, lievem aut fructilıs prominentibus rerrucosam, apice rotundato-obtusissimam. Color ex livirlo fuscescens. Sulıstantia gelatinosa, exsiccata cartilaginea. - Juveniles frondes (3-4 lineas longæe) sunt leviter canaliculatie, magis obovate, apice sulorecurvo.

Species sine dubio distincta, licet xgre definienda. Cxteris minor, tamen matura, ut ex fructibus patet. Stipes ut in Jr. Laminarioide evidens, sed planior. Lamina non ita sensim in stipitem attenuata ac in Ir. Lalminarioide. Forma denique alia. Jureniles frondes Ir. Laminarioides sunt omnino cucullatie, acumine eridenti superata; in prosenti sunt vix canaliculatæ. Ex loco natali hanc speciem potius l. Cornucopix Post. et Rupr. sistere forsañ quis crederet; sed ex tota descriptione patet, Iridxam Cornucopix esse Ir. Laminarioidi proximam et ni fallor identicam.

4. Ir. Lanisaromes (Bory Voy. Coqu. p. 105) fronde obovatolineari, simpliciuscula aut in lacinias fissa, levi, in stipitem cridentem elongatum canaliculatum longe attenuata.

Jridea Laminarioides Bory l. c. lab. 11 fig. 11 Mont. Voy. D'Orbign. p. 24! Bonite p. 63! Pol. Sud. p. 103 ! hülz. sp. p. 726.

Irid. Cornucopix Post. el Rupr. Illustr. p. 18 lab. 38 fig. b!

Var. «. Cornucopice fronde obovata subcucullata.

Irid. Laminarioides juvenilis Bory l. c. fig. A. B. C.!!

Var. $\beta$. Laminarioides fronde elongata, sæpe laciniata, laciniis lanceolato-linearibus.

Irid. Laminarioides adulta Bory l. c. fig. D!

Hab. in oceano pacifico australi ad littus Chilense (D'Crville! Mus. Parisiense! IIb. Binder!) et in boreali ad confines Imperii Rossici; in occano australi ad Insulas Aucliland.

Frondes al expansione radicali gregariæ, juveniles canaliculato-subspathulatio apice in acumen brevissimum producto; adultiores stipite canaliculato 1-2pollicari surgentes, integræ obovatæ, fissæ lacinias offerunt magis lanceolato-lineares, nunc breviores, nunc fere ad basem laminit progredientes, erectiusculas aut subpatentes, margine integerrima minute undulatas, in acumen plerumque distinguendum productas. Color a violaceo-purpurascente in lividum tendens. Substantia Ir. Capensis.

Stipite evidentiori el magis elongato atgue canaliculato, frondis forma atque tendentia in lacinias dilacerari, hæc species præcijue dignoscatur. küitzing in Phycologia hanc speciem cum Ir. Cordata Turneri ut varietatem conjunxit; in Speciebus Algarum utramque distinxit. Ipse plantam Turneri reram uon vidi; Specimina Ir. Laminarioidis, in Iconem Turneri quadrantia, nulla mihi obvenerunt, quare utramque speciem distingnero malui. Cælerum speciem aliter quam ipse Bory forsan limitavi. IIic colore potissimum insistens, fragmenta retusta Ir. micantis ad Ir. Lamina- 
rioden retulisse videtır, quum margines ciliatas his tribuit, quod in nostris nou observasi. Deseriptio Ir. Comncopice ita in nostram cadit, ut de iulentitate vix dubitandum. A verbis auctorum ruoute elucet ipsos species affines Boryanas non cognovisse,

5. Ir. Condita (Turn. Ilist. II n. 1/6) Ironde cordato-ovata sulbacuminata levi, in stipitem brevissimum canaliculatum abruptius attenuata.

Fucus cordatus Turn. Hist. iab. 116 !

? Irid. Lilacina Post. el Rupr. p. 171. Küts. sp. Alg. p. 226.

Hab. ad Insulas Banlis justa littus occidentale America Septentrionalis (Menzies).

Frondes ex eadem basi plurimæ, ortu angustæ et compressæ, exinde se sensim, lenissime tamen, ad trium quatuorve linearum altitudinem dilatantes, ut stipitem simulent, ibi subito explanate in folium unicum simplex planum, pedem circiter longum et semipedem Iatum, formæennrmiter cordatie vel cordato-ellipticæ, apice acutiusculum, margine integerrimum et leniter undulatum: - in illa inferiore frondis parte ubi angustior est, margines insigniter sunt elevati et incurvi. Color livido-fuscus non sine purpurascentia quadam, diaphanus, exsiccatæ multo intensior ut fere nigrescat.

Descriptionem verbis ipsis Turneri dedi, ne ulterioris confusionis detur ansa. Jam locus natalis indicat hane speciem a Capensi, cum qua sxpius confusam vidi, esse diversam. Ceterum nullo inspecto specimine authentico judicium de hac specie ferre non audeo. Si ex tigura a Turmero data quid conjicere liceat, species Turneri Ir. micanti forsan proxima sit; qunm vero de margine ciliato-aspero non loquitur, utramque conjungere nondum ausus sum.

6. Ir. Micass (Bory Voy. Coqu. n. 16) fronde cordato-ovali rotundato-obtusissima breviter stipitata, disco levi, marguinibus minutissime ciliato-asperis.

Ir. micans Bory Fl. Mal. n. 25 el Voy. Coqu. l. c. lab. 43 et 13bis! Mont. Bon. p. 62. Pol. Sud. p. 104! Hook. et Ilarv. in. Lond. Journ. IT. p. 26.3. Tasm. n. 68. hülz. sp. Alg. p. T26?

Iridaea cordata (partim) var. $\beta$. Hool. et Harv. Crypt. Ant. p. 1791 Iridxa ciliata Küts. sp. Alg. $p .726$ !

1Iab. ad insulas Malouinas (I)'Urville) et Cap Horn (Hooker); ad Valparaiso (Poepliog! IIb. Binder!); ad insulas Auckland (D'l Iville).

frons 1-2pedalis, basi cordata, caterum ambitu oralis obtusissima, stipite evidenti (plano?) adfixa. Ubicumque lasa (foraminibus aut laciniis) margines incrassate ciliis brevissinis simplicibus ant substellatim ramosis mox ormantur. Colores sec. Bory magnopere iridescentes. 
Bory fragmentis Ir. Laminarioidis quoque margines ciliatos triluit, quorl errore quodam factum fuisse suspicor. Tendentian cilia emittendi plane nullam in speciminibus illius speciei numerosis observavi. In fragmentis vero, que ad I. Nicantem pertinentia credidi, margines omnes numquam non ciliato-asperos vidi. Hoc sane huic speciei ommino characteristicum puto. Hooker et llarvey in Crypt. antarctica aliam omnino de limitibus hujus speciei opinionem prolitentur, quum Ir. Capensem, Ir. micantem, Ir. cordatan et Ir. Laminarioidem (var. $\gamma$. dichotomam) conjungere propensi videntur.

7. IR. Augustixe (Bory Coqu. n. 15) fronde cordato-subreniformi undulato-plicata ohtusissima, disco marginilussue ciliato-asperis, stipite evidenti camaliculato.

Ir. Augustina Bory l. c. pl. 12!! Küls. sp. Alg. p. 726.

Ir. crispata Bory Dicl. Ct.

Ir. undulosa Bory Fl. Mal. n. 26.

IIab. in mari australi ad Insulas Malouinas (I.esson); ad littora Chilensia (D’Urville! Hb. Binder!).

Frondes a disco radicali gregarie, 3-6pollicares, stipite pollicari canaliculato suffultæ, cordato-subreniformes, latiores quam longæ, margine undulato plicatx et immo sinuosæ, aliquando margine incrassato cinctæ et ciliato-asperæ, cilis minutissimis simplicibus. Superficies frondis pracipue basem rersus processubus minutis ispera. Substantia priorum at fere tentior. Color ex violaceo lividus.

Planta, quam Bory ut Irid. Augustinx formam juvenilem descripsit et pinxit I. c. fig. E, est nullomodo juvenilis, sed contra planta vetusta in lacinias fissa et fructibus ornati, ut ex specimine a I)'Uivilleo dato comperi. Riitzing duobus locis Iridxam Augustine Boryanam enumerat; inter Porphyras! (Sp. Alg. pag. 693), et inter Iridæas loco supra citato.

\section{Species inquirende.}

\section{* Iridece forsan genuince.}

8. Irid. Pustulosi (Post. el Rupr. Illustr. p. 18) "lamina crassa gelatinoso-glutinosa, in sicco membranacea, breviter pediccllista, late cordata, margine integerrima, sinuata vel appendiculatofimbriata purpurea; soris undique dispersis, pallide rubris, margine elevatis, centro depressis, persistentibus.

Iridxa pustulosa Posl. el Rupr. l. c. Lab. XXXII! Külz. sp. p. 727.

Hab. ad littora liamtschatica.

Specimina adulta pedem et ultra lata, nec minus longa, hinc inde lacunoso-perforati. Substantia in sicco tenuis membranacea, lumecta- 
tione in gelatinam crassam facile dilacerendam inlumescit. Sori diametro semilineales. Chartx adhæret."

9. Ir. heterocahpa (Post. et Rupr. Illustr. p. 18) "lamina firma, subcoriacea, (sicca) fusco-violacea, olbiculata, sintato-lobata, lobis obovato-rotunditis, margine sinuatis vel crenato-lobulatis; soris undique dispersis, diametro semilinealibıs, nodulos adproximatos, rotındos vel ovales, demım elevatos, determinalos, rubro-fuscos, epidermide rimoso excidnos efformantibus." Кӥtz. $s p . p$. Ћפт.

Hab. in oceano pacifico sep̣tentrionali.

10. IR. овоулта (Kütz. sp. p. т28) "plyyllomate latissime obovato, basi cito attentato, in stipitem brevem teretiusculum producto; cystocarpiis remote sparsis. Substantia membrauncea eartilaginea. Color purpureus. Structura perenclı̣matica."

llab. ad Cap. Horn (Ilooker).

11. Ir. Dextata (kï̈tz. sp. p. 728) "phyllomate bi- aut pluries partito, segmentis latis palınatifidis aut laciniatis, hasi cordatis vel cuneatis, laciniis margine inequaliter et acute dentalis. Color obscure violaceo-purpureus. Substantia coriacea, firma, cartilaģinea. Cystocarpia immersa pustulæformia. Long. 3-6"; lat. laciuiarum 1/2-3". Structura perencliymatica.

$\beta$. minor phyllomate basi cuneato, pluries dichotome lobato, lobis apice sinubusque rolundatis, obsolete denticulatis aut integerrimis."

flah. ad Insulas Falliland (Ilooker).

12. IR. діспотоми (llook. et llarv. Lond. Journ. 1845 p. 262) stipite brevi cartilagineo mos cuncalo furcato rel plurics dichotomo sensin in phylloma membranaceum ample cuncatum vel obovatum desinente, segmentis vel simplicissimis integris vel furcatis vel dichotomis, ad marginem denticulatis vel grosse dentatis, vel lobatis, vel nova plyyllomata cmittentibus. Substantia tenuis nitens lubrica demum eystocarpiis immersis numerosissimis verrucosa. Kütz. sp. p. 728.

Hab. ad insulas Falkland.

Dubitant Auctores an a Iriud. micanti revera diversa sit. - In Cryptogamia antarctica hace species omissa videtur. 
* Species ad Gigartinam forsan transferende.

13. Ir. PIItlocarpd (Post. et Rupr. Illust. Alg. p. 18) "lamina filma clartaceo-pergamena, supra stipitem 2-3linealem dilatati, sinuata, appendiculata, appendiculis suborbieulatis, margine integerrimis undulatisve, basi insigniter attennatis et tortis, siccis pallide fuscesentibus; soris appendiculo immersis, diametro semilinealibus, nodnlos dispersos, rotundos, elevatos, centro depressos, determinatos, fuscos, pertistentes efformantibus." liütz. sp. p. 727.

IIab, ad littora liamtschatica.

14. Ir. DECIPIENS (Hook. et Harv. Lond. Journ. 184.3 p. 547) pusilla; plyyllomate cartilagineo stipitato flabelliformi plano diclotomo, laciniis cuneatis pluries fureatis ultimis anoustatis lincaribus acutis, axillis rotundatis, margine nunc simplici nunc ramenta linearia simplieia pinnatim emittente, fructibus nune maculieformibus numerosis per totam laminam sparsis ellipticis oblongisve, nunc in verrucis umbilicatis ad apices ramentorum sessilibus immersis. Kï̈lz. sp. p. 728.

Hab. ad Novam Zelandiam (Raoul).

\% Species ad Schizymeniam forsan réferenda.

15. 1R. PUXices (Post. et Rupr. Illustr. p. 18) lamina chartacea ambitu orbiculata, margine vel umbilico affixa, plicata, linc inde perforata, margine integerrima vel eroso-dentata, intense punicea, ambitu fructificante siepe expallicla vel flavo-virescente. Kӥ̈z. sp. p. $\% 27$.

IIab. ad insulam Sitclı.

16. Ir. affins (Post. et Rupr. Illustr. p. 18) lamina crassa, plana, obovato-oblonga, irregulariter lobato-incisa vel fissa; segmentis puniceis, ubique minntissime pellucido-punctatis, iniequalibus, apice obtusis, rotundatis, margine integerrimis vel undulatosimnosis. hülz. sp. p. 728.

Ilab. ad littora kímtsclıatica.

Ilabitu plane eadem ac Iridea edulis, structura tamen interna disersissima. - Irid. punicea et Ir. pinnata ejusdem structure ac Ir. affiuis, et quamris habitu multum inter se diversx sint, forte specie non differunt, 
Frmas transitorias tamen observandi nondun hucusque occasio oblata fuit. - Ita Auct. 1. c.

17. IR. PINitra (Post. el Rupr. Illustr. p. 18) "lamina chartacea, incrassata, lineari, regulariter bi-tri-pinnata, purpurea; pimis pinnulisque linearibus, divaricatis, his angustatis, margine integerrimis vel ciliato-pinnatis. Külz. sp. p. 728.

llab. in sinu Yorfolk ad littora Americe boreali-occidentalis.

Habitu multo magis accedit ad Rhodomeniam jubatam quam ad Iridæam; radice tamen, maculis cellularibus deficientibus et præsentia filorum centralium sul, analysi facile separanda. Radix: discus parvus fronlibus interdum duabus originem prabens semipedalibus et minoriluus. Lamina primordialis linearis, 1--2pollices longa, rarius ultra lineam lata, basi in stipiiem distinctun teretem, fere bilinealem abiens, superne margine utroque regulariter et dense pinnis primariis obsita, quarum inferiores siepe hebetatx, ad denticulos vel appendiculas redactæ. Pinnx primarix superiores lineares, sape 3pollices et ultra longie, duas circiter lineas latx, margine utroque iterum pinnis secundariis homomorphis, sed duplo vel triplo angustioribus obsessie, basi angustatis et margine aut integerrimis aut eiliato-pinnatis; linc inde pinnx pellucido-puncattæ adparent. Sori in spec. suppetentibus nulli. Substantia crassa, plantic exsiccatæ chartaceo-coriacea. Color purpurascens hinc inde expallidus. Charte non adluæret."

18. Ir. Eldiptica (Kütz. Phyc. gen. p. 390) "sanguninea lubrica subdiaphana, phyllomate brevissime stipitato, elliptico-oblongo, hasi ot apice rotundato, marosine integerrimo. Long. $-6 "$; lat. 2-4". Stipes vix 1'" longus. Siccitate chartic adhæret." Külz. sp. Alg. p. 725 .

IIab. in mari mediterranco.

19. IR. petcura (Külz. Bot. Zeil. 1847 p. 24) pliyllomate pulchre coccineo, pergameno, reliculatim ruguloso, olovato, basi cuneato; cystocarpiis papillerformibus, medio retusis, fase sparsis, xqualiter distantibus. (Cellulie interiores amylidee anģlophlore majores). Кӥlz. sp. p. г2̈̈.

llab. ad Kamtschatliam.

20. Ir. Gigivea (Külz. sp. p. 726) "pallide sanguinea; phyllomate chartaceo-subpergameno, diaplano, subovato, integerimo, pedem longo, 4-6" lato. Structura perenclymatica, laıe librosa."

Ilab. in mari allantico (Nus. Berolinense). 
21. Ir. Temasts (Mlont. Pug. Alg. Yem. n. 19) "fronde (mediocri) membranacea, gelatinoso-cartilaginea, informi, ambitu angulato ciliata, basi in stipitem hrevissimum attenuati, tetrasporis cruriatim divisis."

Ilab. in mari rubro ad oras Arabix.

\section{: Species forsan ad Grateloupiam revocanda.}

22. IR. vior.ıces (Kütz. Phyc. gen. p. 396) "plỵllomate irregulariter lanceolato, inæqualiter sinuoso-subdentato, violaceo.

$\beta$. prolifera; phyllomate latiusculo curvato dense obsesso prolificationilus foliaceis marginalibus, rarius discoideis." $S p$. Alg. $p$. 726 .

Ilab. ad oras Peruanas (Ilampe).

De hac conferatur Gir. Cutleriæ, supra pag. 184.

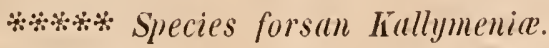

23. Ir. tacera (Post. et Rupr. Illustr. Alg. p. 17) "lamina tenui, membranaceo-chartacea, reniformi, deorsum in stipitem $\mathbf{Q}-3$ linealem abiente, laciniati, erosa et perforati, sicca badia et line inde sanguineo suffusa; soris imprimis ad apicem laciniarum evolutis, sparsis, minutis, fuscis, elevatis, convexis, determinatis, lamina perforata exciduis." Kü̈z. sp. p. т๑̈̈.

Ilab. in oceano pacifico septentrionali.

Laciniæ frondis semipedales, foramina rotunda rel ovalia, in diametro 1-4 lincalia."

*6\% Species quoad a/finilatem ominino obscura.

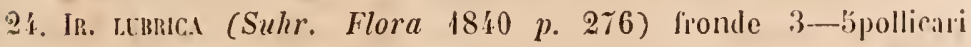
irregulariter rotunda sublobata undulata, gelatinosa, roseoflarescente, sporis sparsis et in soros aggregatis.

Ilab. ad oras Nove Ilollandix.

Suhr tum (in Algis. Ecklon. n. 49) Halymeniam lubricam c Cap. l). Spei, tum (in Flora $1840 \quad p$. 276) Iridicam lubricam e Nura Ilollandia descripsit. Lüutzing $\left(S_{p} . A l y, p\right.$. T28) plantam in Ilerhario Binderi visan, ex Africa meridionali oriundam, nomine Iridxa lubrica detinivil, ad quan IIalym. lubricam Suhr Flora 1840 p. 276 ut synonymon duxit. IIoc vero loco non IIalymenia lubrica e Cap. b. Spei, sed Irid. lubrica e Nova IIollandia descripta exstat. 
20. Ir. socuass (Post. et Rupr. Illustr. Alg. p. 18) "lamina olivaceo-viridi, gelatinoso-membranaces, exsiccalione coriacea, plana, late cuneata et basi in stipitem cylindricum attemuata, plerumque bipartita, margine integerrima; segmentis integris vel iterum bipartitis. Kü̈tz. sp. p. 728 .

Ilab. in oceano pacifico septentrionali.

Iridææ nullie descriptie arcte cognata, structura tamen ad Iridam affinem vergit. Radix: discus crassus 2-4 linearum in diametro, frondes numerosas et varias alias algas immixtas sustentat. Lamina in Spec. multis suppetentilus superne læsa, 4-pollicaris et minor. Stipes manifestus, teres, 1-2 lineas et ultra longus, sensim complanatus et plerumque dichotomus, partitionibus in laminas cuneatas abeuntibus, integras vel fissus, aut vario modo læsas. Color olivaceo-riridis, plantxe exsiccatie fuscescens. Specimina humefactil gelatinosa, facillime dilaceranda, superficie numerosis bullulis olsessa; exsiccata autem fiunt rigida, fragilia, chartaceo-coriacea et imperfecte tantum chartx adharent."

Quoad affinitatem mihi omnino obscura, vix Floridea.

26. Irib.? Reticlata (Mont. Alg. Yemens. n. 20) fronde e basi attenuata stipitata sursum dibatata maroine lobata, lobis sium rolundo divisis, purpureo viridique variegata, superficie tenuissime reticulato-rugulosa; fructu. . . .

llab. in mari rubro ad oras Arabix.

XLi. Gigartina J. Ag. Alg. med. p. 103 el Alg. Liebm. in Act. Holm. Ofvers. 1847 p. 10. Endl. Gen. Plant. Suppl. III. p. 4 (excl. specieb.) Ilarv. Pliyc. Brit. sub tab. CIV; Gigartina, Iridxe, Gracilarix, Gelidii, Chondri, lihodomenia- et Sphrerococci sp. Auct. Cliondrodictson, Mastocarpus, Sarcotlialia, Cliondracantlus (Clondroclonium) el Gigartinx sp. Kütz.

Frons gelatinoso-carnosa plana aut eylindracea varie ramosa, stratis duobus contesta; interiore cellulis cylindraceis, in reticulum laxissimum undigue anastomosantibus; exteriore, filis moniliformibus verticalibus, muco solidescente colibitis, constante. Favellidia nucleolis pluribus in unum confluentibus, placentia reticulatim ambiente suffultis, composita, intra pericarpium externum, demum carpostonio pertusum, excepta. Spharospore in soros sulprominentes, infra stratum superficiale nidulantes, plurime collecte, rotundate, cruciatim divise. (Kütz. I'lyycol. tab. 70, I; 75, II; 76, III.) 
Frondes aut ommino teretes, aut compressa, aut oumino plane sed basem versus plus minus evidenter canaliculatie, semper calnosie, statu recenti duriusculie, exsiccatione plerumque cartilaginea, iterum madefactic aquam avidissime imbibentes, in gelatinam solvuntur; ramificatione fere ad duplicem typum formatie, alie nimirum diclıotome, alix pinnatx. Pimnate sunt lineares atyue pinmulas offerunt ultintis acuminatas, simpliciusculas, demun capsuligeras. Dichotomic sunt plerumque inferne teretiusculie et ramosie, dein plus minus candiculate et ramis singulis in expansionem foliacean sinplicem ant dichotomam explanitie; nounulle dichotome per totam Iongitudirem canaliculitic et conformes. Nonnullæ, qui steriles dichotome, cum pinnatis in eo conveniunt quod fructifere pinnulas cmittunt capsuligeras. Capsulæ in dichotomis aut ad frondem sessiles, aut papillis propriis a limina emergentibus adnatæ.

Stratis duobus contexte sunt; interius cellulis multangulis in reticulum laxius anastomosantibus constat; cellulæ in juvenili planta et partibus superioribus anguste et cylindracex, sensim ampliores evadunt et stratum peculiare, cellulis rotundatis contextum, mentiuntur. Stratum externum cellulis rotundatis minutissimis, in filat moniliformia ab interiore verticaliter excurrentia conjunctis, constat.

Fructus duplex. Favellidia nucleolis pluribus, placenta reticuJatim intertesta suffultis, in nucleun compositum filorum anbientium plexu reticulato colibitum confluentibus, constantia, intra pericarpium externum, cellulis frondis interioribus exterioribusque conflutum, apice denique poro (sæpe obliquo) pertusum conservilta; gemmidia plurima angulato-rolundata, forentia. Sphærospore in soros rofundatos, favellidia mentientes, extus subprominentes, plurimx conjuncte, a cellulis inferioribus strati exterioris formalie, rotundatie et demum cruciatim divise.

Genus Gigartinx primus quidem creavit Lamouroux, sed lic velut sequentes auctores, qui illud adoptaverant, in forma frondis cateriore teretiuscula claracteres generis querentes, plantas diversissimas sub nomine Cigartinac conjunxertint. In Nyis Britannicis Grevillei tentamen melioris constructionis generis quidem factum fuit, distincto genere Gracilarie; sed utroq̨ue genere manco elsaractere condito et utrodgue speciebus laad Iegitimis uimimm onusto, utrumque jam ab initio vaccillavit, dum deniquese in flora llooleriana, consentiente Mgologo Scotin, ambo genera iterum conjuncta fuerunt. In $\mathrm{Alg}$. Mediterrancis genus novo fundamento condere 
molitus sum, et dein in posteriore opusculo limites generis legitimos ducere tentavi.

Genus vero ita constitutum in plura rursus dissolvit kiützing; sed nec ab ipso ullos nova genera distiıguentes characteres propositos video, nec milhi ullos invenire hueusque contivit. Structurie enim differentix, quæ adsunt, ab xtate potissimum pendere mili vise sunt; claracter vero cystocarpiorum, quæ in Clondracantloo clausa, in Gigartina carpostomio aperta nuncupat, ita certe est corrigendus ut in utroque pericarpia initio clausa, demun carpostomio rupto aperta sint. Analyses diversarum specierum dedit pro moro admirabiles, et splıærosporas primus, ni fallor, rite descripsit. Endlicherus genus nostrum adoptavit, sed species nonnullas haud legitimas introdusit. Ilarvey quoque nostrum genus amplecti videtur. Montagneus in Fl. Algeria nostra vestigia demum secutus, splıærosporas triangule divisas generi male tribuit.

Genus, quale illud intelligo, eximie sane naturale, a Gracilaria longe diversum, structura cum Iridæa (Bory), Clıondro, Rissoclla, Polsope et Grateloupia fere conveniens; pericarpio externo apiceque aperto ab Iridiea et Clondro dignoscendum; farellidiis compositis et soris splærosporarum a Polyope et Grateloupia nullo negotio distinctum, sphærosporis quoque et intima farellidii structura a

- Rissoella diversum.

Diutius quidem cognilum fuit, fructus in nonnullis speciebus esse diverso modo sitos, nune frondi nunc pippillis nimirum inclusos. Ltrumque fructum esse cjusdem generis, nimirum favellidia, diu credebatur (Conf. IIarv. Alg. Nov. Zel. in Hook. Journ. Bot. IV. $p . \ddot{477}$ de Irid. stiriata et I. radula). Ilookerus et IIarvey, (Crypt. Antarct. p. 77 ) rem primi illustrarunt, ficuctus frondi immersos, non favellidia, sed sorum splıærosporarum sistere indicantes. Kützing loc quorge bene intellexit et depinsit, licet aliquando (de) Chondrodictyo verba faciens), apparentia deceptus, sorum splacrosporarmm ut favellidium descripserit.

Species generis naturali nexu colwrent; substantia frre firmiore aliquantulum abludit G. mamillosá, structura tamen conveniens. P'ericarpia illius semper clansa vidi, nec splherosporals observari. Ogue ulterius observanda animadvertere debni. 
I. Fronde teretiuscula aul compresso-plana subline ari, ad ramos pinnase plus minus acuminalas cystocarpia submarginalia gerente.

* Fronde tereliuscula quoquozersum ramosa.

1. G. X.s. (Ag. sp. Alg. I p. 289) fronde nana tereliusculi, quoquoversum decomposito-ramosa, ramis ramulisque abbreviatis crassis patentissimis obtuse acuminatis; fructibus. . . . .

Sphrococcus nanus Ag. l. c. el Syst. p. 228!! liülz. sp. p. 778!

llab. in conchis ad oras lirasilix (Tilesius!)

Frondes minuter vix semipollicem longitudine superantes, penua passerina tenuiores, pyramidato-ramosissima, ramis quoquoversum egredientibus patentissimis, inferioribus longioribus ramulosis, superioribus sensim brevioribus; ramis supremis indivisis, ramulisque minoribus a hasi latiore sensim attenuatis, obtusius acuminatis. Color exsiccatie purpureo-nigrescens. Substantia cartilaginea.

Fructus non vidi. Structura vero cum Gigartina ita convenit, ut huic generi illam adnumerare debeam.

2. G. acicularis (IFulf. Crypt. aqu. n. 50 ) fronde cylindracea quoquoversum decomposito-ramosa, ramis elongatis patenlissimis recurvatis subulatis, cyslocarpiis ad medium ramulorum muilateralibus sessilibus.

Fucus acicularis Wulf. l. c. Turn. IIist. lab. 126 (cxcl. rar.)! Engl. Bol. tab. 2190 .

Gig. acicularis Lam. Ess.; Grev. Alg. Br, p. 147 lab. 16! IIarv. Man. p. is el Phycol. lab. CIV! Honl. Fl. Aly. p. 100! hülz. Sp. Alg. p. 749!

Sph. acicularis Ag. Sp. p. 322 el Sysl. p. 237!!

F. plicatus Clem. Ens. p. 319.

F. spinosus Gouan.

Hab. ad rupes veliementiori fluxu expositas infra limifem maris; in Adriatico et Mediterranco freyuenter; in oceano Allantico a Britannia usque ad Gides; in oceano Indico et dustrali (fide Ilarvey.)

Cæspites intricati supra rupes expansi gregarii, a radice scutata et demum tibrosa repentes et erectiusculi. Frondes penuam columbinam crassi, 2-4pollicares, adscendentes, irregulariter dichotomx aut sippius pinnatim ranosa, ranis basi subaltenuatis, dein cylindraceis, apice longe acuminatis, majoribus apice longe producto recurvatis, inferioribus longioribus decompositis; superioribus ramulisque simpliciusculis, eximie subulatis, plurimis sxpe secundis. Cystocarpia unilateraliter in ramulorum media parte sessilia, plerumque in ranulo solitaria, apice sterili reflexo. 
Splixiosporæ in soros collectr, qui plerumque ramulorum inferiorem partem unilateraliter incrassatam reddunt. Substantia firma coriacea, unde rharta vix adhæret; madefacta facilius dissolvitur. Color recentis purpureus aut atrovirescens.

Hooker et Harvey varietatem pinnatam hujus speciei, ex Tasmania oriundam, memorant, ruam ipsi speciem dirersam suspicantur.

\section{Fronde leretiuscula aut compressa, dichotomo-flabellala} ramulisque distichis subpinnatim olsita.

3. G. Pistillata (Gm. Hist. Fuc. p. 159) fronde teretinscula diclootoma-fastigiata flabellata, ramulisque distichis pinnata, segmentis pinnisque subacuminatis, eystocarpiis in pinnulis subterminalibus, soris in segmentis superioribus plurimis demum in lineas elongatas subconfluentibus.

Fucus pistillatus Gm. l. c. lab. 18 fig. 1! Lamour. Diss. p. $\ddot{1}$ tab. XXVII el XXVIII!

Gigartina pistillata Lam. Ess.!! Grev. Alg. Bril.p. 146. Harv. Man. p. 75. Mont. Fi. Alg. p. 99! Yoy. Pol. Sud. p. 119? Külz. sp. Alg. p. 749 !

Fucus gigartinus L.; Turn. Hist. tab. 28! Engl. Bot. Lab. 908; Good. el Woodiv. in Linn. Tr. 3 p. 183 tab. 17 f. 3 el 4.

Splixrococcus gigartinus Ag. sp. Alg. p. 274 el Sysl. p. 224!

Cer. gigartinum liolh. Cat III. p. 109!

Fucus Oederi Esp. $\ell .135$.

Hab. in rupibus maris allantici demersis a Britannia australiori usque ad Tingin! ad insulas Aucliand (sec. Montagne).

Frons pennam corvinam crassitic equans, 6-8pollicaris, a radice scutata surgens erecta, subregulariter dichotoma fastigiata et subflabellati, apicibus patentibus. Sterilis hoc fere statu manet; planta vero fructificans, in inferiore parte nudiuscula, in superiore emittit pinnas numerosas patentissimas, lineas paucas aut fere semipollicem longas, subsecundas vel listichas, subulatas aut cystocarpio terminatas, simplices aut nova serie plerumgue secundis pectinatas. Cystocarpia infra apicem pinuarum pinnularumve sessilia, mucrone brevissimo fere inconspicuo superata aut terminalia, in pinna singula aut plura. Sori spharosporarum sulprominentes, in superioribus segmentis crolutæ plurima, initio maculirformes distantes, demum in lineas longas confluentes. Color obscure purpureus; Sulstantia cartilaginea. - Peremnis, lieme fructifera.

lar. pectinala fronde compressa pinnis densioribus pectinata.

Gigartina pectiuata Bory!

Chondroclonium horridum Kü̈z. sp. $p$. 740 !

llab, ad oras llispaniæ (llb. Webb!) 
Specimen quod coram oculis habeo unicum, aspectum offert quodanmodo alienum, inter G. pistillatam et G. Teedii fere intermedium. Ramificatione et consistentia cornea cum priori convenit; pinuis densioribus alteram amulatur.

Quantumcumque diversæ sint formæ typicæ G. pistillatæ et G. Teedii, tamen formas intermedias ohventre dicere fas est, qux utrum ad hauc an illam pertineant, lraud facile dicitur. Equidem specimina mediterranea, in Speciebus Algarum Agardhi sub G. pistillata memorata, potius ad G. Teedii referenda existimo.

Sph. gigartinus var. costatus (Suhr. Alg. Eckl. p. 9) est forma valde dubia, mihi ignota.

4. G. flabeldata (J. Ag. mscr.) frondo teretiuscula dichotomofastigiata, flabellata ramulisque pinnation dispositis subcorymbosa, segmentis pimnulisque obtusis, cystocarpiis in pinnulis corymborum lateralibus, soris in segmentis ultimis utringue sublineariter expansis abbreviatis oppositis.

\section{Ilab. ad Port Pliilippe Australix (dedit Malm!).}

Frons 4-6pollicaris, pennam fere corvinam inferne crassa, sursum sensim tenuior, apicibus obtusis pennam columbinam fere iequantibus; Sterilis dichotoma fastigiata, segmentis patentibus flabellatim expansis; Sporifera superue subcompressa et densius dichotoma pinnisve conformibus paucis obsita: in segmentis ultimis penultimisve sori utrinque singuli et plerumque oppositi, sublineares, lineam longitudine vix expansi: colore purpurascente in fronde carnea conspicui; gemmidiifera denique frons pinnas emittit superne plurimas, frondem dense corymbosam reddentes, pinnatim in rachide dispositas, decomposito-dichotomas, teretiusculas: Cystocarpia in his, lateralia (in nostris non bene evoluta). Color carneo-lutescens. Substantia exsiccatæ cartilaginea; madefacta facile dissolvitur. - Structura generis.

Ramificatione hæc species cum G. pistillata potissimum convenit, colore et ramis olstusioribus habitu sat diversa, choracteribus cxterum in dispositione fructuum precipue quacrendis. Giv. pistillata Monl. Voy. Pol. Sud. p. 119, ex insulis Auckland, forssn ad hanc speciem pertineat.

5. G. Contonta (Bory Voy. Coqu. n. 4.8) fronde compressa dichotoma, segrmentis ramulisque lateralibus subdistiche a margine cxeuntibus apice densioribus subfasciculatis decompositis, ramellis a basi lata acuminatis quoquoversum patentilus, fruclibus.

Gigartina contorta Bory l. c.!!

Hab. in liltore Chilensi ad Conception (b'Urville!).

Frons a radice fibrosa 2-3pollicaris, compressa, inferne distanter 2 -3chotoma, superne segmentis densis fasciculata. Segmenta in idem 
planum revera expansa, sed torta et aggregata quorquorersum spectantia videntur, ramulisque inchoantibus brevibus, a basi lata acuminatis, cervicomia et horridula. Color atrovirescens. Substantia exsiccate cartilaginea.

Species a me parum cognita, fragmentis tantum suppeteutibus. Ilorum nonnulla cum speciminulo anthentico a me viso identica credo. $\Lambda d$ G. Lessonii forsan nimium accedit.

\section{Fronde compresso-plana lineari pinnatim decomposita,} pinnis acuminatis.

6. Glg. Fuccata (llering mscr.) fronde compresso-plana lincari pinnatim decomposita, apicibus teretiusculis longe productis acutissimis nudis, pinnis pinnulisque distichis, recurvato-patentissimis, cystocarpiis in pinnula sæpe pluribus.

Sphrerococcus falcatus Hering mscr.

Gigartina compressa hü̈ъ. Phycol. p. 403. Sp. Alg. p. 70̈0?

Ilab, in vecano atlantico ad Biaritz (IIb. Martens!).

Frons 2-3pollices alta cæspitosa, quadripinnata. Rachides utrinque allenuatx, basi paululum angustate, apice longissime in acumen productx, medio planx ultra lineam latæ. Pinnæ distichæ, juxta basem rachidis pauciores, medio plurimæ, superne nullæ, apice rachidum in acumen elongatum nudum fere tereliusculum sæpe recurvum continuato. Pinnulie simpliciusculæ fere teretes, pinnatæ comprimuntur et rachidem offerunt pinnarum. Cystocarpia in pinnulis teretiusculis sita, aut infrà apicem recurvatum solitaria, aut ipsa terminalia, aut in eadem pinnula plura, sessilia aut pedicellata. Color carneo-purpurascens. Substantia fere cartilaginea.

Hec forma plures alias species simul tangit. Ramificalionis norma ad Gig. Teedii accedit, consistentia crassiore, apicibus rachidum nudis teretiusculis et toto habitu diversa. Utrum G. pistillata, cum qua pinnis distichis fructiferis et situ cystocarpiorum sat bene convenit, an G. aciculari, cujus ramulos subulatos apices rachidum et pinnulie nuinores mire referunt, potius comparetur, dubito.

7. G. TEedn (Rolh. Cat. III p. 108) fronde plana lineari pinnatim decomposita, pinnis pinnulisque distielris patentissimis aut sublorizontalibus, sterilibus lineari-subulatis, fertilibus cystocarpia ad margines plerumque solitiria aut pauca gerentibus, soris splterosporarum rotundatis demum linearibus, mingini adprovimatis.

Cor:ımium Teedii Rolh. l. c. lab. 4!

Gigartina Teedii Lamour. Ess. p. 49 lab. 4 fig. 11? Htorv. Man. p. 75! 
Fucus Teedii Turn. Ilisl. lab. 208!

Sphærococcus Teedii Ag. Sp. Alg. p. 27\% et Syst. p. 느․ Grev. Crypt. l. 3̈̈6. Marl. Fl. Bras. p. 31!

Rhodomenia Teedii Grev. Alg. Br. p. 96 !

Chondroclonium Teedii Kül. Sp. Alg. p. 740 !

Exs. Chanv. Norm. n. 170! Hyall. Alg. Danm. n. 27.

Hab. ad rupes sinum tranquilliorum infra limitem maris; in Adratico et Nerliterranco; in oceano allantico a littore Britamite usque ad Tingin! ad orus Brasilix (Martius).

Frons a disco minuto surgens, $2-4$ pollicaris, aut immo fere pellalis, omnino compresso-plana et linearis, decomposito-pinnata, jugamento semilineam aut usque 2 lineas lato. Pinna majores minoresque intermixtar inferiores ut plurimum longiores et subhorizontaliter expanse, frondis circumscriptionem latitudine magis quam longitudine expansam sæpe reddunt. Pinnulæ nunc simpliciusculie, nunc iterum iterumplue disisn; simplices aut brevissimæ fere serraturas inmulantes, aut longiores subulatæ, aut longissimæ et fere filiformes. Cystocarpia ad pinnas minore. pinnulasque plerumque solitaria et ad medium pinnula unilateralia apice refracto, nunc plura, attamen pauciora, in marginis parte intumescente evoluta. Sori sphærosporarum secus margines evoluti, rolundati aut brevius lineares, rarius subcontigui et lineam longiorem marginalem formanttes. Color purpureus aut atrovirescens. Substantia exsiccate fere cornea.

Pulcherrima species ramificatione, fronde plana et cystocarpiorum situ aliquantulum diverso a (is. pistiilata distinguenda. Ab altera parte sequentes species proxime tangit.

8. G. Cunursor (Mert. mscr.) fronde plana lineari irregularius pinnatim decomposita, pinnis distichis subhorizontalibus, pinnulis sterilibus lineari-subulatis, fertilibus cystocarpia ad margines plurima demum aggregata gerentibus, soris. . . .

Fucus Chamissoi Mert. mscr.

Sphærococcus Chamissoi Ag. Icon. Ined. lab. 6 el Sp. Alg. p. 278. Syst. p. 22:3. Bory loy. Coqu. n. 59. Mlarlius Icon. Sel. Bras. lab. 3 fig. 1 el Fl. Brasil. p. 3!!

Gigart. Chantissoi Monl. Boliv. p. 30. Bonil. p. 71.

Chondroclonium Chamissoi Külz. sp. $p$. эł0.

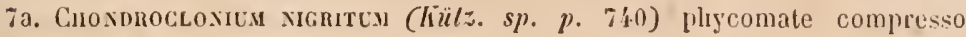
pinnatim multipartito, aut supradecomposito, fruticuloso, pinuis pinnulisque patentibus, divaricatisie, linearibus, superioribus acutis, congestis, apicibus disaricatim furcatis spinescentilus. Color purpureo-

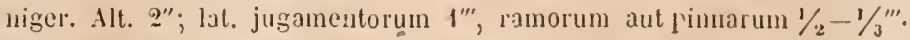
Structura perencliymatica.

Hab. ad Yan-Diemens-Land. 
Var. uvifera cystocarpiis botryoideo-agglomeratis.

Sph. uvifer Bory Coqu. n. 64! (tide synon.)

llab. in oceano pacifico ad littus Chilense (Chamisso! Hb. Risso!).

Caspes intricatus frondibus numerosis constitutus, ex quilus nonnulla prolongata eminent. Frondes $4-6$ pollicares, 1-2lineals lata, pinnatim decompositæ sed satis irregulares. Pinnæ inferiores sublorizontales, superiores patentes supremas altitudine æquantes et cum bis sæpe cervicornem ramificationem xmulantes, omnes decompositæ, najores minoresque intermixtæ. Pinnæ minores pinnulieque nunc simplices et basi vix latiore lineari-subulatæ, nunc furcatæ aut irregulariter pinnatæ, ramis pinnulisve subdivergentibus. Cystocarpia in pinnis pinnulisque numerosa, aliquando densissima, apice pinnæ sterili parum conspicuo. Substantia exsiccatæ cartilaginea.

Species G. Teedii valde alfinis, tamen distincta, licet notie distinctive ægre exhibeantur. Character præcipuus in cystocarpiis aggregatis situs mihi videtur, quo cum sequentibus dualus consenit. Cystocarpia in pinnis minoribus G. Teedii aliquando quoque plura, nec tamen aque aggregata, et in pinnulis fere semper solitaria.

9. G. Lessoxil (Bory Coqu. n. 60) fronde compressa lineari irregulariter pinnatim decomposita, pinnis distichis sublıorizontalibus, pinnulis sterilibus lanceolato-subulatis, fertilibus cystocarpia ad margines plurima gerentibus.

Sphærococcus Lessonii Bory l. c.l! (excl. syn. omn.)

IIab. ad oras Chilenses (I'Urville!).

Frons ex tereti compressa, ut plurimum valde angusta, jugamento primario lineam lato, cæteris angustioribus. Formas in cæterun antecedentis speciei fere percurrit et difficilime ab hac distinguitur, fronde crassiore el substantia minus cartilaginea.

Bory hanc speciem instituens, partim cum Sph. corniculato, quæ est species longe diversissima, parlim cum quibustam formis antecedentis conjunxit. Si allatie hie formie al Sph. Lessonii pertinerent, certe specie ab antecedente non differret. Specimina vero a nobis visa speciem aliter circumscribendam esse munstrant.

10. G. Cnsuvwn (Bory Coqu. n. 58) fronde plana lincari pinnalim decomposita et a disco prolifera, pinnis distichis patentibus apice producto sub-nudis, strilibus lanceolatis, fertilibus cyslocarpia ad margines plurima gerentibus, soris sphierosporarum lineam secus margines subcontiguam formantibus.

Sphrecoccus Chauvinii Bory Coqu. $n$. 58 lab. 20! (eximie); Mont. Fl. Boliv. p. 29. 
Gigartina Chaurinii J. Ag. Mont. Voy. Bon. p. 72.

Chondrocloninm Chaurinii hülz. sp. $p, 7 \& 1 !$

spl. formosus Chawe. mscr.

Sph. botryosus Sultr. mscr.

Sph. Teedii var. in Ag. sp. Alg. (spec. c mari pacifico) p. 27\%.

Ilab. in oceano pacilico a Cap IIorn (IIb. Clsauvin!) usque ad Guanclaco Peruvix (Humboldt!); ad Nov. Zelandiam (J'Urville).

Planta antecedentibus major, pedalis et forsan longior, magis regulariter pinnata, pulcherrima. Jugamenta primaria bis lineam aut immo semipollicem latitudine superantia, pinnis distichis atque prolificationibus numerosis ornata. I'imn majores, 3-4pollicares, minoresque I-3lineas longæ intermixtæ; minores densissimæ; majores fere unciam distantes, basi eximie attenuatr, per mediam parten? pinnulis fimbriatæ, apice producto acuminato nudx. Pinnula steriles fere ovato-lanceolata; fertiles magis liıeares, cystocarpiis numerosis ornatæ. Color fere Grateloupix Iilicinæ, nunc violaceus. Substantia membranaceo-subcartilaginea.

Ramificatione magis regulari, prolificationibus fere semper prinsentibus, pinnis magis erectis, basi eximic attenuatis, pinnularumque forma ab antecedentibus dignoscatur, labitu fere magis quam certis characteribus diversa. Proliticationes in G. Chamissoi numquam olservavi; in G. Teedii rarissimas vidi. Pinnula steriles in G. Chamissoi magis lineares, apice acuminato; in G. Lessonii basi quoque attenuatæ, attamen formam fere linearem conservantes; in G. Chaurinii sunt sape omnino orato-acuminatæ.

Fionde plana crassa pinnatim decomposila, pinnulis oblusiusculis; cystocarpiis. . .

11. G. DISTiCHa (Sond. Bot. Zeit. $1840 \%$ p. 5̆5) fronde compressoplana crassa lineari pinnatim decomposita, pinnis distichis conformilus, pinnulis cylindraceis obtusiusculis furcatis, ramis divergentibus, apice cystocarpia solitaria gerentibus.

Gigartina disticha Sond. l. c. et Aly. Preiss. p. 28!! liü̋. sp. p. 750! Ilab. ad littus occidentale Nova llollandia (Preiss!).

Frons spithamea, basi teretiuscula, mox compressa, 2 lin. lata, lavissima, nitidula, distiche ramosa. Rami oppositi vel alterni, jugamento similes, basi subattenuata teretiusculi, dichotomi rel subpinnati. Ramenta disticha sparsa, nunc creberrima, cylindracea, 1-2 lin. longa, plicato-rugosa, apice plerumque bifurcata, rarius simplicia vel trifurcata et ramulosa. lavellidia pericarpio sulicyathiformi, demum poro pertuso, in apice ramentorum sito inclusa, granulis obovatis numerosissimis. Sphierosporæ sub strato peripherico ramentorum nillulantes, nucleo demum cruciatim quadridiviso. Color livide purpurascens. Substantia gelatinosocartilaginea, exsiccatæ cornea. 
Descript. Auctoris transscripsi. Fragmenta, qux vidi, plantam pulchram et distinctissimam hujus generis monstrant. Pinna plane crasse, pinnulaque cylindraceæ obtusæ furcatæ ramis divergentibus, a cateris speciebus facilius distinguunt.

12. G. Pixiata (J. Ag. mscr.) fronde compresso-plana crassa lineari pinnatim decomposita, pinnis disticinis conformihus, pinnulis cylindraceo-compressis obtusiusculis pinnatis, pinnellis patentibus, soris splaerosporarum secus margines linearibus.

Ilab. ex Port P'hillippe Australia misit Malm!

Frons videtir pedalis, crassa et compressa, utrinque attenuata, jugatmento frondis mediæ 3 lineas et ultra lato, per totam longitudinem pinnis conformibus $2-3$ lineas distantibus pinnata. Pinnæ 2-3pollicares, basi altenuatie cylindracex, sursum mox dilatatx, saltem tripinnatx. Jugamenta pinnarum pinnularumque sensim angustiora evadunt, magisque teretia, donec pinnule ultimæ indivisæ fere cylindraceæ sunt. Pinnula inferiores longiores $1-1 / 2$ pollicares, superiores sensim minores, apice jugamenti supereminente nudo. Axillie omnium patentes angulo $43^{\circ}$. Sori sphærosporarum secus margines jugamenti inter pimnellas indivisas expansi, nunc in his prosenientes, lineam circiter longi, lineares. Color in nostris atrovirescens. Substantia gelatinosomcartilaginca.

Quoad ramificationis normam cum speciebus supra enumeratis convenit; ab his vero differt pinnis obtusiusculis et crassioribus. A G. disticha, quam hoc charactere æmulatur, pinnis patentibus pinnellisque longioribus facile dignoscitur.

11. Fronde crassa plana sub-canaliculata pinnatim decomposita, pianis cystocarpia subsolitaria in disco pagina pone apicem gerentibus.

13. G. LIVID. (Turn. Hist. Fuc. n. 234) fronde crassa canaliculaloplana pinnatim decomposita, pinnis pinnulisque distichis lanceolato-linearibus obtusis, linc subcanaliculatis, infra apicem cystocarpia solitaria hemisplıerica umbilicata gerentilus.

Fucus lividus Turn. hist. Iab. 254 !

Gigartina livida J. Ag. Mont. Toy. Pol. Sull. p. 120!

Spharococcus lividus Ag. sp. Atg. p. 276 et Syst. p. 225!

Chondroclonium lividum hülz. sp. $p$. Th0?

Spherococcus crassifolius Ag. sp. p. 273 et Sysl, $p$. 225!!

Chondrus? crissifolius hütz. sp. p. 737 !

lar. $\beta$. IIareyana frondis una pagina evidentius plano-canaliculata.

Gigartina livida IIarv. Alg. Tasm. n. 73!! 


\section{Gigartina.}

llab. in mari australi (Menzies); ad littora meridionalia Nove Hollandia (Ilus. Paris!); ad Tasmantim (Lyall!).

Frons crassa plana margine angusto canaliculatil, tripinnata aut ulterius decomposita, a radice fibrosa erectiuscula spitharnaca, jugamento primario 3-4 lineas lato, basi in stipitem teretiusculum, superne in apicem obtusum attenuato. A margine exeunt pinnie numerose conformes, inferiores majores. P'innulæ basi eximie attenuate, oblongo-lanceolatx, aut paulo supra basem summam attingentes latiludinem et exinde in apicem ohtusum attenuate; fertiles magis oboratie, infra apicem cyslocarpiis solitariis magnis, in alterutera pagina bemispharice prominentibus instructx. Cystocarpia quasi lobis spiraliter tortis umbilicata, apice ipso enarginato, infra sinns ita formatos nucleum sat conspicuum foventia. Substantia crassa ex gelatinoso cartilaginea. Color lividus aut purpurascens.

Nullo viso specimine plantie Turnerianx quedam de ideutitate specierum, quas supra conjunximus, dubia manent. Si descriptiones comparautur ita tamen conveniunt, ut species diversas vix suspicarer. Planta, quam nomine Gig. lividie a Harvey accepi, a Splt. crassifolio fronde evidentius canaliculata differt. - Attamen dicere fas est, omnes auctores characteres plures speciei, quales supra exhibui, silentio prateriisse. liaitzing in suo Ch. livido pinnulas fructiferds teretes et cystocarpia marginalia describit, quare species plures sub nomine F. lividi confusas credere liceat.

III. Fronde hinc canaliculala dicholoma rel subpinnala, cyslocarpiis umbilicatis in pagina convera emergentibus submarginalibus plurimis.

14. G. Alveata (Turn. Hist. n. 239) fronde line convexa, illinc canaliculita lincari diclıotomo-fastigiata, segmentis superioribus approsimatis, summis rerolutis, cystocarpia umbilicata ad margines pagine convexæ emergentia plurima gerentibus.

F. alveatus Turn. l. c. lab. 239 !!

Sph. alvealus Ag. sp. p. 272 et Syst. p. 223!

Chondrus alveatus Grev., Hook. el IIarv. Alg. nov. Zel. p. 5\$7.

Mastocarpus alveatus hü̈z. sp. Alg. $p .732$ !

Ifab. ad oras Nora Zclandixe (Banlss! Hb. Greville! et IIarre!!).

Frondes 2-4.unciales, a radice scutata erectiuscnla numerosa gregnrix, lineares, vix lineam late, per totam longitudinem introrsum canaliculatie extrorsum convexiusculie, in inferiore parte parcius dichotoma, superne segmentis adproximatis fastigiata, segmentis supremis revolutis, apice obtusiusculo; axillie acutiusculd patentes. Cystocarpia ad seginenta superiora in pagina convexiuscula juxta margines emergentia, rarius ipsum 
dorsum occupantia, in singulis segmentis plura umbilicato-depressa. Color ex amethystino lividus. Substantia gelatinosa subcartilaginea.

Fronde profunde canaliculata regulariter dichotoma, apicibus revolutis, cystocarpiis in una pagina sessilibus, ab omnibus facile distinsuitur.

13. G. axcistrocladd (Mont. Prodr. Phyc. ant. p. 6) fronde linc convexa illinc canaliculata lineari irregulariter hi-tripinnata, pinnulis alternis oppositis rel et fasciculatis uncinato-incurvis - recurvisve.

Gigartina ancistroclada Mont. l. c. Toy. au Pol. Sud. p. 121. Pl. 7 fig. 4! Kiülz. sp. p. 731 !

Ilab. in oceano australi ad insulam Akaroa (D'Crville).

"Fulcrum callus exiguus. Frondes aggregate", biunciales, corneocartilaginea, rigidæ, e basi filiformi lineares, mox compressa', semilineam latæ, leviter canaliculatæ, ita ut segmentum horizontaliter positum reniforme appareat, post intervallum lineare nudum pluries pinnata aut fasciculato-ramosæ. Pinna pinnularfue alternæ, oppositæ, etimn subvagx, immo fasciculatim congestæ, basi attenuata, ultimi ordinis uncinato-incurva vel recurvie, subfiliformes. Fructus desideratur. Structura: tila tubulosa, hyalina, articulata, materic colorata farctil in cellulas ad speciem polygonas anastomosantia et peripheriam versus in alia fila horizontalia subcylindrica breviter articulata densissime stipata abenntia. Substantia cartilaginea, sicca cornea. Color caulis olivaceus, pinuarum pinnularumque amoene violaceus.

Licet hanc speciem cum G. Alseata non comparaverint auctores, tamen huic speciei proximam ex icone citata concludere audeam.

16? G. Canaliculata (Harv. Beech. p. 490) fronde hinc convexa illinc canaliculata lineari inferne nudiuscula, supra medium diclıotoma, segmentis pinnatim ramulosis, ramulis aculeiformibus brevissime conicis divaricatis.

Gigartina canaliculata Ilarm. in Iloolier Bol. of Beech. Voy. l. c. Sphærococcus Lindleyanus $J$. Ag. Syml. 1 p. 16.

Chondroclonium canaliculatum lüls. sp. p. 741 !

Ilal), ad oras Californix (Douglas!).

Frons bi-tripollicaris a basi scutata surgens, aut decumbens stolouifera et frondes erectiusculas pinnatim emittens; lineam fere lata, hinc convexiuscula illine canaliculata, inferne simpliciuscula aut pinnis sparsissimis simpliciusculis ornata, paulo infra apicem dichotoma, segnentis finnatim solutis in aculeos brevissimos linea breviores conicos divaricatos. Color exsiccate e purpureo nigricans; substantia cartilaginea. Fructus non vidi. 
Formam fere refert F. corniculati Turn. sed inferne est magis nuda, superne densius corniculata, aculeis divaricatis brevissimis. Plantam IIarreyanam non vidi, sed cum nostra identican esse suspicor.

IV. Fronde crassa in segmenla cuneala vel oblonga (aliquando maxima) hinc canaliculala dichotome aut pinnalim expansa, papillis ab ulraque pagina frondis pullulantibus cystocarpia gerentibus.

17. G. Manillosa (Good. et Woodw. in Lin. Trans. $3 p$. 174) fre ie canaliculato-plana lineari decomposito-diclıotoma fastigiatiı, segmentis superioribus cuneatis bifidis, papillis a disco et margine prolificantibus lingulato-oboratis cystocarpia singula mutica gerentibus.

Fucus mamillosus Good. el W'oodw. l. c. Turn. Hisl. Fuc. lab. 218! Sm. Engl. Bol. lab. 1034. Esp. Fuc. lab. 122.

Gigartina mamillosa J. Ag. Alg. med; Ilarv. Pliycol. lab. 199!

Mastocarpus mamillosus Kütz. Pliycol. Lab. io fig. 3 el Sp. Alg.p. 733 !

Sphærococcus mamiltosus Ag. Sp. Alg. 1 p. 260 el Syst.p. 220. Lyngb. Ilydr. Dan. p. 14 lab. 3 !!

Chondrus mamillosus Grev. Alg. Br. p. 127!! Harv. Man. p. 77!

Rhod. mamillosa Aresch. Enum. p. 74.

Fucus polymorphus Lamour. diss. (partim) tab. 17 fig. 37 et lab. 48 fig. 39 !

F. echinatus Stackh. Ner, Br. tab. 12.

F. alveolatus Esp. Fuc. n. 61 lab. 70. (1\%, canaliculatus).

F. canaliculatus var. Iluds.

Exs. Wyall, Danm. $n .117$.

Ilab. perennis ad rupes maris atlantici a Norvegia suprema et Terra nova usque ad Gibraltar! in occano pacifico ad littora Americie Rossicæ (Lutlie!); in oceano australi (Hb. Agardlı!).

Frondes a radice scutata numerosæ radiantes, cæspitem hemispliaricum efficientes, 3-6pollicares, ima basi teretiusculir, mox planæ et plus minus evidenter canaliculatir, lineares, decomposito-dicholoma et fastigiate, axillis patentibus. Segmenta nunc omnia conformia linearia $1-1 \frac{1}{2}$ lineas lala, nunc omnia cuneata 1 - - lineas lata, nunc inferiora linearia superiora cuneata; terminalia ad divisionem prona, apice emarginata aut bifida, subacuminata aut plerumque olstusinscula, aliquando rotundatoobtusa. A disco et margine frondis superioris exeunt papillar nunc paucx, nunc numerosissimæ, aut verrucaformes breves, ant elongatæ subeylindraceo-lingulato $\mathrm{rel}$ in segmenta frondi consinilia alseuntes, raro ramose. Favellidia papillarum apice immersa oblonga. Sphærospora . . . 
Color purpurascens. Sulstantia magis coriacea quam gelatinosa et cartulaginea.

Species formarum varietate magnopere ludens, sed ramificatione fastigiata, segmentis vix pollicaribus canaliculatis, et papillis numerosis distinguenda. Substantia quam in cateris speciebus multo minus gelatinosa, quare aquam difficilius imbibit. Papillæ in pagina canaliculata plerumque frequentiores.

18. G. P.Pillita (Ag. Icon. Ined. tab. 19) fronde plana inferne subcanaliculata simpliciuscula aut parcissime dichotoma, segmentis late truncato-cuneatis, papillis a disco ef margine prolificantibus ohoratis cystocarpia singula mutica gerentibus.

Sph. papillatus Ag. I. c. el Sp. Alg. p. 267. Sysl. Alg. p. 22z.

Mastocarpus papillatus Kü̈lz. sp. p. 733 !

Llab. in oceano pacifico ad insulas Sandwich (Chamisso!).

Frondes a radice scutata gregariæ et numeros $x$, simplices aut semel rel bis dichotomæ, segmentis frondi simplici conformibus et magnitudine xqualibus, 2-Rpollices longis et ultra semipollicem latis, a stipite brevissimo subcanaliculato sensim dilatatis cuneatis planis, apice obtusissimo truncatis aut irregulariter emarginatis. Papillæ numerosissimæ apice fructiferæ, angustiori basi stipitatæe. Color ex amethystino purpurascens. Substantia G. mamillose.

G. mamillosa sine dulio proxima species, sulstantia et structura conveniens; frondis forma simpliciore et hinc magis expansa satis diversa.

19. G. onxinuonycuos (J. Ag. Act. Ilolm. 1849 Öfoers. p. 86) froude plana inferne subcanaliculata simpliciuscula aut parce divisa pinnato-dichotoma, segmentis cuneato-lanceolatis, papillis a disco et margine prolificantibus, marginalibus in segmenta frondi conformia excrescentibus, cystocarpiis ovatis rostratis in papilla singulis aut numerosis.

Var. a. cystocarpiis obsolete mucronatis.

? Mastocarpus corymbiferus liülz. Bol. Zeil. 1847 $\%$. 24! Sp. Aly. p. 73 \%.

V'ar. P. cystocarpiis spinoso-rostratis.

? Mastocarpus spinosus Kül. Bol. Zeil. 1847 p. 24. Sp. Alg. p. 734!

Ilab. in oceano pacifico ad oras Callifornix (Donglas!)

Frondes a disco radicali nunerosa, semipedales, basi ex tereti compressie, mox plane et obsoletius canaliculate, sensim latiores cuneatoaut lanceolato-lineares, simplices aut semel rel bis dichotomer, aliquando subpalmatre, immo papillis marginalibus in segmenta frondi conformia excrescentibus pinnatx. Segmenta pollicen fere latil, Papille a disco et 
margine in superiore frondis parte erolute numerosissime, initio subulata, demum cystocarpiis erolutis mutate, in disco breves et cystocarpia singula ferentes; marginales sensim in segmenta frondi conformia, linearia et demum lanceolato-linearia, evolutie, pinnas 1-2pollicares mentientes, fructibus plurilus pinnatie. Cystocarpia sphxrica in rostıum terminale aut sxpissime obliquum producta. Color fere fuscescens. Substantia gelatinoso-cartilaginea aquam avidissime inbibens.

Species distinctissima et facile distinguenda, cum G. volante Ag. tamen ulterius eomparandi. llxc species, cujus in Hb. Agardhiano nullım exstat fragmentum, in multis cum nostra convenire videtur, et utramque immo identicam diu suspicatus sum. Scd G. volans incola Cap. b. Spei dicitur; nostra e California; illa vere pinnata, papillis marginalibus horizontalibus et capsulis muticis depingitur (Ag. l. c.); hæc dichotoma, pinnis a papillis marginalibus evolutis evidenter oriundis, patentibus, et

19a. Mastocanes Harrexanes (Kül. Sp. Alg. p. i34) pliycomate (pedali) firmo plano coriaceo, basi stipitato cuncato gracili, in laminas elongatas anguste lanceolatas diviso, in utraque pagina et margine obsesso carpocloniis, in statu sterili ciliiformibus spinescentibus, in statu fructifero papillaformilus; cystocarpiis numerosissimis densissimi.s minutis globosis retusis spinescentibus brevissime stipitatis vel subsessililuus.

Iridæa microphylla IIarv. ap. Beechey Yoy. (sec. Kütz.)

IIab. ad oras Californiæ (Coulter.)

19b. Gigartixa rolass (C. Ag. Icon. Alg. ined. lab. 18) fronde simpliciuscula vage et parce pinnata, pinnis ovatis ramenta e disco emillentibus brevia, c margine longiora linearia apice subfurcata.

Sphærococcus rolans $\mathrm{Ag}$. l. c. Sp. Alg. p. 266.

Gigartina volans J. Ag. Icon. ined. ed. II.

Nastocarpus volans fiüt. $s p . p$. $73 \%$.

Hab. ad Cap. b. Spei (Chamisso).

Frons spithamad, plana, enervis, basi angustata, et vix $2-3$ lineas lata, mox dilatatur, et dividitur in segmenta 3 vel k, ovata, basi attenuata, ligitalia, unciam vel ultra lata, parum crispa, obtusiuscula, vel interdum apice fissa, disco utrinque obsessä papillis erectis, rigidis 2-lineis longis, planiusculis, apice tamen teretiusculis, rotundatis, obtusis; e margine emittens ramenta semi- 1-uncialia, plana, lineam lata, horizontalia, parallela, linearia vel leviter cuneata, apice subfurcata. Fructus: calpsulæ papillieformes ad apicem rameutorum. Color fusco-purpurascens, soli objecte sordide pallescens. Substantia cartilaginea, crassiuscula, tenax, exsiccate cornea.

Habitu fere gaudet Laminarix, cujus crassitiem et substantiam habet, sed color purpurascens.

Specimen hujus ab Agardhio depictum, in IIerb. Chamissoi asserratum, non vidi. 
capsulis evidenter rostratis differt. In editione Iconum Ineditarum nova, quam pullici juris feci, utramque plantam identicam esse, et errorem ruoad locum natalem irrepsisse finxi; re vero accuratius perpensa et precipue ratione habita cystocarpiorum, quæ in nestra rostrata, in Icone semper mutica, utramque distinguendam esse credidi. Dubia non nisi inspecto Herbario Clianissonis solvenda.

Formas hujus speciei in Ilarv. ap. Beechey Voy. nomine Ir. papillatæ et l. stiriatæe memoratas fuisse suspicor. lïitzing speciminibus Harveyanis inspectis easdem sub nom. supra citatis descripsit. Formas nounullas coram oculis habeo, quæ cum descriptis speciebus kützingianis sat bene conveniunt, quare easdem plantas a nobis intellectas fuisse vix dubito; nostræ autem omnes ad eandem speciem pertinere mihi videntur.

20. G. fistigiata (J. Ag. Act. Holm. 1849 Öfvers. p. 86) fronde carnoso-crassa tereti-compressa obsuletissime canaliculata diclıtomo-fastigiata, segmentis superioribus congestis compressolinearibus, terminalibus obtusiusculis mmargुinatis aut dentiformibus et subdivergentibus.

Chondrus scutellatus IIering. in Regensb. Fl. 1846 p. 210 ? (vix lïitzing).

Hab. ad Cap. b. Spei in sinu tabulari (Pappe! Ilb. Areschoug!).

Frons fere Chondrum, qualem in Lamour. Diss. Tab. 11 fig. 4 depictum video, habitu referens sed multo crassior; a disco radicali erectiuscula 2-3pollicaris, inferne simpliciuscula et teres, dein dichotomo-decomposita subflabellata. Segmenta superne auprosimata fastigiata, compressa et incrassato-plana, ita ut sectio trunsrersalis oralem formam recuperet, subcuneato-linearia, terminalia conformia obtusiuscula aut enıarginata. Axillæ patentes, terminalium patentissima, ita ut segmenta terminalia subdivergentia evadant.

Species sine dubio distincta, at fructu ignoto quoad genus adhuc forsan dubia. Structura plantæ sterilis Gigartinam indicat; et si synonymon Heringii ad hanc jure trahitur, fructus, quos describit, Gigartinam quoque suadent. Planta ejusdem nominis Kuitzingii diversa mili videtur; ille enim coccidia scutellata in sua planta describit; hic apices frondis scutellato-spathulatos dixit.

21. G. Bonusixy (Ag. Sp. Alg. p. 272) fronde carnosa crassa planocamaliculata dichotoma aut segmentis marginalibus subpinnati, segmentis sursum expansis cuneatis aut sublinearibus margine involıtis, apicibus obtusiusculis, cystocarpiis. . .

Sphrococcus Burmanni Ag. l. c. el Syst. p. 92:? !

Sarcothalia Burmauni Külz. sp. p. 739 !

Iridiea lissa Sultr, in Fl. 1836. I. Beitr. n. 2 pag. 24. fig. 26 !!

Ilalb. in sinu tabulari ad Cap. b. Spei; ad Cap IIorn sec. Sulı. 
Frondes in exspitem conjuncte, inferne lereliusculæ ramosæ et intricatx, aliis ramis decumbentibus et radicantibus, aliis in frondes, extra cxspitem radicalem eminentes, sese crolientibus. Frondes hx 3-6pollicari altitudine surgentes, erectiusculir, inferue teretes aut leviter compressa, cuneato-dilatata, plane at marginibus involntis subcanaliculate, dichotoma fastigiatx segmentis suhlinearihus, ant latiores palmatifide segmentis Cuneatis, aliquando inımo pinnatim divisa. Segmenta lineam aut usque pollicem lata; suprema a basi latiore sensim attenuata aut basi parum angustiora, omnia in apicem obtusiusculum acuminata. Color ex violaceo purpurascens aut sxpe in lividum tendens. Substantia gelatinoso-cartilaginea.

Species distinctissima, nisi Gigartinir stiriate sit forma sporifera. Tota frons est fructibus semi-immersis magnis punctata, sed fructus isti non favellidia sed soros sphærosporarum sistere mihi adparuerunt. lidem fructus a Suhrio depicti. Ob magnitudinem facile fallunt, et favellidia existimantur.

22. G. Stinata (Turn. Hist. lab. 16) fronde carnosa crassa planocanaliculata, simpliciuscula aut parce dichotoma vel papillis undicyue pullulantibus irregulariter ramosa, segmentis spathılato-lanceolalis, papillis oboratis demum foliaceis, cystocarpiis muticis in papilla solitariis aut pluribus aggregatis.

Fucus stiriatus Turn. $l$. $c$.

Sphærococcus stiriatus Ag. Sp. Aly. I p. 269; ct Syst. p. 2223!

Iridera stiriata Bory; Hook. el Ilarv. Alg. Nov. Zel. in Journ. Bot. IV. p. 347 !

Mastocarpus stiriatus Kü̈t. sp. $p .733$ !

F. papillosus Gm.?

? Iridxa rolans? Mont. Toy. Pol. Sud. p. 104!

Ilab. ad Cap. b. Spei, in sinu tibulari vulgaris; ad Novam Zelandiam (sce. Hook, et Harr.)

Frondes a surculis decumbentibus radicantibus cæspitose provenientes, 3-6pollicares, inferne cylindracex pennam corvinam crassæ, mox compresex et obsoletius canaliculatix, sensin latiores el cvidentius plane, linceolato-lineares, aliquando late obovate unguem et ultra late; inferiore parte cylindracea ramosæ, ramis singulis in foliola plana simpliciusculi raro dichotoma aut subpalmata expansis; undique olstecta papillis olsoratooblongis, qux nunc breviores fructiferx, nunc cloggatx et foliacese frondem quasi foliolis underue obtectam, aut marginalibus majoribns fere pinnatam, reddentes. Cystocarpia verrucæformia depresso-spharica, mutica, in papillis brevioriluus subsolitaria, in majorilus plura. Sphresporas non vidi. Color ex violaceo purpurascens. Sulutantia eximie crassa, gelatinoso-cartilaginea.

Nomine Sph. gelatinosi farellidia hujus speciei a Fr. Necsio olim (in Regensb. Flora 1824) descripta fuerunt. Turnerus specimina retustiora 
describens, frondem palmatam quasi normalem descripsit. Revera autem sunt frondes foliacee ut plurimum simplicissimæ, rarius dichotomæ aut palmatx; papillæ vero demum valde prolongatæ foliacex segmenta frondis: divise non raro emulantur, et hoc modo frondes valde erregulariter divisæ jinmo fere pinnatæ occurrunt. Juter vicinas species antecedentem et sequentem proxime tangit. Iridæam clavellosam Suhr. et Laurenciam claviferam Suhr. huic speciei jamdudum vindicavi (Symb. p. 20 el 21).

23. G. radula (Esp. Icon. Fuc. II p. 3) fronde carnosa plana inferne sub-canaliculata, subsimplici aut ramis stipitis ramosi in frondes expansis divisa, segmentis maximis obovato-ellipsoideis margine et disco demum papillosis, eystocarpiis muticis in papilla subsolitariis.

Fucus radula IIb. Banlis; Esper l. c. Ial. 113.

Gigartina radula $J$. Ag. Alg. Licbm.

Sphærococcus radula $A g$. Sp. Alg. I p. 268 et Syst. p. 222.

lridica radula Bory in Voy. Coqu.p. 107. Ilook. el Harv. Crypl. antarct. p. 76 !

Fucus bracteatus Turn. Hisl. Fuc. lab. 20.

Var. ce. radula amethystino-violacea, margyinibus integerrimis vel glandulosis, soris splıærosporarum subprominentibus, pluribus in maculas collectis, delabentibus in alterutera pagina cryptam limpuentibus.

* sporifera fronde nuda, soris sphierosporarum minute veriucosa.

22a. Iriden (mastocarpus) insignis (Endl. et Dies. Bol. Zeil. $1843 \mathrm{p}$. 289) fronde plana, vage dicholome ramosa, ramis elongatis subæqualibus v. sursum parum dilatalis, rugosis, papillis marginalibus elongatis, apice capitellatis, rarissime lateralibus.

1lab. ad Port-Natal (IIb. I'oeppig).

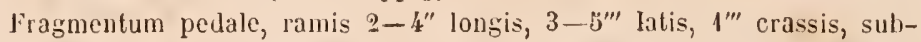
stantid cartilagineo-gelatinosa, succosa, exsiccatx corneo-rigicla, diapha๓a. Color bruneus. Favellidia ovata, papillarum marginalium apici immersa.

22b. Mastocaneus Kefzeixus (Külz. sp. Alg. p. 734) pliycomate plano crassiusculo, irregulariter multipartito vel subdichotomo; segmentis late linearibus vel lineari-lanceolatis, axillis obtusiusculis; sterilibus integerrimis, fructiferis sape denticulato-spinulosis, spinulis minutıs livaricatis, plerumque in cystocarpia papillaformia marginalia simplicia sulcapitata, vertice pertusa, transmutatis, disco plerumque sterili lirvi raro subpapillato. Magn 4- 3 "; lat. 1/2-3/2", segmentorum 1-3"." IJdb. ad Javam (Zollinger). 
Iridica lapathifolia külz. Sp. Alg. p. 729?

** gemmidiifora jucenilis, fronde papillosa, papillis lingulatis longiolibus.

Grateloupia hystrix $A g . S p . A l g . I p .223$ !

Chatungium liystrix Kü̈l. sp. p. 793.

Mastocarpus Radula Kǚl. Sp. dlg. p. 733 !

*** gemmidiifera senilis fronde papillosa, papillis oburato-calpitatis. Mastocarpus bracteatus tiülz. Sp. Alg. $p .733$.

Var. $\beta$. clathrata coccineo-purpurea, marginibus integerrimis aut grosse glanduloso-serratis, soris splærosporarum immersis, sillgulis sparsis, delabentibus foramina pervia linquentibus.

* sporifera fronde nuda demum crassa cribrosa.

Iridiea clathrata Descne in Ann. Sc. Nat. 1844 p. 236.

Chondrodictyon capense Küls. Phycol. p. 396 et Sp. Aly. p. 729!

Fucus Agarum I'eb. et Mohr. Beitr. 1 p. 284 (fide Kiitz.)

* gemmidiifera fronde papillosa, papillis oborato-capitatis.

Nastocarpus polycarpus Kï̈l. Sp. Alg. p. 733!

llab. utraque forma ad Calp. b. Spei (II). Turner! Lalande! Pappe! etc.); ad Noram Zelandiam, insulas Aucliand et Camplocl (lloolier); ad oras occidentales America borealis (Menzies!).

Frondes a radice scutata erectiusculie cæspitosæ, ima basi cylindracex calamum scriptorium crassitie rquantes, vage ramosæ, ramis in expansiones foliaceas simpliciusculas, juniores subspathulatas evidentius canaliculatas, adultas obovatas ellipticas oblongasve simplices aut raro dichotomas 6-20pollicares et 2-5pollices latas abeuntibus. Nargines frondis in diversis formis nunc integerrima, nunc papillis inequales, nunc subregulariter serrata. Discus ifuoque aut nudus, integer vel foraminibus densis cribrosus, aut papillis fructiferis brevissimis obovato-truncatis densissime obsitus, aut tota frons papillis lingulatis 1-2 lineas longis compresso-planis subcanaliculatis obsita est. Favellidia papillarum apice obtuso singula immersa. Sphærosporæ in soros rotundatos subprominentes, infra superficiem frondis collecte. Substantia crassa carnosa, in var. ". tenuior et magis gelatinosa; in var. $\beta$. crassior, exsiccatæ firmior. Color quoque in diversis formis nunc in amethystinum nunc in coccineum tendens.

Formas supra allatas distinxi, ut synonyma suo quoque loco referrerentur. Est revera quædam inter var. $\alpha$. et $\beta$. differentia; sed formis intermediis utramque confluere suspicor. P'ro atate et statu sterili vel fertili habitum disersum cxeterum induta. Planta jurenilis nuda; gemidiifera papillosa. Papilli juveniles subacuminate, breviores aut longiores et lingulatx; adulte capitate, et seniles demum vertice rupto scutellatir. l'lanta spharosporis onusta Irideam mire refert; sori spharosporarum in una forma minuti et plures in maculas subprominentes adproximati, ac sæpe in circulos dispositi; in altera forma sori majores omnino immersi 
singuli et sparsi; horum delapsu tota frons cribrosa evadit. Careas cæterum ne soros pro favellidiis habeas. Kï̈tzingium hoc modo deceptum fuisse, Iridæa lapathifolia et Chondrodictyon capense testari mihi videntur. Hooker et Harrey uno loco has fructuum formas rite distinxerunt (Crypt. antarct. p. 7 ); altero loco (Lond. Journ. 1 Y. p. 34.7 ) de forma duplici favellidiorum loquentes, soros pro favellidis habuerunt.

\section{Species inquirenda:}

24. G. Divaricata (Hook. et Harv. Crypt. ant. p. 75) caule cartilagineo-carnoso compresso lineari subdichotome diviso, ramis distichis pinnatis snbpinnatisve, ramulis patentissimis linearibus subattenuatis.

Gig. divaricatil Hook, et Harv. l. c. Lonl. Journ. IV. p. 263 et 346 ! Hab. in oceano australi aut insulas Campbell et Novam Zelandiam.

Caulis 4-6 unc. longns, subdichotome divisus, 1-2 lin. latus, compressus striclus, ramis subquadrifariis distichisve dense obsitus. Rami divaricati stricti, compressi, rugulosi, nudi, parce pinnati vel subbipinnati, apicibus longe nudis. Pinnulæ horizontales, breves, simplices vel furcati, lineares, acutæ, nunc abbreviata et spiniformes. Color lividus v. nigrorubescens, ad apices ramulorum pallidior purpurascens. Substantia cartilagineo-carnosa, firma, elastica, siccitate valde contracta. Chartæ non adhæret.

Ita auctores. Hxc species cum nostra G. flabellata comparanda videtur.

23. Mlastocarpts valdous (Kï̈l. $s p$. Alg. $p$. 735) "pliycomate rigido, coriaceo-cartilagineo, duro ef firmo, basi tereti elongato, sursum sensim dilatato, compresso, deinde dichotomo, ramis divaricatis; ramellis lateralibus elongato-papilixformibus, fructiferis."

Gigartina pistillaris forma valida. Mont. mscr.

Jlab. ad insulas Auckiand.

26. Gignativa CuONDroldes (Hook. el Harv. Alg. Tasm. n. 75) lividia, fronde stipitata apice flabellatim ramosa disticha cartilaginea, ramis plano-compressis linearibus basi cuneatis pluries dichotomis patentibus fastigiatis, axillis latissime rotundatis, api(ibus oltusis.

Hab. ad Tasmaniam (Lyill).

Ifalitu forman angustam Chondri criepi amulatur, sed structura diversissima; hoc respectu cum G. livida convenil, qux ramificatione dignoscitur. Ila auctores. 
27. G. Ienmeromus (Bory Voy. Coqu. n. 44) fronde filiformi vage ramosa, angustissima, capsularum multiplicatione rugosa.

Ilab. ad oras Peruvia (D'Lrille).

Capillo duplo et triplo crassior, pedalis. Habitu Fuci subtilis Turn. at nigra. Ita auctor.

28. G. Rugulosi (Bory Voy. Coqu. n. 4.5) frondibus ramosissimis, ramis ragis, duriusculis, rugulosis.

Rhodomela rugulosa Bory in D'Erville Fl. Malouin. n. 13.

IIitb. ad insulas Malouinas (Lesson).

Dense crspitosa, rigida, superficie minute rugulosa. Sec. ipsum Auctorem accuratius examinanda.

29. G. melixoturix (Bory Coqu, n. $46 \mathrm{Pl} .19 \mathrm{fig} .3$ ) fronde filiformi elongata rage ramosa, ramis compressiusculis dichotomis, subfastigiatis, acutis, bilobo-dilatatisve.

llab. ad Conception (D'Urrille).

Frondes 2-3pollicares, apicem versus compressæ, segmentis terminalibus furcalis, plurimis subulatis, aliis compressis ut in sequente, cujus forsan sil varietas. Ita Auctor.

Specimen hujus vidi, sed sterile. Stratum internum filis anastomosantibus et ramosis, externum cellulis verticaliter seriatis rotundatis arcte ${ }^{-}$ cohærentibus, contextum. Mihi valde dubium videtur an Floridea sit. Ad Laurenciam dubie relegat küizing, a quo genere longe sane recedit. An Chordarieis referenda?

30. G. Butrachopus (Bory Voy. Coqu. n. 47 Pl. 19 fig. 2) fronde lineari dichotoma; ramis divaricatis, extremitatibus dilatatis bilobis.

Hab. ad Conception (D'Urville).

Dense cæspitosa; præcedenti brevior et crassior. Substantia cornca. Hanc quoque ad Laurenciam refert Küitzing. Potius Ileringix specien ex descriptione et icone suspicarer.

31. G. Cuoxdroines (Bory Coqu. n. 49) fronde dichotomir, ramis dichotomo-fastigiatis et trichotomis subarticulatis.

IIib. ad Conception (I)'Crrille).

llabitu ad Sphærococcum Salicornian Ag. vel Fucum Mackaii accedit; exsiccata nigrescens. Rami quasi articulationibu. juncti. - Ita Auctor; si ex descriptione suspicionem de lac specie forere liceat, cun Fucu constricto Turueri comparandam crederem. 
32. G. Hupxiformis (Bory Coqu. n. 50) frondibus gracile filiformibus vage pinnato-ramosis, intricatis; ramulis subulatis erectiusculis.

Ilab. ad Otaiti (Lesson).

Sph. intricatum huc dubie refert Auctor. Frons quadrinollicaris crassitie chorde musicæ. Color viræ purpureo-vinosus?

33. G. CROCEA (Hornem. mscr.) "plycomute gracili filiformi tereti diclofomo, ramis patentibus ramuliferis, ramulis hateralibus sparsis subsecundis, elongatis acutissimis, apice subulatis, basi attenuatis. Color siccatx croceo-purpureus, apice pallidus albicans. Alt. 6". Crassities penne columbinx, superne pennat merulie. Structura: Basis e stratis tribus composita; medullare magnum e cellulis (filiformibns) farctis vermicularibus reticulatointricatis, intermedium e cellulis parenchymaticis mignis rotundis inanibus, corticale tenue e cellulis monogonimicis purpureis compositum." Külz. sp. p. 750.

IIab. ad insulam St. Crucis.

34. G. spantert (Külz. sp. p. 750) "tenuis filiformis irregulariter dichotome ramosissima, ramis subteretibus prope apicem spinis nonnullis lateralibus subsecundis armatis. Alt. 4"; crassities haseos pennæ merulie, ramulorum pennx passerina."

Hab. ad insulas Malouinas (Delise).

33. G. xODIFER (Hering in Regensb. Flora 4816 p. 210) fronde cartilaginea, tereti, subdiclıotoma; ramulis terminalibus irregulanter dentatis, obtusis; dentibus apice coccidiiforis. Frons crassiuscula, exsiccata atropupurea. fӥ̈z. sp. p. 750.

Ilab. ad Port Natal.

36. G. Elegats (Grev, in Aug. St. Hil. Voy. II. p. 449) fronde cornea livido-purpurea compressa irregnlariter bipinuafia; pinunlis brevilus inultilidis subhorizontalibus, ramulis ultimis crehris, divaricatis, aculeatis; capsulis globosis numerosis in ramulis sessilibıs.

Ilab. Ad blasiliam.

37. (. Posicivius (Mont. Plant. cellul. cent. VI. n. 57) froude cartilininea compressa lineari dichotoma, ramis subalternis 
rage pinnatis sensim minoribus acutis utringute ramulos brevissimos basi laud attenuatos spiuiformes ferentibus.

IIalb. ad Campeclie in peninsula Yucatan (linden).

Frons scmipedilis et ultra, compresso-plana, lasi dichotoma, lineam lata, sensim angustior, utrincue ramos distichos, alternos, cauli conformes cmittens. Rami interdum et secundi, rage pintato-corymbosi, non fastigiati, utroque margine spinis brevissimis, semilineam longis minoribusque simplicibus aut rarissime bifurcis, basi incrassatis, aculis, onusti. Structura Gigartina. Color purpureus. Substantia cartilaginea. liructus deest.

38. G. Flagellaroris (Sond. in Bot. Zeit. 1813 p. 53) fromle filiformi elongala subdistiche ramosa, ramis virgatis oppositis alternisve erectu-patulis apice angustatis indivisis furcatisve, ramulis abbreviatis.

Polyides flagelliformis Sond. $l$. $c$.

Gigartina flagellifornis Sond. Alg. Preiss. p. 29. Kü̋̈. Sp. Alg. p.731.

Ilab. ad oras occidentales Novæ Ilollandiæe (Preiss.)

Pedalis et ultra, habitu rar. denudatæ Fuci nodosi. Frons primaria flexuosa, teres, lineam crassa. Rami conformes basi plerumque angustati, medio incrassati et in apicem subulatum sensim atteruati, 3-pollicare: vel semiperlales, iterum divisi vel hinc inde ramulo abloreviato, subpollicari furcati. Sphærosporæ in cellulis periphericis ramorum incrassatorum nidulantes, creberrimi, oblongi, perisporio hyalino nucleum demum cruciatim quadridivisum continentes. Favellidia ignota. Substantia cartilagineo-comea. Color purpurascens, demum nigrescens. Structura interna fere ut in Polyide lumbricali, sed stratum medullare fibrosum decst.

39. G. muricita (Hart. ap. Beechey. Voy. p. 409) "pusilla fronde filiformi cartilaginea subdichotoma, spiunlis minutissimis aculis muricata, apicibus divaricatis acutis, capsulis spltericis sessilibus. Hlab. ad St. Francisco Californix.

lollicaris, dense cxspitosa, cylindrica, irregulariter dichotoma, segmentis superioribus patentibus; fronde tota spinulis horrita. Capsulie magnæ spharic in ramulis solitariæ. Color intense purpureus." Descr. Auct. transscripsi. Cfr. supra pag. 237 de Gig. muricata Post. el Rupr.

\section{TRIBUS IT. KHLLUIEVILE.}

Frons filis interiorilus clongatis articulatis, cellulisio rotundatis, reticulo filorun cinctis, in cellulas corticales rotumdiatas, quandocpuidem subseriatis abeuntibus, contexta. Kialidii nucleoli plures, iufra stratum exterius tumidum clausum nidulantes, 
discuptione partis fertilis demum liberati. Sphierosporæ inter cellulas corticales sparse, aut in Nematheciis externis inter fila sterilia crolutæ, cruciation rel zonatim disise.

XLII. Kallimenia J. Ag. med. p. 98. Advers, $p$. 40 et Act. Holm. 1847 p. 92. Haro. Phyc. Brit. tab. 13. Endl. Gen. Plant. Suppl. III. p. 40 (partim.) Callymenia Mont. Fl. Alger. p. 112. Enhymenia Kütz. Phyc. p. 400 et Sp. Alg. p. 741 (partim); Halỵmenix, Rhodomenixe et lridæx sp. Auct.

Frons carnoso-plana irregulariter fissa aut in lacinias ambitu definitas divisa, stratis fere tribus contesta; filis interioribus articulatis ramosis dense intertextis flexuosis, peripleriam rersus in cellulas roturuato-multingulas auastomosantes abeuntibus; cellulis superficialibus rotmndatis demum subseriatis. Lialidia in media fronde tumida formata, immersa aut hemispliærice prominentia, clausa, disruptione partis ambientis demum liberata, nucleolis pluribus composita; nucleoli intra periderma gelatinosum hyalinum gemmidia nullo ordine disposita forentes. Spharosporce a cellulis superficialibus formate, rotundatie cruciation divise. (Harv. Phyc. Brit. Lab. 13).

Frondes in cognitis omuibus planx et carnose, exsiccatione membranaceæ, attamen crassiusculæ, aliquando subcoriaceæ aut pergamenæ, integre aut plus minus dirisa, laciniis nonnullarum specierum fere regularibus et ambitu definitis, sed sæpius dilaceratione partium precxistentium, nunc externa ri, nunc extensione frondis iuxquali ortis; plurimæ iusuper species prolificant, et prolificationes, ambitu (initio) definitio, segmenta frondis pinnatim aut palmatim divisa mentiuntur. Partes juniores frondium cellulas labent strati medii longiores, attamen celluleformes et parum intertextas; in partibus magis etate provectis lıe cellule evidentius in fila ramosa abeunt. Precipue in planla regetiore fila hec granulis minulis farcta sunt. Ilis provinæ sunt cellule rotunditæ, sed multangulie (o) anastomoses, quilus nectuntur fila interioris strali cum axterioribus angulito-rotundatis, nunc simplici serie dispositis, nunc verticaliter. pluribus et fila verticalia brevissima formantibus. Cystocarpia sunt proprii fere generis, quasi favellis simplicibns numerosis in sormu globosmun conjunctis constituti, in strato intermedio formata et medium frondis ut plurimum occupantia, rarius in mal pagina emergentia, lıemispharice prominula; nucleoli singuli gem- 
midia numerosa rotundala, singula gelalina lıgalina cincla et ommia peridemate cohibita, fovent. Spharospora ninute, cruciatim divise, per frondem sparsie, transfurmatione cellularum corticalimn ortie.

Cienus, țpo Fuco reniformi, a me ipso in Mggis Mediterraneis fundatum, a plurimis receptum, sed, speciebus immixtis lieterogeneis, apud nonnullos nimium extensum. Endlicherus Constantineas Ruprechtii, sphrerosporis disersas, Kützing Cryptonemias cum nostro genere conjunsit, quod utrumq̨ue mihi parum adprobandum videlur. IIarvey, non perpensa fructus dirersitate, Schizymeniam Dubyi Kallymenie yuoque adnumeravit. Antecedentes auctores speciem unicam melius cognitam nunc Iridæis, nunc Rlıodomeniis proximam posuerunt.

Positione Cystocarpiorum lıoc genus cum lridea Bory (nec Grev.) conrenit; a Italymenia hoc respectu abludens; cystocarpiorum structura a plurimis distinguitur. I IIalymenia quogue, ni fallor, in co differt, quod cystocarpia carpostomio proprio haud donata sunt, sed circulari solutione partis ferlilis elabuntur.

Sphærosporas in plurimis speciclus vidi, raro autem modum divisionis percipere valui. Sphærosporas triangule divisis olim descripsi el Ilarvey (in Phycol. Brit.) atque Montagne (in Fl. Alg.), forsan meo decepti testimonio, declararmont. Postea in nonnullis speciebus ( $\boldsymbol{l}$. dentata) easdem evidenter cruciatas vidi. I)ifferentias hoc respectu in aliis speciebus adesse vix suspicarem. Jeon, quam in Fl. Alg. dedit Montagne, structuram non ita reddit, ut idea clara ab illa percipialur.

\section{Fronde subreniformi integriuscula aul vage fissa. * Cystocarpiis firondi immersis, parum prominulis.}

1. K. scmzopmul.. (llarv. mscr.) fronde gelatinoso-carnosa sulsessili, a disco radicali cuneatim expansa late obovata, margine plano demum in lacinias plurimas longifudinales iregonlariter lacerato.

hihod. schizoplyylla Ilarv. mscr.

Kallynienia schizophylli J. Ag. Advers. in not.; Act. Holm. 1847 p.93.

Ilab. in sinu Tabulari ad Cap. lone spei (llarves!).

Frons 3-6pollicaris a basi late cuncata sensim ital expansa ut tertin parte circuli fere circunscribatur. Sed frons, integra dum juvenilis, in partes finditur, quarum majores, sape dimidiam et ita obliquam partem frondis integra constituentes, plantam integram mentiuntur. Ha insuper in lacinias numerosas flus minus profundas, a peripheria radiatim rersus 
raslicem tendentibus, dilacerantur, ita ut margines sæpe omnino fimbriatx ligulis longis laceris. Color pulchre coccineus. Substantia sat gelatinowi, quare chartæ arctissime adhæret. Structura generis. Sphærosporas inter cellulas corticales nidulantes vidi.

Nullos ad atfines transitus suspicor. Margo nusquam undulata. Euhymenia schizoplyylla (Küls.sp. $p .742$ ) et a Llarreyana Rhodomenia schizophylla, quam hoc loco non citatam invenio, et a Iridxa lanceolata, quam huc duxit, longe alicna mihi videtur.

2. K. Reyfonuis (Turn. Hist. Fuc. n. 113) fronde gelatinoso-carnosa stipitata obovato-reniformi integra aut in lacinias obovatas irregulariter fissa, margine subplano sæpe prolifero, prolificationibus obovato-orbiculatis.

Fucus reniformis Turn. l. c. lab. 113 (partim)! Engl. Bol. lab. 2416. Kallymenia reniformis $J$. Ag. Aly. med. p. 99. Ilarv. Phycol. lab. XIII! Euhymenia reniformis külz. Phyc. p. 400. Sp. p. 743 !

IIalymenia reniformis $A g$. Sp. Alg. I p. 201. el Syst. p. 241. (excl. syn.)

Rhodomenia reniformis Ilook; Harv. Man. p. 64.

Iridxa reniformis Bory; Grev. Alg. Bril. p. 160.

Sarcophyllis Iobata Kül:. Phyc. p. 4.04 lab. 76 fg. 2?

Exsicc. Wyalt. Danm. n. 19 !

llab. in oceano atlantico ad littora Anglix et Gallix (Grifliths! lionnemaison! cet.)

Frons jurenilis a stipite brevi obovata surgit, sensim magis magisque latitudine increscens usque dum omnino reniformis, altitudine $2-3$ pollicari, latitudine longitudinem sesqui-superante; interea finditur quoque frons in lacinias plus minus numerosas, plerumque obovatas et stipite subproprio fultas, integras aul iterum divisas. Margo plerumque plana, raro parce undulata, (secundo? anno) lacinias frondi conformes emittens. Cystocarpia quam in antecedentibus affinibus minora, per superficiem sparsa. Sphrerospora in cellulis corticalibus formate, per frondem sparsa. Substantia gelatinoso-cirnosa; charta arcte adhæret. Color pulchre coccineus.

Sarcophyllis locata hülz., duce Harveyo, ad hanc speciem retuli. Ex icone citata ad Kallymeniam pertinere mihı videtur; sectione vero oblijue ducta stratum corticale unius pagine cellulis radiantibus contextum adparet.

var. cxduata (J. Ag. mscr.) fronde orato-jotundatil sessili, basi cordato-reniformi, margine amplo undubato integriusculo aut suhobato.

Ilah. ad oras l'ingitanas (Schoushoe!) ad Cap. b. Spei (Pappe!).

Frons 3-6pollicaris et parum angustior, stipite omnino nullo, supra discum radicale reniformiter expansa. Margo in senilibus amplissimus et 
undulatus, plicis in exsiccata superimpositis. Color coccineus. Sulstantia gelatinosa. Lialidia magna et conspicua, per totam frondem disposita at admodum sparsa.

Non sine hæsitatione hanc formam H. reniformi subjungo. Speciminl, qua primum vidi, a Schousboe lecta, antea al ki. Requienii retuli, sed, melioribus visis, nec ad hanc pertinere, nec cum aliis speciebus bene convenire video. A k. Schizophylla, cujus liabet substantiam et colorem, forma generali frondis, margine integre et undulato dignoscitur. A $K$. Harvegana substantia magis gelatinosa et defectu stipitis. Pappe, qui las plantas vivas vidit et qui utramque mihi misit, diversas existimasse ex numeris diversis, qubus illas designavit, patet.

var. Ferranu (Lamour. mscr.) fronde termiori elongata deorsm in stipitem eridentiorem attenuata, margine sublaciniato et in foliola obovata circumcirca excurrente.

Delesseria Ferrarii Lamour.!

Fucus reniformis var. tenuior Turn. Ilist. tab. 113 fig. g!

Iridæa Hilliana Grev. Alg. Brit.p. 161 (in not.)!

Iridæa divisa hü̈tz. Phyc. p. 396 ?

Euhymenia divisa hülz. sp. p. 743 ?

llab. in oceano atlantico ad oras Galliae (Bonnemaison! Delapflaic!).

Frons jurenilis oborato-cuneata, stipite elongato gracili plano, a disco radicali surgens, adulta magis oblonga et ob lacinias plurimas, in quas finditur, ambitu inæqualis. Laciniæe nunc circumcirca sinubus parum profundis separatr, ipse plerumque late lineares, a latere et ex apice subtruncato in prolificationes plures extensæ; nunc fronde profundius laciniati et usque ad stipitem et per stipitem fissa, lacinix basales cuneatie evadunt, simili modo a margine prolifere. Phylla prolificantia istlımo lineam aut 2 lineas lato cum laciniis trondis cohxrentia, juniora obovata, adulti undulata et ipsa laciniata, 1-3pollices longa, 1-2 pollices superne lata, inferne attenuata, basi supra isthmum ovata. Kalidia quam in specie primaria mistora mihi videntur, in prolificationibus sita. Color et substantia speciei primarix; in parte basali firmior et magis purpurea.

Varietas lise statu simplici, prolificationibus destituta et stipite gracili longiori instructa, jam a Turnero cognita fuit; forma prolifera a Greville 1. c. ita descripta ut de identitate dubitare nequeamu*; ab utroqne species forsan propria habita. Eandem nomine Delesserix Ferrarii al, Algologis

2a. Hatrmexis anoexi (Bory ap. Bel. Voy. p. 269) caule diviso, frondibus ovatis inferne attenuato-stipitatis tenerrimis elegantissime roseis repandis hïts. sp. p. ill.

Hab. ad Cap. Comorin.

Cum K. reniformi fig. B, tah. 113 operis 'l'urneriani hanc comparavit auctor et utramque immo identican fere suspicatus est. 
Gallix intellectam fuisse, specimina a Bomnemaisonio, Montagneo aliisque data, milhi probant. Qui alii speciem Lamourouxianam cum Sch. Dubyi jungunt, gravi errore sine dubio laborant. Utrum species propria an tantum varietas $\mathbf{K}$. reniformis sit, dijudicare nolui.

3. K. Ilarveraxia ( $J$. Ag. Advers. $p$. 40) fronde membranacea stipitata, supra slipitem cuneatum cordato-rotundata, marogine undulato integriusculo.

Kallymenia Harveyana J. Ag. l. c. et Act. IIolm. 4847 p. 93!

Euhymenia Harveyana Kü̈t. sp. Aly. p. 743 !

IJah. in sinu tabulari ad Cap. b. Spei (IIarvey! Pappe!).

Frons semipedalis, latitudine immo amplior, ex stipite brevi, bis lineam longo, cuneatim expansa, nunc latissime obovata, nunc basi omnino cordata, circumscriptione fere orbicularis. Nargo integra sed ample undulata, sinus irregulares hic illic efficiens, tendentia nulla in lacinias dilacerari. Substantia videtur magis membranacea quam gelatinoso-carnosa, charta laxius quoque adhret. Color pulchre coccineus. Cystocarpia per totam superficiem sparsa, satis magna. Sphærosporas non perspicue divisas vidi.

Cystocarpiis supra unam paginam emergentibus, late expansis, pericarpio obtegente superne subplano.

4. R. мiсворнizla (J. Ag. mscr.) frondibus aggregatis minutis, supra stipitein evidentem subramosum rotundatis, oblongis cordatisve, chartaceo-membranaceis, cystocarpiis oblongis permagnis supra unaın paginam proeminentilus hemisphæricis truncalis, pericarpio obtegente superne planalo.

Fucus reniformis Turn. Hist. Fuc. II p. 110 (partim) fig a. $a$ ? Ilalymenia reniformis Desmaz. pl. Crypt. (fide Crouan. mscr.)

Hab. in oceano allantico ad oras Gallix (Ilb. Guillemin! Cronan!) et Britannice (D:na Griffills!); in mari mediteraneo prope Nizzan (Ipse!) et Massiliam (Solier!).

A disco expanso radicali frondes plures gregarie surgunt. Stipes evidens 1-4 lineas longus, inferne teretiusculus, superne sxpe alatus et in ipsam laminam sensim evanescens, nunc unicam laminam sustinene, nunc (lujus divisione?) plures at paucas, lateralesque minores. Lamina ipsa circiter pollicaris longitudine, juvenilis rotundata, adulta ambitu minus regulori nunc oblonga, nunc oblique corlata, sxpins olovata. Cystocarpia pro magnitudine planter maxima, semilineam diametro excedentia, ambitu oblonga, in disco et juxta marginem sparsa, in eadem fronde.pauca $(6-8)$; in una pagina proeminentia, truncato-conica ant hemispherica et superne planata, membrana obtegente pericarpii tenuiori. Stratum inter- 
num filis almolum paucis constat; externum cellulosum sat firmum, cellulis subcontiguis; exsiccatione aretins coalescunt cellulie, ita nt nisi acido superfusa sit, structura minus lene perspiciatur. Sulastantia exsiccate membranacea, adulte et fertilis chartacea; charta lasius adlinret. Color juvenilis coccineus; senilis purpureus.

Cum k. reniformi hes species, ni fallor, confusa fuit; et dubito sone anne huc spectat fig. a. Talbula Turnerianæ. Est vero a specie hodierna lujus nominis hæc nostra diversissima, magnitudine, substantia, qua multo migis Cryptonemiam indicat, structura et fructu. Stipes revera magis erolutus in K. microphylla; cystocarpia triplo majora quam in multo majori k. reniformi. Nomen $k$. reniformis nostra conservaveram, nisi alter. forma apud auctores nostri ari sub hoc nomine sxpius intellecta fuisset. Specimina mediterranea crassiori milhi videntur, et ad alian speciem forsan pertinent.

5. K. Requexil (J. Ag. Symb. I p. 12) fronde gelatinoso-carnosa sessili subreniformi margine undulato-lohato sparsimque crenulis punctiformilus incrassato, lobis ad crenulas subcolicrentibus.

Rhodomenia Requicnii J. Ag. l. c.

Kälymenia Requienii J. Ag. Aly. metl. p. 99. Monl. Fl. Aly. p. 112!

Euhymenia Requienii liül. sp. p. 743 !

Ilab. in mari mediterraneo ad oras Massilix (Ipse!), ad Alger (ex Mont.)

Frons bis pollicem vix alta, sed sxpe latior, 3-4pollicaris; recens crassa et subcarnosa aliquantulum lubrica, exsiccata membranacea et chartæ arcte adbærens; margine eximic undulata et in lacinias ol,tusas, axillis rotundatis discretas, lobata, laciniis expansis sese invicem tegentilus, et sxpe mediantibus crenulis in modum Rhor. hilide conglutinatis et concrescentibus, unde difficilius sicpe supra chartam expanditur. Crenulæ minutie punctiformes sparsissimæ, margine incrassato orta. Rarius

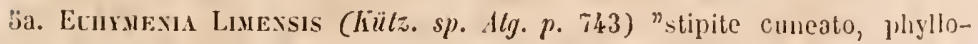
mate palmatifido-orbiculari, lobis obuvatis apice late rotundalis integerrimis icl obtuse lobulatis. Spithamæa."

Halymenia Limensis Sonder mscr.

Hab. ad oras Peruviæ (Hb. Binder).

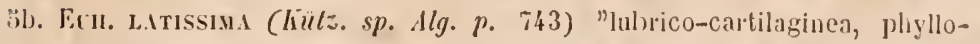
mate latissimo palmatim lobato, in stipitem brevem cito attemate, segmentis irregularibus sinuoso-lobatis, lobulis obtusis sirpe emalginatis. long. 4-8"; lat. 6-9", lohorum 2-4". Color siccita sordide virescens; apicibus sanguineis. Sulstantia crussinscula."

lialymenia latissima Ilering $\mathrm{mscr}$.

Jab. in sinu Neapolitano. 
6: margine prolifera, prolificationibus a forma ovata sensim in reuiformem et frondi consimilem abeuntibus. Sxpius et forsan externa vi frondes dividuntur, et numerosæ narginibus cohærentes cæspitem vix extricandum efficiunt. Juvenilis frons rosea maculis saturatioribus inscripta.

Specimina fertilia, quæ ad hanc speciem certe pertinent, nulla vidi. Duæ enim olim descripsi ad Tingin lecta, ad K. reniformem potius referenda puto. Fragmenta nonnulla ad Massiliam lecta, qux hujus senilem plantam forsan sistunt, gerunt cystocarpia magna in una pagina elevata; crenulæ sunt in his majores dentiformes.

Sectio II. Fronde subpalmatifula, laciniis divisione subregulari ortis, ambilu subdefinitis.

6. K. ORNati (Posl. el Rupr. Illustr. Alg. p. 17) fronde carnosopergamena stipitata reniformi-cordata palmatilobata, segmentis late cuneatis superne el a margine in prolificationes plurimas obovatas, simplices aut iterum divisas, abeuntilus.

Iridæa ornata Post. el Rupr. l. c, tab. XXXI!! in̈̈l.. sp. p. 725!

IIab. in oceano pacifico septentrionali ad Kamtschatkam (Exp. Lülkeana!).

Specimen 1. c. depiclum pedale, latitudine fere bipedale; obveniunt vero (scc. auctores) specimina triplo majora. Stipes tiliformis pollicaris in laminam cuneatim expanditur; lamina supra stipitem cordato-reniformis, palmatilobata; lobi late cuneati, 3-6pollices lati, apice iterum in lacinias angustiores, peripheriam versus sensim densiores et magis angustas, divisi, atque a margine plyyllis obovatis prolificantibus plurimis obsiti. Pliylla prolificantia majora iterum iterumque fimbriata; minora simplicia aut hæc inmo processubus ciliiformibus obsita. Substantia carnosopergamena; charta non adhæret. Color cinnamomeo-viıosus. Cystocarpia linc inde sparsa, diametro linealia, nodulos parum elevatos referentia.

Species distinctissimi, quoad structuram frondis hujus loci videtur.

7. K. DExtata (Sullr. Alg. Eckl. n. 50) fronde carnosa slipitiala dichotomo-palmatifida, segmentis late linearibus aut cuneatooblonģis, apice rotundatis, marghine inequaliter serrato-dentalis, sepe proliferis, prolilicationibus segmento conformibus.

Halymenia dentata Suhr. l. c. in filora 1834 lab. 1 fig. 8!

Kallymenia dentata $J$. Ag. Acl. Ilolm. 4847 p. 93 lal. VII!

Var. «. fronde subpalmato-dichotoma, marginibus integriusculis.

Hlalymenia carnosa külz. sp. p. 718!

Var. pr. fronde subpalmato-dichotoma, marginibus serrato-dentatis. II. carnosa $\beta$. dentata Küls. $\ell$. $c$. 
Var. $\gamma$ fronde clongata (pedali) irregularius fissa, laciniis oblongis. Luhymenia Schizophylla Külz. sp. Alg. $p$. 742? (cxclıs. synon.)

Ilab. in sinu tabulari ad Cirp. b. Spei (Ilarve!! Pappe!).

Frons sxpe ultra pedem alta, ramificatione et forma fere Blıod. palmatx; a stipite plano sensim cuneatim expanditur in laminam nunc matgis dichotomam, nunc omnino palmatam, nunc elongatam et fore pinnatifidam, segmentis iterum iterumque laciniatis, aut fere linearibus, ant cuncatis et apiec rolundatis. A margine insuper undique sape prolifera, prolificationibus conformibus. Margines adultiores fere semper serraturis conspicuis ornantur; lacinix externa vi orta sæpe integriuscule, nunc he rquoque margine incrassate et dentibus ornate. Substantia crassa. Color frondis coccineus. Cystocarpial subprominentia et spllarospora per frondem sparsa. Structura generis; in specimiubus retustis et crassis stratum superficiale cellulis minutis in fila moniliformia seriatis constat.

Species, si quæ alia, facile distincta. Omnium maxime crassa et, in aqua cito resiviscens, valde carnosa; exsiccata subcartilaginea. Ramiticatione a cateris Liallymeniis quodammodo abludit, segmenta offerens ambilu detintita. Sed resera species generis, prolificationibus, in hoc genere fere normalibus, quorgue instructa. Dentes, seu potins serratura, nunc onnes margines ornant, nunc fere nulli; raro tamen specimen occurrere videtur; quod is omnino caret. Species citatas hiitzingianas ad unam eandemque speciem pertinere, vix dubito.

\section{K.? polidess (J. Ag. Symb. p. 12) fronde membranacea stipitata} dichotomo-palmatifida, segmentis late linearibus cuncatisve, it margine integerrimo subpiunatim proliferis, prolificationibus cuncatis dichotomis.

Rhodomenia polyides J. Ag. $l$. c.

Sphrerococcus? polyides liülz. sp. $p .784$.

Ilab. in occano Atlantico ad Corunnan Ilispania (Ilb). Solier!).

Frons saltim 6-pollicaris, segmentis semipollicem et ultra latis, dichotoma aut segmentis pluribus adproxintatis sulppalmata. Segmentit majora late linearia sinulsus subrotundatis discreta, terminalia sxpe truncala et in plures apices excurrentia, demum in plyylla novella transenutia. A margine, præcipue inferioris partis, prolificationes plurime pinnitim

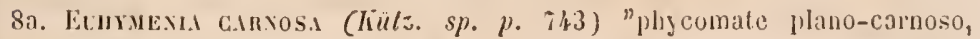
pluries dichotomo, segmentis latis hasi attenuatis, superiorihur palmatitidis, apicibus olutusis rotundatis. Spithamai. Lat. segmentorum inf. 1/2-1", supremorum 1-3"'. Color pallile rulter, virescens. Substantia gelatinosa mollis. Chartw siccitate arcte adharens."

IIalymenia carnosa llering.

Ilal. ad oras Algerix. 
fere proveniunt, multo minores, sxpius pollicares et $2-3$ lineas late, basi al stipitem fere setaccum attenuate, dein cuneatix, raro indivisa et sul)spalhulate, plerumque furcate, aut composite dichotoma, apicibus plerumque attenuatis. Substantia membranacea; charta vix adhæret. Color vivide coccincus. Fructus nullos vidi.

Species sine dubio distinctissima, sed forsan hujus generis incerta. Stratum exterius cellulis contigue coalescentibus, interius filis densius stipatis contextum. Ad nullum aliud genus melius referendam speciem hoc loco disposui. Nisi obstaret color coccineus et frons magis membranacea, Rh. palmatam facile putares; proliticationes separatas Rh. palmettam fere crederes. Descriptio speciei, quam ad fragmentum a Solier anno 1837 datum primus exaravi, vitiis pluribus laborat. Nec enim ita magna villetur, nec ad Massiliam lecta, nec prolificationum (pinnularum) forma normaliter oborata; anno $\mathbf{1 8 4 1}$ ad Massiliam redux, meliora edoctus, speciem inter mediterraneas non enumeravi. Descriptionem ad specimen datum hoc loco corrigere molitus sum.

\section{Species inquirende.}

9. EuIrNexid CApexsis (hütz. sp. p. 742) "pliyllonate coriaceomembranaceo, firmiori, pluries dichotomo, segmentis exacte linearibus, patentiusculis, (axillis obtusiusculis) terminulibus interdum ligulatis, basi constrictis, apice obtusis. Long. 5"; lat. ubique fere aqualis, $1-1 \frac{1}{2}$ ". Color ruber, siccate virescens. Substantia firma duriuscula. Structura generis; strato exteriori tenuiori minori, medullari maximo, laxe fibroso, intermedio parenchymatico achromatico."

Hab. ad Port Natal. (Guciuzius).

10. Hlatuexia reptais (Suhr. Alg. Eckl. p. 14 tab. 11 fig. 17) "parvola, stipite filiformi setaceo reptante, ramis divaricatis planis furcatis vel palmatifidis, segmentis linearibus basi attenuatis, $1 / 4-1 / 2-1^{\prime \prime \prime}$ latis. Alt. 2'"-1". Structura peculiaris; strato corticali subtiliter celluloso, cellulis rolundis monogoniunicis, medullari fibroso, fibris rigudiusculis implicatis lıyalinis." Euhymenia? reptans hülz. $s p . p$. 742.

Ilal. ad Cap, b. Spei (Eclion).

Vix lıujus loci. beseriptionem a Kützingio, qui specimen vidit, mutuatus sum.

11. Ilı. Llbrica (Suhr. Eckl. n. 49) 2-3pollicaris fronde membranaceo-gelationosa subrotunda sinuosa plana, fertilis hullata, sporis ovalibus singulis ant aggregatis.

Jlak, ad Cilp. J), Spei (Echlon). 


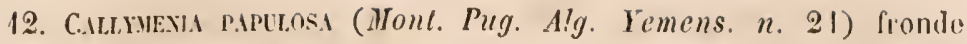
membranicea gelatinosa papulosa polymorpha ruhra lineari maroine apiecque axillis rofundatis lobati, lohis ant conformibus aut cuneatis aut attenuito-icutis ambitu ciliatis, conceptaculis e marogine rof e superficie frondis sphropicis spimulosis.

Ifah. in mari rubro ad lillus Irabiat folicis.

Frons membranaceo-gelatinosa, rerrucis numerosis ad utramque paginam prominentibus exasperati, variolosa, a hasi lineari sursum dilatatil, quindoque cuncata, margine in lobos seu conformes seu flalocllatos dirisa. Lobi iterum inter se latere inferiore sinubus rotundatis sejuncti, et vage multiparti, divisionibus extremis acutis, in indiriduis quibusdam ciliatis. Conceptacula marginalia rel in superficie frondis sessilia, spina unica aut pluribus brevibus armata, globosa, millimetro crassiora, depressa et a papulis valde et semper distinctis. Spore e placenta centrali cellulari undique irradiantes, oblongx aut obovoideo-pyriformes, intense purpurex, perisporio filamentoso basi articulato vestitie. Structura frondis: stratum medullare e filamentis crassis articulato-reticulatis, intermedium e cellulis sphæricis sensim minoribus, corticale tandem e gonidiis minutis oblongis moniliformi-concatenatis formatum.

Cel. Auctor suam plantam cum Eulıym. Schizophylla hǚ. comparat; si vero structuram fructus rite descripserit, planta Sphicrococcoideis forsan pertineat.

XLiII. Constantinea Post. el Rupr. Illustr. Alg. Ross. p. 17. Kallymenie sectio, Constantinea Endl. Gen. Il. Suppl. III p. 40. Neurocaulon Zanard. Saggio p. 49 in adnol. Kü̈ts. sp. Alg. p. 744. Cryptonemix? sp. Harvey.

Frons caulescens ramosa, ramis in laminas carnoso-planas explanatis, stratis fere tribus contexta; filis interioribus parce anastomosantibus, rersus peripheriam in collulas rotundatas abeuntibus, cellulis superficialibus minutis rotundatis. lialidia in media fronde immersa, cliutsa, disruptione partis ambientis demum liberata, nucleolis pluribus compositi; nucleoli intra periderma gelatinosum hyalinum genmidia, nullo ordine dispositil, forentes. Spherosporce in Nentatleciis externis evolute, paranematilus cincte, oblongie, zonatim divisx (Post. el Rupr. lab. XL. fig. 84-88).

Caulis in omnibus adest teretinsenlus et ranosns, ramis sime ordine exenutibns, diclotomiat ortis, sparsis aut immo oppositis, nune laninis pluribus perfoliatim superpositis nunc unical terminatis, senilibus reliquiis limmine perfoliatie annulatis. Lamina crassic 
carnosr, aut perfoliala et orbiculares demum irregulariter a mar:ine fisse, aut reniformes in apice ranormm terminales, margine jutegrx. Laminx stratum centrale constit cellulis elongatis cylindraceis paree anastomosantibus, imfra membranam hyalinam endocluroma dilutius coloratum foventibus. Ilis proximx sunt cellulie rotundate magis contigux. Cellulæ minute, subsingula serie disposite, superficiem efficiunt. Cystocarpia sunt Kalidia; loc est, quasi favellis simplicibus numerosis in sorum globosum conjunctis constituta, strato intermedio immersa et medium frondis revera occupantia; nucleoli singuli minuti et gemmidiis paucis constantes. Sphierosporx (a me non visx) in strato peculiari externo, nemaflecia in pagina (superiore?) prominentia constituente, evolute, oblongæ, zonatim divisæ, paranematilus sterilibus numerosis cinctic.

Genus ab Algologis rossicis supra citatis egregie constitutum, mirabili illi Rosa marina Gmelinii fundatum, nova consimili adjecta specie et distincta tertia, cun aliis antea confusa. Cum Kallymenia structura frondis et Cystocarpiis ifa conrenit, ut de legitima distinctione fere dubitares. Sphærosporx vero egregiun distinctionis characterem suppeditarunt.

Structuram lamina in una Specic satis diversam pingunt auctores generis, guod quonam jure factum fuerit, specimine nullo viso, decidere non potuerim.

1. C. Reviformis (Post. et Rupr. IIl. p. 1\%) cinle tereti examnulato rage ramoso, ramis apice in laminam rotundato-reniformem expansis.

Const. reniformis Post. et Rupr. l. c. in notula. IIart. Phycol. Br. sub n:o 13 in adnot.

Halymenia reniformis $\mathrm{Ag}$. $\mathrm{sp}$. (partim; (quoad sp. mediterr.) J. Ag. Alg. med.p. 99 (sub. Kallymenia). Mont. Fl. Alger. p. 113!

rucus acetabulum Gouan!!

Iridea foliosa Menegh. Sunt. p. 11.

Neurocaulon foliosum Zanard. Saggio. p. 49!! Kütz. sp. p. 74, !

Cryptonemat? Forbesii Ilarv. in Ilook. Ic. Lab. 679.

Ilab. in mari adriatico ad oras Dalmatix (IIb. Meneghini ! et Zanardini!); in mari mediterraneo ad Cette (Silmman!), Marseille (Solice!).

Caulis vix ultra polficaris, crassitic pennie columbinx, teres, annulis nullis instructus, ramosus, ramis densis conformibus nullo ordine excuntibus, paucas lineas longis. Lamina aut in caule ramisve principalibus sessites, aut petiolo brevi (demun in ramum evoluto) suffulta, rotundato- 
reniformes, 6-8 lineas alięuando pollicem kata, jlerumque bresiores, margine integre. Sulstantia satis crassa et carnosil. Color obscure coceineus, srepe in fuscescentem tendens. Kalidia in maculas iuformes, plus minus magnam laminie partem occupantes, congesta.

Confusionis cum Kialymenia reniformi, cui hac: species fuit ohnoxia, primam dedit ansam Mertensius, gui illam nomine Gouani et Turneri simul inscriptam Patri misit. In speciebus Algarum specimen Mertensianum sub 1I. reniformi potissimum descriptum viletur, diversitate liujus plantie eo minus in dubium vocala quod forma una (fig. $\alpha_{\text {. }}$ ) Turnerianx tabula: in præsenten haud male cadit. Hac auctoritate lpse illam in Algis mediterraneis introduxi, uondum cognito opere Rossico. Harvey plantam jam a Postels et Ruprecht distinctam ulterius quoad synonyma extricavit. Speriem esse a Kallymenia reniformi et $\mathrm{K}$. microphylla diversam baud dubitandum. Generice quoque differre ex analogia hodic suspicatur. Quantum enim comperi, sphxrospora a nemine hucusque observata fuerunt.

2. Coxst. Sitciexsis (Post. el Rupr. Ill. p. 17) caule tereti ramoso annulato, interstitiis diametro 4plo longioribus annulos separantibus, ramis apice in laminam orbicularem peltatam integram expansis.

Const. Sitchensis l. c. tab. XL fig. 88 !

Neurocaulon Sitchense liüz. sp. p. 744!

IIab. in oceano pacilico superiore ad insulan sitela.

Omnibus partibus sequente major. Lamina solitaria in appice ramılorum suborbiculata, diametro 4-6pollicaris, integra, cetate tantum provectiore vario modo lesa; interdum jureniles cum majoribus-occurunt laminx, 8 lineas in diametro late.

3. C. rosa marixa (Gm. Hist. Fuc. p. 102) caule tereti ramoso annulato, interstitiis diametro duplo longioribus annulos separantibus, ramorum laminis plerumyne pluribus perfoliatis orbicularibus peltatis mox ad centrum usque laciniatis.

Fucus rosa marina Gm. l. c. lab. V. f. 2! Ag. sp. p. 190.

Const. rosa marina Post. el Rupr. Ill. p. 17 lab. XXX!

Neurocaulon rosa marina liütz. sp. p. 74 ! !

llab. in oceano Pacilico ad liftora Kamtschallic (Steller et Mertens).

"stipes semipedalis et minor, lapidibus vel conchis affixus, jam a liasi ramosus; rami adscendentes, flexuosi, nudi, teretes, 1-2lineas lati, in sirco cornei, 'secus carnosi et intus cartilaginei. Amuli plerumpuc $2-3$ lineas a se invicem distant, in ramulis junioribus densiores sunt. Rami disersi quoar latitndinem non multum inter se differunt et paulo tantum tenuiores sunt quam stipes primarius. Lamina rersus apicem ramulorum 
sitæ verticillatx; suprema oriviculata, diametro 9 -pollicaris, peltata laciniatn, laciniis 3-6 obovato-spathulatis; Centrum sive locus insertioni stipitis obsersus plerumque protuherantix regulari convexa, imprimis vero consistential molli, ceren insignitur. Sub lamina terminali hac verticilli 2-4 laminarum pari modo ad ramum fere fissarum dispositi sunt, quibus deciduis caulis nudns et annulatus efficitur. Raro et rarissime peltæ terminales orbiculatæ atque integræ manent. Substantia laminæ facile dilacerandæe carnoso-coriacea, in sicco rigida multo tenuior et fragilis. Color fusco sanguineus."

Species forma et habitu singularis, precedenti videtur proxima, cum nulla alia facile confundenda. Diu tantum figura et descriptione Gmeliniana cognita, fere fabulosa mansit, donec Illustratores Algarum Rossicarum icone et descriptione data speciem ita illustrarunt, ut illam ad certum systematis locum referre liceat.

Xliv. Callophyllis hiüz. Phycol. p. 400 et Sp. Alg. p. 744. J. Ag. Alg. Liebm. p. 13. Rhodymenix sp. Grev. et Auct. Sphærococcus sp. $A g$.

lirons carnoso-mem!ranacea plana diclıotoma aut subpinnati, stralis duobus contesta; interioribus cellulis rotundatis magnis superficiem versus sensim minoribus, reticulo cellularum anastomosantium cinctis; strato exteriore filis verticalibus moniliformibus constante. Kalidia diseo aut margini immersa, clausa, disruptione partis fertilis demum liberatil gemmidiis minulis plurimis iutra cellulas præognantes, reticulo disjunctas, erolutis, constuntia. Spharospore frondi immerse, sparsw, cruciatim divise. (Kütz. Phyc. tab. 69 II.)

Frondes coccineo-rosex, planæ, enerves, nunc latiores dichotonæe aut subpalmate, nunc angustiores dichotomæ aut pinnatie, margine aut integerrime aut limbriis minutis ornatie vel prolificationibus segmento conformibus instructie; recentes carnosie aut membranticex, exsiccati parum cartilioginex, flesiles et chartx sepe arcte adhærentes.

Stratis duobus constifuta est frons. Interius cellulis constat rotundatis angulatisve, majoribus in medio, superficiem versus ninoribus; spatium inter cellulas angustum cellulis occupatur minoribus concatenatis, que ita in reficulum majores amplectens conjungumtur, et superdiciem rersus in stratum exterius frondis excurunt. Cellule strati peripherici minute, rofundate, in fili brevia monilifornia conjuncter. 
Kialidia disco aut marogine aut immo fombriis marouinalibus immersa et utringue subprominula, intra periearpiun clausum, it strato frondis exteriore magis incrassato et interioris margine formalum, nidulantia, mucleolis plurilus, reticulo dilorum sejunctis, constituta. Nucteoli ab endochromate trimsformato et in gremnidial diriso cellalarum froudis interiorum formati, et membrana cellularum cincti, tot itaque quot cellulie pregnantes. Gemmidia rotundatit, intra singulas cellulas priegnantes plurima. (Sp. 1. 2. 3. 4. 7. 8. 9!)

Splacrospora inter fila moniliformia strati esterioris formatx, splixroidea aut oblongre, sparse, nunc in sorum informem adprosimate, cruciatim divise. (Sp. 2. 3.6!)

Species lıujus generis, labitu Rhodymenix, fructificationem longe aliam gerunt, quare genus illis proprium non immerito formarit Kützing. In Plıycologia hic tantum duas typicas species affert; tertiam speciem generis inter Splacrococes enumeral, determinatione Suhrii deceptus, qui nomine usurpato Splı. Lambertii diversam plantam distribuit. In descriptione $\mathrm{N}$. . Lielmanni noras quasdim species Generi vindicari; Sonder alian, Montagneus et llarvey nonmullas novas adjecerunt. In recentissimo suo opere, speciebus nomullis leterogeneis genus sum ausit Auctor.

Quoad structuram fructus a Kützingio et Montagneo dissentire coactus sum. Cellulæ concitenatæ, que pregnantes cellulas reticulutim ambiunt, ab utroque, si verborum sensum rite interpretaverim, spermopodium efficere considerantur. Nontagneus immo filum ramosum depinxit, cujus in apicibus coloratis spuras (singulas) formari credidit. Sporas minime in articulis lıorum filorum oriri, sed in cellulis majoribus et quidem in cellula quoque plurimis, videre credidi. Sccundum Kützingioum et Ilontagneum fructus favellidia essent; milhi Kalidia obrenerunt.

Nomen a Külzingio datum conservavi, licet forsan cum Calophṛllo Linnæi nimium consonum judicetur.

1. Cas. obresiforiı (J. Ag. mscr.) fronde dichotoma subfistigiatio margine integerrima, segmentis cumeato-linearibus, terminalibus versus apicem attenuatis obtusis, lialidiis diseo frondis immersis.

Cal. australis J. Ag. Alg. Liebm. p. 13.

Ilab. ... e mari itustrali iı Ilb, Igardlı!

Habitus fere et magnitudo Gracilaric polycarpa, qualis hee a Ilamey in Phycol. lab. XV depicta exstat. Sexpollicaris, inferne angustior ct linean 
vix lata prope basin, sensim latior fit, infra segmenta media usque semipollicem latitudine æquans, versus apices iterum longe attenuata. Ramificatio dichotoma, 6-7:ies repetita, axillis rotundatis inter segmenta erectiuscula. Segmenta levissime cuneata, linearia aut potius fere elongato-oblonga. Kalidia in superiore parte ubique frondi immersa, sparsia, diametro semilineam superantia. Structura generis. Color carneo-purpurascens. Substantia membranacea.

Nomen a me antea datum, ob consonum alterius speciei a Sondero descriptx, mutandum credidi.

2. Cal. discigera (J. Ag. Symb. I p. 13) fronde orluiculariter expansa subpeltation affixa dichotomo-subpalmata, segmentis lineari-cuneatis maroine sæpe proliferis, terminalibus crenulatis, kalidiis disco frondis immersis.

Rhodomenia discigera J. Ag. Ł. c. (partim) Külz.sp. Alg. p. 743 (excl. syn.)

Cal. discigera J. Ag. Alg. Liebm. p. 13 !

Ilab. in mari australi ad Cap. b. Spei (Lalande! Harrey! Pappe! IIb. Turner! et Crouan!)

Frons lapidibus conchisque subpeltatim affixa et sessilis, in orbem expansa, 3-spollicaris, in seğmenta numerosissima divisa. Ramiticitio inter dichotomam et palmatam fere intermedia. Segmenta inter dichotomias approximatas brevia, linearia aut cuneata, aliquando usque pollicem lata, margine integra aut segmentis conformibus prolifera, terminalia angustiora apice rotundato-obtusa, margine irregulariter inæequalia et crenulata. Kalidia diametro semilineæ per discum segmentorum sparsa, immersa. Slructura frondis et sphærosporæ generis. Color roseo-coccineus. Substantia carnoso-membranacea. Chartæ vix adharet.

Quum banc speciem primus describerem, cum Chrysymenia depressa, quam sterilem tantum videram, confudi. Postea utramque rite distinxi. -

2a. Cal. onxata (Mont. Prodr. Phyc. antarcl. $p$. 1) fronde stipilata subpalmato-pinnata, segmentis lineari cuneatis, margine sæpe proliferis, terminalilus obovatis, kalidiis disco frondis immersis.

Hhod. ornata Mont. l. c. et Voy. Pol. Sud. p. 159 lab. 11! Hook. et Ilarv. Crypt. antarct. p. 74.

Caloph. oruata hü̈tz. sp. p. 7h.6!

IIab. in oceano australi ad Insul. Aucklind (D'Urville).

Frons carnoso-membranacea, vivide purpurea, oblongo-lanceolala utrinque margine prolifera, foliis seu pinnulis oboratis tandem cuneatis et pulmatifissis, unguem vel ultra pollicem latis.

llabitus omnino lihod. palmatæ, sed magis carnosa, saturatius purpured, nec in violaceum tendens. 
Afrinitale ad sequentem proxime accedil, characteribus insignibus diversam. llarveyo, in Gen. South. A/r. Pl., lane formam a Rlı. laciniata diversam esse jam suboluit.

3. Cal. Lacisista (Huds. Fl, Angl. $p$. 579) fronde flabellatim cxpansa stipitata dichotomo-subpalmati, segmentis lineari-euneatis margine sxpe proliferis, terminalibus subintegris, lialidiis in fimbriis brevissimis marginalibus immersis.

Fucus laciniatus IIuds. l. c. Engl. Bol. tab. 1068. Esp. Icon. Lab. 14.0. Turn. Hisl. lab. 69! Slackh. Ncr. Ed. 2 tab. 13!

Caloph. laciniata Küls. Phyc. p. 401. Sp. Alg. p. 74 !

Sphærococcus laciniatus Lyngb. Ilydr. p. 12 lab. 4! Ag. Sp. I p. 297! et Syst. p. 230! Mont. Fl. Boliv. p. 28?

Rhodomenia laciniata Grev. Alg. Brit. p. 86! Harv. Man.p.60! et Bot. of Becch. p. 164. Phyc. Brit. Lab. 121! Aresch. En. p. 73 !

Delesseria laciniata Ilook. Fl. Lond. new. Ser. Lab. 198. Marl. Fl. Bras. p. 41.

Fuc. crispatus Slackl. Ner. Br. Ed. 1 lab. 13.

Delesseria ciliaris Lamour. Ess. $p$. 37.

Fucus miniatus Müll. Fl. Dan. lab. 769 !

F. ciliatus Gm. lab. 21 fig. 1 !

Clr. delicatula Gm. I lab. 8 (fide Aresch.)

Exsic. Chauv. Norm. n. 96 ! Hyalt. Danm. n. 17.

Ilab. in oceano allantico ah oris Norvegia! et Foeroearum! usque ad Gades! et Brasiliam (Nartius); ad Californiam.

Frondes a radice scutata plerumque plures, stipite brevissimo cuneatim dilatato surgentes, in flabellum semicircularem expansæe, 3-8pollicares. Ramificatio inferue dichotoma, superne plerumque palmata. Segmenta supra axillas rotundatis connirentia, linearia aut infra dichotomias cuneata, semipollicem vel usque pollicem et ultra lata, margine nunc integerrima nunc prolificationibus conformibus instructa, nunc (capsulifera) processubus minutis denticulatis, lineam vix longis, continua serie fimbriata. Kalidia in his fimbriis demersa et utrinque subxqualiter prominula. Spluærosporx in aliis individuis margine integerrimis provenientes, in disco sparsiores, juxta margines in sorum oculo nudo fere conspicuum adproximatæ. Structura generis. Color carneo aut sanguineo-coccineus. Sulstantia carnosomembranacea. Chartie adhæret.

Varietates $\beta$. discigera et $\gamma$. Ferrarii $A g$. Sp. sunt plantx omuino diversa; illa inter Nemastomas a nobis recepta, hire ad Kallymeniam relata.

4. Cal. alcicorisis (J. Ag. Symb. II p. 44i) fronde di-trichotoma subfastigiati, segmentis anguste lincaribus, marwine inaryuali sparsin denticulatis, terminalibus supra sinum rotundatum in- 
teriore latere integris, esteriore eroso-denticulatis, kalidiis disco frondis immersis sparsis.

Rhodomenia alcicornis J. Aq. l. c. Kütz. sp. Atg. p. 779 !

Call. alcicornis J. Ag. Alg. Liebm. p. 13.

Ilab. ad oras Novx Ilollandix (IIb. Diesing!)

Frondes a callo minuto bipollicares dichotoma, raro trichotomæ, finsligiatæ. Segmenta margine valde inæquali quasi erosin, sesquilineam latitudine vix superantia, superiora angustiora, linearia vel infria trichotomias subcuneata, supra axillas rotundatas arcuatin convergential, interiore latere plerumque integra, exteriore erosa aut dentibus sparsis acuminatis simpliciusculis dentata, nonuulla utrinque laciniata. Kalidia media fronde immersa, sparsa. Substantia tenuissime membranacea. Color carneo-purpurascens. Chartæ arctissime adhæret. - Structura et fructus generis.

5. Cal. Linberti (Turn. Hist. Fuc. IV p. 96) fronde dichotoma, segmentis anguste linearibus a murgine pinnatis, pinnis segmento conformibus, supra sinum rolundatum interiore latere integris, exteriore duplicato-crenatis, kalidiis margine frondis immersis.

Fucus Lambertii Turn. l. c. tab. $23 \%$.

Sphærococcus Lambertii (partim) Ag. sp. p. 302 et Syst. p. 232 !

Rhod. Lambertii Grev. Alg. Bril. Syn. p. XLVIII!

Cal. Lambertii Ilook. el IIarv. Alg. Tasm. n. „̋̈?

Ilab. ad oras Nove Hollandix (King, Labillardicre! Hb. Areschoug!)

Frondes a callo scutato plures erectiuscula, 6-pollicares rel ultra pedales, dichotomo-ramosissimœ. Ramificatio inter pinnatam et dichotomam iutermedia, ita ut rarnus quisque initio est dens aut pinna; nonnulli autem præ cxteris elongati formam recuperaut ramorum principalium. Ramus quisque sed præcipue terminales supra sinum rotundatum arcuatim convergentes, interiore latere fere integerrimi, exteriore dentati, dentibus denticulatis, denticulis obtusis; terminales ob formam eximie falcatam, apice procipue denticulati (seu palmato-multifidi T'urn.). Pinnæ ut majores evadunt interiore latere quoque dentibus aut pinnulis ornantur. Rachis inter pinnas leviter flexuosa. Substantia firma subcartilaginea. Color e carneo coccineus. Chartæ vix adhæret. Fructus ipse non vidi.

Substantia firma inter affines insignis, ramificatione accuratius inspecta ab his quoque abludens. Species a Turnero eximie depicta; characterem ramificationis tamen non ita ac fas fuit exposuit. A sequentibus Auctorilous cum aliis confusa. Al Agardhio specimina sequentis ut F. Lambertii descripta fuerunt. Dein a Sulrio planta Capensis, omnino diversa, nomine l. Lambertii distributa fuit et hac a Kützingio (Sp. p. 732) ut planta Turneri et Agardbii proponitur. Veram autem speciem hujus nominis, 
quam coram oculis halhuisse vilentur llook. et llarvey, ut speciem siloi plane incognitam alio operis loco $\left(S_{p}\right.$. p. ih7) memoravit kützing, identitate Rhod. Lambertii Grev. cum Fuco Lambertii Turneri nullo modo, ut videtur, suspecta.

6. Cal. Carnea (J. Ag. Act. Holm. 1849 öfoers. p. 87) fronde dichotoma lic illic multifila, segmentis anguste linearilus a margine pinnatis, pinnis segmento conformibus utrintue sequalibus apice subdilatatis laciniatis dentatisve, dentibus anguslis, lalidiis margine [?] frondis immersis.

Sphærococcus Lambertii $A g$. (partim).

Ilab. ad occidentales Nove Ilollandia oras (Mus. Paris.!).

Frons videtur usque pedalis, linearis et dichotoma at inequaliter hic illic extensa, ex parte dilatata ramos sxpe tres, aliquando plures, emittens. Rami itaque non raro oppositi. Prater ramos principales, a margine exeunt pinnæ minores, principalibus plus minus conformes, ulsi ahbreviatæe evidentius infra apicem dilatata, dentibus pluribus abbreviatis aut elongatis angustis a parte dilatata lateraliter et præcipue sursum egredientibus; ubi elongate cadem ramilicatio licet minus conspicua. Partem inferiorem usque 6 lineas latam, superiorem lineam latitudine æquanten vidi. Color madefacte pulchre carneus, exsiccata coccineus. Cicatrices capsularum ad margines videre credidi, capsulas vero nullas. Structura et sphærosporæ generis. Chartæ non adhæret. Substantia madefactæ carnosa, exsiccatæ membranacea.

Est planta a Cal. Lambertii certe distincta, madefacta magis carnosa, exsiccata multo magis flaccida. Ramificatio quoque alia, a diversitate segmentorum terminalium in utraque pendens. In Cal. Lambertii sunt hæc constanter gemina, arcuatim convergentia, exteriore latere duplicatodentata; in Cal. carnea sunt segmenta terminalia infra apicem dilatata, laciniis aut dentibus pluribus circumcirca exeuntibus; ut dentes in segmenta prolongantur, plures simul elongati ramos trichotomos aut multifidos reddunt.

7. Cat. Coccisea (IIarv. Alg. Tasm p. 8) fronde dichotoma sxpe triclotoma aut multifida, segmentis anguste linearibus a malgine pinuatis, pinnis segmento conformilus, exterioribus trichotomix interiore latere supra sinum rotundatum integriusculis, exteriore laciniatis, laciniis angustis, laalidiis disco fromdis immersis.

Cal. coccinea Ilarv. l. c. hüul. sp. p. 746.

Sphærococcus australis Ilarv. in Hook. Lond. Journ. III p. 44.̈.

Chondrococcus australis hiül. Bol. Zeil. 1847 p. 23.

llab. ad oras fasmannix (Smilh et Gunn in IIb. Haryey!). 
Frons membranacea tenuis, 4--6pollicaris, segmentis principalilus 2-3 lineas latis, terminalibus semilineam latitudine baud attingentilous. Segmenta linearia infra trichotomias sxpe cuneatim dilatata. Prater segmenta principalia, siepe plura minora a fronde dilatata exeunt, ita ut mon raro polychotoma; terminalia plerumque semipollicari ab apice distantia trichotoma, aut repetitione ejusdem ramiticationis opposite pinnata, pinnis sepe unilateraliter laciniatis, laciniis linearibus attenualis simplicibus aut ipsis dentato-laciniatis. Kalidia disco laciniarum immersa, sed ob angustiam laciniarum non raro marginem attingentia. Color pulclire coccineus.

Substantia tenui ad C. alcicornem et C. variegatam accedit; priori forsan proxima.

\section{CAL. TExERA (J. Ag. Act. IIolm. Öfeers. 1849 p. 87) fronde} decompositu-pinnata, pinnis pinnmlisqne basi simplicioribus linearibus, superne decompositis expansis, termiualibus ambitu rofundatis duplicato-incisis, laciniis oblusis emaroinatisve, halidiis per discum frondis sparsis.

IJab. ad Slıetlandian australem (IIenzies!).

Frons circiler 3-pollicaris dense pinnatim decomposita. Pinnæ $2-3$ lineas lata', superiores angustiores, basi simpliciores residuis pinnularum inaquales, superne expansa decompositx, pinnulis conformibus. Pinne finnulcque apice rotundatie dilatatx, al ambilu incisæ, laciniis iterum incisis, partibus olılongis ovatisve obtusis aut emarginatis. Kalidia per discum laciniarum sparsa, diametro semilineam æquantia, in nostris fere effoeta. Substantia quam in cateris magis membranacea. Color coccineus.

9. Cas. varaegata (Bory Coqu. $p$. 179) fronde decomposito-pinnatil, pinnis pinnulisque basi simplicioribus linearibus, superne decompositis expansis, terminalibus obtusis duplicato-crenatis, crenis obtusis, kalidiis juxta marginem frondi immersis.

Halymenia variegata Bory l. c. pl. 14!! Monlagne apud D'Orbign. p. 22 II

13hod. variegata J. Ag. Symb. I p. 13̈. Monl. Bonite p. 106. I'ol. Sud. p. 1:36. Hook. el llarv. Crypt. anlarct. p. 169 (partin?).

Callophyll. variegata liulz. sp. p. т43.

Rhod. glaphyra Sulir. Fl. 1839 p. 69 fig. 43 !!

lhod. Hookeri Ilarv. in Lond. Journ. Bol. IV p. $2: 38$ (fide Jlook. et Harv. I. c.)

IIal). in oceano Pacifico ab oris Permia meridionalis uspue ad Concepcion Chilensium (1)'Urville! Baume! l'Onbigny! Ilb. Binder!); atl novan Guineam (sec. Bory). Nel insulas Aucklaud (b'lluille).

Frons circiter semipedalis, lripinnata ulteriusque pinnatim decomposita, pimns valde adproximatis, alternis et fere oppositis, plurimis 
jmmo aliquando approximatis, hasi simpliciusculis et pinnulis abbreviatis obsitis, superne pinnulis sensim longioribus sufcunealim expansis, terminalibus obtusis, plus minus profunde incisis crenatisve, laciniis crenisfue oltusis sape truncatis emarginatisve. Kalidia intra maryinem at ipso margini immersa, semilineam diametro iefuantia, in ulraque pagina subprominentia. Color cocciueo-purpurascens, raro variegatus. Substantia membranacea. Cliartæ adhxeret.

Hooker et Harvey varietates plurimas valdeque dissimiles 1. c. enumerant; ex quibus pateret plantam hanc magnopere variare. Inter plurims, quæ a diversis locis vidi specimina, differentiæ parum insignes adsunt; unde ad opera citata relegare e re esse judicavi. Specimina elierguelen. land duo coram oculis habeo a Harvey benevole communicata, quorum unum fructiferum cum Cal. variegata dispositione fructutum, vix autem ramificatione, convenit; alterum sterile Cal. teneræ nob. quoad formam simile. An forsan suspicandum sit species plures in unam conjunclas fuisse, qux fructu accuratius inspiciendo distinguendx sint? - Specimina ex Malouinis Insulis, qua in $S p$. Alg. Agardhi $p .299$ ad Sphær. fimbriatum referuntur, ad C. variegatam rel ad Cal. teneram pertinere videntur. Sph. Gaudiclıaudii (Bory Voy. Coqu. n:o 67) partim ad eandem plantam adnumerandus; species praterea toto coclo diversas quoque complectens.

10. Cal. Honbrosiaxa (Mont. Prodr. p. 3) fronde decompositopinnata, pinnis pinnulisque basi simplicioribus linearibus, superne decompositis expansis marune fimbriatis, terminalibus obtusis dentitis, kalidiis in fimbriis immersis.

Rhod. Hombroniana Mont. l. c. et Voy. Pol. Sud. p. 157 tab. 1 fig. $2 !$ Hook. el IIarv. Crypl. antarct. $p$. is tab. LXXII fig. II! Lond. Journ. Bot. IV p. 843 !

Cal. Hombroniana Kütz. $s p . p .746$ !

Ilab. in stipitibus Algarum ad insulas Auckiand et Noram Zelandiam (llombron, D'Urville, Raoul.)

Frons semipedalis a stipite planiusculo subtlabellata, subdichotome decomposito-pinnatifissa. Pinna patenti-erectæ, 2 lineas late dentati, sub axillis leviter dilatatæ, iterum divisa, apice cristato-multifide, axillis dichotomiarum ol,tusis. Lacinix ultimi ordinis lineam sesquilineam latis, ex utrogue margine ramenta proferunt minuta ciliiformia, lanceolata, cliarata aut spathulata, extu; dentata, lineam et ultra longil fructifera. Conceptacula [Kalidia?] hemisphxricd, scmen Papaveris diametro arquantia, mamilla centrali perfor.ta [?!] instructa. Spore in globos conglomerater, ovoidex minutissimie, numerosissima, rosex, in extremo endochromate filamentorum formatie, mox libere et per ostiolum conceptaculi crumpentes. Sphærospore (sec Hook. et Harr.) cruciatim disisa. Substantia membranacea tenuis chartie male aut non adhareus. Color vivide purpureus baccarum Rihis rubri. 
Ita fere Montagneus. I pe Callophyllis speciem divit et cum pluribus speciebus generis comparavit; structuram quoque generis omnino in antilysi depinxit. Ad hoc genus quoque a Kützingio ducitur. Vix itarque de Genere dubitandum. Altamen originem gemmidiorum aliam, et conceptacul:s poro pertusa! nuncupasit, quod utrumque generi alienum mihi videtır.

\section{Species inquirende:}

11. Cat. australs (Sond. Alg. Preiss, $p$. 28) fronde lanceolita bipinnata, pinnis lineari-lanceolatis elongatis, pinnulis abbrevialis linearibus margine ciliato-dentatis.

Calloph. australis Sond. l. c. lï̈lz. sp. p. 746.

Ital). ad Noræ Ilollandiæ littus occidentale. (Preiss.)

Frons spithanæa et uitra. Jugamentum 6-lineas latum. Pinnæ $2-3$ pollicares 2 lin. latæ, pinnulæ 3-6 lin. longæ. Sphærosporæ strato corticali immersæ, oblongre, nucleo crucialim quadridiviso. Structura frondis: stratum corticale e cellulis minutis, horizontalibus concatenatis, stratum intermedium e cellulis parenchymaticis maximis constans. Substantia membranacea lubrica. Color purpurascens.

12. Cal. finduata (Hook. et Harv. Aly. Tasm. p. S) fronde purpurea tenuissime membranacea venulis ramosis tenuissimis percursa flabelliformi profunde laciniala, lacinis cuneatis vage furcatis, margine ramentis creberrimis pusillis dentatis polymorphis fimbriato, apicibus laceris.

Calophyllis fimbriata Hook. et Harv. l. c. Kü̈ъ. Sp. p. 736!

Ilab. ad oras T'usmannice (Gunn.)

Ilabitus Rh. Ifombronianx, sed frons multo tenuior, cellularum stratis paucioribus constituta, et systemate venularum, iis Pollexfenix pedicellatie sulssimilium, ab illa distinguenda. Fructus ignoti.

13. Rirod. dichoтoma (Hook. el Harv. Cr. Antarct. p. 74.) fronde membranacea rosea basi cuneata latissima dichotoma, axillis rotundatis, laciniis patentilus linearibus v. cuneatis obtusis demum emarginatis et bifilis.

Bhod. dichotoma Hook. el Ilarv. l. c. lab. 72 fig. I. Callophyllis dichotoma hülz. sp. p. T46.

llibl), in oceano australi ad insulas Campbell (Ilooker).

Frons flabellatim expansa, $4-7$ unc. lata, basi cuncata, pluries dichotoma, laciniis linearibus cuneatisve $1 / 4-1 / 2$ unc. latis et ultria, patentibus, apicibus obtusis emarginatis bifidisre. Substantia tenuis mem- 
branacea e cellulis superficiem versus minimis coloratis formata, interioribus magnis hyalinis. Chartie non adhxret.

Specinina sterilia formam Plhyllophorie obtusa referunt, consistentia longe alia. Rhod. palmettx affinitate proxima. Ita Auctores. Kuitzing, qui specimen a Bindero datum vidit, Callophyllis specien declaravit.

\section{Polycoelia J. Ag. Act. Holm. Öfvers. 1849 p. 87.}

Frons gelatinoso-carnosa plana dichotoma vel subpalmata, duobus stratis constituta; interiore cellulis maximis rotundato-cubicis, simplici serie, frondis plano parallela, dispositis, parietibus crassis gelistinosis separatis, et strato crasso cinctis cellularum minutarum, in reticulum laxum undique anastomosantium, snperficiem versus in fila verticalia moniliformia abeuntium. Fructus. . .

Frons carneo-coccinea, gelitinosa, calnoso-membranacea, exsiccatione subcartilaginea plana, diclotoma aut segmentis approximatis superne subpalmata et a margine prolifera, prolificationilus segmentisque juvenilibus oblongis, margine inærquali, adultioribus ant linearibus dichotomis ant subcuneatis et apice palmatis. Apices truncati ant rotundati, emarginati crenatique. Alga major, saltim semipedalis, segmentis $3-6$ lineas latis.

leticulum, a cellulis minutis oblongis undique et laxe anastomosantibus contextum, frondis internum ita occupat ut areolas unagnas, simplici seric dispositas, undique circumdat. Arcolæ propria, ni fallor, at gelatinosa membrana inclusa, fere cubicie, angulis anteın rotmodate, medium frondis planum occupant; invicem separantur tum parietibus propriis, tum reticulo demum inter parietes intruso. Extrorsum cinguntur strato reticuli satis amplo, quod demum in fila verticalia moniliformia extrorsum desinit. Fructus liodic ignoti.

Planta pulclira, fere lablitu Callophyllis laciniate aut potius C. discigere, structura peculiari ab omnibus facile distincta. Reticulum Jixum fere Gigartine, cellulis concatenatis in Calloplylli parum simile. Cellulie interiores maxime, cum cellulis rotundatis in Callophylli quidem comparandie, sed unico plano omnes seriata, et ob magnitudinem lacunas magis quan cellulas amulantes. - Mfcliodea, genus IIarveyanum, et ei saltim proximum Cystoclonium adluc longius distant strato medıllari in fronde teretiuscula. 
1. P'OL. I.Acinhta J. Ag. l. c.

Ilal, ad littus occidentale Noræ Ilollandiæ (Mus. Paris!).

XLVI. Cystocloniuil Kï̈lz. Phycol. p. 404. Sp. Alg. p. 756 (mut. limit.) J. Ag. Alg. Liebm. p. 12 (excl. spec.) Sphrerococci sp. Ag. et Auct. Gracilariæ sp. Grev. Hypneæ et Mycliudex sp. Harv.

Frons carnoso-membranacea, teretiusculi, dichotomo-ramulosa, stratis fere tribus contesta; strato medullari filis elongatis dichotomis et anastomosantibus, arcuatim inter cellulas strati intermedii magnas rotundatas excurrentibus; cellulis superficialibus rotundatu-angulatis. Kalidia frondi sub-immersa, intra pericarpium clausum nidulantia, gemmidiis minutis plurimis intra cellulas pregnantes, filis sterilibus disjunctas, evolutis constantia. Spharospora frondi immerse, sparsæ, zonatim divise. (Kütz. Phyc. gen. tab. 58).

Frondes purpurex, filiformes, ramosissimæ, ramilicatione nunc magis dichotoma nunc ramulosa, ramis utrinque attenuatis filiformilus; recentes carnoso-membranaceæ, exsiccatæ parum cartilaguinex, flexiles ot chartie laxius adherentes.

Stratis tribus diversis constitumntur. Nedullare filis elongatis di-triclıotomis, a cellulis cylindraccis, diametro pluries longioribus, concitenatis, granulosa substantia faretis aut canali colorato percursis, constat. Intermedium cellulis magnis, rotundatis aut longitudinaliter elongatis et oblonģis, superficiem versus minoribus contextum est. Superficiale stratum cellulis coloratis angulato-rotundatis, sulssingula serie dispositis, conflitum. Fila strati medullaris arcuatim a longitudinali cursu deflectuntur, et inter cellulas amplas strati intermedii extensa, laarum parietes cellulis minutis rotundatis circumdant; denique; ni fallor, in ipsis cellulis superficialibus terminantia.

Kalidia (in sp. 1 et 2 observata) sunt frondi immersa, sed plus minus prominentia, intra pericarpium clausum, a strato superficiali incrassato et parte intermedii frondis constitutum, nidulantia, adparatu filorum contortorum cincta, nucleolis plurimis, adproximatis at invicem filis sterilibus sejunctis, constantia. Nucleoli a cellulis strati intermedii frondis transmutatis orti, obovati, in maturo fructu subradiatim dispositi, gemmidia plurima, rotundato- 
angulata, sat magna, geclutina lygalina invicem sejuncta et peridermate gelatinoso inclusa.

Splaxrospore in ramis incrassatis evolute, infra cellulas strati epidermatici nidulantes, oblongæe, zonatim quadripartitie.

Genus a Kützingio in Plıjeologia constitutum, et egregia analysi speciei typica illustratum, quoad limites adluc forsan incertum. Stratum medullare in nonullis eximie conspicuum (sp. 1-2), in aliis satis angुustum adest (sp. 3). Cellulx, quibus hoc constituitur, nunc canalem angustum, substantia liomogenea coloratum, ferunt, nunc latiorem, substantia granulosa farctum. Sed las differentias atatis suspicor.

Genus Myclıodeæ, a Harvey in Mles. Tasmanicis institutum, vix a Genere liützingiano differt, si quidem lıoc a structura frondis et splıærosporis dijudicare liceat. Kützing aliam quiden structure analysin C. purpurascentis dedit, aliamque structuram in Myclıodea descripsit; comparatis vero speciminibus structuram in utroque eandem invenio, spluerosporas easdem. Nisi itaque in fruetu capsulari Nychodee differentix adsint, ambo genera vis retinenda puto.

Quale Cystoclonii genus a Kützinguio, in ultimo ejus opere, limitatum fuit, diversissimas plantas sane comprehendit. Dicranemie species, quas ei injunxit, structura fructus capsuliris ad longe aliam tribum pertinent. C. Gaudichaudii et C. turgidulum milii ignotx sunt species; illa vix lıujus loci.

1. Cist. purdurascexs (Huds. Angl. p. 589) fronde tereti subpinnatim decomposito-ramosa, ramis ramulisque filiformibus utrinque attenuatis, medio subcrassiore, cystocarpiis in ramulis nodosoinflatis immersis circumcirca prominentibus, singulis aut plurilus concatenatis.

Fucus purpurascens Iluds. l. c. Sm. Engl. Bol. lab. 1243. Turn. IIisl. lab. 9! Slackh. Ner. tab. 18!

Cystoclonium purpurascens Küts. Phycol. p. 404. Sp. Alg. p. 7866!

Sphærococcus purpurascens Ag. Sp. Alg. I p. 318! Sysl. p. 236! Fl. Dan. Lab. 1833 !

Gigartina purpurascens Lamour; Lyngb. Ilydr.p. 46 lab. 12 ! Ilarv. Man. p. 73. Aresch. Enum. p. 79 !

Gracilaria purpurascens Grev. Alg. bril. p. 122.

Hypuea purpurascens Ilarv. Phycol. lab. C.I1T!

Fucus hiberculatus Lighll.

Fucus scorpioides Fl. Dan. Lab. 887!

Fucus corallinus Fl. Dan. lab. 709!

Fucus capillaceus Esp. lab. 3:3 I 
Fucus acicularis Esp. tab. 91.

Exs. Wyatt. Alg. Danm. n. If.

Ilab. in lapidibus Fucisque oceani atlantici a littore maris glacialis usque ad Galliam inferiorem; ad iittus Americe borealis (llarrey).

Frons a radice scutata aut demum, fibris radicalilous ab inferiore parte stipitis pullulantibus, tibrosa surgens, sape pedalis, subpinnatim ramosissima et decomposita, ramis nunc frondi conformibus et eodem modo ramulosis, nunc multo tenuioribus abbreviatis et subcorymbosis. Ramuli patentes elongati et filiformes, basi plus minus altenuati, medioque incrassati, apice semper acuminati, $1 / 2$ - I pollicares aut longiores, crassitie capillares, setacei aut immo pennam passerinam aquantes. Kialidia in ramulo hinc nodose inflato immersa, singula vel usque quaterna, raro plura in singulis ramis, invicem distantia, ramulo triplo crassiora et ita circumcirca prominentia, semilineam diametro æquantia. Sphærosporæ in ramulis incrassatis immersæ. Color carneo-purpurascens. Substantia membranacea. Stratum medullare hujus value conspicuum.

Verruca verruculosæ in ramis majoribus, et apices ramulorum cirris ramulosis instructæ non raro obveniunt. Hanc varietatem Scorpioidem aut Cirrhosam plurimi faciunt. Nomine Gracilarix cirrhifoliæ Suhr. mscr. specimen a Cap. b. Spei a Sulrio ipso communicatum habeo, quod a formis Europeis Cyst. purpurascentis dignoscere non valeo. Sphærosporas zonatim divisas, inter cellulas corticales immutatas nidulantes, in has quoque vidi.

2. Cist. DIfFicile (Ag. sp. p. 317) fronde tereti subpinnatim decomposito-ramosa, ramis ramulisque filiformibus utrinque attenuatis, medio subcrassiori, cystocarpiis in ramo unilateraliter prominentibus liemisphacricis.

Sphærococcus difficilis Ag. l. c. et Syst. p. 236. Kütz. sp. p. 776!

Hab. ad oras Brasilia (Chamisso!).

Species quoad externum habitum et structuram internam a C. purpurascenti vix distinguenda. Capsulæ vero mihi videntur majores, uno latere frondis prominulæ, hemisphrerica. Reticulum celiulas prægnantes Kalidii separans, in specie prasenti value evolutum vidi, gemmidiis paucis intra cellulas adhuc inclusis.

Varietatem planicomam, l. c. descriptam, utrum ad hanc speciem pertineat an ad aliam et forsan diversissimam, dijudicare non audeo.

3. Cist. nenbmaceun (IIarv. Alg. Tasm. p. 11) fronde tereti sul)diclıotomo-decomposita, ramis sensim angustiorilus ramulisque fitiformibus utringue attenuatis, medio subcrassiori, cystocarpiis ...., parietibus cellularum tenuibus. 
Mychodea membranacea Harv. l. c. Kü̈lz. Sp. Alg. p. 723.

Ilisb. ad oras Tasmanie (Gunn!)

Frons clata subdichotoma ramosissima, ramis patentibus, inferioribus diametrum linex fere xquantibus, superioribus sensim attenuatis, ultimis setaceis, 6-lineas circiter longis. Axillie rolundatre. Sulstantia membritnacea. Color purpureus.

\section{Species inquirenda.}

4. Cist. cariosum (Ilarv. Alg. Tasm. p. 11) fronde carmosa llacea ramosissima, ramis horizontalibus flexuosis crassis pluries divisis, minoribus sefaceis filiformibus acutis, ramulis paucis subulitis, lacunarum parictibus crassis.

Mychodea carnosa Harv. l. c. Kü̈z. sp. p. 723.

Ilab. ad oras Tasmanix (Gunn).

Habitu ad præcedentem valde accedens; sed parietibus cellularum in C. carnoso valde gelatinosis, crassis, lato adparatu cellularum anastomosantium separatis. Ita IIarvey. Species a me non visa, forsan cum speciebus Acanthococci accuratius comparanda.

5. Cist. tergidelun (Külz. Bot. Zeit. 1817 p. 22) caule ramoso, semipedali, pennam corvinam erasso, tereti, a basi ad apicem usque obsesso ramulis fructiferis (carpoctoniis) lateralibus numerosissimis dense congestis, 1-2" longis, basi attenuatuconstrictis, apice acutis; eystocarpiis tuberculiformibus semiimmersis. Külz. sp. p. 7̈̈\%.

IJab. ad oras Britannix minoris (Hb. Montagne.)

\section{TRIBUS V. TILOCARPEE.}

Frons cellulis interioribus rotundato-angulatis et exterioribus verticalibus radiatis contexta. Kalidii nucleoli plures, infra stratum exterius tumidum, aut intra pericarpium extermun clausum nidulantes, disruptione partis fertilis demum liberali. Sphrerospora in Nematheciis externis et ex articulis filormu transformatis crolute, cruciatim divisæ.

XLVII. Annfeltia $J$. Ag. Alg. Liebm. $p$. 12. Ninfeltia sp. liries Fl. Scan. p. 309. Gigirtinx sp. Lamour. el Auct. spherocoeci sp. Ag. et Auct. Gynnogongri sp. Llarv. et Kütz. Sp. Tylocarpi sp. liülz. Phycol. 
Frons carnoso-cornea teretiuscula, dichotoma et secundatim prolifera, stratis duobus cellularum constituta; interiore cellulis densissimis angulatis, in asi longioribus, superficiem versus brevioribus; exteriore filis moniliformibus verticalibus muco solidescente colibitis contesto. Kalidia frondi immersa subprominentia clausa, disruptione partis fertilis demum liberata; gemmidies minutis paucioribus intra cellulas pregnantes plurimas, in nuclemm compositum coalescentes, constantia. Nemathecia [?] extertui ramis circumfusa, a cellulis subradiantibus arcte colırentibus, granulosa substantia farctis, constituti....

Frondes terctinscule, rigide et exsiccatione cornex, violaceopurpurex aut sordide lutescentes virentesve, dichotomo-ramosissime, ramisque consimilibus secundatim a fronde proliferis obsitie.

Stratis duobus contexte sunt. Cellulic angulate, interiorem frondis partem occupantes, densissimæ ita ut ægre discernantur, nisi in fronde adulta cellule granulosa substantia farctie obserrentur. Conspiciuntur loo modo fila in ipso axi satis elongata et tenuia, articulata et ramosa, longitudinaliter excurrentia; a centro sensim arcuatim versus peripleriam excurrunt, articuli breviores evadunt et in cellulas veras niutantur; omnes cellulæe arctissime juxtapositie et cohrentes. Externum stratum satis crassum, filis moniliformibus verticalibus elongatis et ramosis constitutum.

Kalidia, in unica specic observata, frondi immersa aut hemispherice prominentia, pericarpio clauso seu frondis strato exteriore magis evoluto inclusa, demum circulari solutione [?] pericarpii liberati. Celluli parum mutatie frondis mediæ prægnantes evadunt, nucleolos plurimos, membrana ambiente cellularum separatos, formantes, demum in nucleum densum coalescentes. Gemmidia minuta, angulato-rotundati, intra cellulas pregnantes pauciora evoluta.

Nemathecia, in unica specie visa, verrucieformia, ramos amplectentia, a cellulis arcte conjunctis radiatim dispositis, granulosa materia farctis constituta; functione dubia. An in splaxrosporas more Gỵmogongri demum solvenda?

Genus adluc characteribus dubium, et quoad circumscriptionem nondum forsan definitum, Gymnogongro proximum, sed vix cum eodem conjungendum, licet characteres distinctivi hodie desint. Substantia alia et Nematlecia forsan natura diversa. Specierum diagnosis quoque vix rite eshibenda, characteribus fiuctumn nondum suppetentibus. 
Quale primum Genus a Friesio constituhm fuit, haud sane adoptandum. Complectebatur r. Griffilhsix, l. plicatum et Spls. durum, (que species, me julice, tribus generibus diversis pertinent.

1. AIINE. PLIC.ra (IIuds. Angl. p. 589) fronde cornea tereti filiformi decomposito-di-triclıotoma et a ramis subsecundatim prolifera, prolificationibus segmento conformilus, segmentis supra sinum rolundatum erectis, terminalibus elongatis.

lucus plicatus Iluds. l. c. Gm. Fuc. lab. 14. fig. 2! Stackh. Ner. lab. 7! Turn. Hist. Lab. 180! Engl. Bol. Lab. 1089.

Ahnfeltia plicata Fr. Scan. p. 310!

Sphærococcus plicatus Ag. sp. p. 313! et Sysl. p. 234 (excl. var. plur.)!

Gymnogongrus plicatus Külz. Sp. Alg. p. 789 ! Harv. Pliycol. lab. 288!

Gigartina plicata Lamour.; Lyngb. Ilydr. p. 42! Grev. Alg. Bril. p. 130 ! Harv. Nan. p. 76 ! Aresch. Kuum. p. 80.

Fucus albus Fl. Dan. lab. 408.

Gigartina flavescens Bory!

Gigartina Girffithsix Lyngb. Hydr. p. 43 lab. 11!

Exsicc. Chauv. Norm. n:o 146! Chalm. Scol. n. 30. Aresch. Scand. n. 4! Wyall. Danm. n. 116.

Hab. in oceano arctico ab Islandia ad Lapponiam rossicam; in atlantico usque ad Ilispaniam et Terram noram descendens; ad Brasiliam (Salzman! Kotsliy!); ad Kerguelen Land (Ilooker).

Cæxpes late expansus, altitudine 3-4pollicaris, sæpe valde intricatus. Frons crassitic fili tenuioris, vix quartam lineæ partem diametro æquans, ubique xqualis, filiformis, dichotomo-decomposita, segmentis inferne distantibus, superne approximatis, supra sinum rotundatum erectis, terminalibus plcrumque elongatis. I'rolificationes a ramis principalibus secundatim exeuntes, sæpe fasciculatx, subhorizontales, clongatæ simpliciusculæ ct flexuosæ, aut segmentorum more dichotomo-decomposite. Nemathecia? ramos amplectentia oblonga, cellulis radiantibus granulosa materia farctis tota constituta. Color recentis purpurascens aut in violaceum tendens, facillime in luteum vel sordide albidum subdiaphanum abiens, chordas musicas non male referens. Sulstantia cornea rigida.

Speciei vulgatissime fructus vix cogniti. Verrucæ rotundatix sparsæ aut opposite sæpe adsunt; ex structura rero haud fructus judicanda. Nemathecia, qualia depinxit Lynghye, vidi; fila radiantia autem magis invicem cohærent, quan hoc sulgo in Nematheciis obveniat.

Varietatem e nova Hollandia memorat Turnerus, quie an huc pertineat, ipse dubitat. Scytos. Llippuroides Lyngl). est planta a Fuco plicato longe diversa.

2. Ailv. Gigartinoldes (J. Ag. Alg. Liebm: p. 12) fronde carnosocornea tereti dichutoma et subsecundatim decomposilo-proli- 
fera, prolificationilus patentissimis obtusis, segmentis supra sinum acutiusculum erectis, terminalibus elongatis.

Gymnogongrus Gigartinoides Kï̈ts. sp. p. 789 !

Ilab. ad littus Mexicanım oceani pacifici. (Liebman!).

Antecedenti proxima et it plurimis characteribus conveniens, at planta rolustior et brevior, bipollicaris, diametro semilıneam æequans, madefacta carnosa; in aqua aliquantulum servata longitudinaliter fatiscit et stratum exterius ab interiore solvitur; exsiccata ante alias cornea subpellucida. Ramificatio, ut in antecedente, nunc dichotomo-decomposita segmentis supra sinum subacuminatum erectis, nunc prolifera prolificationibus sæpissime unilateralibus fere horizontalibus, plurimis abbreviatis obtusis atque crassis. Color fere antecedentis.

Huc forsan pertinet Sph. plicatus (Mont. Fl. Boliv. p. 30), cujus juxta Callao lectım specimen nematheciis hemisphæricis onustum fuit.

3. Aisfe. Coxcixis (J. Ag. Alg. Liebm. p. 12) fronde cornea subtereti decomposito-di-triclıotoma et a ramis subsecundatim prolifera, prolificationibus segmento conformibus sæpe fasciculatis, segmentis supra sinum acutiusculım subdivaricato-patentibus.

Sphærococcus concinnus $\beta$. immersus Ag. sp. $p .312$ el Sysl. p. 234.

Hab, in oceano pacifico ad insulas Sandwich (Chamisso! Gaudichaud!); ad insulas Chincla prope littus Peruvix (Oersted!).

Antecedentibus major, 4-6pollicaris, diametro $2 / 3$ linex xquans, inferne obsita prolificationibus secundatis, nune fasciculatim $2-6$ a caule exeuntibus, uunc magis sparsis, simplicibus aut furcatis; superne dichotomo-decomposita. Segmenta teretiuscula, aut infra furcas levissime compressa, exsiccatione collabentia compressa; nunc (an inclioante fructificatione?) corrugato-flexuosa ramosissima. Axillæ eximie patentes, segmentis omnibus angulo $43^{\prime \prime}$ separatis, strictis. Kalidia in segmentis superiorilus numerosa approximata, subhemisphærice a fronde prominentia. Color purpurascens aut expositione demum virescens. Substantia cornea.

Segmenta superiora exsiccatione collabentia facile fallunt, frondem compressam mentientia; madefacta formam sub-teretem recuperant. F. concinnus Turn. est planta diversi Generis.

3a. Grmogoxgrus implicatus (hülz. Phyc. gen. p. 411) "crassiusculus rigidus, vage ramosus, subdichotomus teres, ramis divaricatis implicatis, superioribus congestis subecrymbosis curvatis obtusis. Alt. 2-3"; crassities penna columbina et ultra. Color luridus obscurus. Substantia cartilaginea fragilis. Külz. Sp. p. 789.

1lal. ad oras Pernanas (Hayn.)

Ahıf. gigartinoidi valde alfinem dicit Kü̈zing. 
4. Airve. Durvillat (Bory Voy. Coqu. n:o 38) fronde subcarnusa tereti decomposito-dichotona fistigiata, segmentis supra sinum acutum erectiusculis, terminalibus approximatis subfasciculatis.

Polyides Durvillæi Bory l. $c$.

Ulab. in oceano Pacifico ad oras Chili et Peruvie; ad otaiti (U'Lirille!).

Semipedalis, crassitie pennæ corvinæ, distantiis pollicaribus diclotoma, sed infra apicem in segmenta multo densiora fere fasciculatin, divisa.

Species parum cognita, quoad structuram antecedentibus proxima videtur.

\section{Species inquirenda:}

5. Gigartixa fascigiata (Post. et Rupr. Illustr. p. 16) "fronde subpollicari, cornea, filiformi, exacte cslindrica, ramosissima, dichotoma, fastigiata; ramis patentibus, apice quidpiam incrassatis, teretibus, subsimplicibus.

Hab. ad lapides in mare insulam Sitcliam alluente.

Proxima Gigartinæ plicatæ. Frondes cæespitosx, plures simul uno scuto affixæ, plerumque pollicares, raro majores. Crassities frondis eadem ac Gig. plicata. Rami inferiores divaricati, sıperiores patuli et angulo obtusiusculo inserti, ultimi semper fastigiati. Capsulæ rarissimæ, in dichotomia ramulorum sessiles, globosæ, magnitudine seminis Papaveris, opacæ, cornex, steriles. Color frondis violaceus, hinc inde pollide fuscus, apices ramulorum opaci."

XLVIII. Gymogongrus Mart. Bras. p. 27. Tylocarpus Oncotylus et Clondri sp. Irütz. Phyc. et Sp. Alg. Chondri sp. Lamour. et Auct. Sphierococci sp. Ag. et Auct.

Frons carnoso-coriacea, teretiuscula aut plana, dichotomo-fastigyiata, stratis duobus cellularum constituta; interiore cellulis angulatorotundatis, exteriore filis moniliformibus verticalibus muco cohibitis contexto. lialidia frondi immersa, plus minus prominential clausa, disruptione partis fertilis demum liberata, semmidiis minutis intra cellulas pregurantes plurimas, in nucleum compositum coalescentes, constantia. Nemalhecia esterna hemisphærici, filis radiantibus constituta, intra articulos filor'mn splierosporas, ab apice fili deorsum sensim maturas, cruciatim 
divisas, forentia. (Külz. Phyc. tab. 70. II. Harv. Phyc. tab. 187).

Frondes nunc teretiusculæ per totam longitudinem, nunc inferne teretiusculæ et superne compressix aut omnino planx, nunc plus minus evidenter canaliculate, dichotome aut rarius polychotomx, fastigiatæ, segmentis linearibus ant sulbcuneatis in fronde plana, margine aliquando incrassato integerrime ant rarissime crenulatix; recentes subcarnosi, exsiccate subcoriacex; madefactæ odorem gratum fere Violæ spirantes, in gelatinam hand facile solvuntur.

Stratis duobus frons constituitur; interiore cellulis angulatorotundatis, diametro longitudinali transversalem parum superante, intra membranam sæpe incrassatam endoclıroma parum conspicuum continentibus. Stratum externum filis verticilibus moniliformibus pares dichotomis, in sterili breviorihus, in parte cystocarpium includente magis evolutis.

Kalidia in strato interiori frondis evoluta, nucleolis plurimis demum confluentibus constantia, nunc extra utramque superficiem frondis fere æque sed parum prominentia, strato superficiali magis evoluto tecta, nunc in una pagina hemisplıxice prominula et pericarpio subproprio, structura frondis consimili, inclusa, semper clausa et demum circulari solutione a fronde liberata, foramen frondis pervium aut excavationem in una pagina relinquentia. Gemmidlia minuta angulata, plurima intra cellulas prægnantes formata, demum sublibera.

Nemathecia ex superficis erumpentia, exacte hemispherica aut demum forma plus minus inregularia et plura confluentia, filis radiantibus dichotomis articulatis constituta, intra articulos filorum splıerosporas evolventia. Articuli superiores primum maturi, splıxrosporas enittunt, sequentes ordine deorsum maturescunt, ita ut 6-8 articulos superiores simul maturos vidi. Splierosporas erolutas tantum in G. Norvegico et G. Griffithsix observavi. Nemathecia insuper in G. disciplinali, G. dilatato, G. crenulato et forsan in G. lineati ridi.

Species plane lıujus generis apud Lamourouxium partem Chondri generis constituebant; teretiuscule iuter Gigartinas recipiebantur. $\Lambda$ Grevilleo eoden fere modo dispositie. Agardhio species furrunt Splharococci generis. Celebris Flore Brasiliensis auctor primus genus Gymnogongri condidit, "speciebus Fucorum solımmodo sic dicti Nemathecia ferentilus"; et his quidem verbis sum genus hand male definivit, limitibus autem nullis generi novo ductis. In Algis 
mediteraneis, nulla nec structure nec fructus diversitate in plantis habitu simillimis Clondri erispi et Clı, norvegici suspecta, characteres Chondro generi tribui, in Gymnogongrum tantum adplicandos; Fucum Griflithsia vero a Gigartinis ad Choudrum recte transtuli. liützinģius in pluscologyia dein differentia quadam structurx inter veros Chondros et illis habitu simillimos Gymnogongros indicata, et sphirosporis Chondri detectis, vetus genus Chondri in plura dissulvit. Ex novis his generibus Oneotylum, et partem Tylocarpi ad Gymnogongrum refero; speciem quodue unam illius Chondri Generis ad Gymnogongrum referendam censeo. Tylocarpum et Oncotylum distinxit Kützing, tum forma frondis tereti aut plana, tum nematheciis in uno amplexicaulibus; in altero pulvinatis. In descriptione Algarum Liebmanni, suspicata quadam Sphærosporarum differentia, quam cognitis spharosporis G. Horvegici hodic nullam esse video, Gymn. Griffitlssix a cxteris speciebus separavi. Ilarvey (in Plıyeologia) genus Gymnogongri recepit, huic vero alios limites duxit, tum nempe Fuc. plicatum includens, tum Fucum norvegyicum ad Chondrum refereus. In ultimo suo opere Külzingius gुenera lıec fere eodem modo definivit, nomen vero Tylocarpi in Gymnogongrum mutavit. Genus itaque per varios casus, per tot discrimina formatum, hudie demum stabilitum magis spero quam confido, fructibus in plurimis speciebus nondum comnitis.

Nematliccia in pluribus speciebus jam a T'urnero cognita. Cui bono essent, non nisi ultimo lıoc tempore innotıit. Montagneus primus sphærosporus in articulis filorum nemathecii contentus detexit; nisi sec. observationem gluandam Agardliii (Sp. Alg. p. 316) concludere liceat, illum easdem quoque vidisse. Deiu in eadem specic a pluribus observata. Ipse in G. norveģico sphaxrosporas codem modo constructas primus ut crederem observavi; Montagneus vero in Fl. Algieriæ easdem quoque illustravit.

Genus Gịmogongri a Chondro et structura et fructu differt. A) Ahnfeltia nulla nisi habituali nota hodie dignoscitur, substantia in duobus generibus diversa. Nec hæc distinsissem, nisi jam antea genera distincta proposucrant et diversitatem quandam fructus suspicari liceret.

* Fronde tereliuscula aut compresso-plana angnsle lineari, cystocarpiis fere circumcirca prominentibns nodosa.

1. G. DExSus (Grev. mscr. in Hb. Hook.) fronde pulvinatim cespitosa minuta teretiuscula dicholomo-fastigiata diraricati, segmentis 
superioribus sxpe secundatis, terminalibus subulatis patentissimis, cystocarpiis in segmento nodose-inflato immersis subsulitariis.

Chondrus? densus Grev. l. $c$.

Ilab. in mari Indico ad oras Hindostaniæ (Wigt, sub n:o 172 in Hb. IJooker!).

Cæespituli pulvinatim expansi, pollicem altitudine vix sequantes, frondibus dense conjunctis constituti. Frondes diametrum millimetri dimidii haud superantes, fere onnino teretes, a basi ad apicem dichotomiis lineam circiter distantibus decompositæ, fastigiatæ, segmentis superioriJus non raro pinnatim aut secundatin dispositis patentibus, terminalibus a latiore basi acuminatis, subdivaricatis. Cystocarpia (in nostris saltim) rara, in segmentis superioribus nodose intlatis subsolitaria, in medio frondis immersa. Color purpureo-sanguinens.

Species generis minima, crescendi modo cum Gymn. Griffithsiæ et cum G. pygmæo conveniens. Ab hoc differt colore, tenuitate frondis, forma tereti, ramificatione divaricata, apicibus segmentorum acutiorilous, ct capsulis, quie fructus rostratos Gigartinx purpurascentis $\gamma$. Lyngb. habitu æmulantur. Sectione transversali cystocarpia teretia in G. denso, ancipitia in G. pygmæo adparent.

2. G. GRFfitisi (Turn. Hist. n. 37) fronde pulvinatim cespitosa minuta tereti dichotomo-fastigiata, segmentis superioribus sepe adprosimatis subfasciculatis, terminalibus sæpe compressis, nematheciis unilateralibus demum frondem amplectentibus informilus.

Fucus Griffithsix Turn. l. c. tab. 37! Engl. Bol. tab. 1926. Slackh. Ner. Br. lab. 19!

Gymnogongr. Griffithsiæ Mart. Fl. Bras. p. 27. Mont. Fl. D'Alg. p. 149. Harv. Phyc. tab. 108! Kü̈tz. sp. p. 788 !

Tylocarpus Griffithsiæ Küts. Phyc. p. 411!

Chondrus Griffithsix J. Ag. Alg. med. p. 9̈.

Gigartina Griffithsix Grev. Alg. Br. p. 449!! Harv. Man. p. "76. Mont. Canar. p. 160.

Polyides Griffithsiæ Gaill.

Sphærococcus Griffithsix Ag. Sp.p. 346 et Syst.p. 233.

F. tentaculatus Bert. Am. p. 293 lab. 8 f. 8 !!

Gymnogongr. tentaculatus Kütz. sp. p. 788.

Exs. I'yalt. Danm. n. 28, Chauv. Norm. n. 14:3!

Hab. ad rupes submarinas peremis, in atlantico a littore britamile usque ad Tingin; in mediteranco a littore Hispantie usque all intimum sinum Adriaticum.

Fronles in caspites pulvinatos 1-2pollicares dense collecte, a callo radicali plurimæexeuntes, teretiuscule, seta crassiores, ima basi indivisæe, 
dein dichotomiis densis decomposita; aliquantu dichotomiis adproximatis fasciculato-polychotomx, infra axillas polychotomas sxpe nodosa, supra axillam longius indivisa, dein rursus fasciculata ita ut caspites quasi zonis distantibus pracipue ramosi. Segmenta omnia filiformia, Hreviora aut longiora; terminalia nunc elongata, nunc brevissima acuminata et immo suhulata aut obtusa et tunc sipe compressa. Kialidia nondum detecta. Nemathecia sine ordine provenientia, initio unilateralia, averso latere frondis sappe sub-refracto, pulvinata, demum extensa amplexicaulia et informia. Substantia carnosa, exsiccatione parum cartilaginea. Color intense purpureus, exsiccatione nigrescens.

Species videtur primum a Wulfenio descripta. Etenim mili Fucus fastigialus (Ilulf. in Jacqu. Coll. el Crypt. aqu. p. 33) sec. iconem in Mus. Vindoboneusi asservalam, ad F. Griffithsize spectare videtur; et Turnero quoque ita existimabatur. Turnerus tamen primus speciem ita descripsil, ut confusionis omnem alsutulit ansam. Specics a Lyngbyeo depicta nullo modo ad F. Griffithsia pertinere mihi videtur; substantiam enim corneam dixil, quod melius in F. plicatum duadrat, el specimen F. Griffithsia ad oras nostras inventum numquam vidi. Species mediteranea nomine alio a Bertolonio descripta, et a Kiitzingio adoptata. Secundum specimina, a Bertolonio ipso clata, nullo mollo a planta allantica distal, nisi plerumque minor sit; characteres a Kïtzingio allati, utramque distinguentes, ab xlate sane pendent. Adest quadam formarum differentia, in spec. medilerraneis potissimum a me observata; nonnulla, nimirum segmentis subulatis lateralibus instructa, a vulgari forma abludunt. Agardhius F. Griffithsiæ formam quandam Gig. acicularis declaravit (Au/z. Öeslr. Alg. p. 21); quod sane nullo modo adprobandum.

\section{G. PYGl.Eus (Grev. mscr. in Hb. Hook.) fronde pulvinatim ce-} spitosa minuta, inferne teretiuscula superne compressa dichotomo-fastigiata fabellata, segmentis terminalibus obtusiusculis, cystocarpiis in fronde nodose inflata immersis longitudinaliter subseriatis distantibus.

Chondrus pygmæus Grev. l. $c$.

Hab. in mari Indico ad oras Ilindostania (Wiot, sub n:o 173 in Ilerb. Ilooker !).

Caspituli pulvinatim expansi, sesquipollicem altitudine aquantes, frondihus dense conjunctis constituti. Frondes millimetro latiores, basi teretiusculæ, superne evidenter compressæ, sectionem transversalem ancipitem offerentes, a basi ad apicem dichotomiis sesquilineam circiter distantibus decomposita, subregulariter fastigrata et flalscllatim expansa, sed varie flexæ el haud stricta; segmenta terminalia patentia, attenuata sed obtusinscula. Cystocarpia frondi immersa, nodose prominentia, per totam fere frondem longitudinaliter seriata, invicem distantia, singula latitudinem frondis fere occupantia. Frondes fertiles hoc modo alterne constricta et nodosa apparent. Color a violaceo in lividum tendens. 
4. G. Flrcellatus (Ag. sp. p. 2:33) fronde caspitosa compressoplana dichotomo-fastigiata el sæpe secundatim prolifera, segmentis anguste linearibus, cystocarpiis in fronde nodosa prominentibus sæpe binis oppositis.

Sphærococcus furcellatus Ag. l. c. Syst. p. 217. Mont. Fl. Boliv. p. 26 ! hülz. sp. p. 737 !

Var. «. furcellata fronde regulariter diclotomo-fastigiata, axillis rotundatis.

Spl. furcellatus var. minor $A g . l$. $c$.

Var. $\beta$. prolifera fronde dichotoma a margine prolifera, prolificationibus subsecundatis elongatis diclotomis.

Sph. furcellatus Ag. l. c.

Var. $\gamma$ ? patens fronde irregularius di-tricloloma, segmentis elongatis subdiverogentibus subulatis.

Chondrus patens Suhr. mscr.

Chondrus furcellatus Suhr. (partim).

Var. \$. fasciculala fronde fastigiata, segmentis infra-terminalibus subfasciculatis.

Gracilaria fastigiata Suhr. mscr.

Ilab. ad oras Chilenses Peruviæque oceani pacifici (Ilumboldt! Ilerb. Sulır!).

Formas, (juales mihi obvenerunt, enumeravi, haud certus easdem revera ad unam eandemque speciem pertinere, nec de valore characterum ab affinibus distinguentium rite edoctus. Var. $\propto$. est planta minor, 2-3pollicaris, a basi ad apicem repetite dichotoma, segmentis ubique requalibus angustis, latitudinem linex haud attingentibus, axillis magis rotundatis, cystocarpiis sxpissime geminatis oppositis, extra frondem minus prominentibus. Var. $\beta$. est typica planta Agardhii, cæteris multo major, 5-6pollicaris et densius ramis obsita. Rami primari pauci, unciam distantes, lemum subpinnatim in latus dejecti, supra basin longa seric segmentorum a margine prolificantium ornati, apice velut prolificationes dichotomi. IIanc formam tantum sterilem vidi. Var. $\gamma$. est planta minor, minus dense

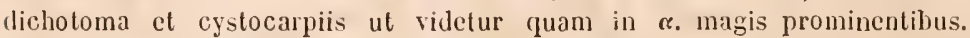
Hec ad G. disciplinalem transitum forsan efficit. Ch. furcellatus Herb. Sulir. partim ad hanc formam, partim ad Chnoosporam pertinet. - Var $\delta$. denique in eo tantum a cateris differt, ut segmenta penultima sint valde prolongata et ab eodem puncto plura proveniant. - Forma omnes sunt compresso-plana, et madefictie hanc formam servantes.

Qualem hanc comprehendo, species nostra a G. vermiculari differt fronde plana, nec non capsularum dispositione, quæ sxpissime linæ opposite, aliqquando plures adproximate, vix tamen umquam ita agglomeratie ac in $G$. vermiculari. A G. disciplinali segmentis ubique linearibus et 
ramificatione distat. Quibus al, G. Torreyi differl, lıodic vix patet, ignota hujus speciei fructificatione. A cateris speciebus habitu longius recedit.

̋. G. TORneri (Ag. sp. p. 254) fronde compresso-plana dichotomofastigiata segumentis linearibus angustissimis, asillis rotundatis, fructibus. ...

Spherococcus Torreyi Ag. l. c. et Syst. p. 218!

Chondrus Torreyi Grev. Iiülz. $s p . p$. 738 !

Ilab. ad orientales Americe Septentrionalis oras; ad New York (Torrey!).

Frons spithamæi, regulariter dichotoma, inferne teretiuscula, mox segmentis linearibus angustissimis vix semilineam latis, iterum apices versus obtusiusculos magis magisque sensim attenuatis. Axillæ rotundatæ; sesmenta omnia adscendentia et quasi forcipe terminata. Substantia exsiccate coriacco-cornea, rigida. Color exsiccate fuscescens.

Species ad nullam aliam bene referenda, at characteribus distinctivis nondum inventis adhuc dubia.

6. G. disciplisalis (Bory Voy. Coqu. n. 62) fronde compressoplana, inferne polychotoma, superne dichotoma fastigiata, segmentis infra polychotomias cuneatim dilatatis, nematheciis (verruculosis subspliericis?)

Sph. disciplinalis Bory Voy. Coqu. n:o 62 !!

Chondrus disciplinalis Grev.; Külz. sp. p. 737 !

llab. ad littora occidentalia America australis; ad Callao (Chatlvin! Gaudichaud!).

Frons $3-6$ pollicaris, vix lineam lata linearis, infra ramificationes principales cuncatim dilatata, duplo latior. Segmenta principalia tri-polycliotoma ramis lateralibus subhorizontalibus, intermedio unico aut binis crectinsculis, omnibus eodem modo pluries divisis; segmenta superiora dichotoma, introrsum tamen subsecundata elongata angusta. Cystocarpia in nostris nulla video. Nemathecia capsulas mentientia adsunt, ita vero compressa ut de forma haud certus sim. Bory capsulas semine Sinapis magnitudine ad ramos evolutas memoravit.

Hujus generis esse speciem legitimam vix dubito et sane G. furcellato proximam, ramificatione facilius distinctam. Specimina vero pauca tantum vidi, ita ut de constantia characteris hodie vix judicandum sit.

** Fronde plana segmentis cunealo-linearibus, cyslocarpiis in pargina plana hemispherice prominentibus.

7. G. rexus (J. Ag. mscr. in Ilerb. Bind.) fronde cxespitosa plana membranacea dichotoma subfastigiata, segmentis linearibus, su- 
perioribus angustioribus, cystocarpiis sparsis in una pagina hemisphærice prominentibus, altera plana.

Chondrus tenuis J. Ag. l. c. Kï̈t. sp. p. 746 !

Gynnog, tenuis $J . A g$. Act. Holm. p. 88.

Var. angusla segmentis angustissine linearibus.

Ilab. in mari Indice occidentalis, ad La Guayra! (Hb. Biıder!); ad oras Mexicanas (Liebman!).

Frons dense cæspitosil, scsquipollicem alta, decomposito-dichotoma atut sæpe infra apicem segmentis approximatis polychotoma, axillis acutiusculis. Segmenta inferiora lineam latitudine superantia, superiora sensim attenuata et angustiora, terminalia obtısa patentia. Cystocarpia pro magnitudine frondis magna, dianetro ferc semilineam ærquantia, in una pagina extra frondem prominentia, altera pagina omnino plana, a medio ad apicem frondis per segmenta sparsa. Color purpurco-amethystinus. Sulstantia menbranacea tenuis.

Forma fere G. norvegicum referens, colore et substantia membranacea atque cystocarpiis magis emergentibus diversa.

8. G. CRendittes (Turn, in Lin. Trans. VI. p. 130) fronde cxspitosa plina dichotomo-fastigialil, segmentis linearibus margine incrassato crenulatis, terminalibus sublanceolatis aculiusculis, nematheciis hemisphæricis minutis, in utraque pagina subserialis.

Fuc. crenulatus Turn. l. c. tab. 8. Ilisl. Fuc. n:0 40!!

Sph. crenulatus Ag. sp. p. 236 et Syst. p. 218 !

Oncotylus crenulatus Külz. Phycol. el Sp. Alg. p. 789!

F. norvegicus Esp. Icon. tab. 153 \%.2.

Hab. in mari atlantico ad oras Lusitanix (Hb. Turner!).

Frondes ex codem callo radicali plurima, longitudine 2-3pollicares, Jasi teretiusculæ, fere statim planæ, iatitudinem circiter bilinearem ubique æqualem ad apices usque servantes, disisa dichotomiis juxta basin incipientibus, mox sexies septiesve repelitis; axille acuta; apices bifidi segmentis ollongo-lanceolatis acutis erecto-patulis; margines hic illic, prasertin apices rersus, leniter incrassati et minutissime sed perquam manifeste crenati. Nemathecia minuta vix semilinea diametro, inferue distantia, superne densiora (demum glomeratil confluentia?)

Specinina paucissima tantum visa, characteribus peculiaribus a G. Norsegico, alias proximo, distincta.

9. G, xonvegicus (Gunn, Fl. Norv, lab, 3 f. 4) fionde cxspitosa plana dichotoma aut infra apicem sape polychotoma fastigiata, segmentis linearibus integerrimis, terminalibus obtusis rotundatis, cystocarpiis in segmentis terminalibus numerosis, in ul- 
raque pagina subprominentibus, nemathecis hemisphrericis in utrayue pagina densis.

Fucus Norvegicus Gunn. l. c. [?] Turn. Syn. p. 222 el llisl. lab. 41! Engl. Bol. tab. 1080. Stackh. Ner. lab. 18. Esp. Fuc. lab. 1:33 f. 4, 3, 4! (lid. Turn.)

Spl. Norregicus Ag. Sp. p. 2033 et Syst. p. 218.

Chondrus Norvegicus Lam. ess. p. 39. Lyngb. Hydr. p. 16. Grev. Aly. Bril. p. 130. Harv. Man. $p$. 7 el Phycol. Lab. 187! J. Ag. Alg. med. p. 93 ! Monl. Fl. Aly. p. H18!

Oncotylus Norvegicus Kï̈t. Phyc. gen. et Sp, .llg. p. 789 !

Fucus polymorphus rar. Lam. Diss. lab. 8 fig. 19?

Sphær. crispus $\%$ dubius $A g ., S p . p .260 ! !$ (sp. cum cystocarp.) synon.)

Chondrus dubius Monl. Fl. d'Alg. p. 117! hülz. sp. p. 73! (fide

Fucus Deroniensis Grev. in Wern. Trans. 3 p. 396 (sp. cum cystoc.)

Exs. Wyall. Danm. n. 120. Chanv. Norm. n. 168!

Hab. iı mari allantico a littore australi Britannia usque ad Gades; in mari mediterraneo ad littora Gallix et Ilispanix.

Cæspites densi, raro ultra bipollicares. Frondes infima basi teretiuscula', intra nonnullarum linearum a basi spatium compressa, dein planx et per totam longitudinem lineares, lineam aut sesquilineam latx, decomposito-dichotome, aut segmentis penultimis adproximatis rarins subpolychotoma, apice rolundata aut cmarginatie obtusx, infra dichotomias vix dilatatæ, axillis plerumque acutiusculis. Cystocarpia frondi fere immersa et in utraque pagina parum prominentia, liametro semilineam vix æquanlia, in segmentis terminalibus numerosa. Nemathecia in disco frondis sessilia hemisphærica, in utracue pagina provenientia, nunc lineam diametro æquantia, magis regulariter disposita sulsseriata, nunc minora majoribus mixta densius disposita. Color coccineo-purpureus.

Specimina nematheciis instructa semper vegetiora et intensius coccineo-purpurea, regularius dichotoma. Quæ Cystocarpiis ornantur plerumque angustiora, dilutius purpurascentia, non raro polychotomo-flabellata. Hec quoque ut diversa species pluries descripta fuerunt. Ad eandem speciem utraque pertinere, intermedia docent.

Speciem jam a Gumnero cognitam dicunt, sed numquam specimen supra meridionales Anglia oras lectum, a hodiernis Algologis visum fuisse, novi. Turnerus speciem ita illustravit, ut postea semper illam agnoverunt.

10. G. Coningosus (J. Ag. Act. Holm. Öfoers. $1849 \mathrm{p}$. 88) fronde plana membranacea inferne diclotoma, apices versus flabellito-corymbosos polychotoma fastighiata, segmentis linearibus, superioribus brevissimis, terminalibus angustioribus multifidis crenulatisque, cystocarpiis iufra apices solitariis aut paucis, sublıemispherice in una pagina prominentibus. 


\section{Hill. ad Cap. b. Spei (Harvey!).}

Frons circiter 2-3pollicaris, inferne linea latior distanter dichotoma, superne divisionibus creberrimis multifida et flabellata, flabellis invicem incumlentibus et segmentis terminalibus plerumque angustioribus plurimisque, ramorum apicem corymbosum reddentilus. Axillæ acutæ. Segnenta terminalia cæteris plerumque semiangustiora, apice rotundata aut emarginata crenulatave. Cystocarpia infra apices segmentorum solitarid aut pauca, subliemisphærice prominula, minuta, ut in cæteris speciebus generis constructa. Substantia membranaceo-carnosa. Color purpureus.

Idxam hujus speciei meliorem vix dare potuerim, quam quæ Turneri Fuci spermophori data icone (figura dextra) concipiatur; frons tantum inferne latior quam apud Tumerum pingitur. Iconen tamen ad hanc speciem pertinere non posse, fructus adpositi suadent. Cystocarpia enim in nostra bene eroluta adsunt omnino Generis; nemathecia vero nulla. Species Turneriana fructus Pllyllophoræ subsimiles habere videtur.

Inter species generis ad G. glomeratum forsan proxime accedit, fronde membranacea plana et ramiticatione ab hac recedens.

11. G. Glomeratus (J. Ag. Act. Holm. Öfoers. 1849 p. S8) fronde inferne ancipite-plana, superne densissime diclıotoma flabellata fastigiata, flabellis invicem dense incumbentibus sub-imbricatis, segmentis brevissimis linearibus, terminalibus apice crenulatis subrecurvis, cystocarpiis ad segmenta terminalia numerosis, lıemisplıarice in una pagina prominentibus, altera plana.

Chondrus capensis Külz. $s p . p$. 738 (exclus. syn.)?

Sph. norvegicus $A g$. Sp. (quoad specim. capensia!).

Ilab. in mari austraii ad Cap. b. spei (Lalande! Pappe!)

Cæpes fere glomeratus, diametro circiter pollicari. Frons densissime dichotoma decomposito-flabellata, flabello quoque proximis incumbente, ita ut frons tota undique imbricata evadat. Segmenta inferiora sesquilineam fere lata, superiora lineam æquantia, linearia aut leniter cuneata, inter divisiones vix lineam longa; terminalia obtusa, apice crenulata et recurva. Cystocarpia in una pagina hemispherice prominentia, ad segmenta superiora numerosa, illis Ch. norvegici vix majora. Substantia coriacea.

A reliquis speciebus glomerata forma caspitum, et segmentis terminalibus apice crenulatis et subrevolutis differt. In creterum vero antecedentibus sine dubio proxima.

*\%* Fronde lereliuscula cystocarpiis hemispherice prominenlibus verrucosa.

12. G. POLYCLAdes (Külz. sp.p. 73\%) fronde cespitosa teretiuscula subcompressa diclıotomo-fastigiata et secundatim prolifera irre- 
gulingus fabellata, prolificationibus segmentisque terminalibus curvalis acutiusculis, cyslocarpiis subhemisplacrice prominentilus densis lice illic aogregatis.

Clıondrus? polygcladıs külz. $l$. $c$.

Ifab. ad Calp. b. Spei (Harrey! Pappe! IIb. Areschous!).

Caspites 2-4pollicares, densi. Frons media crassitien penne columbinx fere aquans, utrinque attenuata, jusenilis compressa, adulta fere teres, basi simpliciusculi, superne irregularius dichotomo-flabellatia, proliticationibus plurimis precipue ramosa. Proliticationes simpliciuscular aut furcatx, segmentis terminalibus conformes, curvate, acumindtx. Cystocarpia in segmentis et prolificationibus plurima, nunc sparsiora, nunc densiora et hic illic aggregata. Color purpureus. Sulstantia coriacea.

Formam hanc ad G. verinicularem semper retuli, cui sane proxima, sed forsan distincta, fronde fere omnino tereti, apicilus acuminatis curvatis, cornu Bovis fere referentibus. Exsiccata collabitur et compressa adparet. (Compressam haud bene describit Kiitzing).

13. G. Vernicularis (Turn. Hisl. $n$. 221) fronde caspitosi teretiuscula subcompressa dichotomo-fastigialia el sape sparsim fasciculatit aut secutulatim prolifera, prolificationibus segmentisque terminalibus obtusis, cystocarpiis subhemispharice prominentibus aggregatis.

Fucus rermicularis Turn. l. c.!

Sphærococcus icrmicularis Ag. Sp. Alg. I p. 311 el Sysl. p. 234!

Chondrus vermicularis Grev.; hïls. sp. p. 739.

? Gracilaria concinna Mont. Bonil. p. 100.

IJab. in mari australi ad Cap. J. Spei (IIb. Nertens! Pappe!); ad littora Chilensia (11b. Binder!).

Frons 2-4pollicaris, diametro $1 / 2-1$ linex, jurenilis compressa, adulta inferne compressa, superne teretiuscula aut pluribus segmentis una egredientibus parum compressa, initio subregulariter dichotoma fastigiati, dein prolificationilsus fasciculatis secundatisie irregularius ramosa, aut apice 3-polychotoma, immo aliquando cervicorniter expansa. Cystocarpia rariıs solitaria, sxpissime plurima adproxinata, ramum undique inx'g̨ualem reddentia, hemispharice prominul:ı. Color purpurascens.

Hanc esse speciem Turnerianam tum a specimine conveniente Mertensiano tum a descriptione congruente concludere audeam. Specimind Capensia et Chilensia distinguere nequeo. Plinta sine fructu ad Californiam lecta liuc quorue in beechey loy. $p$. 164 refertur. Ch. sejninctus (Bory Voy. Coqu. $u$. "33) est seć. spec. authentica, als ipso et a D'Urrilleo data, G. rermiculari proximus; sed major et fere magis regulariter dichotomo-fastigiatus. Quun vero tantum sterilem vidi, utrum revera identicum an diversum sit, dicere non ausim. 
In G. vermiculari cellulas interiores crassis parietibus instructas, seu pluribus membranæ stratis cinctas vidi. Stratum exterius frondis introrsum valde evolutum, et quasi cryptas, in interiore strato excavatas, cellulis minoribus implens, aliquando observavi; fructus his locis aut inchoantes, aut jam delapsos esse, suspicor. Idem in aliis speciebus generis quoque ridi.

***:* Fronde coriacea crassa canaliculata ant marginibus levissime involutis subplana.

1'. G. CAPENSis (J. Ag. mscr.) fronde cespitosa inferne teretiuscula sursum compressa crassa canaliculata dichotomo-fastigiata, segmentis superioribus polychotomis fasciculatis dense congestis tortis et complicatis, terminalibus emarginatis crenatisve, fructibus. . . .

Halymenia furcellata var. Capensis $A g . S p . A l g . I p .244 !$

Chondrus? complicatus Külz. Sp. Alg. p. 737 !

Hab. ad Cap. b. Spei (De la Lande! Pappe!).

Frons 3-4pollicaris, a basi scutata cxespitosa, inferne teretiuscula, sursum sensim magis compressa, attamen crassi, linc sub-convexa, illine parum profunde canaliculata, marginibus rotundatis. Crassities inferne pennæ columbinæ, superne infra dichotomias dilatata, lineam aut sesquilineam lata. Ramificatio inferne lichotoma, semipollice inter furcas proximas, superne et infra apicem polychotoma, furcationibus adproximatis. Segmenta superiora 3-9 eadem altitudine provenientia fasciculata, erectoadpressa, hinc canaliculata, complicata, exsiccatione longitudinaliter plicato-rugosa, terminalia rotundata obtusa aut emarginata aut crenato-polychotoma. Color atropurpureus. Substantia firma coriacea.

Quomodo hæc forma umquam cum Ialymenia furcellata comparari potuerit, me sane fugit. Certe tamen species nostra cum Agardhiana supra allata identica est. Species Nontagnei ejusdem nominis diversa videtur, quum et ipse illam Halymeniæ adnumeravit, et kïtzingius, qui specimen vidit, ad Gymnophlixam (Sp. Alg. p. 712) illam retulit. Chondrum Capensem Kíitz., ad quem (Sp. Alg. p. 738) et Halymeniam furcellatam Capensem Agardbii et Halymeniam Capensem Montagnei (quam alio loco nomiue Gymnophlæx canariensis proponit) duxit, speciem a nostra omnino diversam puto. Aliam contra speciem, nempe supra citatam liützingianam, cum nostra identicam suspicor.

15. G. PAtExs (Good. el Woodw. Lin. Trans. III. p. 173) fronde ciespitosa, inferne ex tereti compressa canaliculata, sursum membranacea plana diclotomo-fastigiata, scymentis linearibus, terminalibus cuneatis truncato-rotundalis emarginatisye, cystocarpiis 
in segunentis terminalibus plurimis, in utrạne pagina subprominentilus.

Fincus patens Good. el Woodir. I. c.

Fucus crispus var. $\zeta$. patens Turn. Syn. Fuc. p. 227 et Ilisl. Fuc. IV p. 48 lal. 21; fig. a (parum characteristica)!

Spharococcus crispus var. patens Ag. Sp. Alg. 1 p. 2.59.

Fucus polymorphus rar. Lam. Diss. fig. 12? 21! 22!

Chondrus celticus Kül. Phycol. p. 399!

Chondrus crispus var. Külz. Sp. Alq. p. 73̈̈! Harv. Phyc. et Auct.

llibl. in oceano atlantico calidiori ad littora Deronia, Gallice prope Bay̧onne (Blytt!) et Biaritz (Endress!) usque ad Gades (Cabrera!).

Alga 4 -6pollicaris, eximie caspitosa, stirpibus numerosis a disco radicali expanso provenientibus, erectiusculis. Frondes juveniles ima hasi teretiusculæ, mox compressæ crassæ et infra apicem canaliculatæ subspathulatæ; adulte caulescentes, inferne teretiuscula, superne complanatie, subcaualiculato-planæ, substantia sensim tenuiores, apice membranacex. Ramiticatio subregulariter dichotomo-fastigiala. Segmenta inferiora cune:1to-linearia, terminalia cuneata, apice rotundato-truncata aut emarginata. Cystocarpia in his immersa rel utrinque parum prominentia, in singulis segmentis plurima (aliçuando ultra 20 numeravi), pro magnitudine plantie minuta, semilineam diametro vix superantia, intra cellulas rotundatoangulatas gemmidia minuta rotundata forentia. Color purpureus, in lividum aut viridem tendens.

Species sane distinctissima, a specie, cum gua illam conjunxerunt auctores, revera multo magis dirersa quam a G. norregico, licet ab hac facilius distinguatur. A Goodenough et Woodward jam distincta, charactere a fronde canaliculata petito, a Turnero ad F. crispum relata, eodem charactere tamen indicato, a Küizingio denuo distincta, sed nale inter Chondros recepta et duce Harveyo in recentissimo opere iterum cum Ch. crispo conjuncta, quod sane mirandum quum non tantum structuram diversam descripsit sed etiam fructus vidit. Cystocarpia revera et dispositione et adparentia (relicta quoque structura diversa) tam longe a Fuco crispo recedunt, et ita ad unguem cum Cystocarpiis Fuci norvegici conveniunt, ut qui umquam has plantas fructiferas viderit, illum diversitatem comprehendere, necesse sit.

16. G. lisesris (Turn. Hist. n. 22ิ0) fronde subcanaliculato-plana diclotomo-fastigiata, segmentis linearibus marume subincrassito integerrimis, terminalibus rotundalo-obtusis dilatatis, nemitheciis [?] subglobosis ad unam paginam fore tantum obvenientibus, demum plurimis approximatis.

Fucus linearis Turn. l. c. lab. $220 ! !$

Sphrococcus linearis Ag. sp. p. 20̈0 el Syst. p. 216! 
Chondrus linearis Grev.; Fülı. sp. Alg. p. 73s!

Ilab. in oceano pacifico ad Americam Septentrionalem (IIenzies!).

Frons $4-6$ pollicaris, inferne subteretiuscula, sensim compressa et denique plana (in nostra fere canaliculata, marginibus in pagina fructifer: prominentibus), linearis, inferne lineam, superne sesquilineam lata, pollicari a radice distantia divisa, et dein paucis dichotomiis fere aque distantibus decomposita. Segmenta terminalia dilatata rotundato-obtusa. Axillie omnes acutiuscule. Nemathecia inchoantia (aut cystocarpia?) subsphærice prominentia et fere omnino emersa, diametro fere lineæ, in segmentis superioribus plura adproxinati, et in eadem pagina fere omnia obvenientia. Substantia coriacea. Color atropurpureus.

In Icone Turneri apices magis acuminati pinguntur quam in nostro specimine sunt. Cæterum pro more eximia.

Fructus descripti nucleum fovent cellulosum, densissimo strato filorum radiantium tectum. Gemmidia vero in cellulis nuclei nulla vidi. Cujus itaque generis sint, mihi incertum videtur. Ob magnitudinem et dispositionem nemathecia credidi nondum matura.

17. G. DILatates (Turn. Hist. n. 210) fronde cespitosa subcanaliculato-plana dichotomo-fastigiata, segmentis subcuneato-linearlibus margine subincrassato integerrimis, terminalibus truncatoobtusis subinvolutis, nematheciis hemisphericis ad unam paginam (fere tantum) obvenientibıs, demum plurimis approximatis.

Fucus dilatatus Turn. I. c. Tab. $2\{9$ !

Sphærococcus dilatatus Ag. Sp. p. 250 et Syst. p. 216 !

Oncotylus dilatatus Kütz. Sp. Alg. p. 789.

Chondr. atropurpureus Sulir. Beilr. 4840. Flor. p. 264.

Hab. in mari australi ad Cap. b. Spei (Lalande! Irarvey! Palppe!).

Frons 3-4pollicaris, inferne teretiuscula, mox plana el divisa, decomposito-dichotoma, coriacea el crassa, segmentis sublinearibus infia dichotomias $1 / 2-$ pollicem circiter distantes, leviter cuneatim dilatatis, cxterum late tinearis, apicibus truncato-obtusis aut emarginatis, axillis sæpius rotundatis. Margines integerrimi et levissime incrassati, quod ad apices sub-involutos pracipue conspicialur. Nemathecia hemisplıærical, ambitu lentis aut majora, quantum video ad unam paginam, hinc convexam marginilus revolutis, limitata, uno alterove ad paginam aversam conspiciendis, demum ita dense provenientia ut pluribus confluentibus irregularia evadant atcque igglomerati. Color a sanguineo intense purpurascens aut immo in fuscum tendens. Substantia fere coriacea.

Cateris crassior et magis coriacea, 3-- 4 lineas hata aut infra dichotomias huplo hatior. Characterem vero pracipum in margine incrissato, et apicibus versus paginam nemathecia gerentem involutis, tum etiam in 
nematheciis ad unam naginam sublimitatis demum agglomeratis, pagina aversa tunc canaliculata, - Margines aliqquando cremulati et proliferi.

\section{Species inquirende:}

18. Cu. pusicus (Mont. Crypt. Barb. n. "77) "minimus (semiunciau altus) exspitosus, fronde sublereti dichotoma, segmentis patentibus, ultimis bi-trifidis apice axillisque acutis.

Ch. pusillus Mont. l. c. tab. 13 fg. 9. Fl. Alg. p. 118. Küls. sp.p.739! llab. ad Bone Nigerix (Stcinlıeil).

An G. Griflithsia planta capsulifera? Conceptacula filis medullaribus immersa, utrinque prostaitia, pro ratione magna, ocellata, semper clausa, congeriem sporarum ovoidearum dissolutione frondis tandem elabentium forentia. Structura Gymnogongri, fructus vero Chondri." Descr. Auct. transscripsi.

19. G. Flreldatus (Kütz. sp. $p$. 788) "exspite denso pulvinato humili; phycomatibus dichotomo-ramosissimis, ramis divaricatis fastigiatis vel corymbosis, abbreviatis, coarctatis, apice bifurcatis (sæpe expallidis) complanatis subdilatatis. AIt. 1/2"; crassities pennæ passerinæ - merulinie."

llab. in mari mediterraneo prope Gaeta.

20. G. parthexopeus (Kütz. sp. p. 788) "pliycomate guracili elongato setaceo irregulariter dicholome ramoso, ramis siepe fasciculatis apice fureatis altenuatis subulatis, implicatis. Long. 2-4". Substantia pellucida cartilaginea."

Fucus parthenopæus Bridel.

Hab. in Sinu Neapolitano.

llabitus Fuci plicati, sed tenuior.

XlNilla. P.scirycsness Fï̈l. Phycol. p. 4.12 tab. 63 fig. II. Spec. p. 790. Phycoma coriacco-cartilagineum stipitatum, sursum planum anpligenetum. Stratum corticale crassiusculum perenchymaticum, internum parenclỵmaticun cellulis sensim majoribus intinis maximis. Cystocarpia in disco plrycomatis sessilia, plano-lıemisphærica, clausil, spermangio crassissimo e cellulis radiatim ordinatis, excentricis densissimi. composito; spermopodium compactum parenclymaticum; loculanentis monospermis remotis sparsis. Tetrachocarpia. . . . .

P. Dls.ıтarus (iiüls. l. c.) pollicaris - bipollicaris, phycomate dichotomo, segmentis primariis lasi cuneatis, superioribus dilatatis 1-2" latis, apicibus crenulato-furcatis; margine undulato.

Jfab. iı mari mediterraneo ad oras Hispania (Willkomm.) 
XliX. Pityllopiona Grev. Alg. Br. p. 135 (mut. limit.) J. Ag. Alg. med. p. 93. Alg. Liebm. p. 11 in not. et Act. Holm. 1849 Öfvers. p. 88. Endl. Gen. Plant Suppl. III p. 38. Aresch. Enum. p. 8I. IIarn. Phycol. sub tab. XX. Mont. Fl. Alg. p. 120. Plıgllotylus, Coceotylus, Acanthotylus et Plı̣llophora liütz. Phycol. p. 412-3 et Sp. Alg. p. 790-2 Spliærocueci sp. Ag. Delesserie sp. Lamour.

Frons inferne caulescens aut costata, superne in laminas planas sxpe prolificantes expansa, stratis cellularum duobus constituta; interioribus cellulis angulato-oblongis subinanibus, corticalibus verticaliter radiatis minorilus. Iialidia intra pericarpium proprium, sessile aut pedicellatum, sxpe tuberculosum aut rugosum, clausum, nidulantia, gemmidiis minutis intra cellulas prognantes plurimas, in nucleum compositum coalescentes, constantia. Nemathecia externa pulvinita, in disco rel ad basin folioli evoluti, nunc globosa pedicellata, filis radiantibus constituta, intra articulos filorum splærosporas cruciatim divisas foventia. (Grev. Alg. Br. tab. 45).

Frondis prima origo est folium sinplex, inferne costa plus minus cridenti instructum, superne sensim furcatum aul laciniatum. Lt prolongatur hoc, costa evidentior evadit, lamine marginantes in nonnullis obliterantur et stipes caulisve oritur, demum teretiusculus et ramosus. Lamine itaque stipitate aut ab ima basi inchoantes, obsoletius costate aut costa pereurse, lineares aut cuneato-flabellatæ, sparse furcate ant decomposite dichotomx, fere in omnibus insuper foliolis prolificantibus ramose. Substantia frondes membranacex sunt, at satis firme, colore e roseo purpurascentes.

Duplici strato frons contestia est. Cellulie medie oblonge angrulatx, in costa et caule magis longitudinales, esteriores sensim minores et magis verticales, cellulis superficialibus minutis, rerticaliter radiatis.

Fructus duplicis generis, in diversis individuis obvenientes, ('arissime in eodem individuo fructus uterque observatus fuit).

Kálidia intra pericarpium proprium, sessile aut pedicellatum, extus leve aut sxpissime tuberculis rotundatis vel rugis elevatis inieduale, nidulantia, a cellulis transformatis strati medii orta. Gemmidia rotundato-angulati,plurima intra cellulas singulas evoluta, demum meubrana cellularum obliterata, in catervas distinctas conglomerati, hoc modo nucleum comprositum efficientia. P'ericarpinn clausum, 
filis moniliformibus verticalibus conflatum, (disruptione partis demum apertum?).

Splierosporæ intra articulos filorum Nematlıcii evolutæ, oblongx, ab apice filorum deorsum sensim maturæ, cruciatim in sporas 4 divisie. Nemathecia externa, nunc pulvinatin supra laminam folii expansi; nunc in apice folii prolificantis sphxrica, et inferiore parte folii suffulta pedunculata; munc ad basin folii prolifieantis evoluta ot lamina persistente pellatim tecta, pelta pro forma folii integra aut Iaciniata.

Species, quæ hoc genus constitumnt, diutius cognitie, apud Agardhium ad Sphærococci diversas sectiones, apud Lamouroux ad Delesseriam relatie fucrunt. Greville genus proprium Plyyllophore condidit, cui, præter species typicis generis, plures male ei pertinentes introduxit, alias vero affues exclusit. Fructus indolem in specie $15-$ pica pro suo tempore eximie illustravit. In "Ag mis moditerancis" genus justis limitibus circumscribere conatus sum. Suhriam nonuullis Phỵllophore speciebus, Cryptonemiam aliis condidi. Plures contra species ad Chondrum antea relatas Plybllophore vindicari. Ngas Lichmannianas dein describens, species antea dubias suis locis disposui; ignota mili vero adhuc nematheciorum natura, nemathecia F. membranifolii et $\mathrm{F}$. repentis ejusdem esse indolis suspicatus sum, et species las in idem genus male consociavi. Limites generis in "Ngis mediterraneis" ductos Harvey in sua Plıycologia aynovit. Endlicherus nostra premit restigia, sed nomine a me antea dato deceptus, Chryptonemix speciem inter Phyllophoras adhuc cnumeravit. Kützing Phyllophoris nostris \& genera nova, forma externa Nemathecii fundata, distinxit. Vix antem lıæ genera agnoscere voluerim. Idem revera omnihus typus. Nemathecia enim ubique a folio transfomato oriuntur. In Plı. membranifolia folium vix transformatum manet. In Pl. Rubenti et Pl. Nervosa lamina guodue pars suprema manet, licet forma propria peltata supra nemathecium espandatur. Idem omnino obtinet in Plı. IIeredia, ea tantun differentia, quæ a forma ipsius rolii pendet. In Plı. Brodixi obliteratur pars rolii suprema, et nemathecium glohosum evadit. Differentix milit videntur specificx, non genericie. Species sunt aflines et rix direllendie.

Quoad naturam fructus diu valde obscuri manserunt. Cystocarpia matura et bene evolutil pauci observarunt; Greville eadem inter omnes optime cognovit. Ipse non ante hoc ultimum tempus matura inveni; hodie in plurimis olsservavi. 
Nemathecia in pluribus speciehus diu cognita, sed male explicalu, a nonnullis immo cum capsulis confusa, quoad naturam fre hucusque dubia. Splærosporas vidit at non coonovit Greville. Nontagne in Pl. Heredia, ipse in plurimis maturas demum vidi; hodie illas ita intellectas spero, ut ulterioris confusionis nulla maneat ansa.

1. Coccotrus fronde subcaulescente superne in laminas planas ecostatas expansa; nemalheciis spharicis ad apices laminarum pluribus pedunculatis.

1. Plt. Brodial (Turn. Hist. Fuc. II p. 1) stipite compresso prolificationibus ramoso, ramis in laminas planas lineares cuneatasque vage constrictas simplices bifidasie proliferas expansis, eystocarpiis globosis ad laminas sessilibus, nematheciis sphæricis ad apices laminarmm plurilus pedunculatis.

Fucus Brodixi Turn. l. c. lab. 72! Sm. Engl. Bol. tab. 1966. Fl. Dan. lab. 1476 el $2135 \mathrm{fg} .2$ !

Phyllophora Brodiæi J. Ag. Alg. med. p. 93. Harv. Phycol. Lab. XX (excl. var. $\beta$. )! Aresch. Enum. p. 83 lab. III A.

Sphærococcus Brodiæi Ag. Sp. Alg. I p. 239! Syst. p. 213! Lyngb. Ilydr. Dan. p. 11 lab. 3 !

Chondrus Brodixi Grev. Alg. Br.p. 433! Ilarv. Man. p. 78!

Coccotylus Brodixi hiül. Plycol. gen. p. 414. Sp. Alg. p. 791 !

F. membranifolius Lamour. Diss. $p$. 17 lab. 21 f. $1 \mathrm{el} 2$ !

Fucus crispatus Müll. Fl. Dan. lab. 826 fig. 2 el 3 !

Hab. in mari atlantico superiori a littore Norvegixe et Scotice ad Galliam et Angliam inferiorem.

Frondes plerumque dense caspitosæ, a callo minuto radicali surgentes, stipite compresso et plerumque plano, sensim explanato in laminas lineares aut elongato-cuneatas, superne constrictas iterumque dilatatas, aut sape latius cuneatas bifidasque, apice proliferas, foliolis conformibus aut sxpe obovato-cuneatis. Kalidia intra pericarpia subglobosa ad laminas superne sessilia; strato pericarpii exteriore filis radiantibus verticalibns constituto; interiore a cellulis angulato-rotundatis demum solutis et praynantibus. Nemathecia fere ejusdem former, sed laminan eircumcirca involventia et ita pedunculata, plerumque ad apices numerosa, filis ratdiantibus moniliformibus constantia, intra articulos spherosporas cruciatim divisiss evolventia. Color purpurascens.

Lt in vidis salsulosis saxis adfixa crescat, valde ramosa et caspitosa evalit, atque tominis angustis vix lineam latis pradita. Fructus utriusque geueris fere conformes, alo anctoribus confusi videntur. Pericarpia kalidii leniter tulserculosa, in alterutera pagina scssilıa (a Ilarv. l. c. depicta); nemathe- 
cia (a Lyngb. l. c. depicta) plerumque ad apices plurima et in foliolis minutis subterminalia, extus rotundata. Fila, qua stratum pericarpii exterius constituunt, magis ramosil, quam fila nemathecii. Gemmidia bene evoluta non villi. Sphærosporas jam hene descripsit Greville (l.c.p. 134) sed rem male explicavit; ipse optime erolutas observari.

\section{Pirluopnon fronde caulescente aut in laminis inferioribus} subcostala; nematheciis circa petiolos foliolorum prolificantium exolutis, laminaque folioli sulpellata tectis.

2. P'II. Rubexs (Good. el Woodw. Lin. Tr. III p. 165) stipite compresso in laminas planas lineares sub-ccostatas proliferas expanso, foliolis prolificantibus sublanceolatis simplicibus aut apice furcalis cuneatisque, cystocarpiis rugosis ad foliola sulssessilibus, nematheciis lamina folioli subpeltati tectis.

Fucus rubens Good. 't Woodw. t. c. Turn. Hist. Fuc. I tab. 42 ! Eugl. Bot. lab. 1053. Slackh. Ner. Bril. lab. 19!

Phyllophora rubens Grev. Alg. Brit. p. 433 1. 13! Harv. Man. p. 79! el Phycol. Bril. Lab. 131! Aresch. Enum. p. 84. Külz. Sp. Aly. p. 791 !

Chondrus rubens Lyngb. Ilydr. p. 48 !

Sphærococcus ruliens Ag. Sp. p. 237! Syst. p. 213!

Fucus prolifer Lighlf. Scol. p. 949 tal. 30. Esp. Fuc. t. 129.

Fuc. epiphyllus Fl. Dan. t. 708 !

F. crispus Iheds.

Exs. Wyall. Danm. n. 29.

Hab. in oceano atlantico a Norregia et Islandia usque ad Tingin! in sinu Codano.

Radix scutata. Jurenilis planta foliolo stipitato cuneato, in lacinias 9-3 diviso, apice rotundato constat. In adulta caulis brevissimus adest, mox abiens in laminas obsolete costatas, 2 -3lineas latas, lineares et integerrimas, lic illic furcatas, a superficie juxta marginem proliferas. Foliolit prolificantia juniora elliptica, sensim magis lanceolata, aut inferne longe cunesta, apice furcata. Kialiclia intra pericarpium brevissime pedicellatum, superne rugis elevatis sinuosis notatun, nidulantia; gemmiliis plurimis in catervas plurimas, membrana cellularum (demuin obliterata?) sejunclas, dispositis, constantia. Nemathecia ad basin foliolorum prolificantium evoluta et lamina folioli subpeltatim tecta, filis monilıformibus articulatis constituta; spharosporis intra articulos singulos singulis, in sporas 4 cruciatim divisis. Color cocrineo-purpureus. Substantia membranaceocartilaginea firina.

Species borealis defectu costa a serjuente meridionali potissimum differt. Jam Linna hace species forsan cogntuta fuit; specimina enim in ipsius Ilerbario sub nomine F. rubentis servantur. l:x scriptis vero aliam speciem sul) hoc nomine intellexisse suspicantur. 
3. Pr. yerrosi (Dec. Fl. Fr. II p. 29) stipite compresso in Iaminas planas lineares margine undulatas costatas proliferas expanso, foliolis prolificantibus oblongis simplicibus furcatisve, cystocarpiis ad foliola subsessilibus, nemathecits lamina folioli subpeltati tectis.

Fucus nervosus Dec. l. c. Bertol. Amoen. It. p. 290. Turn. IIist. tab. 43 !

Sphærococcus nervosus Aj. Sp. p. 236! el Syst. p. 213!

Phylloph. nervosa Grev.; J. Ag. Alg. med. p. 94! Zanard. Syn. p. 109. Nont. Fl. Alg. p. 121! lab. 16 fig. :3 g. hült. Sp. Alg. p. 791!

Epatica spirale Ginn. op. post. lab. 26 n. 61.

Ilab. in mari mediterraneo, nigro et adriatico, usque ad Gades!

Ralix scutati. Frondes peilales et ultra, erectæ, caule brevissimo, fere nullo, in laminas costatas mox abeunte. Laminie clongatæ sæpe pluripollicares, 2-3lineas circiter latæ, inferiores semper costata, costa in supremis obsoleta, prolificationibus densis ramosx, apicibusque sape furcatis divisæ. Foliola prolificantia ab angusta loasi oblonga aut linearia, obtusa, simplicia aut furcata. Margines ubique undulati. Kalidia intra pericarpium subglohosum, minus quam in Ph. rubenti rugosum, nidulantia, in nostris non bene evoluta. Nemathecia omnino Pl. rubentis; sphærosporas maturas non vidi. Color coccineo-purpureus. Sulstantia membranaceo-cartilaginea.

Species Ph. rubenti proxima, sed major, evidentius costata et margines undulati.

Synonyma Wulfeni et Gmelini, quæ ad hanc citant, vix eidem pertinere puto.

4. Pur. Heredia (Clem. Ens. p. 314)-caulescens stipite cyllindraceo ramoso, ramis in laminas planas cuneatas dichotomo-multilidas expansis, laciniis terminalibus angustissimis, cystocarpiis tuberculatis stipitatis, nematlıeciis laciniis folii dissecti subpeltatim tectis.

Fucus IIeredia Clem. l. c.!!

Ihyllophora IIeredia J. Ag. Alg. med. p. 94! Mont. Fl. Alg. p. $122 \mathrm{lab}$. 16 fig. $\$ 3 a--e$.

Acanthotylus IIeredia Kütz. Phycol. p. 413 et Sp. Alg. p. 792!

Sphærococcus IIeredia Ag. Sp. Alg. p. 243! el Sysl. p. 2131

Chondrus Heredia Gircv. Zanard. Syn. p. 108.

Fucus Cypellon Bert. Op. Bol. 2 p. 290 lab. 11 fig. 5 et Imoen. It. p. 292 tab. V fig. 8 !!

1. laciniatus Ball.

Delesseria spermophora Lamour. Ess. p. 38 !!

llab. in mari meditertaneo a littore Italia Insque ad Gades; in atlantico usfjue ad Armoricam adscendens. 
Frondes a callo radicali caspitosa, 4-6pollicares, inferne caulescentes, stipite teretiusculo sursum sensim complanato et subcostato, demum plano enervi et in laminas expanso. Laminæ sublabelliformes densissimo decomposito-dichotoma atque proliferie, laciniis majoribus basi cuneatis, sesquilineam latitudine vix superantibus, superioribus sensim angustiorilus, supremis angustissimis. Kalidia intra pericarpia pedicellata, axillaria ant a disco prolifera, tuberculis minutis inequalia. Nemathecia ad basin folioli proliticantis evoluta et laciniis bujus folioli peltatim tecta, spliærosporas cruciatim divisas intra articulos filorum moniliformium foventia. Substantia membranacea. Color purpurascens.

llabitu ad F. membranifolium proxime accedit, at multo magis el profundius divisa, laciniis angustissimis. Fructus forma insuper diversus et magis ad F. rubentem accedens. -- Fucus Spermophorus Turneri tum inter synonyma Acanthotyli IIeredix, tum ut species propria Chondri, a liuitzingio enumeratur.

\section{Purlotruts fronde caulescente superne in laminas planas} ecostatas expansa, nematheciis in lamina pulvinatim expansis.

5. PiI. Palmetroldes (J. Ag. Act. Holm. Öfvers. 1849 p. 88) stipite compresso parce ramoso, ramis in laminas planas oblongas cuncatasque, simplices aut furcatas (aut palmato-laciniatas?) vel proliferus expansis, cystocarpiis ..., nematheciis in disco laminæ expansis rotundatis.

Phyllophora palmettoides J. Ag. l. c. Hlarv. Phycol. Brit. lab. CCCX! Fucus membranifolius var. roseus Turn. Ilisl. Fuc. lab. 7l fig. m! Chondrus Brodiæi var. simples Grev. Alg. Hr. p. 133. Harv. Man. p. 78 .

Phyllophora Brodiæi var. simplex IIarv. Phycol. lab. XX fig. 2-4!

? Sphærococcus Palmetta Lyngb. Ilydr. Dan. p. 11.

Exs. Wyall. Danm, n:0 121.

Llab. in oceano allantico ad littora meridionalia Anglix D:na Griffitlıs! et Gallix (Crouan!); (? ad Ilelgolandiam! et in sinu Codano!).

Est planta affinibus minor, 1-3pollicaris, in disco radicali late expanso gregaria. Stipes ima basi excepta compressus et planus, in laminas ollongo-cuneatas, apice plerumque rotundatas, simplices aut superne proliferas, expansus. Alipuando in plantis, qua ad hanc speciem pertinero suspicor, laminæ cuncatic evadunt et profunde laciniata, laciniis conformibus. Nemathecia minuta sorum rolundatum, diametro lineam parum excedente, referentia, in disco lamina expansa, demum delabentia, cicatricem relinquentia, 
Planta diu cognita, nunc sero F. membranifolii, nunc F. Brodiei var. considerata. Al illo distat stipite compresso, Jaminis proliferis et forma nematlecii. Ah hoc differt pracipue nematheciis. Color quam in utraque plinta magis roseus. - Sph. palmetta Lyngh). luic proxima milıi videtur, sed differt forma laminarum cuneata et laciniata. Fructus nondum in hac forma observati, quare vix dijudicatur utrum ad hanc an ad proximam (quandam pertineat.

Greville frondes hujus plante ad F. Brodixi transeuntes, se observasse contendit. Animadvertendum vero hoc tantum formam frondis respicere posse; constat enim Grevilleum nemathecia F. Brodixi pro capsuls descripsisse; unde diversitatem in situ et forma Nemathecii ei latuisse, facile intelligatur.

6. P'Il. мaмrвastalu (Good. et Woodw. in Linn. Tr. 3 p. 120) stipite cylindaceo ramoso, ramis in laminas planas cuneatas simplices ant palmato-laciniatas expansis, cystocarpiis oboratis slipitatis, nemaltacciis supra laminas late expansis pulvinatis.

Fucus membranifolius Good. et Woodw. l. c. tab. 16 fig. 4. Lamour. Diss. lab. 21 fig. 3! Turn. Ilist. Lab. 74! Engl. Bol. lab. 1965. Stackh. Ner. Br. lab. XX!

Phyllophora membranifolia J. Ag.; Aresch. En. p. 81. Harv. Phyc. Bril. lab. CLXIIII!

Sphærosoccus membranifolius Ag. sp. Alg. 1 p. 240 ! Syst. p. 214. Lyngb. Ilydr. p. 10 tab. 3!

Rhodymenia membranifolia Ilarv. Syst. List. in. Phyc. Brit.

Phyllotylus membranifolíus Külz. Pliycol. el Sp. Alg. p. 790.

Chondrus membranifolius Grcv. Alg. Br. p. 131! Ilarv. Man. p. 78!

Fucus rubens Miull. Fl. Dan. lab. 827!

Fucus crispatus Müll. Fl. Dan. Lab. 826 fg. 1!

luc, timbriatus IIuds.

Fuc. palmetla var. Lamour. Diss. Lab. XX!

Exsic. Grev. Alg. Brit. n:0 21! Chauv. Norm. n:0 94! Wyalt. Danm. 1.: 76 .

Ilab. in oceano atlantico a littore Norregix et Islandiae usque ad Galliam inferiorem; ad littus Americe borealis (sec. Harvey).

Frondes cæspitosæ erectiusculi, plermmque 3-6pollicares, callo scutato affixe, stipiteque elongato pennam columbinam crisso plus minus rage ranoso, demum cylindraceo instructa, stipite ramisque superne compressis et explanatis in laminas forma sat diversits. Iamina nunc anguste ct fere lineares, sapius cuneatr, integrae el apice truncate, nunc latiores apice parum incise aut profundius palmato-laciniate, rarius in lacinias aiteruas sulpimnatifidx. Cystocarpia satis magna, diametro lineam vix altingentia, olovata et stipitata, extus lavia et nuda, ad inferiorem partem ramorun procipue obyenientia, rarius ipsis laminis affixa. Nema- 
thecia maculaformia magna et ipsius limmina ad formam couformata, linearia ant cuneata, filis radiantibus crassis dichotonis constituta, intra articulos filorum sphrerosporas (a me nou omnino maturas conspectas) evolventia. Substantial membranaceo-carnosa. Color purpureus.

Quoad formam et dissectionem lamine valde varians, immo in codem individuo. Nemathecia et Capsulas in eodem indiviluo semel invenit D:ta Griffiths.

\section{Species inquirende.}

7. F. Spernorhonus (Linn. Syst. Nat. II. p. 719) caulescens slipito mox compresso ramoso, ramis in laminas planas diclotomomultifidas expansis, segmentis subcuneato-linearibus, cyslocarpiis [?] rugosis ad margines subsessilibus.

Fucus spermophorus L.; Turn. Ilisl. Fuc. lab. i6 (excl. syn.)

Sphærococcus spermophorus $\mathrm{Ag} . \mathrm{sp}$. p. 247!

Chondrus spermophorus hïlz. $s p . p$. 738 !

Acanthotylus Heredia (partim, quoad synon.!) Külz. sp. p. 792 !

Hab. in mari lndico circa Ceylonam (11b. Linnæi.)

"Radix callus exiguus. Frons palmaris. Caulis basi teres, pennæ passerinæ crassitic, mox fit compressus, et inde sensim complanatus in laminam lineam vel sesquilineam latam, et ubique nisi juxta apices linearem, enervem, dichotomam, axillis acutis. Segmenta fustigiatu, apice plerumque multifida, laciniis brevissimis varie divisis, acutis vel obtusis truncatisque, triplo quadruplove angustioribus et fere capillaribus. Capsulæ exiguæ, orbiculares, rugulosæ, juxta marginem sessiles. Color dilıte ruber, fugacissimus, exsiccate intensior. Substantia membranacea, tenuis; siccitate rigidiuscula."

Planta valde olsscura. Synouymon Gunneri, quod huc ducunt, aliam plantam sine dubio spectat. Idem de Ceramio spermophoro (Rolk. Cat. III. $p$. 113) valere suspicor. Külzing ad diversa duo genera eandem plantam refert.

8. Ph. Diversifous (Suhr. Regensb. Flora 1840 p. 262) caulescens, stipite corneo 4 -5pollicari lineam crasso parum ramoso, tım laminis pollicaribus lingulatis costatis irregulariter ef sparsim obsito, tım foliolis minutissimis pyriformibus, lineam longis, medio inflatis, fructiferis fimbriato. (Deser. Auctoris).

Ilal). ad Cap. b. Spei (I)rege).

Planta, olim a me inspecta, sui juris species milhi risia est, sed quoad affinitates forsan duljia.

9. PII. siculus (hütz. Bot. Zeit. 1817 p. b̈) plincomate basi stipitato sursum foliaceo dichotomo, segnentis lingulatis, basi con- 
striclis apice obtusis, stipite elongato ramoso filiformi. Iï̈t. Sp. Alg. p. 790.

llab. ad oras Sicilix.

10. Phislomiona ccxeifolis (Hook. et Harv. Alg. ant. in Lond. Journ. IV p. 260) fronde stipitata lato-cuneata v. flabelliformi integra vel cunarginata, e disco vel apice frondes consimiles emittente.

Hab. ad insulas Falliland.

Stipes compressus brevis in frondem late cuneatam aut inverse deltæformem sensim expansus. Frons corneo-membranacea, rosea, 11/4-9pollices longa, pollicem aut sesquipollicem lata, truncata et integra aut obtuse emarginata et quandoguidem erosa. A disco aut apice hujus frondis, frondes proveniunt conformes, quae suo ordine similes emittunt, ita ut denique planta evadat concatenata pluripollicaris. Fruclus ignoti.

Hæc forsitan sit forma quædam lata Phyllophoræ Brodiæi, at quæ admodum insignis adparet. Ita fere Auctores. 


\section{IDDENDA.}

Obs. Species noras et Icones Floridearum Phỵcologia Harreyana, que post inpressioam operis nostri nobis allatæ fuerunt, ultimo volumine addendas hoc loco omitto.

pag. $22 \%$ inseratur:

1i. Criptovenia dexticctata (J. Ag. miscr.) subacaulis, slipite breissimo mox in frondem ecostatam decomposifo-dichotomam abeunte, segnentis linearibus margine minutissime denticulato undulatoque crispis, sphærosporis in sorum infrä apices segmentorum rotundatum collectis.

IJab. in oceano atlantico ad insulam Basilan prope littus Ifrice (IIb. Cronan!).

Stipes brerissimus cuneatim expanditur in frondem altitudine usque semipedalem, ah ima basi dirisam, inferne segmentis subconcretis intricatam, superne flabellatim expansam, decomposito-dichotomam. Segmenta omnino linearia, $z$ linens circiter lata, axillis patentibus separata, margine ubique undulata et denticulis minutissimis acutiusculis subduplicato-crenulata, apicibus obtusis. In segmentis senilibus denticuli fere obsoleti. Infra apices segmentorum sori rotundati evolvuntur, maculam pellucidiorem æmulantes. Sphærosporæ his locis dense aggregatæ, minutæ, oblongorotundatx, cruciatim divisæ, inter cellulas superficiales parum mutatas nidulantes. Structura et substantia generis. Color pulchre raseus.

Species distinctissima et pulchra, Cr. crenulatie proxima, sed multo tenuior et angustior, atque colore roseo potins Rlıdymeniam palmettam aut Rh. bifidam æmulans. Madefacta a:ıtem substantia sua fere chartacea alian affinitatem prodit, qua structura et fructu contirmari videtur. 



\section{N I) E X.}

obs. Nomina admissa litteris Romanis, synonyma cursivis tradmntur.

Aranthobolus hüts. 236.

Brasitiensis Külъ. 238.

Acanthoceras echionotum hül. 131. oxyacanthum 1.4.

Shullevorthionum hü̈s. 133.

transcurrens 144.

Acanlholylus lleredia hül. 332.

Acrotylus 192.

australis 193.

prismaticus 193.

Ahnfeltia 309.

concinna 312.

Durvillxi 313.

Gigartinoides 311 .

plicata 311.

Antilhamnion crucialum Nag. 28.

Asperocaulon compressum Rud. 68.

Ballia 74.

Brunonia Harv. 75.

Callitricha $7 \ddot{0}$.

chilensis $\pi 6$.

crassa lï̈l. 7\%.

Ilombroniana Mont. 7ï.

P'rieurii 76.

lialsachospermum allenualum Bonnem. 103.

Rivularioides Bory. 108.

Boryna Grat. 113.

Borbonica Gral. 149.

ciliaris Grat. 134.

ciliala Bory 149.

cinnabarina Grut. 148.

compacta 137.

diaphana Gral. $12 \%$.

elegans Bonn. 12:3.

rlegans $\beta$. cinnabarina Bonn. 148.

gracilis Bonn. 128.

Lessonii Del. 14?.
Boryna lorulcsa Bonn. 149.

variabilis Bonn. 127.

varinbilis vat. Bonu. 128.

Bolryocarpa oblusa hiil. 220.

Byssus purpurea Lighl/18.

Callithamine: bै.

Callithamnion 5 .

abbrevialum hüŁ. 2'.

acinthophorum 6.3 .

acrospermum 52.

affine $4: 3$.

alfine hïls. 13.

allernalum Schoust. 41).

anguslatum 64 .

apiculatum 67 .

arachnoideum $\mathrm{Ag} .40$.

arbuscula 60 .

australe 26.

axillure Schousb. 2't.

barbatum 22.

Borreri 49.

brachialum Ilarv. 3̈.

Brodiaxi :37.

Byssaceum 14.

Byssoilles 40 .

byssoides Aresch. 37.

caudatum 35.

caspitosum 18

ccramicola liulz. 1.3.

cladodermum 6:3.

clandestinum 63.

cluvalum Schonsb. Ti.

compaclum Schousb. 20.

constrictum 18.

corallinum L.). 79.

corymbosum 41 .

roryunbosum llecsne. 42.

crisgrellum $\mathrm{Ag} .69$. 
Callithamnion Crouanii lï̈z. 34. cruciatum 27.

cruciatum IIonk. el IIarv. 29. cryptoplerum hivi. $\ddot{3}$. dasycludum J. Ay. 32 . dasytrichum 59.

Daviesii 11.

Daviesii a. Aresch. 1:i. Daviesii ๙. Lyngl. 14. Daviesii ค. Lynyob. 13. Daviesii o. Aresch. 13. Daviesii Desm. 14. decipiens J. Ag. 28. decompositum 45. densum 66. divaricatum 67. dubium Zan. 28. efflorescens 15. elegans 23 . ellipticum 68. elongellum 36 . fasciculatum 49 .

Felixii 56.

flabellalum Schous. 72. flaccidum 31 . flagellare 36 .

flexuosum Ag. $7 \%$.

floccosum 27.

floridulum 19.

floridulum Lyngb. 19.

fruticulosum 56 .

Furcellariæ 37.

Gailloni 38.

Gaudichaudii 58 .

Gaudichaudii Ilook. 58 .

Giraudii 38.

Giraudii Sol. 24.

gracile 48 .

gracillimum 43 .

gracillimum Ag. 44.

grande 62.

graniferum 62.

granulatum 61 .

gramulatum IIarv. $\$ 4$.

Grevillei IIarv. 48

guttatum 5̈.

Harveyanum J. Ag. 54. hirtum 53.

hirtellum Zan. 47.

Hookeri 51 .

Hookeri Ag. 40.

Hookeri $\beta$. fruliculosum Aresch. 56. imbricalum Schousb. 28.

humile 16.

implicatum : 0 .

inordinatum 20.

interruplum 3?.

intricatum 1?.
Callitlamnion irregulare 20 .

Lamourouxii Dub. 23.

lanosum llarv. 51.

lanuginosum Lb. 12.

latissimum 50.

Lenormandi Suhr. 13.

leptoclathm Vont. 22.

luxurians 1 k.

macropterum 30.

mesarthrocirpum 63.

mesocarpum 16.

micropterum Ilook. et II. 33.

microplerum Mont. 26.

microscopicum 12.

minutissimum 12.

mirabile 15

Montagnei šs.

mucronatum 29.

Mytili Schousb. 22.

myurum 32.

Naccarianum Rud. 28.

noululosum liülz. 105.

oclosporum Ag. 37.

oppositifolium J. Ag. 69.

Orbignyanum 30 .

pallens 43.

paniculatum Schousb. 17.

pectinatum Mont. 22.

pedicellatum Ag. 71.

pedunculatum 63 .

pellucidum 33.

peregrinum 63.

planum 64 .

pluma 25.

pluma Mont. 25.

pluma var. micropterum Mont. 26.

plumosum 64.

plumula 29.

plumula Lyngb. 27.

plumula var. pusilla Lyngb. 27.

Pollexfeni IIarv. 27.

polyacanthum 31 .

polyspermum 48 .

Posidoniæ 13.

Preissii 33.

Ptilota 32.

pubes $\mathrm{Ag} .12$.

pulchellum Ag. 12.

pulchellum Schousb. 2:5

pumilum Ilarv. 28.

purpurascens IIarv. 57.

purpurascens Johnsl. 48.

purpuriferum 59.

pusitlum Schousb. 4.7.

pygmaeum 13.

pyramidalum Liebm. 57.

Ralfsii Ilarv. 2.2.

ramulosum 66. 
Cillithammion refructum fiutz. 29. repens $L b .21$.

rigescens 42 .

rigidulum $6 \ddot{ }$.

roseolum 21.

roseum 36.

roseum .1g. 48.

roseum Chauv. 52.

roseum Grev. 48.

roseum Schousb. 49.

roseum var. lenue $L b .47$.

Ruthii 17.

Savianum $1 k$.

scoparium 33 .

scopulorum 47.

secundatum 13.

seirospermum $\mathbf{4 2}$.

seminudum Ag. 49.

semipennalum J. Ag. 34.

sertularioides 66 .

sessile 39.

simile 30 .

sparsum 15.

sphæricum 20.

spinescens 33 .

spinosum Ilarv. 51 .

spinulosum 17.

spongiosum Harv. 61.

striatulum 65.

strictum 34 .

stuposum 60 .

subtile 63 .

subverlicillalum Zun. 23.

tenuissimum 64 .

ternifolium 32 .

tetragonum 53 .

tetricum 32 .

lelricum var. $\because$. Ag. 33 .

Thouarsii 66.

Thuyoides 44 .

Thuyoides Chauv. 4h.

trifarium 67.

tripinnatum 46 .

lipilunalum IIarv. 4-k.

truncatum 44.

Turneri 23 .

unilaterale 34 .

variabile Ag. 24.

variegatum 66 .

versicolor 41 .

versicolor $\beta$. seirospermum IJarv. 42.

verticillatum 34 .

verlicillalum hül. 108.

Vidovichii 67.

virgalulum llarv. 12.

Callophyllis 296.

alcicornis 299.

australis 304 .
Callophyllis australis J. Ag. 297.

carnea 301.

coccinea 301.

dicholoma fiülz. 30\}.

discigera 298.

fimbriata $30 \%$.

Hombroniana 303 .

laciniata 299 .

Lambertii 300.

obtusifolia 297.

ornata 298 .

tenera 302 .

variegata 302 .

Callymenia papulosa 293 .

Campylaphora 149 .

Ilypneoides 150.

Carpoblepharis 152.

capensis $\hbar \ddot{\iota z .} 153$.

densa Кйъ. 153.

tlaccida 153.

pinnatifolia 153.

Carpolham̃nion fï̈lz. 102. Gunnianum hüzl. 102.

Laurencia Kü̈z. 103.

Plilola fiulz. 103.

Celeceras monile liülz. 13\%.

Centroceras $14 \%$.

cinnabarinum 148.

clavulatum 148.

Sp. omn. Kü̈lz. 149 .

Ceranie. 1 .

Ceramium 113.

acantlionotum 132

Agardhianum Grifl. 122.

arachnoideum 117.

attenuatum 138 .

Ancklandicum 142.

australe 124.

Azoricum 144

barbatum Dub. 80.

barbalum lï̌lz. 128.

bolryocarpum Grev. ol IIIro. 127.

brachialum bonn 5s.

Byssoules Jucl. 41.

cancellatum 136.

Capense 142.

capillaceum 138.

ciliatum 133.

cilialum $\beta$. acanthonolum Harv. 133.

circinatum 126.

clavagerum Bonn. il.

clavulalum A!. 149.

coccinenm 137.

congestum Bonnem. i2.

corullinum $\beta$. Desin. 87.

crispum Ilucl. 29.

crislatum 143.

Dalmaticum 14\%. 
Ceramium dasylrichum Mont. 59.

Maviesii Bomn. 12.

I)aviesii Chauv. 13.

Derbesii 130.

Deslongchampii 122.

Desmazierii Crouan. 87.

diaphanum 125.

diaphanum var. arachnoideum Ag.

118.

diaphanum var, rigidum Griff. 121. diaphanum var. lenuissimum $L b$. 121.

didymum Bonn. 48.

divaricatum C'rouan. 123.

divaricalum Gral. 32.

divergens Schousb. 72.

Juclusei Bomn. \&1.

Judresnaii Bonn. 34

echinophorum 144.

echionotum 131.

elegans 124 .

elegans Gral $12 \%$.

erumpens 138

fasligiatum 119.

Felixii Gaill. 36.

flabelligerum 134

flaccidum Harv. 118.

flagelliferum Kü̋z. 128.

flexuosum Ag. 72.

fruliculosum Bonnem. 41.

fruticulosum Roth. 1 .

fruticulosum Schousb. 61.

furcellatum 142.

Gailloni C'rouan. 138.

Fasparinii Menegh. 149.

gibhosum 139.

giganteum $1 / 4$.

giyartimum Roth. 264.

gracillimum 148.

granulatum llucl. 61.

Graleloupii Bonnem. 72.

Graleloupii Dub. 61.

gultalum Ronnem. ¿̈.̈.

gymnogonium 138.

inconsficuum 137.

interruplum nigrescens Ag. :.8.

intricalum A\%. 19.

imoolulum hül. 128.

irregulare 14.2.

Kellneri 139.

Lamourouxii Jub. 24.

lanciforum liulz, 128.

leptoplilam 1:2.

I.essonii 142.

miniatum 433.

miniolum Ag. 19.

monile 132.

Morisianum Bert. 12\%.
Ceramium muscosiom Drap. 61. nitens 430.

nodosum Harv. 121.

obsoletum 129.

ordinalum fï̈z. 14.

Orsinianum 438.

pallidum Nog. 14.

patens 137.

pedicellalum Dec. $8 \%$.

pedicellatum Dec. 128.

pedicellalum Duh. T1.

pedicellatum Fl. Dan. \$1.

pedicuhs Suhr. 1?!

pellucidum Auct. 122.

jenicellalum IJucl. 8i;.

pennatum 136.

l'erreymondi I)ub. 71.

pinnulalum Ag. 49.

planum 14.7.

plumula .1g. 29.

polyspermum Crouan. 40.

puberulum Sund. 13:, 146.

pulchellum Gral. 72.

ramulosum Hook. 121.

ramulosum Menegh 143.

roseolum Crouan. 12.

roscum. Bonn. 48.

Rolhii Berli. 17.

rubrum 127.

rubrum var. firmum $\mathrm{dg} .129$, $1: 50$.

rubrum var. nitens Ag. 130.

rubrum var. pennatumi Crouan.

136.

secundalum Lb, 127.

selaceum Dub. 83.

simplicifilum Dec. 94.

spiniferum liülz. $13 \ddot{\text {. }}$

strictum 123.

subtile 120.

Teedii Roth. 266.

tenuissimum 120.

lenuissimum Aresch. HIS.

tunislulum 143 .

Turueri Jerl. 23.

unyululum Suhr. 14.

uniforme 143.

villosum 142.

virgalum Ilook. 137.

Chatmyium hystrix hüt. 279.

chetoceras echionolum hints. 131.

Chondria fircala ig 216.

woria Ag. 214.

Chondroclonium conaliculalum hülる. 272.

Chamissoi hüls. 267.

Chunvinii Külz. 269.

horridum fïlz. 264. 
Chondroclonium lividum fints. 270. nigritum $26 \%$.

T'edlii hülz. 267.

Choudrococcus ausiralis lï̈tz. 301. Chondrodiclyon capense hülz. 276.

Chondrus 244.

affinis 247.

alcealus Grev. 271.

alropurpureus Suhr. 326.

Bangii Lb. 223.

Brodiai Grev. 330.

Brodici var. simplex Grev. 333.

canaliculatus 248.

Capensis hül. 322.

Cellicus liülz 325 .

complicalus hü̈. 324.

coriaceus 249.

crassifolius hï̈z. 270.

crispus 246.

crispus var. Ћйtz. 32.

crispus Monl. Canar. 179.

densus Gr. 316.

disciptinatis $\mathrm{Gr} .319$.

divaricatus 249.

dubius Mont. 321.

furcellatus Suhr. 318.

Griffilhsia J. Ag. 316 .

Heredia Grev. 332.

linearis Grev. 326.

manillosus Grev. 273.

membranifolius Grev. 334.

microcarpus Kütz. 187.

Norvegicus Lam. 321.

palens Suhr. 318.

platynus 246.

polycladus Кйた. 323.

pusillus Mont. 327.

pygmeeus Gr. 317.

rubens L.b. 331.

scutellatus 249 .

scutellatns Her. 276.

sejunctus Bory. 323.

spermophorus hïl. 33 s.

lenuis J. Ag. 320.

tuberculosus 248 .

Torreyi Grev. 319.

vermicularis Giev. 323.

violaceus 249.

Tilovichii Menegh. 225.

Chrysymenia 209.

Chiajeana 214.

depressa 212.

dichotoma 211.

pinuulata 212 .

uvaria 214.

ventricosa 213.

vesiculosa 213.

Cludostephus dubius Bory. 109.
Cladostephus flavidus Bory. 91.

Coccolylus Brodici liütz. 330.

Couferra arbuscula Dille. 60. barbata E. Bot. 80.

Borreri Engl. Bot. 48, 4!

cancellate Roth. 91.

ciliata Ell. 133.

corallina Lighl/. 79.

corallinoides L. 79.

corymbosa E. Bot. $\$ 1$.

Daviesii Dillw. 12.

delicala Clem. 123.

diaphana Lighl. 123.

Equiselifolia Light. 90.

foccosa. Mill. 27.

foridula Dillw. 19.

flosculosa Ell 127.

geniculata Ell. 79.

grata $A g .12$.

Hookeri Dillu. 51.

imbricala Iluds. 91.

inlerrupla Eugl. Bol. 39.

lanuginosa Dillu. 12.

miniala Drap. 49.

nodulosa Lighl. 127.

pedicellata E. Bol. 61 .

pilosa Roth. 133.

pluma Dillu. 23.

plumula Ell. 29.

purpurascens Sm. 57.

repens Dillw. $24,4.8$.

rosea Roth 37.

Rothii Turt. 17.

rubra IIuds. 127.

setacea Ell. 85.

selacea Spr. 83.

tenella Dillw. 25

lelragona IIilh. 5 \&.

telrica Dillw. 52.

Thuyoides Engl. Bot. 4 4.

tubulosa Iluds. 127.

Turueri Dillw. 23.

Turneri Engl. Bot. 29.

versicolor Diap. 41.

verticillata Schmied. 91.

violacea Rolh. 17.

Constantinea 293.

reniformis 294 .

rosa marina 295.

Sitchensis 293 .

Corynospora 69.

clavata 71 .

flexuosa 72.

pedicellata 71 .

pinnata 73.

ramulosa 73 .

Crouania 104.

attenuata 105. 
Crouania bispora 106.

CRYTTONEME.E 150.

Cryptonemia 224.

crenulatí 223.

denticulata 337.

dichotoma 220 .

Forbesii IIart. 294.

Lactuca 227.

lomation 227.

luxurians 228 .

seminervis 226 .

CRYpToNenis 223.

Cypellon palens Zanard. 218.

Cystoclonium 306.

carnosum 309.

difficile $\mathbf{3} 08$.

membranaceum 308 .

purpurascens 307 .

turgidulum 309 .

Dasya spongiosa Ag. 60 .

Dasyphila 103.

Preissii 104

Dasyphlæ3 245.

insicnis 2130.

Tasmanica 216 .

Delesseria alala var. dentala Mont. 222.

ciliaris Lamour. 299.

Ferrarii Lamour. 287.

glandulosa Ag. 4 s.

laciniala Ilook. 299.

spermophora Lamour. 332.

Dichophycns Zanard. 247.

Diclyderma Bonnem. 113.

Dudresnaya 106.

Boryana 109.

coccinea 108.

formosa Bonnem. 108.

purpurifera 108.

Dumonlia cystophora Monl. 199.

furcalı l'ost. el Rupr. 235.

prismalica J. Ag. 193.

vfnlricosa Laniour. 213.

Echinoceras armatum 145.

crislalmm hülz. 143.

diaphanum 148

giganlemm lin̈ls. 144.

hamulatum 146.

hilsutum 1400 .

imbricatum $14: 3$.

julaceum $14: 5$.

nudiusculum 146.

o ryacanlhum liülz. 131.

pellucidum 146.

puberulum 14.6 .

ramulosum liülz. 143.

secundatum $446^{\circ}$.

spinulosum 145.
Echinoceras Inmidulum fiülz. 143. miforme hülz. 143.

Endocladia 236 .

muricata 237 .

vernicata 237.

Epatica spirate Girnn. 332.

Epymenia 219.

obtusa 220.

variolosa 221.

Euhymenia Capensis 292.

carnosia 291 .

dicholoma hӥ̈. 225.

livisa liülz. $28 \pi$.

llubyi hïlz. 171.

Ilarveyana lï̈lz. 288.

Laclinca Kӥlz. 228.

latissima 289.

Limensis 289.

lururiuns fïlz. 228.

reniformis lï̈l. 286.

replans Kü̈lz. 292.

Requienii hïls. 289.

schizophylla lï̈l. 291.

seminervis $h \ddot{1} l z .226$.

Enplilola coralloidea liülz. 101. formosissima kïlz. 102.

Ilarveyi К̈̈̈ъ. 9:3.

Pappeana liüls. 100.

Fauchea 217.

repens 218.

Fucus abscissus Schousb. 179.

acelabulum Gouan. 294.

acicularis Esp. 308.

acicularis $11 \mathrm{~m} / .263$.

Igarmm Web. el Moler. 279.

albus F\%. Man. 311.

alveains Turn. 271.

alveolalus Esp. 273.

Asplenioides Turn. 98.

Bangii liorn. 223.

bolryoides Hulf. 214.

braclealus Turn. 278.

Brodicei Turn. 330.

canaliculalns var. Ihuds. 273.

capillaceas Esp. 307.

capillaris IInds. 161.

carnosus Schm. 173.

ceranoides Gm. 247.

ceranoides var. Esp. 248.

(hamissoi Merl. 267.

cil alns Gm. 299.

constriclus Turn. 239.

corallinus Fl. I)an. $30 \%$.

crenulutns Tinrn. 320.

crinitus Gm. 194.

crispalus Slackh. 299.

crispalus Fl. Jian. 247, 330, 334.

crispus IIuls. 331. 
Fucus crispus L. 246 . crispus var. Tuin. 323. Cypelton Bertol. 332. Devoniensis Grev. 321. dilatatus Turn. 326. dulcis Gim. 173. echinatus Stackh. 273. edutis Stackh 173. cpiphyllus Fl. Lan. 331. /astigialus Iluds. 196. filicinus I'ulf: 180. filiformis Iluls. 247. fimbriatus lhuds. 334. flaccielus Turn. 1 3̈3. Floresins Clem. 205. gigartinus L. 264. glandulosus Sol. 151. Griffithsice Turn. 316. Heredia Clem. 33 ?. implexus Dec. 151. lacerus Stackh. 217. laciniatus Balb. 332. laciniatus Huds. 299. Lactuca Esp. 173. Lagasca Clem. 127. Lambertii Turn. 300. linearis Turn. 323. lividus Turn. 270. lomation Bert. 227. lumbricalis Gm. 196. luxurians .Vert. 228. mamillosus Good. et Wood. 273. membranifolius Good. et Wootu. 334 .

membrani,olius Lamour. 330. membranifolius With. 247.

membranifolius var. roseus Turn. 333.

minialus Müll. 299. nervosus Dec. 332.

Norvegicus Esp. 320.

Norvegicus Gunn. 321.

Oedleri Esp. 264 ovalis $\beta$. botryoides Turn. 214 palmatus $\beta$. Light/. 173. palmetta var. Lam. 334. papillosus. Gm. 277. parthenopceus Brid. 327. patens Good. et Wodw. 325. pistillatus Gm. 264. plicatus Clem. 263. plicatus Iluds. 311. plumosus L. 96. polymorphus Lam. 247, 273, 321, 323.

prolifer Lighte. 331. proteus Del. 203. purpurascens IIuds. 307.
Fucus radula IIb. Banks. 278. reniformis Turn. 286, 287, 288. Rissoanus Turn. 241. rosa marina Gm. 295. rubens Good. et Woodw. 33. rubens Mill. 334. scorpiodes Fl. Ilan. 307. spermophorus L. $33 \ddot{3}$. spinosus Gou. 263. steltatus Stackh. 247. stiriatus Turn. 277. Teedii Turn. 267. tenax Turn. 236. tentaculatus Bert. 316. tuberculatus Lightl. 307. uvarius Hulf. 214. vermicularis Turn. 323. verruculosus Bert. 241.

Furcellaria 194.

fastigiata 196. lumbricalis Lb. 196.

Gaillona arbuscula Bonnem. 61. Lehmanni Rud. 129. punctata Bonn. 61. versicolor Bonnem. 61.

Gastroclonium uvaria hü̈s. 214. Gelidium constrictum liütz. 239. crassifolium Post. et Rupr. 191. crinitum Kütz. 191. decipiens Mont. 188. lanceolatum Harv. 189. negliclum Bory. 180.

Gelinaria 197.

Ulvoidea 197.

Gigartina 260.

acicuiaris 263.

alveata 271.

ancistroclada 272.

Batrachopus 281.

Burmanni 276.

canaliculata 272.

Chamissoi 267.

Chauvinii 268.

chondroides Ilook. et Ilarv. 281.

chondroides Bory 280.

compressa kütz. 266.

contorta 26.5 .

crocea 282.

disticha 269.

divaricata 280.

elegans 382.

falcata 266 .

fastigiata 276.

fasligiata P'ost. it Rupr. 313.

flibellata 263.

flagelliformis 283.

flavescens Bory 311.

Griffithsia Gr. 316. 
Gigartina Griffthsice Lb. 314.

Hypniformis 282.

Lemanxformis 281.

Lessonii 268.

livida 970.

lubrica Lb. 161.

mamillosa 273

melanothrix 281.

muricata 283.

muricala Post. el Rupr. 237.

nana 263.

nodifera 282.

ornitlorynchos 274.

papillatis 274.

peclinala Bory 264.

pinnata 270.

pistilluris var. Monl. 280.

pistillata 264.

pistillala Mont. 263.

plicala Lamour. 311.

polyacantha 282.

purpurascens Lam. 307.

radula 278.

rugulosa 281.

spinifera 282.

stiriata 277.

Teedi 266.

volans 273 .

GHGARTINEE 229.

Gloiocladia 216.

furcata 216.

Gloioderma 243.

australis 244.

Gloiopeltis 234 .

furcata 238 .

tenax 236 .

Gloiosiphonia 160 .

capillaris 164.

Gongroceras Deslongchampsi hül. 122.

fasligialnm Кülz. 119.

gibbosum lï̌lz. 139.

gymnogonimm hül.s. 138.

fiellneri hïzl. 139.

nodifcrum hïlz. 121.

Orsinianum hiulz. 138.

pellucidum 14.1.

penicillatum 14.

plicatumn 14.1.

ramulosum lï̈l. 121.

strichum lï̈z. 123.

lenvicorne lü̈z. 118.

lenuissimum lïlz. 124.

ungulitum 14.1.

Goxgruosilenese 1.

Gracilaria concimna Monl. 323.

fasligiala Suhr. 318.

jurpurascens Grev. $30 \%$.
Gracilaria repens J. Ag. 218.

Grateloupia 177.

Aucklandica 183.

concalenala liülz. 180.

Cosentini 184.

cuneala Menegh. 168.

cuneifolia 181.

Cutlerix 183.

denticulala Monl. 242.

dichotoma 178.

filicina 180.

filiformis 184.

fimbriata 184.

hieroglyphica 183.

hortida hiül. 180.

hystrix Ag. 279.

lanceola 182.

ornata var. crispa Ag. 242.

pennalula hülz. 180.

porracia Suhr. 180.

prolongata 181.

Proteus 184.

spathulata 179.

Slernbergii var. versicolor J. Ag. 182.

versicolor 181.

veriucosa fül. 241.

verruculosa Grev. 241.

Griffithsia 76 ,

antarctica 87.

arachnoidea 88 .

Argus Mont. 89.

barbata 80.

Binderiana 86 .

crspitosa 82.

Chilensis 88 .

confervoides Sulur. 82.

corallina 78 .

corallina Ag. 87.

corallina var. $\beta$. Bonn. 87.

crassa Кül. 87.

crassiuscula 79 .

Devoniensis 79.

Duriai 89.

Equisetifolia Ag. 94.

pabellala Moni. 72.

flabelliformis Harv. 79.

furcellata 83.

Giraudii Sol. 78.

imbricala Schousb. 78.

inlermedia Lenorm. 87.

irregularis 84 .

nodulosa Ag. 103.

omenlia J. Ag. $7 \mathrm{~S}$.

opuntioides 82.

pliyllamphora 81 .

pinnala Crouan. 73.

pogonoides 88 . 
Griftithsia radiciformis Ilonli. el Ilate 91.

repens Zanard. 34.

schoushoei 78 .

secunda 830 .

secundillora 86 .

setacea 8.i.

selacea var. intermedia Chamu. 87.

simplicifulum Ag. 91.

spharica Ag. $8 \ddot{\text {. }}$

tenuis 84 .

temnissima Zunard. 89.

torulosa 88 .

Gymnogongrus 313 .

Capensis 324 .

corymbosus 321 .

crenulatus 320 .

densus $31 \%$.

dilatatus 326 .

disciplinalis 319 .

furcellatus 318.

fircellatus Jïlz. 327.

Gigartinoides lint: 31 ?.

glomeratus 322 .

Griftillsia 316.

implicatus lïtz. 312.

linearis $32 \%$.

Norvegicus 320.

parthenopæus 327.

patens 324.

plicalus fï̈lz. 311.

polycladus 322.

pygmaus 317.

leniaculatus Jiutz. 316.

tenuis 319 .

Torrexi 319.

Gymnophliea Biasoletliana lin̈t. 16:.

canariensis 468 .

dicholoma hïts. 165.

fircellata liulz. $16 \%$.

incrassata kints. 16:.

prismatica livt 193.

Ilolarachnion Covinaldi liüts. 20:5.

cystoptiorm livts. 199.

lanceola hïlz. 182.

ligulalum hintz. 202.

pinnulatmm hiits. 213.

spathulalım Kïiz. 204.

trigonum liütz. 201.

ventricosum liutz. 213.

Ilalichrysis depressa Schousb. 212.

IIaloplegma 110.

africanum 111.

Duperreyi 111.

Preissii 111.

Halurus 89 .

equisetifolius 90.

simplicifilum liviz. 91.
Ifalแrus radiciformis 91.

Halymenia 197.

Algeriensis Hont. 213.

amoena 287.

botryoides 214.

Capensis Honl. 16?.

carnose ller. 291.

cornosa fints. 290.

cervicormis J. .lg. 167.

chondricola 206.

clavaformis 207.

Corinalili $20 \ddot{3}$.

cyclocolpa Mont. 166, 167.

cystophora 199.

decipiens 200.

dentata Sulur. 290.

depresso Mont. 212.

doryphora 207.

dubia 206 .

Dubyi Chanv. 171.

Durvillaxi $20: 3$.

Polutis Ag. 173.

edulis var. media Ag. 179.

elongata 200.

elongato hïlz. 206.

fastigiata 199.

Floresia 205.

Floresia var. angnsla Ag. 164.

fircetlata var. Cupensis Ag. 324.

lanceola J. 1g. 182.

latissima 204 .

latissima Her. 289.

ligulata 201.

lobata $20 \%$.

lnbrica Sulur. 292.

marginata Rous. 171.

maiginifera Her. 184.

mesenteriformis Mom. 203.

Monardiana 203.

Monardiana Menegh. 165.

multifila J. Ag. 166.

Nrgelii 207.

Nova Zclandix $20 \%$.

patens 203.

pinmulata Ag. 213.

platyna Ag. 246.

Protens II6. Iunth. 184.

pusilla 206.

ramosissima 207.

reniformis Ag. $286,294$.

reniformis llesm. 288.

replans Sutir. 292.

spathulata 204 .

Irigona 204.

trigona Ig. 200.

lrigona var. cartilnginen Ag. 201.

utvoidea lintz. 197.

Creillian! Mont. 207. 
Halymenia variegata Bory 302. ventricosa Ag. 213.

Hanovia 109. australis 109.

Hormoceras Biasolettianum 140. cateniforme 139.

catenula 139.

circinalum Кй̋. 126.

confluens 140.

decurrens fiülz. 127.

duriusculum 139.

fruticulosum 140.

gracillimum Kï̈z. 118.

monitiforme lülz. 124.

nodosum hülz. 121.

perversum 140.

polyceras 139.

putchettum liütz. 125.

pygmæum 140.

siliquosum hütz. 128.

sytrophum 140.

transfugum 12:, 140.

variegatum 140.

IIypnea purpurascens Ilaro. 307.

Iridæa $2 \% 0$.

affinis 257.

Augustinx 255.

Belangeri Bory $20 ̈ 2$.

Binderi J. Ag. 174.

Capensis 25:.

carnosa J. Ag. 173.

ciliala liülz. 254 .

clathrala Decsn. 279.

clavellosa Suhr. 278.

cordata 254.

cordata var. Ilook. el IIarv. 25\%.

cordata Aucl. 252.

cornucopia Posl. el Kupr. 233.

crispala bory 253.

curvala liüz. 176.

Cullerice Bind. 183.

decipiens 257.

dentata 256.

dichotoma 236 .

divisa lï̈tz. 287.

etutis Bory 173.

elliptica 238.

fissa Sulir. 276.

foliosa Menrgh. 294.

gigantea 258.

heterocarpa $20 ̈ 6$

Ilittiana Grev. 287.

insignis Endt. et Dies. 278.

labyrinlhifotia hütz. 183.

lacera 259.

Laminarioides $2: 33$.

lanceotala Ilarv. 166.

lıpathifolia hülz. эั79.
Jridara lilacina Post. et Rupr. 234.

lubrica 239.

marginala Endl. 171.

Merlensiana Post. el Rupr. 174.

micans 2044 .

microphytta IIarv. 273.

minol 202.

minor Endt. 172.

Monlagnei Bory 172.

obovata 2306.

orlitosa 232.

ornata Post. et Rupr. 290.

Pappeana Sond. 166.

phyllocarpa 257.

pinnata 258.

platyna Post. et Rupr. 246.

pulchra 238.

punicea $2: 37$.

pustulosa 25̋.

radula Bory 278.

renifor mis Bory 286.

reticulata 260.

socialis 260 .

stiriala Bory 277.

undistosa Bory 230 .

volaus Moul. 277.

violacea 259.

Yemensis. 2309.

Kallymenia 284.

dentata 290.

Dubyi Ilarv. 171.

Harveyana 288.

microphylla 288.

orruata 290.

polyides 294.

reniformis 286 .

Requienii 289.

Schizopliylla 285.

Lamourourio polysperma Bonn. 48. Servanti Bonnem. 48.

Laurencia rlavifera Suhr. 278.

Leptothamnion 69.

Rabenhorstii 69.

Mastocarpus alveatus lintz. 274.

bracteotus liütz. 279.

corymbiferus Кӥı. 274.

IIarveyanus hïlz. $27 \ddot{\text { s. }}$

Klenzeanus Küız. 278.

mamiltosus hïl. 273.

papillalus hïlz. 274.

potycarpus lï̈lz. 279.

radule liütz. 279.

spinosus lï̈l. 274.

sliriatus hït. 277.

validus 280 .

volans liülz. 273.

Mertensia decomposita Grat. $4: 3$

tripinnata Gral. 46. 
Mesoyloia allenuala .1y. 10:", capillaris $A g .161$. coccinea Ag. 10.8. fruliculosa Ag. 109. moniliformis Griff. 10:3.

Microclidia 130 . slandulosa $1: 31$.

Mychodea carnosa Ilarv. 309. membranacea llarv. 309.

Naccaria Schousboei J. Ag. 209.

Nemalion coccineum hüts. 108. purpuriferum liüઢz. 108.

Nemastoma 162.

cervicornis 167. cuneata 168.

cyclocolpa Zan. 166.

dichotoma 164.

discigena 167.

Dubyi J. Ag. 171

Dumontioides 164.

lanceolata 163 .

marginifera 163 .

minor J. Ag. 172.

multifida 166.

vernicularis 163.

Neurocaulon foliosum Zanard. 29k. rosa marina lü̈z. 295.

Sitchense lü̈t. 295.

Nolhogenia luberculosa liüz. 248.

Oncolylus cremulatus liüt. 320. dilalatus liutz. 326.

Norvegicus liül. 321.

Pachycarpus 327.

dilatatus 327 .

Phlebolhamnion arbuscula hülz. 60 . Brodicei. Lülz. 57.

byssoides liül. 40.

corymbiferum hülz. \&1.

corymbosum liülz. 41 .

fruliculosum hütz. 56.

Gailloni Külz. 38.

Gaudichaudii kïulz. 59.

Giraudii liülz. 38.

gracillimum hütz. 44.

grande hiulz. 62.

granulatum lï̈lz. 61 .

Ilookeri liütz. äl.

implicatum liüz. 50 .

latissimum liüz. 5̋.

Montagnei hülz. 58 .

pachycialon 68 .

polyspermum liüt. 48.

purpuriferum Kй̈. 59.

roseum liulz. 37.

scoparium liulz. $3 \ddot{\text { s. }}$

seirospermum hülz. 42.

spinescens 68.

spinosum huに. כ๋. spongiosum hiuts. 64.

squarrosum 68.

telragonum hülz. bs.

telricum Kü̈lz. อ̈2.

tripinnalum Külz. 46.

versicolor liüt. 41.

Phyllophora 328.

Brodixi 330.

Brodici var. simplex IIarv. 333.

crenulala J. Ag. 226.

cuneifolia 336.

diversifolia 33 .

Heredia 332.

luxurians Monl. 228.

memhranifolia 334 .

nervosa 332.

oblusa Grev. 220.

Palmettoides 333 .

rubens 331.

spermophora $33 \ddot{3}$.

Phyllotylis australis J. Ag. 188.

membranifolius liülz. 334.

microcarpus J. $A g .187$.

siculus 33 .

Phyllymenia hieroglyphica J. Ag. 183.

Plaloma mullifulum Schousb. 166.

undulalum Schoust. 202.

Plılymenia apoda J. Ag. 173.

carnosa J. Ag. 173.

cordala J. Ag. 176.

erosa J. Ag. 176.

undulala linearis J. Ag. 176.

undulata obovala J. Ag. 173.

Plumaria Stackh. 92.

Poecilothamnion versicolor Nag. \$1.

Polycoelia 30 ä. laciniata 306.

Polyides I) urvillai Bory 313. flagelliformis Sond. 282.

Griffithsice Gaill. 316.

rolunda Mor. el DeNol. 196.

Polyopes 238.

constrictus 239.

Prionitis 185.

australis 188.

chondrophylla $18 \%$.

crinita 191.

decipiens 188.

julsata 190.

ligulata 189.

nicrocarpa 187.

pectinata 189.

Sternbergii 490.

Pterucreres cancellatum häls. 136. flexuosum hiuts. 137.

Plilocladia 142.

pulchira 113. 
I'tilota 92

Ptilota articulata 100.

A:plenioides 98.

Asplenioides Ag. 97.

Asplenioides Auct. 100.

coralloidea 104.

densa 98.

elegans 94.

flaccida Ag. 133.

formosissima 102.

Harveyi $9 \ddot{8}$.

IIspnoides 97.

lappesana 100.

pectinata 99.

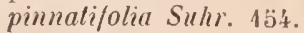

plumosa 9:.

plumosa Asplenioides Ag. 97.

plumosa capillaris Grev. 94.

plumosa serrata hütz. 97.

plumosa lenuissima Ag. 94

sericea Ilarv. 94.

serrata 96 .

setigera 100.

Rhizophyllis 221 .

Bangii 223.

dentala 222.

squamarice liütz. 222.

Rhodocallis Asplenioides fiütz. 98. elegans 104.

setigera kiitz. 100.

Rhodomela rugulosa Bory. 281.

Rhodoplexia Preisii Ilarv. 111.

Rhodymenia alcicornis J. Ag. 300.

Bangii Grev. 223.

dentala Suhr. 226.

dichotoma 304.

discigera J. Ag. 298.

Dregeana Suhr. 220.

glaphyra Suhr. 302.

Hombroniana 303.

llookeri llarv. 302.

laciniata Grev. 299.

Lambertii Grev. 300.

mamillosa Aresch. 273.

membranifolia Ilarv. 334.

ornate Mont. 298.

perreplans $J$. Ag. 222.

polyides J. Aq. 291.

reniformis llook. 286.

kequienii J. Ag. 289.

schizophylla llarv. 283.

Squamarice DeNot. 22.

Teedii Grev. 267.

variegata J. Ag. 302.

variotosa llook. 221.

Rissoella 240.

crispa 242.

denticulata 212.
Rissoella verruculosa 241.

Rivnlaria verticillala Engl. Bol. 108.

Sarcophyllis lobala liütz. 286.

Sarcothatia Burmami hiils. 276.

Schimmelmannia 208

ornata Schoust. 209.

Schousboei 209.

Schizymenia 169.

apoda 173 .

Binderi 174.

carnosa 173.

cordata 176.

Dubyi 174.

edulis 172.

erosa 176.

marginata 174.

Mertensiana 174.

minor 172.

obovata 173.

undulata 173 .

Seirospora flaccida hütz. 43.

Griffithsiana Ilarv. 42.

humilis lï̈z. 43.

Spermothammion Turneri Aresch. 21

Sphaceluria callitricha $\mathrm{Ag}$. $7 \mathrm{~s}$.

crassa Ag. 75.

Spherococcus acicularis Ag. 263.

alveatis $\mathrm{Ag} .27 \mathrm{1}$.

australis Harv. 301.

Bangii Ag. 223.

botryosus Suhr. 269.

Brodiai Ag. 330.

Burmanni Ag. 276.

canalicnlatus Ag. 248.

Chamissoi Ag. 267.

Chanvinii Bory 268.

chondrophyllus Bory 187.

concinnus var. immersus Ag. 312.

constrictus Ag. 239.

crassifolius Ay. 270.

crenulatus $A g .320$.

crinitus $A y .191$.

crispus Ag. 247.

crisplus var. Ag. 321, 325.

crislalus var. $\mathrm{Ag}$. 131.

difficilis Ag. 308.

dilatatus Ag. 326 .

disciplinalis Bory 319.

falcalus Iler. 266.

formosus Chauv. 269.

furcellalus Ag. 318.

Gundichaudii Bory 303.

gelalinosus Nees. 277.

gigarlimus Ag. 264.

gigartimus costatus Suhr. 26.3.

Griffilhsio Ag. 316.

Ileredia $1 \mathrm{~g} .332$.

laciniatus Ag. 299. 
Spherococcus laciniulus var. discigena $A \eta .16 \%$.

Lactuca Iy. 227.

Lactuca var. A\%. 278.

Lambertii Ag. 300, 304.

Lessonii Boiy 265 .

Limelteguinus J. Ag. 272.

linettis dg. 323.

lividus $1 \mathrm{~g} .270$.

luxurians Mart. 228.

Mamillosus Ag. 273.

membrunifolius Ag. 334.

microcarpus Ag. 187.

micrococcus Mart. 130.

nanus Ag. 263.

nervosus dg. 332.

Norvegicus Ag. 321, 322.

palmella Lymigb. 333 .

papillalus. Ay. 274.

plicalus Ag. 311.

polyides liütz. 294.

punclatus Ag. 248.

purpurascens $.9 g .307$.

ialula Ag. 278.

repens sig. 218.

inbens Ag. 331.

Schousboei J. Ag: 209.

seminervis $\mathrm{A} g$. 226 .

spermophorus Ag. 335.

Sternbergii Ag. 190.

stirialus Ag. 277.

Teedii Ag. 267.

Teedii var. Ag. 269.
Spharococcus tenax ig. 236 .

Torreyi Ag. 319.

weifer Bury 268.

vermicularis Alg. 323 .

cerruculosus Ag. 24.

volatis Ag. 270.

Spongotrichum 112.

dichotomum 112.

Sporoctmus pennalula Pocpp. 180.

Spyridia clavutata J. 19. 149. pellucida Ilarv. 34.

Thamnocarpus 102.

Gunnianus 102.

Laurencia 102.

Ptilota 103.

Trentepohlia Daviesii iar. Aresch. $12,15$.

mirabilis Suhr. 130.

Rothii Ilarv. 17.

Trichoceras pallidum 141 .

tasmanicuin 141 .

villosum 141.

Tylocarpus Griffihsice hütz. 316.

Utva coccinea Poir. 108.

delicalula Gm. 299.

ligulata Huodw. 202.

ribra lluds. 202.

moides Bory 214.

Verticillaria Equisetifolia Grat. 91.

Hormshjoldia Squamarice Menegh. 222.

Zonaria rosea Suhr. 111. 


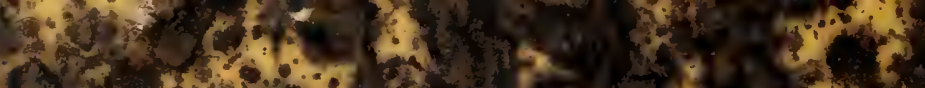

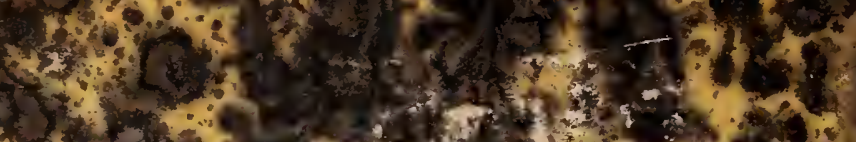

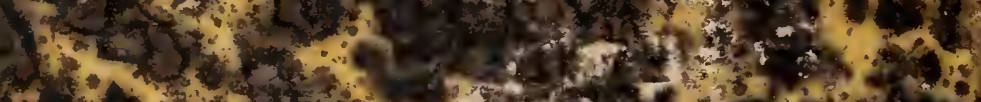

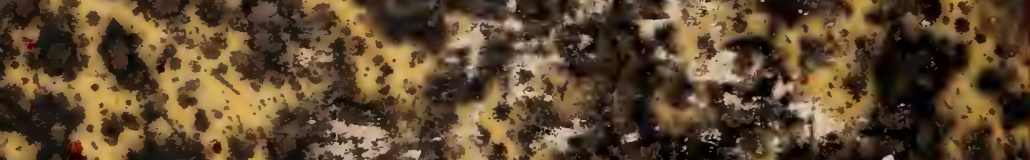

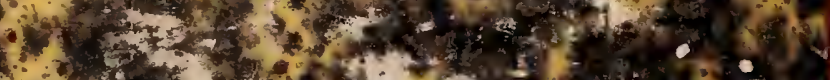

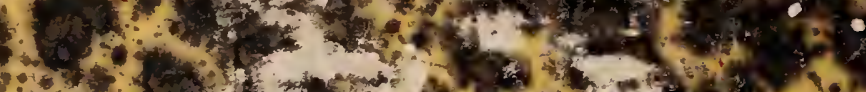

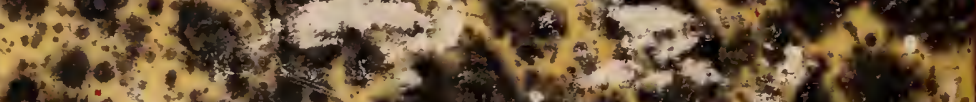

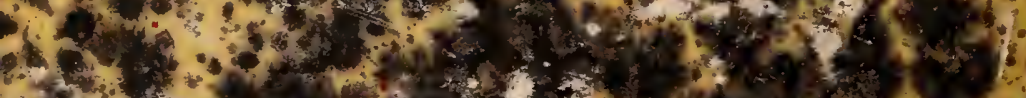

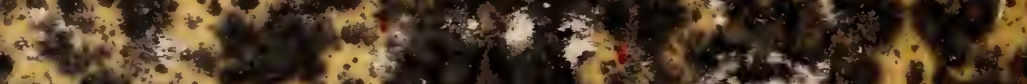

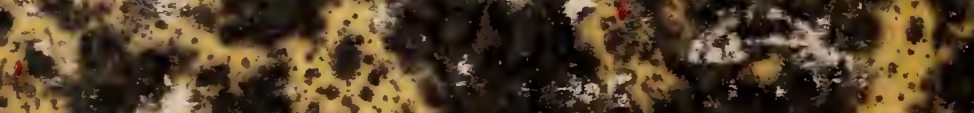

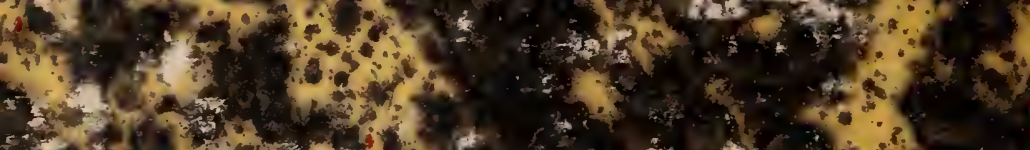
H.

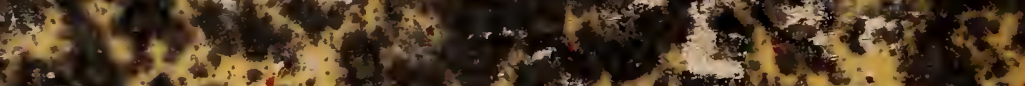

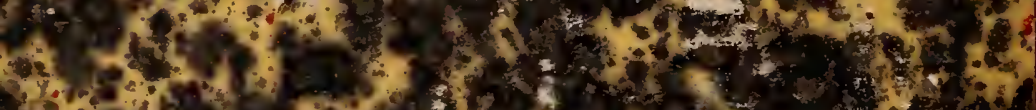

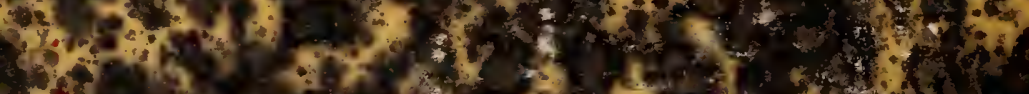

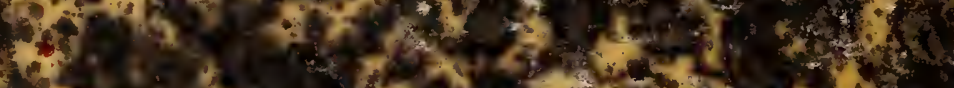
(25)

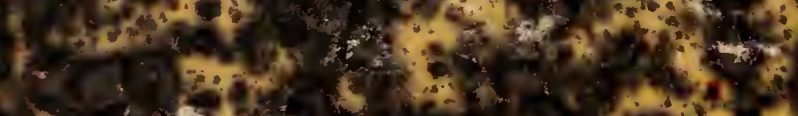

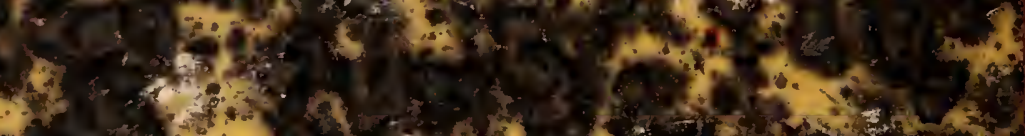

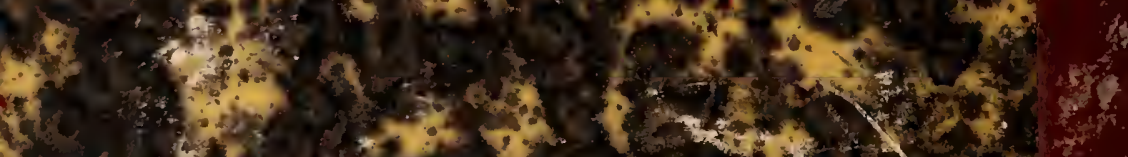

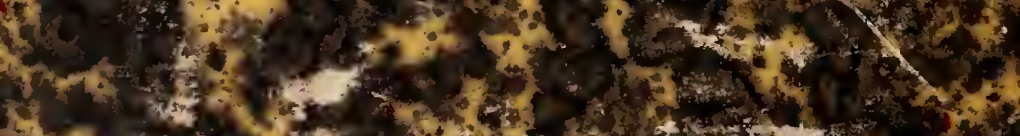

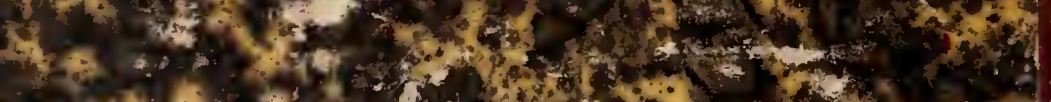

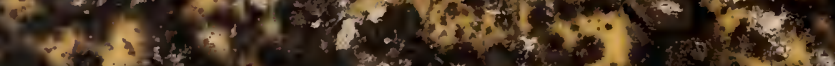

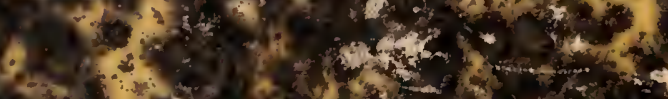

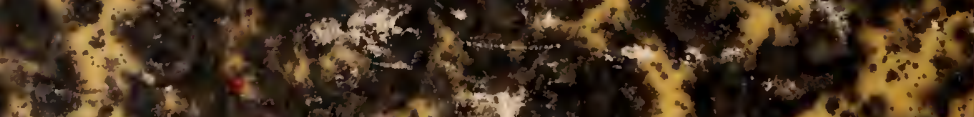

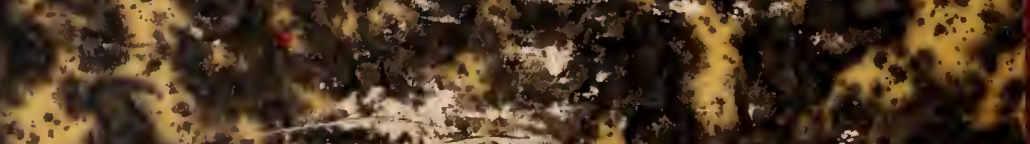

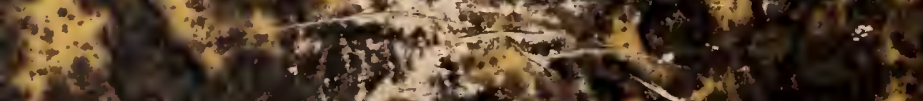

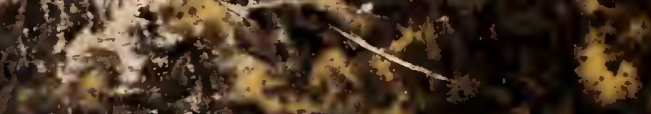

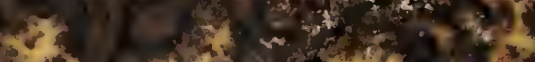

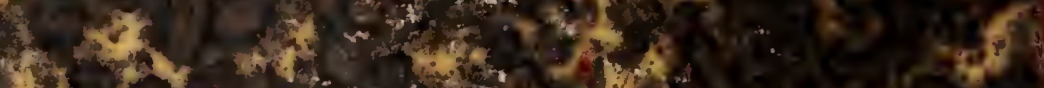

